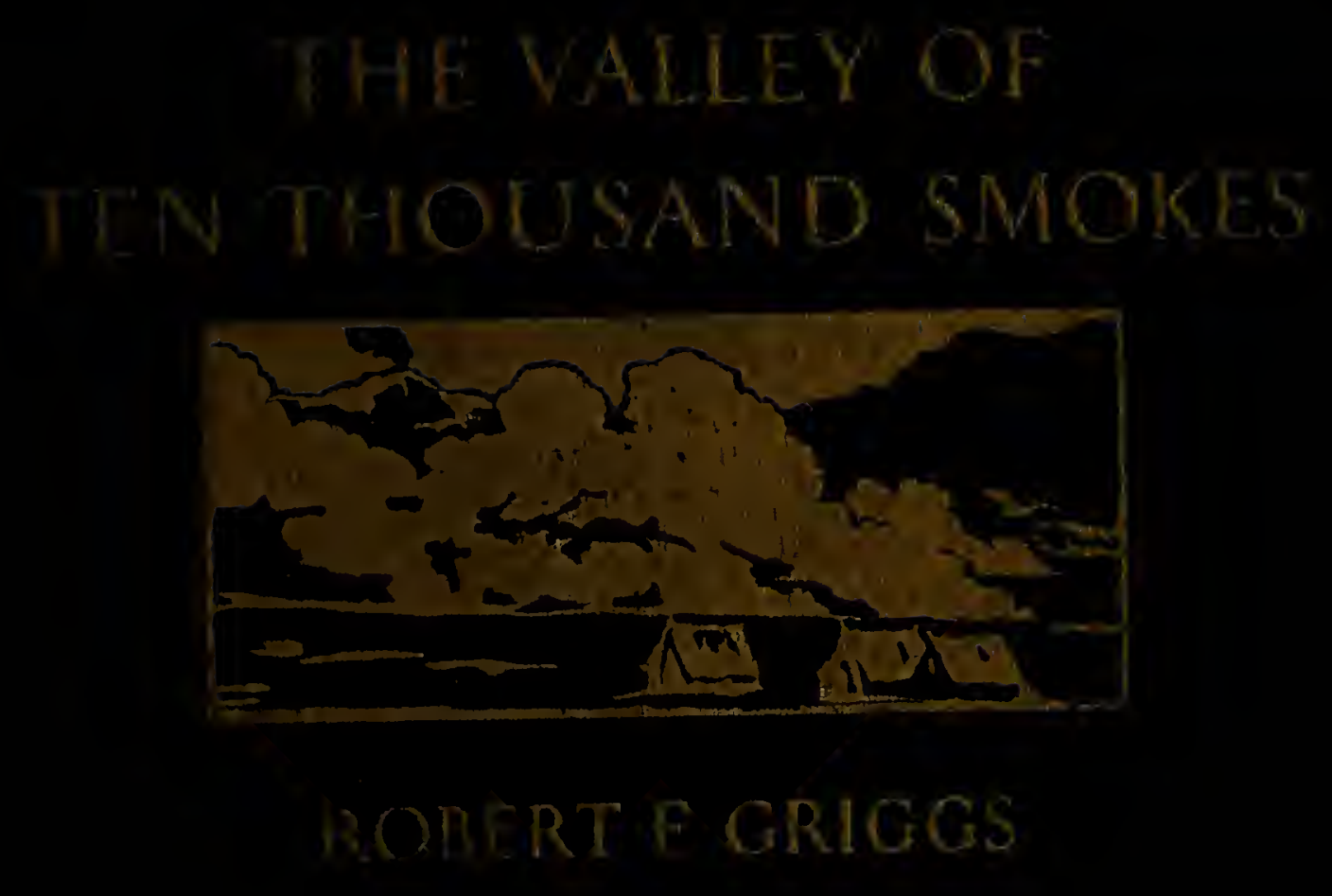

GATESHA STCORAPHL SOCIETY 


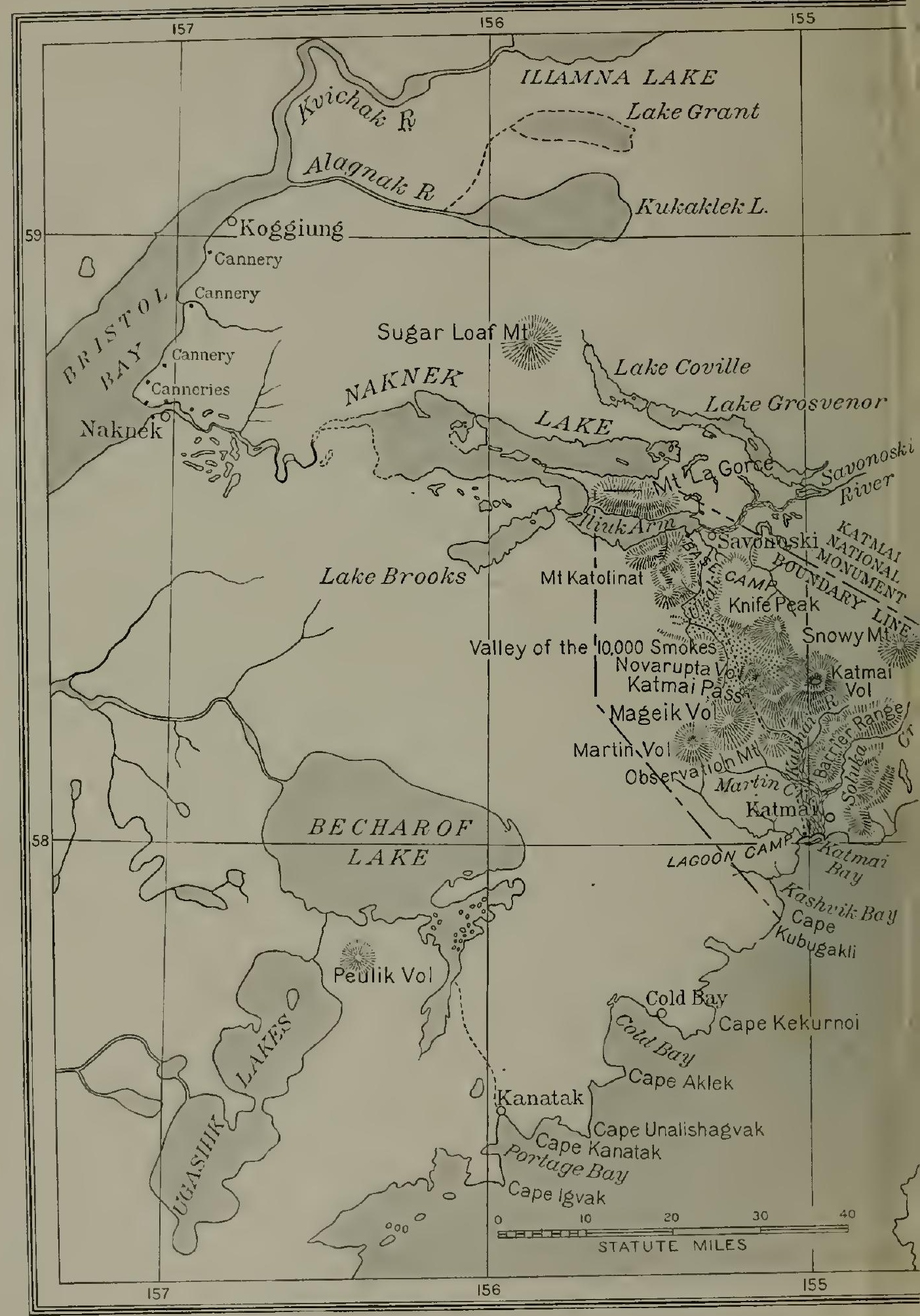




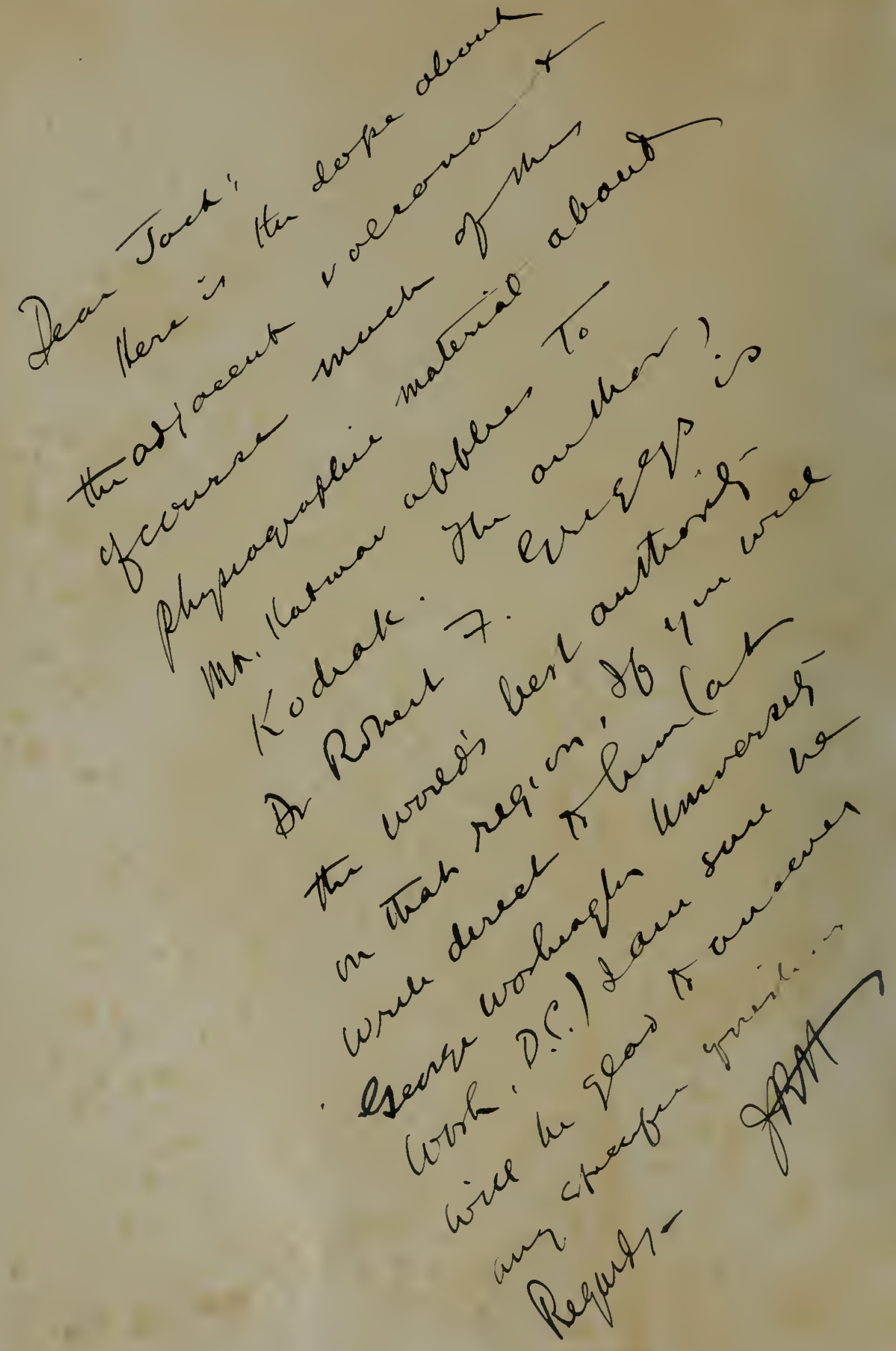




\section{THE VALLEY OF \\ TEN THOUSAND SMOKES}

GRIGGS 


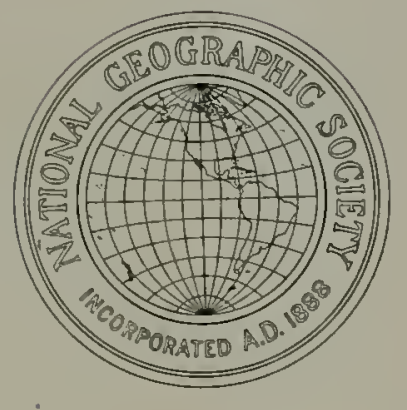




\title{
The Valley of \\ Ten Thousand Smokes
}

\author{
By \\ ROBERT F. GRIGGS, Ph.D.
}

With 9 Maps and 233 Illustrations

WASHINGTON

The National Geographic Society 
Copyright, 1912, 1913,1917, 1918, 1919, 1921, 1922 By The National Geographic Society

Published, December, 1922 
To the Inspiration

of my life and work -

My Wife 


\title{
THE VALLEY OF TEN THOUSAND SMOKES
}

\author{
TABLE OF CONTENTS
}

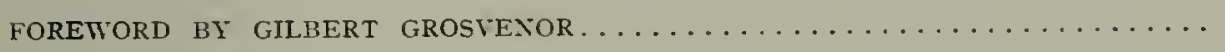

CHAPTER I: THE ERUPTION AND ITS SIGNIFICANCE . . . . . . . . . . . . .

Eruption felt over all northwestern America - A similar eruption in New York City would be seen in Albany, heard in Chicago, tarnish brass in Denver, prostrate Philadelphia, destroy Greater New Jork - Crater largest in the world - No lives lost - Geological bearings; eruption of a new type; aid in understanding mineralization; may throw light on mechanism of rolcanoes - Revegetation has important agricultural bearings - Discovery of one of the greatest wonders of the natural world, the Valley of Ten Thousand Smokes - Safe for tourist travel - Can be made readily accessible.

CHAPTER II : THE ERUPTION AS EXPERIENCED AT KODIAK . . . . . . . . . . .

Introductory - Premonitory symptoms unknown; ashfall began without warning - Kodiak not situated in volcanic district - Ignorance of seat of eruption Darkness which obscured lanterns held at arm's length - People collected in warehouse - Rescue of crew of tug; people taken aboard the Manning; suffering from overcrowding - Tribute to bravery of inhabitants - Suffering due more to terror that to danger.

CHAPTER III: RECORDS OF THE ERUPTION FROM OTHER LOCALITIES . . . . . . . .

Identification of the volcano by steamer Dora; other vents supposed to have been responsible; final determination of seat of eruption not made until I9I5Reports of eyewitnesses from Katmai Village - Statement of chief of Savonoskinatives - Experiences of people at Kaflia Bay, where the ashfall was three feet - Preliminary symptoms as observed at outlying stations - Maximum violence for 60 hours - Gradually subsiding activity continued all summer - Records of earthquakes accompanying eruption; records of explosions as heard at distant stations; explosions not heard at Kodiak, perhaps because of dust screen - Sulphuric acid rains destroy vegetation at Seward, La Touche and Cordova, more than 300 miles anay - Brass tarnished and clothes destroyed in the Puget Sound region, I,500 miles away - Ashfall a foot deep or more over an area one and one-half times as large as Delaware - Dust fell I,500 miles away - Records from Puget Sound Ejecta from eruption totalled over six cubic miles, a quantity equivalent to the output of the stone crushers of the United States for over joo years.

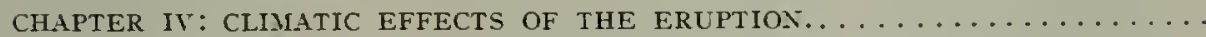

Haze from volcano held responsible for cold summer of 1912 ; lowest point erer reached in terrestrial temperatures followed eruptions of $I_{7}-83-1785$; the "dry fog" of 1783 ; "the year without a summer" followed eruption of Tomboro, I8I 5 - Haze from Krakatoa caused remarkable sunsets for two years; haze from Katmai appeared in II isconsin before the eruption was over, in Virginia two days later; peculiar haze persisted all summer in Algeria - Interference with astronomical observations - Dust cloud absorbed Io per cent of the sun's heat; whole Northern Hemisphere cooler because of eruption - Slight changes in mean temperatures of great practical importance - Volcanic dust shown to be capable of producing glacial climates - Water liberated in eruptions probably of vast importance in economy of nature; all life perhaps dependent on continuance of volcanic action. 
CHAPTER Y: THE RECOVERY OF VEGETATION AT KODIAK..............

Remarkable recovery of vegetation; not due to any fertilizer in the ash; ash forms a very poor soil; composition similar to pulverized granite; beneficial action due to effect as a mulch - Revegetation result of recovery of old plants; plants resurrected after three y'ears' burial - Seedlings slow to start; revegetation retarded by sand blast - Importance of horsetail as a soil binder - Bizarre appearance of ash-laden trees overgrown with moss - Network of moss on forest floor - Seedlings starting under protection of trees - Ash rapidly eroded; earthworms active in mixing it with old soil - Little damage to fields.

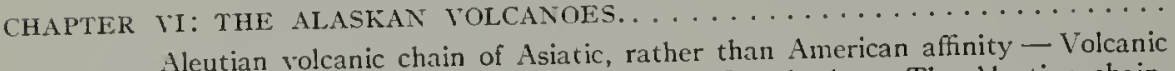
festoons fringing Asia, from East Indies to Kamchatka - The Aleutian chain, traversing mountain plateaus and ocean deeps, evidently a more fundamental feature than ordinary geologic structures - Cones of lliamna and Redoubt Explosions of Augustine - The volcanoes of Unimak, Shishaldin and Pogromni - Birth of a new island, Bogoslof; upheaval of Grewingk, companion to old Bogoslof; formation of Metcalf Peak and McCulloch Peak; eruption of I909; present condition of Bogoslof - Importance of further study of Aleutian Volcanoes.

CHAPTER VII: CARRYING THE IVORK INTO THE VOLCANIC AREA — GEOGRAPHY —

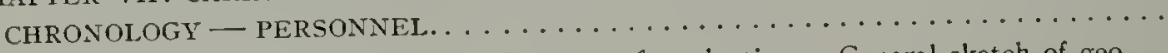

Remoteness of the region - Dangers of navigation - General sketch of geographic features - Broad valleys key to geography of district; Katmai Valley; Katmai Canyon; Second Katmai Valley; X-shaped valley on Naknek slope Lesser geographic features - Geographic order of description adopted in preference to chronological narrative - Previous attempts to reach the crater - Expedition of 1915-Expedition of I916; Walter Metrokin, the one-armed bear hunter of Kodiak; area traversed in 1916 - Organization of expedition of 1917; ground covered; creation of Katmai National Nonument-Considering pack horses and airplanes for transportation - All supplies carried in on man-back Only the most concentrated foods conld be used - Sending in the expedition of I9I 8 from Bering Sea-Objectives of expedition of I9I9-Coöperation by Geophysical Laboratory of Carnegie Institution - Organization in Igrg; personnel.

CHAPTER VIII: THE FIRST JOURNEY TO THE TOLCANO - DEVASTATION OF KATMAI VALLEY . . . . . . . . . . . . . . . . . . . .

Weird appearance of desolated shores - Dread of casting loose in such an outlandish country - Difficulty in choosing a landing - Supply of drinking water assured - Sticky mud everywhere - Luxuriant poplar groves - Comparative damage to different plants: poplars growing from dormant buds; alder and birch exterminated; willows suffered less than other trees because of capacity for forming adventitious roots - Exploring in a dust storm - Starting up the valley First view of volcanoes - Discovery of a new volcano, Mt. Martin - Climbing slides of loose ash - Fording Soluka Creek, a mile of quicksand - Straining drinking water out of pumice - Pressing forward for fear of bad weather; fear of caverns formed by snow melting away beneath the ash - Upper Katmai Valley; awe-inspiring desolation - All animal life destroyed - Comparative verdure of lower valley - Surprising absence of damage by fire - Progress up the valley; stopped by Katmai Canyon - Katmai mudflow - First crossing Katmai River with aid of poles; later experiences in crossing; use of ropes in fording; folding boat with a " $\mathrm{G}$ " string - Waiting for sight of volcanoes through the clouds Second new volcano, named Trident - First sight of Katmai - Volcanoes obviously piles of lava rather than cinder cones.

CHAPTER IX: THE KATAIAI FLOOD. . missed disaster - Katmai Bay full of wreckage brought down by flood - Exceptional height of flood evidenced by condition of Katmai Village; houses entirely submerged - River formerly used by schooners, choked with ash - A maze of 
quicksands fire miles wide - Speculations as to the cause of the flood; could not have been tidal; confined to Katmai River - Forcsts uprooted and heeled over before the waters - Trees sheared off at ground for miles at a stretch - $125^{0}, 000-$ pound bowlder picked up by the flood - Temporary Niagara over obstructing ridge - A river whose bottom was higher than its banks - Freak of the flood - Thankful for the lucky chance that had delayed our landing until after the flood - Later exploration show's that flood was caused by downpour of water impounded by landslide - Slide occurred at a natural dam site; impounded lake of $95^{\circ}$ acres - Probable condition of dam - Katmai Canyon filled many feet deep with cobbles - Thirty-five times as great as Johnstown Flood - Destructive power a million times that of a Mississippi flood.

CHAPTER X: THE CANYON AND SECOND VALLEY OF THE KATMAI........

Habitual underestimation of sizes of physical features; grandeur of Latmai Canyon not appreciated at first - Beautiful waterfalls near foot of canyon liatmai Canyon almost as deep as Grand Canyon - Prospect Point - Descent into canyon - Contrast with other canyons of district; pre-glacial rather than post-glacial - Proof that last lava flows from Katmai were post-glacial - Gravel banks set rolling by wind - Second Valley of the katmai - Beaches of former "flood lake" - A possible explanation of the Second Valley - Curious physiography; numerous regular conical mounds; all wood buried in débris; drainage very irregular; bowlders in river bed sharp and angular - Noisy Mountain in action: rock falls; mud avalanches, intermediate between landslides and overloaded streans; key to other unusual physiographic features - Upper portion of Second Valley; Princess Glacier - Passes at head of Second Valley - Attempt to find route to sea - Discovery of hot spring - Supperless night in the rain.

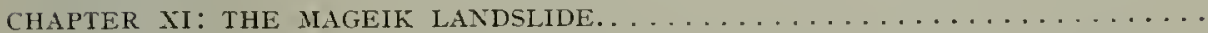

Head of Martin Creek strewn with rocks, some as big as a house - Evidence that they could not have been thrown out from a volcano-Resemblances toglacial deposit - Broken bushes intermingled with débris - Much peat in terminal portion - Lateral edges show slumping back of material from highest level reached - Terrane forked halfway down - Original plants still growing on bowlders - Indications as to date; "infantile" physiography; buried fragments of wood not decayed; covered with ash; contemporaneous with eruption - Evidently some sort of landslide - Surface studded with remarkable cones; geological structure favorable for landslides - Dimensions of slide - Surprising liquidity manifested by slide - Description of similar slide in motion - Mageik Slide compared with others: Elm, Frank, Rossberg, Katmai, Noisy Mountain, Falling Nountain; the greatest recorded slides: Gohna and Bandai San-Rank of Mageik Slide.

CIIAPTER XII: KATMAI VALLEY IN LATER YEARS.................

General appearance of Katmai Valley in 1916 similar to that in 1915 , but much changed in detail - Instability the key to the abnormal physiography - Shifting surface most striking characteristic of devastated country; cut and fill at Observation Nountain; frequent avalanches from the overloaded mountains - Snowdrifts buried by ash persist for years - Wind erosion of ash slopes; bark of trees cut away by sand blast - Fickle Creek shifts its course 1,000 feet in a year - Antics of pumice-choked streams - Caricatures of aggrading rivers building fans, dikes and deltas - Observations on depth and character of ash deposits - Irregularities in ashfall due to variable winds - Three major strata, with a fourth near the volcano and a cap-layer of fine mud - Plants that lay dormant for three years until uncovered by ftood wash - Seedlings first started in numbers in 1916 - Seeds, scattered mostly by wind, fail to lodge on pumice flats - Lupines the most important pioneer plants; abundance of root tubercles; a few plants growing in situations extremely poor in nitrogenous compounds - A few small fish on the quicksands - Trout in a brook tributary to Katmai River - A perverted run of salmon - Remarkable increase in insects in 1916 - Flies dying of starvation Insects mostly predacious or parasitic - Speculations as to source of insects First mammals carnivorous - Notable increase of herbivorous animals in $1919-$ Return of Herbivora not correlated with increased food supply - Similar conditions observed at liodiak. 
CHAPTER XII: KATMAI CRATER...... Reconnoitering the lower slopes
mud - Scenery from upper levels superb; clouding up as rin is approached Crater rim a knife edge of loose unstable ash, the same layers as those below Waiting for clouds to lift - First view of crater; an abyss of inconceivable size Second ascent - Ash-covered glaciers - Magnitudes too great for senses to grasp - Second view of crater - Glaciers on crater rim - Ascents in $1917-$ Comments of new members - Perfect proportions of crater - No changes during four years - Weird effect as crater is walled in by clouds - Dinensions of crater; would hold water enough to supply New York City over four years; skyscrapers of New York would not begin to fill crater - The largest active crater in the world - Comparison with Kilauea.

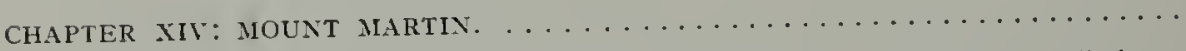

Inaccessibility by reason of position and cloudiness - First attempt to climb Mount Martin a subordinate lava cone on flank of Mageik - Despite present activity, Martin seems not to have thrown out ash in great eruption - All vegetation in vicinity kept down by acid rain - Second attempt - Third climb, from Baked Nountain - "A real glacier" - Waiting for a break in the clouds Climbing a $60^{\circ}$ dirt slope at the end - Descending into the crater in thick stean Returning - Fear of being caught on glacier by a cloud.

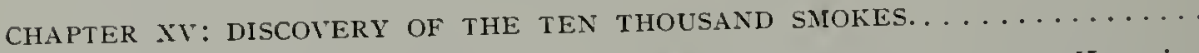

Reconnaissance up Nageik Creek; the Nageik "mudflow" - Ascent to Katmai Pass - Discovery of first fumarole in the pass - First sight of the Valley of Ten Thousand Smokes - Character of the vents - Entrance to the main valley First sight of Novarupta - An interpretation of the fumaroles - Return to camp - Reflections on night of discovery.

CHAPTER IVI: EXPLORATIONS IN THE TEN THOUSAND SMOKES IN I917....

Impatience to reach the Valley again - No change in the Smokes in a year's interval - No probability of recurrence of explosive condition - Effect of Valley on uneducated native - Crossing the mountains against a hail of pumice Comments of new members of party - Overawed by wonderful valley - Fear of cave-ins and fumes - Learning to travel safely - Effect on shoes - Cooking at a fumarole - Temperatures too high for our instruments - A steam-heated tent - Therapeutic possibilities of the Valley - Katmai Pass a notorious weather breeder-A few signs of animal life - Surveying the Valley - Collecting gases for analysis - Practically all plant life destroyed - Testimony of associates: L. G. Folsom; Paul R. Hagelbarger; J. D. Sayre; Clarence F. Naynard; James S. Hine; J. W. Shipley; D. B. Church.

CHAPTER ITII: THE TEN THOUSAND SMOKES IN $1919 \ldots \ldots \ldots \ldots \ldots \ldots$

Fumaroles unaffected by seasonal variations in streams - Some indications of slackened activity - Melting lead and zinc in the fumaroles - Kindling a fire by plunging stick into water - A red-hot fumarole - Valley becoming green in spots with moss and algae - Bacteria invading soil - Bears investigate Valley; one of them digs a new fumarole of his own - Baked Mountain Camp - Acid from cookstove eats the pots-Cookstove on roof of a bridged-over fissure; any desired temperature available - Corn pone à la fumarole - Frying bacon in superheated steam - Varied menus at Baked Mountain - Trouble with storms - Protective measures - Final wreck of Baked Mountain Camp; apparatus and sleeping tents torn up; "grub" tent begins to weaken; extra tarpaulin tears away; hail of pumice; holding down the last corner of the tent; waiting for dawn; gale picks me clear up off ground; fleeing before the wind; relief at Ukak; camp noved to Mount Cerberus. 
Valley shaped like great $\mathrm{Y}$ - Underlain by sedimentary, not by volcanic rocks Fissure fumaroles - Craters - Steaming mud areas - Steam rising through undisturbed sandstone strata - Hot springs - Mud pots - The new volcano, Novarupta - Falling Nountain; catacly'sm began with great slide from Falling Mlountain; fumarole action on Falling Mountain - Baked and Broken Mountains - Fissure Lake; warm water from snowdrifts - Drainage water nearly all evaporated by heat of Valley - Bewildering complex of odors - Chemistry of fumaroles: all emanations 99 per cent steam; no relation between temperature and composition of gases, - ammonia - unparalleled abundance of fluorine sulphur - arsenic - corundum - potassium alum - iron; pyrite; venetian red; magnetite - petroleum-like emanations - Wonderfully colored deposits; shoes daubed with brilliant pigments - Color photographs.

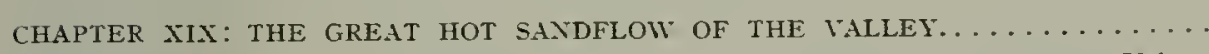

The great mass of tuff filling the Valley - Valley floor remarkably flat - Volume of tuff about a cubic mile - Valley surrounded by conspicuous "high water mark" - Comparison with frozen pond - Fissures suggest sagging of original surface - Proof that activity of Yalley began before explosion of KatmaiRelation to forest showed that tuff originally flowed like a liquid - Every stick touched by sandflow reduced to charcoal — Search for origin of sandflow - Hot sand must have broken through floor of Valley itself - Sandflow an eruption of new type; gives volcanologist new viewpoint.

CHAPTER IX: ANTECEDEXT CONDITIONS. . . . . . . . . . . . . . . .

Little information concerning antecedent conditions available - Petrof's description of Katmai district; Katmai Pass; Katmai lillage - Importance of Katmai Pass revived by discoven: of Nome - Spurr's account of original condition of country and his experience in crossing liatmai Pass - Katmai Pass probably in unstable condition before eruption - Difficulty of judging weather across the pass - Travelers give no account of Katmai, although it must have been dominant peak of district - Only information concerning Katmai derired from U. S. Coast Survey Chart - Comparison with present stub.

CHAPTER XXI: A HYPOTHETICAL CHRONICLE OF THE ERUPTION..........

An account pieced together from evidence left behind - In the beginning a beautiful green valley - Great landslide from Falling Mountain opens the cataclysm - Valley floor cracks open and seething magma rushes out - Impenetrable black clouds probably veil the scene - Lava froths up into fiery foam - Roaring fires sweep up the mountain side; misery of entrapped animals quickly ended Fumes must have been indescribable - Valley becomes seething fiery torrent An analog: from Hawaii - Red-hot ash rolls down Valley like liquid - Explosion of Xovarupta - Opening of Katmai and the other volcanoes - Summary of events of eruption.

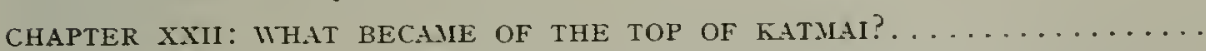

Interpretation of subterranean disturbances the real problem of the volcanologist - Rock of original mountain disappeared utterly - Rock of old mountain distinguishable from new lava at a glance - Could the old mountain top have been swallowed up in the bowels of the earth? No evidence of subsidence Much of old mountain eaten away by new magma - All stages in penetration of old rock by new magma shown in fragments ejected; ash at liodiak carries many crystals from old mountain - Much of old rock permeated with gases from new: magma - Temperature of new magma low, less than $I, 000^{\circ}-$. All the ash could be packed into crater - A portion of old mountain probably sank into depths Old rock mixed with lava of Novarupta may have been derived from Katmai Explosions appear to have started at summit of mountain, not in depths - Lava formed molten lake in crater; frozen foam from lake surface; chilled scum Magma did not explode immediately on reaching surface; explosions not a simple physical process like popping of carbonated liquors - What is the character of the magma chamber beneath the region? Sill or batholith? - Decision on theoretical questions best deferred. 
CHAPTER TXII: GEOGRAPHICAL ANI BIOLOGICAL OBSERVATIONS IX TIE SUR-

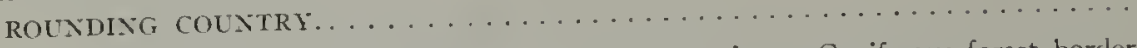

Northern end of park not desolated by eruption - Coniferous forest border migrating west ward - Naknek Lake cxtremely beautiful - Majestic mountains rising out of lake - View from Mount Katolinat - Discovery of Lakes Grosvenor, Coville and Brooks - Resemblance to Finger Lakes of central New York Trout 32 inches long - One of the greatest of spawning grounds for sockeye salmon - Salmon Falls - Enormous numbers ascending - Remarkable homing instinct of salmon - Countless waterfowl on lakes and ponds - Professor Hine's collections of birds and insects - Big game returning - Alaskan brown bear, the largest of carnivorous animals, abundant - Necessity for protection - Bear trails everywhere - Bears inspect our trails - Going into interior unarmed, despite bears - Feeding habits - First sight of bear - Encounter with sleeping bear - Going after Bruin with a pistol - Problem of finding a harbor - Possibilit ies of Kukak and Kinak Bay's - Discovery of ideal harbor, named for National Geographic Society - Geographic Harbor fitting entrance to Valley of Ten Thousand Smokes - Feasible route for road into interior - Strategic importance of road across Alaska Peninsula - Sixty miles of automobile road would open up whole district - Nore accessible than Yellowstone at time of its discovery Predictions of the future.

PRESIDENTIAL PROCLAMATION ESTABLISHING THE KATMAI NATIONAL MONL- 


\section{COLOR PLATES}

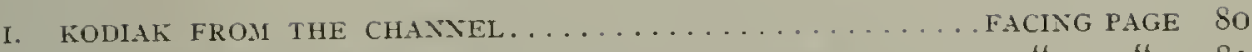

II. A CANTON IN THE MICDFLOW AT THE HEAD OF KATMAI VALLEY

III. ALPINE GLOW OX MOUNT IIARTIN. ............

IT. FUMAROLES AT THE FOOT OF FALLING MOLTTAIX . . . . . .

r. MOUNT MAGEIK, WITH CERBERLS CROLCHING AT ITS FOOT, STANDS GLARD AT THE HEAD OF THE VALLEY . . . . .

II. THE OVEX WHERE CORY BREAD WAS BAKED BI NATLRE'S FIRES . . . . . . . . . . . . . . . .

VII. BRILLIANT INCRLSTATIONS FROM THE FLMAROLES.......

VIII. A ROW OF GORGEOUS "STOVE HOLES" ..............

IX. THE CAIERTOUS MOUTH OF ONE OF THE FUMAROLES . . . .

$x$. A RED-BURNED FISSURE ON THE WEST SIDE OF THE VALLEY, LOOKING TOWARD THE GLACIERS OF MAGEIK . . . . . .

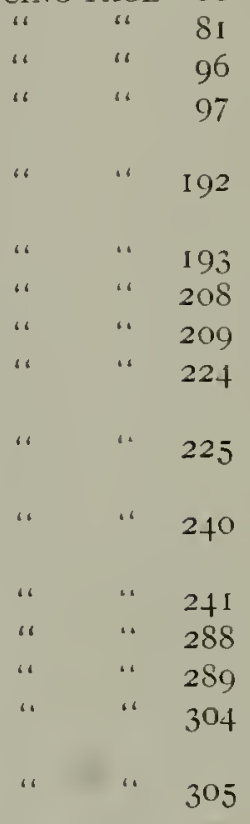

\section{MAPS}

BASE OF ALASKA PENINSLLA AND ADJOINING ISLANDS.

IN FRONT COTER

ASHFALL FROM THE ERUPTION OF KATMAI. FACING PAGE I VOLCANIC AXES AND STRUCTURE LINES IN EASTERN ASIA ANDD ALASKA YOLCAYOES AND HOT SPRINGS OF THE ALEUTIAN REGION ...... CENTRAL PORTION OF THE KATMAI NATIONAL MONUMENT . . . . .

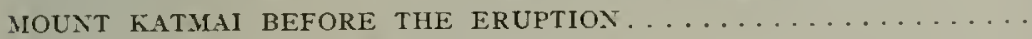

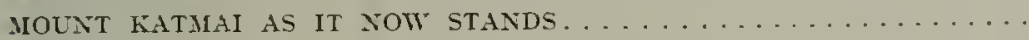
A RECONSTRUCTION OF MOUNT KATMAI AS IT WAS BEFORE THE

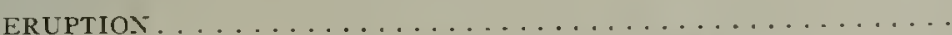
TOPOGRAPHIC MAP OF THE KATMAI NATIONAL MONUMENT . . . . .

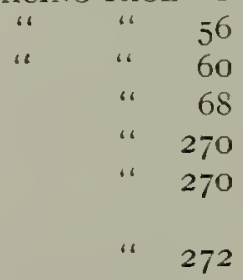

IN BACK COTER 



\section{FOREWORD}

The following pages tell the story of the discovery by the National Geographic Society expeditions of one of the wonders of the world, "The Valley of Ten Thousand Smokes," and the prolonged study of one of the most gigantic volcanic eruptions in history.

This remarkable exploration of Mt. Katmai by Professor Griggs and his associates, which continued for five years, was financed by the 750,000 members of the National Geographic Society, each of whom, millionaire and college professor, captain of industry and clerk, had an equal share in its support. Every member of the organization may thus derive considerable satisfaction that he or she has assisted to bring about such important additions to our knowledge of the young and active planet upon which we live.

To Dr. Griggs, the leader of the National Geographic Society's expeditions to the Katmai region, and to each of his able assistants, the congratulations and thanks of the Society's membership are herewith extended. Their intrepid, intelligent and faithful services achieved results of historic value and reflect great credit on all participants.

\section{GILBERT GROSVENOR}

President, National Geographic Society 


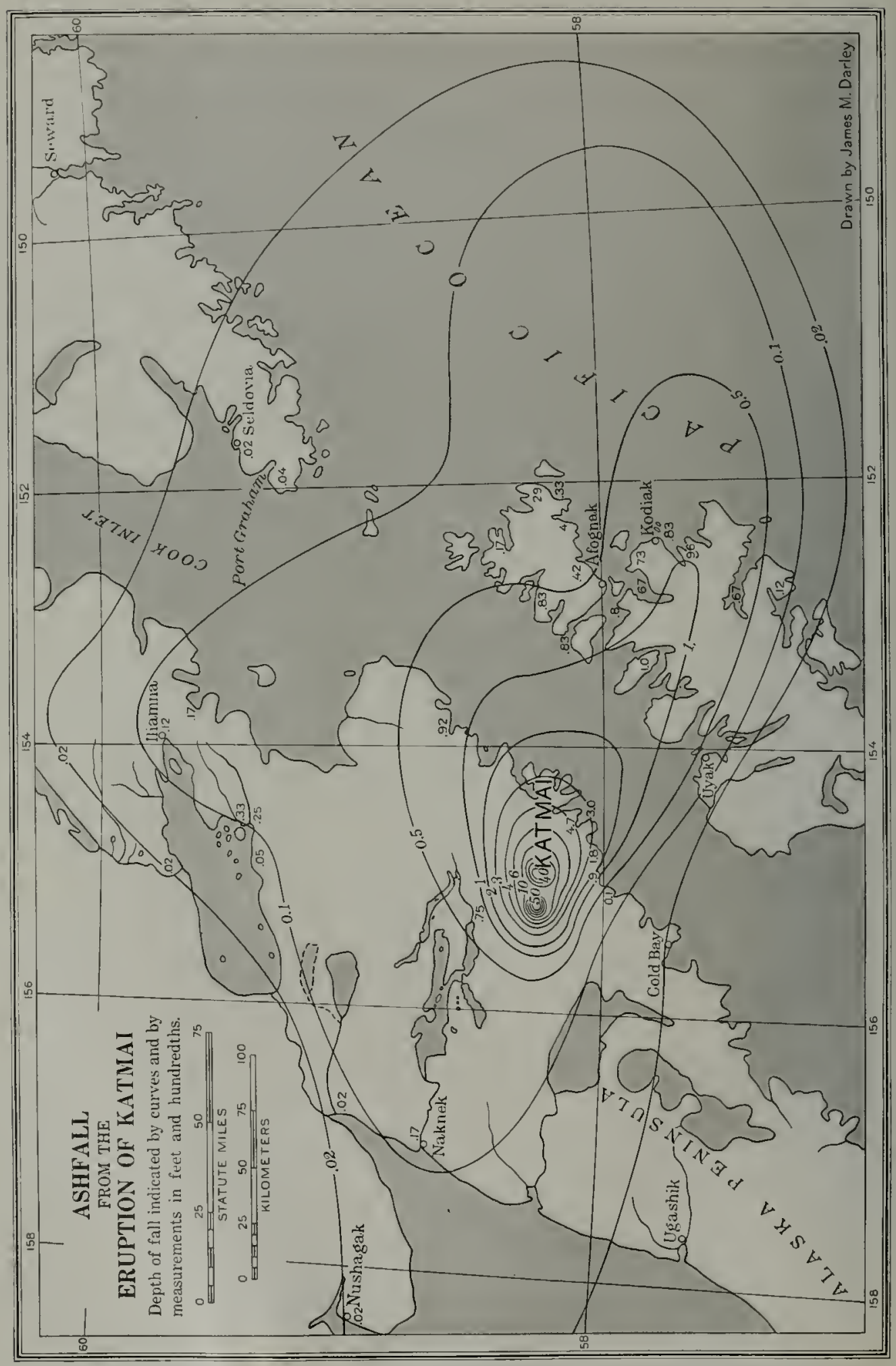




\section{THE ERUPTION AND ITS SIGNIFICANCE}

The Story of the Valley of Ten Thousand Smokes begins with the great volcanic eruption of 1912 which brought it into existence. Exploration, undertaken primarily for the scientific study of the effects of the ashfall, led to the discovery of one of the great marvels of the natural world, a place unseen and unsuspected by white man and native alike until entered by a National Geographic Society Expedition.

Over an area of fifty square miles the ground is all broken open, and hot gases from the molten material below are even now everywhere pouring out, forming the several millions of fumaroles that constitute the Valley of Ten Thousand Smokes.

No one suspected that such a cataclysm was in progress until the 6th of June, when volcanic ash suddenly began falling over all of northwestern America. Kodiak, in southwestern Alaska, was reported as the chief sufferer. But as Kodiak is one hundred miles from any volcano, the actual seat of the disturbance was uncertain. Katmai ${ }^{1}$ volcano was mentioned in the first dispatches, yet it was not settled for a long time that it was Katmai which had blown up.

The eruption was one of the dozen greatest of historic times, yet it attracted comparatively little attention, because of the remoteness of the region concerned. Katmai was, in fact, merely a name on the map, unknown except to local pilots along the unfrequented coast of Shelikof Strait. It may aid in giving some conception of the magnitude of the outbreak if we can picture to ourselves the effects a similar eruption would produce if centered in a better known region, say New York City.

1 Pronounced Kăt-mai'; ă as in cat, ai as in aıle.

2Nore properly termed magma, for it had not given up its surcharge of gases. Strictly speak-
If such an eruption should occur on Manhattan Island, the column of steam would be conspicuous as far as Albany. The sounds of the explosions would be plainly audible in Chicago. The fumes would sweep orer all the states east of the Rocky Mountains. In Denver they would tarnish exposed brass, and even linen hung out on the line to dry would be so eaten by the sulphuric acid content as to fall to pieces on the ironing board. As far away as Toronto the acid raindrops would cause stinging burns wherever they fell on face or hands.

Ash would accumulate in Philadelphia a foot deep. To add to the terrors of the catastrophe, that city would grope for sixty hours in total darkness-darkness blacker than anything imaginable, so thick that a lantern held at arm's length could not be seen.

As for the horrors that would be enacted along the lower Hudson, no detailed picture may be drawn. There would be no occasion for rescue work, for there would be no survivors. The whole of Manhattan Island, and an equal area besides, would open in great yawning chasms, and fiery fountains of molten lava ${ }^{2}$ would issue from every crack.

This, disrupted by the escaping gases, would be changed into red hot sand, which, consuming every thing it touched, would run like wildfire through the town. The flow of incandescent sand would effectually destroy all evidence of the former city. In its deepest parts the near-molten sand would probably overtop the tallest skyscrapers, though the tip of the Woolworth tower might protrude, if its steel supports could endure the fiery furnace surrounding them. It is doubtful, indeed, if there would be any ing, there were no lava flows in connection with the eruption of Katmai. 

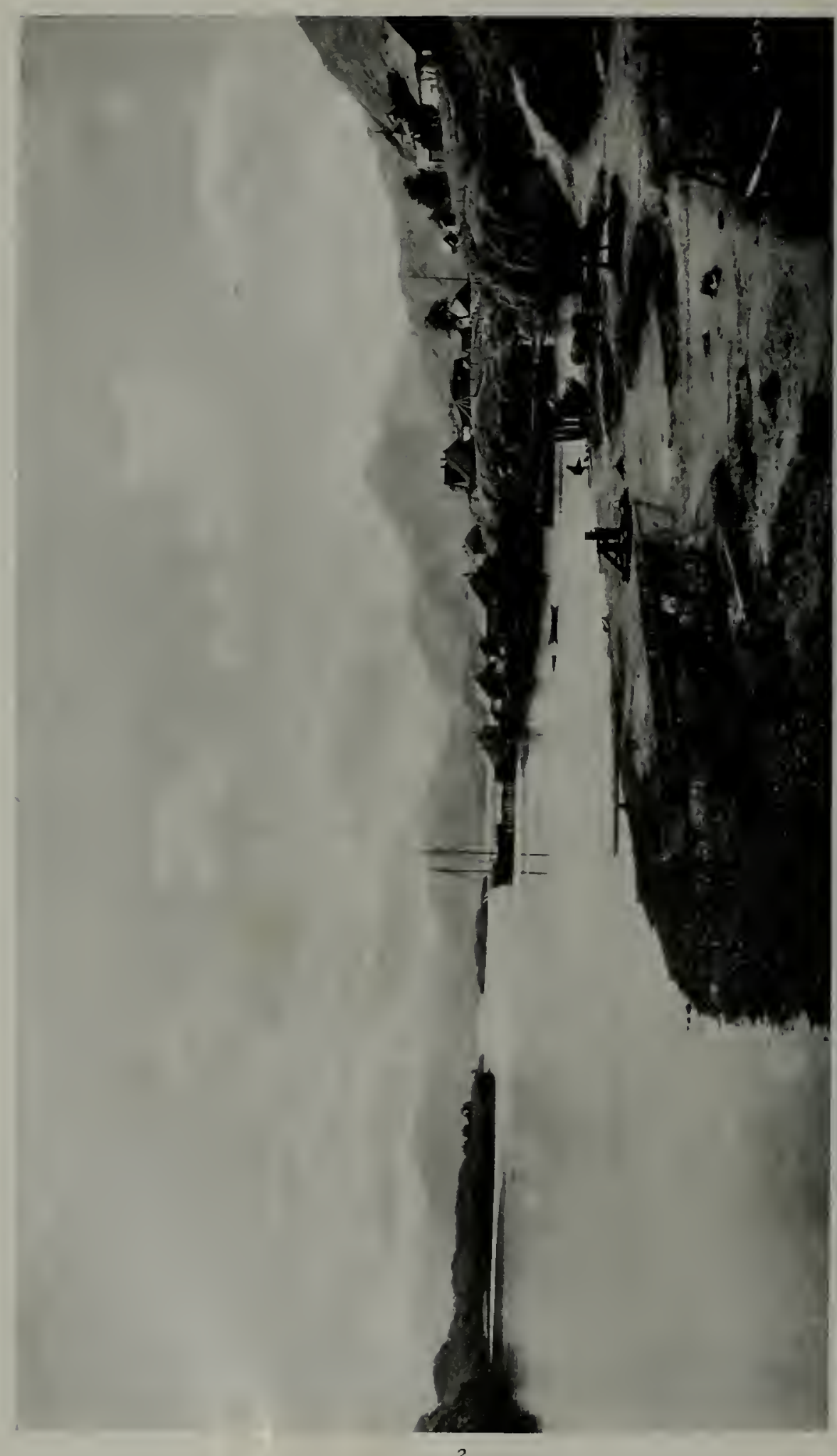

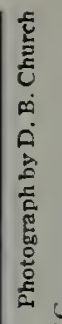

:

官

हू

能

舆

$\stackrel{\Omega}{\circ}$

당

(

ड

(4)

(9)

(2)

苍

受

द

$\approx$

年

돈

$\sum$

$=$

है

응

证

z

武

范

登

0

空

红

$\rightarrow \cong$

됭.

a

ร

产

造 
considerable ruins left behind to mark the site of that great city.

In any case, for several months no one could approach the place nearer than Paterson, New Jersey. In addition to this, a hole would have been blown in the ground big enough to hold all the buildings of Greater New York several times over.

With such a frightful comparison in mind, the reader will be prepared for an account of suffering and devastation unparalleled in the annals of volcanic disasters. But of this he may be reliered at the outset. Terror of the most frightful sort there undoubtedly was; but of actual destruction of life there was none: not a single person perished in the eruption.

Mankind may thus be congratulated on having one of the greatest opportunities ever afforded to study the manifold problems of volcanism, without having to pay the terrible toll of human misery that usually accompanies such cataclysms.

The flow of incandescent sand, alluded to above, constitutes an outburst of a new type, different from all recorded eruptions. The recognition that outpours of this nature probably occurred in the past may help to explain many deposits now puzzling the geologists.

The phenomena here occurring at the surface suggest what must have taken place in the formation of many a heavily mineralized region. A study of the fumaroles of this area bids fair to throw light on the formation of metal-bearing veins in the depths of the earth. If we can gain a satisfactory knowledge of the activity here going on, it will help greatly. toward an understanding of the deposition of metalliferons ores generally.

The explosions, too, constitute a problem of great interest and import. Similar outbursts in the past have left little clue to the processes responsible for the liberation of the enormous amounts of energy involved. Up to the present no carefully reasoned theory of volcanic explosions has been proposed. Here also Katmai, by reason of certain accidental circumstances, gives an unusual insight into the events preceding the great explosions, and seems likely to permit us to come nearer to an understanding of then.

No less important than the questions of rolcanism are the problems of revegetation of the devastated region, both in their practical and theoretical bearings. The extent of the area covered by ash gives an unprecedented opportunity for study of the means by which ash is converted into a soil fit for the growth of higher plants. The processes by which such a mass of raw mineral débris is transformed into a soil rich in organic matter have the largest bearing on certain problems of practical agriculture.

The Valley of Ten Thousand Smokes is far beyond other volcanic districts in the number of its vents and in the quantity of steam given off. It is well within the truth to say that, except during periods of dangerous eruption, the sum total of the emanations from all the other volcanoes of the New World, from the Aleutians to Patagonia, is less than is given off continuously, within the range of one's vision, from the Valley of Ten Thousand Smokes.

To find a parallel to this Valley we must search the records of geology, for here was a volcanic outburst such as the geologist finds recorded in the rocks of past ages but has never before had opportunity to observe in the world of the present.

The violently explosive eruptions characteristic of the opening stages of the activity have, moreover, entirely passed away. The innumerable vents function as a gigantic safety valve, through which the titanic forces gathered beneath find avenue for harmless escape.

There is, therefore, no likelihood of return to a dangerous condition. The observer may indeed travel in security anywhere among the volcanoes, with no fear of a sudden change in conditions. He may even with perfect safety peer over the edges of the orifices from which 


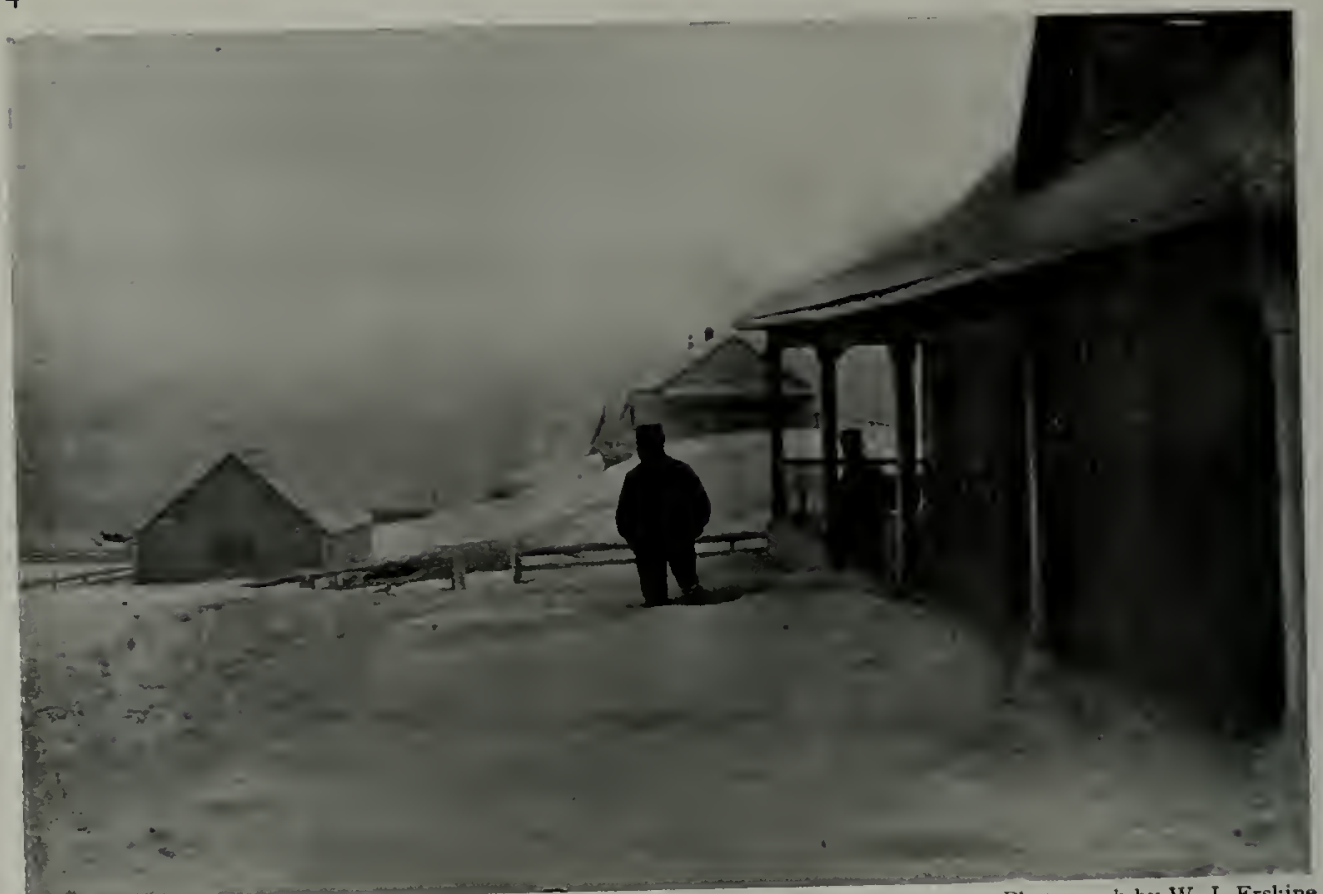

THE END OF THE ASH FALL AT KODIAK

At first the ash was comparatively soft and fluffy. Later it settled down into a hard compact layer ten inches thick.

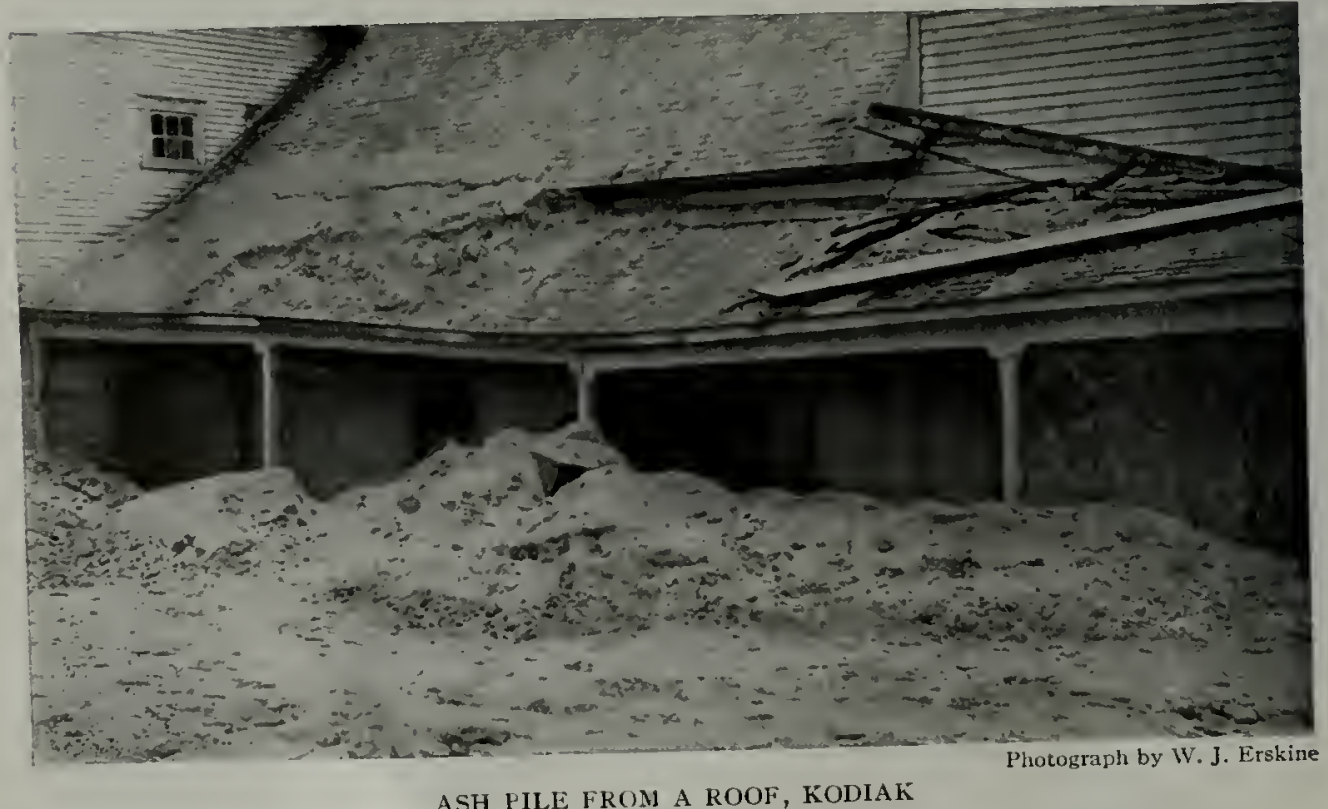

It looks very much like snow as it lies on the ground but, being in reality pulverized rock of great weight, it did much damage. 


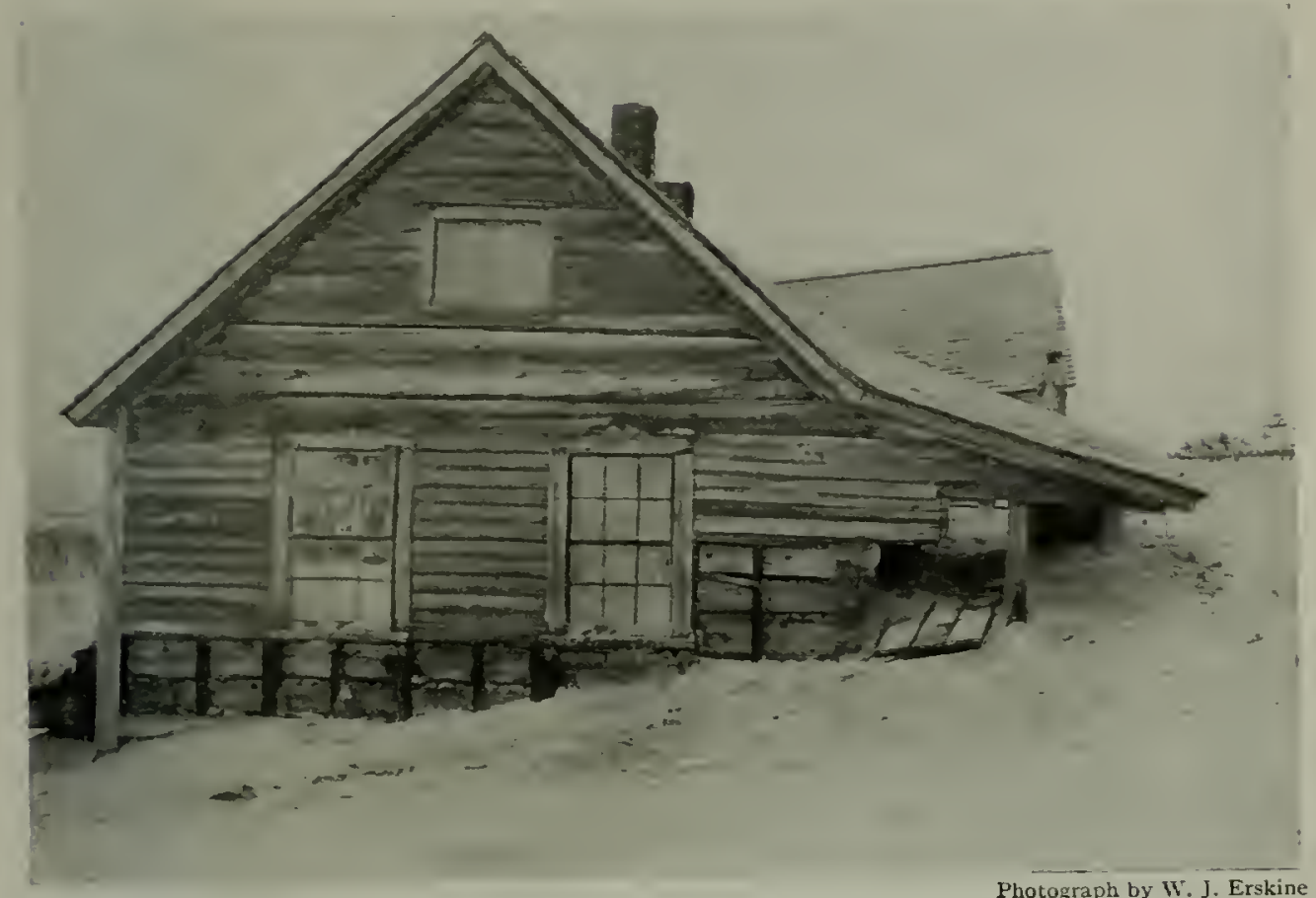

HOUSE IN KODIAK HALF FILLED WITH ASH BY AVALANCHE FROM THE HILLS

The level of the ash within may be seen through the window at the left.

the gases issue, and look far down into the depths through swirling currents of superheated steam that rush forth at his very elbow.

So many natural phenomena of interest to the general public, as well as to the scientist, are exhibited in this remarkable region that President Wilson paused in the midst of the World War to set aside the whole district as the Katmai National
Monument, which embraces over a million acres.

Finally, a new harbor, discovered by the expeditions, permits the opening of the region to travel. A few miles of road connecting the harbor with the volcanic area will render the Valley of Ten Thousand Smokes as readily accessible as the geysers of Yellowstone National Park. 


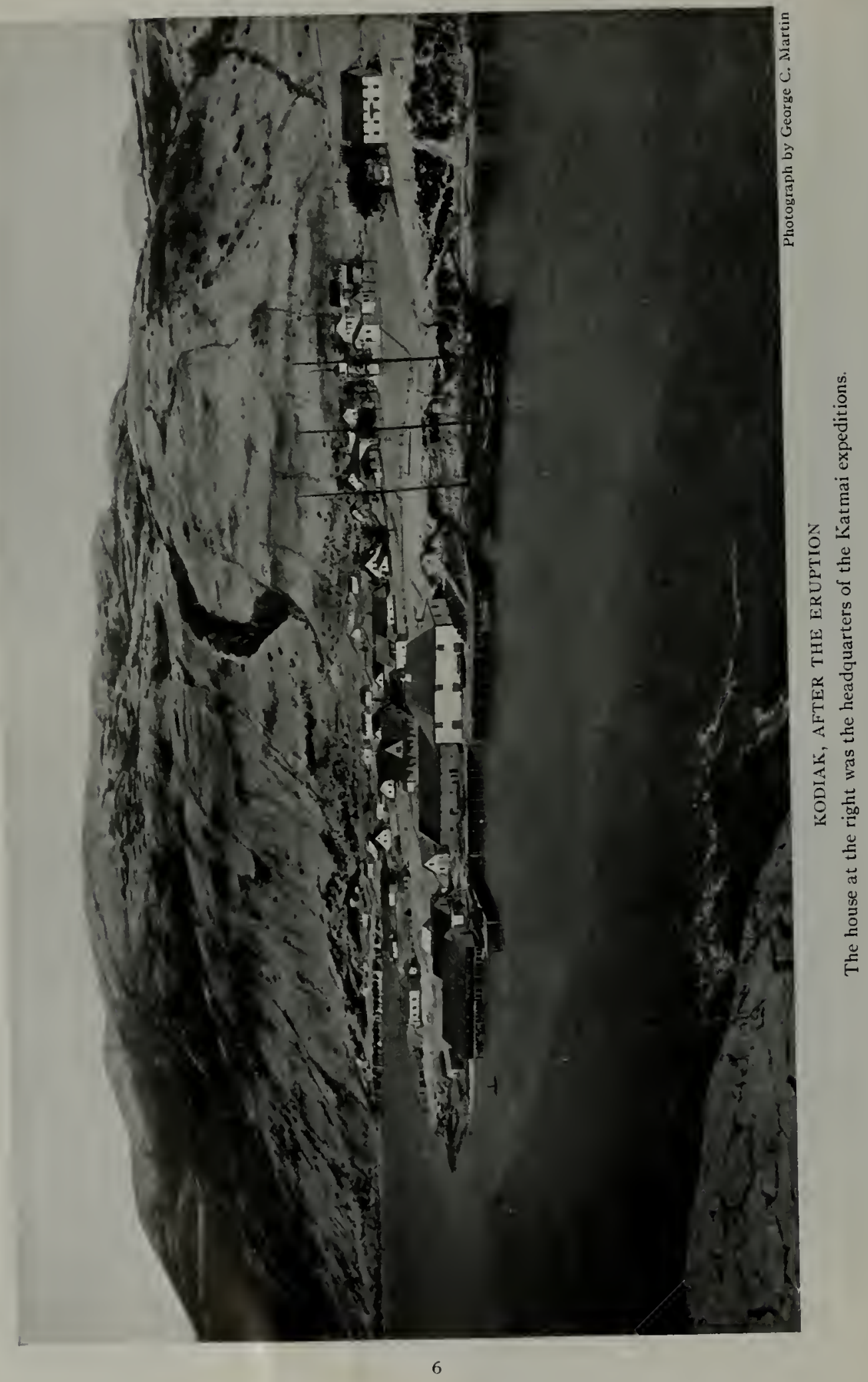




\section{THE ERUPTION AS EXPERIENCED AT KODIAK}

The chronicle of the eruption does not begin with a description of the volcano and the premonitory symptoms that must have preceded the great explosions, for all these passed unnoticed by reason of the remoteness of the region from human habitations.

No one suspected that anything unusual was in prospect until the full force of the explosions had broken loose. Many hours before any notice was taken of the eruption, disturbances must have occurred which, in a thickly populated territory. would have been heralded around the world in flaming headlines. Not until the lives and property of the people of Kodiak, a hundred miles from the volcano, were threatened, was it realized that a great eruption was in progress.

\section{ASH BEGAN FALLING WITHOUT WARNING}

The weather was fair; there was a strong northwest breeze, which in that region betokens a high barometer, and there were none of those signs of impending disaster which one is wont to associate with rolcanic eruptions. Suddenly, and without other warning than the gradual approach of a peculiar dark cloud from the northwest, gray ash began falling at Kodiak at about five o'clock in the afternoon, Thursday, June 6 th.

The only abnormal manifestations in advance of the falling ash were thunder and lightning: but, as these are almost unknown phenomena on the rainy northwest coast of America, their occurrence excited more than usual comment, especially among the natives, many of whom had never before heard thunder. Not even thunder and lightning were observed, however, at the neighboring town of Afognak.

In the beginning, the falling ash was hailed as a great curiosity, and the people carefully swept up samples for mementoes of an event such as they had never witnessed before and were not likely to see again. ${ }^{1}$

\section{KODIAK FOT IN A VOLCANIC DISTRICT}

For it must be remembered that Kodiak is not situated in a volcanic district. There are no volcanic formations anywhere on the island; and the nearest of the dormant volcanoes of the distant mainland was a hundred miles away, which under ordinary conditions is an altogether safe distance.

Kodiak was, therefore, almost as much surprised as New York would be if one of the extinct rolcanoes of Connecticut should suddenly awake and shower it with ash.

Indeed, the people of Kodiak had but little more cause to expect serious damage from an eruption than has New York; there was no known reason for alarm. Neither did they possess that careless confidence born of familiarity with volcanoes and frequent experience with minor eruptions, which often lulls the inhabitants of a volcanic district into the belief that nothing really serious is going to happen, until they fail to heed warnings which everyone agrees afterward should have been sufficient to drive the people out of the danger zone.

Beginning gradually, the ashfall increased until it was regarded as "heary" at 6 p.m. By 6.30 it had become so thick as to blot out the daylight, covering the country with total darkness at a season when, in that latitude, daylight is almost continuous for the whole twentyfour hours.

The ash steadily accumulated through the night, but the fall began to slacken

1 There is, however, a record that in March, 1867, half an inch of rolcanic ash fell at Kodiak from some distant eruption (see page 62). 


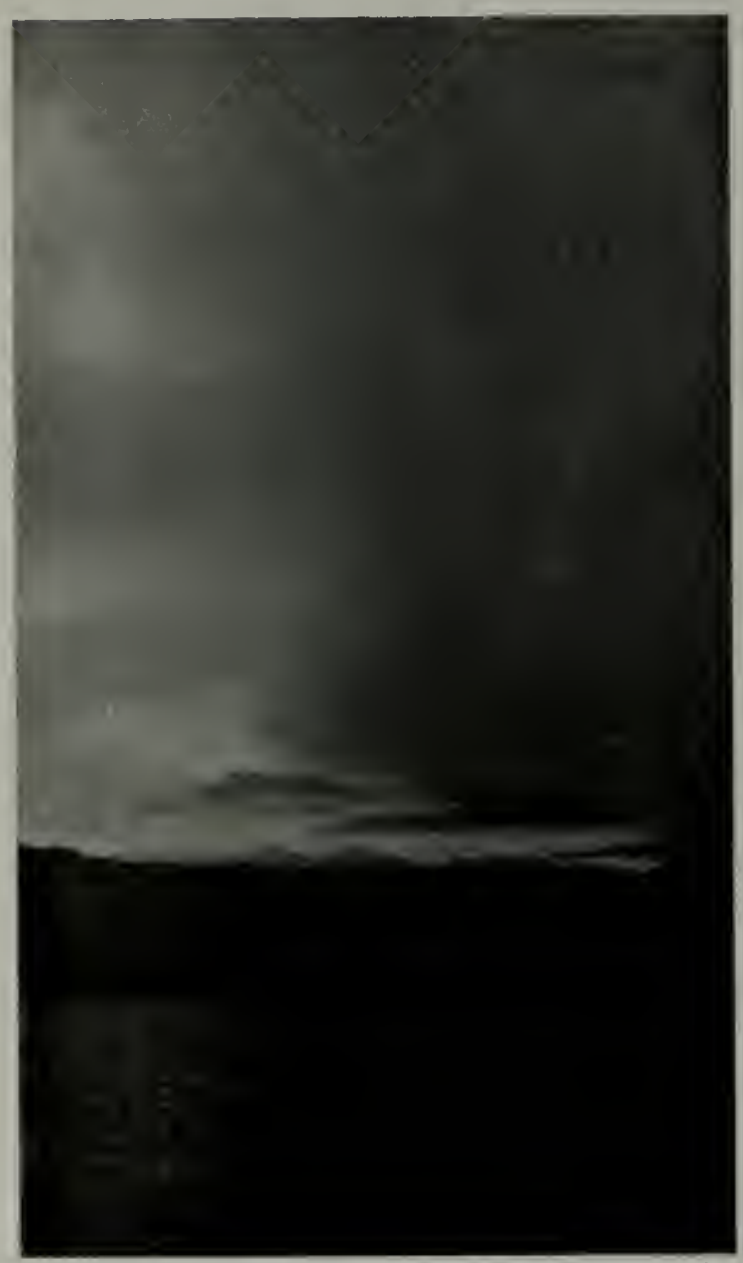

(c) John E. Thwaites

EDGE OF VOLCANIC CLOUD, LOOKING SOUTHWEST FROM THE "DORA," 75 MILES FROM THE VOLCANO

at about 3, and ceased at 9.10, on the morning of the 7 th.

This fall constitutes the bottom layer of relatively coarse gray ash, as it now lies on the ground. As it originally fell, this stratum was about five inches deep at Kodiak, but it has since settled down to about four-fifths of that thickness.

During the night the people retained their composure to a large degree; and when, in the morning, the ashfall gradually diminished and ceased, they believed that it was over. They had, however, no inkling as to the seat of the eruption.
Then, and for many days thereafter, they were completely isolated by the failure of the wireless service. The Kodiak Radio Station on Wood Island had been struck by lightning and burned down at some time during the eruption. The wireless apparatus of the United States Revenue Cutter Manning, which was coaling at Kodiak at the time, was useless because of the electrical condition of the air, which was excessively charged with "static."

The report of Captain K. IV. Perry of the Manning furnishes at once the most vivid and most authoritative account of the experiences of those who went through those trying days together. From it, all the following quotations not otherwise credited are taken. ${ }^{2}$

\section{TERROR BEGAN WITH THE SECOND FALL}

"All streams and wells had now become choked, about five inches of ash having fallen, and water was furnished the inhabitants by the Manning and the schooner Metha Nelson, lying at the end of the dock. We started evaporators to provide drinking water and continued this for several days.

"At noon ashes had begun to fall again, and at $\mathbf{1 2} .30$ were increasing until at I p.m., it was impossible to see over fifty feet. Deep concern was visible on every countenance, and the advisability of the Manning's getting to sea was discussed.

"However, this was out of the question, as few of the inhabitants wished to leave, and the voice of the ship's company was "take all or none.",

With the beginning of this second phase of the eruption the confidence which had carried the people through the first fall deserted them. When it was realized

2 Perry, Captain K. IV. Report of June 21 . Annual Report Revenue Cutter Service for 1912, pp. 115 et seg. 


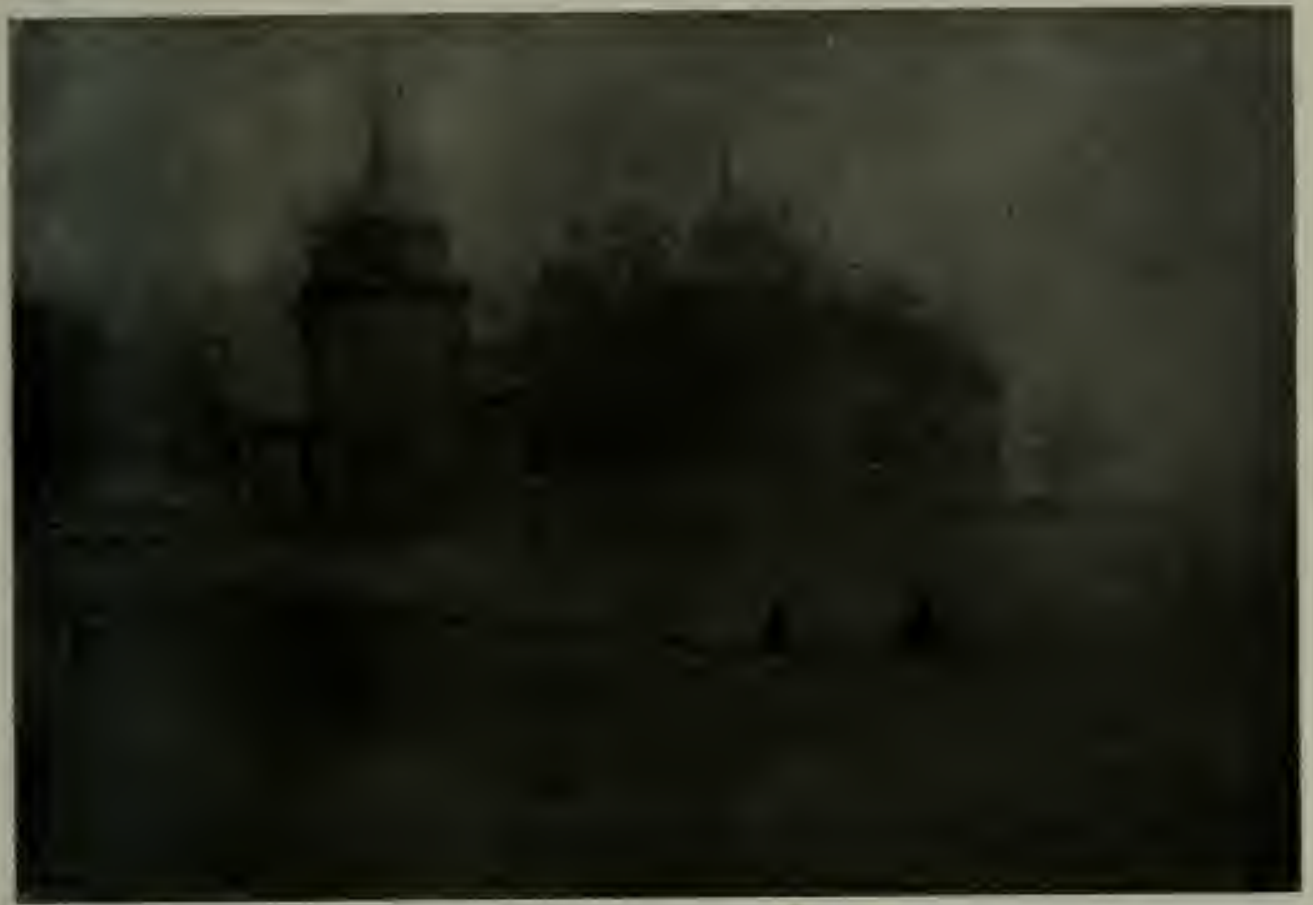

THE GREEK CHURCH AT KODIAK DLRING THE ERUPTION

One can only imagine the feelings of the inhabitants as they groped their way to church through the utter blackness when the bells boomed out the call to prayer on the morning of the third day:

that Kodiak was experiencing not merely such a passing shower of ash as might befall almost any community on the Pacific, but was in the grip of a tremendous eruption, one of perhaps unprecedented violence, the worst fears were naturally engendered.

Once the affair had passed beyond the limit of reasonable probability, no one knew what to expect, and a spectre of abject terror took possession of the place. This was kept from degenerating into panic only by the character of the men in command of the situation. Captain Perry goes on:

"During the afternoon I visited the two saloons in the place and, finding considerable drinking, requested the proprietors to close. This they readily did, agreeing with me that it was a time for every man to keep his mind clear.

"At 2 p.m. pitch darkness had shut in; heavy static disturbances were observed, and our radio was dumb. A few refugees were on board, and the night of the 7 th was spent in anxious watching. We got little sleep, and the dawn of the 8th, which we anxiously awaited, failed to appear.

"While all ashes of the previous day" had been removed, decks, masts, and yards were loaded, as were also the ship's boats. The ashes now were fine dust and flakes, and of a yellowish color. Sulphurous fumes came at times in the air, and many thought and spoke of the destruction of Pompeii. Aralanches of ashes on the neighboring hills could be heard, and these sent forth clouds of suffocating dust and ashes.

"All hands were on duty from 7 a.m. Men often collided in working about decks, as the feeble glow of the electric lights and lanterns failed to dispel the awful darkness for any distance. The crew kept constantly at work with shovels, and four streams of water from the fre mains were playing incessantly in 


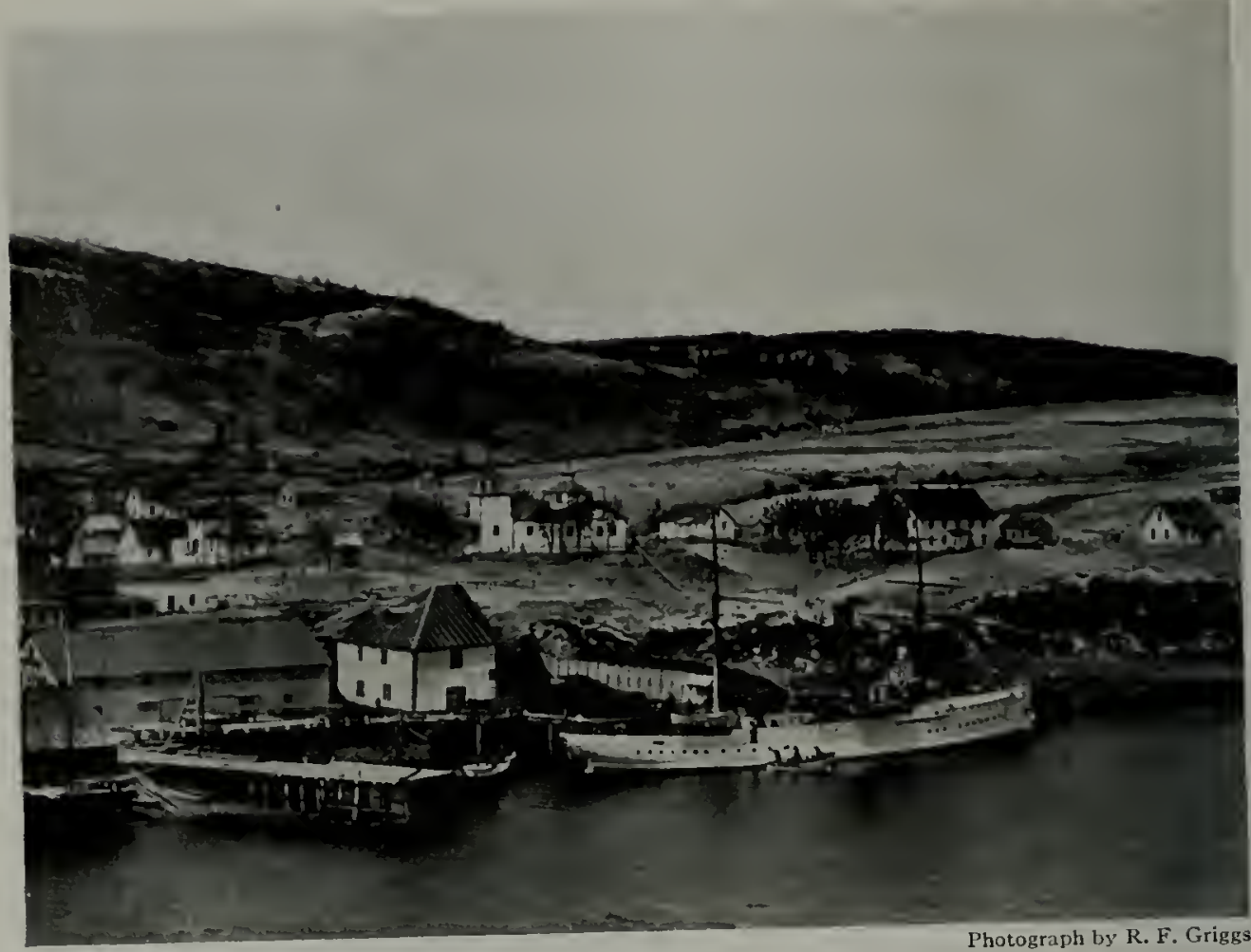

THE "MANNING" LYING AT THE DOCK IN KODIAK

When we frst visited Kodiak a year after the eruption, the Manning was again coaling alongside the warehouse which had sheltered the population before she took them aboard.

what at times seemed a vain effort to clear the ship of its horrible burden.

"'The bells of the Greek church boomed out in the blackness, and few, if any, of its followers there were who did not grope thcir way to the call to prayer."

\section{DARKNESS SO THICK A LANTERN COULD NOT BE SEEN AT ARM'S LENGTH}

None of those who went through those day's of terror fail to mention, in recounting their experiences, the awful darkness which is universally described as something so far beyond the darkness of the blackest night that it cannot be comprehender by those who did not experience it. Many have told me that it was impossible to see a lantern at arm's length, so thick was the cloud of ash which enveloped cverything.
The sensations produced by the falling ash are vividly described by J. E. Thwaites, Mail Clerk of the steamer Dora, which crossed the arca of falling ash: ${ }^{3}$

"And now began the real rain of ashes; it fell in torrents; it swirled and eddied. Gravity scemed to have nothing to do with the course of its fall. The under side of the decks seemed to catch as much ash as the sides or the decks uncler our fect. Bright clusters of electric light could be secn but a few fect away, and we had to feel our way about the deck.

"'The officers of the deck had to close the windows of the pilot-house tightly, and even then it was with the greatest difficulty that the man at the wheel could see the compass, through the thick clust that filled the room. 


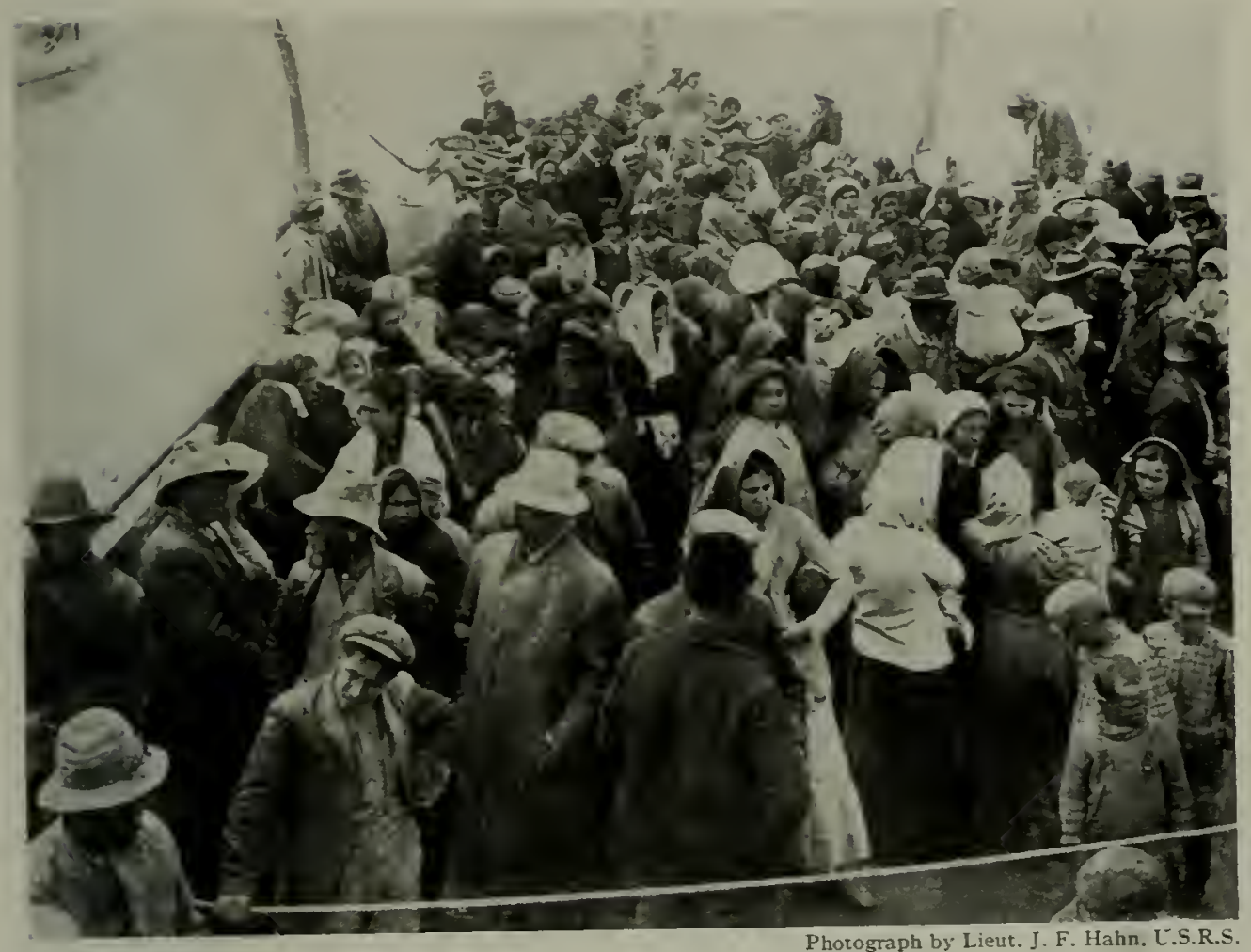

REFLGEES FROY KODIAK OX BOARD THE " MAXXIXG"

The suffering caused by overcrowding was far worse than that due to the eruption. On to a vessel capable of accommodating at most a hundred people in comfort were crowded more than 500 men, women, and children, all suffering from nervous shock and in fear of their lives. There was hardly room enough on the decks for all the people to lie down at once.

"In the meantime, lurid flashes of lightning glared continuously round the ship, while a constant boom of thunder, sometimes coinciding with the flash. increased the horror of the inferno raging about us. Is far as seeing or hearing the water, or anything pertaining to earth. we might as well have been miles above the surlace of the water. And still we knew the sun was more than two hours above the horizon.

"In the saloon everything was white with a thick layer of dust, while a thick haze filled the air. The temperature rose rapidly, and the air, what there was left of it, became heary, sultry, and stifling. Below deck conditions were unbearable, while on deck it was worse still. Dust filled our nostrils, sifted down our backs, and smote the eye like a dash of acid. Birds floundered, crying wildly, through space, and fell helpless on the deck."

THE PEOPLE ARE GATHERED TOGETHER

When daylight failed to appear on the morning of the third day ( 8 th) it began to be felt that the people of Kodiak should be brought together in order to facilitate the execution of any measures that might be decided upon for their safety. Accordingly, Captain Perry continues:

"At about 8.30 a.m. at my request, the storehouse on the wharf was opened, and after a hurried consultation with some of the chief citizens I sent a message to the priest at the church that all the people could be cared for on the Manning and in the storehouse. Prior to this many had sought refuge on board. 


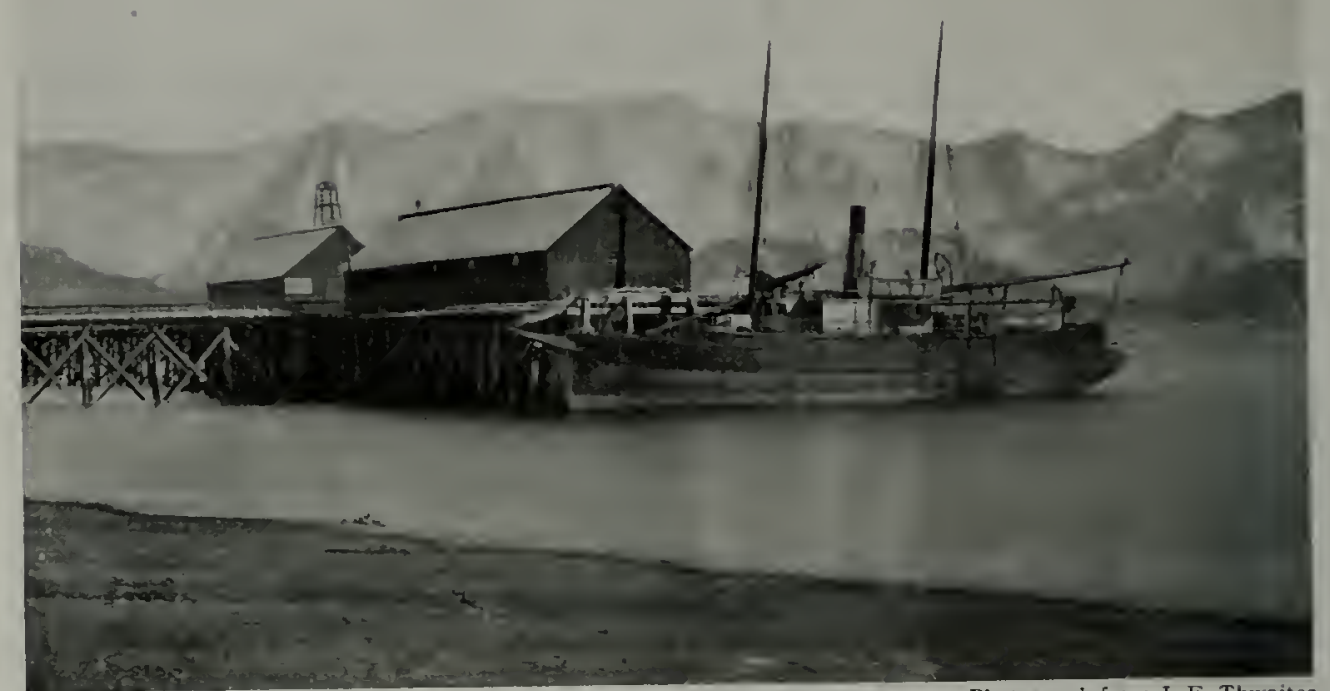

Photograph from J. E. Thwaites

\section{THE "DORA," PARTAKER IN MANY A WILD ALASKAN ESCAPADE}

With uncanny luck the Doro has had a share in almost every adventure in southwestern Alaska. No man can count the number of times she has been on the rocks, but until recently she was still plying those dangerous waters. It was she that located the seat of the eruption and brought the first news to the outside world. Sixteen years earlier it was she that rescued Spurr's party (see Chapter $\mathrm{xx}$ ).

"I then called together a committee meeting of the officers of the ship and several citizens, among whom were local pilots, and it was agreed that, as every landmark was obliterated, it was impossible to see from the bridge, and that as the chances were vastly against a ship making the narrow channel without striking, it was better to stay where we were and take what most of us believed to be only a fighting chance. . .

"At 2.30 p.m. of the 8 th the fall of ashes decreased, the skies assumed a reddish color, and finally objects became dimly visible."

The ashes that fell during this period constitute the second layer of the deposit at Kodiak, a stratum of fine ash of a bright terra cotta color, now $4 \frac{1}{2}$ inches thick.

When the light thus came again, the people looked about them to find that "all clothed and festooned with ashes, nothing looked familiar." This interval of cessation in the fall was considered an opportunity to escape, for-

"As similar phenomena had occurred the previous day, and frequent seismic disturbances were still felt, much fear existed that worse was still to come.

"I hastily summoned a committee of citizens and, after hearing various opinions, decided that to stay might mean death, and there would be a chance of life if the ship could get to sea.

"Consequently all hands were taken on board except United States Deputy Marshal Armstrong (who decided that duty required him to remain) and three other men. While Marshal Armstrong remained ashore, he sent his wife on board. This action furnishes its own comment. Only brave men offer such a sacrifice.

"At 5.30 p.m. the ship cast off and, with two leads going, Capt. Brown, an old and skillful Kodiak pilot, conned her 
through the narrow channel. At 5.55 p.m. we anchored in the outer harbor, having secured a bearing on Woody [Wood] Island that practically assured a safe passage to sea, even though darkness again shut in.

"As soon as the ship anchored, the motor boat Norman stood in to Woody Island and brought off all the inhabitants, I03 in number, many of whom were nearly famished for food and water, while others demanded the attention of doctors and nurses. This day food and water were furnished to 486 people, outside our own crew, quarters to $+\mathrm{I}_{4}$, and 72 were quartered on board the tug Printer, which came out of harbor with the Manning and moored alongside."

The suffering during those hours when the cutter lay at anchor awaiting her doom, as she supposed, was intense. Everyone was worn out from the strain of the ordeal and the work of relief, but there was little rest for those on board. The crew gave up their hammocks to the women and children, but with more than 500 people of all ages and conditions aboard a vessel not capable of accommodating one-fourth that number in comfort, hardly a place to lie down could be found on the crowded decks.

\section{THIRD FALL OF ASH ON THE NIGHT OF THE EIGHTH}

During the night of the 8th ash began falling again and continued until some unrecorded hour in the morning. This fall constitutes the top, third layer of fine gray ash, which amounted to an inch and a half, after being packed down.
Before the air finally cleared, after this last fall, Kodiak had experienced two day's and three nights of practically unbroken darkness.

Notwithstanding the confidence in the possibility of escape on the Manning, the congestion on the little craft was so great as to be intolerable, and when the morning of the gth dawned clear and bright, murmurs to be landed began to be heard.

Accordingly, in the afternoon the inhabitants of Wood Island were taken ashore, since it was possible to care for them all in comfort at the Baptist Mission there. The Kodiak people remained aboard until the morning of the roth, when they also were gradually transferred to their homes.

Everyone agrees that the real and unavoidable discomfort resulting from the eruption was slight as compared to the suffering occasioned by terror and by the overcrowding of those days on the Manning. If the people could have known in advance what was to come, they might have remained in their homes throughout the ashfall in perfect safety and in comparative comfort. It was the vivid descriptions of the "Last Days of Pompeii" and the fear of being buried alive that made the experience so terrible.

If some one had remembered that Pompeii was only five miles from Vesuvius, whereas Kodiak was a hundred miles from any volcano, and had assured the terror-stricken people that nothing worse than they were already experiencing could possibly come to Kodiak, he might have greatly alleviated conditions. 


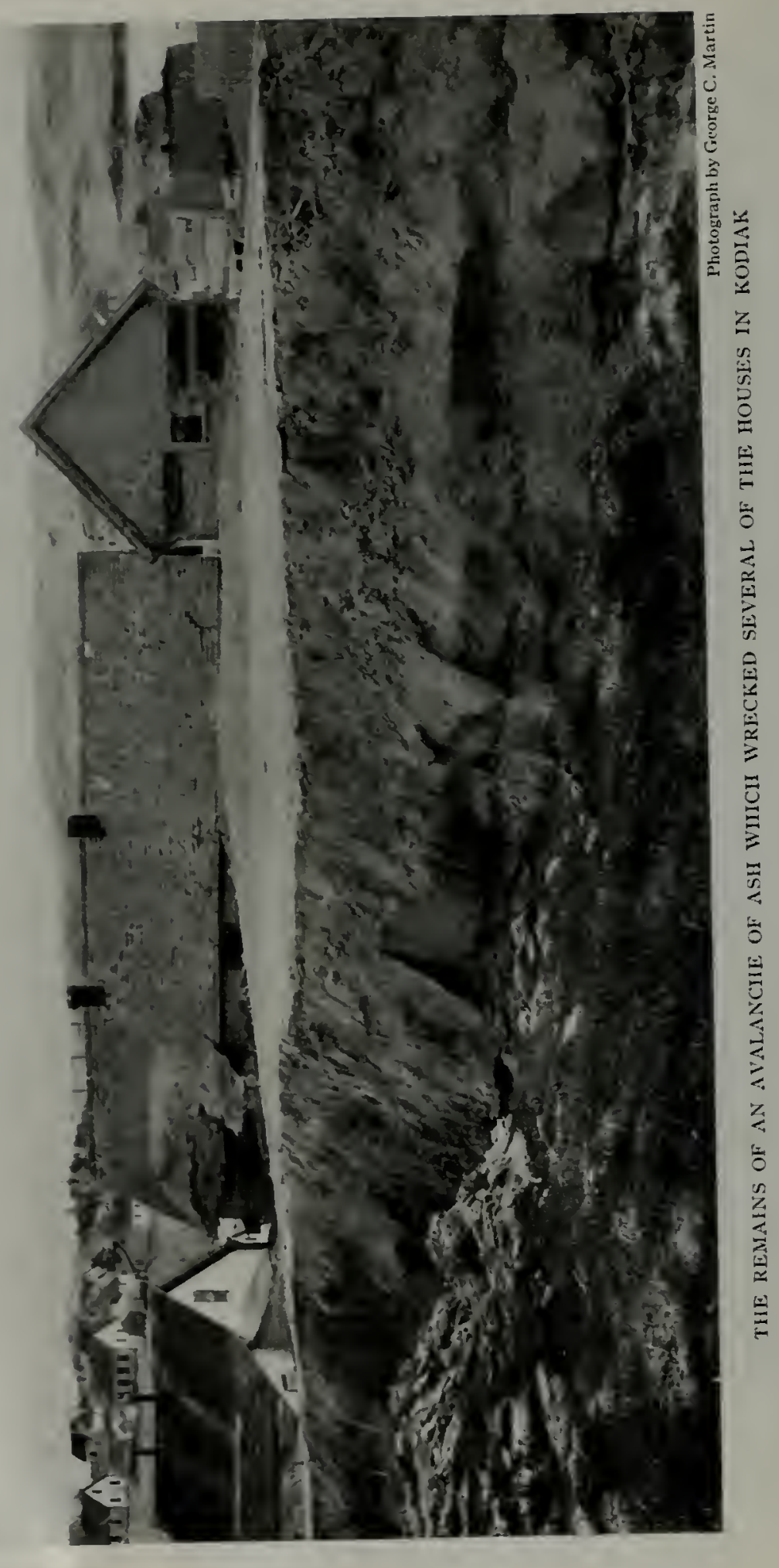




\section{RECORDS OF THE ERUPTION FROM OTHER LOCALITIES}

Among the people of Kodiak imprisoned on the Manning, speculation was rife as to the source of their misfortune. But it was several days before they were to be enlightened.

When the ashfall finally ceased and the outlook began to improve, Captain Perry dispatched one boat to Seward, the terminus of the cable, to communicate with the outside world, and another to ascertain how the neighboring settlements had fared, and offer assistance. It was not until the I 2 th that information was received in a message from one of these boats that the eruption had come from Mount Katmai, a peak which until that time was practically unknown.

\section{THE IDENTIFICATION OF THE VOLCANO}

The determination of the seat of the eruption was first made by C. B. McMullen, Captain of the steamer Dora, "that notorious partaker in many a wild Alaskan escapade," which, with characteristic luck, happened to be passing through Shelikof Strait at the time. Captain McMullen's description of his experience is as follows: ${ }^{1}$

"Left Uyak at 8.45 a.m., June 6; strong westerly breeze and fine clear weather. At I o'clock p.m., while entering Kupreanof Straits, sighted a heavy cloud of smoke directly astern, raising from the Alaska Peninsula. I took bearings of same, which I made out to be Katmai Volcano, distance about 55 miles away. The smoke arose and spread in the sky, following the vessel, and by $3 \mathrm{p} . \mathrm{m}$. was directly over us, having traveled at the rate of 20 miles an hour."

Captain McMullen's determination, although corroborated by other mariners and by the testimony of the natives

1 This portion of our account is almost altogether abstracted from the excellent narrative of George C. Martin, who directed the first ex- quoted below, was not, however, unchallenged.

The press dispatches named Iliamna and Redoubt as equal partners in the disturbance. This uncertainty was, however, due largely to the fact that there were no traditions of previous activity from Katmai. That mountain was, indeed, almost unknown. The Juneau Alaska "Dispatch," in commenting on the news, remarked that Katmai was not shown on the maps. J. L. McPherson, of the Seattle Chamber of Commerce, who had spent a summer prospecting within 50 miles of Katmai stated categorically that there was no Mount Katmai, and supplied pictures of Peulik, on Becharof Lake, which he suspected might be the seat of the eruption. Other less known peaks were also mentioned.

As a matter of fact, the identity of the volcano was not established to the satisfaction of the people of Kodiak until three years later, when the first of the expeditions of the National Geographic Society, under the leadership of the writer, reached the scene and proved that the ash had come from Katmai and not from some other vent.

As there were no considerable settlements anywhere near the volcano, there is so little testimony from eyewitnesses as to the events of the eruption that only a very fragmentary account can be given.

Of the preliminary disturbances which must have preceded the great explosion practically nothing is known. This is the more surprising since, as subsequent exploration has shown, it was during this period, before the explosion of Katmai, that the Valley of Ten Thousand Smokes was opened up and its enormous flows of incandescent sand poured forth.

pedition sent to the scene by the National Geographic Society. For fuller details see the National Geographic Magazine, February, I9I3. 


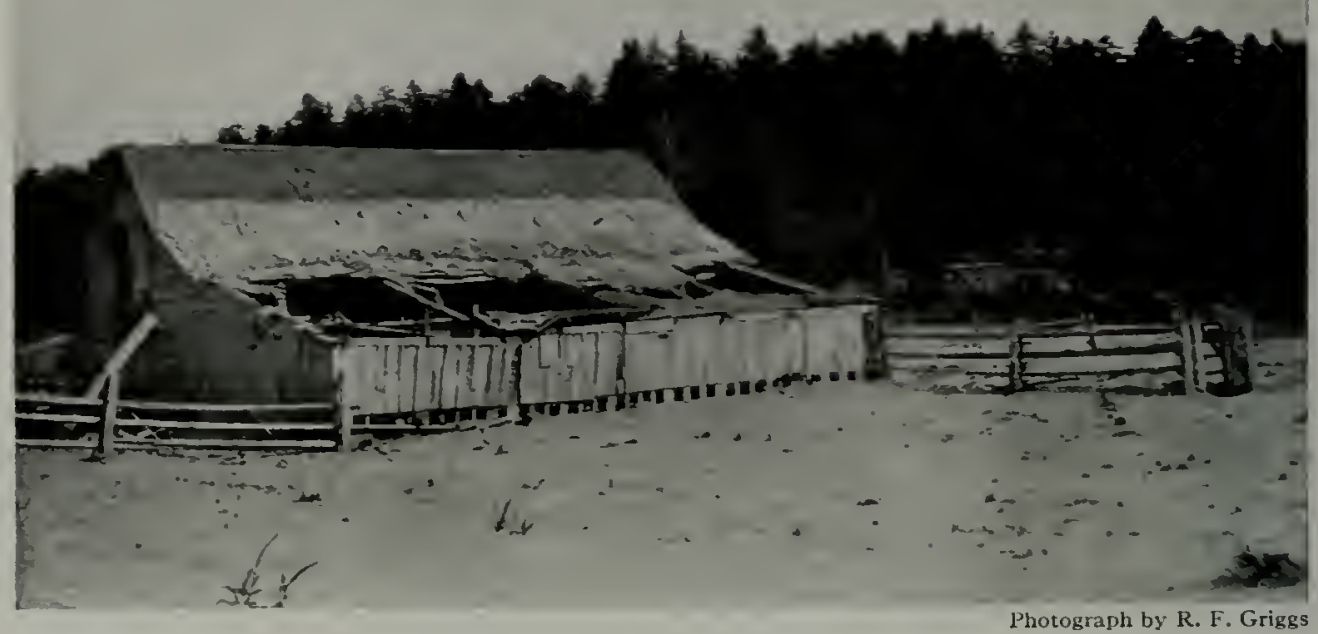

A ROOF CRUSHED BY THE WEIGHT OF ASHES

Picture taken on Long Island, over a hundred miles from Nount Katmai, a year after the eruption.

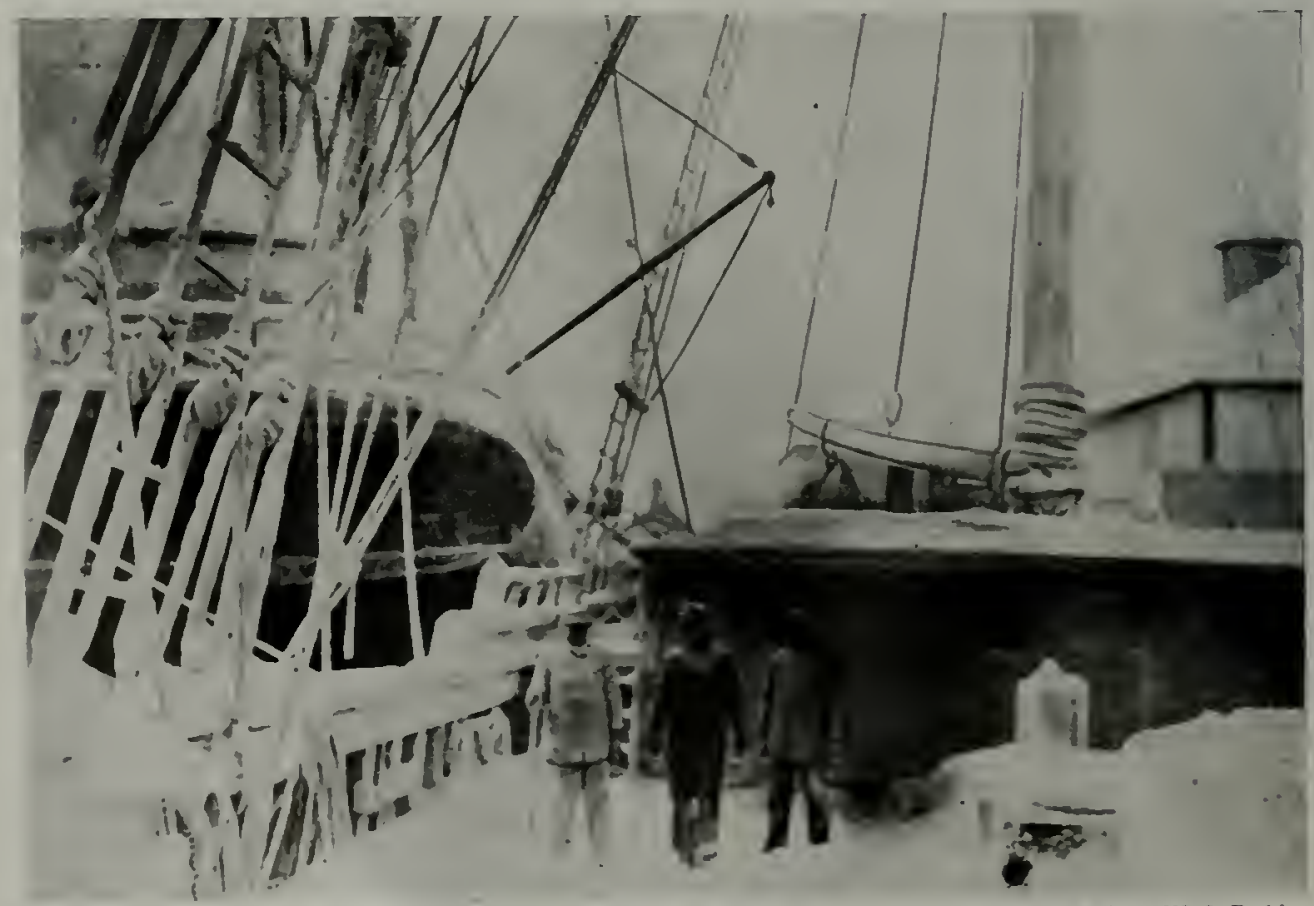

Photograph by. W. J. Erskine ASH FALL COVERED SHIPS AT KODIAK, JUNE 9, I9I2 
Surely we would have supposed that the tremendous cataclysm necessary to open the great fissures of the Valley would make itself felt far and wide, but as a matter of fact there is no definite record of events during this period.

\section{ACCOUNT OF THE ERUPTION BY NATIVES OF KATMAI VILLAGE}

Of those nearest the volcano, the inhabitants of Katmai Village, all but six had been away fishing at Kaflia Bay for some time before the eruption. These two families remained on the ground until June 4, when they were frightened away by the earthquakes and by other signs of impending disaster, but they gave no circumstantial account of the cause of their flight.

They were still camped along the coast in the vicinity of Cape Kubugakli within sight of Mount Katmai when it blew up, and so reported when they reached Cold Bay, where their accounts were transcribed to the diaries of two white men resident at that place. C. L. Boudry wrote, under date of June 8th:

"Two families arrived from Katmai scared and hungry and reported the volcanoes up I 5 mile from Katmai (village) to the left of Toscar trail and that $1 / 2$ the hill blun up and covered up everything as far as they could see also that small rock were falling for 3 or 4 miles at sea but could not say more of it as every thing es closed up with smoke. These people had left Katmai village June 4 and camped between Kashvik and Alinchak bays. The rocks an fall in their boat are of the size of coarse rice and of the pumice stone formation. No one es lost as far as they know but all the natives are east of Katmai and the main flow of smoke go there as a strong $\mathrm{S} \mathrm{W}$ wind blowing so they are in a bad shape."

Jack Lee wrote: "They report the top of Katma Mountain blun of. There was a lot of Pummy stone in their dory when they got here and the say Hot Rock was flying all eraund them."
The only other persons within sight of the volcano at the time of the explosion were the natives in the village of Savonoski at the head of Naknek Lake, 2I miles $(34 \mathrm{~km}$.) from Katmai Crater. The ravages of the eruption caused these people to flee in terror to Naknek, abandoning their village at Savonoski and settling near Naknek, where they were interviewed by P. R. Hagelbarger, of the National Geographic Expedition of 1918.

"American Pete," chief of the village, had barabaras ${ }^{1}$ (houses) both at Savonoski and at Ukak, up the Valley near the present foot of the sandflow. Warned by the earthquakes preliminary to the outburst, he was in process of removing his belongings from Ukak to Savonoski when the eruption began. His account of what followed runs thus:

\section{STORY OF "AMERICAN PETE," CHIEF OF SAYONOSKI}

"The Katmai Mountain blew up with lots of fire, and fire came down trail from Katmai with lots of smoke. We go fast Savonoski. Everybody get in bidarka (skin boat). Helluva job. We come Naknek one day, dark, no could see. Hot ash fall. Work like hell. Now I go back every year one month maybe after fish all dry and kill bear. Too bad. Never can go back to Savonoski to libe again. Everything ash. Good place, too, you bet. Fine trees, lots moose, bear and deer. Lots of fish in front of barabara. No many mosquitoes. Fine church, fine house. Naknek no good."

The fire which American Pete saw coming down the trail from Katmai was probably started by the great Incandescent Sandflow, which was already rolling down the Valley before the explosion of Katmai.

Realizing that this man and his party were the only human beings in Ukak Valley at the time of the bursting forth of the Valley of Ten Thousand Smokes, Mr. Hagelbarger endeavored by questioning to elicit further details, but none were to be obtained. The sole interest 


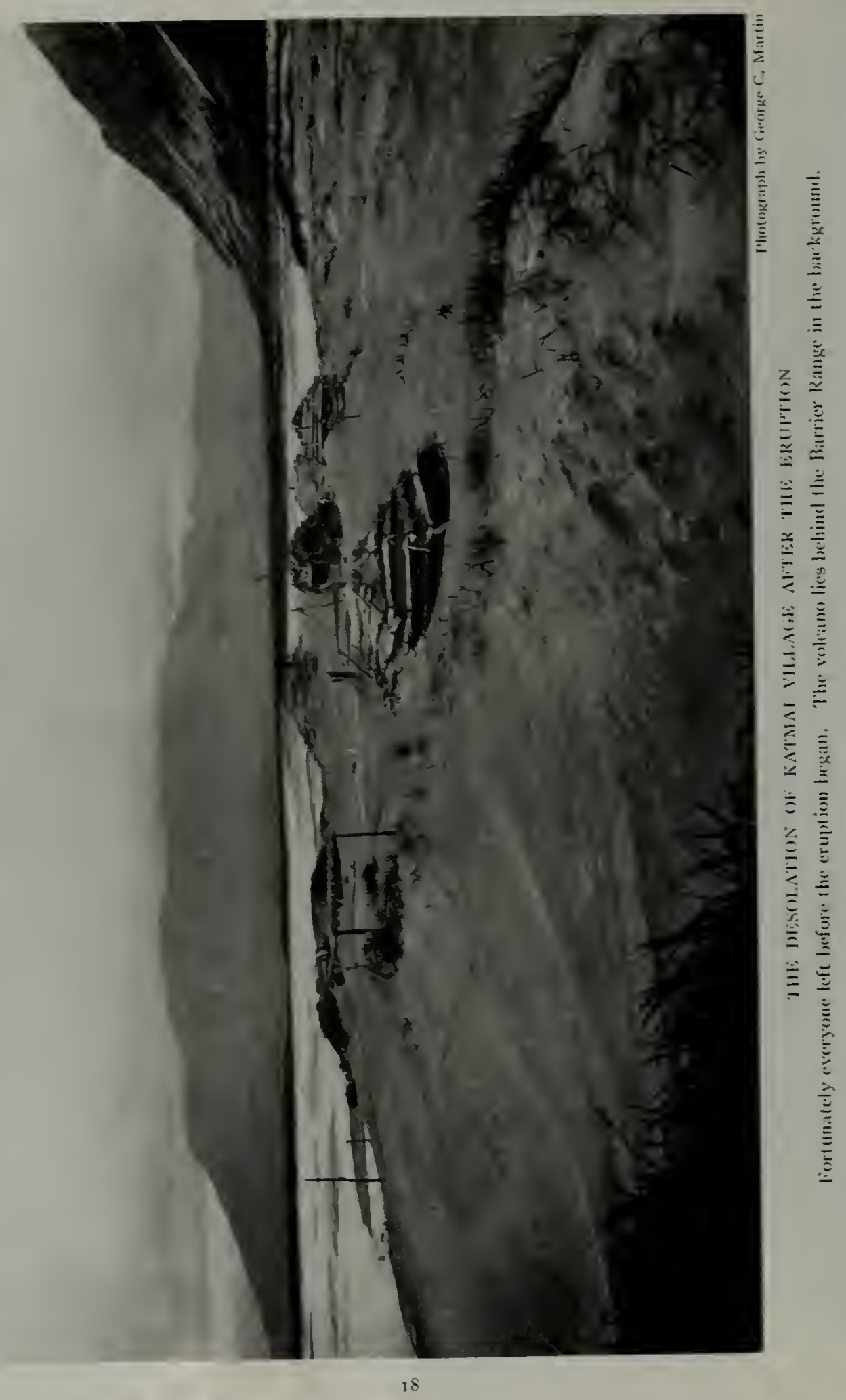


of the natives had evidently been to flee from the coming wrath of the eruption.

The only additional information that could be obtained concerned the condition of the Valley before the eruption, which was described as having clumps of trces along the stream clear up under the glaciers of Mount Mageik, where travelers camped before going over the Pass. The tundra in the upper part of the Valley was firm, and it was a great place for caribou.

\section{EXPERIENCES OF PEOPLE AT KAFLIA BAY}

The only other persons anywhere near the volcano were the natives at the fishing station in Kaflia Bay. They were, to be sure, about 30 miles $(47 \mathrm{~km}$.) from the crater and so situated as to be screened from the volcano by intervening mountains, which, while protecting them, prevented their observing the eruption. Their ordeal, while similar to that of the people of Kodiak, was more terrible, being both much more intense and more prolonged.

Unfortunately, there appears to be no other record of their experiences than this very interesting letter, written by one of them:

$$
\text { "Kaflia Bay, June 9, } 1912 .
$$

My dear IIife Tania:

First of all I will let you know of our unlucky voyage. I do not know whether we shall be either alive or well. We are awaiting death at any moment. Of course do not be alarmed. A mountain has burst near here, so that we are covered with ashes, in some places 10 feet and 6 feet deep. All this began on the 6 th of June. Night and day we light lamps. IVe cannot see the daylight. In a word it is terrible, and we are expecting death at any moment, and we have no water. All the rivers are covered with ashes. Just ashes mixed with water. Here are darkness and hell, thunder and noise. I do not know whether it is day or night. Vanka will tell you all about it. So kissing and blessing you both, good-bye. Forgive me. Perhaps we shall see each other again. God is merciful. Pray for us.

Your husband,

IVAN ORLOFF.
The earth is trembling: it lightens every minute. It is terrible. We are praying."

That there were no casualties among these people is sufficiently conclusive evidence that there is no great danger of being buried alive by a fall of volcanic ash. Their survival makes it perfectly clear that the people of Kodiak were at no time in any real danger, and that if they could have been spared their terror they might have endured the ordeal with comparative ease.

These fragmentary statements contain all the testimony available from points within 30 miles of the crater. We are, therefore, dependent for further information as to the character of the eruption upon inferences drawn from conditions found later around the volcanoes. These may be more appropriately taken up in the discussion of the exploration than at this point and are accordingly deferred to Chapters xxI, and xxr.

PRELIMINARY SYMPTOMS OBSERVED AT OUTLYING STATIONS

Earthquakes began at Katmai Village at least five days before the explosion, while on June 4 and 5 there were more severe shocks, sufficiently strong to be felt at Kanatak, 65 miles (rookm.) southwest of the volcano, at Uyak, 58 miles $(93 \mathrm{~km}$.) southeast, and at Nushagak, 130 miles (2 ro km.) northwest (see map, opposite page $\mathrm{I}$ ).

A considerable eruption of some sort probably occurred in the evening of the $5^{\text {th }}$, since observers at Cold Bay, 40 miles $(65 \mathrm{~km}$.) southwest, noted that the northern sky, i.e., in the direction of the Valley of Ten Thousand Smokes, looked "black and storming" late that night in spite of the fact that there was clear weather on the coast.

During the morning of the 6th explosions were heard at Seldovia, 150 miles $(2$ to $\mathrm{km}$.) northeast of Katmai and at Nushagak, 130 miles (2 ro km.) northwest, but were not noted elsewhere. 


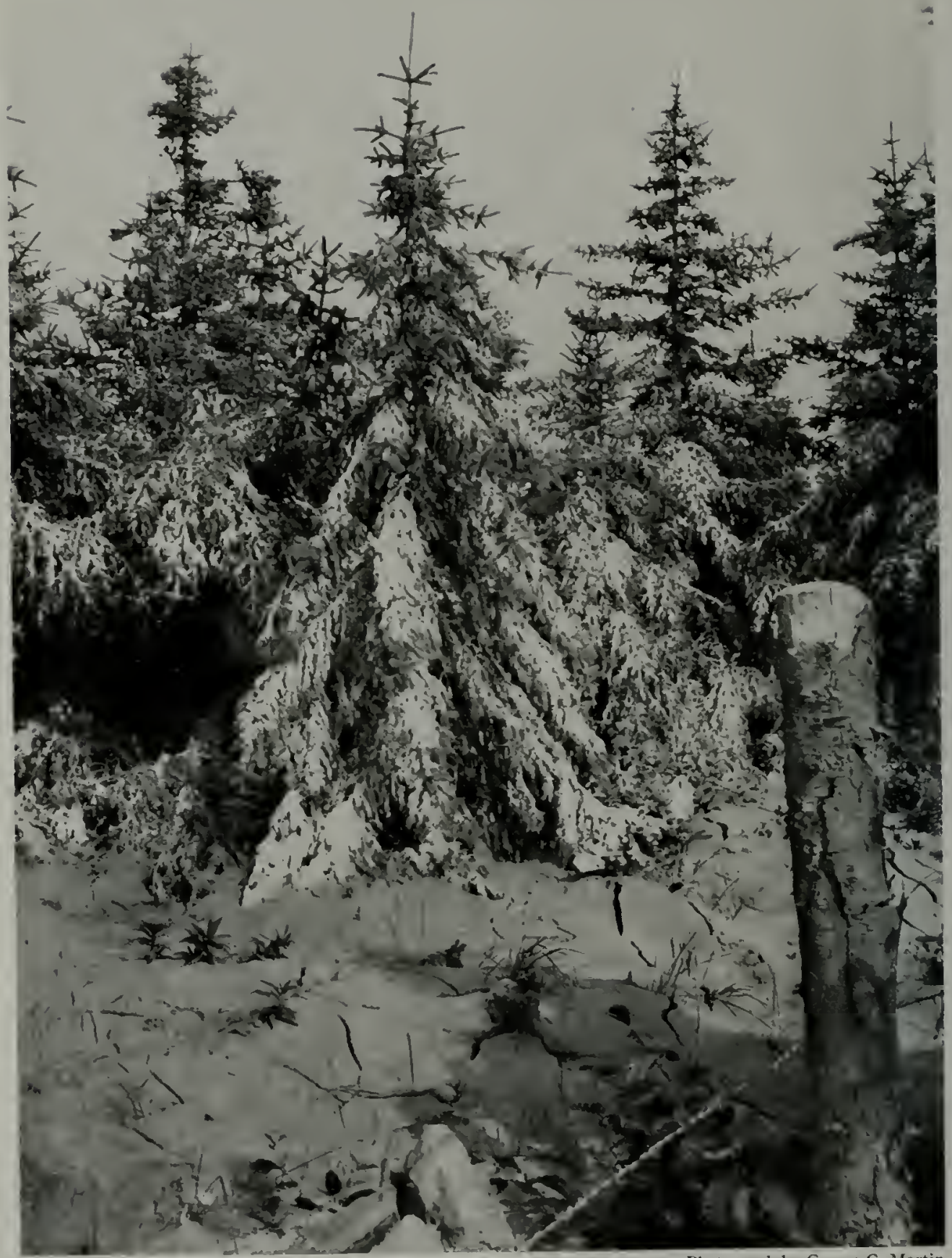

Photograph by George C. Martin

ASH-LADEN TREES NEAR KODIAK, AUGUST 26, I 9 I 2

The branches bending to the ground made a tent under every tree. 
At I p.m., on June 6, the terrific explosions and earthquakes which ushered in the period of violent activity were noted at Cold Bay, while at the same time the Dora first observed the black column rising from the rolcano (see quotation page 15). The same cloud of ash and steam was seen also fron Lake Clark and from Cook Inlet.

\section{PERIOD OF MIXIMUM ACTIVITI}

From this time on the volcano continued in a state of prodigious activity for more than sixty hours, until some time after midnight on the 8 th. During this period especially violent explosions, corresponding roughly, at least, to the three major layers of ash, occurred at 3 p.m. on the 6 th, at I I p.m. on the same day, and at 10.40 p.m. on the 7 th.

Af ter the third of these explosions, the volcano subsided a little, but it remained in a state of violent activity for several days more, as indicated by the letter of Ivan Orloff (quoted above), which, though dated the gth, gives no hint of a cessation of the eruption. The explosions continued to be heard through the 9 th at Seldovia, I50 miles $(240 \mathrm{~km}$.) northeast.

"On the morning of the 9 th observers

${ }^{2}$ Quotation from Martin, op. cit. p. I 58 .

3 The only record of this period of waning activity extant is given in the diary of C. L. Boudry of Cold Bay. From it 1 glean the following:

"9th. Still shaking and fumes are getting strong, ashes are falling steady . . .; Ioth. Still shaking . . . fumes not so bad ". . tremors are not so steady and not so strong .; I th. Shaking some . . .; I2th. Still shaking 7 a.m., and all day, only few hard shake; fumes are not so bad: I3th. Still shaking but not so hard. No more shakes after 12 o'clock and fumes are few; I fth. Not shaking since 7 or $80^{\prime}$ clock last night . . . start shaking at I p.m. but not so hard, about 6 or 7 shocks till 9 p.m. $15^{\text {th }}$ and 16 th same conditions; 17 th. Lots of smoke and fumes are pretty strong. Shaking hard and after 12 o'clock. Can hear the roar every once a while. After each roar a strong shake occur . . . 2 Ist. To-day shake is the hardest since the IIth of June; $23 \mathrm{rd}$. . . at 3 p.m. could see like a large reflection of a large fre; the heaven was very red so was the fog or smoke right over the hills.

"July 21 st. At 2 p.m. fog clear up and could at Naknek, 80 miles northwest of the volcano, saw a beautiful illuminated funnel-shaped cloud which rose straight into the air to a considerable altitude and, as there was no wind, retained its shape. It afterward asstmed different colors and dissolved into cloud banks, being illuminated all the time. A similar cloud was observed from Iliamna, II5 miles north-northeast of the volcano and I 35 miles from Naknek, at the same time, the description differing from the above only in the statement that in losing its funnel-shape form it assumed the shape of a ship." 2

\section{GRADUALLY SUBSIDING ACTIYITY CON- TINUED ALL SUMMER}

All accounts agree that the volcano was very active for a long time after the great explosions, but details are lacking. Apparently the freely eruptive condition continued for many weeks. This appears to have been followed by a gradual subsidence of activity until the present quiescent condition was reached. ${ }^{3}$

Turning now to the record of the eruption preserved in the layers of ash, we find that even such activity as was recorded by Mr. Boudry on June 17 th and 23 rd and on July 2 Ist was not accom-

see smoke from new crater, not a steady flow but puff every 2 or 3 minutes or so some small and other, hard, one smoke far above cloud;

at 5 p.m., the smoke close of the top of hillock was like orer a fire as the color is reddish.

All smoke from new crater is like steam escaping or else light yellow. At to p.nt. a small shock, not over 6 seconds duration, direction $E$. \& IT. One hard shock at $1 \mathrm{I}+5$, hard enough to throw hat off table, duration about I minute to $\mathrm{I}^{1 / 2}$ min. Rock broke loose on cliff on beach."

On November 23 Mr. Boudry described the condition of the volcano as follows:

"The volcano are still raising cane. . . . I will try to go there in winter or spring but can't make it now. I try 3 time. Cannot see notting for smoke and after you are 10 or 12 miles the acid raise hell . . the acid burne the close you got on and raise blister on your hands. The worst shake we got was on the 20 th Sept. Twestie the houses bad and knock the toiling from the houses down-also 1 was outside, just throw me as ef 1 ad received a good rock on the side- Not much dogs, they get blind from acid." 


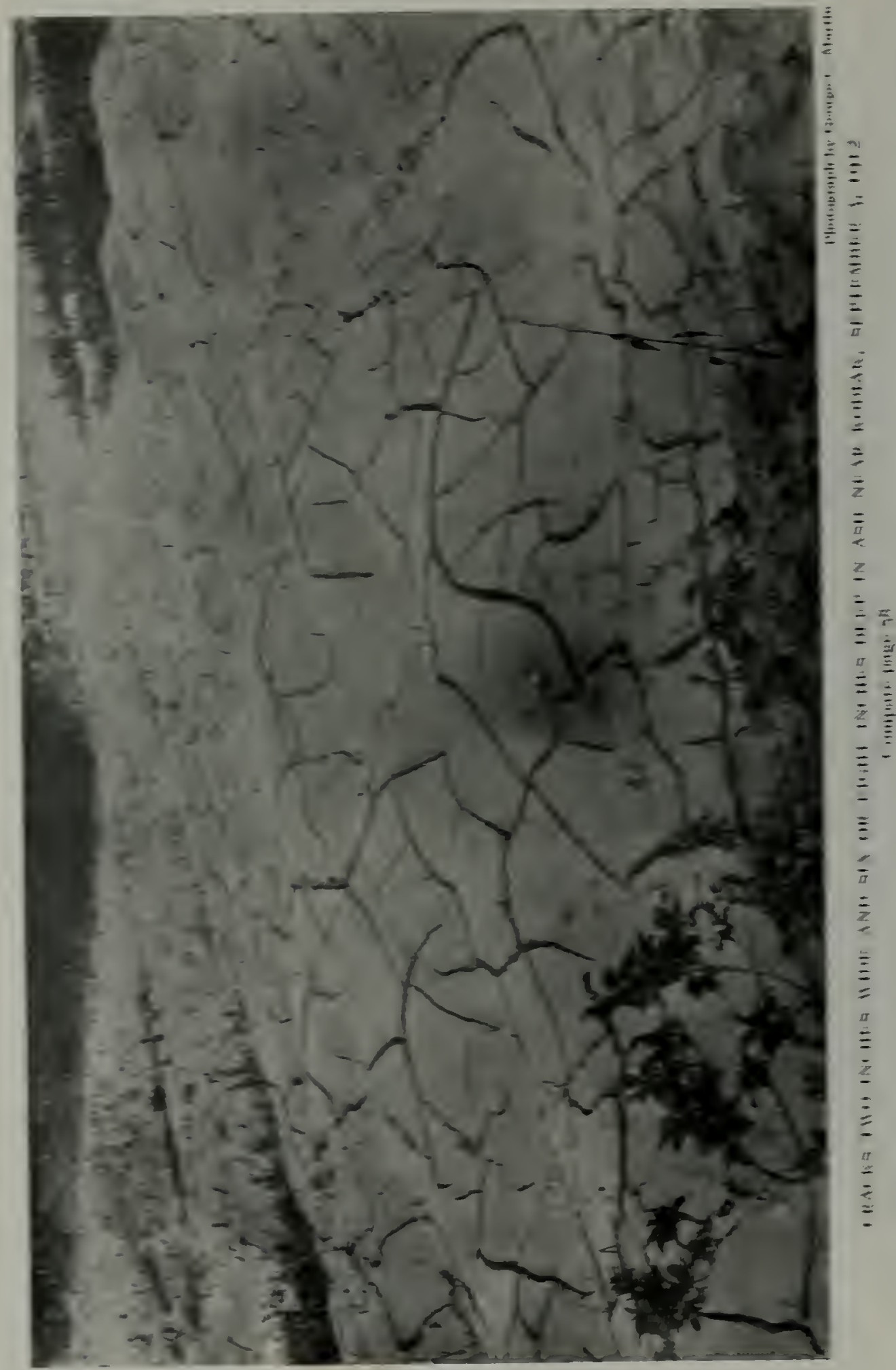


panied by the extrusion of any great quantity of solid matter.

In Upper Katmai Valley a fourth yellowish layer of ash overlies the three primary strata. This was probably thrown out immediately after the more widely distributed layers. probably on the 8 th or 9 th. It was later capped by the stratum of very finely divided mud. which marks the top of the ejecta in Katmai Valley (see Chapter XIII).

RECORDS OF EARTHQUAKES ACCOMPANII.IG THE ERUPTION

The earthquakes accompanying the great explosions were severe enough to be recorded by seismographs at great distances, as evidenced by the following information supplied by- Mr. Napier Dennison, of Victoria, B. C.. who writes:

"I may" also say" that on the 6th and 7 th of June, I912, our Milne seismograph recorded a very large number of quakes and most of them appeared to have had their origin in the Katmai district. Though some of these quakes run into each other, ten are registered on the 6th and twenty on the 7 th (Pacific time)."

The first shock was recorded by the University of Washington (Seattle) seismograph at $2 .+1$ p.m., Thursday, June 6 th, according to the daily press. The Georgetown University (Washington, D. C.) seismograph also recorded shocks almost continuously, beginning at 5 p.m. on the 7 th and continuing through the Sth, some of them being of extraordinary violence.

Notwithstanding the occurrence of shocks strong enough near the volcano to knock a man down, there are no reports of damage from earthquakes. IThether the record would be the same if the country were thickly populated is doubtful.

There are certain evidences, however, that the earthquakes were not so violent as might have been expected. On the mountains around Katmai are large numbers of "balanced" rocks standing in positions of such apparently unstable equilibrium as to suggest that they were never subjected to any very heavy earthquakes.

\section{EXPLOSIONS HEARD 750 YILES AWAY}

The explosions that marked the period of maximum activity were so violent that they were distinctly heard over an enormous extent of country, having been recorded at several places on Iliamna and Clark lakes, Ioo miles (I60 km.) away; at Iliamna Bay. I I5 miles (I 85 $\mathrm{km}$.) northeast, where " the sounds were accompanied by a sudden quick motion of the clouds that would start and stop "; at Seldoria, 150 miles $(2$ to km.) northeast, the continued from the morning of the 6 th until the Ioth; at Cordora, 360 miles $(580 \mathrm{~km}$.) northeast, beginning at 7 p.m., June $6 \mathrm{th}$, they continued till Io p. m., June 7 th; at Copper Center, 450 miles $(-25 \mathrm{~km}$.) northeast, they were heard on the 7 th: at Fairbanks, 500 miles (Soo km.) northeast: at Chicken, 600 miles (I000 $\mathrm{km}$.) northeast, ther were recorded from 2.30 p.m.. June 6 th, until 6 a.m., June 9 th; at Dawson, 650 miles (1,050 km.) northeast; at Katalla, + Io miles $(660 \mathrm{~km}$.) northeast, the detonations "sounded like the explosions of dynamite in the near-by. hills." Juneau, 750 miles ( $1,200 \mathrm{~km}$.) east, appears to have been the most distant place at which they were recorded.

It should be pointed out in this connection that the detection of such sounds at any- place depends largely on the accident of their attracting the attention of some observer, for in this noisy modern world most people take no notice of distant thunder or of explosions that would be distinctly heard by anyone listening for such sounds.

No one at Lodiak observed the sound of the explosions. After the beginning of the ashfall there was, to be sure, so much thunder and lightning that the later explosions, even if heard, were not distinguished from the peals of thunder. But the afternoon of the 6 th is described as quiet and uneventful until the approach of the ash cloud, after $40^{\prime}$ clock. It is not easy to understand why the explosions that occurred prior to that 


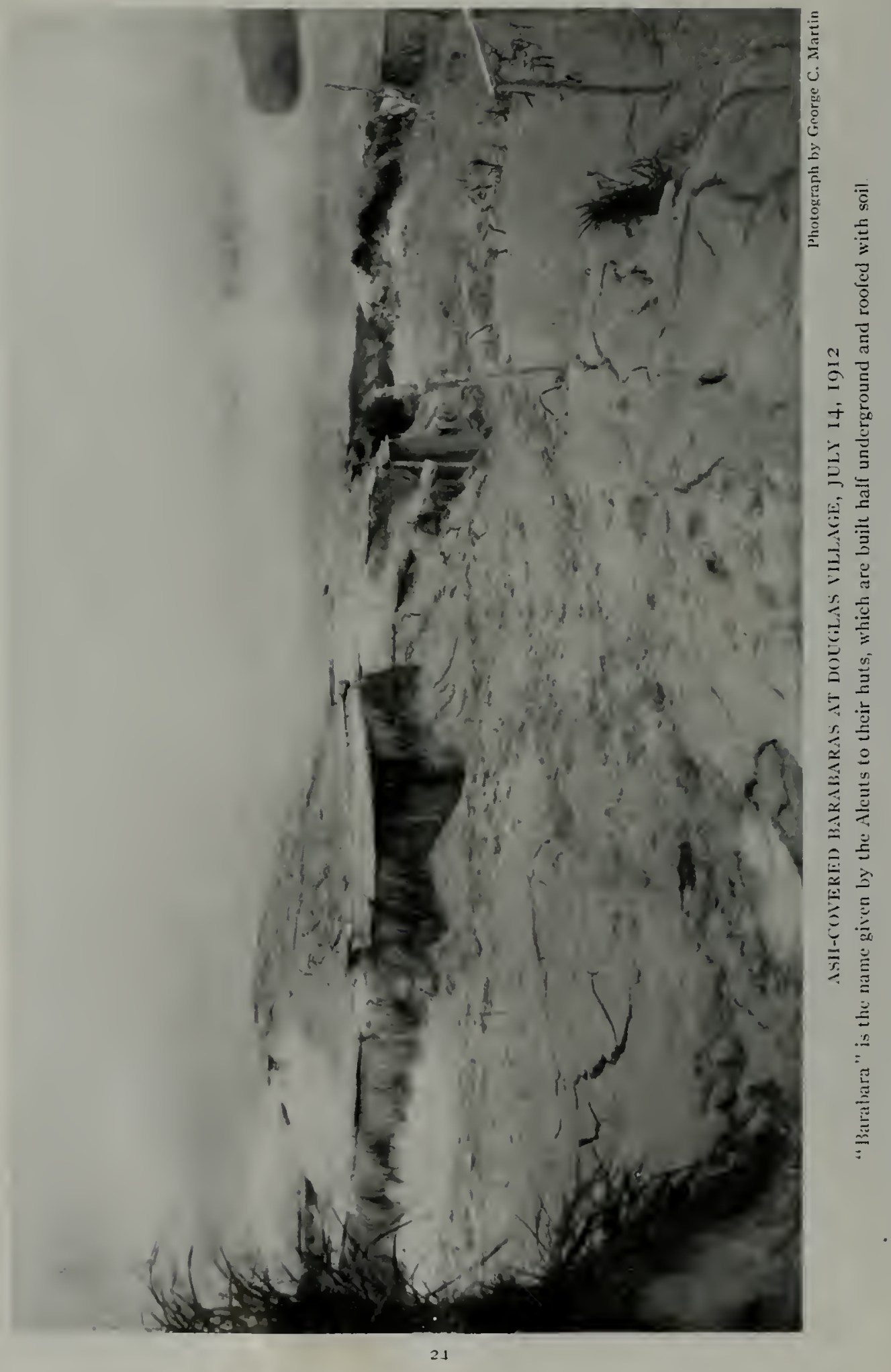


time were not heard at Kodiak and Afognak, since they were noticed at Chicken, 600 miles $(1,000 \mathrm{~km}$.) away.

Curiously enough, a similar phenomenon was observed in the case of Krakatoa, where no sounds were heard in the vicinity, after the beginning of the period of maximum activity, although they were clearly heard (not as one sound but as many) at Rodriguez, 3,000 miles $(5,000 \mathrm{~km}$.) away. This was belicved by the Royal Society's commission, that gathered the data concerning Krakatoa, to be due to the screen of solid matter in the air.

But this explanation appears not to apply to the present instance, inasmuch as there was no such screen of solicl matter around Kodiak until several hours after the explosions began.

SULPHURIC ACID RAINS AT GREAT DISTANCES

The fumes from the eruption penetrated to even greater distances than the sounds. Throughout the area of heavy ashfall disagrceable sulphuric odors were common for many months after the eruption. The gases from the volcanoes, moreover, frequently combined with the moisture of the clouds to produce acid rains which were both disagreeable and destructive. Such acid rains occurred at great distances.

An Associated Press dispatch from Seward, 250 miles $(400 \mathrm{~km}$.) northeast of the volcano, on June IIth, read: "A slight rain fell at Seward today. The water was charged with sulphuric acid, which is killing all vegetation and eating into the metal work of buildings."

On the same day the following dispatch came from Cordova, 360 miles $(580 \mathrm{~km}$.) northeast:"Thefirst real danger here was made apparent when a heavy rain began to fall. The water mixing with the ash in the air formed sulphuric acid which burned painfully whenever it came in contact with the unprotected parts of the bodies of persons in the street. Before the cause was realized many persons received painful burns in the eyes, although none was severely injured."

At Latouche, also, in Prince Villiam Sound, 300 miles $(480 \mathrm{~km}$.) northeast of the rolcano, Mr. F. R.Van Campen, then superintendent of the mines, in a private letter states that, following the eruption, the rain was so acidified by the fumes as to cause stinging burns wherever it touched the flesh. He had his chemist analyze this rain, and found that the trouble was caused by- sulphuric acid, which was present in considerable quantity. Unfortunately the analysis giving the precise concentration of the acid has been lost.

This acid rain did serious injury to plants. The tender annuals of the gardens were completely destroyed, and the leaves of many of the native perennial plants were so burned that they dropped off.

At Cape Spencer, about 700 miles $(\mathbf{I}, \mathrm{I} 00 \mathrm{~km}$.) east of the volcano, the fumes were so strong that "brass tarnished I5 or 20 minutes after being polished" on the decks of the stcamship Admiral Sampson.

The extreme limit reached by the fumes was, however, very much more distant, for their presence was recorded from several places in Washington and in British Columbia, about 1,500 miles $(2.400 \mathrm{~km}$.) from the volcano. It will be advisable, however, to defer citation of authority for this statement until the discussion of the ashfall.

\section{A FOOT OF ASH OVER AN AREA HALF AGAIN AS LARGE AS DELAWARE}

The descriptions of the eruption at different points have already given some conception of the enormous ashfall. A more comprehensive idea of its amount and distribution is furnished by the map opposite page $\mathrm{I}$, on which the varying depths of the deposit are indicated by the contours. This map must not, however, be construed as supplying exact information. Because of the uninhabited character of the country, it was not possible to secure sufficient data to permit drawing 


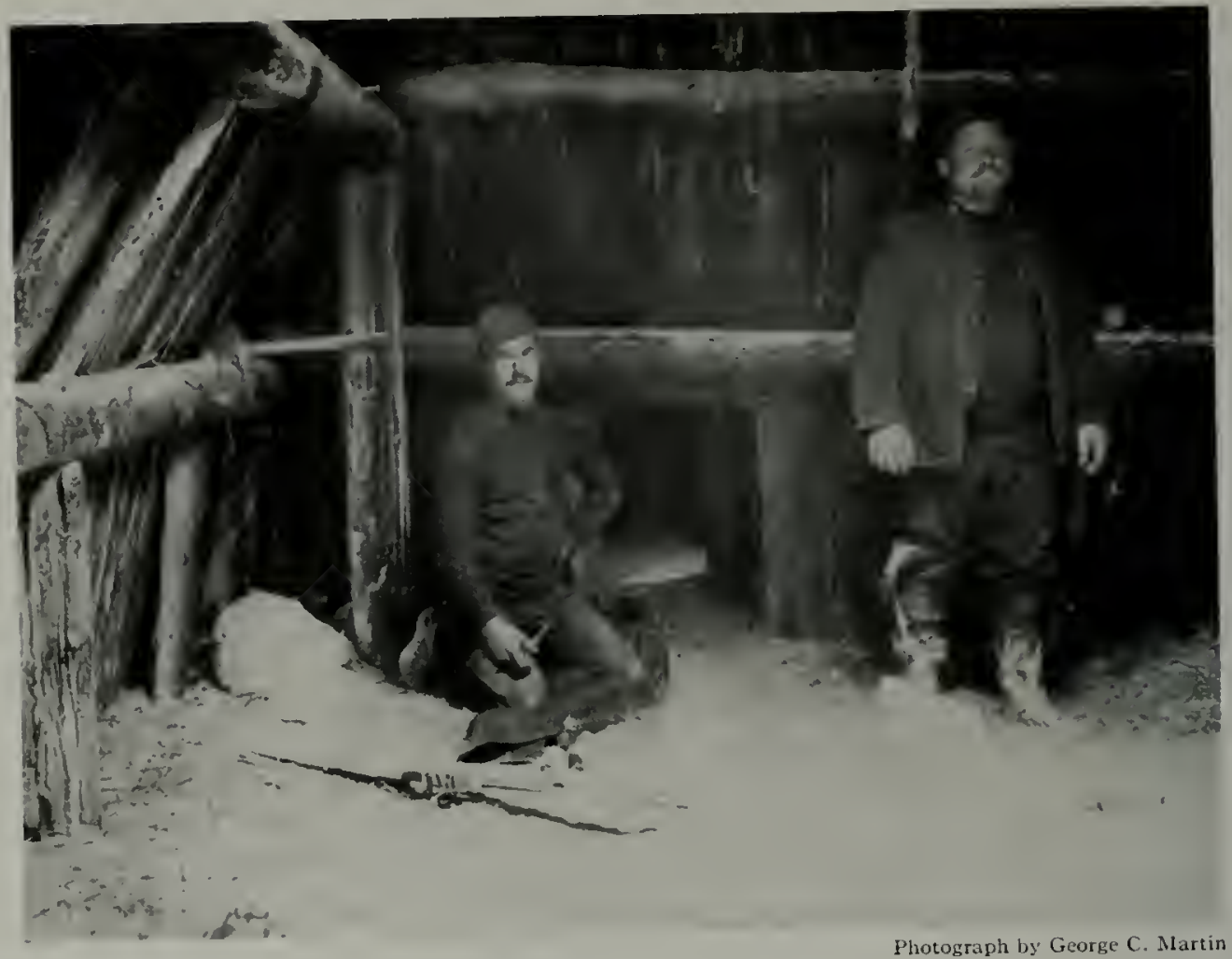

INTERIOR OF A BARABARA SHOWING THE CONSTRUCTION OF THE NATIVE HUTS

Compare with exterior, page 24 . The ash sifted even into such structures.

the contours with any great precision except in the small sector between Kodiak and the volcano.

Accepting, however, the data on the map as the best obtainable, we may list the areas within the different contours.

An area of about 930 square miles $(2,500$ sq. $\mathrm{km}$. $)$ was covered with three feet $(90 \mathrm{~cm}$.) or more of ash. The area covered by a fall of two feet $(60 \mathrm{~cm}$.) includes 2,500 square miles $(6,400$ sq. $\mathrm{km}$.$) . Ash to the depth of a foot (30$ $\mathrm{cm}$.) or more fell over an area of 3,000 square miles $(7,800 \mathrm{sq} . \mathrm{km}$.), half again as large as Delaware. An area of 29,600 square miles $(77,000 \mathrm{sq} . \mathrm{km}$.) was covered with one inch $(25 \mathrm{~mm}$.) or more. The quarter-inch contour $(6 \mathrm{~mm}$.) incloses a territory of $+2,000$ square miles (I09,000 sq. $\mathrm{km}$.), equal to the area of Tennessee.

In addition to this, dust, having an enormous aggregate volume, fell far beyond the quarter-inch mark on our map. It is recorded, for example, that "about one-fourth inch of ash fell" at Katalla, which is 410 miles $(660 \mathrm{~km}$.) northeast of the volcano, twice as far as that depth of fall is indicated on the map.

\section{DUST FELL TO A DISTANCE OF I,50O MILES}

Small but appreciable quantities also fell at much greater distances, ${ }^{4}$ as shown by the following records: Ruby and Innoko, approximately 400 miles $(650 \mathrm{~km}$.) north; Rampart and Fairbanks, 500 miles $(800 \mathrm{~km}$.$) northeast; a point 90$ miles southwest of Eagle, 550 miles $(875 \mathrm{~km}$.) northeast, on the Ioth of June; Dawson, 650 miles $(\mathrm{I}, 050 \mathrm{~km}$.) nor theast, on the IIth; Chicken, 600 miles (I,000 $\mathrm{km}$.) northeast; Juneau, 750 miles ( 1,200

1 These data are partly from Martin's article and partly from Kimball, Monthly Weather Review vol. +1 , pp. 153-59, 1913. 
km.) east; Loring, in the southeastern corner of Alaska, 900 miles $(1,450 \mathrm{~km}$.) east.

Outside of Alaska the ashfall was noticed generally- for a long distance, but definite records are scanty until the thickly populated Puget Sound country is reached. The experience of a steamer in this area was described in a press dispatch, dated Monday, June Ioth, as follows:

"Vancouver, B. C., June Io.-Passengers on the steamer Camosun, which arrived this morning from Prince Rupert, witnessed a wonderful phenomenon all the way down until within Ioo miles of Vancouver. A steady shower of ashes, presumably from the rolcanic eruptions in Alaska, began falling into the sea and on to the ressel's deck soon after clearing.

"The shower kept up steadily from Saturday morning until last night at midnight. 'It was the strangest spectacle I ever saw,' said Dr. U. W. Ewing, the chief surgeon of the Grand Trunk Pacific Medical Service, who was a passenger. The entire heavens were filled with fine dust, which fell steadily.

"The ashes obscured the sun and made everything hazy. Every foot of the steamer was covered, and extra men were assigned to sweeping it away. No sooner was it removed than a fresh supply fell from the sky. We were not aware of the volcanic disturbances in Alaska until we steamed into Vancouver."

Definite records of falling dust were made by a number of observers in the Puget Sound region, which is approximately 1,500 miles $(2,400 \mathrm{~km}$.) southeast of the volcano.

At Victoria, B. C., Mr. Napier Dennison, Superintendent of the Dominion Meteorological Service in British Columbia, vouches for the following quotation from the "Victoria Colonist" of June I1, I912, adding that he himself furnished most of the information:

"Volcanic ash from the Alaskan crater has been falling in Victoria for the past thirty hours, the effect being especially noticeable on brass work on motor cars and elsewhere, due to sulphuric acid in the ash.

"In connection with these remarkable after-effects of the great Alaskan eruption, when thousands of tons of fine ashes were thrown up to the upper air to drift to many quarters of the globe, Mr. Napier Dennison furnishes the 'Colonist' with some interesting notes. Yesterday afternoon he received the following report from Mr. C. D. Rouge, at Malbat Station (on Vancouver Island 20 miles north of Victoria):

"I observed a peculiar haze which settled upon us Sunday, 9 th, about + p.m. and continued till the time of writing (Io a.m. Monday). This haze is apparently heavily charged with sulphuric acid. It is thin in appearance but varied in mass as it crossed the sun. Thinking perhaps it might be sulphuric acid gas, which it resembles both in appearance and smell, I thought perhaps our higher location might render it more noticeable.'

"The presence of sulphuric acid gas or other injurious fumes was noticed in the city (Victoria) by motorists, particularly when driving on the higher and windexposed roads. The effect was to discolour the polished brass work of the cars.

"Mr. Dennison and Mr. C. C. Pemberton also found the windward sides of the exposed trees on the Gonzales rocks covered with a fine white ash, samples of which have been secured for analyses."

The corrosive effects of the acid on brass were reported more circumstantially from Port Townsend, Washington, as follows:

"Port Townsend, June I I.-Sulphuric acid is present in the air in quantities sufficient to blacken the brass work on automobiles. The owners of cars noticed the presence of a peculiar dull-colored corrosion on all brass work. The brass work was repeatedly cleaned but the deposit would quickly return. The deposit is not hard to remove, being in the form of thin dust, but when removed, leares the brass work slightly colored, requiring some little trouble to polish." 


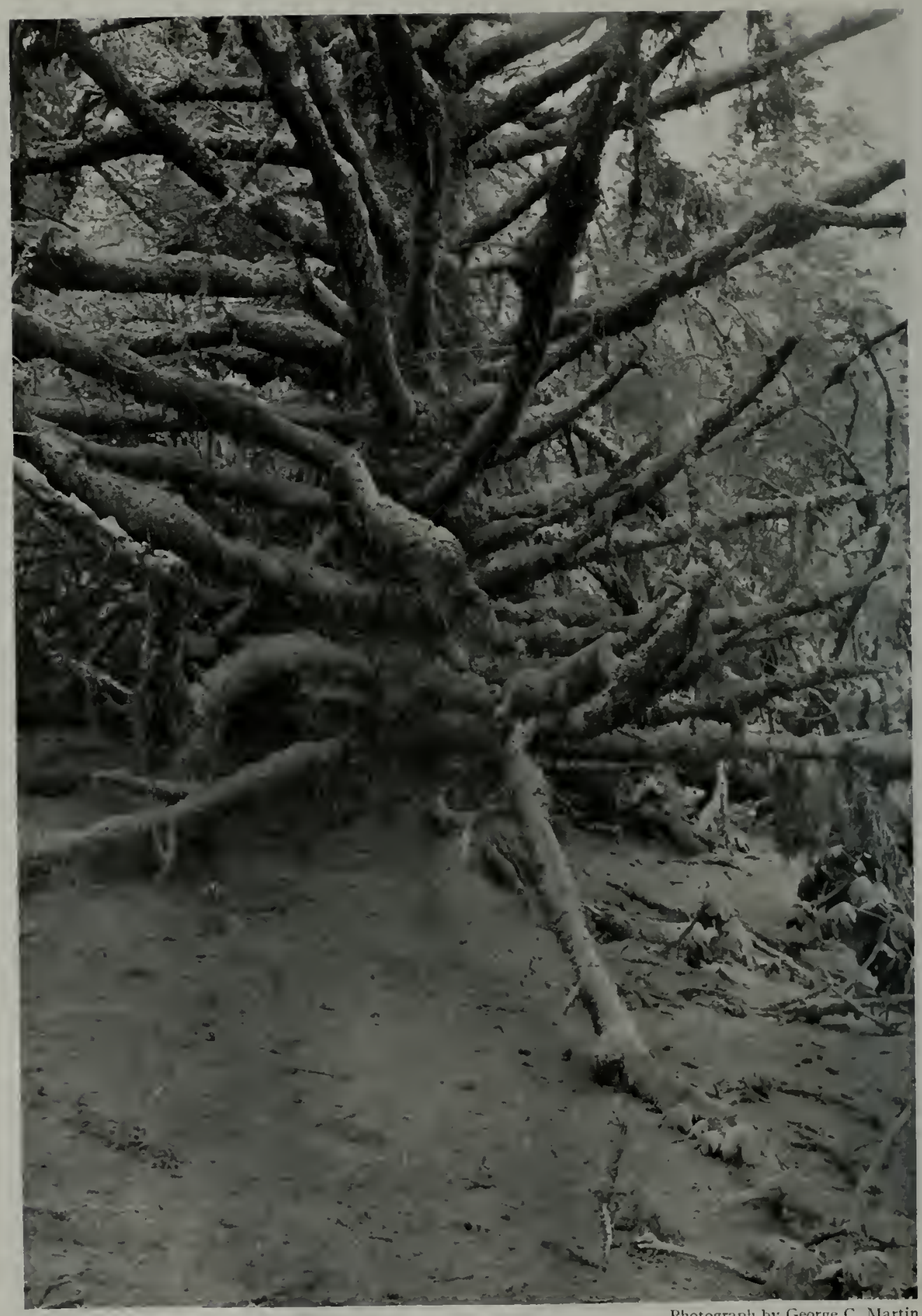


More injurious effects of the acid were reported in a press dispatch from Vancouver the next wash day:

"Vancouver, B. C., June I 2.-Scores of housewives in Vancouver were sufferers because acid, presumably from the Alaskan eruptions, permeated their fine white clothes hanging on the lines after the Monday washing. Linen goods were apparently the only ones attacked. When this white wear came to be ironed it simply fell to pieces, and not until many complaints had reached dry goods houses today were the women able to solve the problem."

The ashfall was likewise detected at Olga and at Tatoosh Island, Washington. At the latter place J. E. Hissong, the weather observer, reported, on June Ioth:

"Light deposit of fine white ash found on southwest side of storm-warning tower at noon. Evidently carried by wind from volcanic explosions in southwestern Alaska"; and three days later: "During the erening of the I 3 th the air was filled with a very fine ash and smoke, a light deposit being noticed on the office furniture on the morning of the Ifth."

Beyond this point the effects of the dust clouds in the upper air belong more properly to the meteorological effects of the eruption, and will be discussed in the next chapter (see page 32 ).

\section{ASH AND SAYD TOTAL SIX CUBIC MILES}

It will be of interest at this point to attempt a rough estimate of the quantity of material thrown out by the rolcano.

Martin, summing up the volumes of the deposits of the several thicknesses shown on his map, arrives at an estimate of 4.9 cubic miles as the volume of measurable ashfall. Since his work was done, a considerable amount of information on matters connected with the ashfall has hecome available. Part of this

\footnotetext{
5 The reader may be inclined to inquire if another liberal allowance should not be made for the dust in the upper atmosphere which was responsible for the meteorological effects treated in the next chapter. Humphreys, however, has
}

tends to increase the estimate, part to decrease it.

Exploration has show $n$ that the ashfall to the northeast of the volcano was not nearly so heary as Martin supposed. Although details are still exceedingly meager, we have ventured to trace contours of ashfall in this region. From the contours of the map, including those in the deeper deposits close to the volcano (which were unknown to Martin), I have estimated the ashfall from Katmai as 4.75 cubic miles.

In this estimate I have assumed that the amount of ash that fell outside the quarter-inch contour was equivalent to one-sixteenth of an inch over a circle of 500 miles radius. This seems conservative, in view of the quarter-inch fall reported at Katalla, +Io miles away and out of the track of the heaviest clouds of ash. $^{5}$

In addition to the ash from Katmai itself, we should consider here the ejecta of other vents thrown out at the same time, for all belong to the same eruption.

In the first place, there is the material composing the great Incandescent Sandflow of the Valley of Ten Thousand Smokes, as described in Chapter xix. Though it is impossible to estimate this with any degree of satisfaction, its magnitude is of the order of one cubic mile.

Second, there is the ash and pumice thrown out by Norarupta in the period of its explosive activity. This covers a circle approximately seven miles in radius to a maximum thickness of about Ioo feet. Allowing for the taper characteristic of volcanoes this may be estimated conservatively as a cone having a radius of seven miles and a height of 50 feet, the volume being, therefore, approximately half a cubic mile.

Summing up these various items, we have in round numbers a total mass of

estimated that one fifteen-hundredth part of a cubic mile of finely divided dust would be sufficient to produce the meteorological effects observed. 'This is much too small a quantity to be considered in our estimate, which is subject to errors of very much larger proportions. 


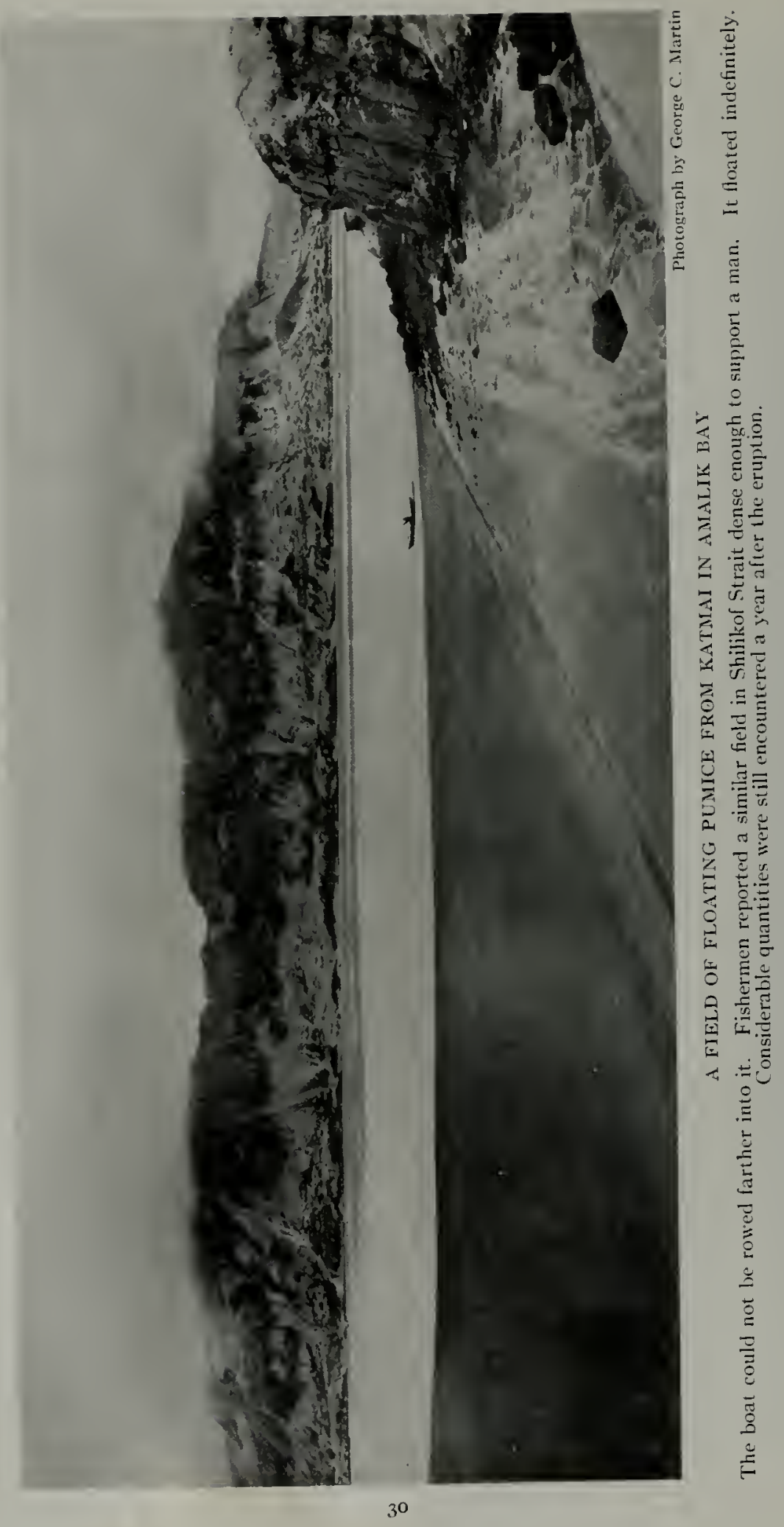


rolcanic ejecta of 6.25 cubic miles thrown out from the interior of the earth during the eruption.

This figure is so stupendous that it quite passes the possibility of comprehension. As it has been my privilege to work over these deposits, season after season, I have found my conception of their magnitude continually growing as my acquaintance with them has broadened. Not because I have gained any concrete conception of their size, but rather because of an increasingly vivid realization that their mass is beyond the grasp of the mind.

\section{EJECTA EQLIVALENT TO OUTPLT FROM STONE CRLSHERS OF UXITED STATES FOR OIER 500 IEARS}

In attempting to form some idea of the bulk of the ejecta, it may be helpful to seek an equivalent in terms of human labor, which is our chief standard of measurement. Since the ash is essentially pulverized rock, the rolcano may be compared to a gigantic stone crusher, except that Katmai reduced a large percentage of its product to dust, thus

${ }^{6}$ This estimate is arrived at by multiplying the volume of the deposits by their specific gravity. I number of samples of the ash as it lies on the ground have been found to average doing its work much more thoroughly than a crusher. The analogy is not quite just, because the ash was formed by the disruption of molten magma rather than by the crushing of solid rock.

Nevertheless, the energy expended in the eruption probably far exceeded the power necessary to crush an equivalent amount of hard rock and, in any case, comparison with the crushed stone production of the country will give a fair idea of the quantity of material thrown out.

The output of broken stone from all the quarries of the Lnited States is about 50 millions of tons annually. The total weight of the ash was about 28,700 millions of tons. ${ }^{6} \quad$ It is thus evident that Katmai "working" only one week, produced as much crushed rock as could be turned out by all the crushers of the Lnited States during a period of 575 vears. That is to say, to catch up with Katmai they would have had to begin operations one hundred and fifty years before the discoverv of America and kept up steadily at their present rate ever since.

a little greater in density than water. The weight of the ejecta nay be computed, therefore, as equivalent to that of an equal volume of water. 


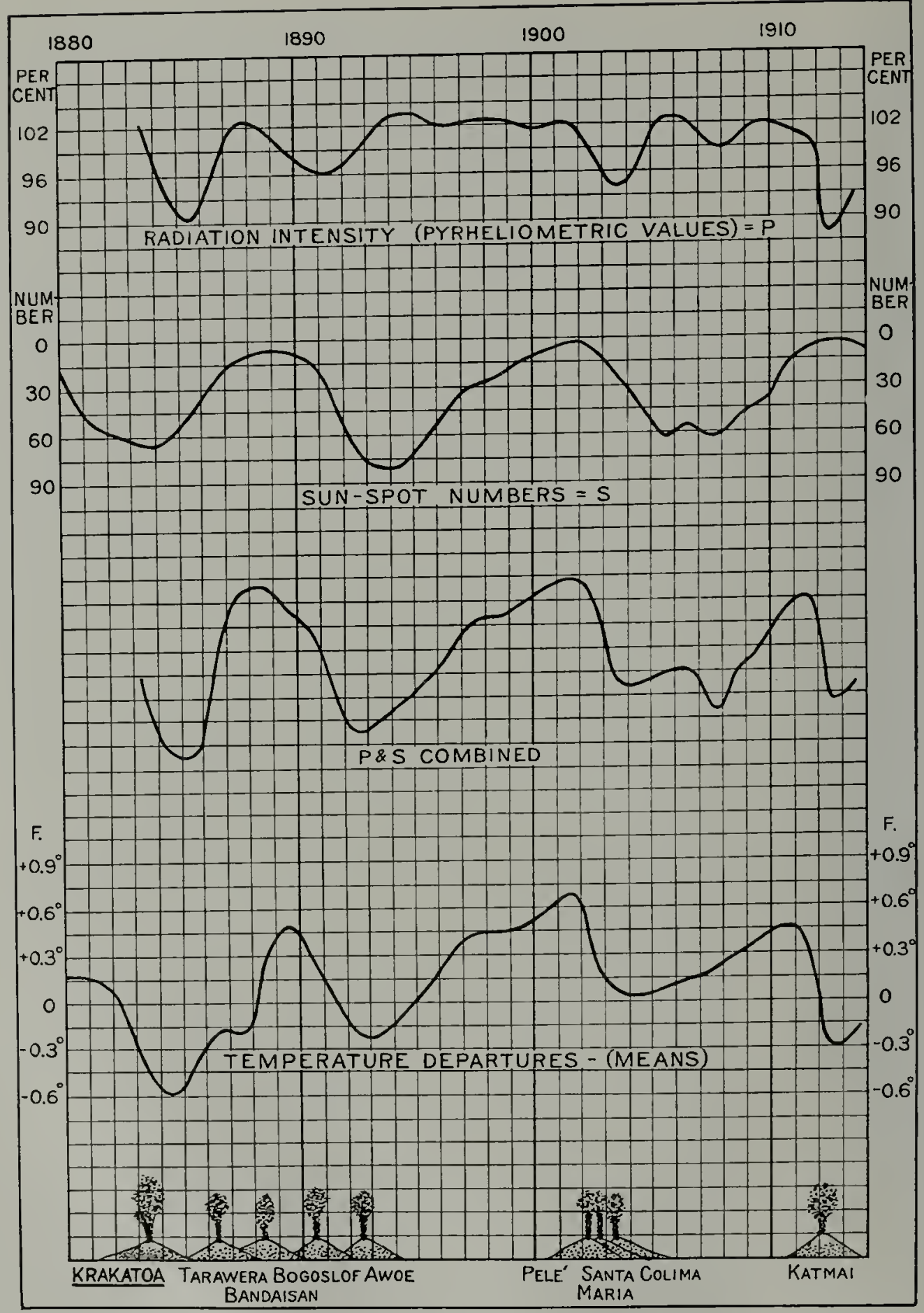

CURVES SHOWING THE RELATIONS OF TEMPERATURE, SUNSPOT NUMBERS AND RADIATION INTENSITY (PVRHELEOMETRIC VALUES) AS AFFECTED BY VOLCANIC ERUPTIONS (After Humphreys.) 


\section{CLIMATIC EFFECTS OF THE ERUPTION}

As intimated in the last chapter, the effects of the eruption were felt far beyond the zone of ashfall. They were in fact world-wide.

The fine dust carried into the upper atmosphere formed a haze which so reduced the intensity of sunshine as to cause the cold summer of 1912, throughout the northern hemisphere. Many readers will probably be surprised to learn that a single localized eruption can have any measurable effect on the weather of so large an area. Nevertheless, an examination of the records shows that all great volcanic explosions have been followed by pronounced drops in temperature, the world over.

The lowest point ever reached in the temperature of the world, since the beginning of reliable records, occurred in the years $1783^{-1785}$, following the eruptions of Asama-yama in Japan, and Skaptar Jökull in Iceland, which are reported as having been among the most frightful known.

Asama hurled enormous rocks in all directions. One of these, said to have measured 264 by 120 feet, fell into a river forming a miniature island. Many towns and villages were buried. The activity of Skaptar Jökull largely took the form of immense lava flows, the greatest within historic times; but there were also explosions producing ashes and fumes that affected a large area, even destroying crops in Scotland, 600 miles away.

These eruptions were followed by a remarkable "dry fog" which appeared simultaneously on June I7, I783, all over Europe. It was world-wide, being recorded in Asia, Africa, and America, as well as Europe. It was so thick that

1 This material is summarized from the Report of the Krakatoa Committee of the Royal Society pp. $388-392$. 1888 . The observations of twi- in some places "large houses 2 miles off could hardly be seen." The sun was invisible for some time after rising and before setting. At noon it was bloodred, and could be observed easily with the unprotected eye. In the middle of a moonless night, the twilight, due to reflection from the dust cloud illuminated the earth as much as a full moon. Strong sulphurous fumes, which accompanied this haze, damaged many plants, were unpleasant to the eyes, and caused some persons inconvenience in breathing. ${ }^{1}$

The effect of the same fog in America was thus described by Benjamin Franklin, who at the time was ignorant of its cause. $^{2}$

\section{"THE YEAR WITHOUT A SUMMER"}

"During several of the summer months of the year 1783 , when the effects of the sun's rays to heat the earth in these northern regions should have been the greatest, there existed a constant fog over all Europe, and great part of North America. This fog was of a permanent nature; it was dry, and the rays of the sun seemed to have little effect toward dissipating it, as they easily do a moist fog arising from the water. They were indeed rendered so faint in passing through it that, when collected in the focus of a burning-glass, they would scarce kindle brown paper. Of course, their summer effect in heating the earth was exceedingly diminished.

"Hence the surface was early frozen.

"Hence the first snows remained on it unmelted, and received continual additions.

"Hence perhaps the winter of $1783-4$

light at midnight were probably made in northern Europe above latitude $50^{\circ}$.

${ }^{2}$ As quoted by Humphreys, Physics of the Air, p. 570. 1920. 


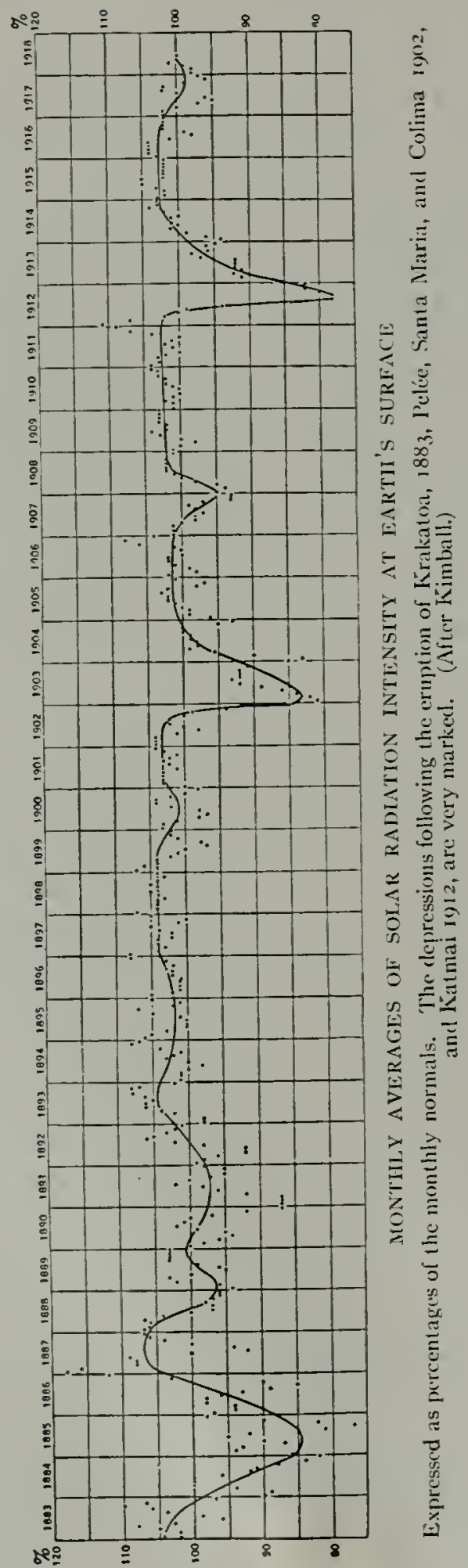

was more severe than any that happened for many years."

In 1815 occurred the eruption of Tomboro, in the East Indies. This, "if the published reports are to be credited, appears to have exceeded all other known eruptions. It caused darkness lasting for three consecutive day's at a distance of over 300 miles. Ash fell to a depth of two feet more than 850 miles away. Dust fell over an area of $1,000,000$ square miles. The explosions were heard at a distance of $\mathrm{r}, 000$ miles. The material ejected has been variously estimated at 28.6 , and even at 50 cubic miles." 3 In this eruption 56,000 people are reported to have lost their lives.

After Tomboro, streaky skies, haziness, and brilliantly colored sunsets were conspicuous in Europe. At the same time the temperature dropped about $1 . \mathrm{I}^{\circ}$ C. below the normal, producing such marked effects on plant growth that the year 1816 is known as "the year without a summer," "poverty year," or "eighteen hundred and froze-to-death."

REMARKABI.E ATMOSPHERIC EFFECTS OF THE ERLPTION OF KRAKATOA

The best known instance of worldwide effects from an eruption is that of Krakatoa. The eruption occurred in August, 1883 , but scant notice of it was taken in Europe until months afterward, when its remarkable atmospheric effects compelled attention.

The dust from the volcano caused such brilliant sunsets that they became matters of universal comment. The dust particles in this case were blown so high that it required two years for them to settle down to the level of the highest clouds. During all this time remarkable sunset colors, haze effects, and abnormally long twilights occurred throughout the whole world.

The amount of material thrown out in this eruption, 3.2 cubic miles, was only about half as much as from Katmai. But in violence, the explosion far exceeded

3 Martin, G. C., National Geographic Magazine, 1913, p. 165. 
Katmai, for it was heard at much greater distances.

In the Andaman Islands, I,500 miles from the volcano, the "report was heard as of a distant signal gun. A steamer was sent round the coast to search for the vessel supposed to be firing as signals of distress." At a point in South Australia 2,023 miles from Krakatoa, people were awakened at midnight by the explosion, which resembled blasting. The extreme limit at which the sounds were detected was, however, nearly twice as far away. At Rodriguez, 2,968 miles distant, the detonations sounded like "the distant roar of heary guns."

In addition to the tremendous sounds, the explosion of Krakatoa set up another type of atmospheric disturbance marked by a fall in air pressure, as recorded by self-registering barometers all over the world. This remarkable air wave proceeding from the volcano spread entirely round the earth to the antipodes; was there reflected and passed back again to the volcano, where it was again reflected back to the antipodes; was again sent back to the volcano; and so on, until it had circled the globe seven times before it finally became too faint to be detected.

After the eruption of Krakatoa the intensity of the sunshine was reduced

${ }^{4}$ Quotation from Report to Royal Society, op. cit., pp. $8+-87$.

${ }^{5}$ The data concerning this haze and its effects have been collected by Kimball, Humphreys, Abbot, and Fowle, from whose contributions I gather the facts summarized below. For more detailed accounts the reader is referred to the original papers:

Abbot, C. G. Do Volcanic Explosions Affect Our Climate? National Geographic Magazine, vol. 24 , pp. $181-198$. 1913.

Abbot, C. G. and Fowle, F. E. Volcanoes and Climate. Smithsonian Miscellaneous Collections, vol. 60 , No. 29 , I9I3.

Humphreys, W. J. Volcanic Dust and Other Factors in the Production of Climatic Changes and Their Possible Relation to Ice Ages. Bulletin MIt. Weather Observatory, vol. 6, pp. 1-34, I9I3.

-, Physics of the Air, Philadelphia, 1920.

Kimball, H. H. The Dense Haze of June 10II, 1912. Bulletin NIt. Weather Observatory; vol. 5 , pp. 161-165, 1912-1913. very much as in the other instances cited, but in this case the greatest effect, amounting to a 12 per cent loss in the sun's power, was not reached until nearly two years after the eruption. These sky phenomena were accompanied by a marked drop in the world's temperature $-0.45^{\circ} \mathrm{C}$. (see page 32 ). . $^{4}$

\section{VOLCANIC HAZE FROS KATMAI APPEARED \\ IN WISCONSIN BEFORE THE ERUPTION WAS OVER}

With these records of previous eruptions before us, we are prepared to accept reports of world-wide effects from the explosion of Katmai that would seriously tax our credulity if they stood alone.

Within the two days after the beginning of the eruption, June 8 , a curious haze different from anything ever before seen by the observer appeared at Madison, Wisconsin..$^{5}$ It assumed "the form of streaks, rapidly moving wave systems, and clotted forms, observed from I I a.m. until late in the afternoon." 6 On the next two days the "high haze continued but became denser, so that definite forms were more difficult to identify."

By June Ioth the haze had spread to Virginia, where it was so noteworthy on the Ioth and IIth as to induce Professor H. H. Kimball to publish a special paper

- The Effect of the Atmospheric Turbidity of 1912 on Solar Radiation Intensities and Skylight Polarization. Ibid., pp. 295-312, I9I3.

- The Effect upon Atmospheric Transparency of the Eruption of Katmai Volcano. Nonthly Tieather Review, vol. 41, pp. 153-159, 1913 .

913. The Relation between Solar Radiation Intensities and Temperatures of the Air in the Northern Hemisphere in 1912-1913; Bulletin Mt. Weather Observatory, vol. 6, pp. $205^{-220}$, 19I4. (With full citations to other literature).

- Volcanic Eruptions and Solar Radiation Intensities. Monthly Weather Review, vol. 46, pp. $355^{-356,1918 .}$

See also Arctowski, Henryk. Volcanic Dust Veils and Climatic Variations. Annals N.Y. Academy of Science, vol. 26, pp. 149-174, 1915. (Also literature there cited.)

${ }^{6}$ Nonthly Weather Review, 1913, vol. 41, p. 154 . 


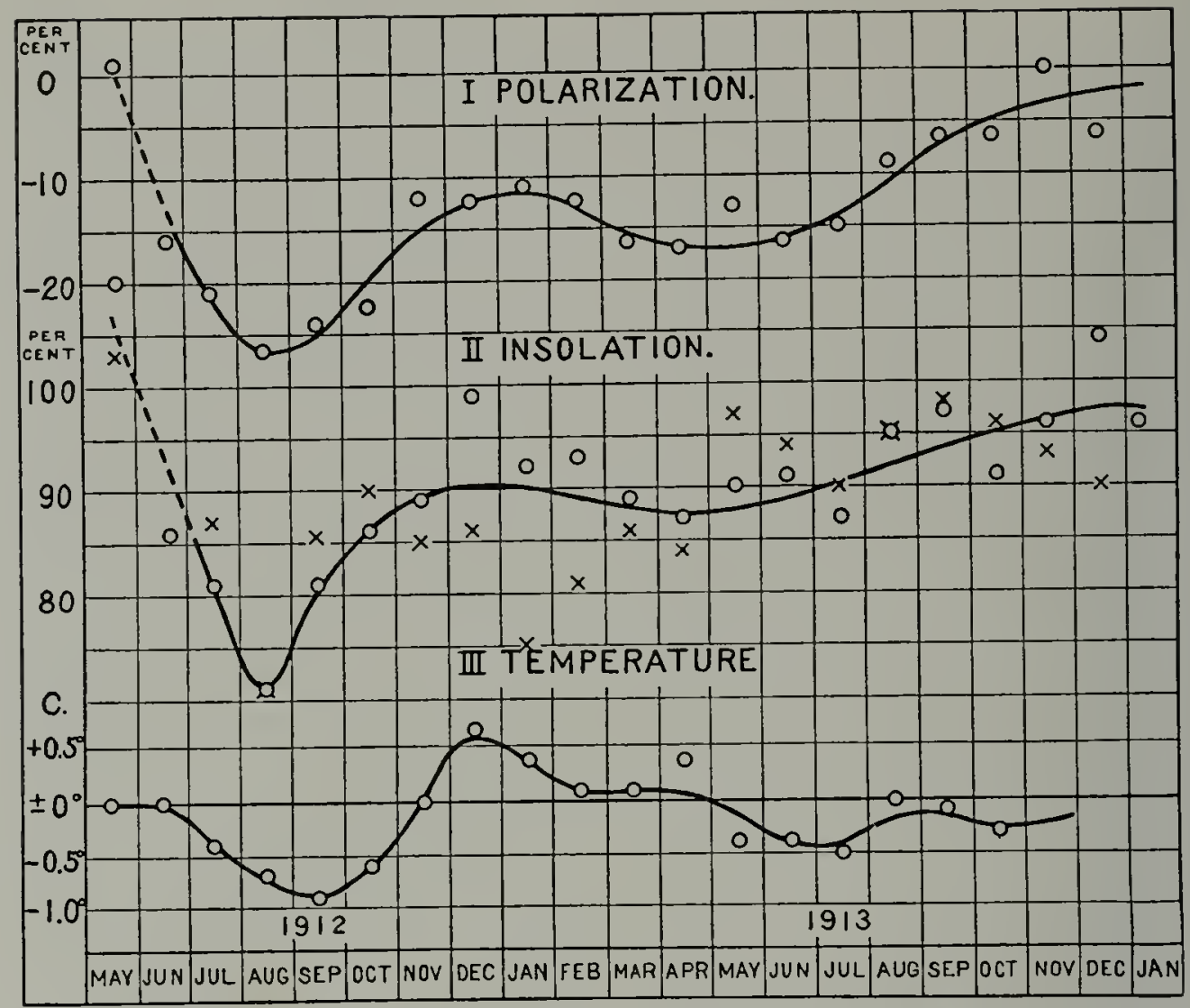

CURVES SHOWING THE EFFECT OF THE DUST FROM FATMAI ON:

I. Skylight polarization at Mount Weather, Virginia.

Ii. Insolation at Mount Weather, Virginia $(\mathrm{O})$ and Madison, Wisconsin ( $\mathrm{X}$ ).

III. Temperature Departures in the Northern Hemisphere, for the period following the eruption. (After Kimball.)

devoted to it, although at the time of writing he had no inkling of its cause.

"On the 8th and 9th the atmosphere was unusually clear for June." 7 But on the Ioth "the upper atmosphere was filled with a white veil of haze," although the lower air "was still clear so that mountains 30 miles distant were distinctly visible." . . . "Just before noon the polarization of skylight, which was 67 per cent at $9 \mathrm{a} . \mathrm{m}$. of the 9 th had decreased to I4 per cent, and the atmospheric transmission coefficient, which was 0.756 shortly before moon of the 9 th, had decreased to $0.589 . "$

${ }^{7} \mathrm{H}$. H. Kimball in Bulletin MIt. Weather Observatory, 1912-13, vol. 5, pp. 162-3.
Abbot and Fowle, who were engaged in studying the intensity of solar radiation, the former in Algeria, the latter in California, soon afterward found their observations interfered with by the same peculiar haze, which, needless to say, was most unexpected in the desert regions which they had chosen especially because of their freedom from clouds. Abbot describes his experience thus: ${ }^{8}$

PECULIAR IHAZE PERSISTED ALL SUMAER IN ALGERIA

"While observing on June 19, I9I2, I noted streaks resembling smoke lying

8 National Geographic Magazine, February, 1913 , p. $18 \mathrm{I}$. 
along the horizon, as if there were a forest fire in the neighborhood of the station.

"These appearances continued and were soon joined by others more noticeable. After a day or two we began to see peculiar mottled figures like those of the mackerel sky, although absolutely no clouds were present. The phenomenon became so marked that we ceased entirely our observations of solar radiation, as the sky seemed to be quite too poor for such work.

"About the 25th of June a cloudy period began, with rain, and, after this, of course, we expected that all these curious sky phenomena would have passed away; but not so, for when the clouds had quite passed by, about the 29 th of June, we found that the whole sky was filled with haze, and this state of affairs continued even more pronounced until the expedition left Algeria, about September ro."

Unusual haze was noticed during this summer at many other stations, both in the United States and in Europe, but few made the precise instrumental observations that give especial significance to the accounts above quoted.

The dust veil interfered also with the work of the astronomical observatories. At the Yerkes Observatory "all observers using the Bruce Spectrograph noted that exposure times had to be lengthened." 9 The Director of the Dominion Observatory, Ottawa, reported: "Photographs of the solar spectrum show a marked decrease in intensity (apparently not less than 25 per cent)." 9 P. G. Nutting, working at the Bureau of Standards, Washington, states: "We detected a change in color of direct sunlight by spectrophotometric comparison with acetylene. First noted on June I I, "9 the next day after it was observed in Virginia.

In the train of this haze was a more or less marked increase in the intensity of sunset colors, somewhat like that which followed the eruption of Krakatoa in I883, but so much less pronounced as not

${ }^{9}$ Monthly Weather Review, vol. 4I, p. I57, I9I3. to have attracted general notice, being recorded only by a few careful observers.

THE DUST CLOUD ABSORBED TEN PER CENT OF THE SUN'S HEAT

The haze had the effect of intercepting a very considerable fraction of the sun's rays and reflecting them back into space, materially reducing the intensity of the sunshine.

Abbot and Fowle's measurements summarized in the table given below ${ }^{10}$

Table Showing Diminished Heating Power of SunLIGHT DUE TO THE DUST FROM KATMAT

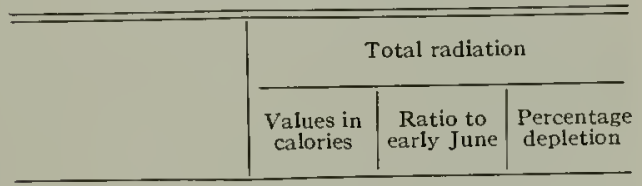

A. Mount Wilson, California

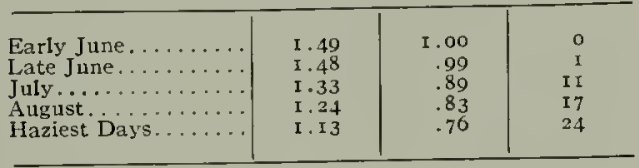

B. Bassour, Algeria

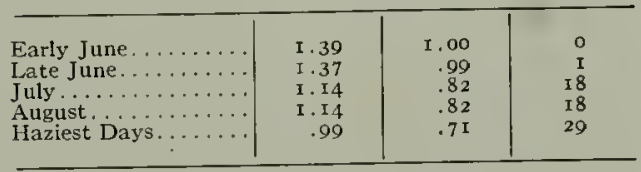

show "that the uncommon haziness of the sky during the summer of r9I2 produced a very marked decrease in the direct solar radiation in all parts of the spectrum, and reached nearly 20 per cent at high sun for the total heat." 11

There was, however, some compensation for this great loss in an increase of the brightness of the sky, due to the fact that dust particles reflect a portion of the light down to the earth's surface as well as off into space. The effect of this diffuse reflection was to increase the twilight both in duration and intensity. Taking everything into consideration, Abbot concluded "that the dust of Katmai diminished the heat available to

10 From Smithsonian Miscellaneous Collections, vol. 60 , No. 29, p. 6, 1913 .

il National Geographic Magazine, February, I913, pp. $184^{-1} 86$. 


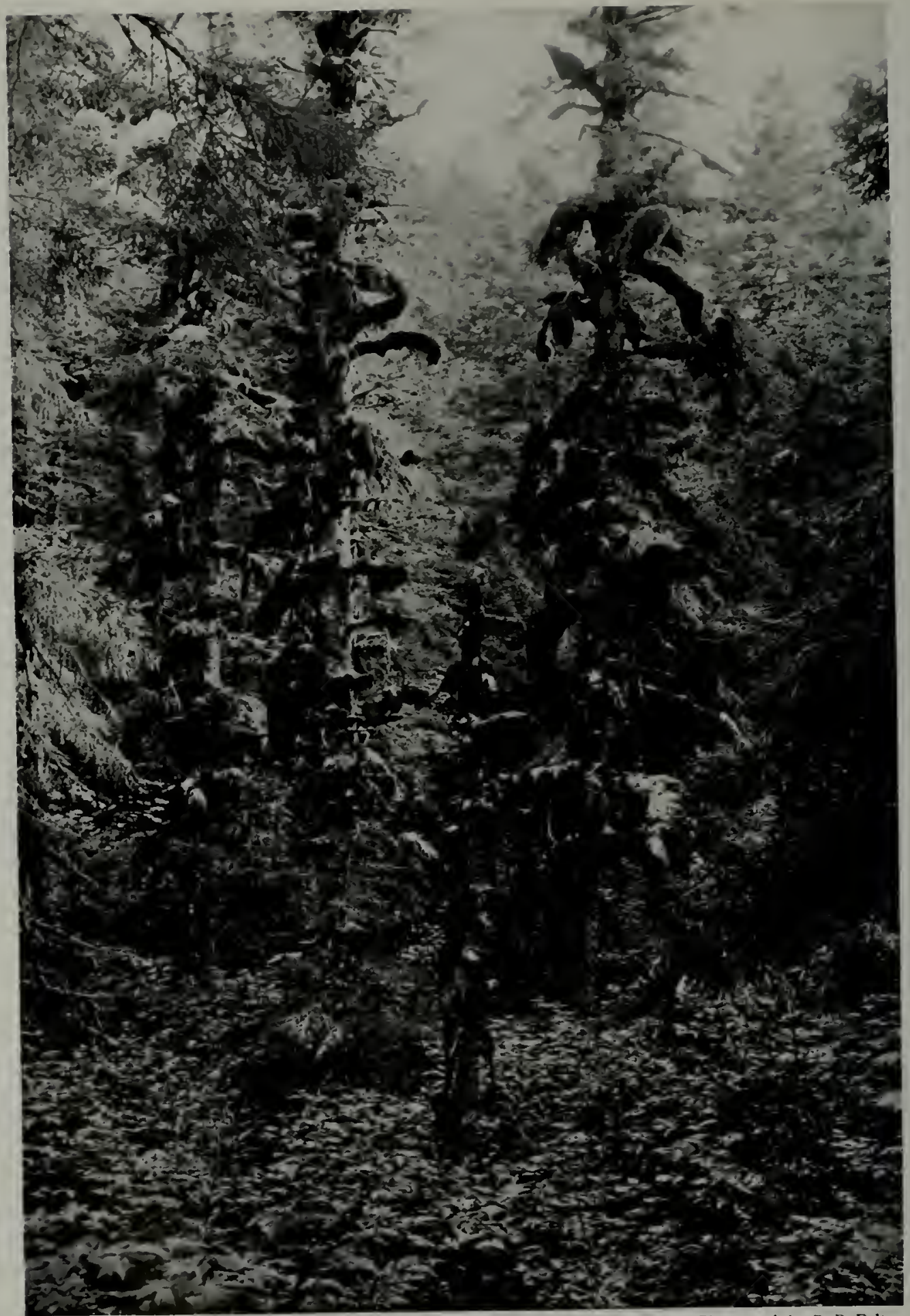

Photograph by B. B. Fulton

MASSES OF MOSS ON THE TREES NEAR KODIAK

These moss balls held quantities of the falling ash, which have since been consolidated and bound in place by new growth. 
warm the earth in the North Temperate Zone by about io per cent during the summer of I9I2.

THE WHOLE NORTHERN HEMISPHERE WAS COOLER BECAUSE OF THE ERUPTION

"In accordance with the laws of heat and radiation, this might produce a fall of $7^{\circ} \mathrm{C}$. $\left[12.6^{\circ} \mathrm{F}\right.$. $]$ in the temperature of the earth as a whole, if it was effective for a long enough period of time, provided that there were no counteracting influences." The records show that the cooling of the earth postulated by Abbot actually occurred.

As summarized by Kimball ${ }^{12}$ they reveal a deficiency in tempcrature amounting to $0.9^{\circ} \mathrm{C}$. [ $1.6^{\circ} \mathrm{F}$.], which reached its maximum in September.

None of the eruptions since the beginning of the record has produced so striking an irregularity in the temperature curve as Katmai, for the reason that it occurred at a time when terrestrial temperatures were at a maximum, ${ }^{13}$ so that the depression it caused appears as a notch out of the top of the curve shown on page 32 , whereas the other great eruptions happened to come at periods when their depressing effect on the temperature curve is not so conspicuous.

A reduction of the earth's temperature by a degree or two will doubtless appear to most people a trivial matter, without any bearing on the affairs of everyday life: this is a great mistake.

We are all so used to variations of several degrees from hour to hour and from day to day that we are likely not to realize that, although short-period daily va-

12 "Temperatures below the normal commenced to prevail throughout Alaska, the United States, and Mexico in June, I9r2; over Canada, the Atlantic Ocean, Europe, and northern Africa in July; over Asiatic Russia to longitude $105^{\circ} \mathrm{E}$. in August; and over the eastern part of Asia in September. Low temperatures persisted generally in low latitudes during the remainder of 1912 and throughout the summer of 1913 , with a maximum deficiency for the whole hemisphere of $0.9^{\circ} \mathrm{C}$. [1.6 $6^{\circ} \mathrm{F}$.] in September, 1912. There was an excess of temperature in high latitudes [due perhaps to increased sky light] during the winter of $1912-13$, with a maximum departure riations compensate each other, the cumulative effect of a slight reduction of temperature continued over a long time becomes very important. A change of even $\mathrm{I}^{\circ} \mathrm{F}$. continued through the season has a marked effect on plant growth. A deficiency of that amount entails a shift of fully 80 miles in the limits at which crops can be grown. That is to say, other things being equal, the occurrence of an eruption like that of Katmai means that wheat would fail to mature over a belt 80 miles wide along the northern border of its range.

In addition to changing the area over which crop production is possible, such changes in temperature may greatly affect the time required for plant development. Thus, a deficiency of only $1.26^{\circ}$ $F$. has been known to postpone the maturing of sugar-cane by a full year!

\section{VOLCANOES CAPABLE OF CAUSING ICE AGES}

An eruption like that of Katmai would lower the temperature of the world very much more than $\mathrm{I}^{\circ}$, if the dust remained in the air long enough for its full effect to be felt. Abbot and Humphreys agree that the dust from Katmai would have reduced atmospheric temperature $6^{\circ}$ or $7^{\circ} \mathrm{C}$. (about $12^{\circ} \mathrm{F}$.), if the dust had remained in the air long enough for the earth to adjust itself fully to the decreased radiation and no compensating factors had intervened to counteract its effect.

Such a lowering of terrestrial temperature, "if long enough continued, would be more than sufficient to produce

for the hemisphere of $0.7^{\circ} \mathrm{C} .\left[1.3^{\circ} \mathrm{F}.\right]$ in December. The average daily deficiency of temperature for the whole Northern Hemisphere for the period of June, 1912, to October, 1913, inclusive, was $0.16^{\circ}$ C. [0.29 F.]" Bulletin Mt. Weather Observatory vol. 6, pp. 214-15, I9I3.

${ }_{13}$ Terrestrial temperatures vary inversely with the spots on the sun's disc, reaching a maximum when sunspots are fewest and vice versa. The discrepancies between the temperature and sunspot curves, T and S (page 32) occurred "in every important case simultaneously with violent volcanic eruptions." Humphreys. Bulletin Mt. Weather Observatory vol. 6, p. 24, 1913. 


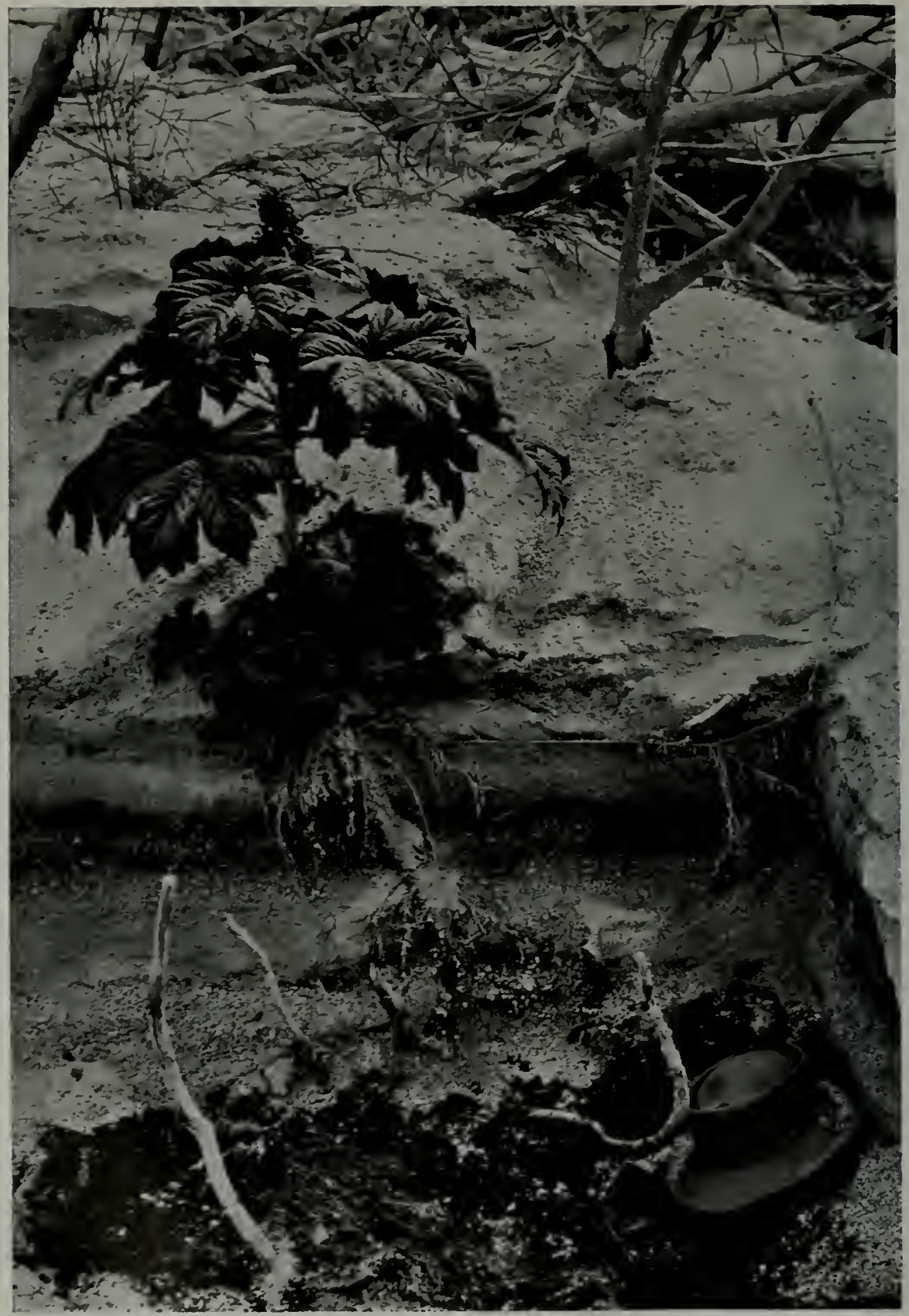

Photograph by Robert F. Gnggs

A DEVIL CLLB GROWING THROLGH THE ASH

There are two sets of roots, one just beneath the surface, the other in the old soil. The three layers of ash are well shown. The ashfall in Lower Katmai Valley averaged 20 inches. 
glaciation equal to the most extensive of any ice age." 14

Whether volcanic explosions actually brought on the great ice ages to which the earth has been subjected repeatedly. in the past is, of course, another question. Because of the ephemeral character of their products, it is difficult to ascertain whether such explosions were frequent enough at any given time in the past to produce the glacial periods recorded. But, even in historic times violent eruptions have been so frequent that they have markedly reduced the earth's temperature throughout that period. Humphreys concludes on this point:

"Since the beginning of reliable records, say 160 years ago, the average temperature of the earth has been perceptibly lower, possibly as much as $I^{\circ} \mathrm{F}$., than it would have been if, during all this time, there had been no volcanic explosions violent enough to put dust into the isothermal region of the atmosphere. Similarly, on the other hand, if, during this period, violent volcanic explosions had been three or four times more numerous than they actually were, our arerage temperatures probably would have been at least $2^{\circ} \mathrm{F}$. to $3^{\circ} \mathrm{F}$. lower, or low enough, if long continued, to bring on at least a moderate ice age." ${ }^{15}$

WATER LIBERATED IN ERUPTIONS PROBABLY OF YAST IMPORTANCE IN THE ECONONY OF NATURE

It would not be proper to bring this chapter to a close without brief allusion, at least, to one other way in which the eruption exerted a world-wide influence of far-reaching significance.

It is recognized that the chief agent in the tremendous explosions was the expansion of gases imprisoned in the molten magma, as the lava is called while yet in the bowels of the earth. We ought

14 Humphreys, Physics of the Air, p. 590.

15 Bulletin NIt. Weather Observatory; I913. vol. 6 , pp. 33-3+.

${ }^{16}$ As quoted by F. IV. Clarke, Data of Geochemistry, $4^{\text {th }}$ ed., p. 209 , I 920 . This work gives authority for my other statements relative to the contributions of volcanoes to the atmosphere. to make some inquiries concerning the quantity of the gas thus liberated, its source, and its effect on the atmosphere.

Analysis show's that the ash has practically the same composition as granite. If the magma had not been extruded, it would have become granite. Now it has been demonstrated that granite, if heated to the temperature prevailing in a volcano, gives off water and gases identical with those of an eruption.

The celebrated French volcanologist, Gautier, ${ }^{16}$ estimated that a cubic kilometer of granite heated to $\mathrm{I}, 000^{\circ} \mathrm{C}$. would give off 160,000 millions of cubic meters of steam and 28,000 millions of cubic meters of other gases. The magma from which the ash and pumice came, before expansion, amounted to something like ten cubic kilometers. Hence, if these data represent conditions in Katmai, the ash and pumice thrown out would have liberated in round numbers $56,000,000$ million cubic feet of steam and $10,000,000$ million cubic feet of other gases.

As a matter of fact, howerer, a highly explosive magma like that in the recent eruption probably contains far more gas than the average granite. Our estimates are, therefore, presumably much too low. Besides, they include only the gases set free by the ash thrown out, and take no account of the vast quantities of steam which have been given off continuously ever since the eruption, without further extrusion of solid matter. The numerical value given is, therefore, too small, but the estimates serve to suggest the enormous quantity of steam given off in a great eruption.

Even this quantity of steam, representing only a fraction of the total output of the volcano, would form, when it condensed, about 300 million long tons of water. ${ }^{17}$

\footnotetext{
${ }_{17}$ It must be recognized that this figure, great as it is, is relatively minute when compared with either the stock of water in the ocean or the rainfall of the world. Its significance lies not in the size but in the fact that it is new water, a permanent addition to the ocean.
} 


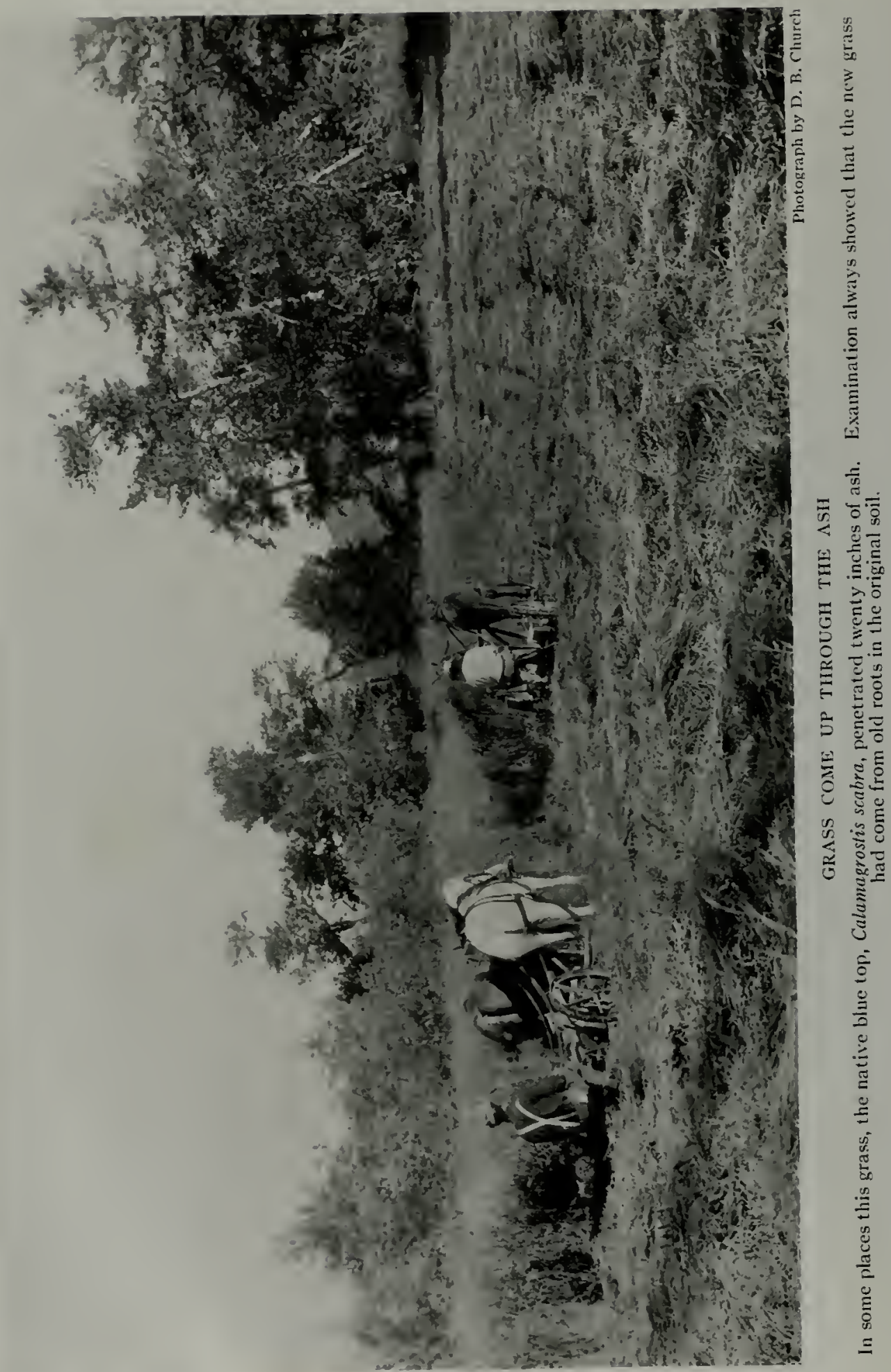


Whence came this great volume of water?

Some have maintained that it was due to the percolation of sea water into the molten magma in the depths. But this view does not stand up well under close examination. It is more probable that it is "juvenile water" brought up from the interior of the earth for the first time, forming, therefore, a permanent addition to the waters of the earth's crust.

In the words of that great master, Eduard Suess, ${ }^{18}$ "Volcanoes are not fed by the infiltration of the sea but the waters of the sea are increased by every eruption." If this view is correct, volcanoes play a rôle of supreme importance in the economy of nature, for their eruptions are the principal means by which the oceans and all of the waters of the world have been separated from the solid crust. If there had been no volcanic eruptions in the past, the earth would be an uninhabitable desert on which life could not have developed.

ALL LIFE PERHAPS DEPENDENT ON THE CONTINUANCE OF VOLCANIC ACTION

One other product of eruptions requires consideration: carbon dioxide. This gas is an absolute essential to green plants; it is the indispensable basis from which all human foods are built up. Moreover, it has been locked up in coal and in limestone in such enormous quantities during past ages that the original source of supply has always been a puzzle to geologists.

It may be seen how vital this problem is when it is stated that the amount of this essential compound that has been withdrawn from the atmosphere and stored away in coal and limestone "is about 30,000 times as much as is now contained in the atmosphere." 19

But it is not probable that any such quantity of carbon dioxide was present at one time in the atmosphere of the primeval world. If it were all liberated

${ }_{18}$ Geographical Journal, vol. 20, p. 520, I902. ${ }^{19} \mathrm{~F}$. IV. Clarke, op. cit. p. 48. at once, it would raise the pressure of the air to several hundreds of pounds per square inch and make impossible the life of any such organisms as we are acquainted with today. No sort of animal life can endure even a moderately high concentration of carbon dioxide.

The abundance of animals throughout the whole period when carbon was being laid away in the rocks indicates a uniformity of conditions throughout geological history and argues against any great concentration at the beginning. Indeed, it is largely by the activity of organisms of one sort or another that all carbon deposits, whether in coal or limestone, were produced.

The facts seem to require us to suppose that carbon dioxide has been steadily supplied from some source at about the same rate at which it was consumed throughout the geological ages. No terrestrial source other than the gradual additions known to be brought in by volcanoes has been suggested.

We do not know the history of volcanic eruptions well enough to enable us to be certain whether they have contributed enough in the past to have maintained the supply. But we do know that the amount of this indispensable substance which they bring up from the interior of the earth is very great. There is no means of estimating how much may have been liberated by Katmai. But an ordinary quiescent volcano may give off tremendous quantities. It has been stated, for example, that Cotopaxi pours forth more carbon dioxide than a city like Paris ( 100 million cubic feet per day). ${ }^{20}$

Although our data are not sufficient to permit assurance, it is evident that we are here dealing with one of the most fundamental questions in the whole realm of nature and one of extreme importance to mankind. In the words of F. W. Clarke: ${ }^{21}$ "Obviously, if the volcanic hypothesis be true, the cessation of volcanism would signify the end of life on

${ }^{20} \mathrm{~F}$. W. Clarke, op. cit. p. 47.

21 Ibid., p. 56. 


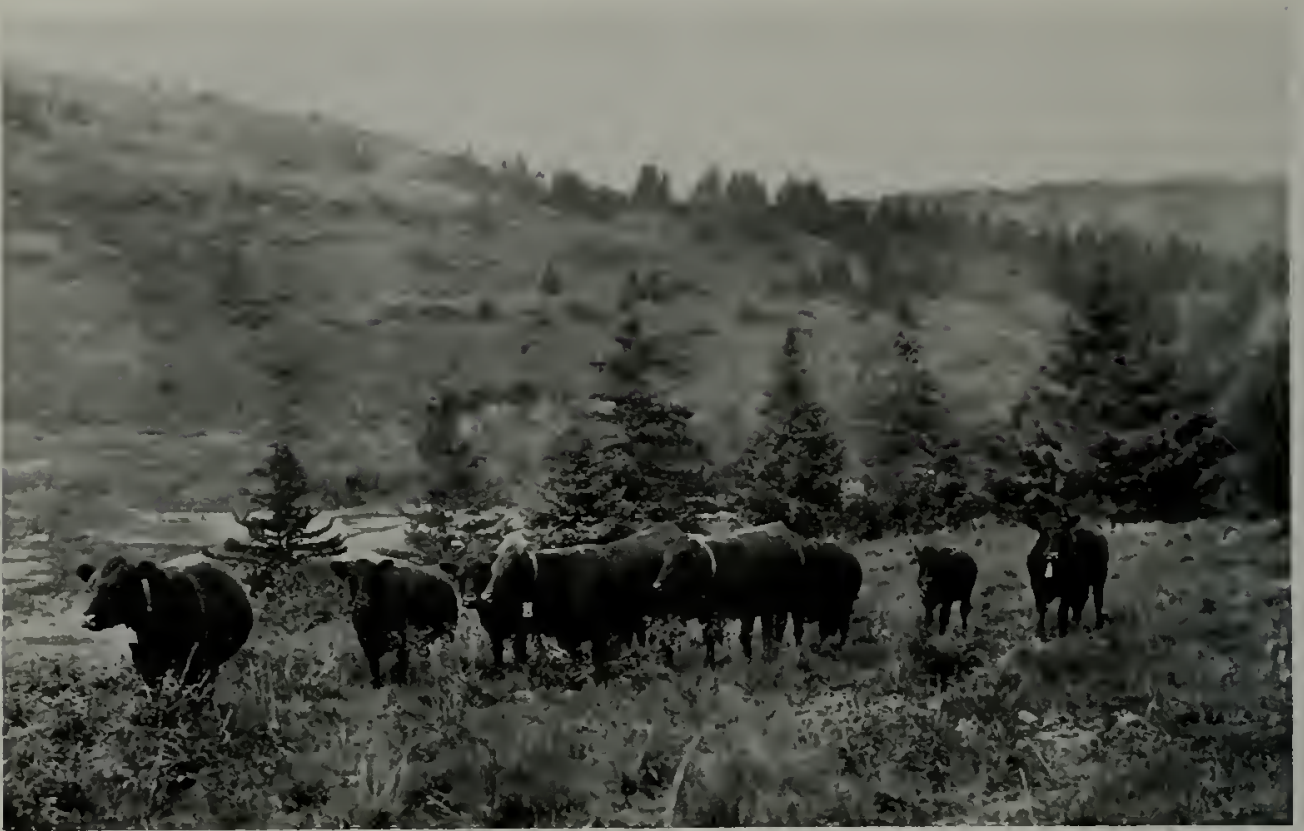

Photograph by R. F. Griggs

SLEEK GALLOWAY CATTLE BELONGING TO THE EXPERIMENT STATION AT KODIAK

After the eruption the station herd had to be taken to "the States" for the first two years; but their pastures made such a remarkable recovery that they were soon returned. A stranger would hardly suspect that this country had been buried under a foot of ash only four years previously.

the globe. It would be followed by the consumption of all available carbon dioxide, so that plant life, and consequently animal life, could no longer be supported."
Suggestive as are speculations of this nature, their pursuit is beyond the scope of this book. We must return to a consideration of our specific subject-the more immediate effects of the eruption. 


\section{THE RECOVERY OF VEGETATION AT KODIAK'}

The effect of the ash blanketat Kodiak, coming as it did just when the plants were putting forth their spring growth, was to strike down all weaker plants, giving "Green Kodiak" the appearance of a pine barren devoid of vegetation, except for the trees and bushes which protruded through the ash uninjured. To everyone who visited Kodiak during the first two seasons after the eruption, the damage done to vegetation seemed irreparable.

It was during this period that I first saw Kodiak, in June, I913, almost exactly a year after the eruption. It was indeed a bleak and desolate prospect. Outside the forest the country had the appearance of a desert, whose graybrown slopes were relieved only here and there by spots of green where some alder or willow pierced the ashy blanket (see page 22).

Lupines, fireweeds, and other strongstemmed perennials had, to be sure, come up through the ash in places, but they were not abundant enough to lend much color to the landscape. Within the forest the prospect was less desolate. Yet even here the undergrowth was gone, and the branches were still heavily laden and bent down to the ground with ash.

The officials of the Experiment Station and of the Kodiak Baptist Orphanage were attempting to grow a crop of oats, to provide ensilage enough to keep their cattle alive over the winter. We felt it our duty to encourage them in this effort, but in reality the prospect seemed very gloomy.

I well remember debating with one of the citizens whether the country would ever come back to its original condition.

\footnotetext{
${ }^{1}$ For a more detailed discussion of this aspect of the eruption, with citations to the literature, the reader is referred to a paper by the writer under the same title in the series of "Scientific Results
}

With the vividness of his memory of things as they had been before the eruption, he was pessinistic; but believing that the ash would probably be beneficial after it was incorporated with the soil, I reassured him with the prediction that in ten years vegetation would begin to come back in some abundance.

\section{THE REMARKABLE RETURN OF VEGETATION}

The recovery of the area was, however, extremely rapid. During the second and third years the old roots of the strongergrowing plants sent up new growth through the ash layer in such profusion as to upset completely even the most optimistic of predictions.

When I landed in June, I9I5, I could not, despite the reports I had received, believe my eyes. It was not the same Kodiak I had left two years before. The mountains were everywhere green with their original verdure. The character of the change is indicated by the picture on page 42 better than by any description. Where before had been barren ash there was now rich grass as high as one's head. Everyone agrees that the eruption was "the best thing that ever happened to Kodiak." In the words of our hotel keeper, "Never was any such grass before, so high nor so early. No one ever believed that the country could grow so many berries nor so large, before the ash" (see page 5I).

I had come to study the revegetation, but I found my problem vanished in an accomplished fact. The revegetation which I had hoped to study at Kodiak had given place to a remarkable recovery of the antecedent plants, transferring the problem of revegetation proper to the

of the Katmai Expeditions of the National Geographic Society," Ohio Journal of Science, vol. 19, pp. 1-57, 1919. 


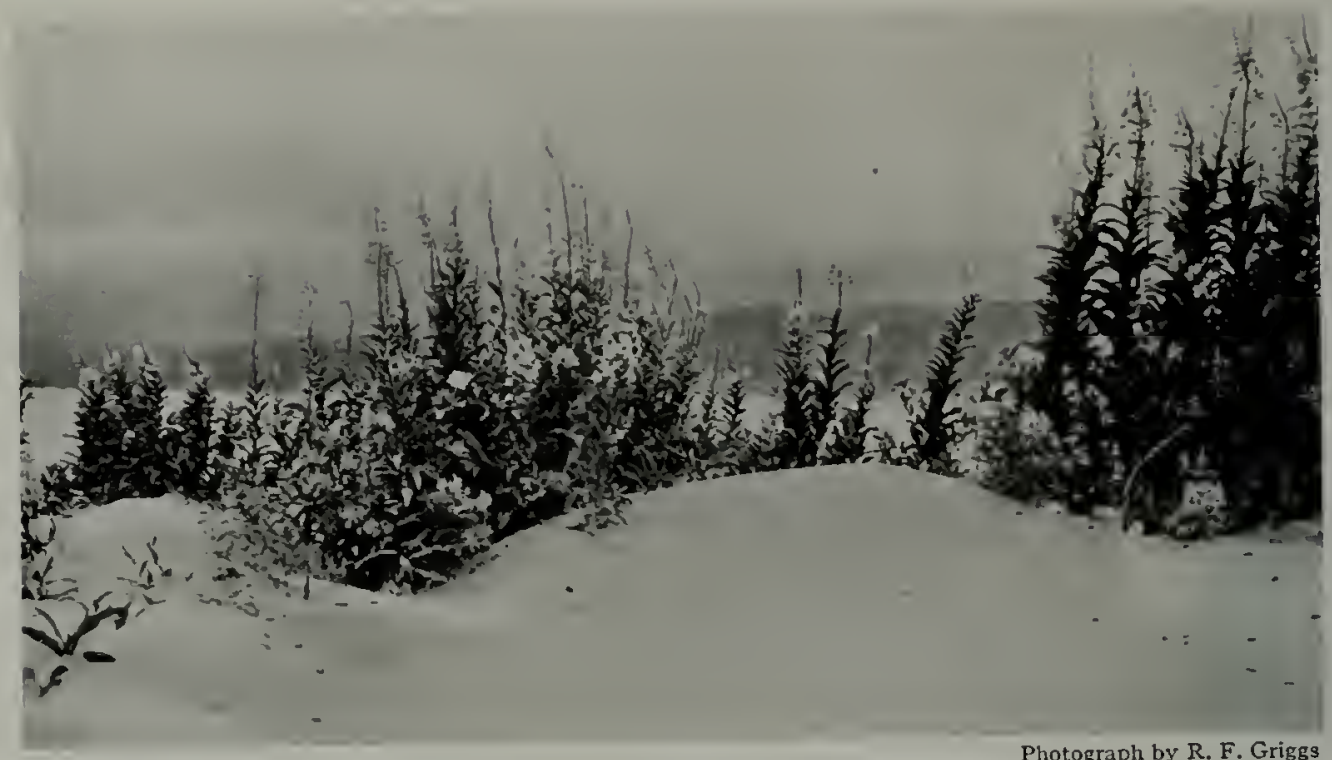

ASH DRIFT LODGED BEHIND FIREWEEDS

The drifts have every appearance of snow banks. The fireweed endured such burial for three years, but then succumbed.

more deeply buried country near the volcano.

\section{THE LUXURIANT GROWTH NOT DUE TO ANY FERTILIZER IN THE ASH}

There is a widespread idea that the luxuriance of growth was due to some fertilizer added to the soil by the ash, which stimulated the plants. This is erroneous. The ash forms as sterile a soil as can well be imagined.

The belief that volcanic ash forms good fertilizer rests largely on misconception. It is commonly supposed that all lavas are very much alike. The fertility of soils derived from the weathering of basaltic lava flows is well known. It is assumed that volcanic ash has the same property. There is, however, a very great diversity in igneous rocks. The content of inert silica may be as much as 77.0 per cent or as little as 35.0 per cent. Potash varies from 8.6 per cent to 0.04 per cent; lime from 15.5 to 0.2 per cent; phosphoric acid from 2.6 per cent to nothing.

These figures are quite sufficient to show the fallacy of generalizations con- cerning the fertility of volcanic soils. Some basic lavas have all the ingredients of a rich soil. Some acid rhyolites are almost as poor as quartz sand. As shown by the subjoined analysis, the ash from Katmai is in the latter class. ${ }^{2}$ It has in fact practically the composition of

2 Analysis made by Elton Fulmer, State Chemist of Washington, for the United States Department of Agriculture. Sample was collected at Kodiak and consisted of all three layers mixed so as to give a fair average of the condition encountered by plant roots.

$$
\begin{aligned}
& \text { Loss on ignition . .......... . . .65 } \\
& \text { Silica }\left(\mathrm{SiO}_{2}\right) \ldots \ldots \ldots \ldots \ldots \ldots 72.16 \\
& \text { Ferric oxide }\left(\mathrm{Fe}_{2} \mathrm{O}_{3}\right) \ldots \ldots \ldots .2 .85 \\
& \text { Manganese oxide ( } \mathrm{MnO}) \ldots . . .0 .4 \mathrm{I} \\
& \text { Titanium oxide }\left(\mathrm{TiO}_{2}\right) \ldots \ldots \text { trace } \\
& \text { Alumina }\left(\mathrm{Al}_{2} \mathrm{O}_{3}\right) \ldots \ldots \ldots \ldots \mathbf{1}_{3} .85 \\
& \text { Lime }(\mathrm{CaO}) \ldots \ldots \ldots \ldots \ldots . . . . .3 .80 \\
& \text { Magnesia }(\mathrm{MgO}) \ldots \ldots \ldots \ldots . . . .40 .47
\end{aligned}
$$

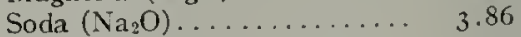

$$
\begin{aligned}
& \text { Potash }\left(\mathrm{K}_{2} \mathrm{O}\right) \ldots \ldots \ldots \ldots \ldots .2 .43 \\
& \text { Sulphuric acid }\left(\mathrm{SO}_{3}\right) \ldots \ldots \ldots . .20 \\
& \text { Phosphoric acid }\left(\mathrm{P}_{2} \mathrm{O}_{5}\right) \ldots \ldots . . .36 \\
& \text { Total................ 101.05\% }
\end{aligned}
$$

Remarks: The ash is highly magnetic; in all probability some of the iron present is magnetic.

Of more interest in the present connection is an analysis made by Prof. C. IV. Foulk, of the Ohio 


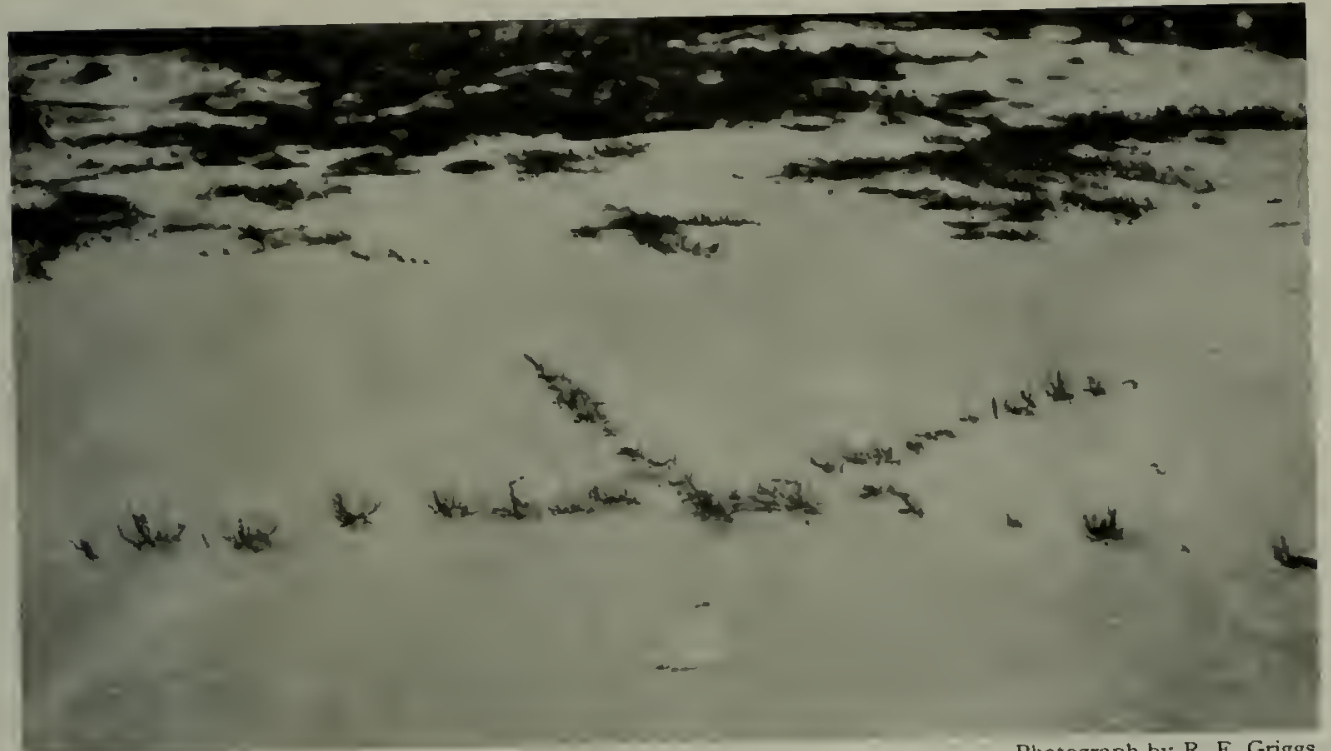

HORSETAIL SENDING RUNXERS INTO B.ARE ASH

This plant has occupied large areas which otherwise would have become dunes of drifting ash. Its importance in the revegetation of the country cannot be overestimated.

pulverized granite. And granite notoriously forms a poor soil.

In order to put the fertility of the ash to a practical test, a number of experiments were set up in which it was used as a soil, either alone or in various mixtures.

One series of these pot cultures is shown on page $5^{0}$. The plants in the lower row of glasses were grown in the ash; in the upper row in the purest quartz sand. To each series were added fertilizing salts as indicated by the symbols on the labels. Whether in sand or in ash, the plants turned red and died of starvation as soon as the food stored in the seed had been consumed, unless they were supplied with a complete fertilizer.

Of the different fertilizer salts, nitrates were more beneficial than any others used singly. This accords with field experience at Kodiak. With the use of nitrate fertilizers ve $z$ : fair crops of oats were grown for ensilage the first year after the eruption. Curiously enough,

State University, to determine the quantity of water-soluble salts, for plants can use only the soluble constituents of the soil. He found the available potash $\left(\mathrm{K}_{2} \mathrm{O}\right) 0.05$ per cent, and the it was not possible to duplicate these results in succeeding seasons, perhaps because the small quantities of other essential salts present were leached out of the ash during the first year.

\section{BENEFICIAL EFFECT OF ASH DUE TO ITS ACTION AS A MULCH}

The cause of the improvement in the vegetation of Kodiak is to be sought not in any chemical added to the soil by the ash, but in its action as a mulch.

It destroyed the smaller plants and gave the quick-growing species, which are of most interest to man, more favorable opportunities for growth than they had ever enjoved under normal conditions. It helped the surviving plants very much as weeding improves a garden.

Probably the most striking example of this fact is furnished by the trees, whose rate of growth increased remarkably after the eruption. A section of a tree

phosphoric acid he denominated as a "small amount." This, according to Professor Foulk, was rather more than a trace, yet it was so small that it would have been difficult to weigh it. 


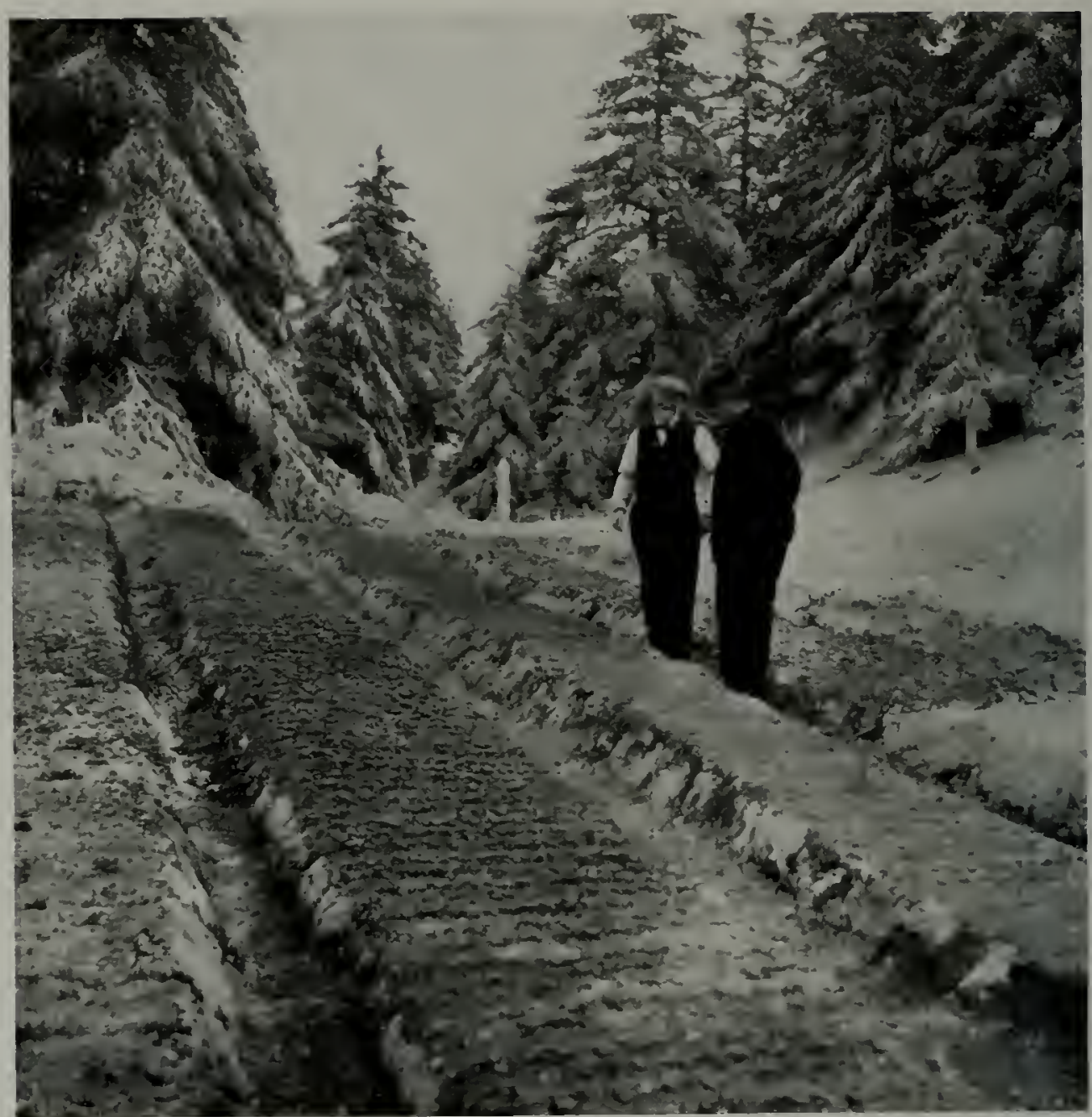

Photograph by George C. Martin

INSPECTING AN EXHUMED GARDEN AFTER THE ERUPTION

Captain Perry and Mr. Learn of the Kodiak Baptist Orphanage speculating on the possibilities of growing vegetables after the eruption. The result may be seen by a comparison with the picture reproduced on the opposite page.

from the ash-covered district pictured on page 53 gives clear testimony of the extent to which the ashfall bettered growing conditions.

For twenty years this particular tree had been struggling along, growing very slowly. During all that time it had reached a diameter of only o.6 inch ( 16 $\mathrm{mm}$.). Then came the eruption. The record of that year appears as a ring of extreme thinness, scarcely perceptible in the photograph. In 1913 the tree re- covered and did a little better than in any previous year. But the next year there came a great jump. Five times as much new wood was produced as before. This greatly increased grow th continued thereafter till the tree was cut. In four years, it had more than doubled its diameter.

The trunk selected for figuring was an extreme case - a suppressed tree from a former bog. Its reaction to the ashfall was, however, typical. In habitats originally more favorable the percentage of 


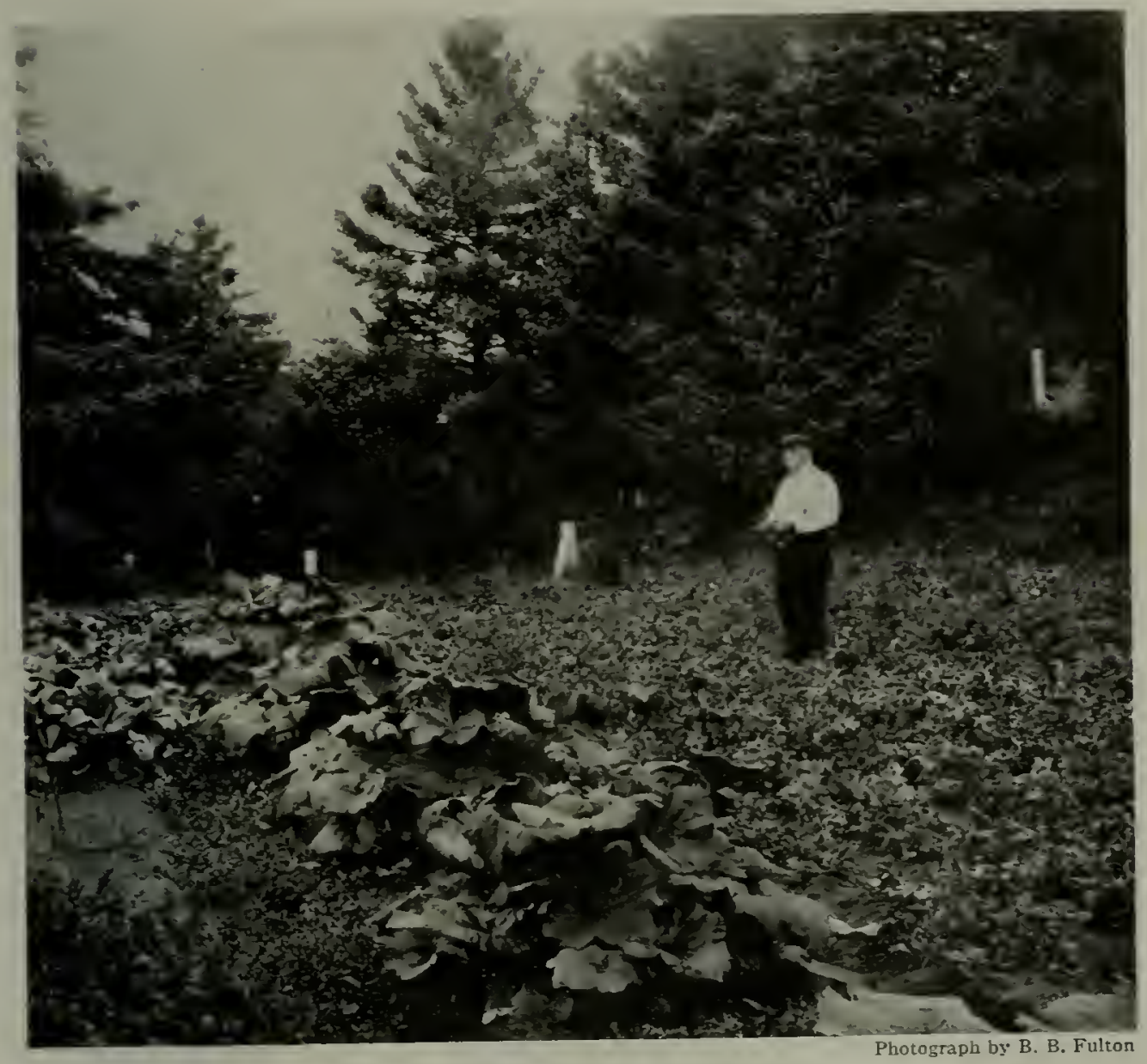

THE SAME GARDEN THREE IEARS LATER

All anxieties concerning the size of the crop have long since vanished.

increase was naturally not so great; yet it is plainly erident in trees from all sorts of situations. Trees of all ages and of all species were, moreover, similarly affected.

Even if the ash were rich in fertilizing salts, the good it did the trees by destroying the grass mould probably outweigh any possible fertilizing effect. It has been shown by experiment ${ }^{3}$ that competition among closely crowded plants, whether of the same sort like the grasses of a meadow, or of different sorts like trees and undergrowth in a forest, stunts grow th to a surprising extent.

3 This will be discussed in detail with citations to the literature in a special paper devoted to the subject.
Before the ashfall the trees were in the condition of an orchard that has been allowed to run to grass. Removal of the sod from a neglected orchard will often more than double the growth. The ashfall had the same effect on these trees that cultivation has on an apple orchard.

\section{REVEGETATION DLE TO RECOYERY OF OLD}

\section{PLANTTS}

It was assumed by all who visited Kodiak during the first two seasons following the eruption that the smaller plants had been practically exterminated, except for the few individuals so situated that ther could readily grow through the ash laver. Consequently, when the re- 


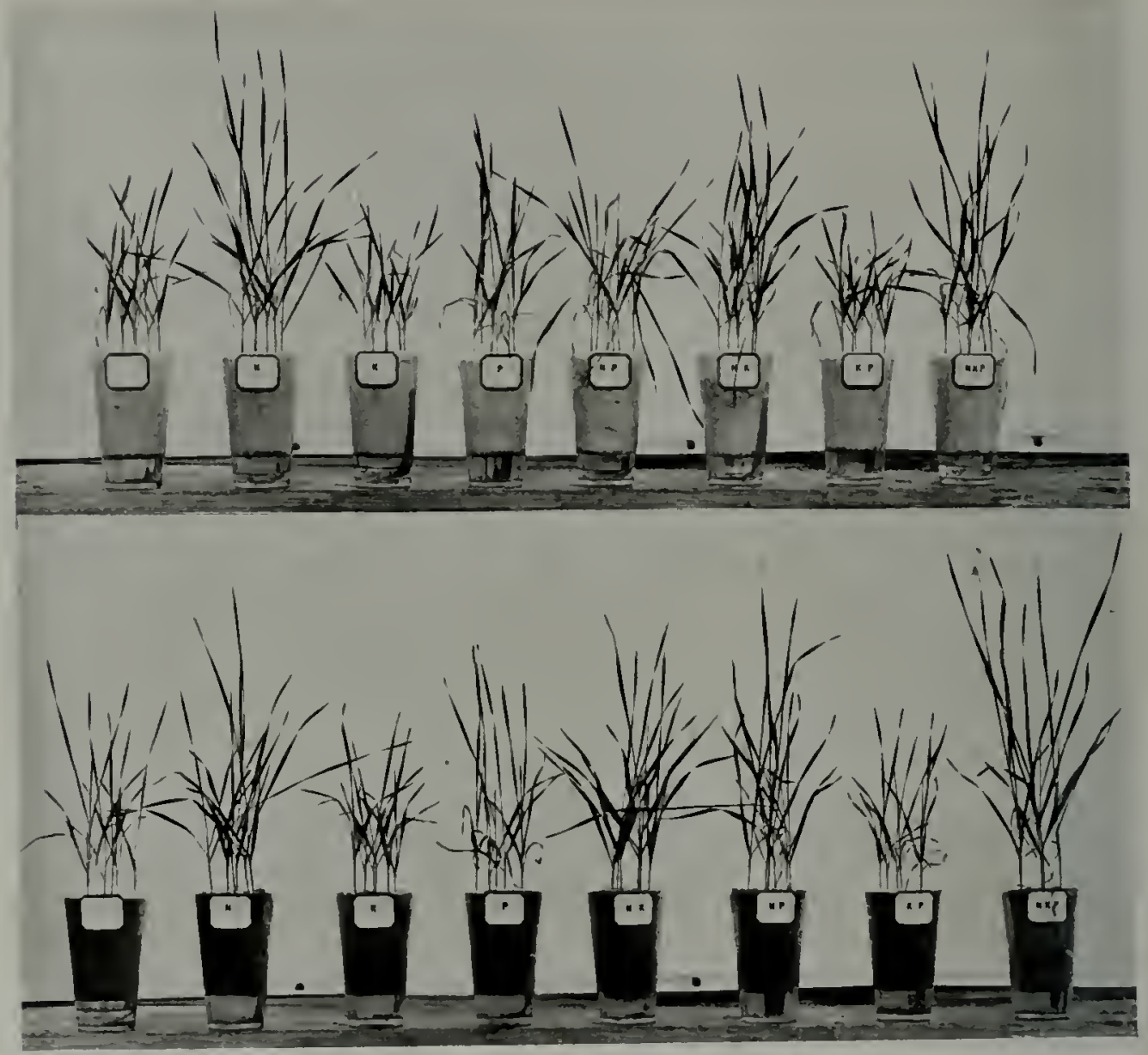

SOIL VALUE OF FATMAI ASH AS COMPARED WITH SAND

Wheat scedlings in the upper row were grown in quartz sand, the lower in ash from Kodiak. The pots at the left were untreated. To the others fertilizers were added as indicated by the symbols on the labels (N, Nitrogen; K, Potassium; P, Phosphorous). Unless a complete fertilizer was supplied, the plants turned red and died when the nutriment stored in the seed had been exhausted.

markable growth of succeding seasons was observed, it was natural to suppose that the new vegetation must consist of new plants which had started in the ash from sced.

Field study at once showed this to be incorrect. Even the most superficial observation indicated that at the beginning of the fourth season (1915) there were practically no seedlings, most of the new plants being directly traceable to the old roots.

An excellent demonstration of this fact was furnished by the condition of a field on the Frye-Bruhn ranch, south of Kodiak, which had been plowed before the eruption. Where cultivation had destroyed the weeds, no new vegetation appeared for five years, but the plants of the uncultivated land all around came up in undiminished vigor and completely covered the ground. The contrast between the bare field and the duxuriant growth surrounding it was conspicuous at a distance of five miles (see page 54).

Excavation around the underground parts of the new vegetation always re- 


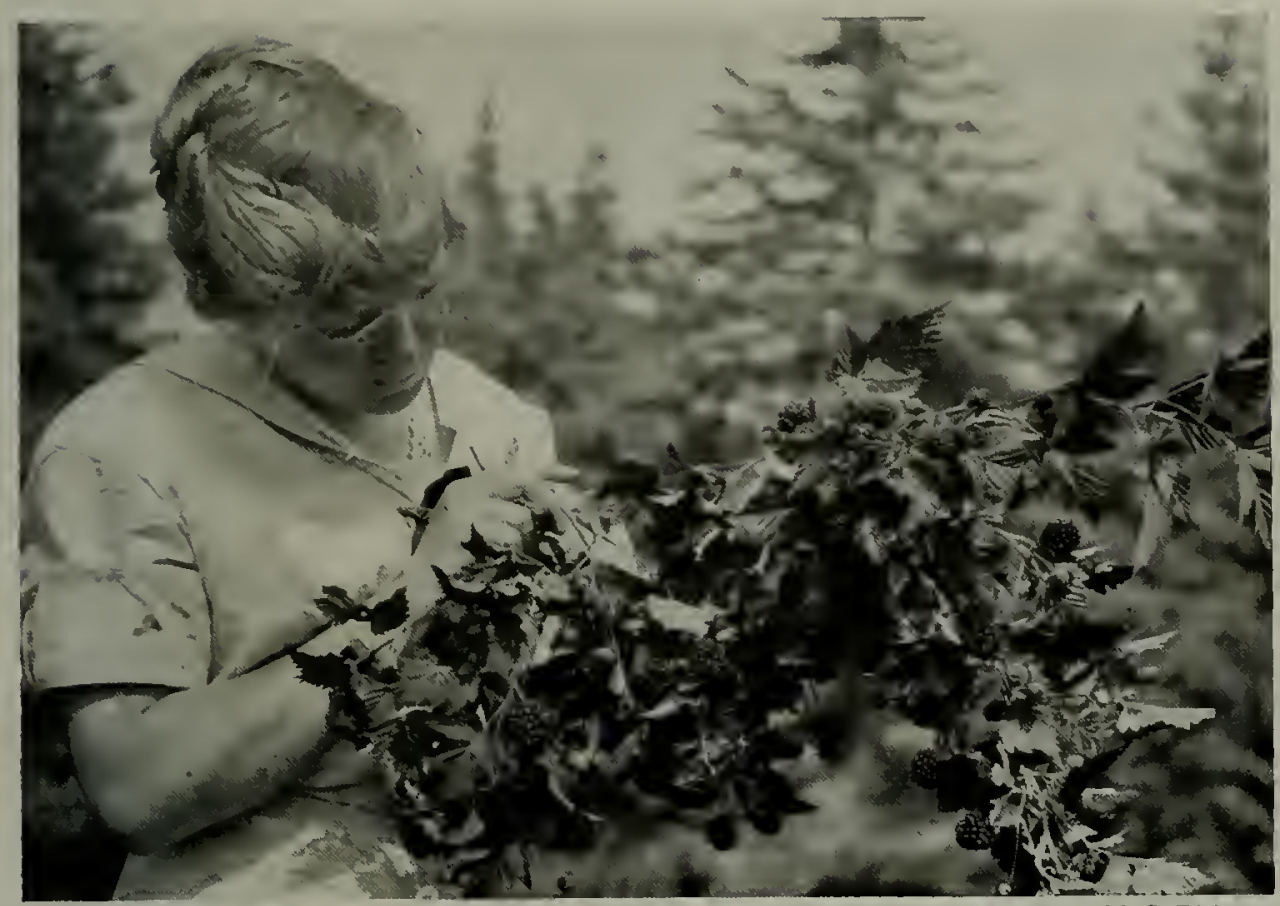

Photograph by M. G. Dickman

A BRANCH OF SALMON-BERRIES, INDICATING THE PROFUSION OF WILD BERRIES AT KODIAK SINCE THE ERUPTION

These berries are somewhat like the persimmon, in that they have an astringent taste that disappears only when they are dead ripe. They have, however, a distinctive and extremely delicate flavor, and when served with sugar and cream equal or surpass any other berry with which the author is acquainted.

vealed its connection with old roots in the original soil.

A number of species of trees and shrubs were found to have developed striking "two-storied" root systems by putting out new roots from their stems just below the surface of the ash (see page I33). It was noteworthy that the new roots were confined to the top of the ash. The intermediate zone between the surface and the old soil was as bare as though still growing in air.

\section{PLANTS RESURRECTED AFTER THREE YEARS' BURIAL}

If the recovery of vegetation had occurred during the first season after the eruption, it would have occasioned no particular surprise. It was the delay in

- For details, see the appropriate technical papers in the Scientific Results of the Iratmai the reappearance of the plants that upset all predictions.

Everyone assumed that only that small percentage of the old plants which reappeared within a few weeks had survived. But, as demonstrated by the event, practically all of the members of the plant society had the capacity of recovering after having lain dormant beneath the ash for an astonishingly long period.

Both at Kodiak and on the mainland it was proved beyond question ${ }^{4}$ that the old roots could send up new growth after a period of enforced dormancy of three years. In a number of cases, where there could be no doubt as to the duration of the dormant period, the new growth was as vigorous as though it had

Expeditions, Ohio Journal of Science, vol. I9, pp. $32,195$. 


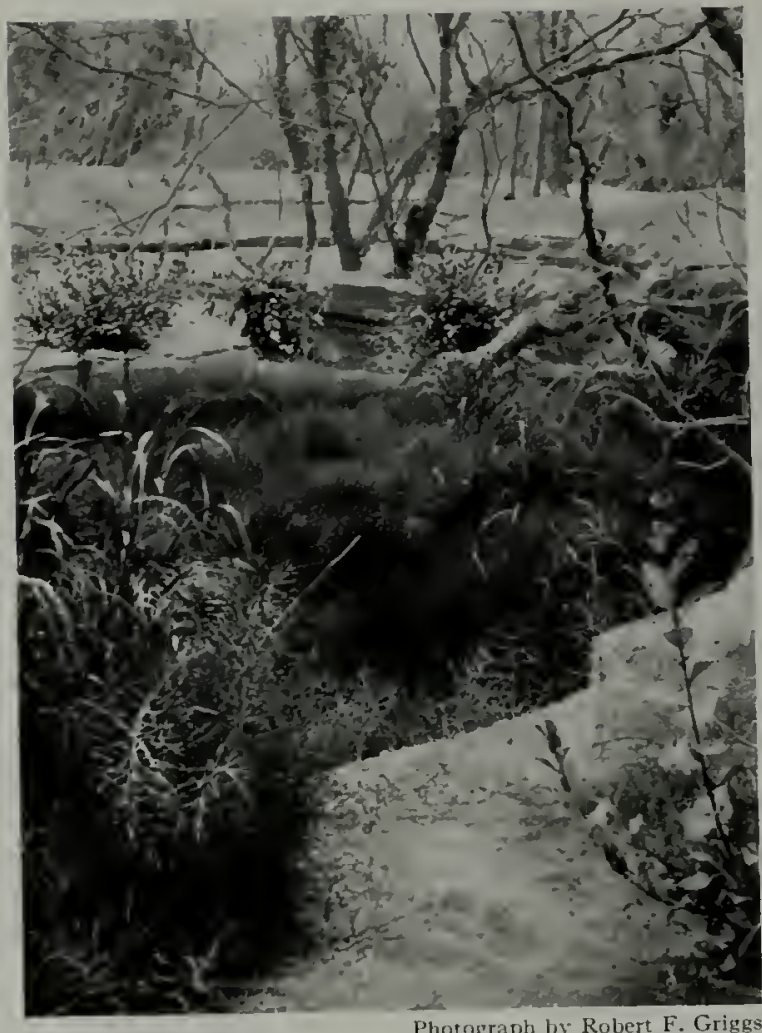

WHERE NO PLANTS COULD COME THROUGH ON THE LEVEL

Horsetail sometimes penetrated the reduced thickness of ash in the bottoms of the gullies.

been buried only a week or two (sce also page 153 ).

The bulk of the regetation that wrought such a change in the appearance of Kodiak after two years consisted of the same species of strong-growing plants that had appeared from the first in smaller numbers. After these had reappeared in full force a number of the smaller plants, such as the little "liostinika" berry (Rubus pedatus), the baked-apple berry (Rubus chamaenorus), and the mountain cranberry (Vitis-Idaea), also began to grow up from the old roots, under conditions that made it certain that they lad lain dormant through the interim.

\section{SEEDLINGS SLOW TO START}

These luxuriant hold-over plants stand in strong contrast to the feeble seedlings which in places came up in the ash. At the Experimental Farm at Kalsin Bay a plot was seeded down with timothy soon after the eruption. Although the seeds had sprouted well and given a 100 per cent stand, the plants were mostly only about 3 inches tall at the end of three years (see page 54 ). The contrast between this grass and that shown on page 42 , which in places penetrated 20 inches of ash, requires no comment.

\section{THE SAND BLAST}

The importance of surviving plants in the revegetation of liodiak cannot be overestimated. Where there was no. plant cover to protect the surface of the ground, the loose ash was picked up in clouds by every passing wind, forming a sand blast that was very hard on the plants exposed to it. All of them were lopped orer before the wind, and their lower leaves were either cut to pieces by the sharp sand or buried beneath it (see pages 46 and 59).

The particles of ash are all very sharp, sharper than ordinary sand. Indeed, volcanic ash forms the basis of numerous commercial scouring agents. The ash is also finer and much lighter than shore sand, and it is more easily carried by the wind. Consequently, this sand blast is a very different thing from the drifting sand common among beach dunes.

One might suppose that the frequent rains which characterize the clinute of the region would hold the sand blast in check, but it is surprising how quickly it starts again after the rain stops. $\mathrm{We}$ found that after a day of soaking rain the sand was blowing early the next morning, although only the very surface had dried off.

This blowing ash lodged behind any obstruction, like snow. Among the 
weeds at the edge of cultivated fields and along the fence rows, drifts two feet deep were formed. On mountain tops and in other places where there was no regetation to catch the ash, it formed dunes like those on a seashore (see page 59).

One could see no prospect of revegetation in such situations until the ash surface should become stable enough neither to bury the young plants before they were well started nor to blow away the soil and expose their roots.

\section{IMPORTANCE OF HORSETAIL AS A SOIL BINDER}

It was of the utmost importance that the ground be covered with regetation, regardless of the value of the plants making the cover.

Of all the native plants the one which could grow through the deepest ash and, once through, spread most rapidly on the bare surface was the field horsetail (Equisetum arvense). This is a common weed of railway embankments and like places in the United States. In Kodiak scattered individuals were frequent before the eruption, though they formed no noticeable element in the landscape. But it has come up everywhere through the ash and has spread out on the surface, forming in many places a beautiful greensward, where hardly anything else could come through.

Its present abundance contrasts so greatly with its former state that, according to Mr. Snodgrass of the ExperimentStation, some of the natives thought it must have "come with the ash," and could only be convinced to the contrary when he dug out the rootstocks and showed that they originated in the old soil beneath the ash.

A deposit of Io or 12 inches would have been fatal to most plants, if it had not been for the contraction cracks in the ash; yet the horsetail in many places came through from 30 to 36 inches of ash! This was especially well shown in the deep deposits on the mainland, where, with the ash four or five feet deep, nothing at all could come through on the level:

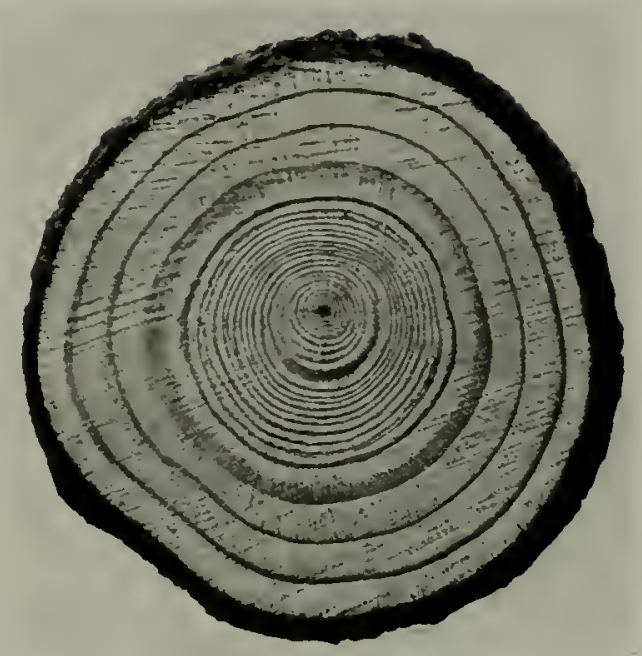

THE EFFECT OF THE ASHFALL ON TREE

The slow growth before the eruption is recorded in the thin central rings. The great increase in vigor since the ashfall is registered by the heavy outer rings. Twice natural size (see text p. 48 ).

but little gullies in the ash were green with a carpet of horsetail (see picture opposite).

The description given thus far applies largely to the open country. In the forest the thick trees greatly modified conditions by protecting the soil from the wind and increasing the humidity of the air. Their branches still retain a good deal of ash in places (see p. 28).

In the deepest, most humid parts of the forest great masses of moss grew on the branches. These have since grown out through the ash and consolidated it into heavy balls, which give the trees a very bizarre appearance (see page $3^{8)}$.

THE NETWORK OF MOSS ON THE FOREST FLOOR

More striking than anything in the trees, however, was a remarkable network of moss which developed on the forest floor. When the ash dried up after the heary rains following the eruption, deep cracks appeared, like the mud cracks in a dried puddle (see page $5^{8}$ ).

The cracks were, of course, quickly 


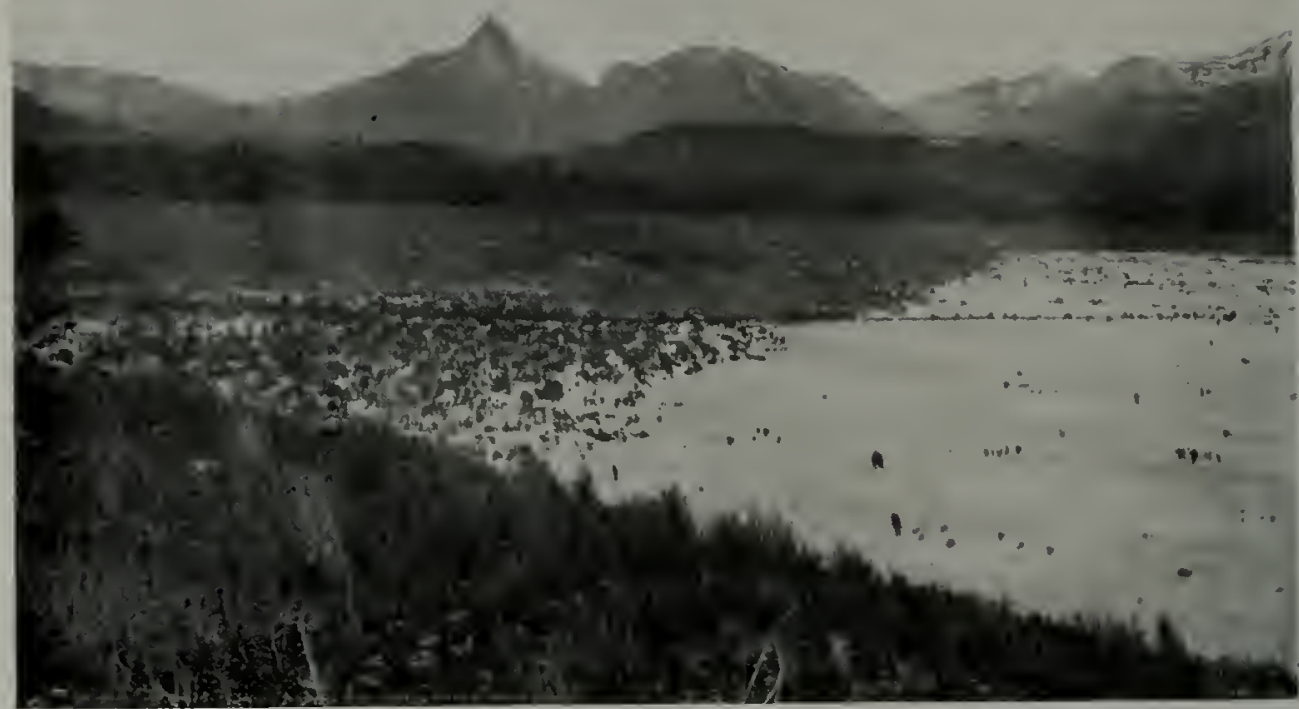

Photograph by D. B. Church

A PLOWED FIELD, PART OF WHICH WAS CULTIVATED JUST BEFORE THE ERUPTION New plants were unable to start in place of the weeds destroyed by cultivation-illustrating the importance of residual vegetation.

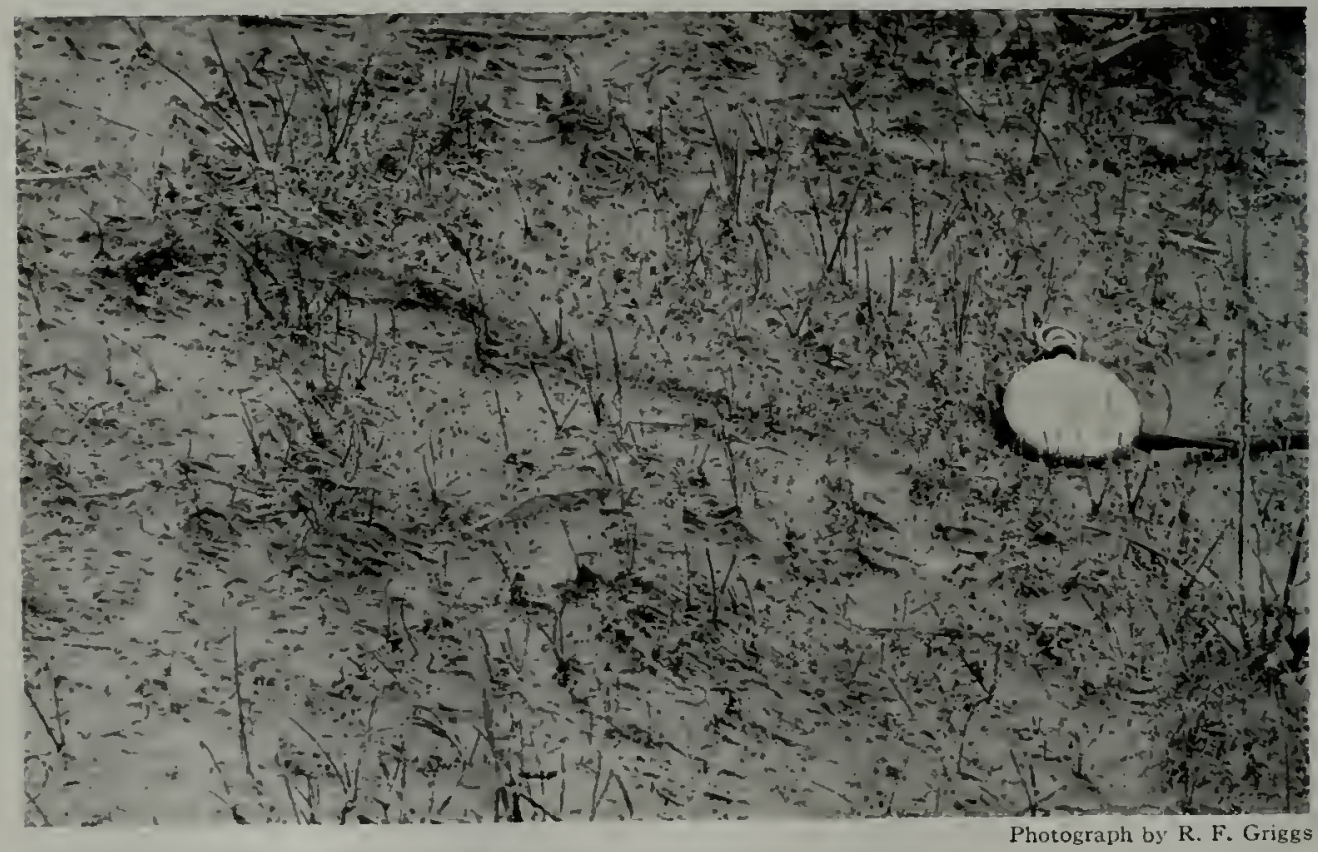

A TIMOTIY PLAT THREE YEARS OLD

Sowed in the ash soon after the eruption, the seed came up well and most of the plants are still alive but have made no growth. Contrast with the grass come up from old roots, shown on page 42 . 
filled up by drifting ash, but their position was preserved by a heavy growth of moss, which formed a most curious network all over the ground. The microscopic spores carried by the wind had settled into the cracks. The same moss was to be found around fallen sticks or other objects that would catch windborne spores.

\section{SEEDLINGS OF ALL SORTS STARTED IN THE FOREST}

In the forest the trees protected the ground from the wind, and insured a stable surface on which new plants could start. It was several years after the eruption, however, before seedlings made their appearance in any numbers, even in the most protected situations. None were observed in 1913 , and in the beginning of the season of 1915 they were few and far between.

But during the latter part of 1915 they began to appear in numbers. The seedlings included representatives of all the important members of the flora. Although they grew very slowly, still they persisted, and some of them survived the winter.

But seedlings had assumed no important place in the vegetation even five years after the eruption.

It is already clear that the recovery at Kodiak is permanent. For with the demonstration that seedlings can start in the ash, it is evident that any gaps which may develop in the ranks of the old vegetation will be filled promptly by new plants starting from seed.

The unstable conditions caused by the shifting sand will be, for the most part, of short duration. Where the ash layer was only a foot thick originally it will not require a very long period for the wind to remove the whole deposit.

Indeed, in many exposed situations the ash is already completely gone. And in any case, it will be only a few years before the larger part of the ash from the mountains has been blown out to sea. Even on the level some places have already been nearly cleared. Thus the field at the Frye-Bruhn ranch, previously spoken of, retains at present only enough ash to veil the black soil beneath, and the sand blast is almost a thing of the past.

In places sheltered from the wind, erosion by water has proceeded rapidly, and where the land is even moderately steep, nearly all the ash has been washed away. On the average grass-covered mountain sides, the present covering of ash amounts to only an inch or two and this is so mixed with plant stems and roots as to form a very indefinite layer. By 1919 it appeared almost incredible to a stranger that the ash had stood a foot deep only seven years before.

\section{EARTHWORMS WORKING OVER ASH}

Another factor which is tending to destroy the identity of the ash as a separate layer is the action of earthworms. Ever since the classic researches of Charles Darwin it has been recognized that the constant working over of the soil by these creatures is of great importance, by reason of the continual additions of new material which they bring up from below and void on the surface.

At Kodiak their castings are abundant on the ash surface. From the character of the castings it would appear that the worms are confining their activity largely to the ash itself; but, even so, their action will serve to bury increasing quantities of vegetable débris. And where they bring up the old soil from beneath the ash, they will thoroughly mix ash and soil till the ash layer becomes hardly recognizable.

On the whole, we must recognize that the experience of Kodiak is decidedly reassuring. The damage to vegetation by an eruption is not likely to be so great as at first appears. Where the ashfall is a foot or less in thickness, no permanent injury to agricultural interests is to be expected. There is no occasion for the people in a region similarly affected to abandon their property and go elsewhere, as some were inclined to do at Kodiak. 


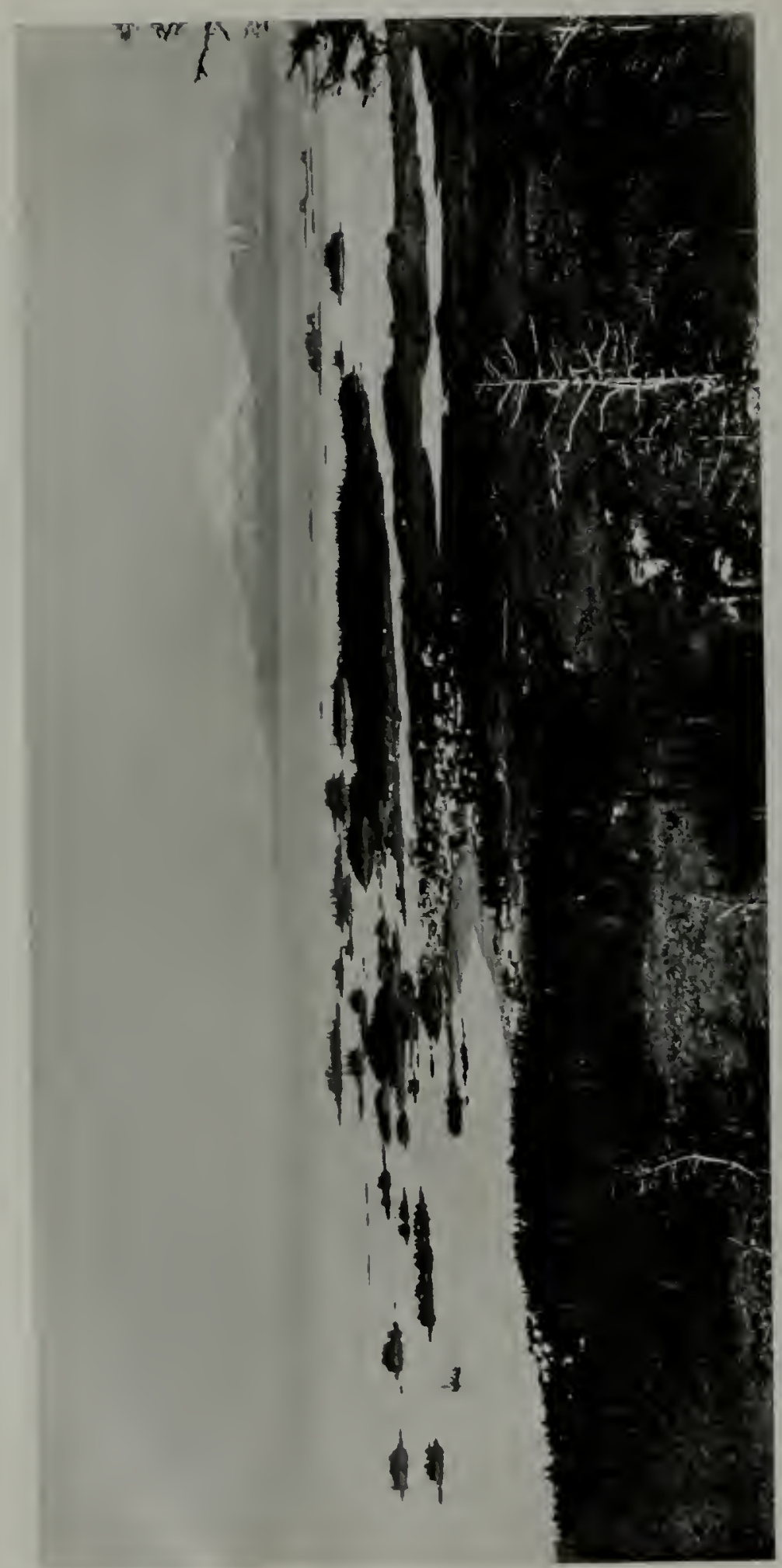

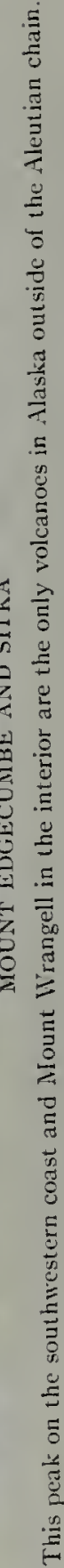






\section{THE ALASKAN VOLCANOES}

The eruption of Katmai was not accompanied, as some eruptions have been, by other sympathetic activity at a distance from the main focus. Yet it should be recognized that Katmai is not an isolated vent but one member of a long chain. In a larger view the chain itself is a single unit whose uplifting and activities are the expression of a set of fundamental stresses that have developed deep down within the earth's interior. Any particular eruption is, therefore, only a trivial incident in the drama.

Nothing could be more fascinating than to unravel the history and discuss the forces underlying the formation of volcanic chains. But that would carry us too far afield. Nor do we possess the knowledge requisite for the purpose. Yet we cannot properly take up the problem of Katmai without giving some idea of its setting and of the Asiatic volcanic complex of which it is a part, for, as will appear, the relations of the Alaskan volcanoes are not American but Asiatic.

It should be observed that all the volcanoes of Alaska except two ${ }^{1}$ belong to the Aleutian chain. This, although reaching many miles into the mass of the American continent, has an unmistakable affinity with the Asiatic volcanic belts, while it shows no connection with other American volcanoes.

\section{THE VOLCANIC FESTOONS OF ASIA}

An examination of eastern Asia (see map opposite) reveals a very curious succession of volcanic chains stretching down the coast, like a series of garlands draped along the edge of the continent. Each member of the series is a gigantic

$1 \mathrm{Mt}$. Wrangell in the interior and Mt. Edgecumbe near Sitka.

2 The data concerning these volcanic festoons and the structure lines are largely summarized crescent, convex toward the ocean Each trends southwesterly, beginning with a southerly course and bending toward the west as it continues along the coast. Each joins the next lower segment approximately at right angles. The crescentic arrangement recurs with remarkable regularity five times in a series of arcs stretching from Alaska to Sumatra. ${ }^{2}$

Directly in line with the prolongation of the Aleutian chain are the Commander lslands (volcanic, though without any modern vents), carrying our chain, the first arc of the series, over to the shores of Kamchatka, where it meets the second crescent, a line of very lofty and notable volcanoes running down through the Kuril Islands into northern Japan.

The third member of the series begins with the Island of Rishiri, in northern Japan (with a theoretical extension northward on a great fault along Sakhalin Island), and stretches south and southwest to the western extremity of the Japanese Islands, where, like the Aleutian and Kuril chains, it meets the next member of the series nearly at right angles.

The only break in the regularity of these festoons of volcanoes occurs in this Japanese arc, which is intersected in the middle by the great transverse fault of Central Japan, along which an independent series of volcanoes, including the celebrated Fujiyama, stretches out at right angles toward the Bonin Islands far to the south. The general relations of this chain suggest that it is a member of the same series of festoons as the others, but it appears to end in deep water, without curving around to join the next at its southern extremity.

from Hobbs' reviews of the work of Suess and Richtofen. See American Geologist, vol. 34, p. 69, 1904. 


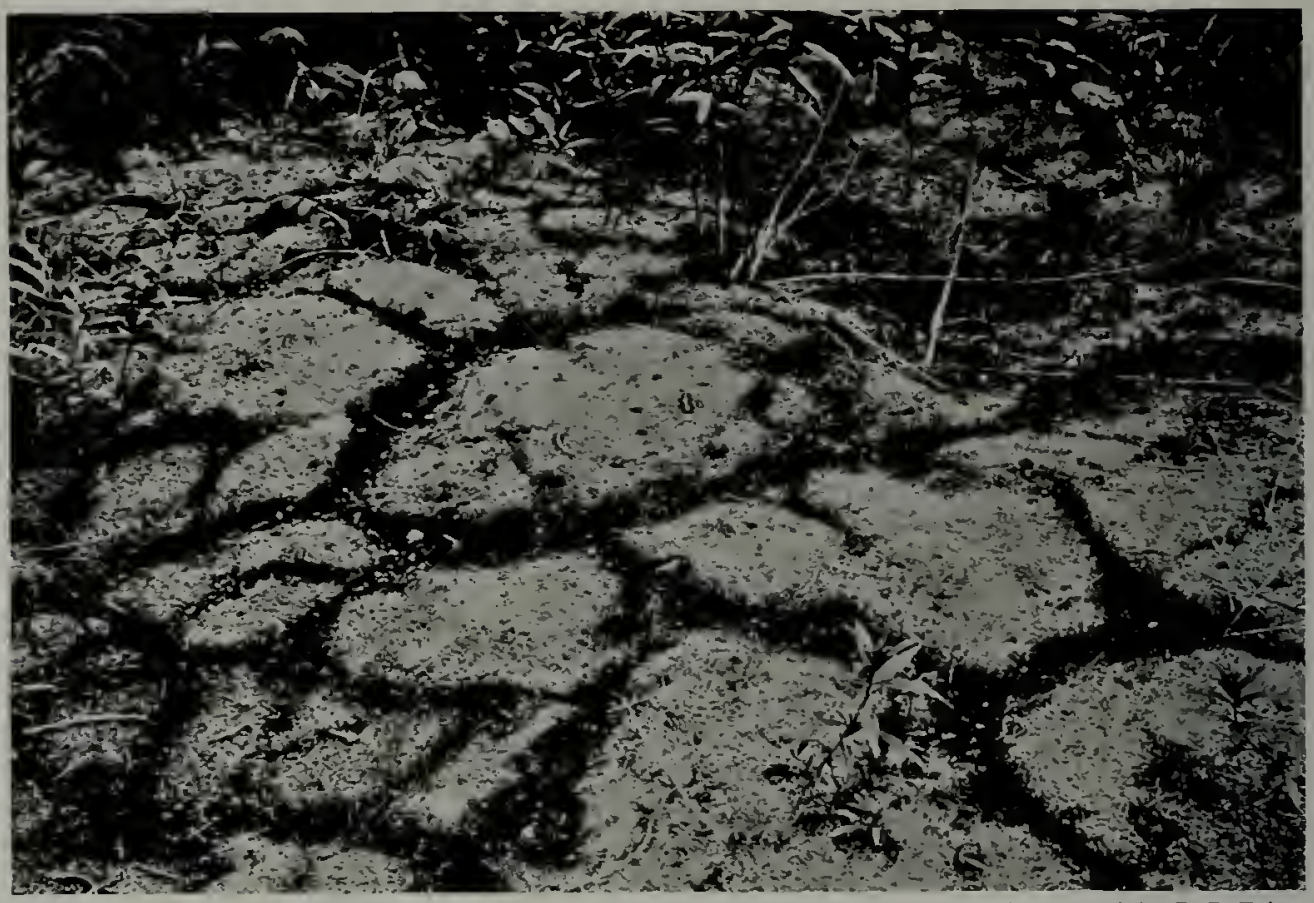

Photograph by B. B. Fulton

THE MESH WORK OF MOSS ON THE FOREST FLOOR

Perpetuating the position of the contraction cracks, see page 22 and text page 53 .

The volcanoes of southern Japan are developed along a fourth great line of weakness, which comes down the east coast of Korea and curves around through the Lu-Chu Islands to northern Formosa. Here again a fifth curving line of volcanoes, also convex seaward, carries the system through the Philippines and Borneo into the great volcanic complex of the East Indies.

REMARKABLE PARALLELISM OF VOLCANIC ARCS

Not only is there a striking similarity in the general position of these volcanic festoons, but there is a very interesting parallelism, perhaps only accidental, but none the less remarkable, between the physiographic features of the several units.

In each case the crescent shuts off a considerable sea. Nowhere else in the world is there anything to be compared with the series of enclosed basins con- sisting of Bering Sea, Okhotsk Sea, Japan Sea, Eastern Sea (Tunghai), and China Sea.

The parallelism is further emphasized by the remarkable fact that in three of the five arcs the northeastern end consists of a large peninsula - the Alaska Peninsula, Kamchatka, and Korea while the distal portion is made up of a narrow chain of small islands-the Alcutians, Kurils, and Lu-Chu Islands.

It is of great interest to observe further that the coastal region of Asia is cut off from the interior by two older series of similar crescents stretching from the Arctic into Central Asia. The two arcs of the Stanovoi Mountains and the Great Ihlingan Mountains are conspicuous even on ordinary political maps of Asia. Farther south are four other crescents, not so readily traced in the atlases because of the rugged character of the country they traverse. Their position as delineated by Hobbs is shown on the accompanying 


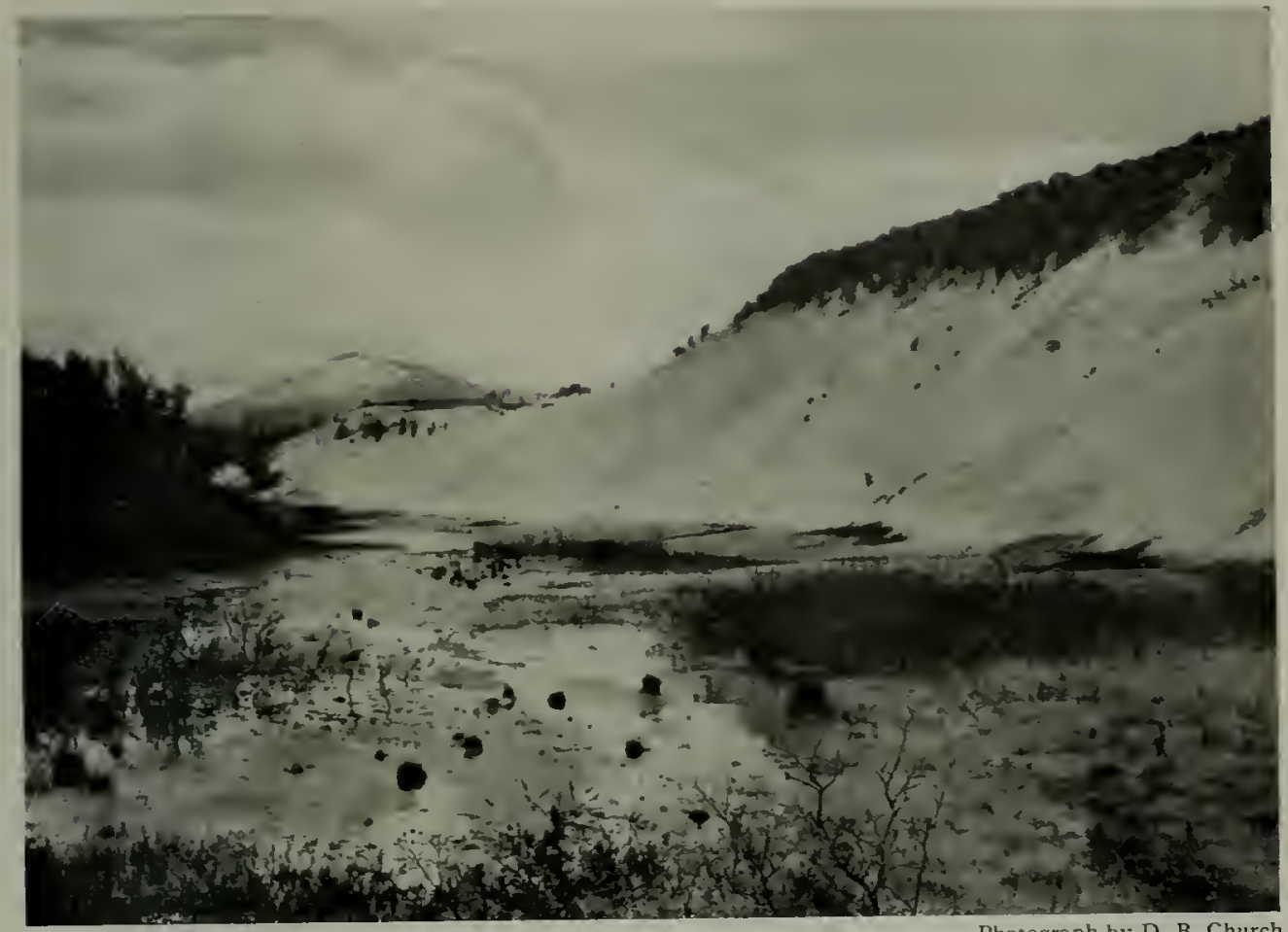

Photograph by D. B. Church

A DUXE OF WIXD-BLOW: ASH: WOMEX'S PENINSULA, NEAR KODIAK

This blowing ash lodged behind any obstruction, like snow. Among the weeds at the edge of cultivated fields and along the fence rows drifts two feet deep were formed. On mountain tops and in other places where there was no vegetation to catch the blowing ash it formed dunes like those on a seashore.

map (facing page 56). Between these and the island festoons is another incomplete series along the coast line.

A study of Eastern Asia discloses the fact that the same type of fractures has dominated crustal deformation throughout the area since the beginning of the geologic record.

The inner crescents are not at present the seat of active rolcanism, but it can hardly be doubted that their formation is due to the same cause as the volcanic festoons along the coast. The regular repetition of such striking lines of crescentic fractures over so large a segment of the earth's crust cannot be thought of as accidental. The cause responsible for such great and long continued movements must indeed be very deep-seated, inherent in the very constitution of the globe.
The fundamental character of the forces which fix the location of the lines of rolcanoes is emphasized by the fact that the course of the rolcanic chains show's in places a complete independence of all surface features of the earth's topography.

\section{ALEUTIAN CHAIN CUTS ACROSS CONTI- \\ NENTAL AREAS AND OCEAT DEEPS}

The Aleutian chain in particular holds its course through continental strata and across ocean deeps with a constancy that is very significant.

The northern end of the chain parallels the Chigmit Mountains, a much crumpled mountain system of typical character. Beyond this, in the Katmai district, the volcanoes are built up on a thick platform of sedimentary rocks, whose strata lie almost as they were laid down on the 


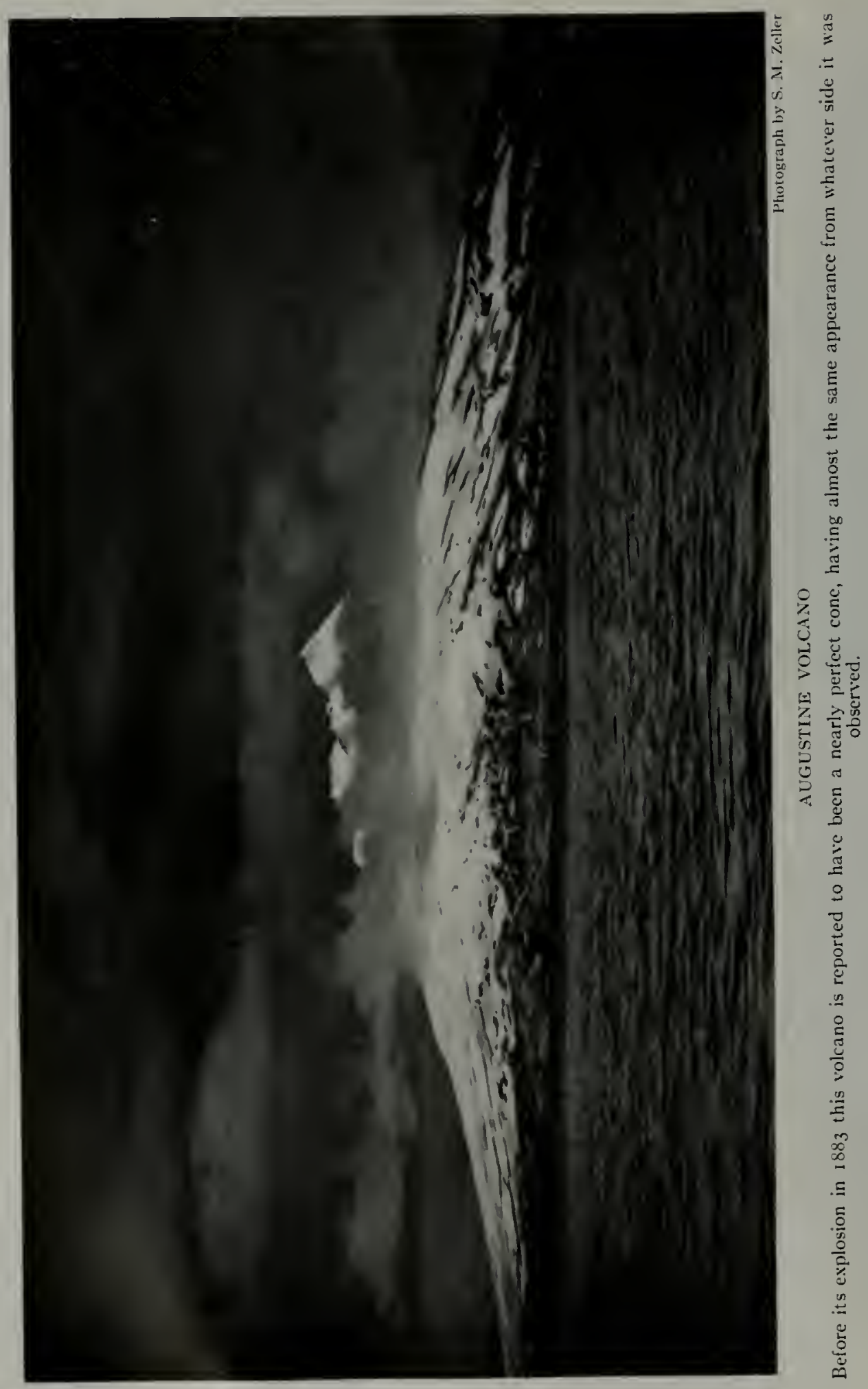




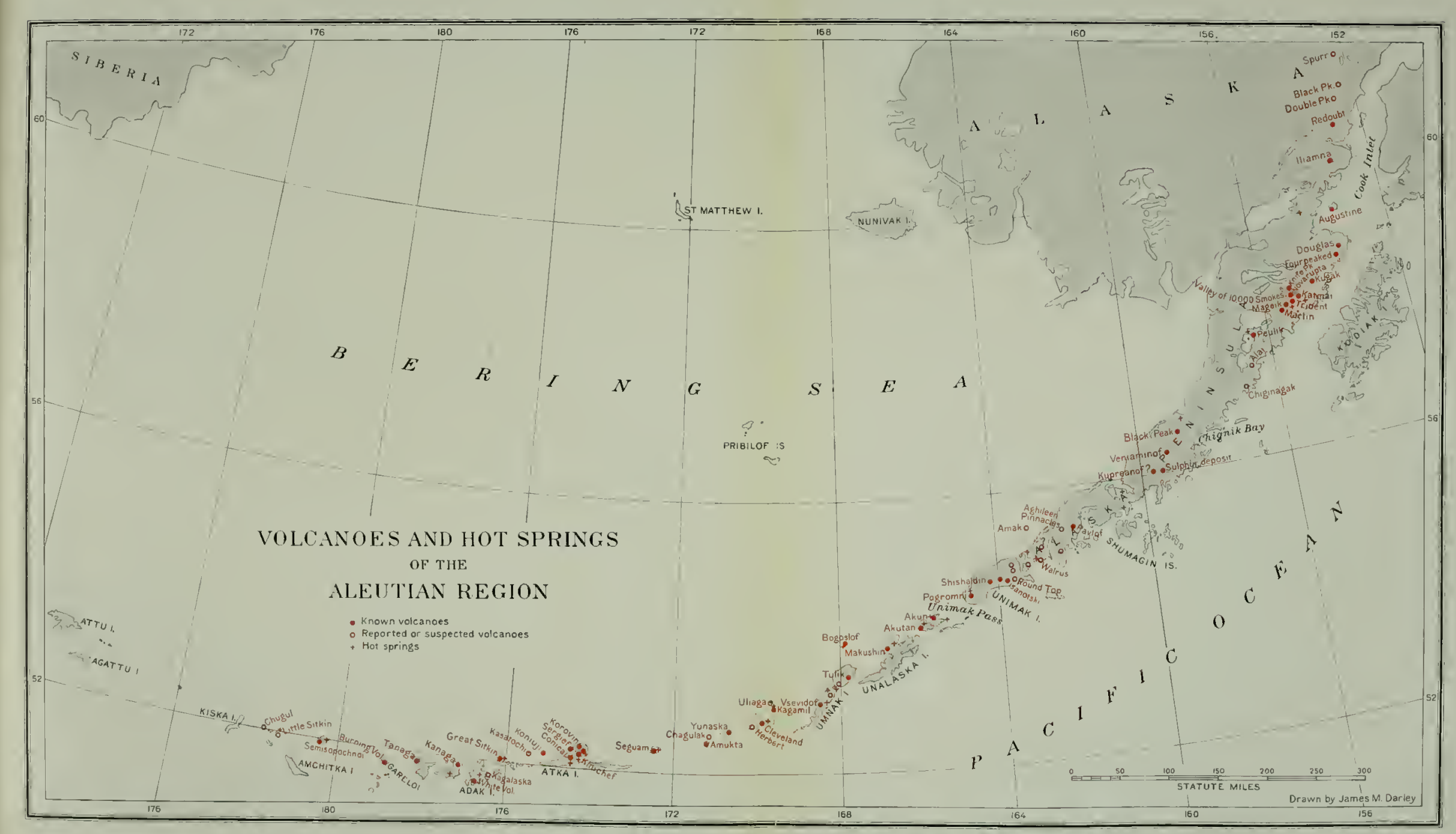



shallow sea bottom, having been raised above sea-level with scarcely any deformation. This whole area, both the folded mountains and the eroded plateau of our district, lies in a distincty continental region, for Cook Inlet and the waters around Kodiak are notably shallow, forming in fact considerable banks, like the Grand Banks of Newfoundland.

In the strongest possible contrast to this is the line of islands which stretches 500 miles beyond the tip of the peninsula. These are the crest of a very steepsided ridge rising directly out of water more than a mile deep. Indeed, the ridge between the thousand fathom marks averages only about 90 miles wide.

Only a few miles south of the islands lies one of the deepest depressions on the ocean floor, a narrow groove running closely parallel to the course of the volcanoes. Within a hundred miles of peaks whose heights exceed 8,000 feet, soundings of more than 24.000 feet have been made. Here is one of the greatest contrasts in elevation on the whole globe.

The basin of the Bering Sea on the north is not so much depressed, yet the depth attained here also is more than 12,000 feet,-as great as the arerage ocean depth. There can be no doubt, therefore, that the Aleutians stretch out into a truly oceanic basin.

YOLCANIC CHAINS AMONG THE MOST FUNDAHEXTAL FEATURES OF THE GLOBE

It is unnecessary to point out the significance of this fact, for as is well known the dogma of the "permanence of ocean basins and continental masses" has been one of the most universally" accepted dicta of geology for fifty years, and an inspection of a physical map of the world makes it evident enough that most of the larger structural features of the globe parallel the boundary of ocean and continent.

It is not only unusual but significant for the Aleutian axis, starting in the interior of the continental mass, to reach

3 Martin and Katz, U. S. Geological Survey Bull. 485 , p. $94,1912$. out into the ocean deeps. That the line of rolcanoes should continue its course straight through such diverse features as folded mountains, elevated plateaus, continental shelres, and ocean deeps, suggests that the causes underlying its formation are among the most fundamental of terrestial forces.

The Aleutian chain is one of the longest and straightest single lines of rolcanoes on the globe. Although situated in a sparsely settled region where few records of eruptions have been preserved, enough is known to demonstrate that it is likewise one of the most active of rolcanic belts.

But many of its peaks are so little known that it is impossible to ascertain whether or not they are volcanoes or conposed of volcanic rocks. Even the geographical position of some of them is uncertain to the extent of sereral miles. It was discovered in 1920 , for example, that the charted position of Bogoslof, one of the best known vents, was in error by six miles.

Beginning near the head of the Cook Inlet, the active vents in the Aleutian chain stretch out in a southwesterly direction for more than $\mathrm{I}, 200$ miles. There is not space for any detailed account of the 50 or 60 volcanoes which compose this long chain. All that can be done is to single out for brief comment a few of the more noteworthy of them (see map opposite).

Everyone who enters Cook Inlet has occasion to admire the great snowy cones of Redoubt and Iliamna, each standing more than 10,000 feet above the water.

The perfection of their conical forms is evidence enough that neither has ever suffered a great eruption, yet both have at different times showered the country with ashes for many miles round about.

On January 18, I902, an eruption of Redoubt which "sent showers of dust over the country from Lake Clark to the Squentra Valley." 3 It has been stated ${ }^{*}$ that Iliamna was the source of half an

\footnotetext{
${ }^{4}$ Davidson, George, Science, vol. 3, p. 286 ,
} I 884 . 


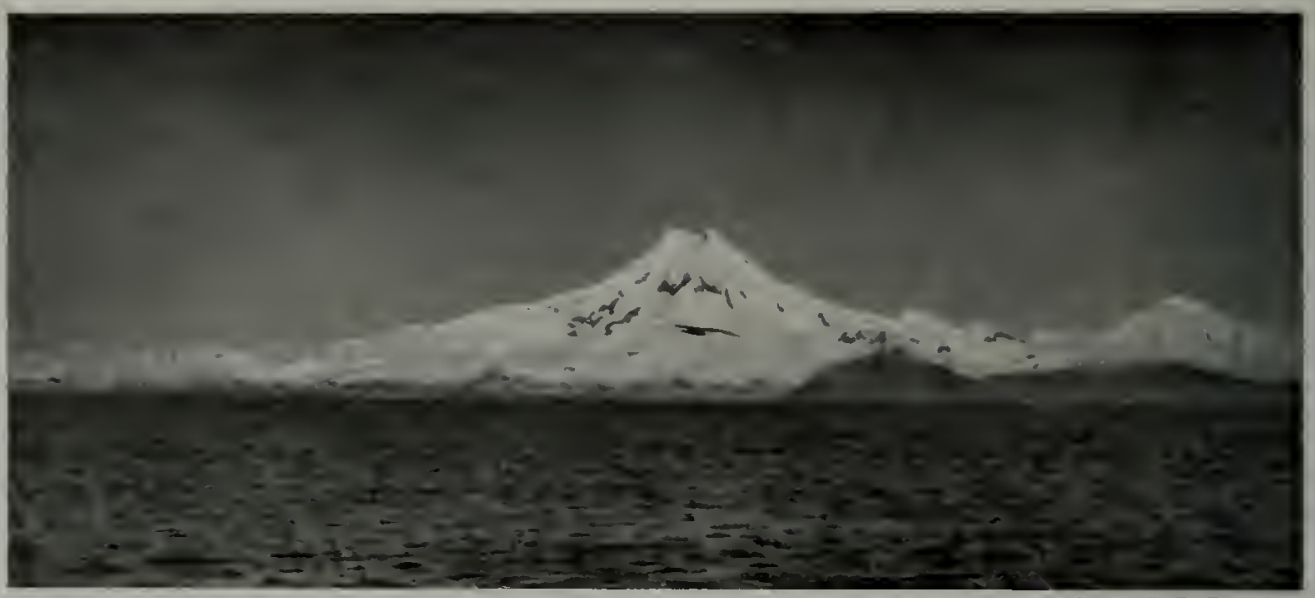

Photograph from Geo. C. Martin, by J. E. Thwaites

ISAXOTSKY PEAKS, UNIMAK ISLANDD

So many craters occur on Unimak Island that there is much confusion as to the location of the various eruptions reported. Isanotsky is credited with a violent eruption within the last century, but there is no confirmation. Its appearance suggests a long period of erosion rather than frequent activity.

inch of ash which fell at Kodiak in March, I 867 , but there is otherwise no record of this eruption.

THE EXPLOSION OF AUGUSTINE VOLCANO

Augustine Volcano affords a good example of what happens to a volcano in a moderately violent eruption. Captain Cook and others of the early explorers describe it as a perfect cone, presenting nearly the same appearance from every point of view.

But some years ago its top blew off, leaving behind a great cavity with a jagged rim, resembling, on a small scale the crater of Katmai (see page 60). This eruption was described by Davidson as follows: ${ }^{5}$

"About eight o'clock of the morning of October 6, I 883 , the weather being beautifully clear and the wind light from the southwestward (compass), and the tide at dead low water, the settlers and fishing parties at English Harbor [Port Graham] (on the Eastern Shore of Cook Inlet) heard a heavy report to windward . . when the heavy explosion was heard vast and dense columns of smoke were seen rolling out of the summit of St.
Augustine. . . Fine pumice dust soon began to fall.

"Twenty-five minutes after the great eruption a great 'earthquake wave' estimated as from twenty-five to thirty feet high came upon Port Graham like a wall of water. It carried off all the fishing boats from the point and deluged the houses. This was followed at intervals of about five minutes by two other large waves estimated at eighteen and fifteen feet; and during the day several large and irregular waves came into the harbor. The first wave took all the boats into the harbor, the receding wave swept them back again to the inlet and they were finally stranded. Fortunately it was low water or all the people at the settlement must inevitably have been lost. The tides rise and fall about fourteen feet."

For several months "flames" could be seen issuing from the summit from a distance of 50 to 60 miles at night, while vast columns of smoke appeared by day.

THE VOLCANOES OF UNIMAK, SHISHALDIN, AND POGROMNI

Unimak Island, at the end of the peninsula, is a focus of volcanic activity 


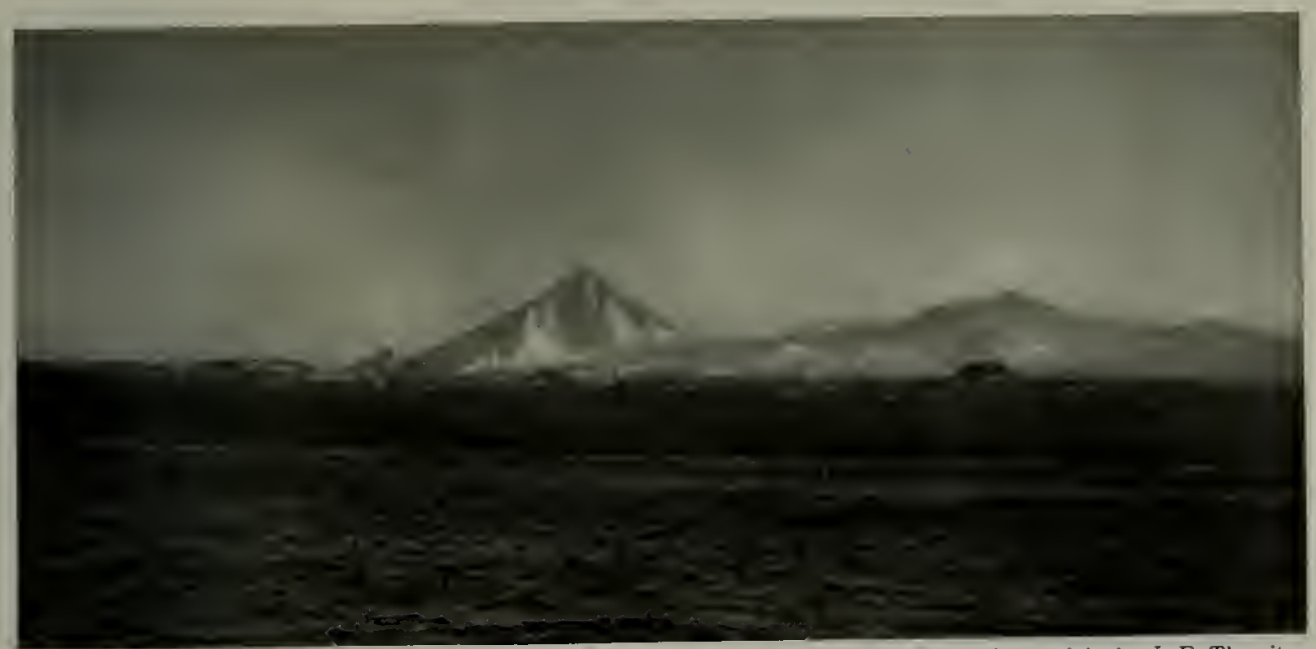

Photo and copyright by J. E. Thwaites

\section{POGROMNI VOLCANO STANDING SENTINEL OVER UNIMAK PASS}

Pogromni is said to have "burst" in 1795 . Other violent eruptions are reported in the years 1827 to 1830 .

little inferior to the Katmai district. Grewingk's map shows no less than eleven craters within its comparatively narrow limits. Because of the multiplicity of vents there is much uncertainty as to which ones were concerned in the numerous eruptions recorded.

The two best known peaks are Pogromni on the west and Shishaldin on the east. The latter is one of the most perfect cones in the world, seeming to float high above the cloud-girt base, recognized by all who have seen its white symmetry as a formidable rival of the celebrated Fujiyama.

THE BIRTH OF A NEW ISLAND, BOGOSLOF

One of the most interesting members of this chain, and indeed one of the most remarkable volcanoes in the world, is Bogoslof, which lies about 40 miles northwest of Unalaska. Here in 1796, a new volcano suddenly appeared above the surface of the ocean. In 1883 another eruption occurred and a companion was born, which was named Grewingk in honor of the great authority on the early history of Alaskan volcanoes.

Since the first advent of the white man, the locality had been marked by a single pinnacle, doubtless the remnant of an earlier eruption, known as Ship Rock, standing high out of the water. Captain Cook sailed close to it on October 29, 1779 .

In March, I906, activity was resumed on a grand scale and two new peaks were successively pushed up in the general position formerly occupied by Ship Rock. These were so close together that the first, Metcalf Peak, was half destroyed by the rise of the second, McCulloch Peak.

"It would be difficult to imagine a more extraordinary spectacle" 8 than that presented by the island at this time. "As a land mass above tide water it was a continuous island about two miles long with the two new steaming cones in the middle. . . Grewingk, flat-topped and cliff-encompassed, guards the north end of the island, while Castle Rock 'old Bogoslof], pinnacled and jagged, rises in the south."

McCulloch Peak between these two was cone-shaped, nearly 450 feet high, and appeared like a steaming heap of bowlders. The top was flattish but

${ }^{6}$ Quoted from Jaggar, Bull. American Geographical Society, vol. 40: pp. 385-400, 1908. 


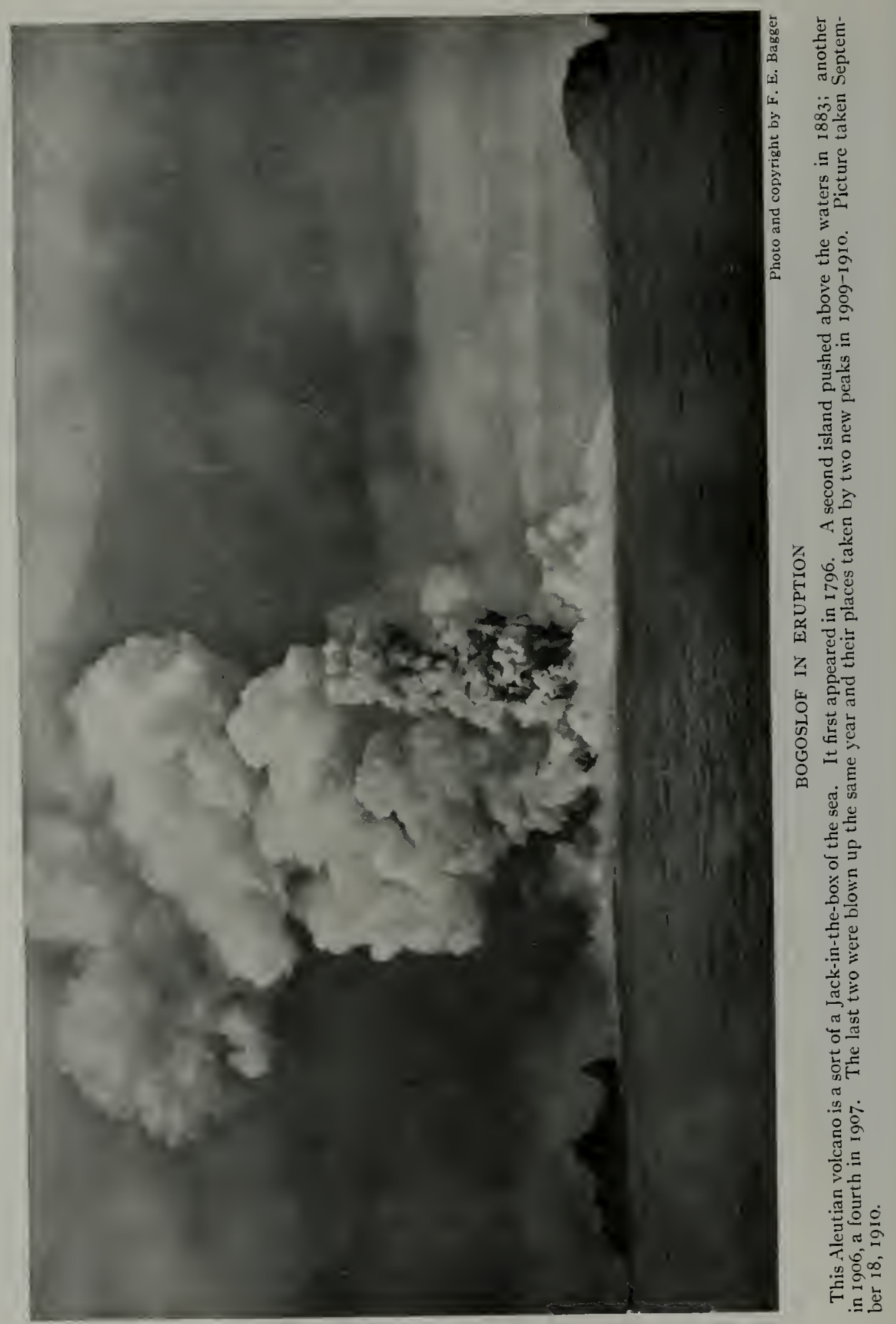


lumpy, made of hard rock and without a crater. It was nearly enclosed by a sickle-shaped lagoon of hot salt water (temperature $90^{\circ}$ ).

If the loose stones "could have been washed away the rock core would have looked like a gigantic potato lifting its lumpy protuberances above the waves.

EXPLOSIONS OF THE PEAKS OF BOGOSLOF

On September I, I907, about six months after the discovery of McCulloch Peak, the inhabitants of Unalaska saw a dense black cloud rising in the west, and the air was full of sulphur fumes, followed by rain and distant rumbling. Ash and sand descended on the town in the evening to the depth of a quarter of an inch. When Bogoslof was visited on October 15 it was found that "McCulloch Peak was absolutely gone, a steaming lagoon in its place and the rest of the island piled high with fallen débris."

The half of Metcalf Peak was still "standing in grim silence as a headstone at the grave of the departed peak." "The lagoon where McCulloch Peak had been was a deep bay open to the west, half a mile in diameter, with steam rising in considerable quantities from the surface of the water."

Renewed activity in the bay between Castle Rock and Grewingk is reported in September, I909, and in June, I9Io, it was found that a new peak with two summits had risen to a height of 178 feet in the center of the island.

On September I 8 of that year the Coast Guard Cutter Tahoma, which happened to be in the vicinity, reported:

"Forked lightning in the direction of Bogoslof was seen before daylight, and when Bogoslof was sighted the new central peak was seen to be in a state of eruption. Immense clouds of vapor, smoke, and ashes issued from the peak, and enveloped the entire island. Flames were reported at the peak, and lightning followed by thunder appeared in the cauliflower cloud of smoke and volcanic dust which rose to a height of several thousand feet above the island. The eruption lasted during the several hours the steamer remained in the vicinity and two days later the central peak was observed to be still steaming." 7

From that time until the present the activity has gradually subsided. The cutter $\mathrm{McC}$ culloch reported a hot pond as late as 1916 , but when visited by the cutter Bothrwell August 9, I920, the rocks and water were all cold. Considerable changes in the configuration of the island, probably due entirely to erosion, had occurred, however.

No man may predict how long the present quiescent condition will continue on Bogoslof. From past experience it is evident that a new upheaval is likely to occur at any time.

It is more probable, however, that the next great eruption will come not from Bogoslof or Katmai but from some one of half a hundred unknown peaks. The history of other regions shows that most of the great eruptions have come from a reawakening of vents that previously had attracted little attention, many of them being considered extinct.

Among the Aleutian volcanoes, where only the most conspicuous and readily accessible peaks are known, it is evident that the probability of an eruption from an unknown volcano is much greater than in most regions.

It is very much to be hoped that before the next great eruption occurs the Aleutian region will have been studied sufficiently to give us definite knowledge of antecedent conditions - information which is sadly lacking in the case of Katmai.

7 Quoted from Sidney Powers, Geographical Review, vol. 2, pp. 218-221, I916.

As this goes to press, R. H. Sargent and IV. R. Smith, of the Geological Survey, report the discovery on the Alaska Peninsula of a gigantic crater si.x miles across, similar to the basin of Crater Lake in Oregon. 


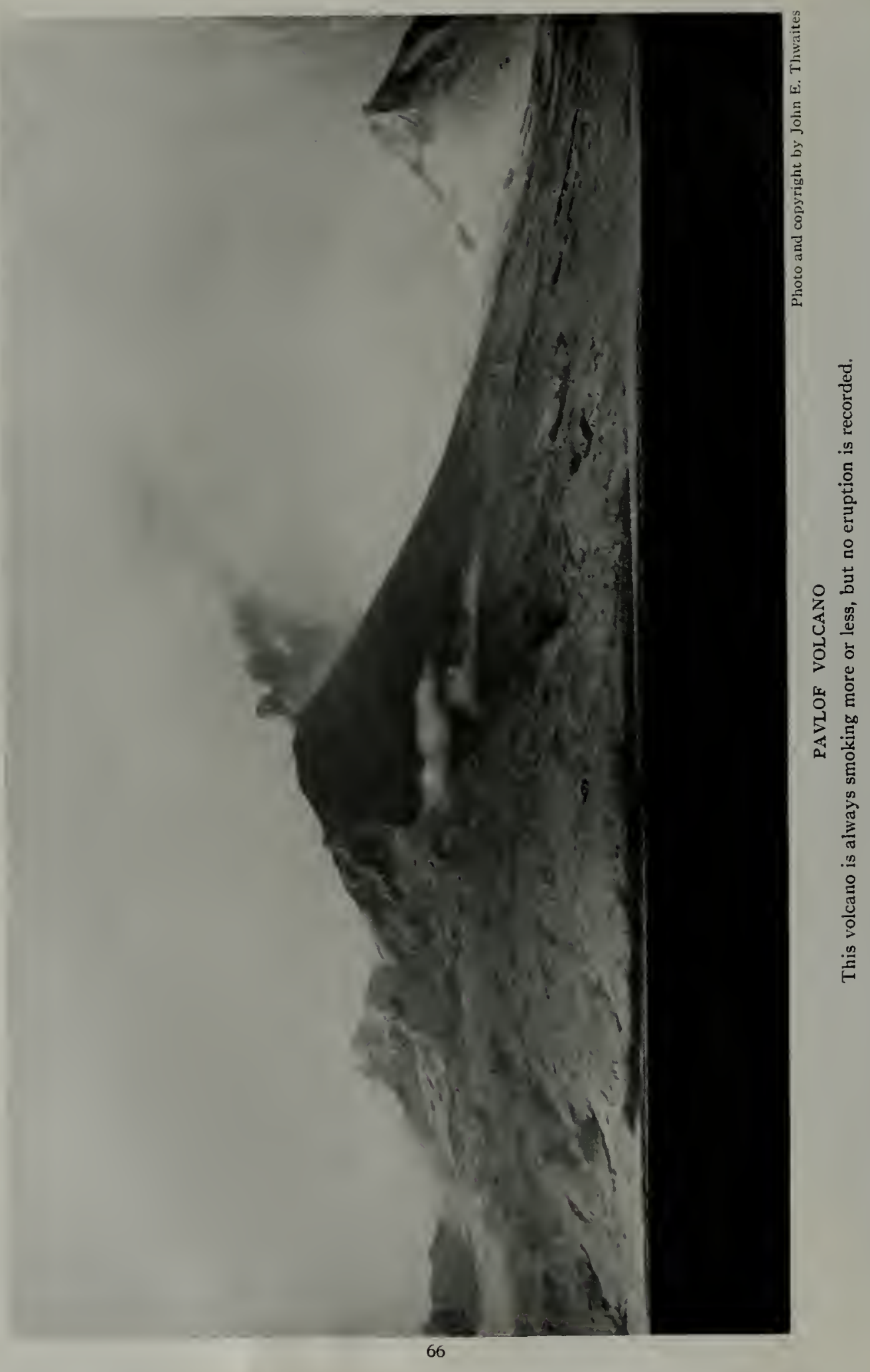




\section{CARRYING THE ITORK INTO THE VOLCANIC AREA; PRELIMINARY ACCOUNTS OF GEOGRAPHY, CHRONOLOGY, AND PERSONNEL}

Although the great distance at which the eruption was felt gives a vivid conception of the tremendous forces involved, the narrative of the effects of the ashfall at Kodiak and elsewhere leaves us without much idea either of the rolcano itself or of the succession of events during the outbreak.

The knowledge that the eruption was of the first magnitude naturally aroused a desire to learn more about the volcano from which the ashes had come, and to find out something of the nature of the forces that had broken loose or, at least, to ascertain their effect on the country immediately surrounding the rent.

The Katmai volcanic district is so remote from the conveniences of civilization that its exploration involved considerable difficulties. Comfortable ocean steamers carry one as far as Kodiak, and there one finds boarding-houses and well-stocked stores. But from that point forward it is necessary" to charter a boat and to provide all supplies, for the country is an uninhabited wilderness affording the explorer only water and fuel.

\section{DANGERS OF NAVIGATION IN THE DISTRICT}

From the time we set sail, the enterprise presented serious obstacles. The waters around the Kodiak Islands are very difficult to travel. The coast is not only imperfectly charted but has many reefs and outlying rocks, which compel the utmost vigilance on the part of the mariner. The narrow channels are, moreover, full of heary tide-rips and the region is subject to fogs, which render navigation unusually hazardous.

Shelikof Strait, which separates the islands from the Alaska Peninsula, has an especially bad reputation, being counted one of the most treacherous bodies of water in the world.

Some of our experiences fully justified the worst that could be said of it. Three separate times during the expeditions a gale, descending without warning from the most promising skies, caught us as we were in the midst of loading our supplies and came near putting an end to our work.

GENERAL SKETCH OF THE GEOGRAPHIC FEATURES OF THE KATMAI DISTRICT

Before proceeding to a circumstantial account of the changes wrought in the volcanic area, and its many phases of unique interest-the immense deposits of ash, the dead forests, the great landslides, the tremendous flood, the innumerable fumaroles-it will be desirable to sketch some of the more prominent topographic features of the district. This will help us keep our bearings as we deal with details, now here, now there. It will best serve our purpose if we can imagine ourselves viewing the country from an airplane skimming over its surface.

The dominant feature of the region in point of altitude is the line of old volcanoes running from northeast to southwest and dividing the drainage of the Pacific Slope from that of Bering Sea. The rolcanoes are not, however, the most striking feature of the district.

The attention of an observer in an airplane would first be attracted by several large open valleys in a country otherwise covered with rugged mountains. The most prominent of these is the broad flat of Katmai River, stretching back northwestward at right angles to the coast for 


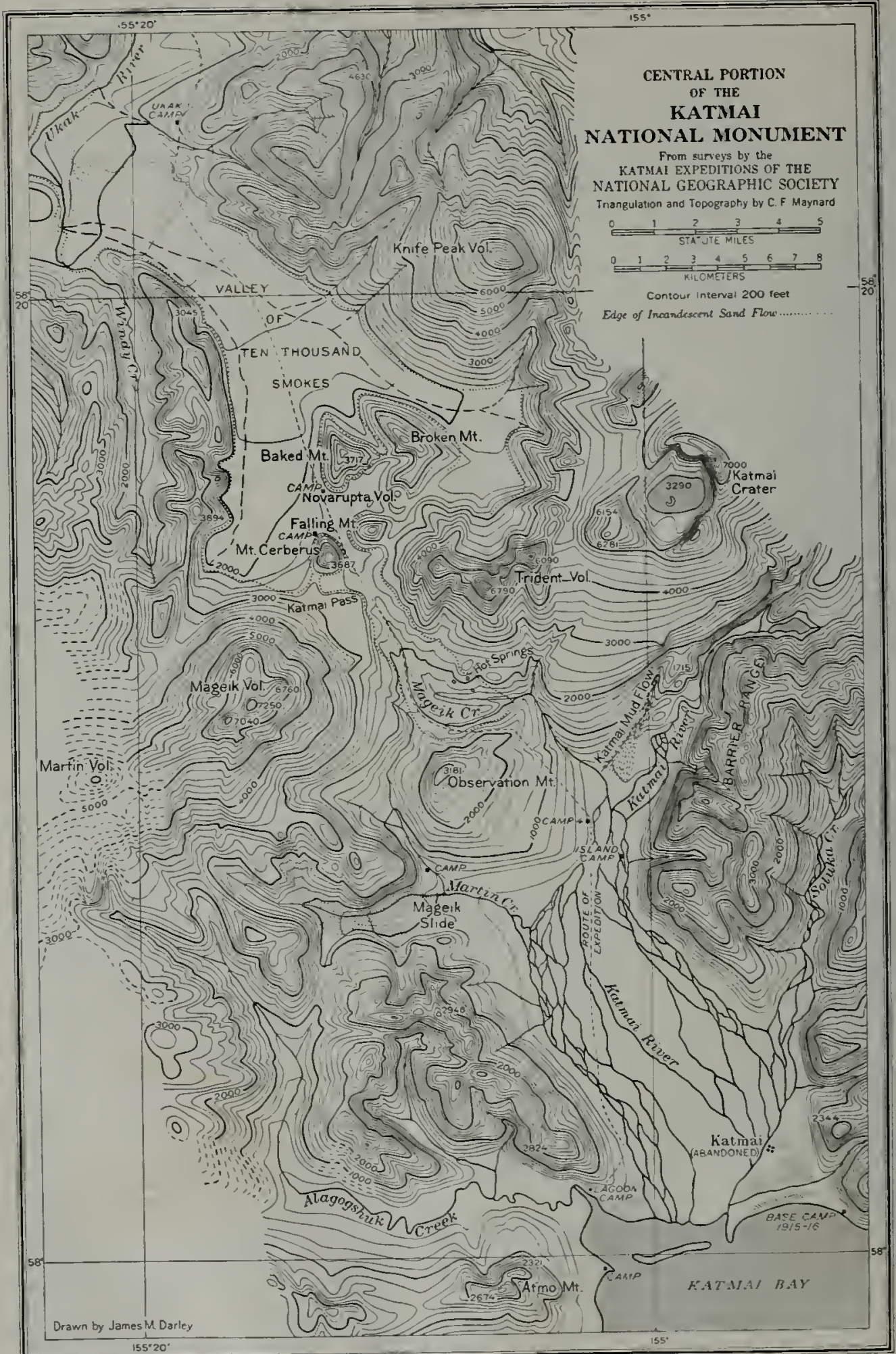


20 miles and furnishing a sea-level route into the very heart of the mountains.

This valley has two important tributaries, one coming from the northeast, the other from the west. Soluka Valley, on the northeast, connects by a low pass with Geographic Harbor at the head of Amalik Bay. Martin Valley in the west, extending up to the foot of the volcano from which it takes its name, is occupied by the detritus of the great landslide which forms the subject of Chapter xI (see map in back cover).

Katmai River is, further, the dividing line between two types of physiography which differ notably from each other. To the south is an open country with broad valleys and mountains of the mesa type-a country readily traversed in any direction. On the north the valleys are narrow V's, crowded in between close-set, precipitous mountains-a country of great scenic beauty, but difficult to explore.

Although six miles wide at its mouth, Katmai Valley narrows rapidly upstream, until, under Katmai Volcano, less than 25 miles from the coast, it is constricted into a narrow canyon 4,000 feet deep.

Beyond the volcano it expands again, however, into a second, broad, open basin. But this Second Katmai Valley trends at right angles to the lower flat, giving the impression that its drainage has not always found outlet through the canyon (see map opposite).

Connecting with Katmai Valley, through the pass of the same name, is another very wide basin, now the main arm of the Valley of Ten Thousand Smokes, stretching at right angles to the volcanic axis from Mageik ${ }^{1}$ Volcano northward to the head of Naknek ${ }^{2}$ Lake. Curiously enough, this is crossed by the broad valley of Knife Creek, also full of fumaroles in its upper end, the two forming a gigantic $\mathrm{X}$ which connects the two ends of Iliuk Arm of Naknek Lake with the two dominant volcanoes of the main chain, Katmai and Mageik.

' Pronounced Ma-gēēk'-g hard as in get.
Indeed Katmai and Mageik may almost be thought of as standing athwart these great valleys. The two parts of Katmai Valley can, without any great stretch of the imagination, be considered as the extensions of the two arms of the great $\mathrm{X}$-shaped valley across the range. The Second Katmai Valley appears almost like the extension of Knife Creek Valley projected beyond Mount Katmai, and the lower Katmai Valley bears a somewhat similar relation to the main arm of the Valley of Ten Thousand Smokes. The alignment in the latter case is not so close, but these two are brought more nearly into physical connection by the pass which joins them.

Katmai Pass is the key to the former geographic importance of the district. Joining two open valleys, it formed an easy avenue for passage through a mountainous country difficult of penetration elsewhere. This route across the peninsula, saving a thousand miles of hazardous voyage into Bering Sea, was much used for the transfer of supplies.

To the north of the volcanic area lies a wide stretch of country occupied by alternating series of mountain ranges and broad depressions scooped out several hundred feet below the level of the sea. These are filled with a number of large lakes, which, with the portages between them, allow ready access to any part of this section.

GEOGRAPHIC ORDER ADOPTED IN PREFERENCE TO CHRONOLOGICAL

The features of the Katmai district were so manifold, as they gradually came to light during the progress of the exploration, that it was necessary for the $\mathrm{Na}$ tional Geographic Society to send no less than five expeditions into the country before even a preliminary account of its phenomena could be sketched with any degree of completeness.

In bringing together the accumulated results of these expeditions, it would be manifestly confusing to narrate the chronological development of work cov-

2 Pronounced Näk'-něk. 


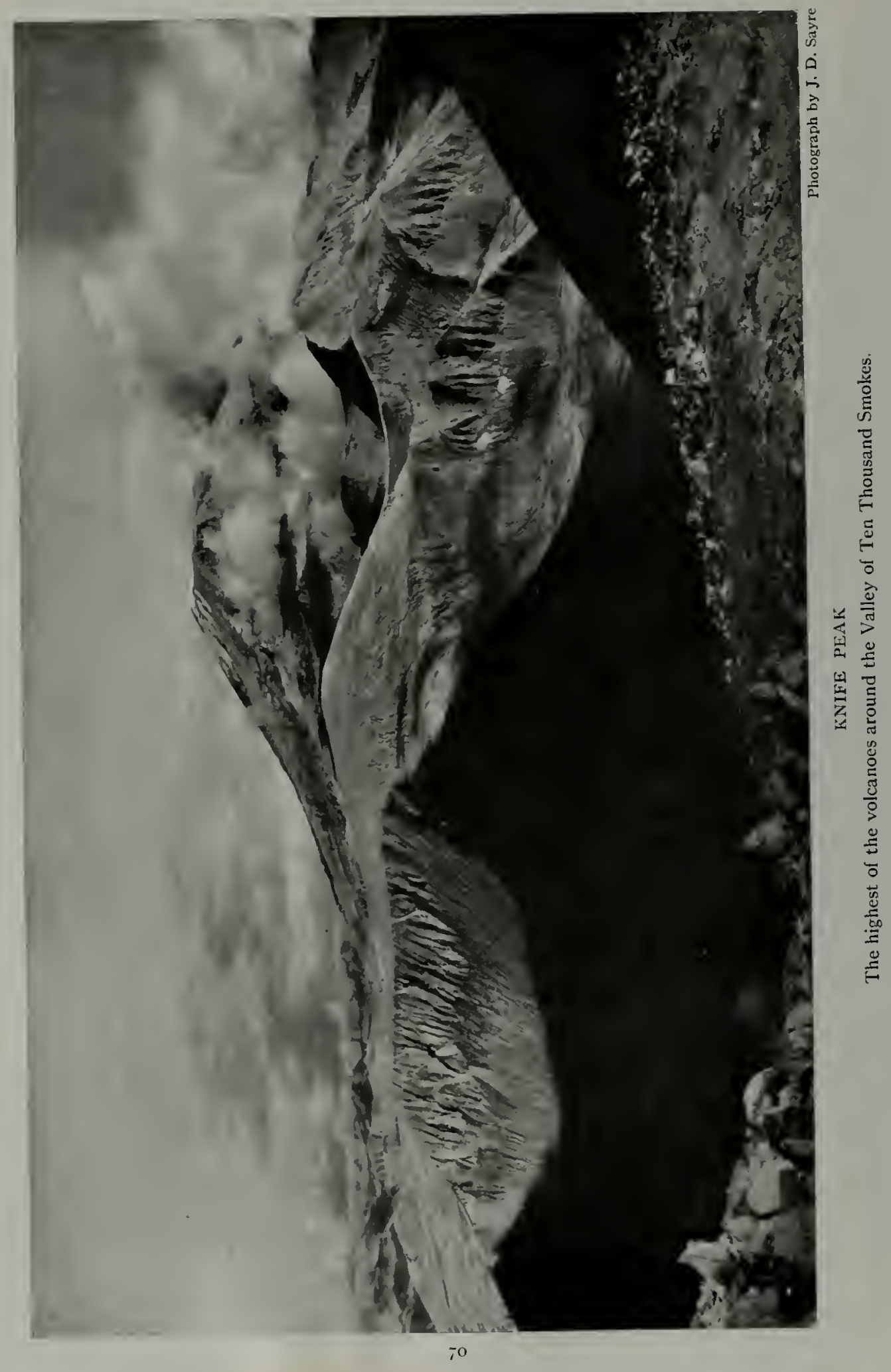


ering somewhat the same area year by year. It has seemed better, rather, to follow a geographical sequence, carrying the description up Katmai Valley, across the Pass into the Valley of Ten Thousand Smokes, and finally into the forested country around the lakes.

It is recognized that in thus piecing together the experiences of different seasons some confusion as to the activities of the various expeditions is likely to develop in the mind of the reader. In order to permit the historical development of the work to be followed it will be well, therefore, to summarize at the outset the personnel and results of each of the expeditions in turn.

\section{PREVIOUS ATTEMPTS TO REACH THE CRATER}

Before 1915 only two parties had attempted any exploration of the mainland. Dr. George C. Martin, gathering material for his account of the eruption published in the National Geographic Magazine of February, 1913, landed at Katmai Village in August, 1912, but was unable to penetrate inland or to see the volcano.

In I9I 3, William A. Hesse, of Cordova, accompanied by M. A. Horner, of Seward, attracted by the possibility of securing motion pictures of the volcano, endeavored to reach the crater. They were not adequately equipped for the undertaking, but after suffering great hardships they managed to secure good photographs of Mount Martin. Postcards from their negatives, labelled "Katmai Volcano," are still for sale in Seward.

Hesse and Horner themselves had, however, no illusions as to the identity of the volcano they had ascended. Both have told me that they saw and recognized the real Katmai from a distance but were utterly unable to reach it. As it was, they told me, they traveled continuously for twenty-three hours the day they made their ascent of Martin.

They agree that they were able to reach only the edge of the volcanic district; that if they could have gone farther they would have seen "much more than they did."

They gave no clear account of what they had seen in the distance, but as a part of the Valley of Ten Thousand Smokes is visible from the summit of Mount Martin I am satisfied that they must have had a glimpse of its fumaroles.

All the information Hesse and Horner have been able to give me indicates that the volcanoes of the district had already settled down to their present steady activity when they visited them in 1913 . Their pictures show that Mount Martin, at any rate, was in very much the same condition then as now.

\section{THE EXPEDITION OF I9I5}

No one realized in advance the probability that a study of the seat of the eruption would yield results of very great interest. Our instructions in 1915 were "not to attempt more than a hasty reconnaissance on the mainland," for it was believed that the return of plants to the devastated district, which was our sole problem at first, could be studied better at Kodiak than elsewhere.

Accordingly we arranged for only a brief trip to the mainland. That year we examined the north side of Katmai Valley and reached the lower slopes of the volcano, but had neither time nor equipment to do more.

There were three of us the first year, B. B. Fulton, Entomologist, now of the Oregon Experiment Station, L. G. Folsom, then manual training teacher at Kodiak, and myself.

\section{THE EXPEDITION OF I9I6}

What we saw of Katmai Valley the first year impressed us so deeply with the importance of a thorough exploration of the immediate environs of the volcano that we felt it imperative to make a study of the center of the volcanic district and especially to examine the crater the next year. 


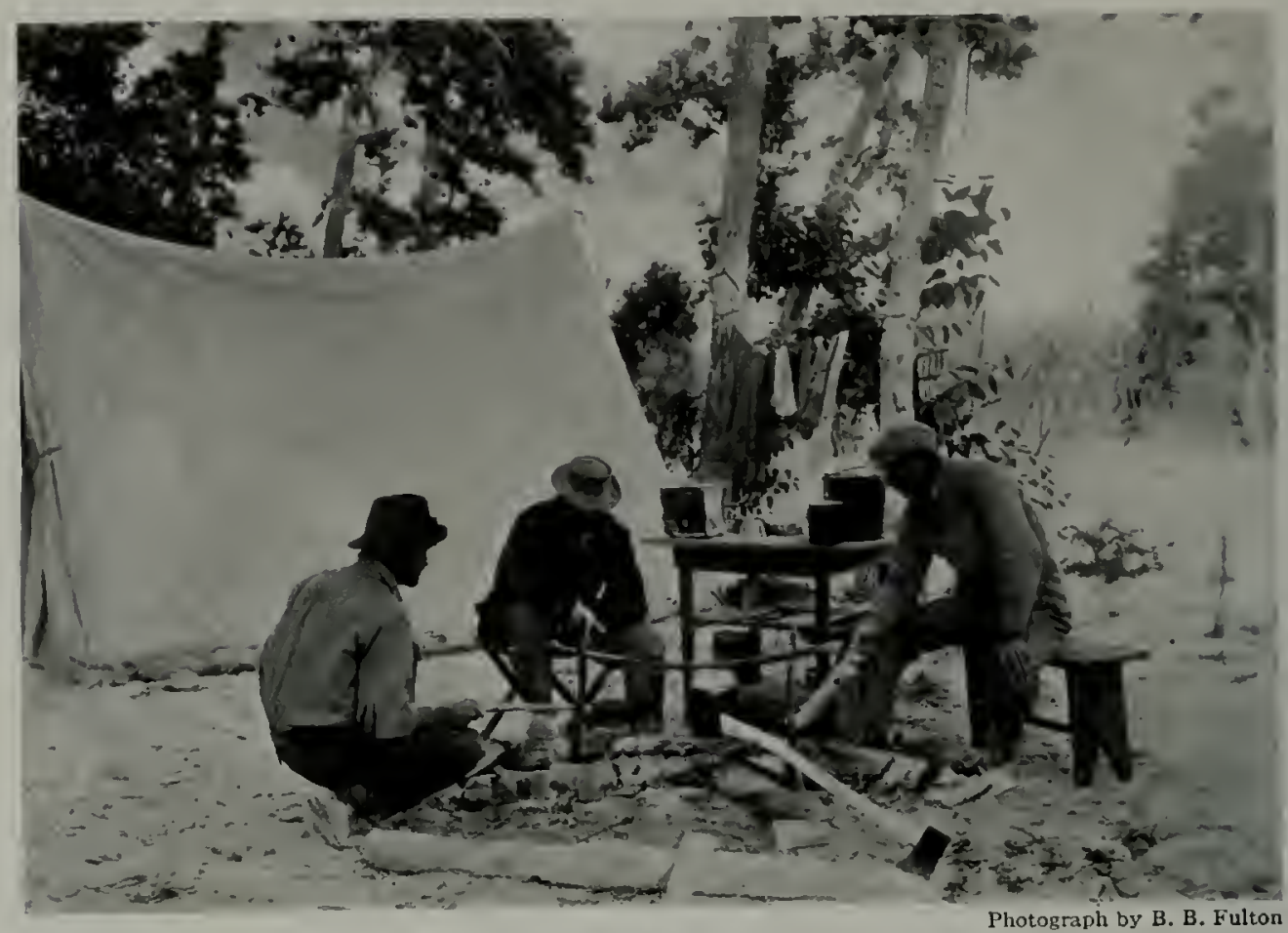

\section{BASE CAMP IN I9I5}

The flat was covered with a layer of white pumice deposited by the waters of the receding flood. It was the only place we could find dry enough for a camp. From left to right, Fulton, Griggs and Folsom.

The first season's work had convinced us that the south side of the valley was preferable to the north, but we were unable to find a satisfactory landing to the south and perforce used the north side once more, crossing the river near the head of the valley. We made the first ascent of the volcano on July Igth. On July 3 I st we crossed Katmai Pass and discovered the Valley of Ten Thousand Smokes. The results of the expeditions of 1915 and 1916 furnished material for an article in the National Geographic Magazine of January, 1917.

This year D. B. Church became the photographer (see page 73). He was a youngster whom I had singled out from my classes by reason of his habit of turning up after a field trip with a set of unusual pictures, which he had snapped surreptitiously en route. His genius for seeing pictorial values made him invaluable.
The experience of 1915 had shown the necessity of employing a packer the second year. Here we met one of our most difficult problems. The natives were afraid of the volcano and could not be induced to go to the mainland. When we broached the matter to the chief, he said at once very positively, "Me no Katmai," and we learned later that he had advised his followers, "Life better than money."

\section{THE ONE-HANDED BEAR HUNTER OF KODIAK}

The problem was most happily met, however, when we thought of IValter Metrokin, a famous one-handed bear hunter of Kodiak. He agreed without hesitation, and stuck to his promise, although, as we found afterward, the other natives used every means to dissuade him (see page 74). Already a hero among his fellows because of his many ex- 


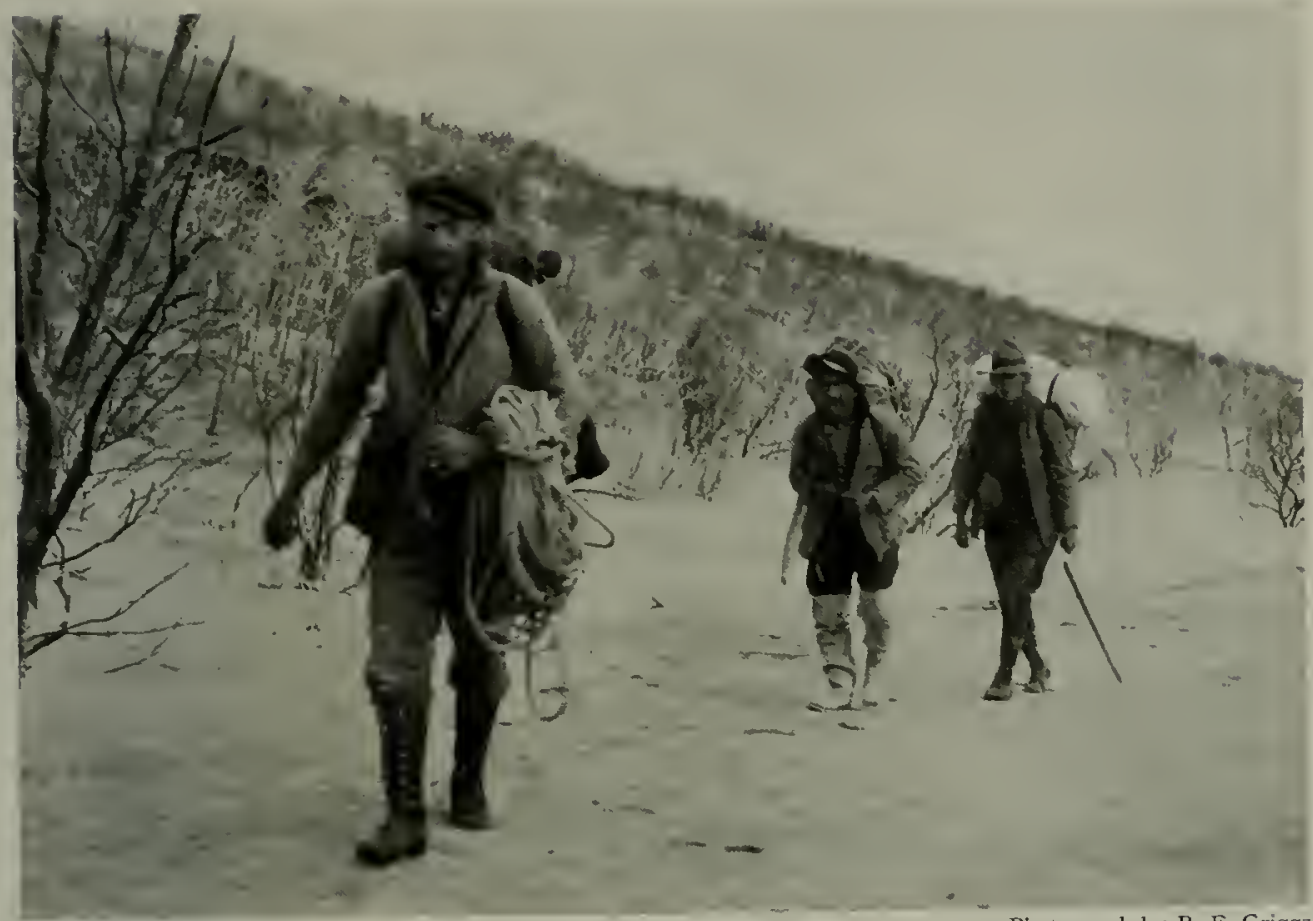

Photograph by R. F. Griggs FOLSOM, WALTER (METROKIN) AND CHURCH ON THE TRAIL IN UPPER KATMAI VALLEY

Since the country was completely devastated, it was necessary to carry everything we had; if any essential thing had been forgotten the expedition would have been stumped.

ploits as a hunter, he was doubly so when he returned safely, having actually looked into "The Hole" out of which had come the devastating blast. Even Walter, however, was very nervous on the crater rim, keeping sheltered behind a rock a good share of the time and shifting about uneasily as he watched us work, finally remarking, when he thought we had overstayed our time, "Can't make nothin' up here."

Walter was one of those strong characters found among all classes, who stand out superior to their fellows. Deprived of his right hand by a hunting accident in his youth, he so overcame the handicap that with his one hand he could accomplish more than most men with two. We found nothing he could not do, even to tying knots and rolling cigarettes.

But when it came to handling a boat, I supposed that he would have to give it up. Not so, however, for in a flash he had somehow lashed one oar to his stub and was rowing along like a sailor.

$\mathrm{He}$ proved a very entertaining companion, as well as a capital assistant, and the stories of hunting exploits he told in his quaint Russian brogue furnished no end of amusement around the camp fire. The boys particularly enjoyed one tale of a bear hunt "with two white men and an Englishman," accompanied by a demonstration of the Englishman's use of his monocles, of which according to Walter, he carried at least half a dozen of different sizes.

\section{THE EXPEDITION OF I9I7}

During the first two years very little organization was necessary, but the exploration of the Valley of Ten Thousand Smokes was another matter.

The physical obstacles to be overcome were so great that success could not have 


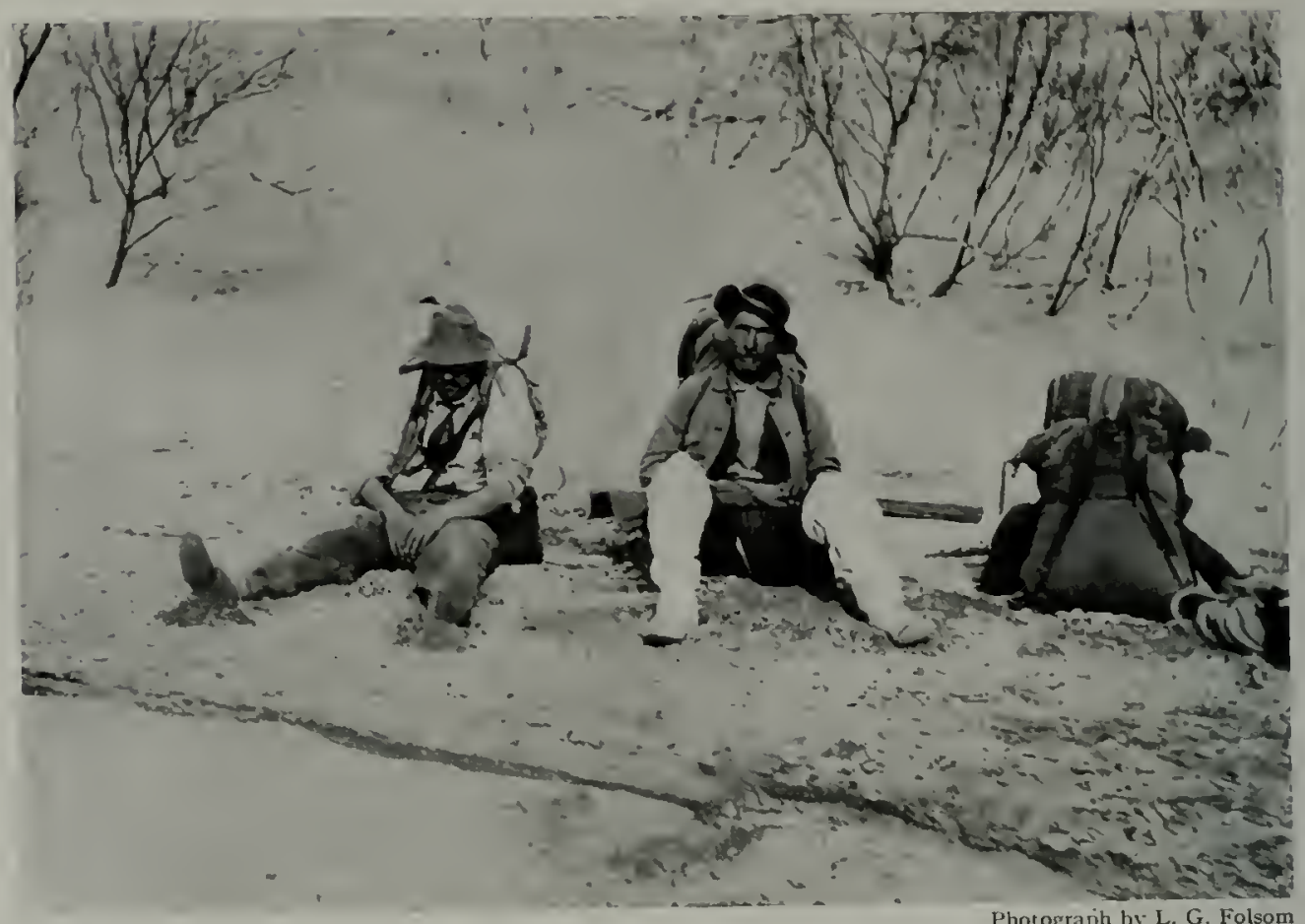

GRIGGS AND WALTER RESTING ON THE TRAIL

been attained without careful planning in advance. Perfecting the details of supplies and equipment, and seeing that they were on the ground, consumed a large share of my time and energy for six months before the departure. But the result justified the labor, for the outfit proved adequate to the strain put upon it and enabled us to carry out the work substantially as planned.

The base camp in 1917 was established on the tundra near Kashvik Bay, and supplies were ferried across the lagoon and carried up the south side of Katmai River to the Pass. The Valley of Martin Creek, with the Mageik landslide at its head, and the Second Valley of the Katmai with Noisy Mountain were explored that year.

The work of 1917 furnished the material for the first adequate description of the V'alley of Ten Thousand Smokes, which was published in the National Geographic Magazine for February, I9I8. As a result of this report, the Katmai
National Monument, embracing more than a million acres, was created by a proclamation signed by President IVilson, September 26, 1918.

All told, there were ten of us in 1917 . Besides the director, Folsom, Church, and Valter, veterans of I9I6, the party included Clarence F. Mlaynard, topographer, previously with the Peruvian Expeditions of The Society; Professor James S. Hine, of the Ohio State University, zoölogist; Dr. J. WV. Shipley, of the University of Manitoba, chemist; Jasper D. Sayre, assistant botanist; Paul R. Hagelbarger, assistant botanist; and Andrean lagashof, packer (see page 76).

The complete devastation of the country made the physical problem of maintaining the expeditions a matter of serious concern. In such a country we were absolutely dependent on our own resources. There was no possibility of living off the country, nor of replenishing supplies or obtaining aid or succor of 
any kind, for the nearest settlements were far beyond reach. One most crucial problem was that of transportation. If we could secure some adequate means of carrying supplies into the country from the coast, we could be assured of all the things necessary for our work and a considerable number of comforts besides.

\section{CONSIDERING PACK-HORSES AND AIR-}

PLANES FOR TRANSPORTATION

Accordingly, we considered very carefully the advisability of using packhorses. While there was no forage for them in the desert, yet they might have been kept outside in the undevastated country and returned thither as soon as unloaded.

But horses would have experienced great difficulty with the quicksands, and where the land was badly gullied it would have been very hard to use them. Nevertheless, we would certainly have tried them if any could have been secured in the vicinity.

It would have been necessary, however, to ferry them across Shelikof Strait and land them through the surf. As this would have entailed not only a heavy expense and the loss of much valuable time, but also a large chance of losing the whole outfit in landing it on those treacherous shores, it was decided that the risk was too great to justify the attempt.

The possibility of using an airplane was very alluring. Often as we labored over the rough ground our minds turned enviously to the thought of skimming swiftly overhead, with no care for the gullies through which we were toiling.

There are unquestionably many landing places available both on the pumice flats and on the numerous ponds which dot the valleys on the Bering Sea side of the range. But an airplane has a delicate mechanism, which cannot be expected to work continuously without repairs which can be made only in a machine shop. In 1919 we did attempt to use a motorcycle, and spent a great deal of time building a trail for it. But just when we got ready to use it, a small spring went wrong in the magneto and we were unable to fix it. The probability of some such accident to an airplane was so great that 1 have never been sorry we did not attempt to use one.

\section{ALL SUPPLIES CARRIED BY MAN-BACK}

We were, therefore, thrown back on the most primitive of all methods of transportation-man-back packing. This had the great merit of being certain in operation, for wherever men could go, there could supplies be transported. But the amount of freight that a man can carry on his back is at best pitifully small. A load of "grub" which is a crushing burden for the packer vanishes quickly into the hungry mouths of an active party.

To minimize the quantity of food consumed by the packers themselves and to reduce the amount of duffel carried back and forth, we adopted a system of relay camps.

We would proceed half a day's march from our base, then establish a new camp at the terminus, returning each night to the starting point, until enough provisions had been accumulated to permit another move forward. In this way the packers drew their sustenance altogether from the rear camp, leaving the advance supplies intact for future use.

Once our system of relay camps was established, we made a practice of parceling out our spare bedding and extra clothes among the different camps in such fashion that a small party could travel rapidly anywhere along the chain without concerning itself about baggage or supplies.

\section{ONLY THE MOST CONCENTRATED FOODS USED}

Our extremely limited facilities for transportation prohibited the use, except at the base camp, of any of the ordinary sorts of canned food, or of any provisions containing a large percentage of water. Our chief reliance was the trusted standby of the prospector, bacon and flapjacks. 


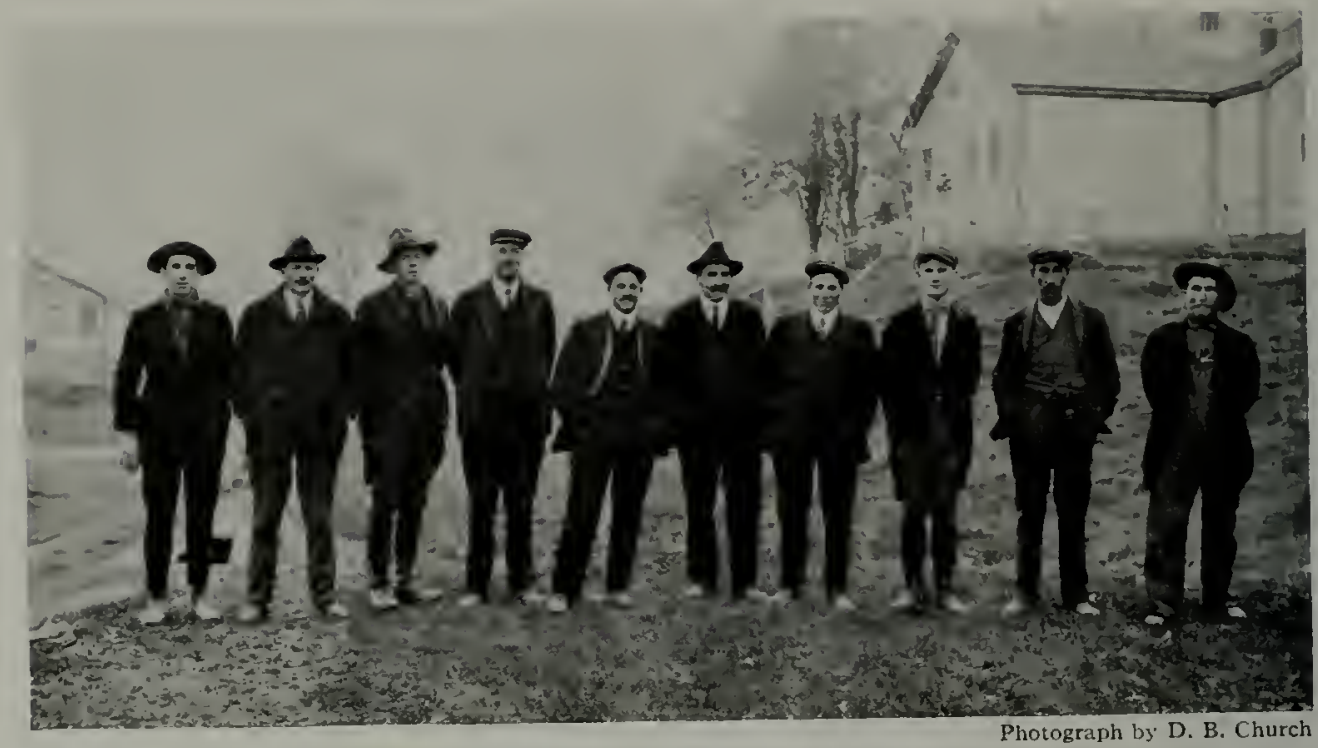

MFMBERS OF THE EXPEDITION OF I9I7

From left to right: Jasper D. Sayre, botanist; Clarence F. Maynard, topographer; D. B. Church, photographer; Lucius G. Folsom, assistant to the director; Robert F. Griggs; James S. Hine, zoölogist; J. IV. Shipley, chemist; Paul R. Hagelbarger, botanist; Andrean Yagashoff, packer, and Walter ÎTetroken, packer.

Next came sugar, rice, oatmeal, beans, soluble coffee, dried apples, and other dehydrated fruits and vegetables such as apricots, cherries, cranberries, pears, raspberries, blueberries, strawberries, string beans, spinach, and potatoes.

Lunch consisted of hardtack, cheese, raisins, kippered salmon and milk chocolate, for we could take time to cook only morning and night.

As an experiment I included tinned butter among our supplies. This proved a boon, for it added greatly to the enjoyment of flapjacks and served as a concentrated substitute for evaporated milk on oatmeal and rice. I was inclined to regard condensed milk as a luxury not worth the trouble of carrying, but I found the men generally enjoyed it so much that as a rule they were quite ready to carry it, despite its weight.

At this time, before the importance of vitamines in the diet was generally recognized, I did not understand the reason for the unusual desire for milk and butter. But when it was shown how essential vitamines are to a suitable dietary, an explanation seemed to be offered, for, as is now well known, butter and milk are especially rich in these substances. I am inclined to believe that they, together with the fruits, are the most important factors in preventing that craving for a change of diet so likely to develop when men are kept long on concentrated rations.

This sort of provisions proved very satisfactory. The members of the parties always kept in excellent condition throughout the field season and most of the boys actually gained heavily in weight, despite the continuous hard work. For the whole party the gain in flesh averaged about ten pounds, while individual members took on as much as twenty-five pounds during the summer.

The demand of the system for energycarrying foods was very great. I soon found that even the small amount of lean meat in bacon was more than was desired. It was not long before bacon began to be used exclusively for its fat. In later years "crisco" was substituted for a part of the allowance of bacon. 


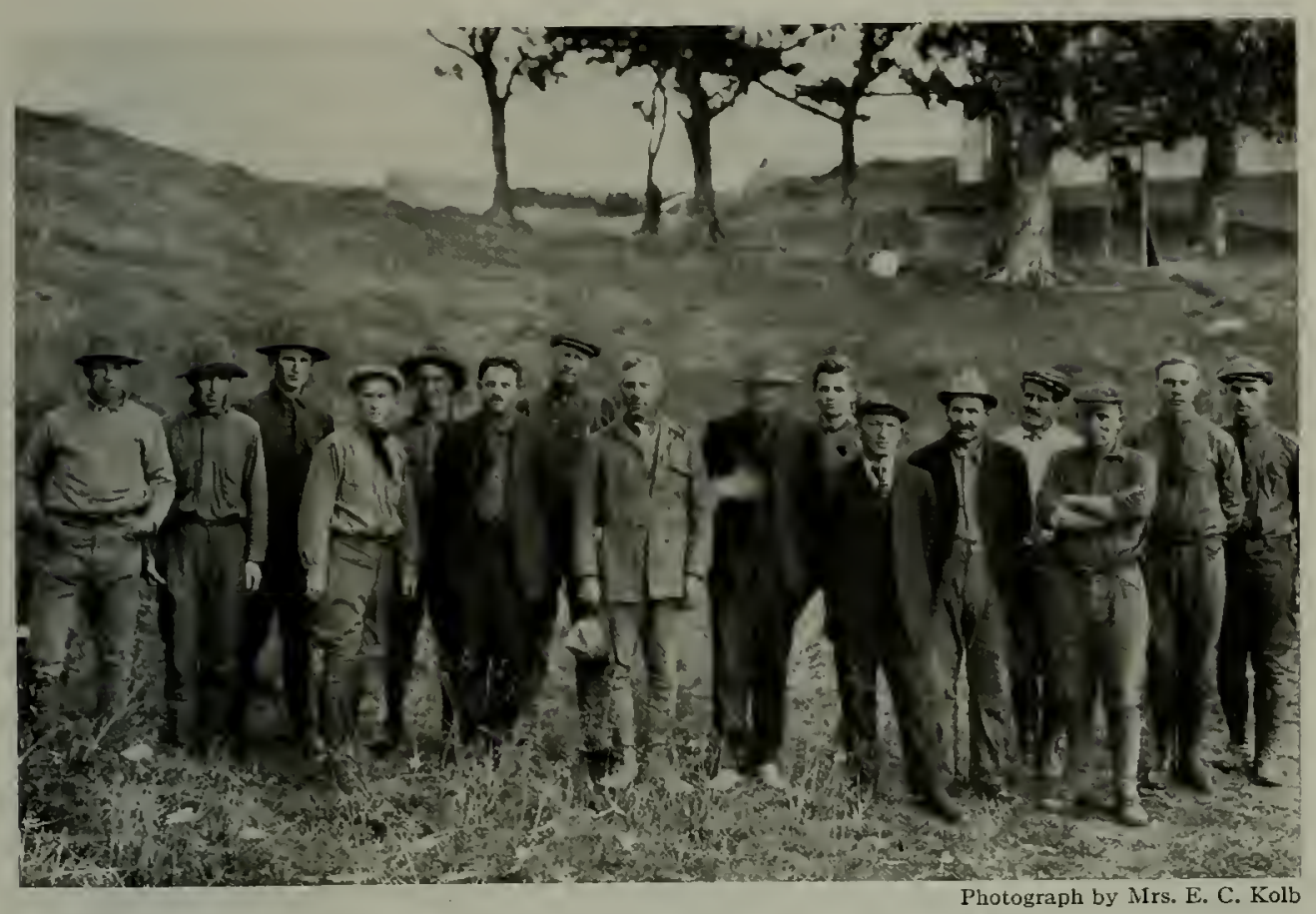

THE LARGEST GROUP OF THE EXPEDITION OF I9I9 EVER ASSEMBLED IN ONE PLACE

Three men-Jones, Jacob and Ralph Hagelbarger-had left before the others came together. From left to right are Helt, Sayre, Paul Hagelbarger, Kolb, Yori, Griggs, Folsom, Fenner, Allen, Miller, Zies, Hine, Wallace, Basinger, Stone, and Henning.

Sweets of all kinds were also greatly desired. A few jars of strawberry jam were provided as delicacies, but it would have been utterly impossible to provide enough jam to satisfy the crowd. The consumption of granulated sugar averaged half a pound per man a day.

\section{SENDING IN THE EXPEDITION OF I9I8 FROM THE BERING SEA}

When the war made it advisable to drop the extensive expedition that had been projected for 1918, Sayre and Hagelbarger of the 1917 expedition were dispatched to the field alone to keep watch over the fumaroles and to begin a study of the temperatures.

Theirs was no easy task. Their mission was not merely to continue the work with which they were familiar, but to break new ground and solve unknown problems. They did not go in from Kodiak, as previous expeditions had done. Instead they circled the penin- sula into the Bering Sea and ascended Naknek River and Lake to the foot of the Valley of Ten Thousand Smokes (see map, front cover).

They surveyed the country traversed, securing the data for the topographic map, and made the first accurate measurements of the temperatures of the fumaroles, bringing back the information that some of them were hot enough to melt zinc.

OBJECTIVES OF THE EXPEDITION OF 1919

While the exploration carried out in I 917 was sufficient to supply the public with evidence of the reality of the fumaroles, the hasty observations which alone had been possible under the conditions served only to arouse in us a keener desire to investigate the scientific problems presented. For we were convinced that nowhere else in the world had there been presented in our time such an opportunity to study the great problem of volcanism. 


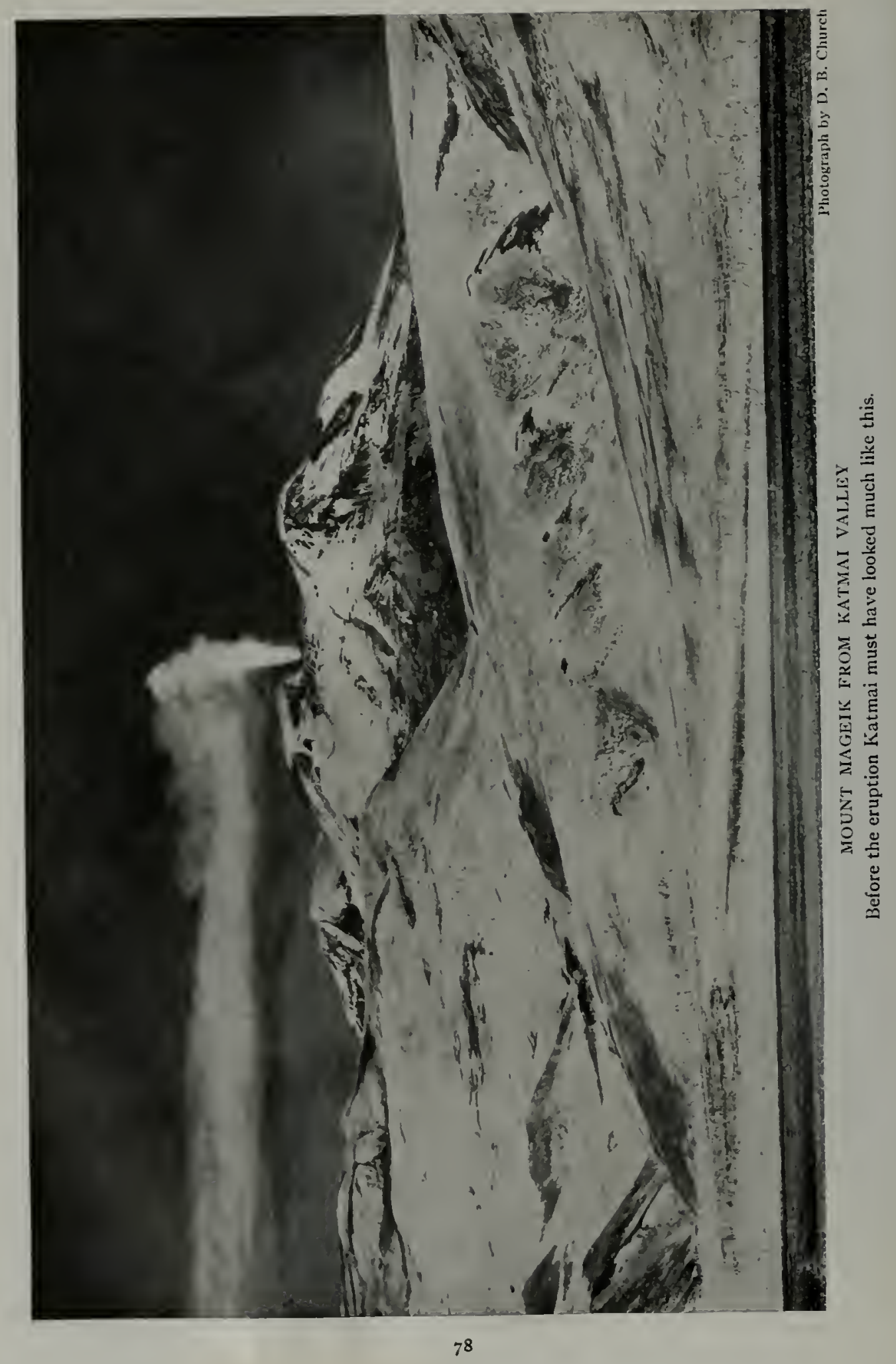


All members of the expedition agreed that the pictures of the Valley brought back in 1917 , while striking enough to excite favorable comment, fell so far short of the reality as to convey no adequate conception of the thing itself.

As an experiment, I had purchased a small motion picture outfit, and Church had learned to operate it, so that we secured incidentally a few hundred feet of films. These had a most checkered career. While awaiting shipment they were "taken by mistake" from the warehouse at Kodiak by an old prospector and carried down to the south end of the island, whence after being dumped out in the surf and left in the dampness of the native huts for months, they were finally returned to us. Despite the rough usage to which they had been subjected, upon development they portrayed the real character of the fumaroles so much better than any still pictures that I decided at once we could not consider the district adequately made known until a representative series of motion pictures had been secured.

With these two very diverse objects in mind, we were anxious to return and carry forward the work. But the World War held us up until I9I9.

When finally the opportunity came to carry out our plans, we tried to equip ourselves in such fashion that we would be enabled to sit down and study our problems at leisure, and to provide some sort of laboratory in which preliminary chemical work could be carried on. The difficulties in the way of the realization of this project were enormous.

The scientific problems encountered in the region were so numerous that we could not resist the temptation to lay out more work than could possibly be accomplished in the time available, even with the very generous appropriation which the Research Committee of the the National Geographic Society had granted. But although many important questions were still unanswered when the season closed, we had nevertheless accomplished a great many things which could not have been attempted on previous expeditions.

\section{COÖPERATION BY THE GEOPHYSICAL LABORATORY}

The various aspects of volcanism described by the earlier expeditions were so exceptional that I felt our findings were too important to stand alone without corroboration by other observers.

After a survey of the field it was decided that no other organization was so well equipped to handle the many-sided volcanic problens as the Geophysical Laboratory of the Carnegie Institution, which was accordingly invited to send a party along with the expedition of 1919 under a coöperative agreement whereby the Geographic Society undertook to assume the field expenses of the party, while the Geophysical Laboratory agreed to work up the results on the return. The party selected consisted of two chemists and a petrologist.

ORGANIZATION OF THE EXPEDITION OF I919

In view of the risk and difficulty involved in landing a large outfit through the surf, and carrying it by man-back over Katmai Pass, it was decided to send in the bulk of the outfit by Bering Sea, whence it could be taken in power dories up Naknek River and Lake almost to the foot of the Valley of Ten Thousand Smokes.

Since there is scant means of public conveyance into those parts, we should have been helpless in this matter without the kindness of the Naknek Packing Company, which undertook to carry up our supplies and the advance party.

Sayre, who knew the ground from his experience in 1917 and 1918 , was sent in by this route with three of my students: A. J. Basinger, Richard E. Helt, and Harry E. Jacob. Their mission was to provision a base camp at the head of Naknek Lake and form a junction with the second party, which I led in from Kodiak to establish a series of relay camps across the peninsula. By this 
means we hoped to make it possible for the specialists, who were to come later, to begin work on their respective problems immediately upon arrival.

\section{PERSONNEL IN I9I9}

There were nineteen of us in all: the Director; the Geophysical party consisting of Dr. E. T. Allen, chemist, Dr. C. N. Fenner, petrologist, and Dr. E. G. Zies, assistant chemist; Professor J. S. Hine, of the Ohio State University, zoölogist; J. D. Sayre, topographer; Paul R. Hagelbarger, topographer; Emery C. Kolb, of the Grand Canyon, motion picture man; Frank I. Jones, of Portland, Oregon, color photographer; Lucius G. Folsom, assistant to the Director; A. J. Basinger, Ralph Hagelbarger, Richard E. Helt, William L. Henning, Harry E. Jacob, August E. Miller, Julius Stone, Jr., H. N. Wallace and Charles Yori, assistants.

It would be hard for anyone who was notalong to realize how these men worked for the success of the expedition. No task, however difficult or disagreeable, was too great whenever it was recognized that it was for the good of the expedition. Many of the jobs for which there were volunteers in plenty would have been altogether unreasonable in the eyes of any except men who were there for the love of overcoming difficulties.

In addition to the regular members of the expedition, visitors were received for the first time. The first "tourist" to visit the Katmai National Monument was Rodney L. Glisan, of Portland, Oregon. Later in the summer the wives of the three members of the expedition whose families were at Kodiak, Mrs. Griggs, Mrs. Folsom and Mrs. Kolb, also came across and visited the Valley, thus proving that despite the necessarily primitive conditions, the place is by no means impossible for women.

It was hoped that the preliminary exploration of the district could be brought reasonably near completion in 1919 , but very much remains to be done. There are several square miles of the most interesting of the fumaroles which have been examined only in the most cursory fashion, a large part of the tributary territory remains unmapped, and of the more detailed problems of revegetation and geology scarcely a beginning has been made. 


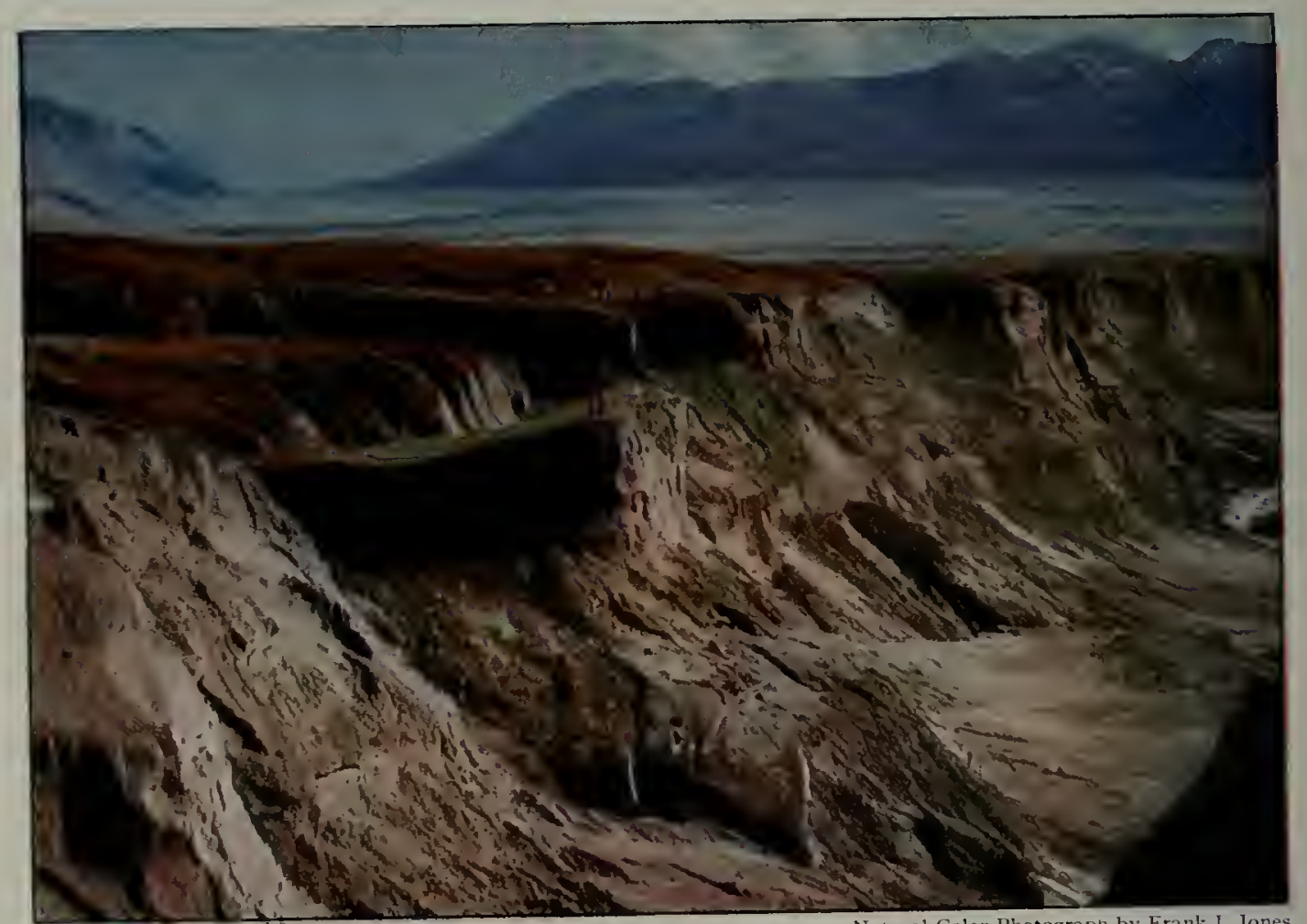

Natural Color Photograph by Frank I. Jones

A CANYOX IN THE MUDFLOW AT THE HEAD OF KATMAI VALLEY The blue waters of Katmai Bay nay be made out in the distance. 


\section{THE FIRST JOLRNEY TO THE VOLCANO-THE DEVASTATIOA OF KATMAI VALLEY}

As the shores of Katmai Bav gradually appeared out of the blue distance when we approached them for the first time (July I I, I9I5), theylooked weird beyond description. Over the sky was drawn a pall of fine volcanic dust which abscured everything above a thousand feet, cutting off the volcanoes which we wished so much to see, and by its curious, diffused light heightening the unearthly aspect of the landscape, giving it somewhat of that ominous effect that raises one's forebodings at the approach of a storm.

The whole scene looked like the entrance to another world, so foreign was it to anything within our experience. The sea was full of fresh pumice. IVe wondered whether this and the cloud of dust might betoken a fresh eruption from one of the rolcanoes. The line of breakers was continuous. We could not tell where we might best pierce it.

It was even more difficult to guess where we should find the best way-back into the interior. Trying to make the right decision, I lay propped upon my elbows studying the shore with a field glass, for I was too weak from seasickness to stand.

\section{THE FIRST LANDIYG}

First we tried the mouth of the river. where the schooners used to land. Since the eruption it had been entered by a boat larger than ours. But it was out of the question now; so much ash had been washed down that there was no possibility of getting inside. (Later we found the river could not be ascended half a mile, even with a row boat.) Then, as the western side looked low and swampy, we turned east, landing under the cliffs of Mount Pedmar at the end of the beach.
Along the base of the cliff was a white sleaming waterfall, promising to settle one of our problems, for in the uncertainty as to the condition of the countryI had made up my mind that I would not allow our boat to leave us until we had at least assured ourselves of a supply. of drinking water.

Everywhere the ground was covered ankle-deep with soft sticky mud from the flood, described in Chapter Ix, whose waters were just subsiding. Fresh tracks of fox and of the huge Alaskan brown bear indicated that we were not alone on the beach, and suggested the advisability of carrying guns.

But the omnipresent mud gave us more concern, for it covered the whole valley, clear up to the cliffs. Between the precipitous mountains and the nuddy. flat no place was left for us to pitch our tent except a mound of aralanche detritus, which we felt was too dangerous, for bowlders were rolling off the mountains round us every few minutes.

Finally we selected a bed of clear white pumice. Although there was very wet mud a few inches below, the porous surface was fairly dry, and there we pitched our tent (see page 72 ).

Our camp was surrounded by good. sized balsam poplar trees. We had expected no such luck as this, for the best information we had been able to secure in advance indicated that Katmai was well beyond the limit of trees, so that we might expect difficulty, at least in the country deeply covered with ash, in finding eren enough sticks for firewood.

In view of this probability we had prorided jointed poles for the tent and a small blue-flame oil stove for cooking. We were most happy to be relieved of the necessity of packing the store with a supply of oil on our backs, but finally did 


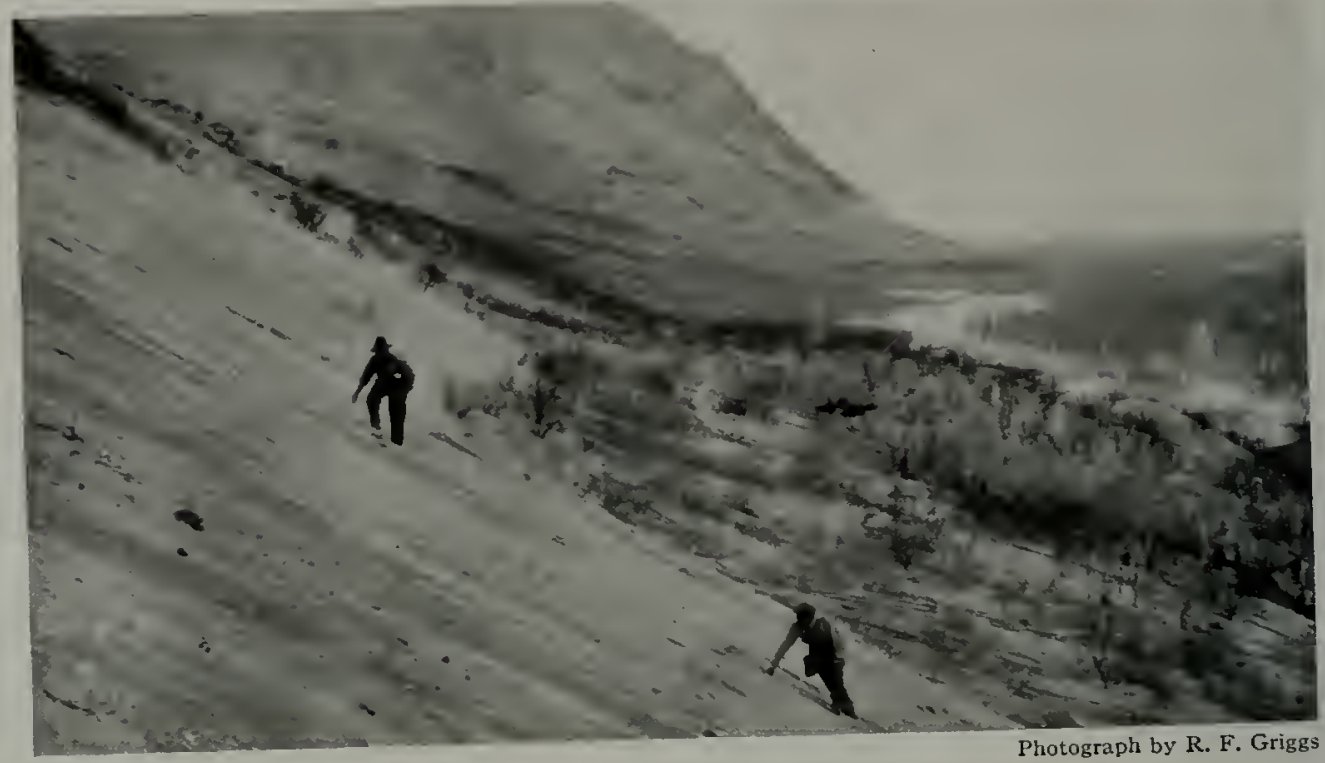

AN ASH SLIDE: SOLUKA CREEK

Some of these slides spread out into gigantic fans more than a thousand feet high. Standing at the critical angle, their slopes are very hard climbing. We soon ground our finger-nails to the quick in their sharp sand

carry the tent poles clear up to the head of the Valley in the groundless fear that we could not find poles there to serve our purpose.

Near the coast the poplars were in scattered groves and somewhat stunted in the more exposed situations, but farther inland there were forests, whose trees sometimes exceeded four feet $(\mathrm{r} 35 \mathrm{~cm}$.) in diameter and commonly reached a height of 70 to 80 feet.

\section{COMPARATIVE DAMAGE TO DIFFERENT PLANTS ${ }^{1}$}

The desolation of the country beggared description. All the trees had perished, except those favored by some special circumstance, such as proximity to the protecting mountain sides.

In one way the trees and bushessuffered more seriously than the herbage, for wherever the ground had been swept bare of ash the old roots of the herbaceous

1 For a more detailed discussion of the effect of the eruption on mainland vegetation the reader is referred to a special paper devoted to the matter. Scientific Results of the Katmai Ex- plants sent up new shoots, so that in a few fortunate spots flowers were blooming in their pristine profusion.

Where the ash remained to a depth of a foot or more, however, the ground under the dead trees was absolutely bare. No vegetation had come through cracks, as at Kodiak, and indeed such cracks may not have been formed, because the deposit here is much coarser grained.

Under the mountain sides, where a few remnants of the forest remained alive, various species had suffered in different ways.

The only large trees were the balsam poplars (Populus balsamifera). All of the growing parts and the ordinary buds of these had been killed, but deep down in the bark of old shoots dormant or adventitious buds had pushed out short, bushy branches which gave the trees a most bizarre appearance.

peditions of the National Geographic Society, No. 4. The Character of the Eruption as Revealed by its Effect on Near-by Vegetation, by R. F. Griggs. Ohio Journal of Science, vol. 19, pp. 173-209, 1919. 
One would not have believed that a growth of leaves so slight. as some we saw could possibly suffice to keep the bark and roots of a large tree alive. Nor did it always do so, for we found many poplars that had perished from starvation, after a vain attempt to put out leaves enough to keep the system alive.

The alder (Alnus sinuata), which is the most characteristic Alaskan bush everywhere, was simply exterminated. For our purpose this was somewhat fortunate, for it was easy to break our way through the dead thickets which otherwise would have made traveling difficult. Not a single live twig of alder was seen until after we had explored a wide stretch of country, and then we found only two or three very small sprouts coming up from the roots.

The birch (Betula kenaika), the Alaskan representative of our canoe birch, which was formerly abundant, suffered only slightly less than the alder. Without exception, this species perished in the main valley, but a few individuals with living sprouts were found in Soluka Valley.

\section{WILLOWS SUFFERED LESS THAN OTHER TREES}

The willows suffered less than the other trees, but the pussy willows (Salix scouleriana) were killed down to the ground. Curiously enough the new growth did not assume the erect form characteristic of the species, but instead produced a rosette of prostrate branches close to the ground, like the alpine willows of exposed places.

Of all the trees the big Alaska willow (Salix alaxensis) suffered the least or, at any rate, had made the best recovery by the time of our visit. This was probably due to its very great capacity for forming adventitious roots on burial.

Where shifting streams had disinterred some of the buried trees, we found that they had developed a very strong growth of new roots, just beneath the surface of the ash. It was interesting to observe that these new roots were confined to

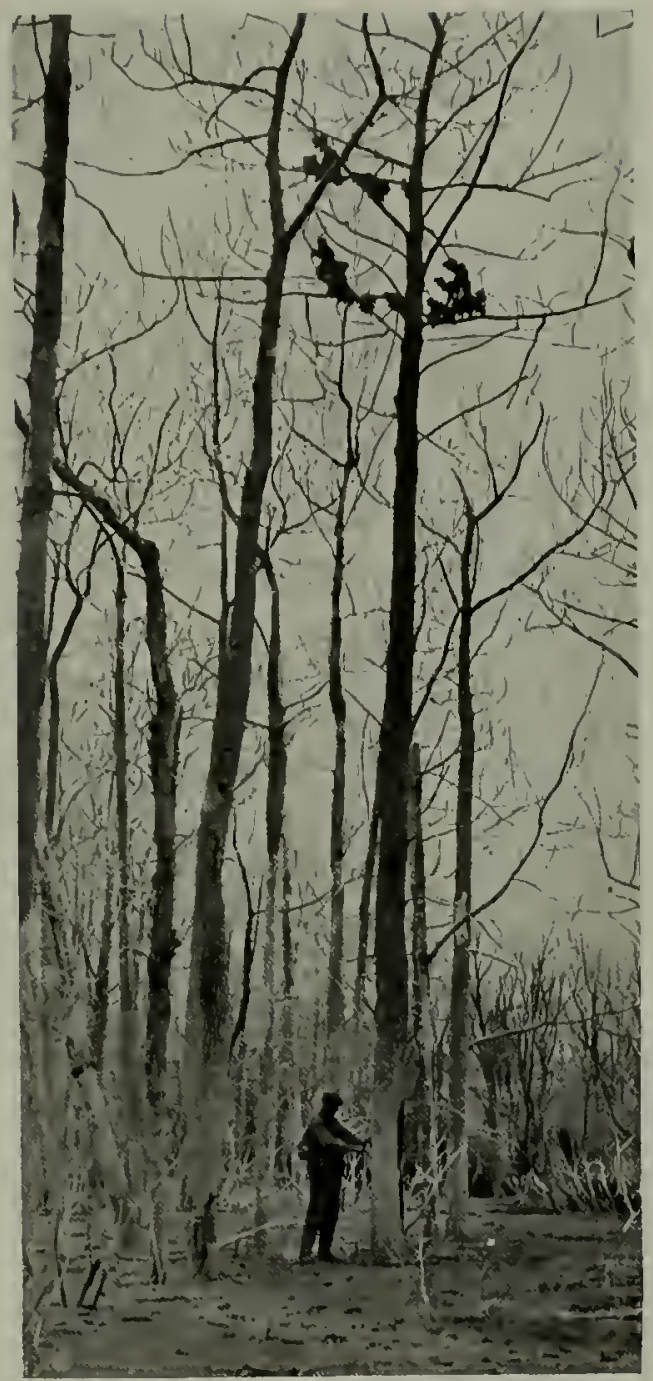

Photograph by R. F. Griggs

A TALL POPLAR ON WHICH ONLY A FEW BUDS SURVIVED

It seems incredible that so slight a leaf surface should have sufficed to keep the extensive trunk and roots alive for four years.

the area immediately beneath the surface of the ash, leaving the intermediate section of the trunk down to the original surface of the ground as clean as before burial (see page 133).

On the mainland as at Kodiak, the formation of such two-storied root systems is the characteristic reaction of the buried plants when their underground parts show any response at all to burial. 


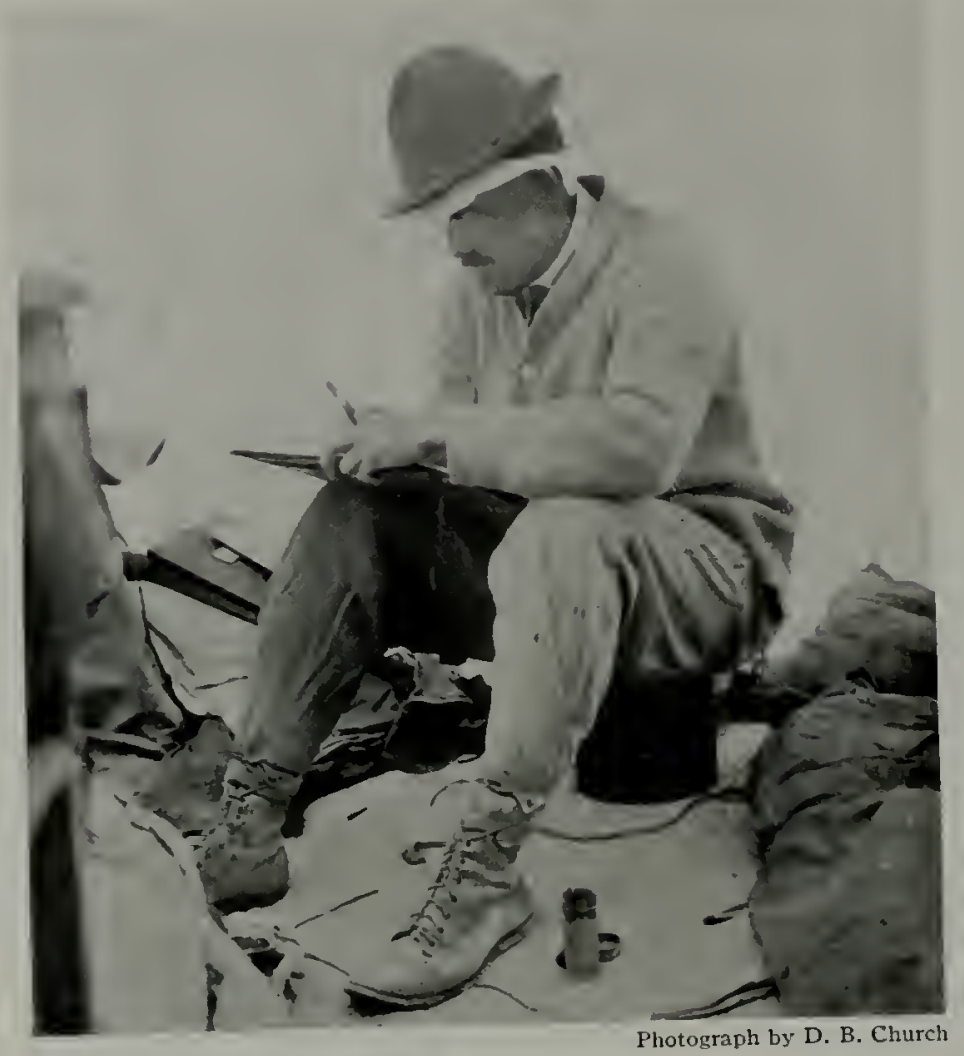

WRITING IN THE TENT DURING THE SAND-STORM

While outside a piece of pumice lodged in myeye with such force that it had to be dug out with forceps, causing considerable discomfort for a couple of days.

On the first day we were able to devote to exploring the valley we awoke to find that a westerly gale, which had started during the night, had picked up the fine dust from the mountains until it had changed the haze of previous days into a terrific dust storm. The dust was so thick that it obliterated all objects beyond the immediate ricinity.

\section{A DUST STORM}

It permeated everything about our camp, and we were extremely worried lest it should get into our cameras and ruin the shutters and films. It matted our hair so that we could not comb it for days. It caused acute discomfort in our eyes.

At first we were afraid it might do us permanent injury, for particles of rolcanic dust are sharper even than bits of broken glass. After a time, however, the irritation stimulated an increased flow from the tear glands, which helped to keep the eyes washed out.

During this day of dust storm we explored the valley as far as Soluka Creek. The dust heightened the already weird character of the landscape, giving it an indescribably uncanny appearance. The effect was much like that of a heavy snowstorm. This was increased by the outlines of the bare dead trees. Indeed, so strong were the visual sensations of snow that every little while I would realize with a start of surprise that it was not cold. About noon we fell to speculating on the state of the weather above the dust cloud and were surprised on searching the sky to find the sun, whose disc mas just visible, pale white, something like the moon in daytime, but fainter.

It is impossible to describe our feelings on this day, as we groped our way forward into the devastated country, utterly different from anything we had ever seen. Fortunately, the loose sandy surface of the ash everywhere held our tracks, so that even without our compass we could hardly have hecome lost.

We followed all the way a well-worn bear trail, which skirted the foot of the mountain, finding that the bears had selected the easiest going to be had. It was very noticeable that these trails, 


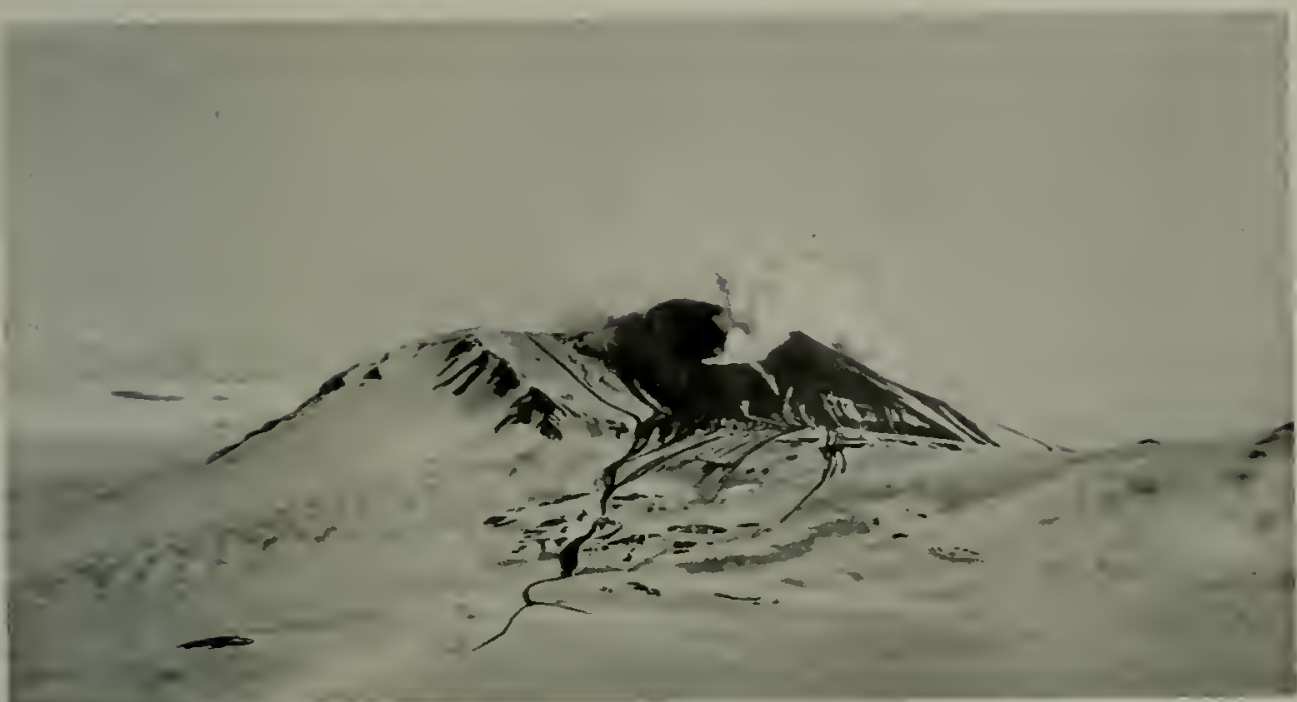

Photo and copyright by M. A. Horner

\section{MOUNT MARTIN IN I9I3}

except for an occasional side branch into the mountains, all ran lengthwise, up and down the valley. The bears had made no attempt to cross the river. Apparently they had learned by experience not to try that.

After four days spent in such preliminary observations we packed up our outfit and as much food as we could carry and started up the valley for the volcanoes. The remaining provisions, together with everything not essential to our work, were left in the base camp.

Although things were made as snug as possible, it was not without a good deal of trepidation that we turned our backs on our supplies; for in such a desert country we were absolutely dependent on our provisions, and if a bear or wolverine had taken it into his head to wreck the camp in our absence, we should have been in a bad way.

Three or four miles up the valley we came out into the open, where we could see the distant mountains of the main range. Standing square across the head of the valley was Mount Mageik, its magnificent three-peaked snow-cap brilliant in the sunshine.

From a small crater east of the central peak issued a column of steam which, although plainly visible on a clear day for 50 miles out to sea, appeared diminutive in comparison with the bulk of the mountain. Only rarely does it rise straight up into the sky, as shown in the photograph on page 78 .

Mount Katmai itself was concealed beyond the bend of the valley, so that we were to have no glimpse of it until we camped at its foot.

\section{DISCOVERT OF MOUNT MARTIN}

To the west of Mageik, in a position where no volcano is indicated on the chart, was a comparatively low mountain from which rose a column of steam a thousand feet in diameter and more than a mile high.

Comparison with Horner's picture showed at once that this was the mountain he had photographed in July I9I 3 as "Mount Katmai." It was clear enough from its location west of Mageik that it could not be Katmai, for that is on the other side of Mageik. Even from our position it was evident, however, that it was at that time the most active volcano of the district.

The discovery of this rolcano was a complete surprise, for we had had no intimation of the existence of any such 


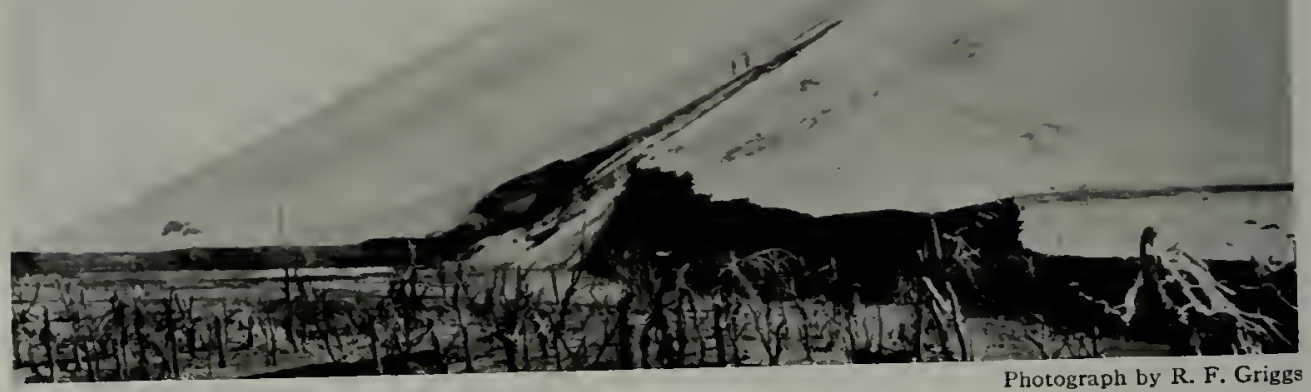

ASH SLIDES IN UPPER KATMAI VALLEY

Wherever the mountains were too steep for the ash to stick, it slid down into the valley, covering the lower slopes with great fans of sand.

vent before our landing. There appears to be neither record nor tradition of any volcano in this quarter. No map shows a volcano near its position nor even names the mountain.

We agreed that no more fitting name could be given to the new volcano than that of Dr. George C. Martin, whose account in the National Geographic Magazine will always stand as the first authoritative report of the eruption.

Accordingly, from the first it has been known to the members of the expeditions as Mount Martin. Its position is approximately Lat. $58^{\circ} 10^{\prime} \mathrm{x}$., Long. $155^{\circ}$ $2 \mathrm{I}^{\prime \prime} \mathrm{W}$., and its altitude about 5,500 feet. Its great column of steam was a continual challenge to our efforts, but it was not for us to approach it that year nor the next, nor did we ever succeed in studying it as we desired (see chapter Xrv).

The activity of Mount Martin, like that of all the volcanoes of this district is remarkably constant. When first seen by Hesse and Horner in I913, it was quietly steaming away, exactly as in I9I9 (compare pages I80 and I82).

In the absence of witnesses it is, of course, impossible to ascertain exactly when this quiet activity began, but presumably its initiation was coincident with the reawakening of Katmai.

One can hardly image the opening up of a crater of such dimensions except by an explosion violent enough to rend the mountain walls asunder. Great as is the power necessary to tear open a conduit like the crater of Martin, however, it is so slight in comparison with the other forces operative at the time of the great eruption, that no mark of its action has yet been discovered in the surrounding country. We have diligently searched for ejecta from both Martin and Mageik, but no evidence that they threw out ash or pumice at the time of the recent 


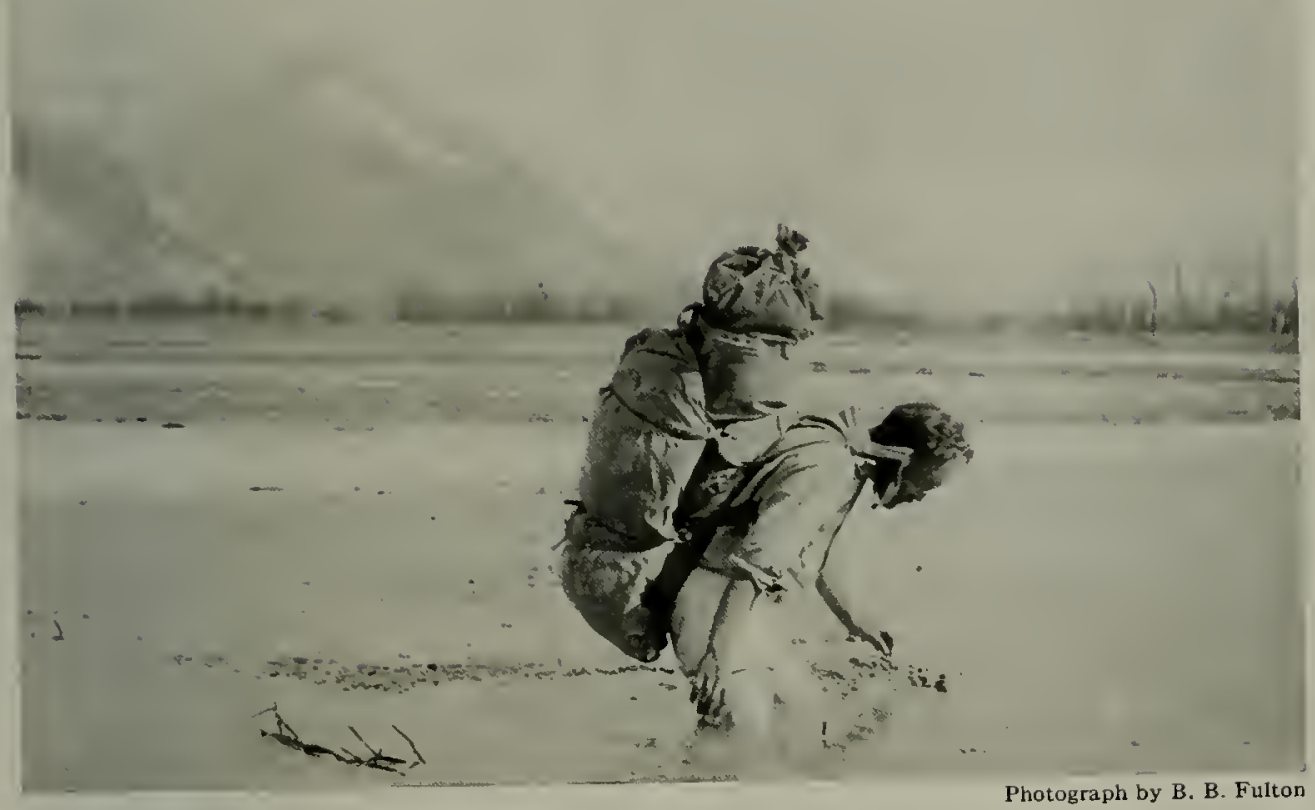

THE AUTHOR STRUGGLING THROUGH THE QUICKSAND OF KATMAI RIVER

After working our way to within a hundred yards of the trees in the distance we had to turn back. The swift water running over the ash and pumice packs the surface, giving it a crust which sometimes holds a man and sometimes breaks under his weight. Crossing these flats is somewhat like traveling in snow with a weak crust. One will go along easily ankle deep for a few steps and then suddenly drop down to his waist. The labor involved in such travel cannot be described, but must be experienced to be appreciated.

eruption has been detected (see page I82).

When we reached Soluka Creek we found it more formidable than our reconnoiters in the dust storm had indicated. Leaving the others on the bank, I dropped my pack and waded out through the dead forest for half a mile in the icy water. From that distance it looked wider, deeper and swifter than from the starting point. I decided, therefore, that it was impracticable to attempt to cross it under our heavy packs, so we camped that night in the dead forest on the flat near by.

\section{ASH SLIDES MORE THAN I,500 FEET HIGH}

Next morning, starting to hunt for a practicable ford, we climbed up on to the shoulder of a mountain where we could get a bird's-eye view of the creek below and select the likeliest place.

Here we found a new experience in climbing the great ash slides with which the lower slopes were covered. Wherever the mountains were precipitous, too steep for the ash to stick, it slid down into the valleys, covering the lower slopes with great fans of sand, standing as steep as it will lie. Some of these ash slopes are more than $\mathrm{I}, 500$ feet high.

When we first entered the country in I9I 5 their surface still consisted of loose, rolling sand, ready to slide down at the least disturbance (see pages 82 and 86 ). With the passage of time they gradually became more stable, as the angular grains settled closer together. But, during our first season, it required all the power we could muster to climb them. 


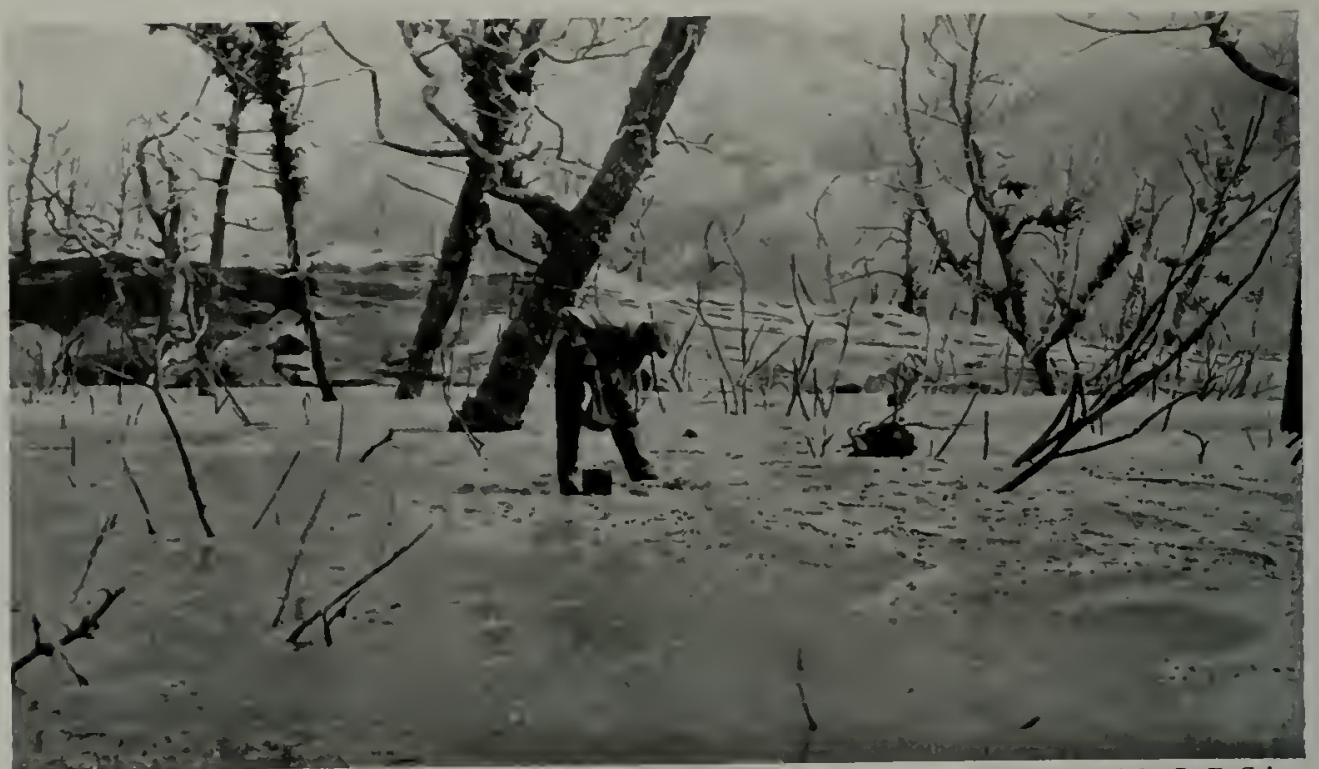

Photograph by R. F. Griggs

STRAINING DRINKING WATER OUT OF PUAICE

The water we had to drink was so muddy that Folsom refused to wash for three days because he "would not dirty his face with it."

One sank to his ankles at every step, while new sand poured down upon him, either burying his feet or carrying him bodily down the hill. It was a treadmill, in which one must either keep moving or be shifted to the bottom. The effort of such climbing soon became so wearisome that we avoided it whenever we could, but occasionally it was necessary for us to ascend a thousand feet over such slopes.

In climbing these slides, much the easiest method of progression was to go on all fours. But the sharp pumice soon ground away our finger tips. We were seriously embarrassed from this cause the first year. Before we were aware of the danger, we had worn our nails down to the quick and so ground the skin as to make it painful to use our fingers in any way.

But the labor of climbing the ash slopes was somewhat compensated by the sport of sliding down. Since the ash stood at the critical angle, the effect was practically to eliminate gravity. One could cut loose and almost fyrdown the slopes, bouncing down the steep slides in great bounds without the least consideration of his footing or of where he would bring up.

When we descended to the ford we had picked out, we found that it was little better than the place where we had turned back the night before. But it was the best that was to be had, so we decided to try it. It was not the low temperature nor the swiftness of the water that alarmed me, but the character of the bottom, which was a continuous quicksand clear across.

\section{FORDING A MILE OF QUICKSAND}

Sometimes the surface would hold like the crust of a snowdrift; but we were in constant fear of going down, for on sounding with our alpenstocks we found that the whole length of the stick went down six feet into the sand anywhere without striking bottom. Often our footing gave way and we found ourselves floundering up to the middle in quicksand. But as none of us went deeper than that, we returned and started across with our packs (see page 87 ). 


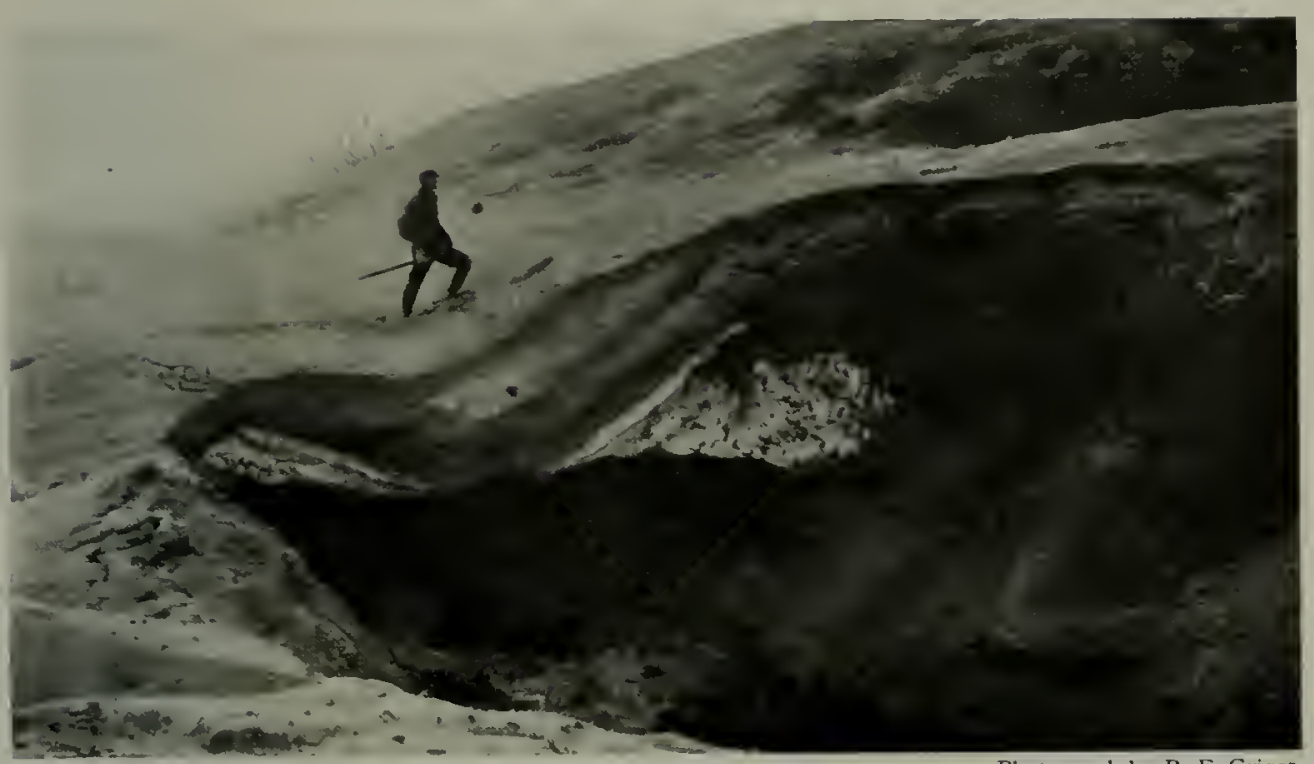

AN ASH BRIDGE

Photograph by R. F. Griggs

The caverns formed beneath the ash by melting snows gave us much concern at first. Later we learned to trust ourselves freely on such bridges.

With all our crossings, in the expeditions which followed, no one ever got in so deep that he could not get out alone. But I must confess that, often as we crossed Soluka Creek, I never got used to it. There was the ever-present knowledge that we never touched bottom and the fear that next time it would "get" one of us.

Besides this, the labor of carrying a pack through such quicksand exceeds anything else I know. Every step takes all a man's strength, and soon his weary muscles ache from the strain. But once in, he has no chance to rest until he reaches the farther shore, for he can neither lie down nor sit down; even if he merely stands still he begins immediately to sink.

\section{STRAINING DRINKING WATER OUT OF THE PUMICE}

It was very much of a problem to secure water from the overloaded brooks beside which we camped. Never more than an inch deep, the water always carried such quantities of large angular chunks of pumice, not to speak of sand and mud, that it was out of the question to use it as it was.

If we so much as dipped our hands into it in an effort to wash, sharp pieces of pumice stuck thickly to our fingers. When we tried to rub them off again they ground into our flesh painfully, preventing any further attempts at cleanliness.

The density of the ash was so near that of the water that it would neither float on the surface nor settle to the bottom. Fortunately, we had a spare bag through which we could strain it. Often we had to strain out a quart of pumice to get a pint of water. The stream changed so rapidly that it sometimes ran dry before we could fill our bucket (see page 88). And even by the best straining we could take out only the coarsest grit, leaving the water still full of mud.

At one of our camps Folsom refused to wash for three days, because he "would not dirty his face with the water we had to drink." Washing is a matter of choice, but one must drink whether he will or no.

After crossing Soluka Creek we camped 


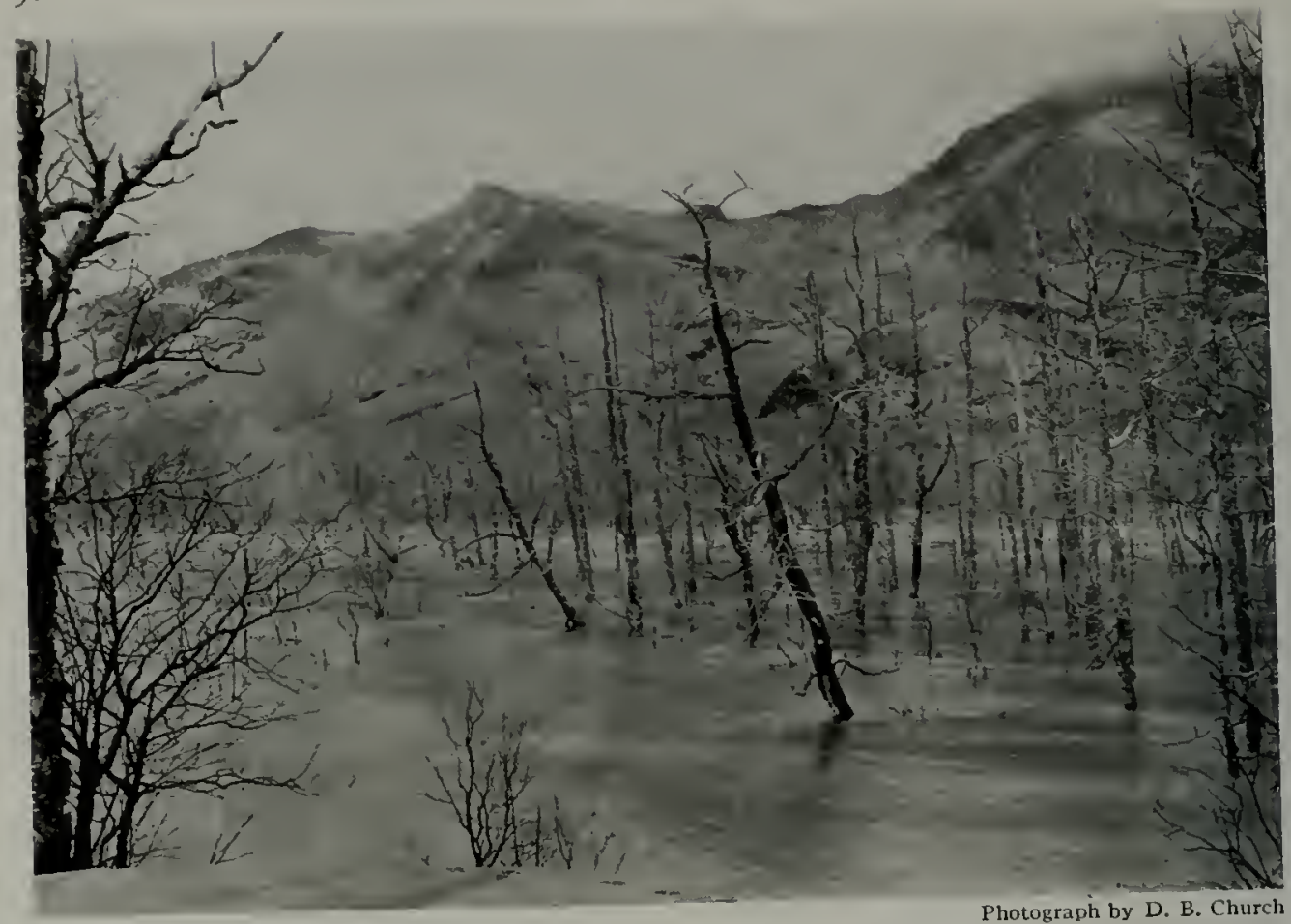

THE GLOOMY STRETCHES OF SOLUKA CREEK

I must confess that even after many crossings of this sinister stream without mishap I could never plunge in without a shudder of dread. So wide that from the middle we could see neither shore, its wick swift current everywhere churning the quicksand, it presents a party would be mired in its depths, ing a pack. I was in constant fear lest some member of the party would be milh of our alpenstocks for, although we seldom sank below our knecs, we could plunge the full

at the foot of the range that had shut off the view of Mount Katmai all the way up the valley. We reasoned that from the summit of these mountains, which we named the Barrier Range, we could most quickly obtain that sight of the volcano for which we were so anxious.

Haste, we felt, was imperative, because we feared lest the fine weather, which favored us almost miraculously the first season, should fail us. I well knew from previous experience that fair weather such as we were having was most exceptional in this district, for one may often camp here for days without a glimpse of the high peaks - as we did in 1917 and 1919, when we waited for nearly two weeks before we could climb Katnai. But on our first trip our provisions were so short that we could not hope to stay among the volcanoes for more than a few days.

The day after crossing Soluka Creek we attempted, therefore, to get a sight of Katmai from the Barrier Range. In this we were disappointed, for on reaching the top of the mountain selected we found a higher peak ahead, cutting off the view of Mount Katmai.

\section{FEAR OF CAVERNS FORMED BY MELTING SNOW BENEATH THE ASH}

When we tried to cross over to this higher summit we encountered for the first time one of the characteristic features of the ash-covered mountains that for a long time gave us much concern.

Part way up the slope, one of us, stick- 


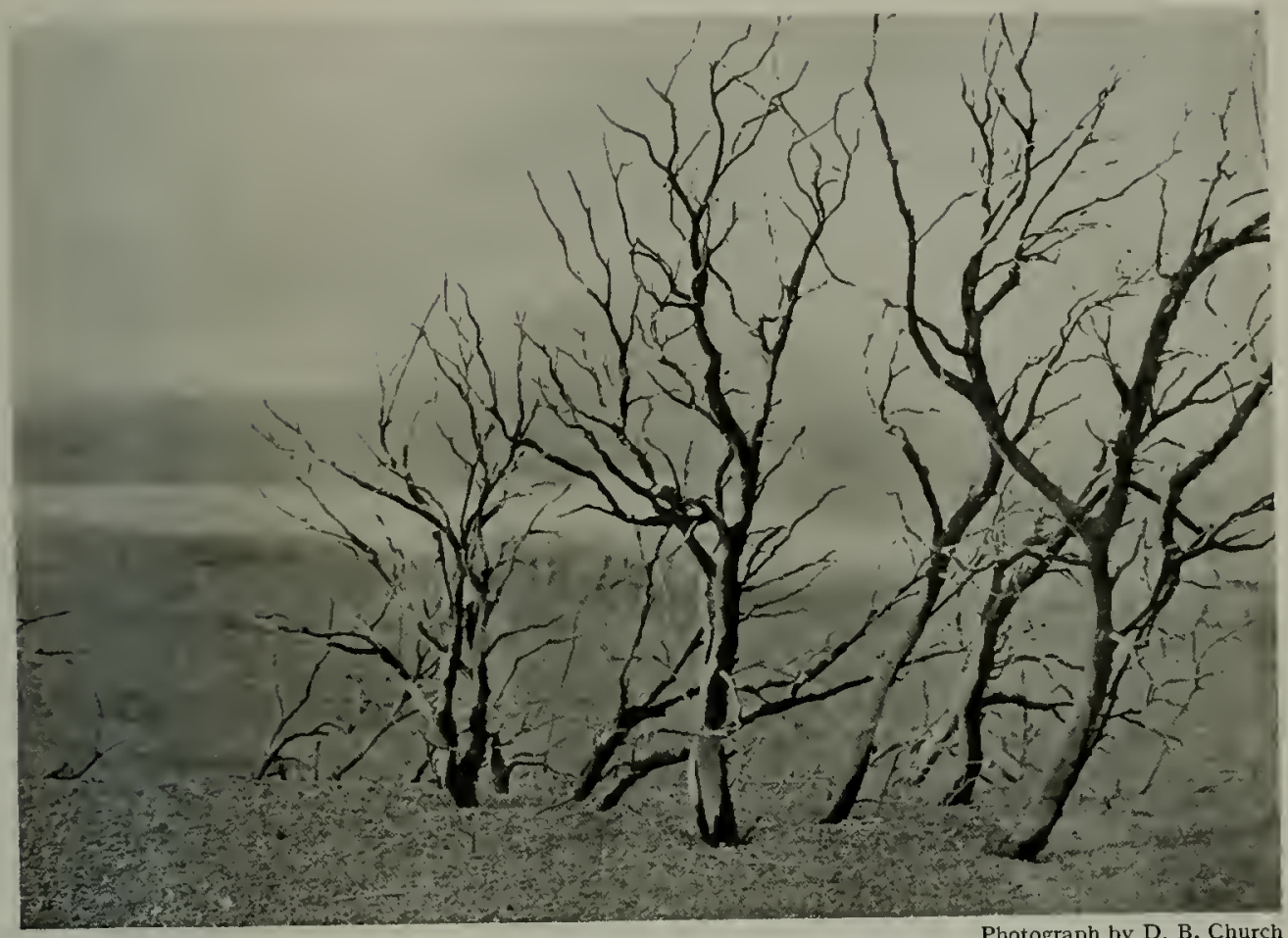

Photograph by D. B. Church

BIRCHES WITH THE BARK CUT OFF BY SAND BLAST

Over large areas such abraded trees give clear testimony of the direction and severity of the prevailing wind.

ing his staff into the ground harder than usual, found that it went through into a cavern beneath. Examination showed that we were supported on an arch of ash a foot thick, spanning a deep hole.

We found that the mountains everywhere were deeply covered with snow, which was concealed by a mantle of ash and pumice. The snow beneath was rapidly melting out in the warm weather, leaving the ash surface standing as smooth as ever above the cavity.

Such small holes as the one into which we had accidentally broken were, of course, of no consequence; but as we looked down one of the side valleys, we could see great cave-ins in an apparently smooth ash field, where a stream, burrowing through the snowdrifts beneath, had undermined the surface.

For half a mile or so the tunnel thus made had caved in, and then for another half mile it was still intact, giving no indication of its presence to an unwary traveler.

Alive to the new danger, we carefully chose a path free from all appearance of buried snowdrifts. But we had not gone a hundred yards when, happening to stamp my foot, I was astonished to hear the "ground" ring hollow beneath me. We quickly retreated, spread out, and tried another place.

Again we had not gone far when all three of us at once, though 50 feet apart, detected a cavern beneath us. We had absolutely no means of judging whether the hole was 5 feet deep or 50 , nor of estimating the strength of the roof. The danger of such a situation seemed altogether too great, so we reluctantly turned back, with as yet no view of the volcano.

In later expeditions we found stretches thus undermined by melting snow characteristic of much of the area of deeper 


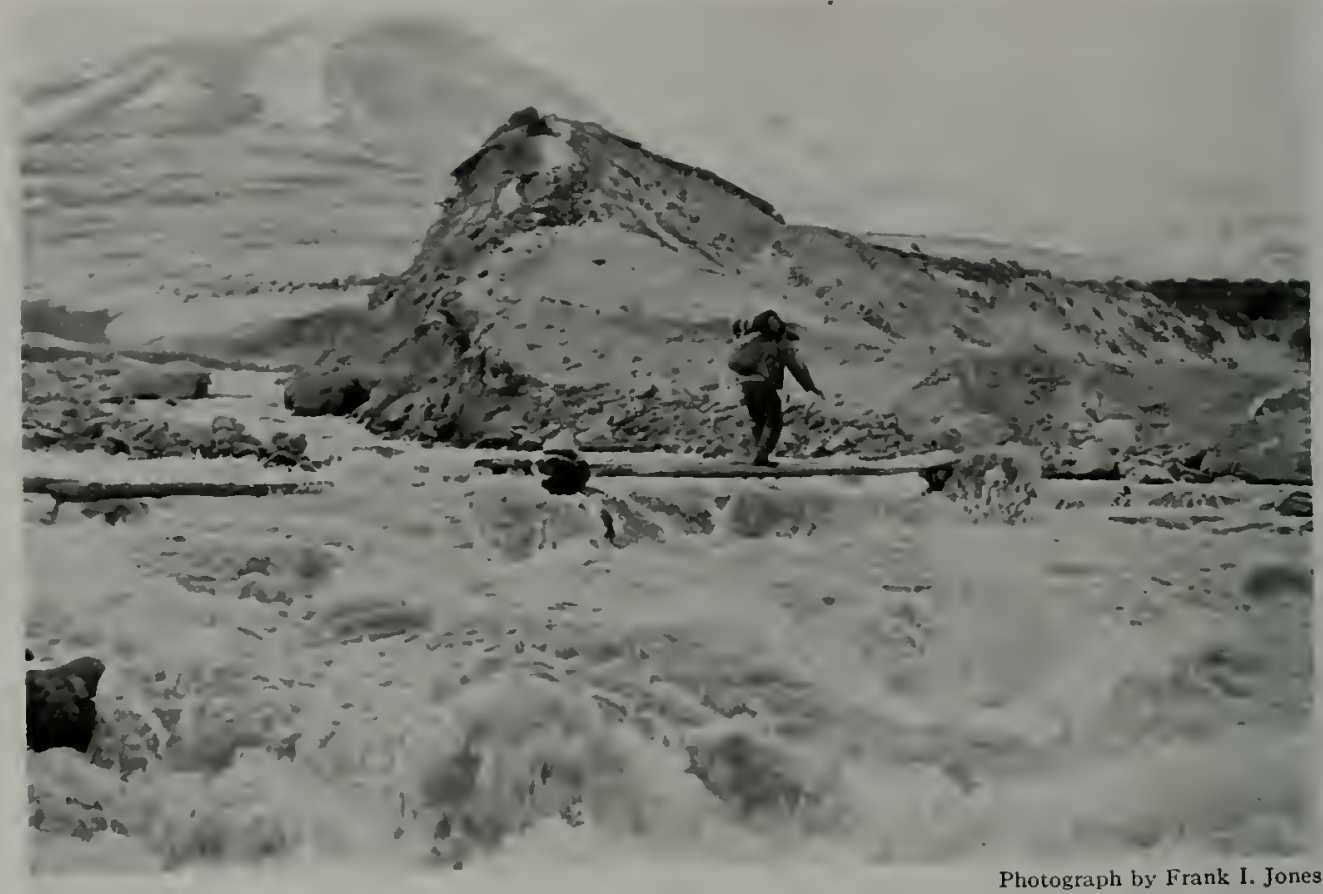

A JOB FOR A TIGHT-ROPE WALKER

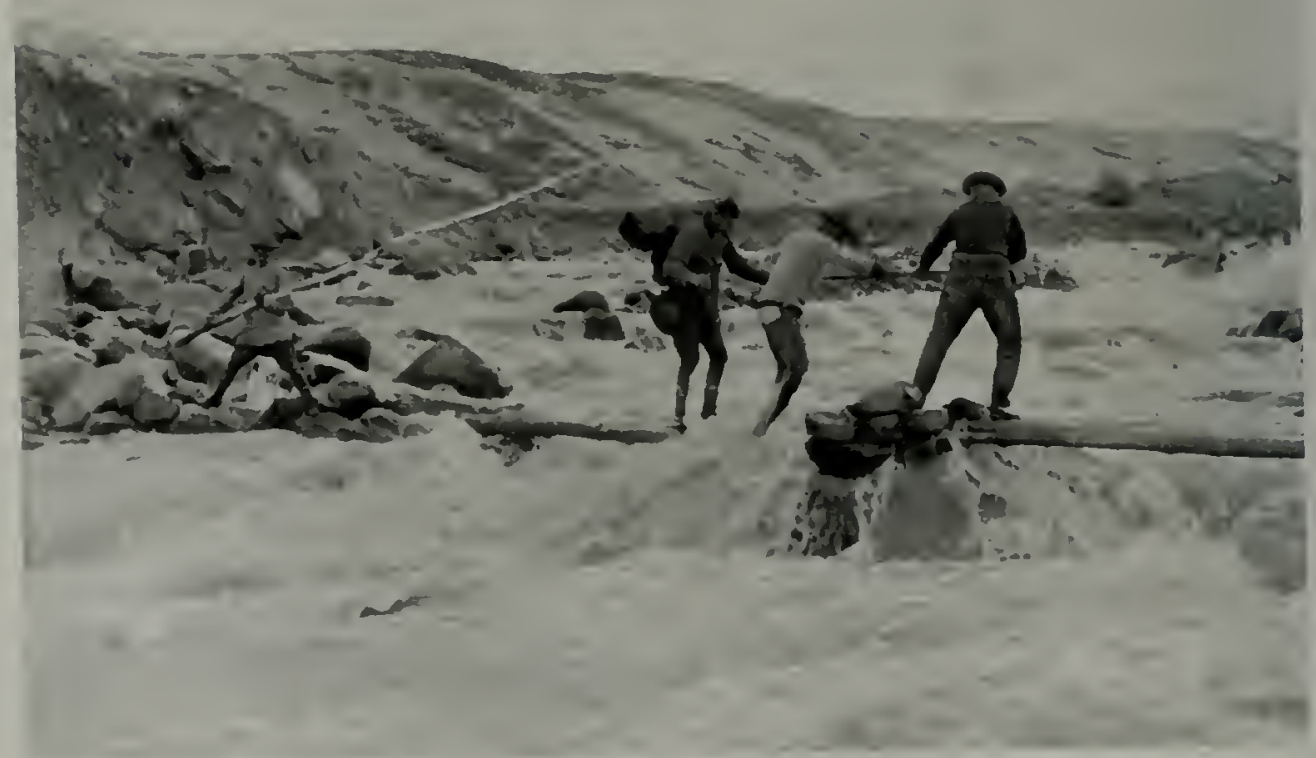

THE BRIDGE OVER MARTIY CREEK

All the materials for color photography were in this pack; if Jones had slipped there would have been no illustrations in color. Some of the boys hesitated a long while before trusting themselves on those wet, slippery logs. 


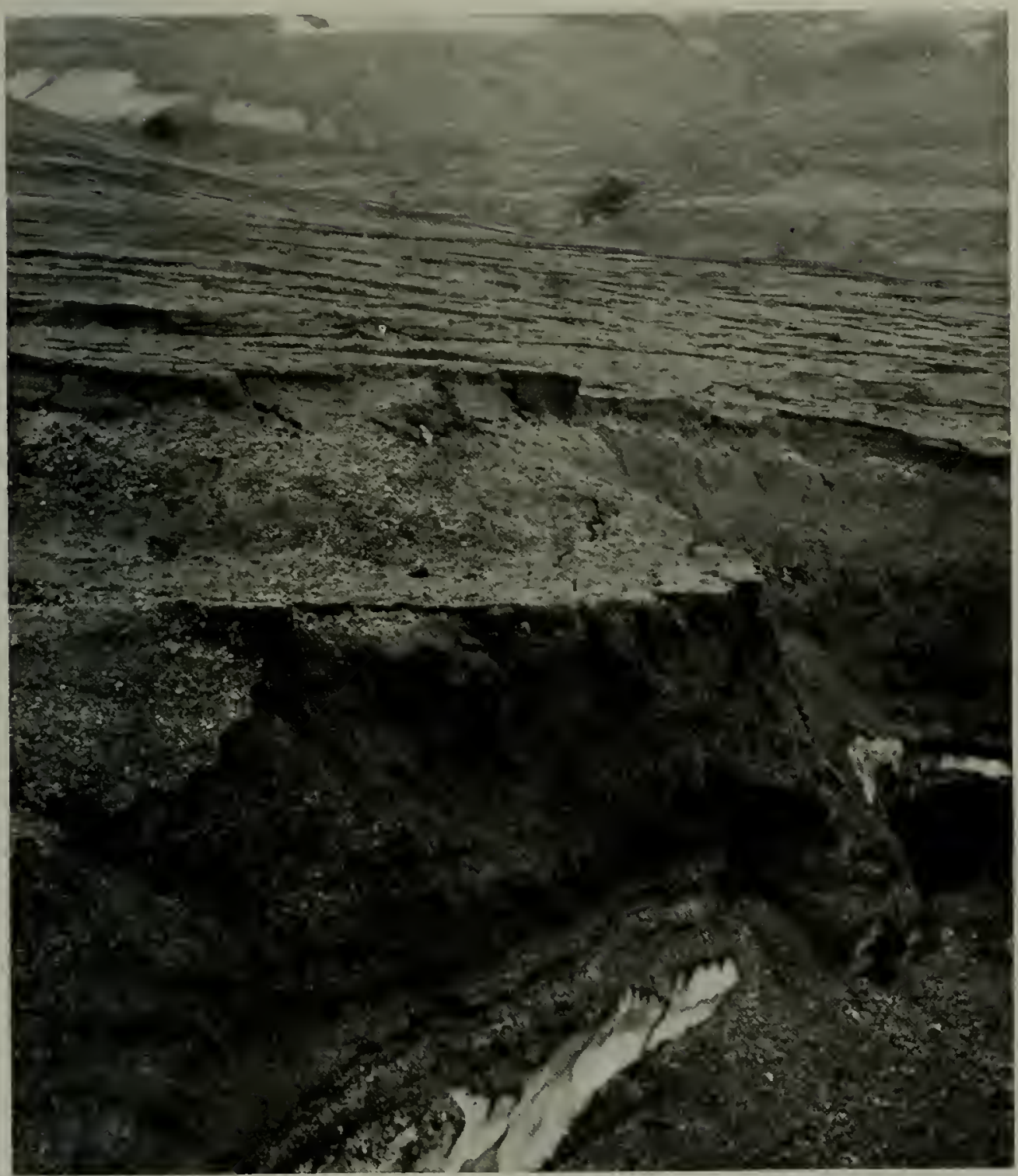

Photograph by R. F. Griggs

EVENLY BEDDED STRATA OF KATMAI ASH LYING ON TOP OF A SNOWDRIFT

The smooth contact and the absence of the ice, which would have formed on refreezing, indicate that the falling ash was not hot enough to melt the snow. The ash blanket prevented melting for five years. On Observation Mlountain, about seven miles from the crater.

ashfall and, as we were enabled gradually to experiment with such caverns, we learned that the danger from cave-ins is very slight. Before the exploration was completed we came to strike out boldly across places where we dared not venture in the beginning.
The following day we circled the mountains into Upper Katmai Valley. As we proceeded the country became progressively more desert. Small birds, which were common in the lower valley, were absent here.

The stillness of the dead forest was 


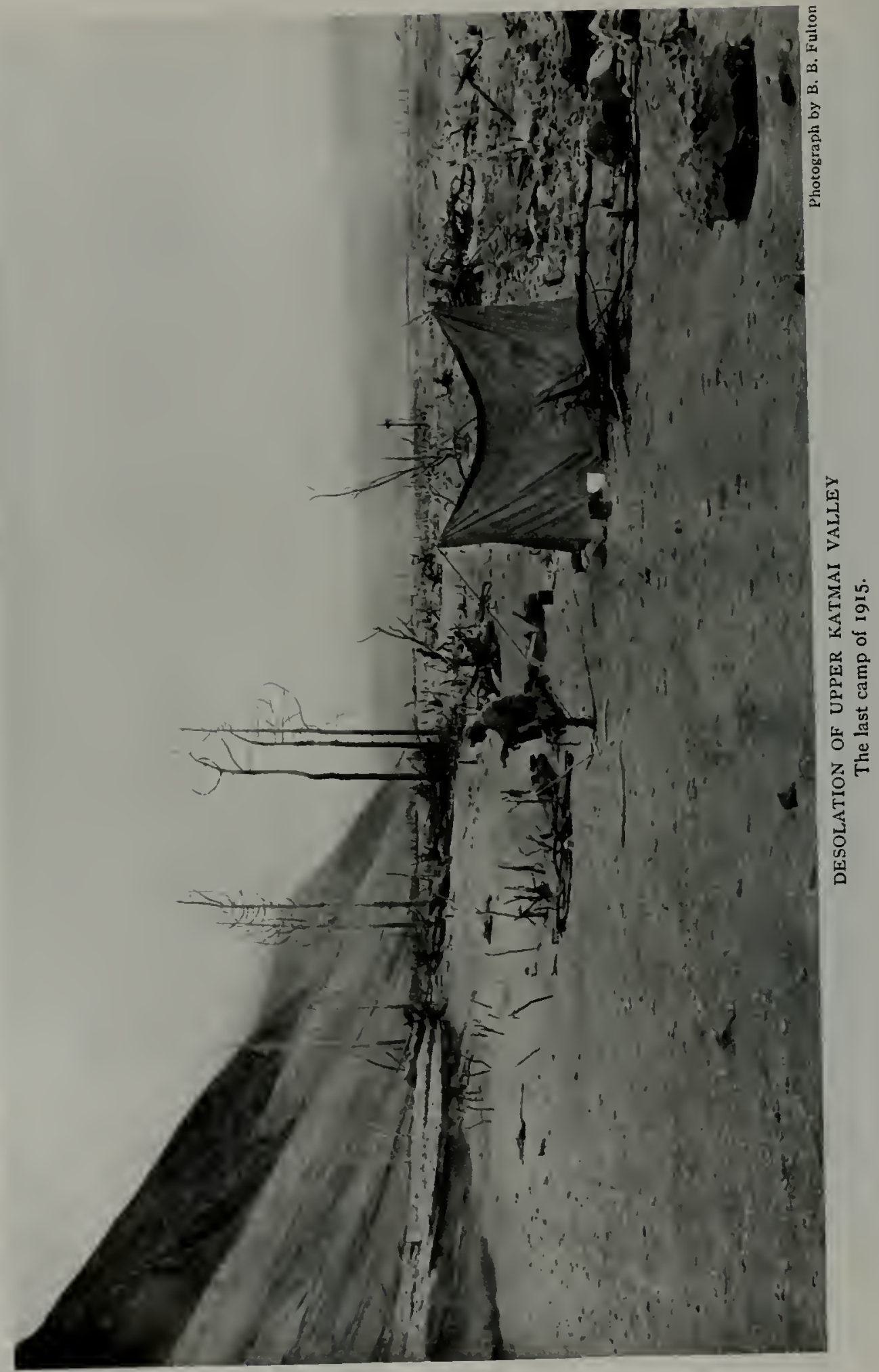


oppressive. One could travel all day without hearing a sound but his own footfalls and the plunge of rushing water. Bear trails persisted until we turned the corner into the upper valley, but there they disappeared.

Every vestige of animal life must have been destroyed in the eruption, unless perhaps some wood-boring insects sheltered beneath the bark of the trees had escaped. But even of these, few, if any, remained at the time of our visit. The bark had dropped off the dead trees, leaving gaunt white skeletons standing up out of the deep ash deposits.

We saw no signs of animal life around our camp except a pair of bald eagles, which flew over at a great elevation the first night, a few mosquitoes, and a single humming-bird moth, which seemed strangely out of place in such a valley of death.

AWE-INSPIRING DESOLATION OF UPPER KATMAI VALLEY

Clouds hung low, obscuring everything above a thousand feet. As we pushed up into the valley a feeling of tremendous awe possessed us. We had altogether exhausted our vocabularies in the lower valley and found ourselves altogether without means of expressing the feelings that arose in us or of describing the scene before us.

lndeed, we did not ourselves fully realize the terrible desolation of the upper valley until our return to the base camp. Coming back into the lower valley after the total desolation of the country in the shadow of the volcano was like regaining the earth after an exile in the inferno.

When we came back across Soluka Creek we were astonished at our feelings of exhilaration, as we relaxed from the unconscious tension of the upper valley. The broken remnants of the former trees appeared the most luxuriant verdure. The branches seemed alive with singing birds. The mountains seemed covered with herbage from base to summit. And this was the country that a few days before had seemed utterly devastated in comparison with Kodiak!

Despite the complete devastation, one of the expected agents of destruction was conspicuously absent. Nowhere did we detect the slightest evidence of fire.

We would not have been surprised to find that the explosion was followed by flows of molten lava, and we supposed that the ash falling close around the vent was hot enough to set the trees afire. Nowhere in Katmai Valley did we detect the slightest evidence of high temperature.

\section{ASH COOL WHEN IT FELL}

On the contrary, the deposits give the clearest testimony that the ash was cool as it fell. So far as we could see, it did not melt the snow where it had fallen on the drifts on the mountains. We found places where even coarse lapilli had sifted in among the stems of the dry grass without visibly affecting them.

The ash did not even cook the plants on which it fell. Later we found places well up on the slopes of the volcano, from which the ash had slid off, where roots of the old plants were sending up new shoots. It is difficult to see how these could have survived, if the ash had had a temperature even approaching the boiling point.

The valley had become gradually narrower as we ascended, and was now seen to terminate in a precipitous canyon, which, because of our inexperience with the country, seemed close at hand. Nor did we realize at first the great height of the cliffs, which are very impressive on nearer view (see page r 8 ).

Later we found that the mouth of the canyon was nearly two miles beyond us, instead of the short half mile it appeared. Fortunately for our purpose we had already reached a position which we judged must be opposite Mount Katmai, though we could have no assurance of our location because of the low-hanging clouds.

Across the valley from our camp we 
could see what we supposed to be the base of Mount Katmai. Here we beheld a formation quite different from any thing we had ever seen.

A ravine that branched off from the main ralley behind a spur of the mountain was filled by what looked like a great glacier, except that its color was a terracotta red. In every detail of its form, except for the crevasses, it was exactly like a glacicr. Beginning at a considerable elevation, where the ravine was narrow, it sloped evenly down to the valley level, widening as it descended, so as to assume a triangular form.

\section{THE KATMAI MUD FLOW}

If the color had not been so different from everything else in the landscape we would assuredly have taken it for a glacier covered with dirt. But so close to the volcano no glacier could have escaped a thick covering of the omnipresent ash. We concluded, therefore, that it must be a mass of mud which had rolled down the volcano after the ashfall.

Later, when we risited it, its structure confirmed this theory. Sections cut by a marginal stream showed that it lay on top of the strata of ash, proving that it had been formed after the ash had fallen. Although it was hard and firm, affording easy walking, both its structure and its form showed clearly that it had reached its position in a semi-fluid condition. Like a glacicr, it had a relatively steep front and was convex, highest in the middle, turning the drainage off to the edges, along each of which a deep canyon had been cut.

But despite the indications that it had once been fluid, we saw no mud cracks or other evidence of shrinkage upon drying out, such as one would have expected to find in a mud flow. Its length was two and a half miles. Its highest part was nearly I,00o feet above sea-level, from which point it sloped gradually to about 300 feet at the base.

Vie were not able to estimate its thickness so well, but along the edge where it was cut into by the stream a section about 50 feet thick was exposed. In the middle it may have been much thicker, both on account of the convexity of the surface and the greater depth of the valley floor.

\section{FIRST CROSSING OF KATMAI RIVER}

The river, as it debouched from its canyon into the wide valley, spread out in a dozen streams over the broad fan of gravel that had been carried out of the canyon. These leaping, ever-changing streams were the most serious obstacle we encountered in all our exploration of the district.

The quicksands may be more dangerous, as their passage is certainly more fatiguing, but the force of these torrents so overpowers a man that his strength is useless against their rush. We were naturally anxious to cross over and explore the mudflow, whose outlandish appearance excited our keenest curiosity. Procuring strong poles we started out. From a little distance the streams looked easy enough, but when we waded in we found the current more than we could stand against.

It was extremely hard to lodge our poles against the bottom or to maintain our balance while we shifted our props. We could hear the ominous roar of great bowlders, rolled along with the current. Smaller stones were continually bumping against our shins. Wherever we set our feet the bottom had a most disconcerting way of washing out from under us. In the first attempt both Fulton and I went down helpless. Luckily, the packing of our cameras kept them dry, but we came so near to disaster that we rlared not try it again.

LATER EXPERIEXCES IX CROSSING THE RIIER

During the winter of preparation for the next expedition, I racked my brains and sought counsel from all my friends for some device by which this river could be masterel. The streanis were too wide and too changeable to permit 


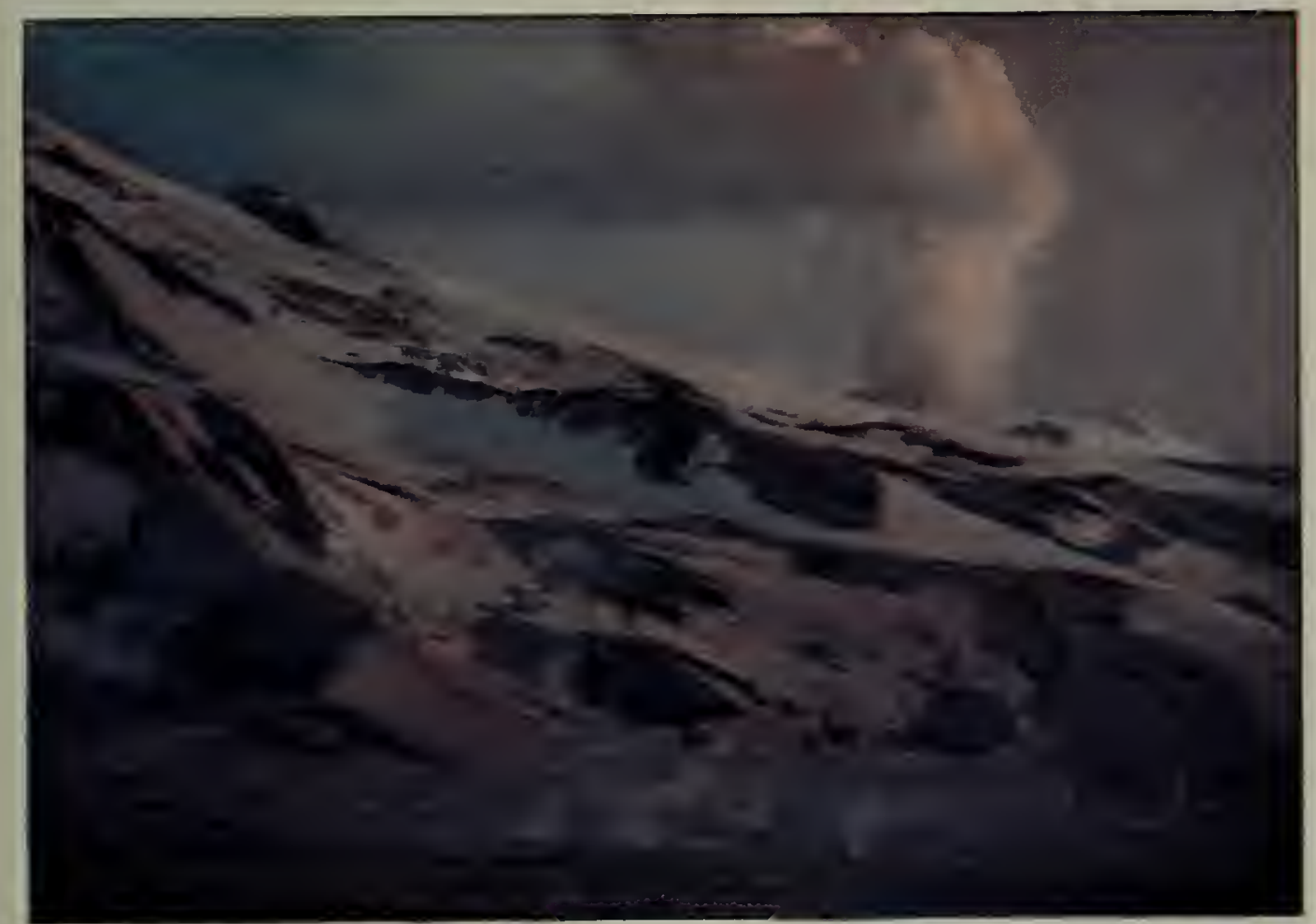

Natural Color Photograph by Frank I. Jones

ALPINE GLOI ON MOLNT MARTIX

Under the last rays of a setting sun a few small fumaroles are still discernible in the shadowy Talley. 


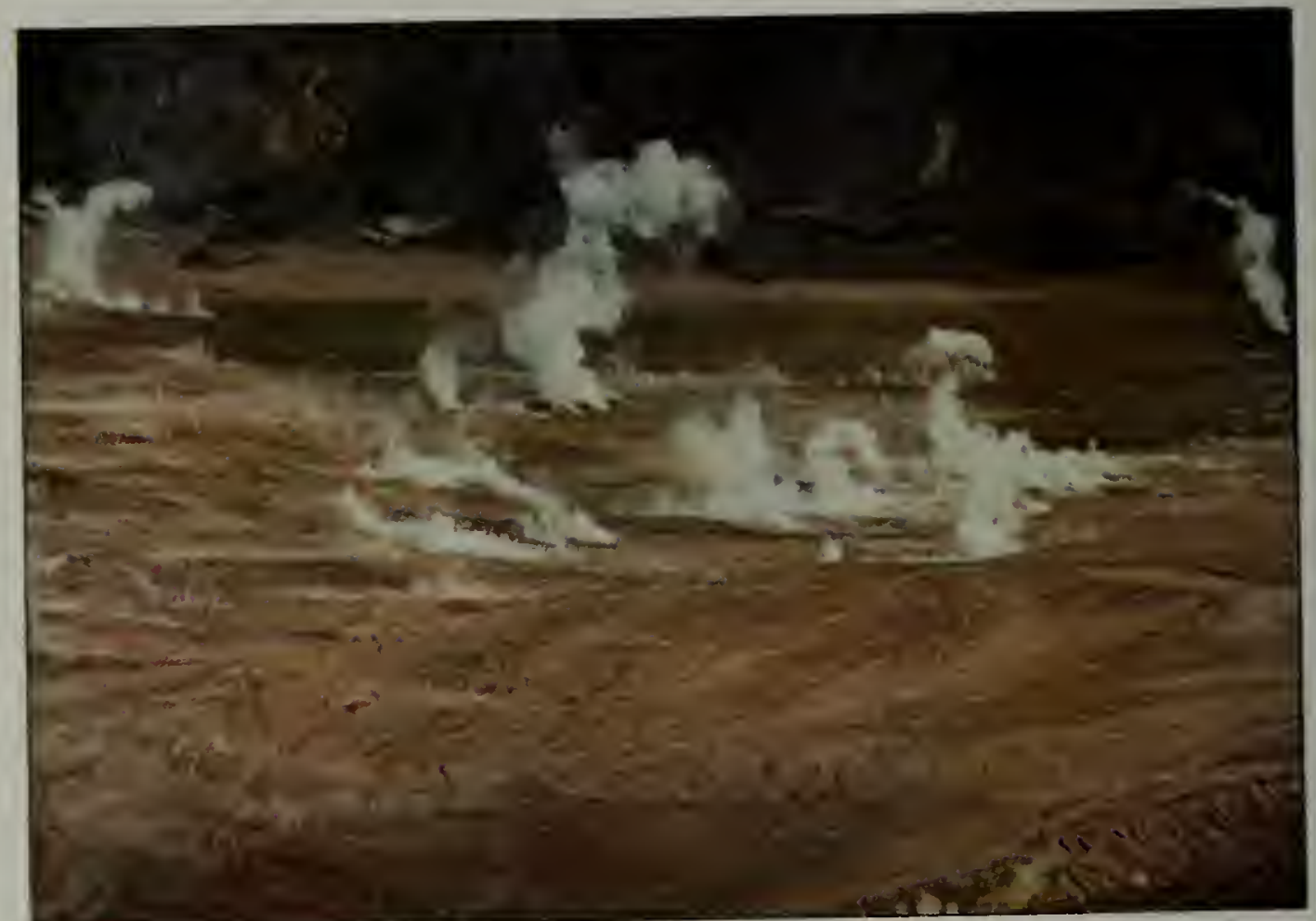

Satural Colot Photograph by Frank \&. Jones

FLMAROLES AT THE FOOT OF FALLI.IG MOL'IT.AIX

Seen from Greased Hill between Baked and Broken Mountains. 
bridging, even if the expedition could have summoned force enough to bring the necessary logs into position. The best expedient we could devise was a rope, which was used throughout the summer of I9I6.

One man took a long rope upstream, while a second tied the other end around his shoulders, and, bracing himself with the rope held on the bank, slowly worked his way across. After the first man was over, it was comparatively easy for the others to slip along the rope, held taut on both banks. The last man had the advantage of using the rope as a radius, swinging downstream.

Even with this assistance, the ford had to be chosen with extreme care. If we tried a place where the water was too strong, the man on the rope went down and had to be hauled ashore like a fish. Such an accident is great sport for those on the bank, but one of the most horrible of experiences for the man in the water. As he goes down, struggling his hardest, a sickening realization of utter impotence comes over him. Despite the strong rope, he is sure he is lost and feels all the terrors of a drowning man.

We gave the problem renewed consideration in planning the expedition of 1917, and after watching motion pictures of boats in the Grand Canyon, decided that a boat might be used here, although the problem was very different, namely that of holding a boat against the current, rather than of merely drifting with it. As an experiment, therefore, we procured a folding canvas boat.

It was with great interest that we awaited an opportunity to try it at Martin Creek, which is so swift that neither oars nor poles could be used. The procedure was to fasten a line to the bow, with which the boat could be held against the current. Then, by means of a "gee string" attached to the line a few feet from the bow, the man in the boat could turn it in to the current, forcing the water to push it across the stream, just as a kite rises when the wind strikes it at an angle. The thing worked perfectly, except that it was hard to land. The first time I tried, the boat steered out across the channel close to the opposite shore, but there it stopped and could not be made to go farther. I had forgotten that the current slackens against the bank, and I suddenly found the power cut off almost within arm's length of the goal.

Here was a predicament, and not until one of the men had foundered the boat in an effort to jump ashore was a solution found. Even close in, the water was too swift for oars or poles. So we decided to try grappling. Throwing an improvised anchor ashore, we could catch hold in the gravel and pull ourselves in.

\section{WAITING FOR A SIGHT OF THE VOLCANOES} THROUGH THE CLOUDS

Katmai River so nearly overpowered us on our first crossing in 1915 that we dared not risk another attempt, and so gave up all expectation of exploring the volcano that year. But we still hoped at least to get pictures of it. Up to that time it had never been photographed nor even described.

The clouds which shut us in as we first came up the valley continued to hang low without any sign of breaking throughout the next day. All that night and the next I peeked out under the side of the tent at frequent intervals, to make sure that we should not miss a sight of the mountain if it cleared for a few moments. But there was no change and we waited on all through the third day. As the hours passed, anxiety grew into fear that we might be altogether cheated. In this country I had often seen the clouds hang unbroken for a week around much lower mountains than these, and $I$ knew it was not at all unlikely that our slender food would be exhausted before the sky cleared.

But finally the clouds lifted, slowly at first, and then with a sweep. At the head of the valley stood the I,ooo-foot cliffs which guard the entrance to the inner canyon of Iratmai River, while behind us, towering aloft over inaccessible precipices, the summits of Slide and 


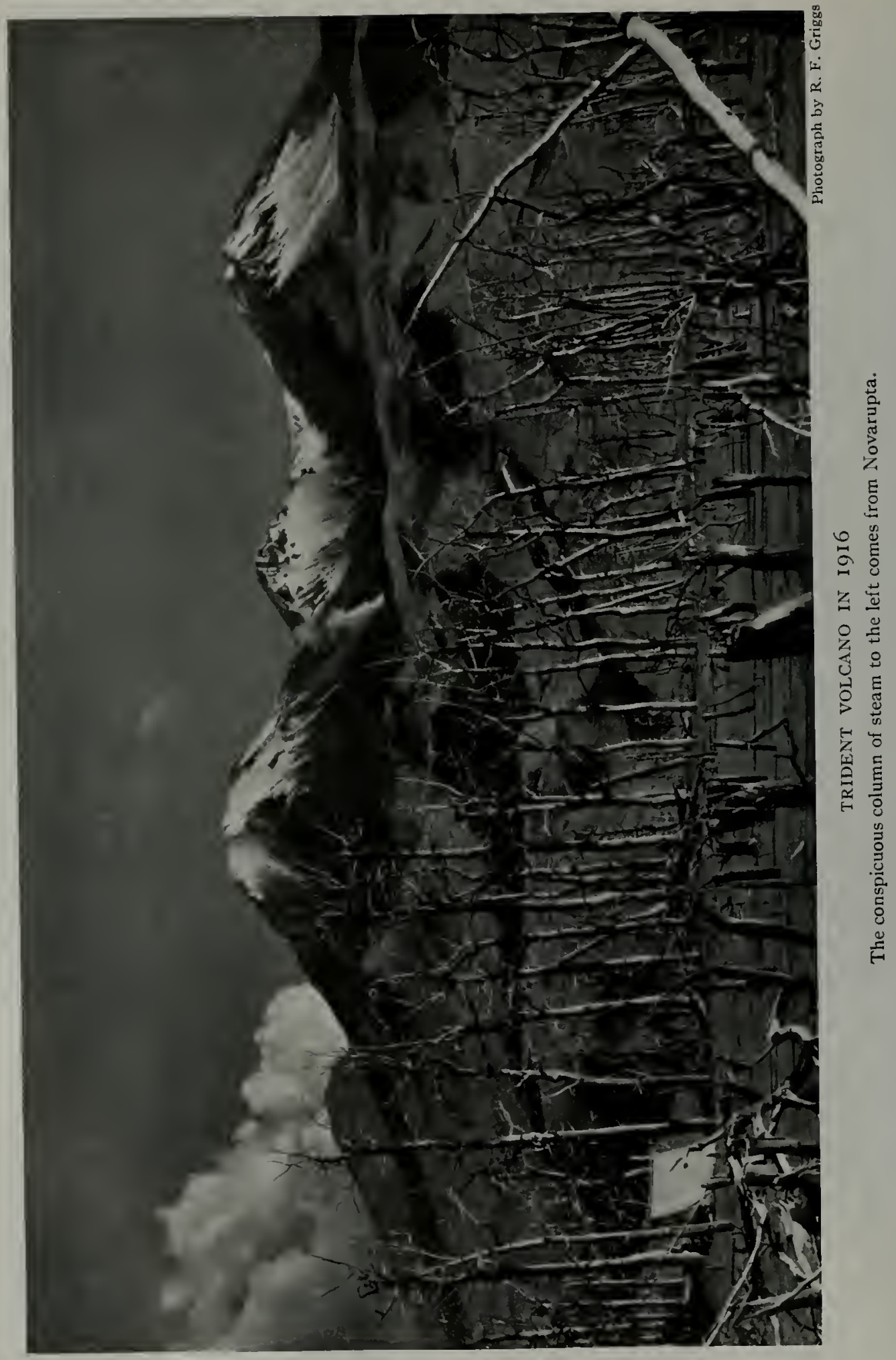


Avalanche Mountains themselves presented spectacles fine enough to command attention in any other setting. But here they were eclipsed, for on the other side lay the whole chain of glacier-covered volcanoes in a continuous series, broken only by Katmai Pass, whose 2,500 feet looked low indeed by comparison.

\section{A SECOND NEW VOLCANO, TRIDENT}

Farthest to the westward stood Martin (see page I8o), shooting a column of white vapor a mile into the air; next the threepeaked summit of Mageik (see page 8o), covered with a mantle of freshly fallen snow; then, beyond Katmai Pass, another volcano which we named Trident; and at the end of the line, Katmai.

Trident was a lofty mountain (altitude 6,790 feet) which from our position showed three peaks, suggesting the name. The whole mountain was clearly rolcanic, but it was much eroded, leaving little indication of the crater from which the lavas composing it had come.

Evidently it had not been active for a long time, until, in the general shake-up accompanying the recenteruption, a small fissure had opened on the flank toward us. From this issued a thin column of smoke that of ten rose 3,000 feet or more before dissolving (see page 98 ).

Between Trident and Mageik lay Katmai Pass, which, though in no wise interesting as a piece of scenery, excited our curiosity because of its historic interest as the route of the gold seekers at the time of the Nome stampede.

Could we have known what lay beyond it, awaiting our discovery, we would have studied its contours with even greater interest. Although reputed difficult and dangerous, it looked very easy from our position.

\section{FIRST SIGHT OF MIOUNT KATMAI}

Finally, east of Trident, stood Katmai itself at the end of the visible portion of the range. But how different from the Katmai of former days!

Before the eruption it must have dominated the country round about as
Mageik does now, for although much less favorably located than Mageik, it was given the name of the town, as were Katmai River and Katmai Pass. It must have been the dominant mountain of the district, but the first glance showed how completely it had been eviscerated in the eruption.

The three-peaked summit, formerly towering 7,500 feet high, was entirely blown away, leaving a great crescentic rim at the top of the stub. We could not then suspect the stupendous magnitude of the crater that lay within, but it was evident at once that it was of enormous proportions (see pages I 00 and I 68).

It must be confessed that at first sight the appearance of this broken cone was somewhat disappointing. Its great bulk so reduced its apparent height that our first estimates of its altitude had to be increased by half, as we compared it more carefully with Trident and Mageik, whose elevation we knew. No snow was visible anywhere on its slopes when we first beheld it, and the dirty ash-covered surface suffered in comparison with the glistening snow fields of Mageik.

The slopes were gentle and the ascent looked easy. But as we studied them with our glasses we saw that the absence of snow and ice was only apparent. Even from our station at a distance of five miles we could see that a large part of the mountain was corered with glaciers, whose yawning crevasses we could make out, despite the heary mantle of ash which concealed the ice.

Remembering our experience with melting snowdrif ts beneath the ash, whose treacherous caverns we still feared greatly, we decided that the risk of climbing without an alpine rope was too great to undertake. We made use of our opportunities for observation, however, by studying the slopes, both to pick out for future use the best route to the rim and to ascertain something of the structure of the mountain.

The first glimpse of the volcanoes sufficed to reveal something of their character and to suggest a number of 


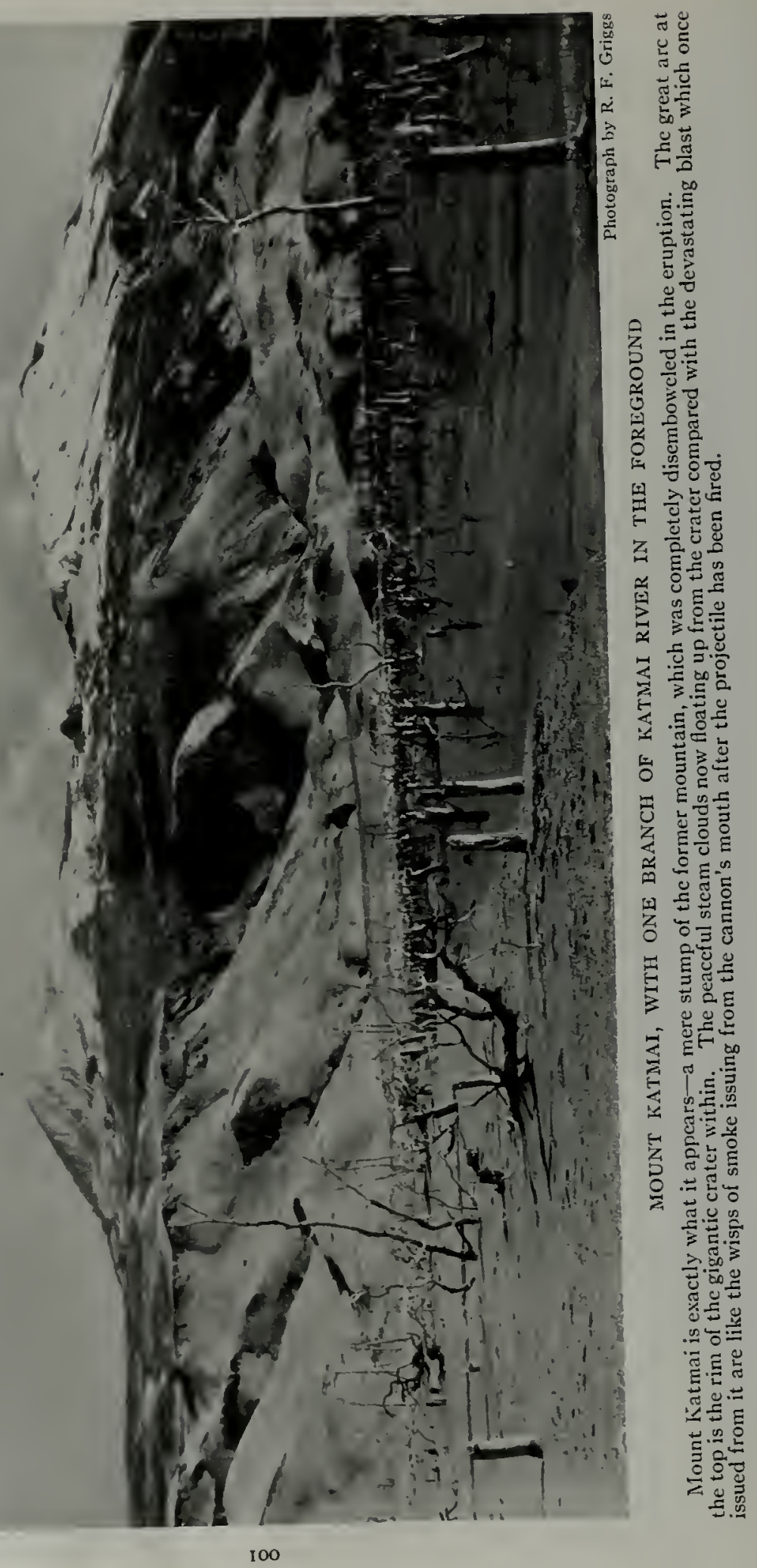


considerations which subsequent study enabled us to confirm. From their outline alone it was evident that previous to the recent outburst none of them had ever suffered a major eruption of the explosive type.

VOLCANOES ALL OBVIOUSLY PILES OF LAVA RATHER THAN CINDER CONES

Nowhere in the district are there any decapitated mountains or old craters such as would have been left by a great explosion. These mountains, moreover, showed little resemblance to the typical steep-sided cones formed by alternating deposits of fragmental cinders and fluid lava, like Shishaldin or Fujiyama.

On the contrary, their round domes and gentle slopes were built up almost entirely by successive lava flows, without the intermixture of any considerable amount of pumiceous material. Some of the other cones, like Cerberus, not visible from our position, were indeed steep enough to remind one of cinder cones, but an examination proved that they, too, were built of compact lava, probably squeezed out in a nearly solid condition like the well-known spine of Pelée.

2 This statement refers only to the lavas of the present volcanic cycle. The numerous lavas of
The lavas were poured out on a platform of sedimentary rocks, Jurassic sandstones and shales, which suffered remarkably little change in the formation of the volcanoes. In many places their strata are bent up against the flanks of the volcanoes, as though blistered up by the injection of a mass of magma beneath, but otherwise they still lie in nearly horizontal layers, almost as they were laid down on the former sea bottom.

Not only the type of eruption but the composition of the lavas of the district has been remarkably constant from the beginning of their activities up to the present eruption. ${ }^{2}$ All the specimens examined are basic andesite approaching basalt in composition.

In view of the uniformity of the ancient lavas, the strikingly different character of the ejecta of the recent eruption, which is an acid rhyolite with a high silica content, is interesting.

This sharp contrast between old and new lavas has made possible some very instructive petrological studies, which bid fair to carry us farther in an understanding of what really happened in the eruption than any other line of evidence, as detailed in Chapter xxII.

old Tertiary volcanoes round about have not been studied extensively. 


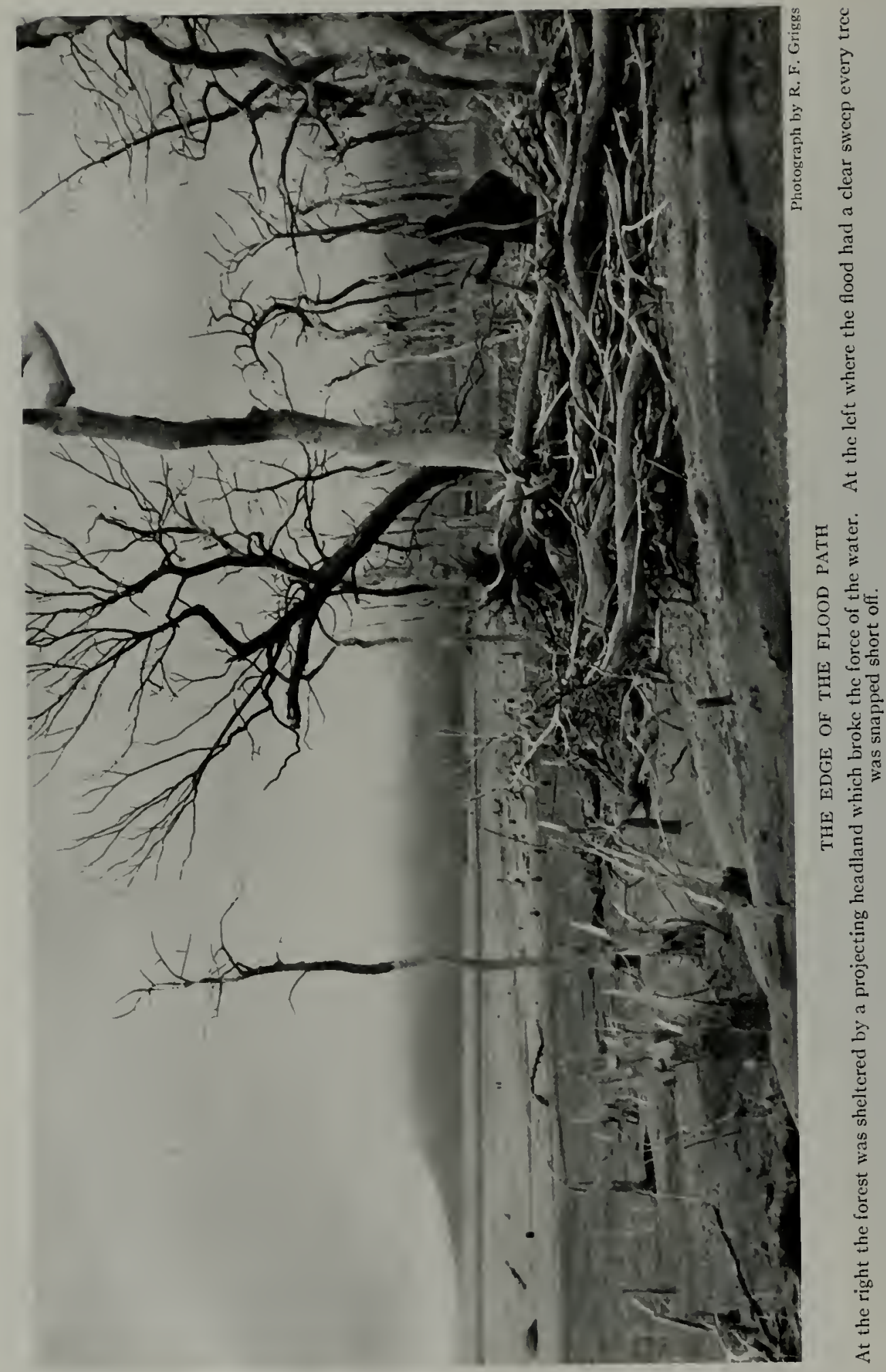




\section{THE KATMAI FLOOD}

When we first landed on the shore of Katmai Bay, we found the countryside ravaged by a great flood whose waters were just subsiding. The whole flat six miles wide had been covered with water. Considering the enormous volume of water necessary to inundate a valley opening freely to the sea, we might have realized that such a flood was a very unusual occurrence.

But we would not have been surprised at anything we might have encountered in that weird country where so many physiographic relations were turned topsy-turvy. We did not therefore recognize at once that the flood was an altogether unprecedented event.

Even before our landing we began to observe the evidences of this flood, for we found Katmai Bay full of uprooted trees, bushes, and fields of floating pumice, which had but recently been brought down by the flood waters.

The soft sticky mud previously mentioned made it difficult for us to find a suitable place for our tent. The bed of pumice that we finally selected was indeed only freshly floated into place by an eddy in the waters. It was possible as a camp site only because its loose porous character readily permitted the water to drain through it. We were in constant fear, however, lest the water should suddenly rise again in the night and drive us out.

EXCEPTIONAL HEIGHT OF FLOOD EVIDENCED BY CONDITION OF KATMAI

\section{VILLAGE}

When we came to explore the remains of Katmai Village, to which, fortunately, the people had not been permitted to return after the eruption, the magnitude of the flood was impressed on us as it could not have been on the brush-covered flats.
Here we found that the little Russian church in which the people had worshipped for years without interruption had been floated loosefrom its foundations and left standing in a sea of mud. The high-water mark could be plainly seen across the front, about nine feet above the normal river level (see page I04).

Some of the native houses werc solidly packed with pumice, full to the eaves. Some had been completely submerged, as might be seen by the stranded pumice which had washed on to their roofs. The roof of one had floated away from the body of the house and lay at a little distance.

It was evident enough to us, as we looked about the village, that the builders of the houses had not contemplated the danger of any such flood, for there had been no effort to select high ground. On the contrary, convenience to the landing place and shelter from the winds had apparently been the most important factors in the choice of building sites. This was the more significant because of the manner of construction of the native "barabaras." These are semi-dugouts with their rooms deeply excavated in the ground and, therefore, require a well-drained site far more urgently than an ordinary house, built above the ground.

Directly in front of the houses had been the landing place. Before the eruption, boats drawing five feet of water had freely crossed the bar and anchored at the village; and even after the cruption, Martin had succeeded in entering the river in a 35 -foot schooner. But at the time of our visit it was so choked with volcanic ash that even the main channel was impassable to a rowboat.

Where deep water had been before there was now only a maze of shifting 


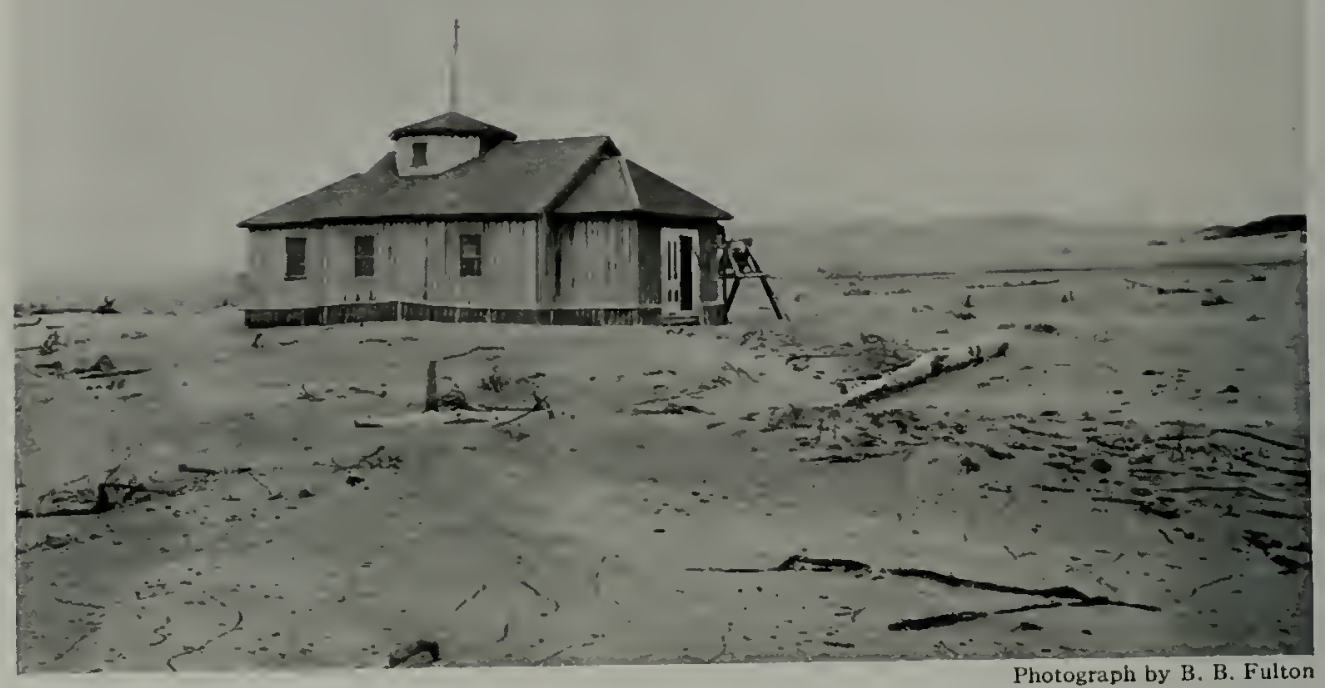

KATMAI CHURCH STANDING BLEAK IN THE DESOLATE MUD FLATS LEFT BY THE FLOOD

The high water mark even with the bottom of the bell may still be made out. Some conception of the volume of the water necessary to fill the valley to such a level may be gained from the fact that the flat valley is six miles wide at this point. Moreover, it opens freely out to sea so that there was no barrier to retain the water.

quicksands, spreading out for five miles all the way to the foot of the mountains across the valley. Over this vast stretch the water was on the whole hardly five inches deep, yet the current was so strong and the quicksands so treacherous that it was equally difficult to ford from side to side or to follow the channel. We tried once to "track" a light canvas canoe up the river, but found it out of the question. We also tried to cross with skis, which helped considerably with the quicksands, but became unmanageable in the currents.

\section{SPECULATING AS TO THE CAUSE OF THE FLOOD}

Conditions at the village greatly increased our respect for the magnitude of the flood, but failed to enlighten us as to its cause. The volume of water had been tremendous, considering the size of the watershed, for although the main stream is less than 40 miles long and has a steep gradient through much of its course, the water had filled the whole valley, six miles wide, reaching a maximum depth of about to feet. We knew that there had been no general storm which could have caused any unusual quantity of rain.

As tide-water towns are rarely affected by any floods, except inundations caused by incursions of the sea, our first idea was that the spring tides which had just passed had overwhelmed the land.

Katmai Valley in particular opens so frecly out to sea that it seemed impossible that anything less than the ocean itself could furnish water enough to cover the whole of it. A little examination showed also that the water had risen many feet above any former tide mark. An unusually high tide is, however, not a local 


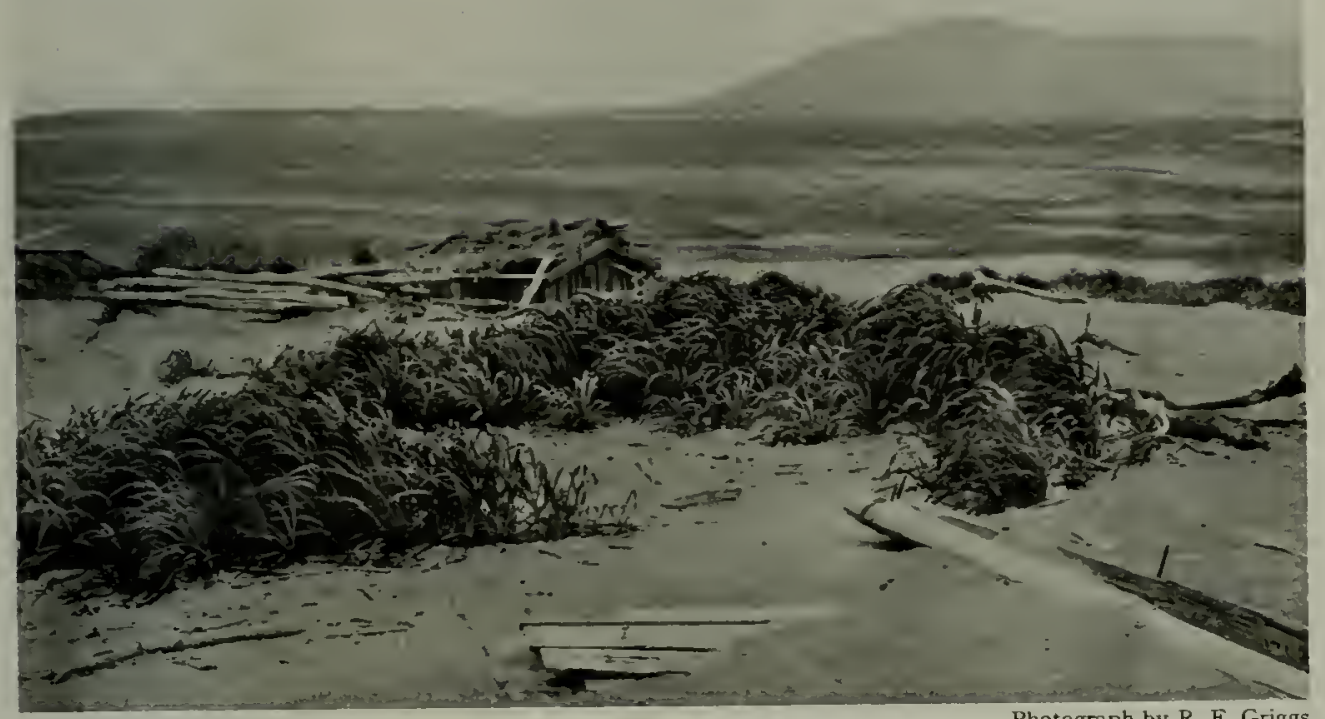

KATMAI RIVER AFTER THE FLOOD

Before the eruption boats drawing as much as five feet of water used to enter the river and anchor at this point. A good-sized gas-boat entered the river some months after the eruption, but it is now impossible to navigate a rowboat even in the main channels.

affair, and would have affected Kodiak as well as Katmai.

We saw at once, therefore, that the flood could not have been tidal, unless, indeed, the whole valley had been sunk as a result of the eruption. As the condition of the beach at once negatived this possibility, it was evident that the water must have come down from the mountains, rather than up from the sea.

We then suspected volcanic rains up the valley, for at that time we had no knowledge of the condition of the rolcanoes. As a matter of fact this hypothesis was incorrect, and our exploration of the village left us none the wiser as to the real nature of the situation we had to face.

Nevertheless, our examination of the village was very reassuring, for in giving a better conception of the enormous volume of water that had poured down the valley, it enabled us to rest a little easier in the thought that such a deluge would not be likely to come upon us unawares.

This, as it turned out, was not altogether correct, for the flood must have pushed down the valley at a high velocity. Everything at the village, however, indicated that the flood was an altogether unprecedented event, not likely to be repeated. This we later found more nearly in accord with the facts.

\section{FLOOD CONFINED TO KATMAI RIVER}

As we explored our way upstream, we were surprised to find that the tributaries gave no evidence of having participated in the flood. When we thus observed that, like the smaller brooks, neither Soluka Creek on the north nor Martin Creek on the south had contributed in any way to its waters, our suspicions 


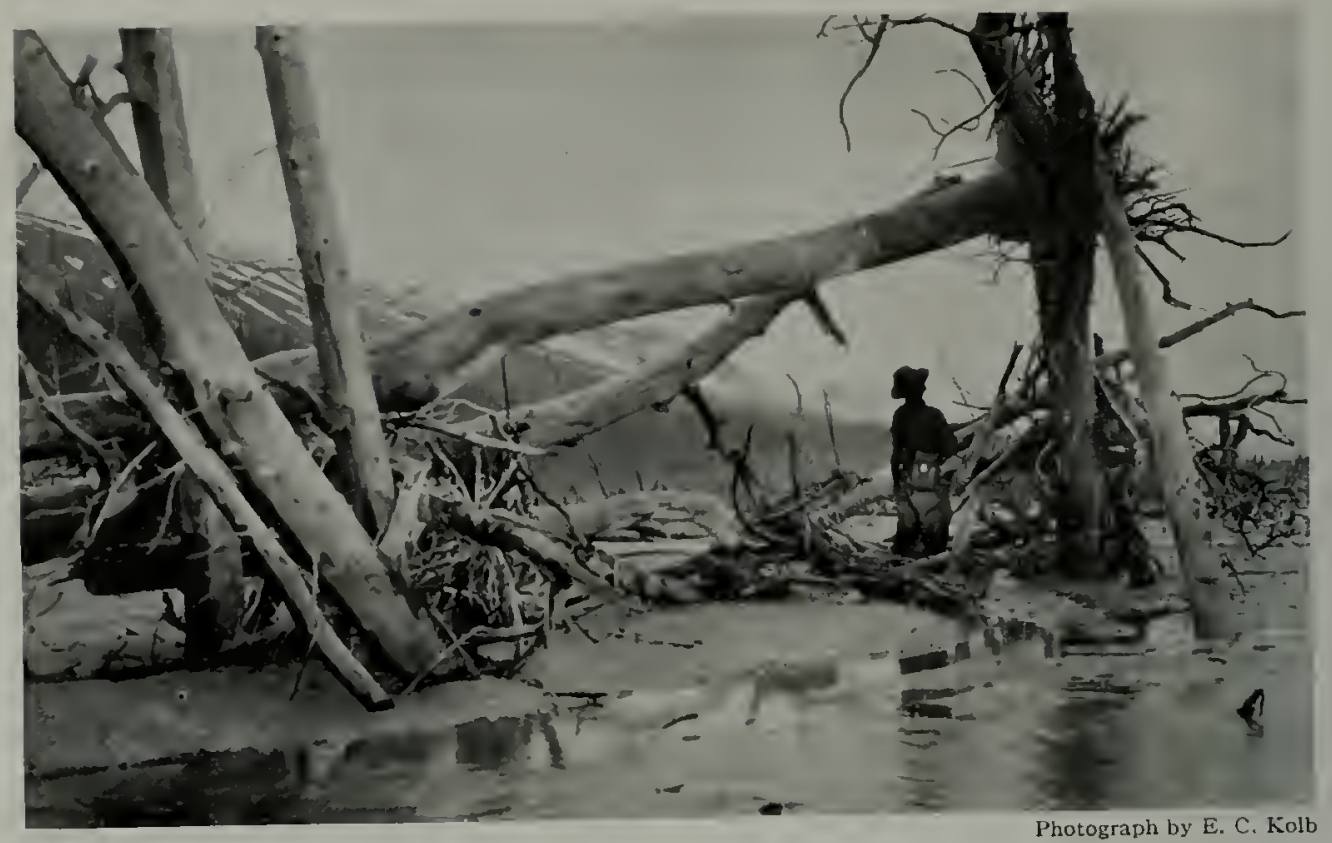

A TREE LODGED HIGH UP IN THE BRANCHES BY THE KATMAI FLOOD

Occurring far down near the mouth of the river this is significant evidence of the volume of water.

as to its exceptional character were strengthened, for all of the water had evidently come down from under Mount Katmai itself.

Evidences of damage rapidly increased upstream, particularly along the south bank of the river. Indeed, one of the most striking fcatures of the flood was the difference in its action on the opposite banks of the river.

All along the north side of the valley, which is the concave side of the great curve formed by the river's course, the wreckage had evidently been deposited only from slack water backed up over the flat. But along the convex south bank, signs of a strong current were in evidence far down toward the mouth of the river. Strange as it may seem, the high water marks along that bank were many feet higher than on the opposite bank. Near the south bank, for example, we found a large tree torn up by the roots that had floated down through the forest and almost out to sea before it finally lodged io feet above the ground in the forks of another tree. But on the north side, the wreckage consisted entirely of logs and sticks, such as could be carried by shallow water.

Upstream, the high water marks gave increasingly impressive testimony of the enormous volume of water. Just above the mouth of Martin Creek it had reached 25 feet on the slack water (north) bank.

FOREST UPROOTED AND HEELED OVER BEFORE THE WATERS

The different degrees of violence of the flood were well manifested by the varying effect on the forest in its path. In the outermost zone the trees were simply piled high with wreckage, as happens in any ordinary freshet.

In places where the water, though not approaching the violence of the center of the stream, yet surpassed the power of ordinary floods, the trees were laid over before the current almost flat to the ground. These trees (sce page 107) were not merely bent over before the waters as in an ordinary freshet; they were uprooted or broken and partially torn loose from the ground. 


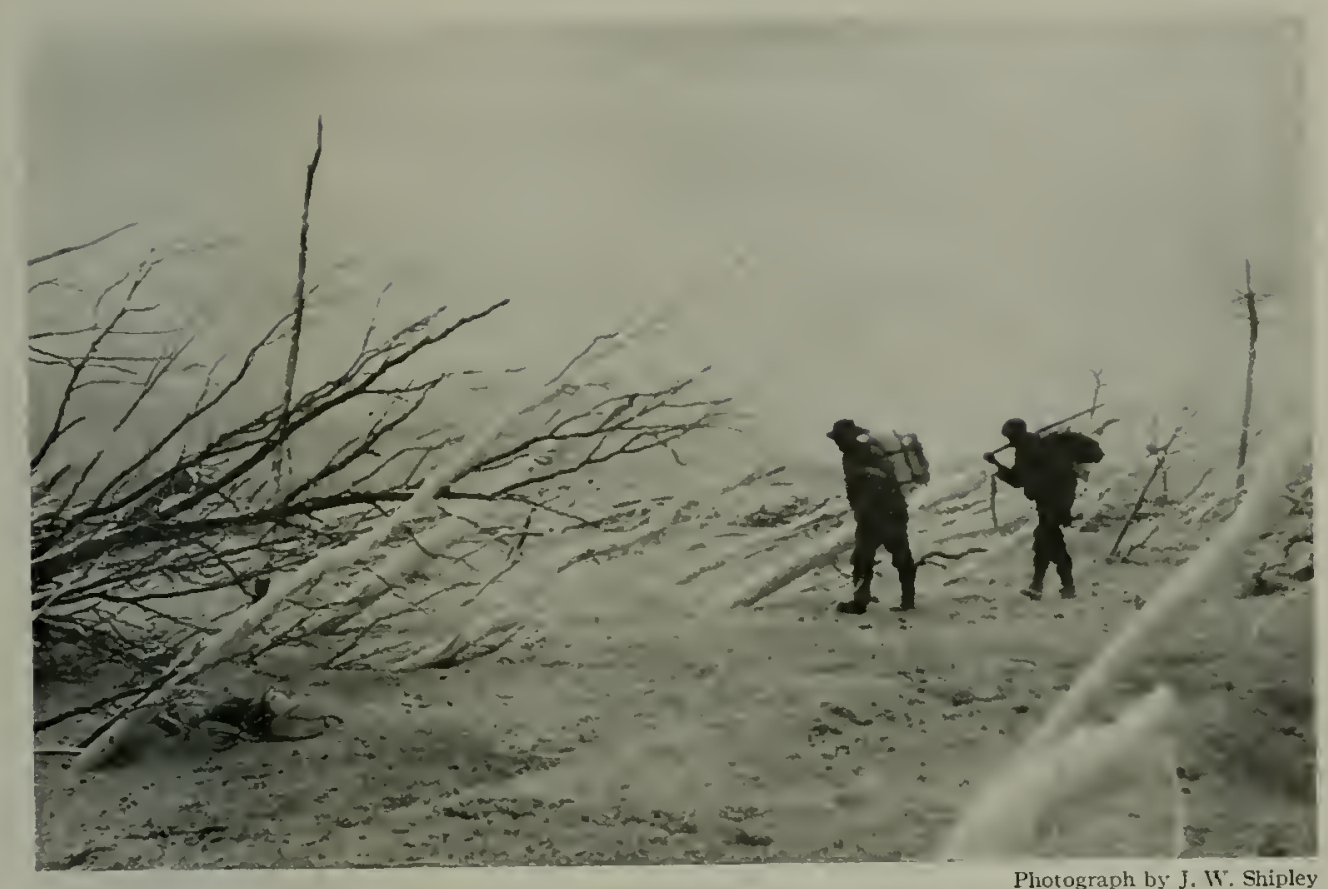

WORK OF THE FLOOD IN A MORE SHELTERED PORTION OF THE VALLEY

Where the flood waters were not so violent as to completely uproot or break down the forest, the trees were laid over before the current for miles at a stretch. The ash in which the trees are buried must all have been deposited by the flood itself for it would be impossible to tilt the trunks in this way while imbedded in the ground.

In the later stages of the flood, ash and sand were dumped deep around them, leaving only their stiff straight tops sticking out of the smooth plain at an acute angle, like the bayonets of an army that would deny passage to the invader.

The exposed tops of these trees bear impressive testimony to the abrasive action of the flood waters. They were deeply scarred by the fragments of pumice hurled against them by the raging current. Often the tips of the branches were thus ground into sharp points, dangerous to a man traveling upstream. The bleached whiteness of these sticks, so small as to be inconspicuous at best, rendered them almost invisible against the background of white ash.

$$
\begin{gathered}
\text { TREES SHEARED OFF FOR MILES AT A } \\
\text { STRETCH }
\end{gathered}
$$

But where the forest lay directly across the path of the flood, the violence of the waters was too great to admit of the trees being uprooted. Here for several miles the sudden violent impact of the water snapped them off at the level of the ground (see pages Ioo and 102). One would never suspect that these places had ever been forested, except where the stumps had been exposed by subsequent erosion.

Some of the trees apparently were sheared off by bowlders carried along by the waters. Others were bent and splintered indicating that they were twisted off by the direct power of the rushing water itself, without the assistance of rolling bowlders. Occasionally later erosion has uncovered and washed out the stumps of such trees, but for the most part they remain fast in the ground where they grew (see page iro).

There is another zone, where annihilation was still more complete the area where the trees were completely extir- 


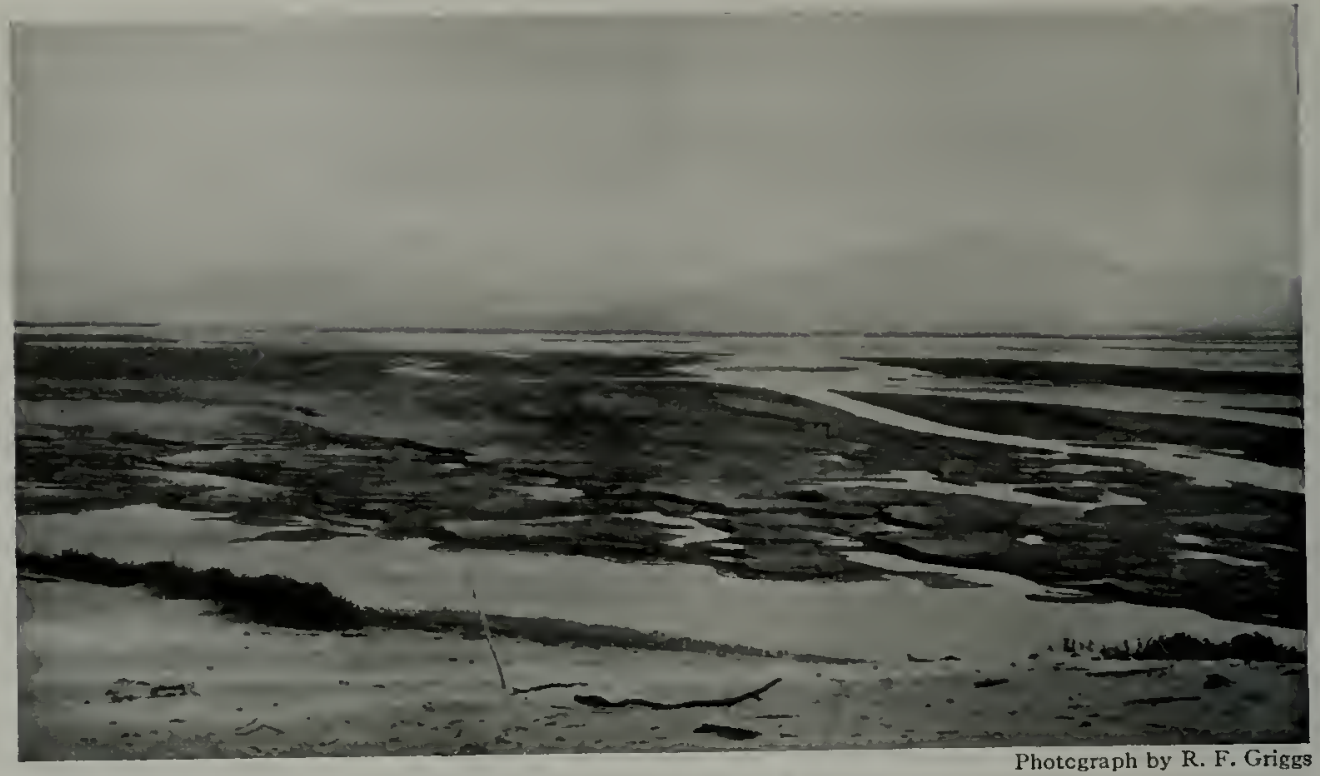

THE QUICKSANDS OF KATMAI RIVER

After our experience in Soluka Creek none of us was willing to try crossing the river, but it probably could be done.

pated, root and branch. But, since no one knows the country as it was before the eruption, it is impossible to guess how extensive this zone of complete destruction may have been. There is, however, good reason for the belief that trees once occupied considerable areas which now show no evidence of ever having supported vegetation.

\section{A 250,000-POUND BOWLDER PICKED UP BY THE FLOOD}

The head of the flat, where the river debouches from Katmai Canyon, is covered with a great train of bowlders, carried by the waters and spread for a distance of two or three miles down the broad valley. The general distribution of these bowlders is similar to that of the bowlder trains to be found along any mountain stream.

What is peculiar here is the great size of the rocks. Many are to feet in diameter, and a few considerably larger. The largest of all measures 56 feet ( 7 meters) in circunference. Although only 7 feet ( 2 meters) of this bowlder is visible above the present surface of the ground, it is probable that there is as much more below ground. The sand plain in which it lies is also a product of the flood, having probably been built up several feet above the original surface by deposits from the falling waters, as may be seen by the half-buried trees in the picture (see page IIO).

It is altogether likely, therefore, that the big bowlder rests on the ground in which the trees were rooted. It is, moreover, composed of compact heavy lava (specific gravity 2.5), and so nearly spherical as to present a minimum surface for the waters to take hold of. A little computation shows that its weight is between 200,000 and 300,000 pounds.

That such enormous rocks had actually been transported long distances by a current of water, however, was not easily to be credited. Only after we had gone over the situation carefully did we permit ourselves to accept such a conclusion.

At first sight, one would be inclined to assign a glacial origin to these bowlders, for to a glacier their size would offer no 


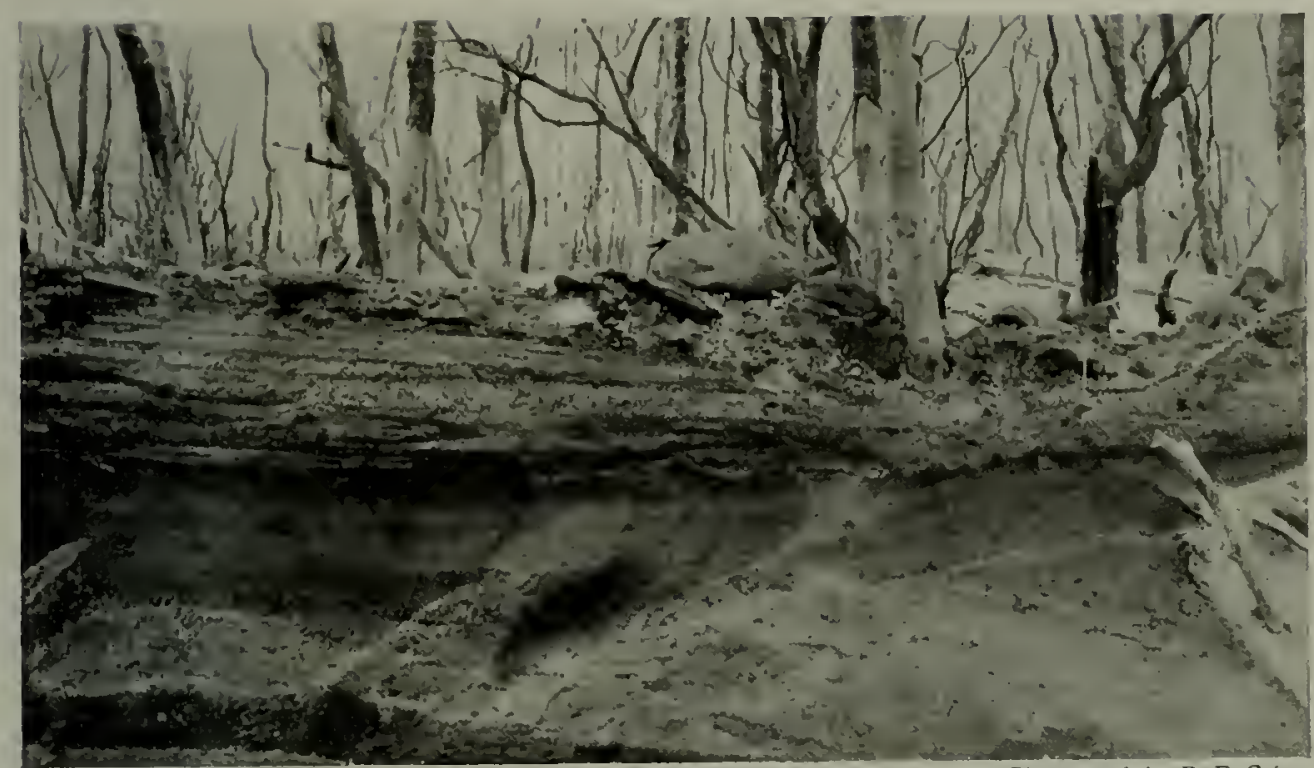

Photog raph by R. F. Griggs.

FREAK OF THE FLOOD

Bowlders washed up on top of a bed of ash which was later sectioned by a stream. Under ordinary conditions the soft sandy ash bank would have melted away at the first touch of the water, but in the rush of the flood it stood undisturbed by waters capable of carrying large stones. One rock so deposited measured 5 by 3 by 2 feet.

such obstacle as to running water. But their distribution does not conform to that of a glacial terrane; they occur exclusively over a fan-shaped area radiating from the mouth of the canyon, and are altogether absent from the sides of the valley, where they would inevitably have been strewn by a glacier.

Moreover, we later found places where a relatively insignificant flood from Mageik Creek had rolled large bowlders up against the trees in such a way as to leave positive proof of what had happened. The Great Flood was so much more violent that it had destroyed those evidences of its action which are left behind in an ordinary freshet.

\section{A TEMIPORARY NIAGARA OVER AN OBSTRUCTING RIDGE}

Farther upstream, where the valley is about half a mile wide, it is thwarted by a transverse ridge of rock stretching almost across it like a baffle. At ordinary stages the river winds from one side of the valley to the other, around the ridge.
But the marks left behind show that the swift rush of the flood abandoned the ordinary channel, for over most of the ridge, the ash and soil had been washed away, exposing the bedrock beneath and showing that the flood waters rose clear over the obstruction.

At each side were clear-cut high-water marks, where the ash layers had been left untoucher by the water. As it poured over this ridge, the flood formed a tremendous waterfall, a thousand feet wide and a hundred feet high (see pages II 2 and I 4 ).

Observing that these dimensions are inferior to Niagara, the reader may have concluded that my caption, "A Temporary Niagara," is not justified. If I may anticipate a little, however, I may state that when our survey was carried up the canyon we found that the "flood-fall," while it lasted, had greatly surpassed Niagara in the volume of its discharge.

At one side of the flood-fall a deep hole, which still retained a pool of clear water, had been excavated, offering us a most 


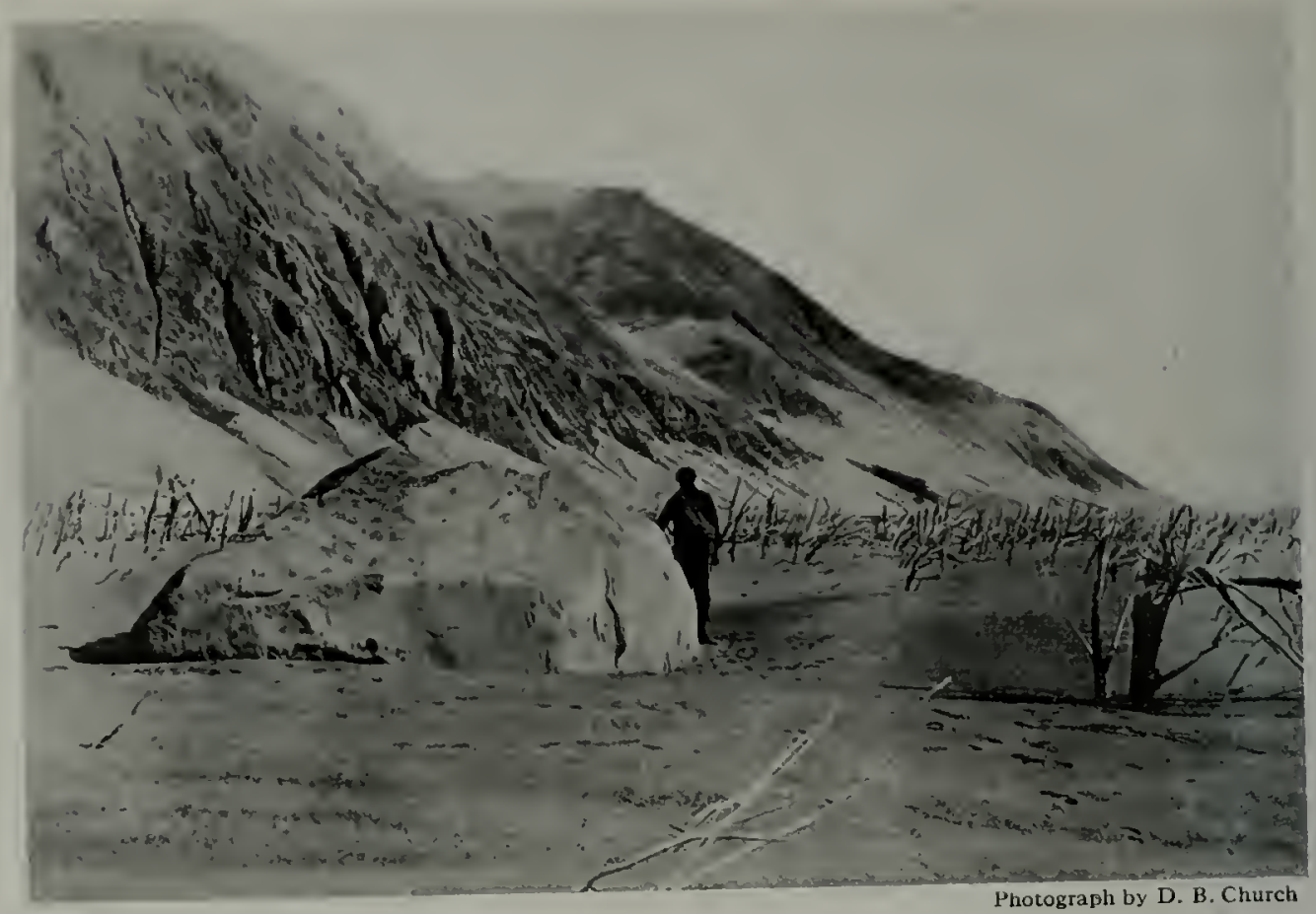

\section{A FLOOD-BORNE BOWLDER WEIGHING OVER A HUNDRED TONS}

This lava bowlder was carried a mile and a half out of the canyon on to the flat. In the background the broken forest sheared off at the level of the ground when the flood struck.

welcome opportunity for a plunge in a country where bathing facilities are few and far between. It was here that we came upon the first decisive indications of the nature of the flood.

It had evidently consisted of a single quick terrible wave, rather than any long-continued inundation. So sudden had been the rush of the waters and so quickly had they subsided, that in many places they had not removed all the soil from the rock on the ridge, but had left behind considerable masses of earth and hardpan, which must soon have crumbled away if the action of the water had been long continued.

\section{A RIVER IVHOSE BOTTOM IVAS HIGHER THAN ITS BANKS}

The crest of the rock ridge is not level, but shows an irregular profile. At the right is a low notch directly above the pool, which, by drawing an increased flow of water, was doubtless responsible for the excavation of a hole at that point (see page III).

Beyond this is a high place which stood up out of the water, as shown by its cap of ash undisturbed by the current. At the left the ridge gradually sinks to the level of the river bed. We were astonished to find that this, the lowest part of the ridge, marked (A) in the picture, also had a cap of undisturbed ash, showing that the water had never risen over it. All around it is a clear high-water mark, indicating absolutely the edge of the stream. This high-water mark is no less than 40 feet lower than the hill to the right, from which the water washed all the soil (see page II2).

That is to say, the water rushed over a high hill in the middle of the ridge but did not overflow the lower ground at the side. In other words, the bottom of the stream was 40 feet higher than its bank! 


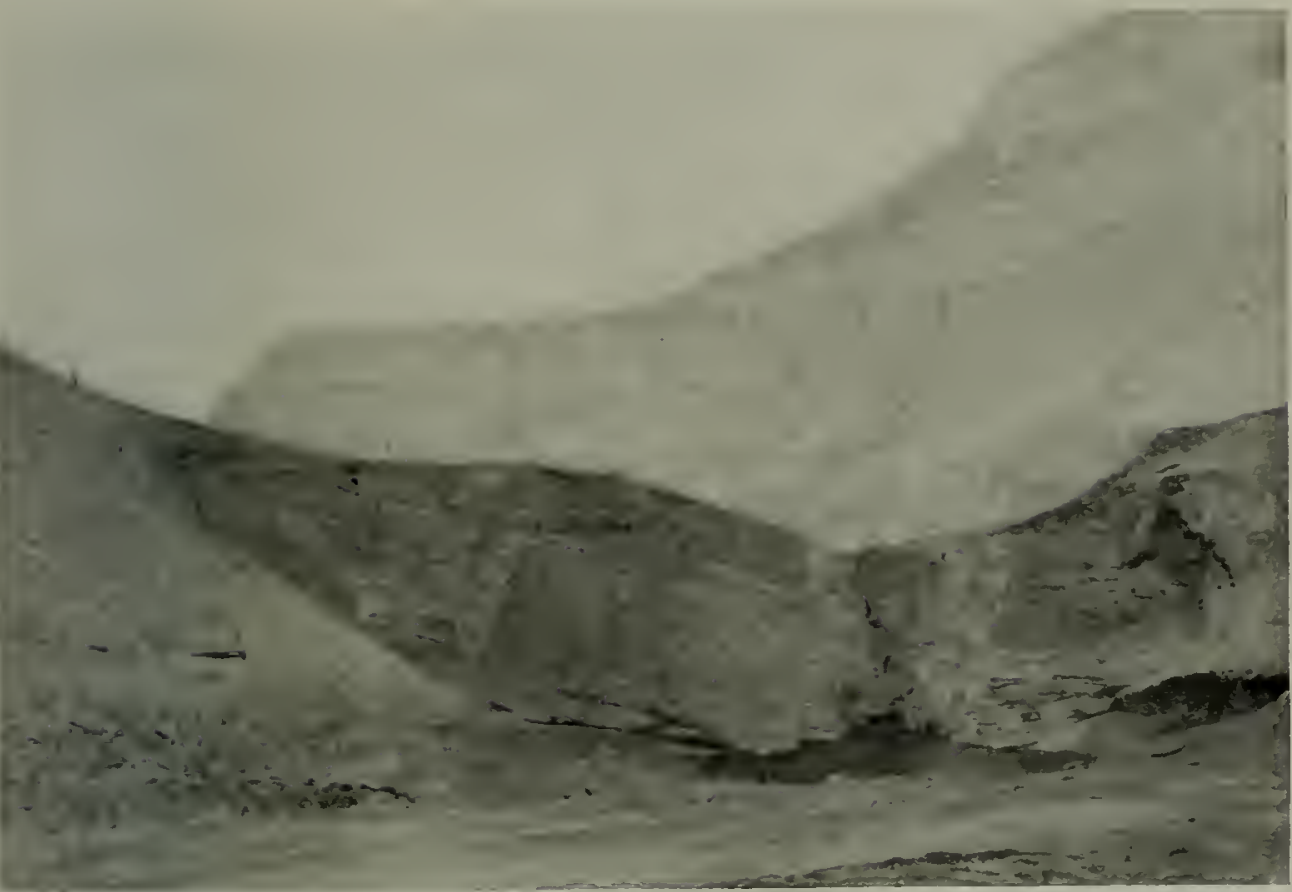

Photograph by D. B. Church

A NEARER VIEW OF THE RIGHT HALF OF THE FLOOD FALI, SHOWING THE POOL EXCAYATED BY THE FALIIYG WATER

A man is posted at the high water mark to the left.

The bottom of the stream, as shown in the photograph, stands at an angle is degrees above the horizontal, as seen from the shore. To this must be added a further elevation to allow for the depth of the water over the rock, which must have been considerable, amounting by the least calculation to sereral degrees. I have sketched in by dotted lines on the photograph the approximate "level" held by the surface of the water. The figures are the elevations of the several parts of the flood-fall in feet above sealevel, as determined by triangulation by our topographer, C. F. Maynard.

If one had been so fortunate as to be standing on the end of the ridge, at the point marked $A$ in the photograph (page I I4), he would have seen literally a mountain of water rising far above him, yet never "seeking its level" nor overflowing the lower ground on which he stood, and could have remained in safety till it was past! But if on hearing the warning roar of the flood water up the canyon, and realizing the danger, he had attempted to escape by climbing up the ridge on to the higher ground, he would have been swept to destruction!

Incredible as this may seem, even in the face of photographic evidence, yet it is to be explained by perfectly wellknown principles of hydraulics, whose operation on a small scale is familiar to everyone.

Whenever the stopper is pulled out of a wash bowl, the water swirling around the vortex is driven altogether out of the center of the whirlpool. The centrifugal force becomes greater than the weight of the water, which is displaced accordingly.

It is seldom that this familiar behavior of water may be observed on a large scale, because neither high velocities nor sharp turns are met with in ordinary streams. But the flood rushed down the canyon at such speed that it could not 


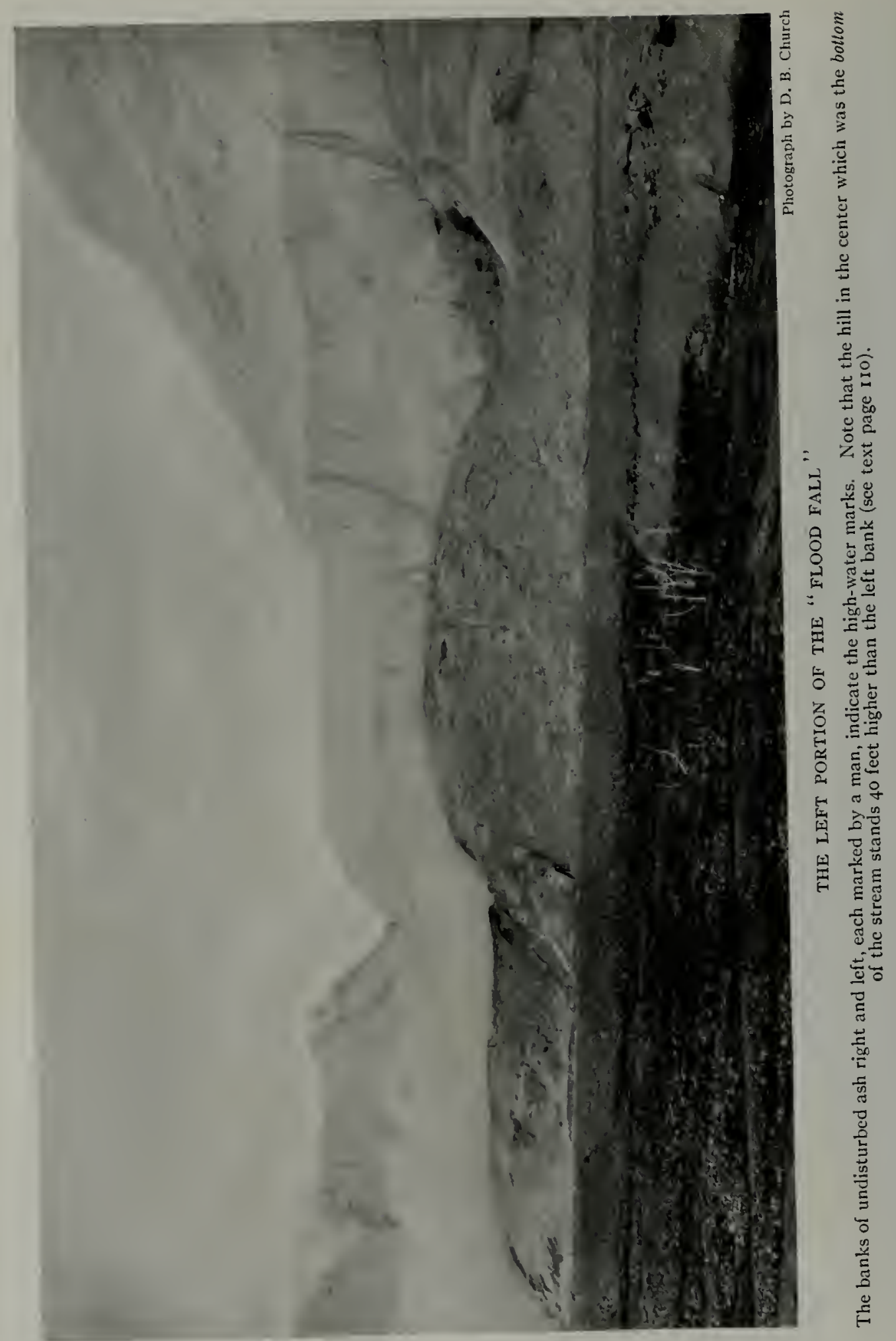


make the turn around the ridge, and so ran over it, swelling up especially on the outer side of the curve.

This is, however, only part of the story, for it was observed that the highwater mark was 15 feet higher against the rock in midstream than against the outside bank (see page II4). The stream must, therefore, have bowed up in the middle. This also is a very wellknown phenomenon to students of hydraulics, but is less familiar to most of us because of our limited experience with swiftly running streams.

The fact is, however, that any very swift stream in a clear channel bulges up in the middle. The reason is that friction retards the flow so much at the edges that the water piles up in the middle, where the path is open. One rarely has the opportunity of observing such behavior in a great river, even in flood, but in the rapid Alaskan streams it is by no means uncommon on a smaller scale.

In the swift channels of Katmai River, which gaveus so much trouble in fording, the water frequently stood a foot higher in the middle than at the edges, so that we often saw the profile of the current of rushing water against the skyline before the restraining banks came into view.

In a stream with such tremendous velocity as the Katmai Flood, this bulging up in the middle would, of course, be much greater than in the channels of a small river. The evidence that it occurred should not, therefore, excite particular surprise.

\section{A FREAK OF THE FLOOD}

Below the fall, and especially around the edge of the pool, the water had washed up a considerable quantity of coarse shingle. This was like the gravel brought down by any freshet, except that the stones were larger.

The remarkable thing about it was its position. It had been laid up on top of ash that still lay undisturbed as it fell. Since the ash here has the character of coarse, light, loose sand, it melts away at the first touch of a current of water under any ordinary conditions.

That a flood capable of carrying goodsized stones should have left untouched a sand bank seems impossible. But here, laid neatly up on top of such a sand bank, was not only a pile of gravel, but also stones of large size. Lava cobbles, a foot in diameter, were numerous and there was one block of sandstone measuring $5 \times 3 \times 2$ feet.

The largest of these bowlders were not so situated that their relations could be shown by a photograph, but in another place far downstream we found a bed of cobbles similarly deposited on top of the stratified ash in a position that could be shown clearly in a picture (see page 109).

Folsom and I, who were alone at the time of our first visit to the place, found ourselves in complete disagreement as to the origin of this shingle. From the crest of the fall, where the origin of the bowlders was clear, I had concluded that the stones must be flood-borne. Folsom had remained below, on one of the largest bowlders, where the difficulties of such an interpretation were more manifest. When I told him that the stone on which he sat had been left on the sand bank by the flood, he burst into violent opposition. "Nothing of the sort could be possible."

"Yes," I told him, "I know perfectly well that it looks impossible; but, nevertheless, there is unquestionable proof that it actually occurred."

He could not believe it; so I asked him to explain how else the bowlders could have reached their present position, and we began to go over the ground step by step. The only possible alternative was that the stones had rolled down from the mountain side.

But a little examination showed this hypothesis untenable. They were far from the base of the cliff. They were located in one definite hollow, surrounded by a clear high-water mark, and separated from the talus of the cliff by a long interval of bare ash. Many of the cobbles 


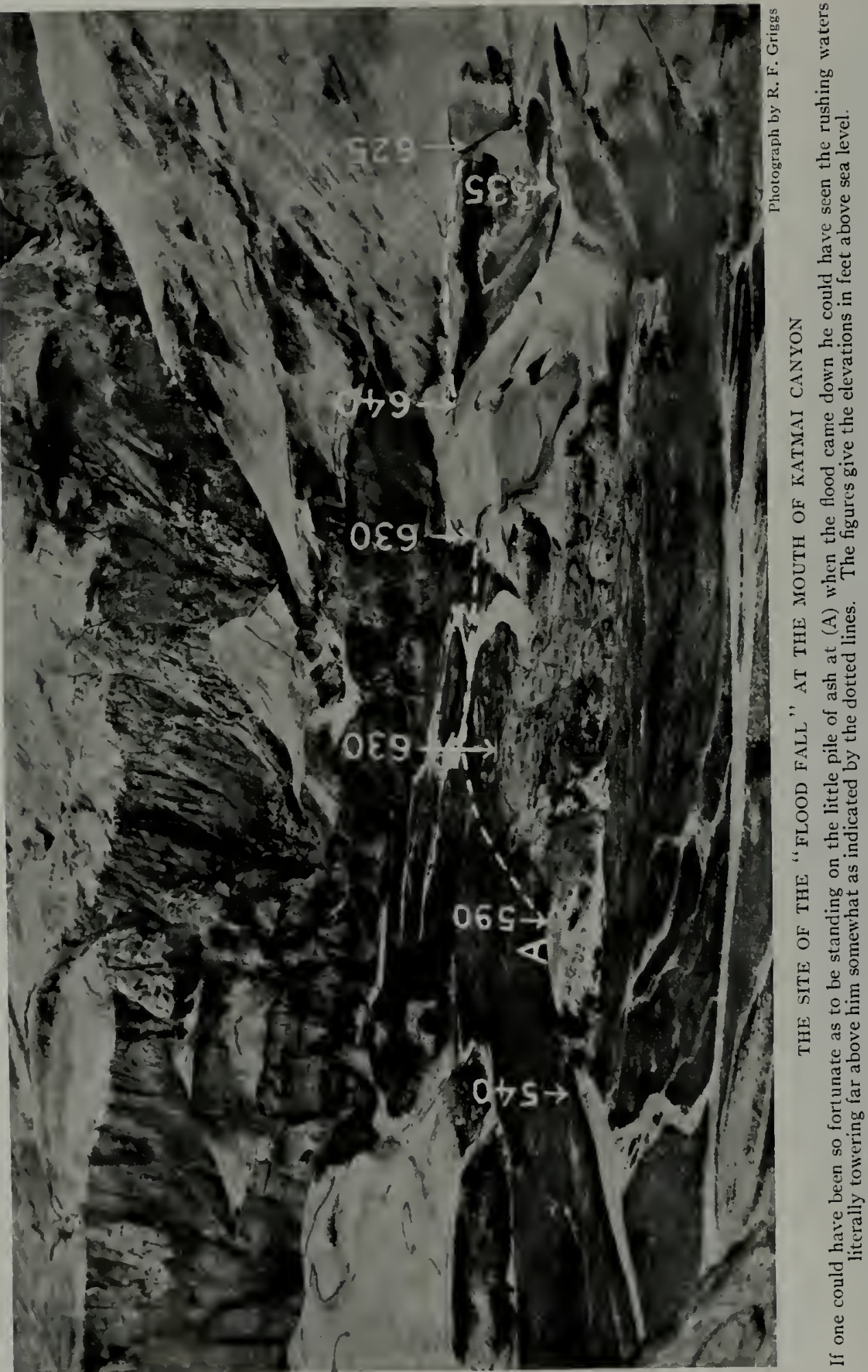


were of dark lava, whereas the cliff was composed of light-colored rock. Most of the cobbles were clearly water-worn, and bore a very different appearance from the angular blocks of the talus.

If the bowlders had lain on an ordinary bed of sand, we might have supposed that the sand had been deposited by the receding waters afterward, but here they lay on top of the undisturbed ash, still regularly stratified as it had fallen during the eruption three years before the flood.

It was, therefore, impossible to interpret the bowlders otherwise than as flood débris; and in the end, though neither Folsom nor I could comprehend how the thing had been accomplished, we came into complete agreement as to what had happened.

As we came gradually to a fuller comprehension of the magnitude and power of the flood, we were more and more thankful for the good luck that had delayed our landing. If we had landed a week earlier, we would almost inevitably have been overwhelmed, for our work kept us on the flats and there would have been no time to escape. Even if by a lucky chance we had been on the hills out of reach of the waters, our stores would have been washed away and the expedition would have been so crippled that we should probably never have been able to go on with the exploration, which was finally to lead us into the Valley of Ten Thousand Smokes.

\section{FLOOD CAUSED BY THE ESCAPE OF WATER IMPOUNDED BY A LANDSLIDE}

While we studied the ravages of the flood, our minds were busy with speculations as to its cause, and as we traveled up the valley and saw increasing evidence of the localization of its source, one after another of our hypotheses had to be discarded.

When the evidence began not only to point to a very local source, but to indicate that it had lasted but a very short time, there seemed to remain only one possible explanation. Apparently a lake somewhere up the canyon, dammed in perhaps by material from the eruption, had burst its banks and deluged the valley. This was, however, merely a speculative hypothesis, and so remained for two years.

It was not until I9I 7 that we were able to penctrate the canyon and examine the Second Valley and the Katmai Lakes, which, meanwhile, we had discovered from the mountain top.

When we finally made our way up through the canyon, we found, high up on the slopes of Katmai, a thousand-foot cliff of bright, new, unweathered red rock, where the mountain side was gouged out by a great slide. This, falling into the canyon, had formed an immense dam, which, after holding for three years, had yielded just before we landed, causing the tremendous flood.

The material that broke loose was a great mass of ancient lava, which, having originated in the crater above, was flowing down the slopes of the volcano when it solidified. It thus probably occupied an unstable position which may have been rendered still more unstable by undercutting from the river, so that it was easily shaken down by the earthquakes preliminary to the eruption.

That it broke loose just before the eruption was indicated by the fact that its surface was everywhere covered by the layers of ash as they fell after the great explosions. In this case, there was apparently only one major slide, for there were no indications of the continuous activity so prominent in Falling Mountain and Noisy Mountain.

Although all the material came from what looks from below like a relatively small area of the cliff, it piled up in the valley to a depth of over 400 feet, and spread up and down the canyon for about a mile, making a flat, low dam capable of resisting much more pressure from the water than a less massive barrier.

THE SLIDE OCCURRED AT A NATURAL DAM SITE, IMPOUNDING A LAKE OF $95^{\circ}$ ACRES

By a curious coincidence this landslide occurred at precisely that point which an 


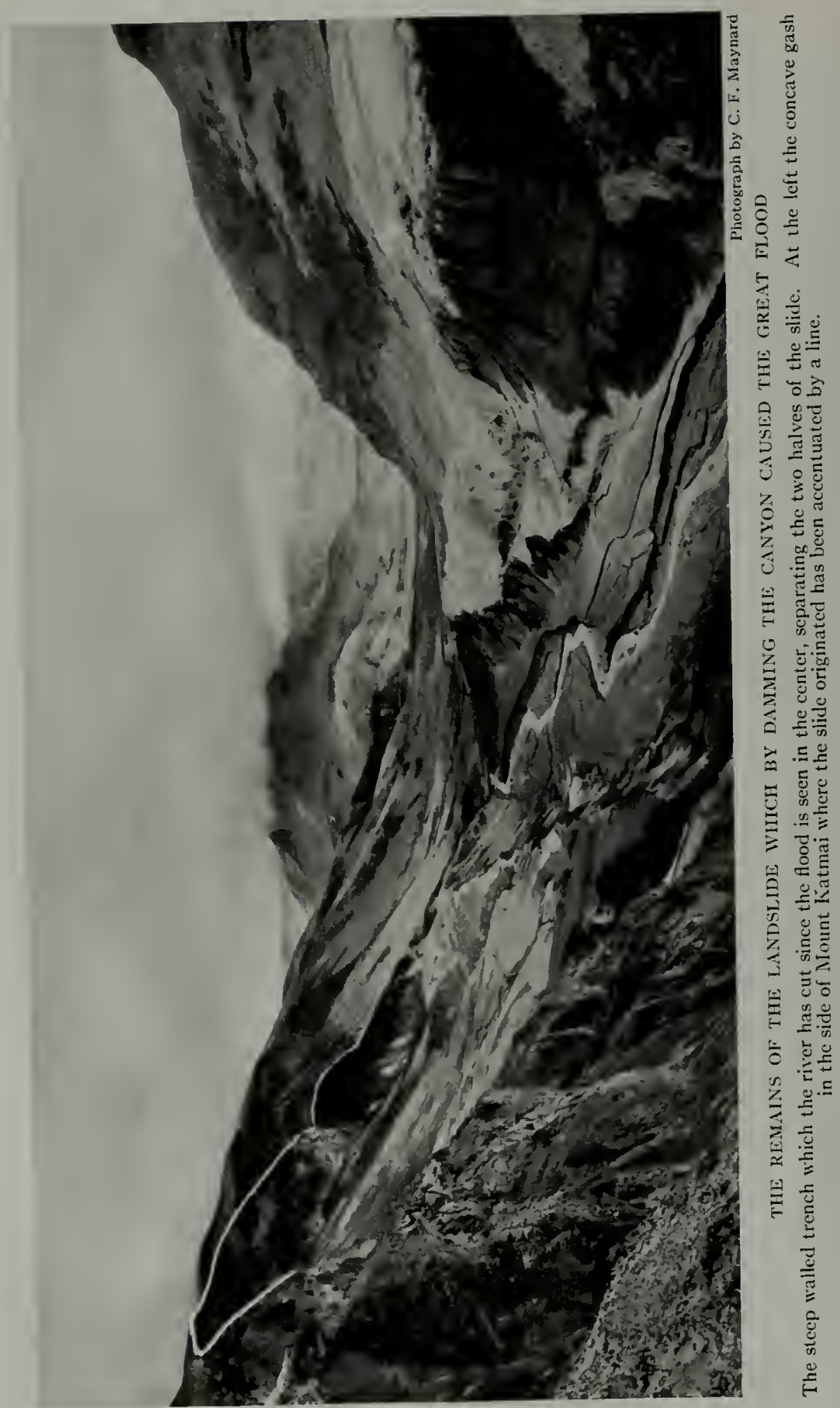


engineer would have selected for a dam site, if he had desired to construct a reservoir of maximum capacity with a dam of minimum size.

The configuration of the valley is most peculiar, for just above the slide the narrow canyon gives way to a second broad flat valley in which a very large quantity of water could be held by a relatively small dam in the canyon. This very remarkable combination of circumstances greatly augmented the magnitude of the flood.

If the valley had been a normal drainage system, gradually narrowing to the head-waters, the volume of water impounded would have been small and capable of doing relatively little damage when the dam went out. Indeed, $\mathrm{Ma}$ geik Creek furnished an example of just this condition, for a slide also dammed up its canyon. But, in this case the lake, although probably 500 feet deep, was so small that almost all of its energy was consumed in destroying the dam, and as a consequence the flood of Mageik Creek was comparatively gentle.

In the broad expansion of Katmai Valley above the dam there is abundant evidence of the former presence of the flood lake which it impounded. Across the base of the mountain is clearly drawn the line marking the beach left by the waves of the former lake. This shore line is 2 ro feet above the level of the present Katmai Lake. Our survey showed that at this level the lake covered no less than 950 acres. Its maximum depth was about 400 feet, and the quantity of water impounded more than 8,000 millions of cubic feet (see page 120 ).

THE PROBABLE CONDITION OF THE DAM

Conditions in the Second Katmai Valley, where the upper lake is retained behind the slide from Noisy Mountain (see page 127), presumably give a fair idea of the character of the dam that held back the flood. The slide débris was probably loose and porous, allowing a great amount of water to seep through and appear below as large springs.
The probability is that the dam held for some time after the reservoir was full, for the break coincided with a period of unusually hot weather, when the heavy snow-melt had raised the waters of the lake to an abnormal level, giving them an increased head which enabled them to cut into their bed and remove the slide.

No evidence remains to indicate exactly how the dam broke, but when the waters had done their work the central portion had been cut away. In its place remained a trench as straight and cleancut as though excavated by man to carry some great engineering work, like the Panama Canal (see page $\mathrm{rr} 6$ ).

Indeed, I can find nothing with which to compare it except the Culebra Cut. It is, to be sure, only about half as large, involving the excavation of some 33 million cubic yards of material, as compared with the 53 millions called for by the original estimate at Culebra.

\section{KATMAI CANYON FILLED WITH COBBLES MANY FEET DEEP}

The power of the waters was not sufficient to cut down through the dam to the original level of the canyon floor. Not only did the "head" of the rushing flood decrease as the water was drawn off from the reservoir, but an immense amount of débris from the dam itself accumulated in the canyon below, so that before the lake had been emptied a barrier was formed sufficiently strong to retain the remainder of the water, which forms the present lower Katmai Lake.

The present flat gravel floor of the canyon was formed from the remains of the dam. Probably nothing at all similar existed before the catastrophe.

A knowledge of conditions here before the flood would be of great service, not only because of our direct interest in the effect of the flood itself, but because the canyon is the key to the unraveling of much of the geological history of the volcano and surrounding country. But, as there seems to be little hope of finding a record of antecedent conditions, we are 


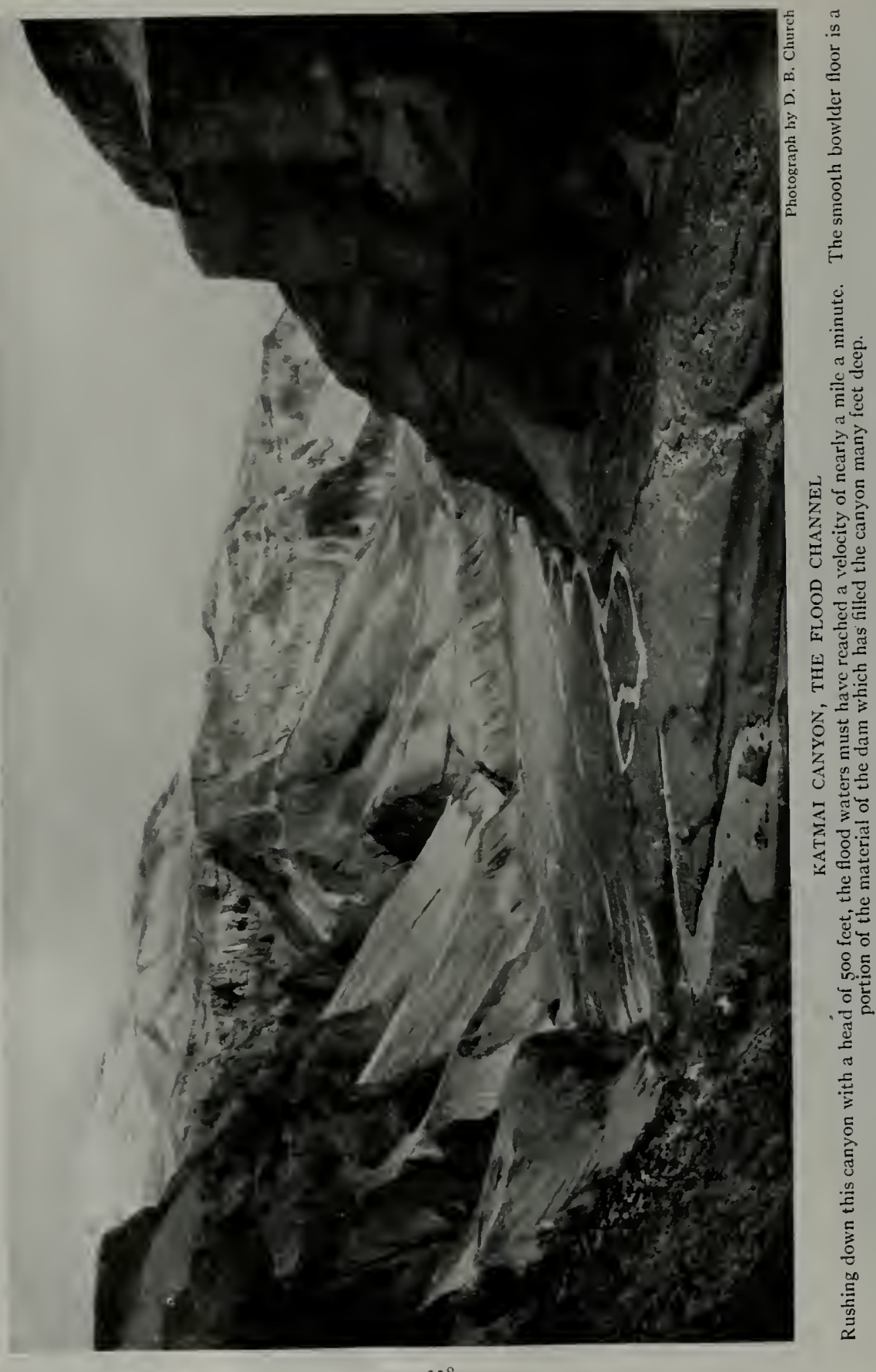


reduced in this, as in so many other matters, to speculation.

The Katmai Flood was of an order of magnitude so far beyond the floods familiar to residents of the Mississippi Valley, for example, that there is need of comparing it with other catastrophes of the same sort, to gain some perspective by which its rank may be judged.

THIRTY-FIVE TIMES AS GREAT AS THE JOHNSTOWN FLOOD

For everyone who, like the writer, grew up in the northeastern United States, the Johnstown Flood will always remain the standard of comparison by which all similar events are to be measured. This is generally considered to have been the greatest flood disaster of history.

A reservoir impounding 640 million cubic feet of water, forming a lake 400 acres in extent, was held by a dam about 400 feet above the city of Johnstown, which was 12 miles distant in a narrow but winding valley. On May 31, I889 the dam broke. Everything within the path of the waters was dashed to destruction. The exact number of victims could never be ascertained, for few of the bodies were recovered; but it is certain that between 10,000 and 15,000 people lost their lives.

Every tree within reach of the water was destroyed root and branch. Dimension stones of bridge abutments were not only carried away, but so ground up that they could no longer be distinguished from the cobbles of the stream. Credible witnesses reported that of the bricks from the destroyed buildings not one-twentieth part could be found after the flood, the rest having been ground to powder in the waters. The locomotives in a roundhouse struck by the waters were scattered far and wide. Some were found at variable distances up to I,500 feet away, but several were carried off bodily and were never found. One man, standing in a three story window, saw one of these "come dancing along the top of the flood 30 feet from the ground."
Such accounts give but a faint idea of what the Katmai Flood would have done in a populous valley. For the Katmai Flood was much greater than that of Johnstown. The volume of the water was twelve and one-half times as great, and its fall nearly three times as much, giving the waters a total energy (which is the measure of the magnitude of the flood), thirty-five times as great!

\section{THE GREAT GOHNA FLOOD}

Although the Johnstown Flood was the most disastrous in the annals of engineering, both it and the Katmai Flood were surpassed in magnitude by the Gohna Flood of 1895 in India. Like the Katmai Flood, this was caused by a gigantic landslide, which formed a dam 900 feet high, impounding more than 16,000 million cubic feet of water.

When the dam broke 10,000 million cubic feet of this water was discharged in the space of four hours, producing a flood 260 feet high. Thirteen miles downstream the flood was 160 feet high (as compared with 30 feet at Johnstown 12 miles below the dam); 50 miles below it rose II 3 feet; 72 miles downstream it attained 42 feet; at Hardwar, 150 miles away, its height was still I I feet.

In the upper part of its course the Gohna Flood filled the valley with gravel to a depth of no less than 234 feet, while I 3 miles below, the river bed was raised 5o feet. As at Katmai, the basin was not completely drained, a permanent lake, two miles long, one mile wide, and 300 feet deep, being left.

But, although the Gohna Flood was much greater than the Johnstown, and, like it, occurred in a populous valley, it stands in great contrast in that not a single life was lost, except that of a Hindu fakir who persisted in returning to the danger zone after being forcibly removed twice.

Profiting, perhaps, by the fresh memories of the Johnstown disaster, the British engineers began the task of dealing with the anticipated flood almost as soon as the landslide occurred. 


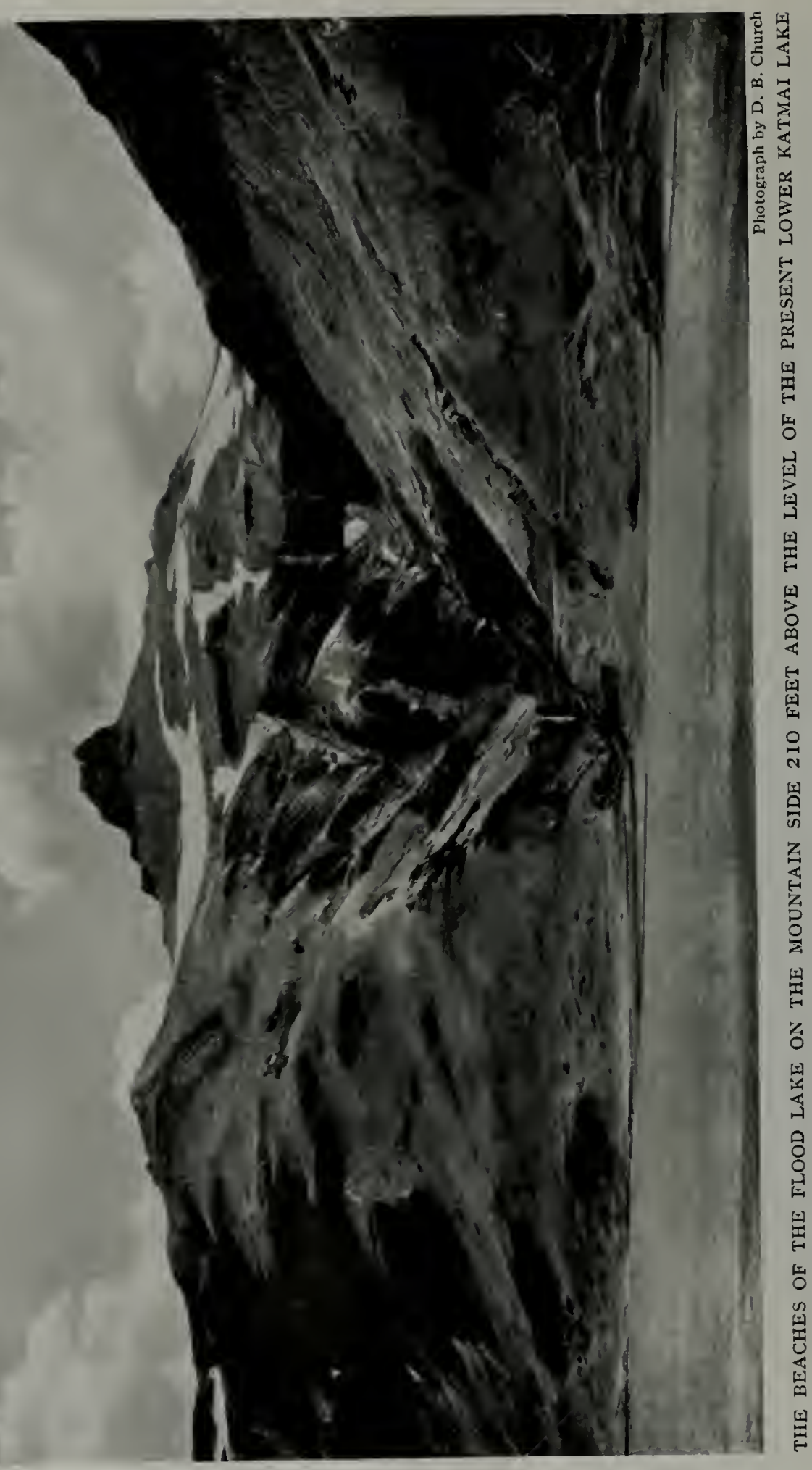


By means of a careful survey they were enabled two years before to predict to within ten days the time when the flood would occur. They constructed a telcgraph line down the valley to spread the warning and erected a series of monuments, above which the people could rest in the assurance of safety. By these means they converted an otherwise inevitable disaster into a triumph for civilization and engineering.

AN ESTIMATE OF THE VIOLENCE OF THE KATMIAI FLOOD

IVithout going further, these comparisons will enable us to fix with sufficient accuracy the rank of the Katmai Flood. While not the greatest of recorded floods, it must evidently stand well up in the front rank among such catastrophes.

In one respect, indeed, it should be given first place; that is, in the violence of its waters as they issued from Katmai Canyon. Conditions here are almost unique, for the narrow, clean-cut, nearly straight rock canyon offered a minimum of resistance (see page I 8 ). The volume of the water, as compared with the quantity of material that had to be moved in opening the passage through the dam, was also very large, so that little of its energy was expended in clearing a path.

The velocity of the waters as they issued from the canyon must, therefore, have been terrific. I have tried in some way to get a numerical valuation of this velocity, but find it difficult because engineers have never had experience with such enormous torrents. After the Johnstown Flood, the editor of the "Engineering News" estimated on theoretical grounds that half of the energy of the rushing waters was consumed in friction, leaving the remaining energy free to accelerate the speed of the water. This estimate he found in close agreement with the actual rate of flow as recorded by observers on the ground.

If half the energy of the water was consumed by friction at Johnstown, probably a smaller amount was so expended at Katmai because of the smoother, straighter, deeper channel and the much greater volume of water. It will, therefore, give us a conservative value of the velocity of the flood if we assune that friction consumed as much energy here as at Johnstown. On this basis the waters as they issued from the canyon must have been running about Ioo feet per second, or nearly 70 miles per hour.

In these days of automobiles and airplanes, 60 or 70 miles an hour may not appear a very high velocity. As a matter of fact, however, a river flowing 60 miles an hour is as extraordinary as would be an automobile running at three times that rate, for flood waters never attain such velocities as have become familiar to us in other objects. The tremendous power manifest in a great river in flood is such an impressive thing that almost irresistibly one overestimates the speed of the current.

\section{DESTRUCTIVE POWER A MILLION TIMES} THAT OF A MISSISSIPPI FLOOD

Although floods are often described as running at "express train speed," an examination of the records shows that even the destructive floods to which the Mississippi and its tributaries are subject rarely attain current velocities exceeding seven miles per hour (ro feet per second).

The difference in energy between a stream running roo feet a second and one running Io feet a second is so great as to be utterly inconceivable. For the power of water to carry off obstructions in its bed-its destructive capacityvaries as the sixth power of its velocity. That is to say, if the velocity be doubled, the transporting power is increased sixtyfour times. If, therefore, the Katmai Flood ran ten times as fast as a Mississippi River flood, its destructive power was increased a million times! 


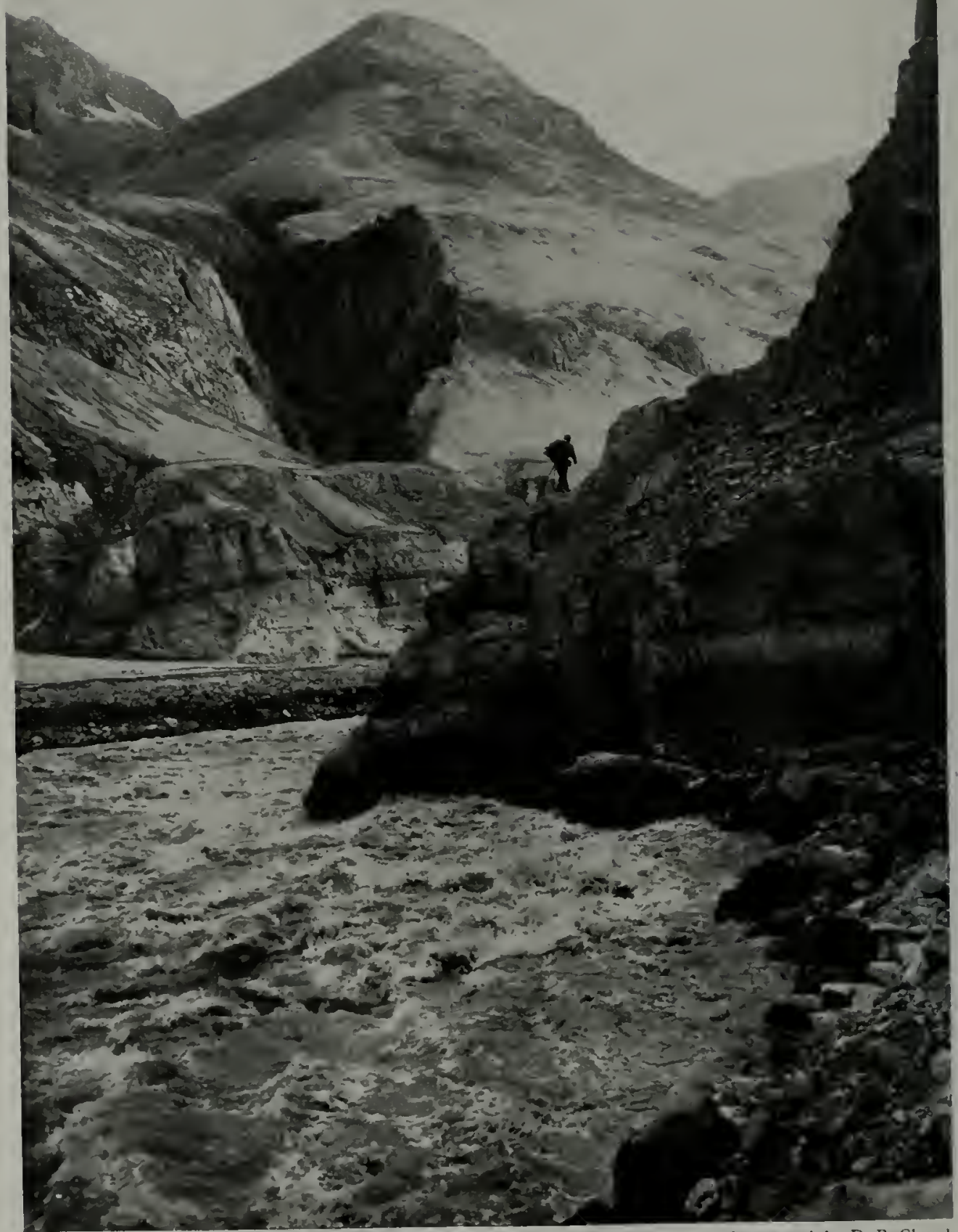

Photograph by D. B. Church

CLIMBING OUT OF KATMAI CANTON

The wall opposite is as high as parts of the Grand Canyon, as beautifully colored, and as precipitous. 


\section{THE CANYON AND SECOND VALLEY OF THE KATMAI}

During the exploration of the country we found ourselves many times in the position of the man who on first seeing Pike's Peak, from Colorado Springs, started out to walk over before breakfast.

We underestimated the size of almost every feature we encountered, and subsequently had to enlarge our ideas as familiarity gave opportunity for better judgments or the survey supplied accurate measurements.

In no case was this more conspicuously true than in our estimate of Katmai Canyon. We paid little attention to it in the beginning, but when we came into a position where we could observe it to advantage we realized that it was one of the most stupendous features of the whole district.

Our first approach to the canyon was by the natural path up the banks of the stream. We were soon stopped, however, by the meandering river, which turned against first one cliff and then the other. We tried climbing along the precipitous walls, but after some very slow and difficult work gave it up and sought another route. This we found by way of the Katmai mudflow, which made an easy path around the obstructions.

BEAUTIFLL WATERFALLS NEAR THE FOOT OF THE CANYOY

Near the head of the mudflow are four beautiful waterfalls which my wife, when she camped there in 1919, named for our four children. Halfway up the mudflow a clear brook comes cascading over the rocks, a laughing, babbling "baby" falls appropriately named, for the youngest child, Rosamond's Falls.

A little farther on a good-sized stream comes down from Katmai, leaping the cliff at a single bound- 255 feet, we found it, by triangulation. Originating in the glaciers above, the water is alway's full of silt. Such a muddy fall is quite appropriately named for a harum-scarum small boy, Darid's Falls. Rising at one side of the notch cut in the mountain side by David's Falls is an impressive domed cliff of black lava, I,610 feet high, recalling in its form El Capitan in the Yosemite.

Across, on the south wall of the canyon, is a third, a beautiful misty, maidenly wisp of a fall, where a small stream coming out from a hanging glacier above tumbles over the cliff in a series of cascades 750 feet high. This is Ruth's Falls (see page 130).

$\mathrm{L}_{\mathrm{p}}$ in the middle of the canyon another strong stream comes tumbling orer the edges of the lava flows, dropping altogether nearly 2,000 feet in a series of cascades. Two of these are graceful falls upwards of a hundred feet high. AIthough too far away to show up to advantage in the pictures, they may be made out on page I26. These she called Julian's Falls.

\section{KATMAI CANYON ALMOST AS DEEP AS THE GRAND CAYYOY}

Few views in any country can be compared with that from the head of the mudflow across the canyon. The wall opposite is higher than any single cliff in the Grand Canyon, for Katmai Canyon though only a few miles long is almost as deep $(4,000$ feet $)$ as the Canyon of the Colorado. Its colors-delicate greens, lit up br- pale vellows, blues and soft pinks - though totally unlike the brilliant reds and yellows of the Arizona Canyon, are perhaps quite as beautiful.

At the farther side of a tract of irregular, rounded hills which lie between the head of the mudflow and the river is a sharp knob that stands right in the jaws of the canyon. This hill has been bisected by the river. When one has 


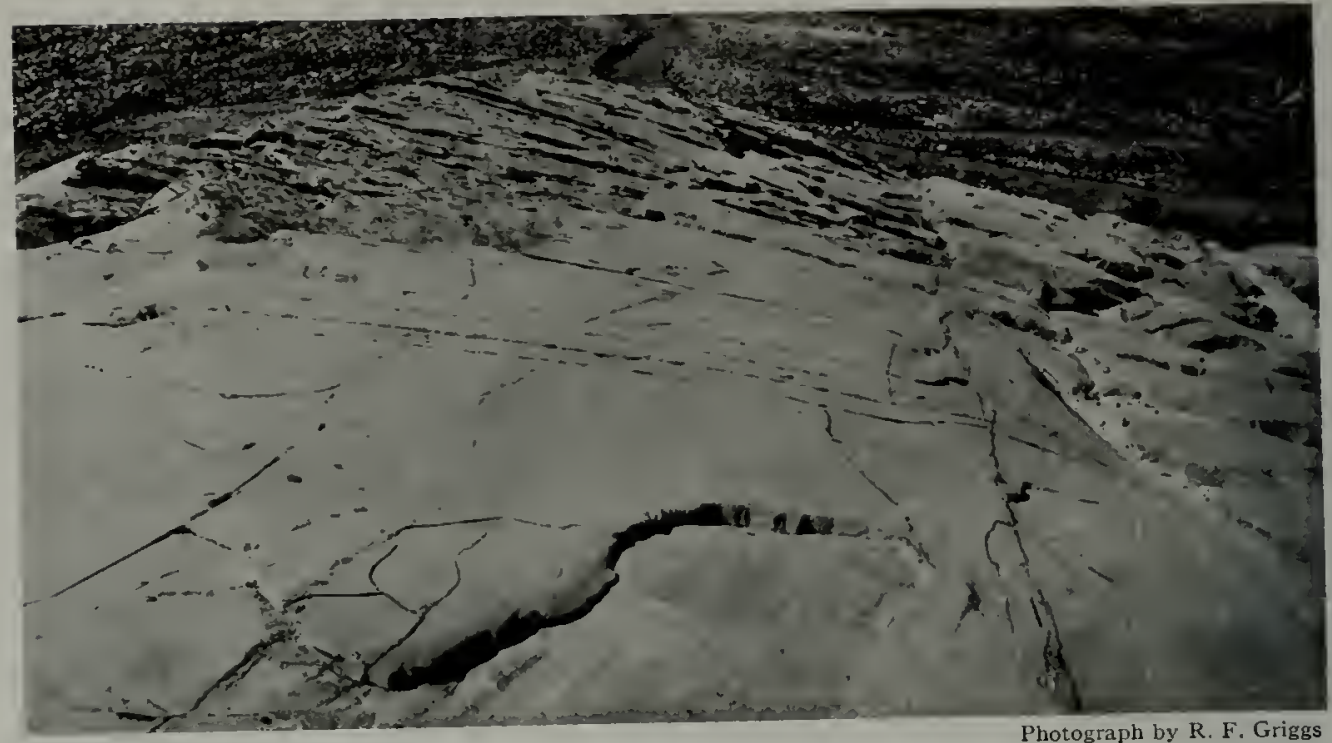

\section{GLACIATED ROCKS AT THE MOUTH OF KATMAI CANYON}

These and the similarly planed-off rocks in the bottom of the canyon, shown in section on the opposite page, are clear evidence that Katmai Canyon is pre-glacial.

climbed up its nearer slopes and reached the top he finds himself on the brink of a perpendicular cliff, 500 feet directly above the roaring river that is undermining its foot. From this hill-Prospect Point, we named it-the finest views of all are to be obtained (see page 126).

\section{FATMAI CANYON CUT BEFORE THE GLACIAL PERIOD}

The opposite walls of the canyon show very diverse rock structures. On the south the wall is made of stratified rocks dominantly gray-green in color. But on the north the river is hemmed in by massive lava flows varying from mahogany color to dead black.

From Prospect Point the flat floor of the canyon may be reached by a rather difficult descent, almost straight down to the swirling waters of the river.

Katmai Canyon differs very markedly from the other canyons of the region in having a broad flat bottom, despite its stecp walls; it is U-shaped, not narrowly $\mathrm{V}$-shaped as are the other canyons of the district, for example, the Canyon of Mageik Creek. This flatness could be accounted for only in part by the débris left by the flood. Consequently we were not surprised to find clear evidence of glacial work in the bottom, proving that it was already in existence during the glacial period.

Mageik Canyon on the other hand, although 500 feet deep, is post-glacial. Its rim is lined with glacial gravels evidently laid down before the canyon was cut. A study of the drainage area shows, moreover, that before the glacial period Mageik Creek drained into Martin Creek. It was apparently diverted to its present course by the glacier that once filled the depression between Mount Mageik and Observation Mountain.

\section{PROOF THAT THE LAST LAVA FLOWS FROM} KATMAI WERE POST-GLACIAL

The exposures of Katmai Canyon furnished us also with our first clue to the date of the previous activity of Katmai. We discovered that one of the last lava flows had reached into the very bottom of the canyon, where its base rests on the glaciated surface of the sandstone. Evidently then the last eruption, though ante- 


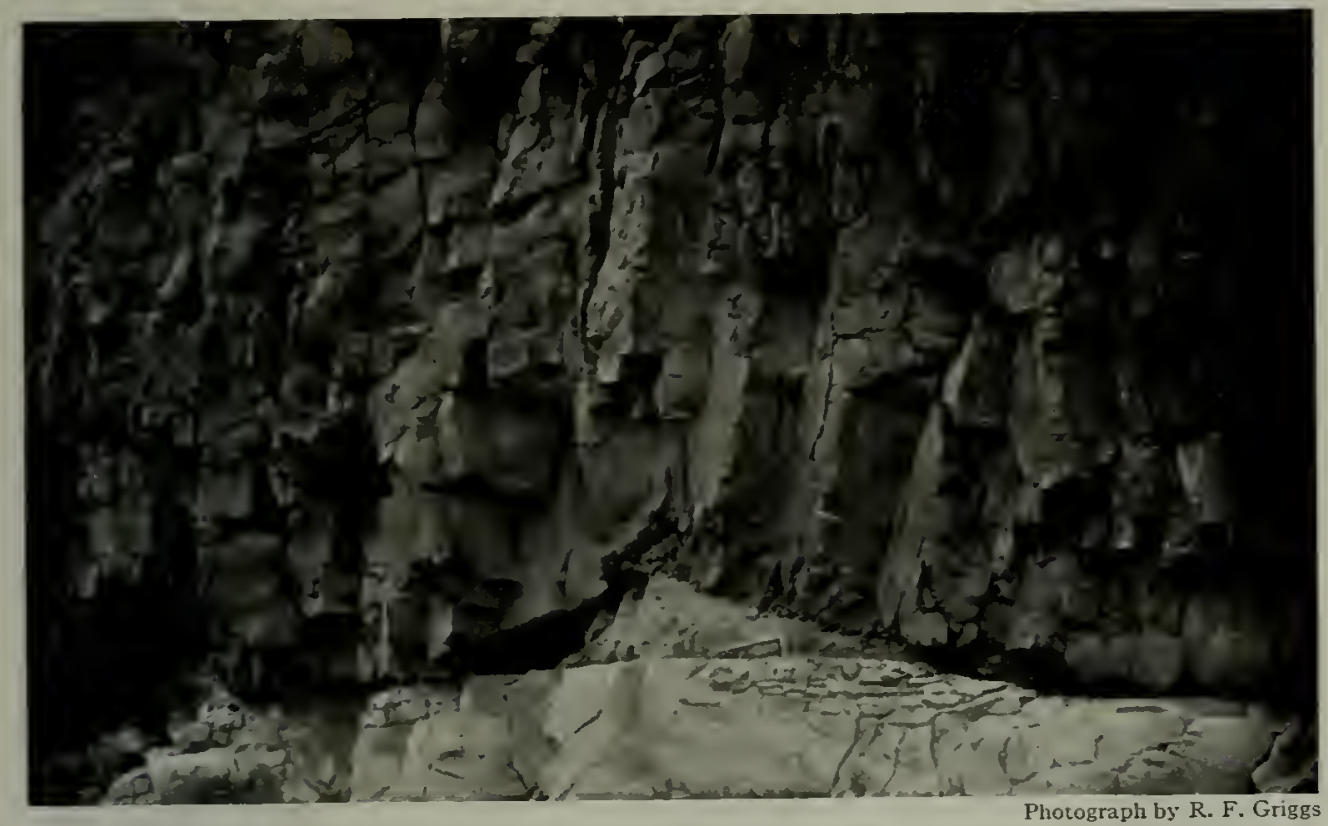

AI OLD LATA FLOW FROM MOLXT FATMAI RESTING ON GLACIATED ROCK IN KATMAI CANTON

At the base of the cliff shown on page 126, the bed rock is Naknek sandstone (Jurassic), which is beautifully planed and striated by glacial action. Here and there a small remnant of till, indicated by the hammer, still remains below the lava.

dating the historic record, had occurred in geologically recent times.

GRATEL BA.KS SO LISTABLE AS TO BE SET ROLLING BI A SLIGHT BREEZE

At the remains of the dam, which had held back the waters of the Katmai Flood, we found that the impetus of the torrent had been exhausted before the dam was entirely cut away. There remained a considerable bank of unstable material into which the river was busily gnawing at the time of our visit, lowering its level perhaps ten feet a year.

Near the position of the former crest of the dam the stream was constricted into tumultuous rapids and was undermining its banks so rapidly that they stood at the critical angle, sometimes misnamed "the angle of repose."

So unstable was the equilibrium of the banks at this point that eren a good breeze was sufficient to start them tumbling into the river. During calm weather we could clamber over the bowlders up and down the gorge with safety, but I have seen the wind tear up yard upon vard of loose material and send it rolling into the river.

Because of my ignorance of this condition I had a narrow escape the first time I traversed the canyon. I was standing on a rock, photographing the rapids, when a sudden gust started the stones above me rolling, and before I realized what had happened a big one went whizzing into the water, just missing my head. It was only the first fragment of a small avalanche that was coming my way.

\section{THE SECOND VALLEY OF THE KATIAI}

Above the remains of the dam we emerged into the Second Valley of Katmai River. Across the base of the mountain opposite was the conspicuous horizontal line made by the beaches of the old flood lake, 2 Io feet above the level of the lower Katmai Lake, which still persisted in the lowest portion of the basin (see page I20). 


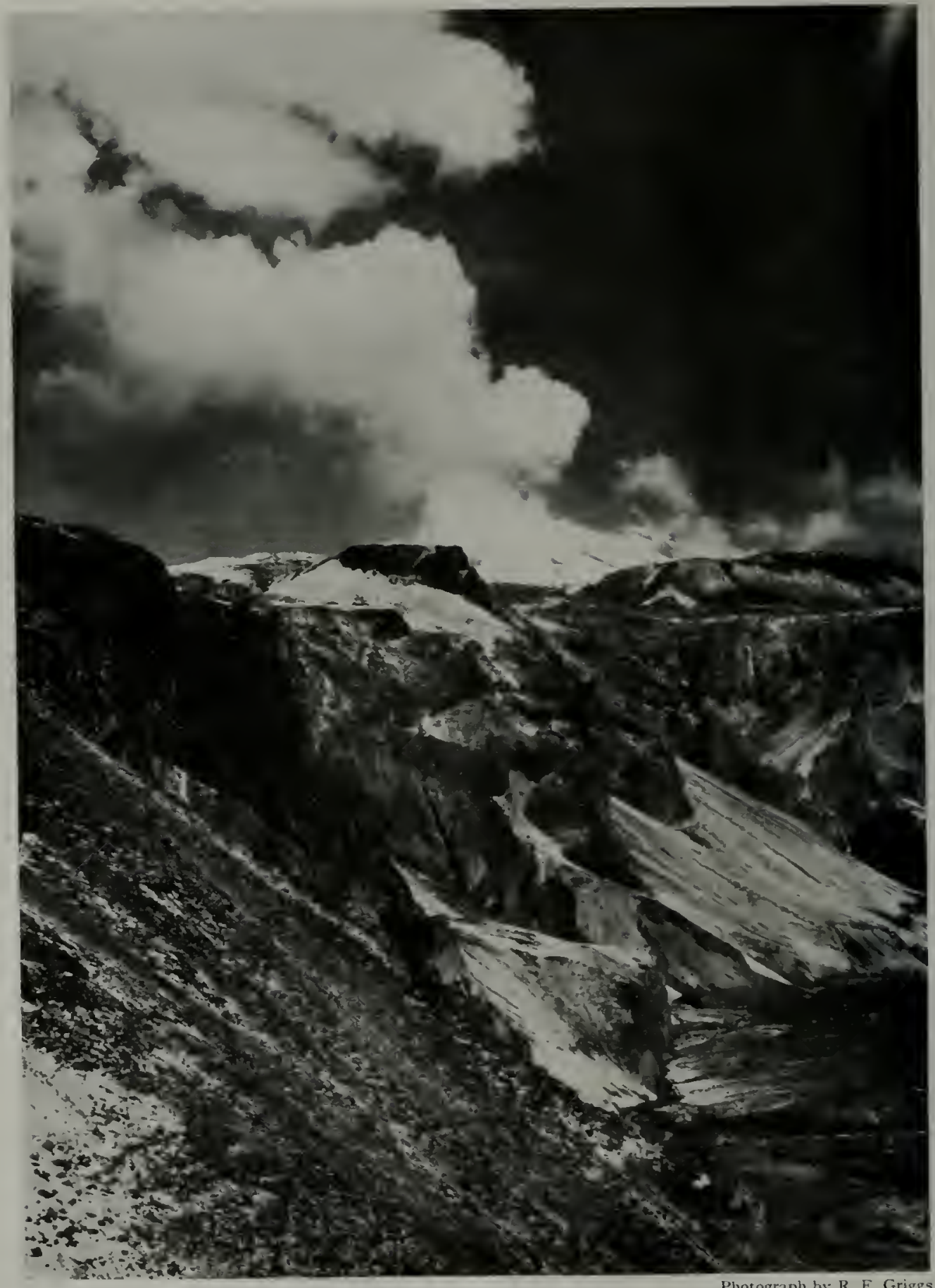

Photograph by R. F. Griggs

\section{STEAM RISING FROM MOLNT KITMII SEEN FROM PROSPECT POINT}

The ash slides of the recent eruption contrast with the massive ancient lava flows. At the right are two fine waterfalls. The summit stands about a mile above the observer. 
Before the last lava flow the canyon evidently lay closer to the volcano than the present gorge. By filling the river bed the lava forced the stream against the opposite bank, compelling it to cut into the south wall and form the present cliff.

From the general appearance of the rolcano we were inclined to suspect that such a process had occurred repeatedly;, but we could not find evidence enough to reach a definite conclusion as to the original course of the drainage.

\section{CURIOUS PHYSIOGRAPHY}

The Second Valley lies in such a position, however, as to suggest that it might once have formed a continuation of Knife Valley (see map, back cover). If Katmai Volcano were remored bodily the Second Valley would drain straight across through the north arm of the Valley of Ten Thousand Smokes to the lower end of Iliuk Arm of Naknek Lake.

The evidence is not sufficient to warrant the assertion that Knife Valley was an antecedent feature, beheaded by the formation of Katmai Volcano, yet it is difficult to understand how its broad basin could have been eroded by its present drainage.

As we passed up the Valley we were much perplexed by the conditions we encountered. In contrast to the peaceful beauty which marked the lower lake, the rough piles of broken rocks that cover the isthmus between it and the upper lake had a certain rawness that obtruded the desolation of the place on our senses.

Apart from its appearance of total devastation, the conspicuous features of the landscape are a great number of very regular conical mounds, which are strewn over the isthmus and rise from the waters of the upper lake (see page 128).

The irregular disposition of these hillocks recalled a glacial moraine, but we were puzzled by the complete absence of regetation, for the moraines of an old glacier should long since have been occupied by bushes. Moreover, they lacked the characteristic disposition of morainic deposits. Some of them were covered with the ash, lying in regularly bedded layers; others were entirely free from it and many of these were so situated that it was difficult to see how the ash could have been removed by erosion.

The absence of wood gave me much concern the first time we came into the place. We were tired and anxious to camp, but I could find no suitable site. Finally I turned to the others for counsel.

"Why, here is plenty of wood right here," said Folsom; "here is a good place." I looked incredulously about me. Not the smallest bush was to be seen.

"Well, if you will provide the wood, we 'll camp," I replied.

So, dropping his pack, he proceeded to one side a few yards and pulled a stick out of the ground. My eyes had not been sharp enough. When we began searching we pulled out a considerable quantity of sticks from the rock débris. We even managed to find a couple that would answer for tent poles. So we set up our camp on the bank of the river, between the two lakes.

These upper reaches of Katmai River are curious, indeed. Although it is a tumultuous mountain torrent, the bowlders of its bed are sharp and angular, entirely different from the rounded cobbles usually found in such streams. The river occupies no proper bed of its own, but simply finds its way at random over the irregular surface, now cascading over a group of bowlders, now slackening to fill a depression with a small pond.

The rock-covered ground is so loose and porous that much of the water strikes in and travels along beneath the surface. There are several hollows filled with clear, deep, green water, forming little ponds. These have neither inlet nor outlet, but are kept sweet by the rapid underground seepage. At the foot of the belt of hills the underground water reappears in several large streams which come from the ground as springs.

\section{NOISY MOUNTAIN}

Immediately behind our camp rose a tall mountain whose base was screened 


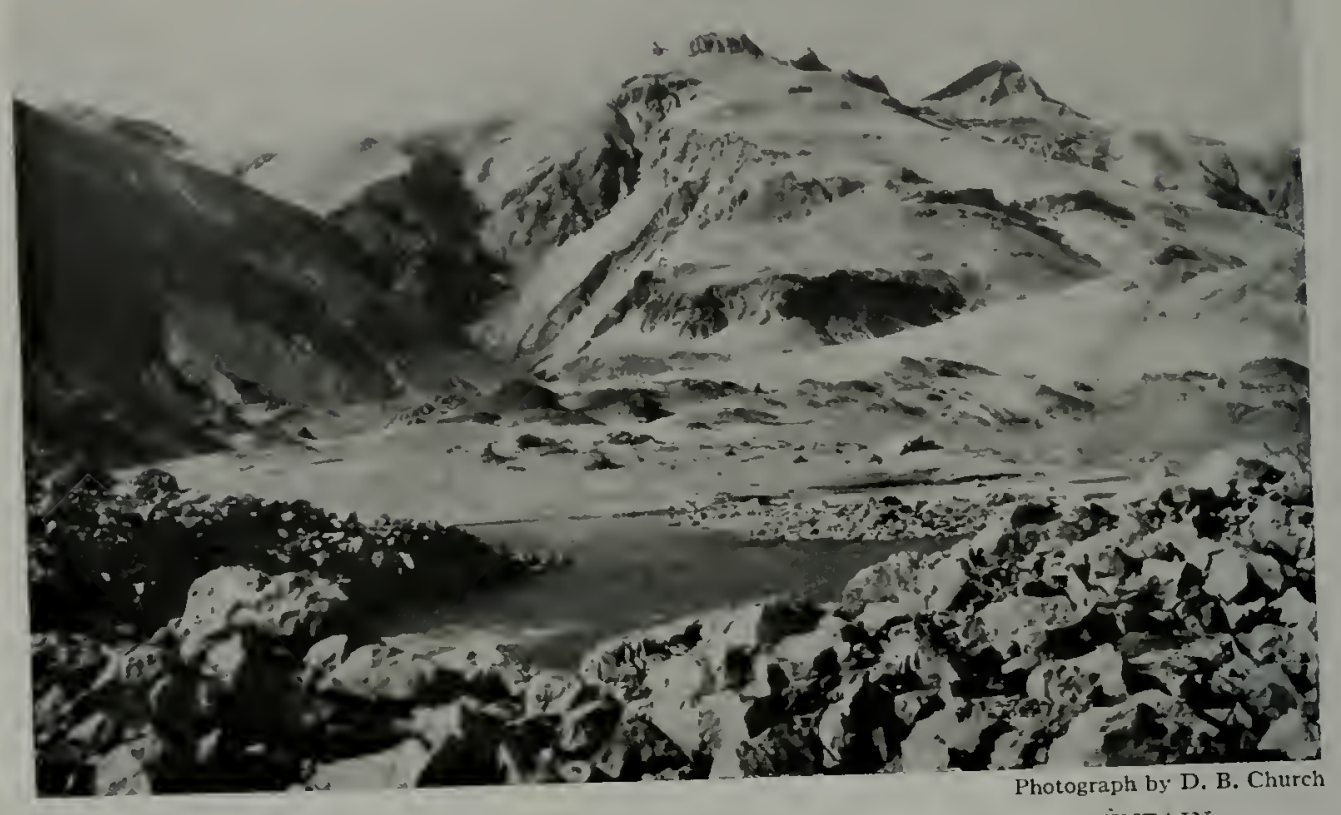

A PORTION OF THE ROCK SLIDE FROM THE SLOPES OF NOISY MOUNTAIN The cones of detritus in the middle distance are everywhere the characteristic feature of the angular of the slides. In the

by an enormous mass of talus. Accustomed to the avalanches, which were abundant everywhere in the volcanic country, we paid no attention to the frequent rock falls from the precipices of this peak until after we had settled ourselves for the night.

But all night long our sleep was disturbed by fresh avalanches. Never during our sojourn was there a lull of five minutes. "Noisy Mountain," for so we named it, was evidently a counterpart of "Falling Mountain," which we discorered in the Valley of Ten Thousand Smokes (see pages $241-243$ ). Its constant avalanches gave us a new clue to the anomalous character of the country.

Next morning, when we could climb up and get a general view of our surroundings, the explanation of the curious physiography of the valley became evident enough. We could see where the whole side of the mountain had broken loose and slid out into the valley, burying several square miles under a mantle of débris.

As in the other big slides, the bright, fresh rock cliffs, newly exposed, contrasted strikingly with the old, weathered slopes of the mountain. IVe could form no intelligent opinion as to the quantity of material that had broken loose, but some of the piles of débris appeared to be 3 oo feet high.

\section{CONICAL MOUNDS CONSPICUOUS}

Like the other great slides of the district, the rockfall from Noisy Mountain shows little of the hummocky surface characteristic of the ordinary slow-moving landslide; instead are the above mentioned conical mounds (see also Chapter XI).

Another feature not to be found in the ordinary landslide is the frequent presence of shattered rocks. These evidently started from the top of the cliff as solid masses and held together during the avalanche. But they were subjected to 
such strains, that; although they still retain their original form and appearance, they fall to pieces at a touch.

\section{NOISY MOUNTAIN IN ACTION}

Directly in front of the mountain, and circling its base, was a mass of detritus which, having been discharged with less violence than the rest, was not shoved out into the valley like the bulk of the material. The rim of the ridge thus formed stood 600 to 800 feet above the valley floor, completely screening it from further slides by forming a retaining wall behind which all the new débris from the mountain was caught.

The rounding top of the ridge like the rest of the slide area was covered with cones, but around its base the surface was thrown into something resembling the hummocky ridges of the ordinary landslide, indicating, perhaps, a slow settling into position rather than a sudden drop into the Valley.

This crescentic barrier largely cut off the view from below, hiding the face of the mountain whence came the incessant noises that had disturbed us. But its crest was a fine vantage point from which to watch the activity of the mountain.

The noises were of two sorts: a low ominous rumble, continued for a considerable period, and the familiar boom, rattle, and bang of falling rocks loosened from their hold.

Some of the falls consisted of large masses of rock, weighing several tons, which would let go and come down all at once, breaking into fragments and raising a cloud of dust, with a terrific roar which lasted several minutes. More commonly they were single bowlders which came rolling and bounding down the slopes. This noise continued night and day.

But the other type of disturbance, the long-continued rumble, was confined to the hours when the snow was melting rapidly. It occurred at short intervals on bright sunny days and less frequently in cloudy weather. The first of these rumbling noises that came when we were in a position to see the face of the mountain furnished the explanation.

The continuous small falls from the cliff periodically choked the precipitous channels which carried the drainage of the steep slope, filling them with detritus. As water from the melting snow trickled down the channel, the débris clogging it was gradually changed to mud. Eventually the point of flowage was suddenly reached and the whole mass would then start moving downstream, gathering momentum and picking up additional material as it went roaring down the steep slope.

This moving mass of rock, mud, and water had the consistency of a batch of coarse concrete, as it comes fresh from the mixer. The rock fragments which it carried varied all the way from mud and sand to bowlders three feet in diameter, which were rolled, spattering, end over end, down the channel with the rest.

Starting high up on the mountain, these "water slides" flowed for the first few hundred feet down a precipitous slope approaching the perpendicular, rapidly gathering momentum which carried them across the gentler slopes below, until they brought up in the depression behind the barrier-slide.

Considering the consistency of the flows, it was rather surprising how far they ran out into the comparatively level basin. For several hundred feet at the terminus the gradient of their courses was hardly more than ten per cent. The total drop was about 1,500 feet.

The quantity of material brought down in a single flow often amounted to more than a hundred cubic yards. The slides occurred several times a day all summer and kept up at least for several years, accomplishing in the aggregate a considerable amount of erosion. Adding to these the rock falls, which certainly move as much material as the bowlder flows, one gains a new conception of the forces here at work. Yet the whole of the material brought down since the great 


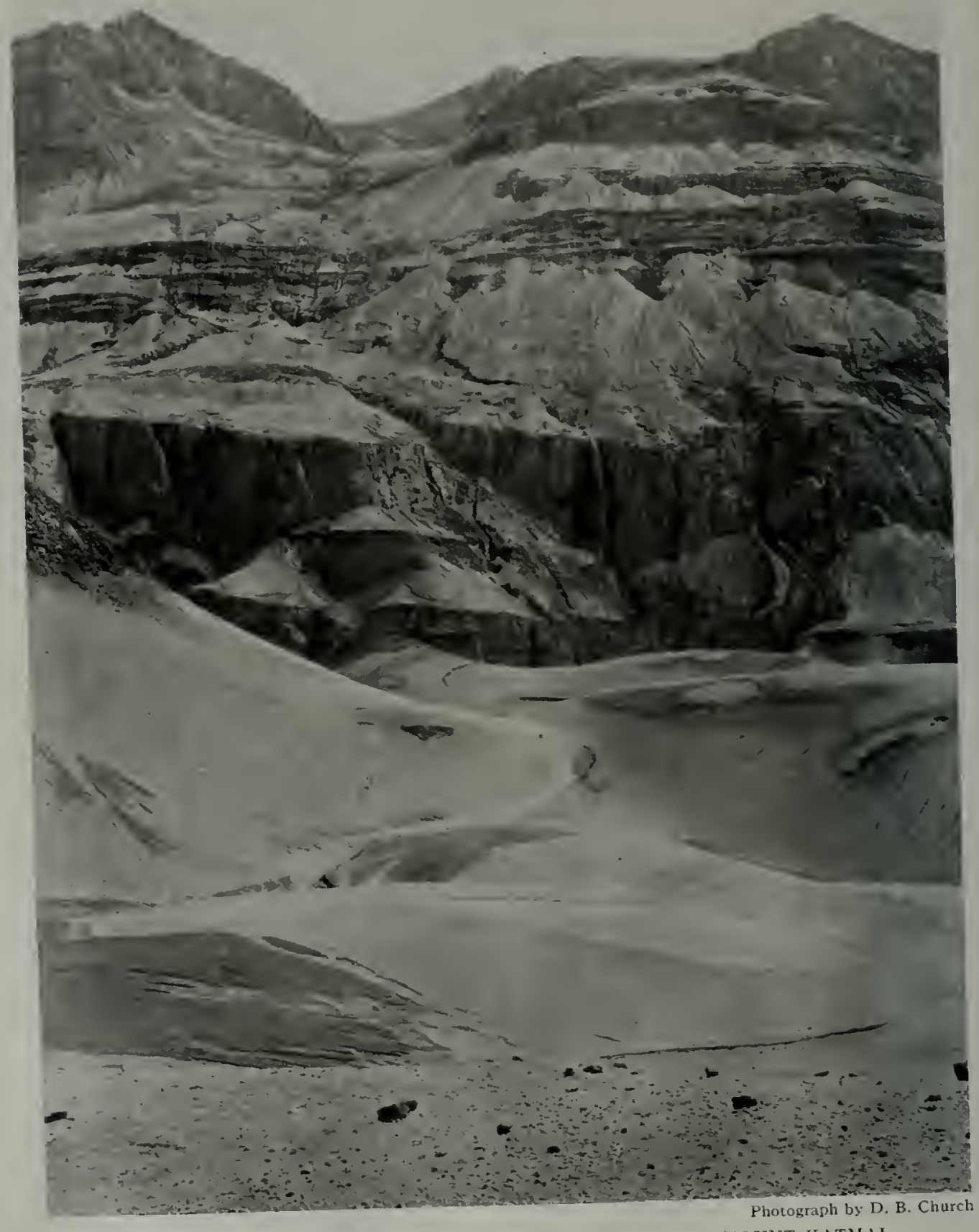

ACROSS KATMAI CANYON FROM THE LOWER SLOPES OF MOCXIT KATMAI

The scale may be judged by the man, who may barely: be made out on the trail near the center of the picture. The waterfall, Ruthis Falls, is 750 feet high. 
landslide is insignificant in comparison with the enormous mass of broken rock that fills the valley.

\section{AN INTERMEDIATE BETWEEN LANDSLIDES} AND RIVERS

The bowlder flows or "water slides" stand as curious intermediates, connecting two agents of erosion not ordinarily thought of as intergrading, namely, landslides and rivers.

They have many characteristics of both, which make it possible to consider them either as slips or as overloaded streams. Being largely made up of rocks, which grate and grind and jostle each other on the way down, they are like slides. Moreover, at their termini they often assume the crumpled, hummocky surface of landslides.

They are closer yet in their relations to streams loaded with more detritus than they can carry. They follow a single definite course in their upper channels and spread out into divergent distributaries like a delta, when they approach their termini. At the point where they debouch from the single channel, they build up regular convex "alluvial fans," highest in the middle, like those of lateral streams in a main valley.

Like all overloaded streams from the great Mississippi to the diminutive brooklet filled with pumice from the eruption, they build their banks higher than the level over which they flow, forming dikes on each side of the channel.

The automatic flushing to which the channels of Noisy Mountain are periodically subjected furnished the key to a number of unusual features in the abnormal physiography of the devastated district.

Comparison of the moving flows with the forms assumed by the detritus after motion had ceased permitted the interpretation of the larger and more important terrane that forms the subject of the next chapter, which otherwise would have been hard to understand.

The ability of the thick, heavy mud of the flows to transport large bowlders made it clear how the Mageik Flood had rolled great rocks through the forest without breaking down the trees. That also must have consisted of mud so thick as to move rather slowly, and so heavy as to have a power of flotation much greater than ordinary water.

Moreover, it was evident that if these bowlder flows had had a higher proportion of water their velocity would have been greatly increased and the stones they carried would have become formidable missiles capable of doing great damage, like the rocks carried in the swift Katmai Flood.

On the other hand, seeing in action a mass so largely composed of solid material aided greatly in a comprehension of the amazing fluid character evidently possessed by the great landslides, such as that described in the following chapter.

THE UPPER PORTION OF THE SECOND VALLEY

One of the primary objects of the exploration of the Second Valley was to cross a low pass which we had descried at its head from the slopes of Katmai. Even in 1917 we were anxious to find some better entrance to the country than Katmai Bay.

As the Second Valley trended toward Kinak Bay, which we knew to be a good harbor, we hoped that the pass at its head might provicle an easy avenue for passage thither.

The morning after our arrival, therefore, we set out skirting the west shore of the upper lake. Beyond the corner of Noisy Mountain we came upon a large glacier, a valley tongue coming down from the névé that lies between Katmai and Snowy Mountain (see map, back cover).

This néve is much more extensive than any other snowfield of the region, and the glacier - Princess Glacier, Church called it - though not yet surveyed, is clearly the largest thus far discovered in the district. It is not improbable, how- 


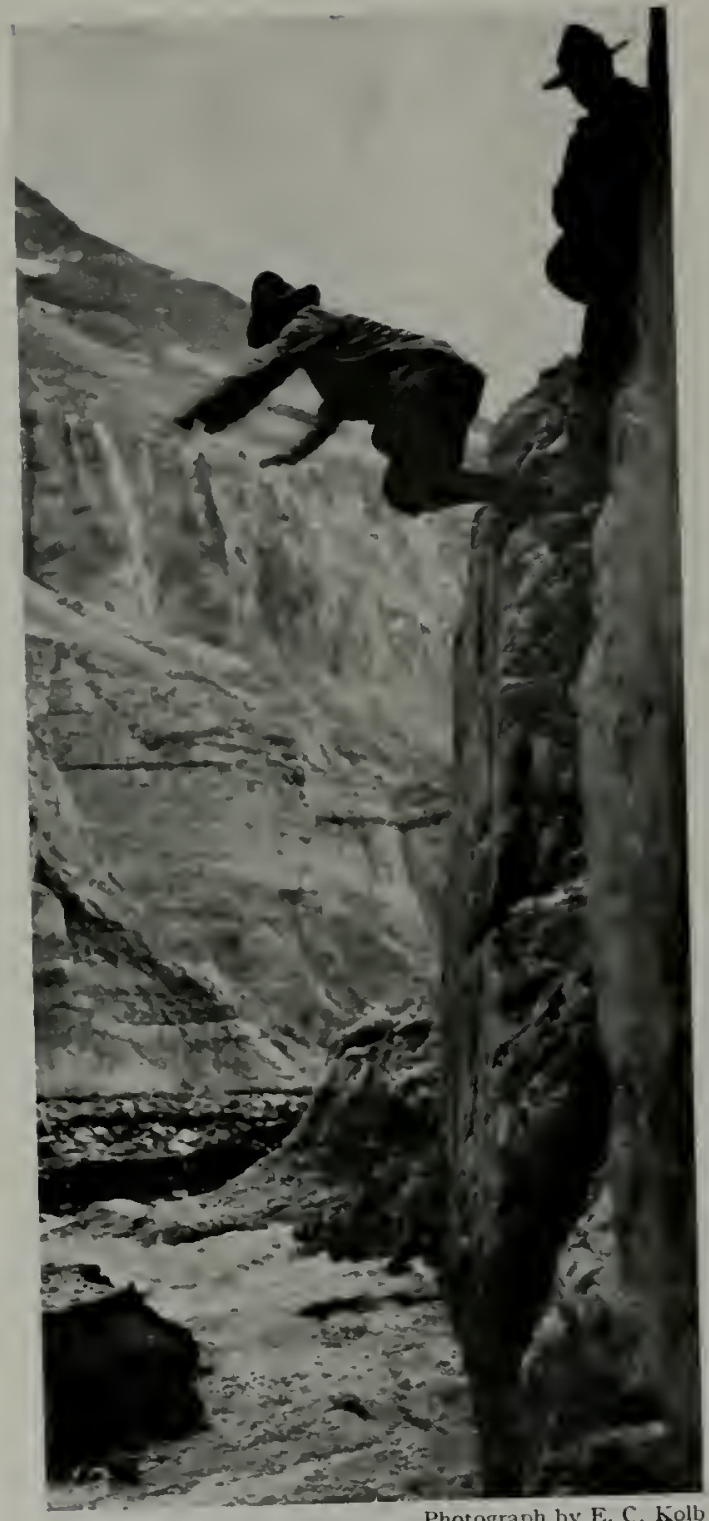

THE LAST LEAP IN THE DESCENT INTO KATMAI CANYON

The descent is not so difficult or hazardous as might be supposed from this picture. Before taking off, I took good care to see that there was a way back.

ever, that other glaciers of equal or greater size will be found in the unexplored sections of the area. Princess Glacier is the chief source of Katmai River, for it furnishes much more water than the brook which comes down from the end of the valley.

When we came near enough to examine the head of the valley in detail we found two passes rather than one, both comparatively easy. The question was which of the two would lead us to Kinak Bay, which we knew lay a dozen miles to the east. Consulting my compass I decided to try the more southerly. This turned out to be the wrong choice.

Our mistake was of no consequence, however. for the ent rance to the country discovered in InIg is far superior to either of these passes, which are above 2.000 feet high and always deeply covered with snow.

The valley that we descended on the opposite side was wild and rugged in the extreme - a narrow $\mathrm{V}$. constricted and difficult of passage. Sometimes the cliffs forced us to wade in the stream and sometinies cascades compelled us to climb a thousand feet up the mountain side.

Before we had gone far we realized that we had taken the wrong pass, for the valley, trending at first south, turned more and more westerly instead of easterly, as we had hoped.

Had it opened to the east there would have been time to reach the sea and return again the same day. But it was evident that we were not making much progress scaward by traveling southwesterly, parallel with the coast. Yet hoping for a bend in the valley, we kept on till five or six o'clock. But there was no indication of a turn, so at last we gave up and turned back.

\section{A HOT SPRING DISCONERED}

On our way down we had passed a fine hot spring close to a sightly waterfall, which appeared at a place where a fault seemed to cross the valley. IVe decided to return and spend the night there. Though we had neither supper nor blankets, we could at least enjoy the luxury of a hot bath. 


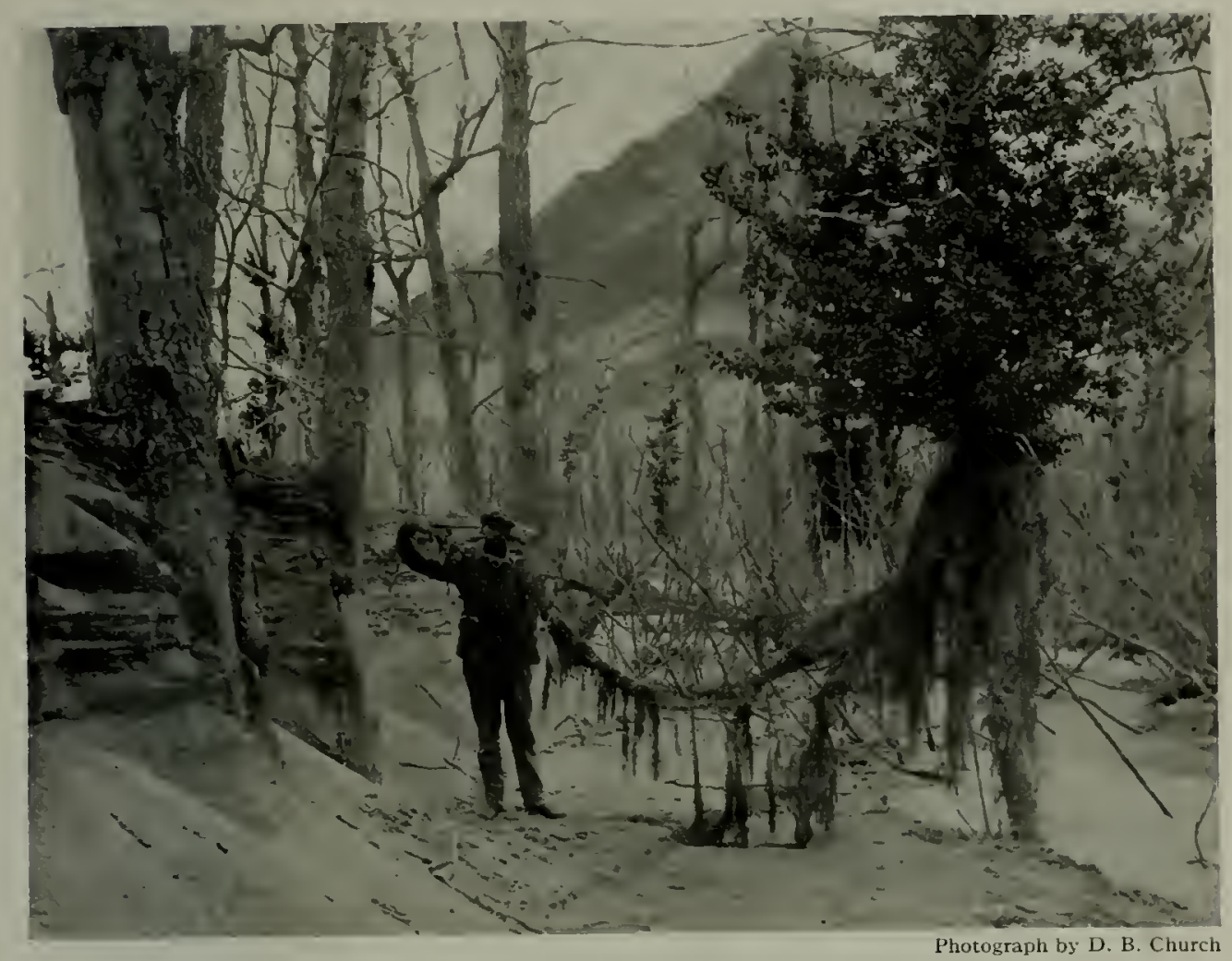

ROOTS PUT OUT BI A WILLOW AT THE SURFACE OF THE ASH

Later washed out by a stream. The new roots are 8 feet above the original surface of the ground. All the new roots were put out immediately below the surface.

This was much desired by the natives, who have great faith in the curative properties of hot springs for the rheumatic complaints with which they are affected. The temperature was just right for the best effect. We could bear our hands in it, though it was too hot for our feet.

The drizzle which had been falling all day continued most of the night. All the wood was pretty thoroughly wet, but by whittling off the outside we procured some dry shavings and soon had a roaring fire, partly compensating for the lack of blankets, and enabling us to get a few hours of sleep. Having no breakfast to delay our departure, we were off at daylight and reached camp about noon.

When we laid out our compass traverse of the new valley, the most probable outlet appeared to be Soluka Creek. We were loth to admit that with all our trouble we had merely walked around the Barrier Range, and tried to believe that our stream flowed at least into Takkala Bay. The survey made in 1919 showed, however, that we were wrong. Had we continued half an hour longer, we should have been able to look out in to Katmai Bay.

If we had only known it, we might have attained our quest that day. Hagelbarger's Pass, by which the route from Geographic Harbor crosses into Soluka Valley, lies just below our hot spring. When the surveyors came across from the coast in 1919 the first thing they saw from the pass was our waterfall and hot spring, which they recognized from the description. 


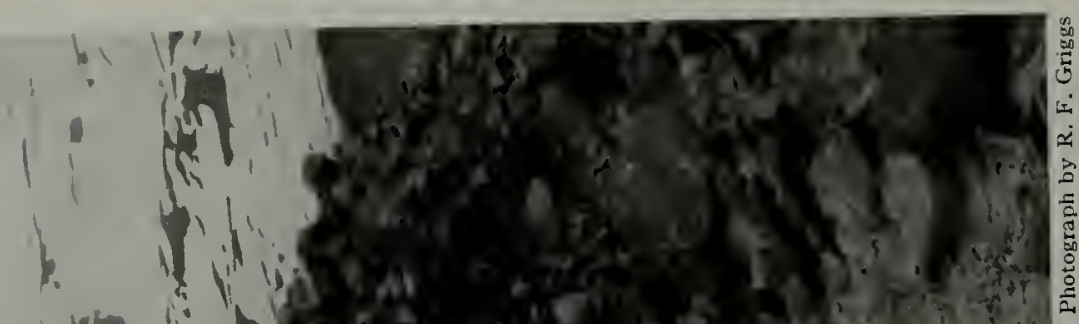

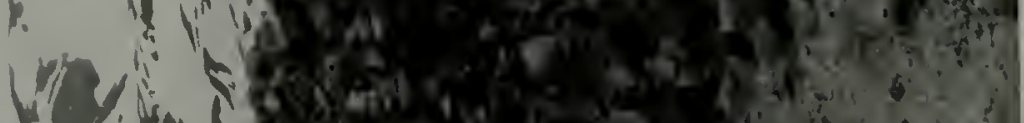

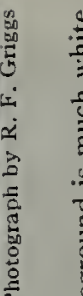

$4 ;, 0$ f

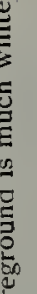

$\stackrel{5}{8}$

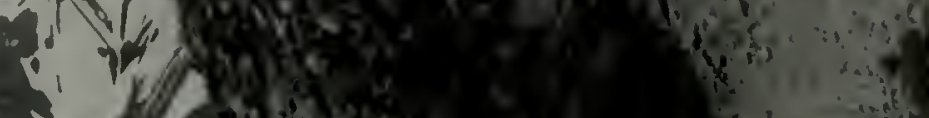

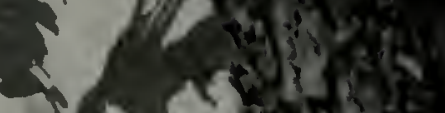

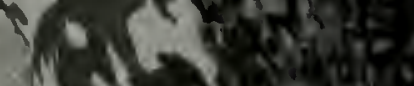

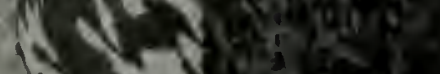

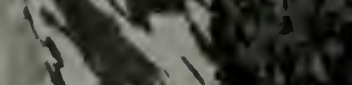

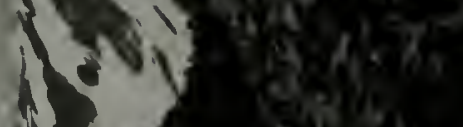

Y
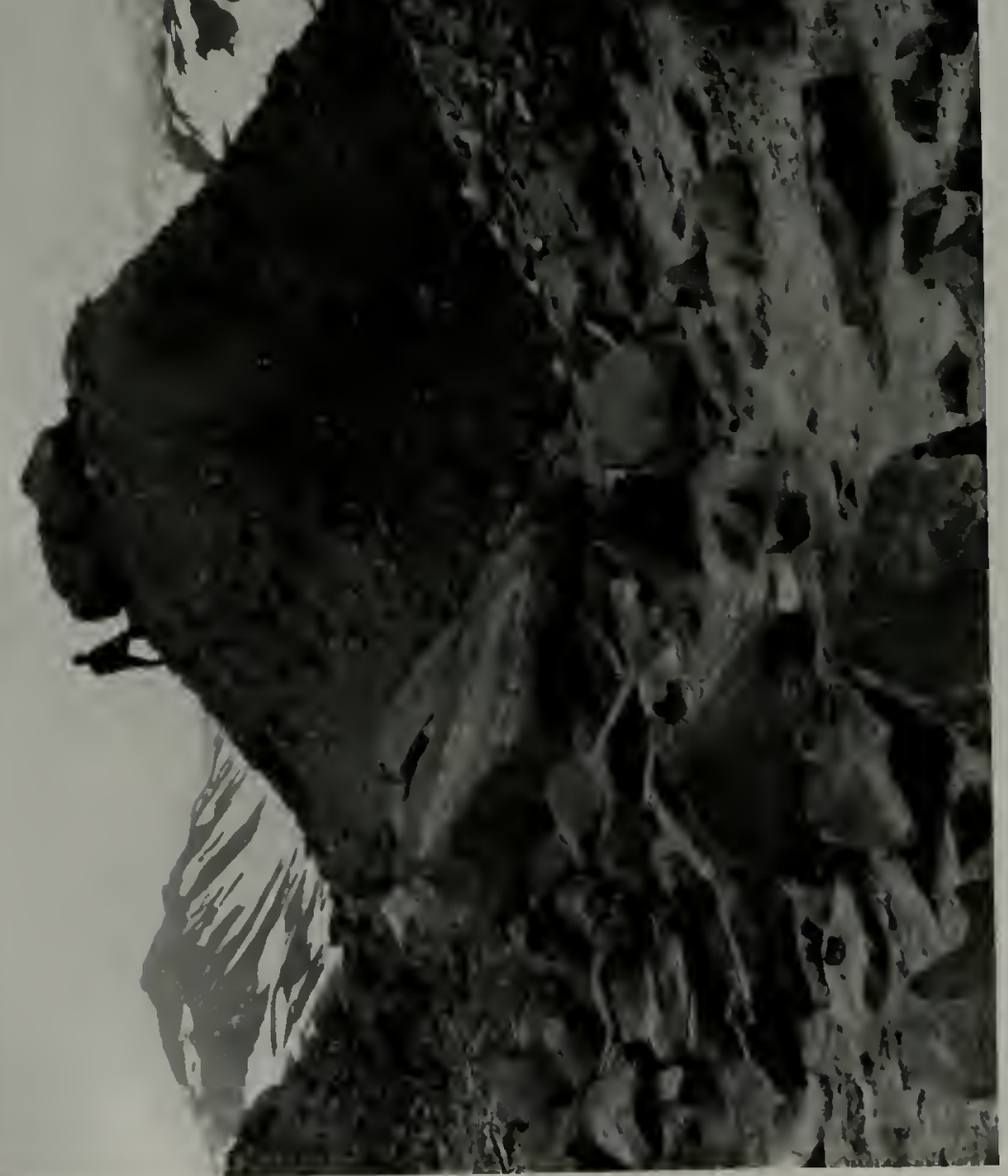

บ

ว के

(1)

焉 完

ज

ह

$\% 8 \frac{1}{8}$

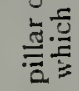

宽

욤

5. 


\section{THE MAGEIK LANDSLIDE}

When our explorations carried us into the Valley of Martin Creek, early in I9I7, we came upon a remarkable terrane, as noteworthy, in its own class, as Katmai among eruptions.

For several miles the valley is strewn with enormous bowlders thrown promiscuously about. M. A. Horner, who saw them in 1913 , was rather more impressed by these bowlders than by the volcano itself. Realizing that they were contemporaneous with the eruption, he concluded that they must have been projected from the crater. Accordingly he labeled his pictures of them "Rocks thrown out by the Volcano." Postcards bearing this legend are probably still for sale in Seward.

BOWLDERS AS BIG AS A HOUSE STREWN ACROSS THE VALLEY

Bowlders io feet long are abundant, and much larger rocks are frequently encountered, some of them as large as a good-sized house. Many measure 30 or 40 feet. The largest single stone observed was 75 feet long and 35 feet wide. Its height could hardly have been less than 20 feet, though this could not be measured, for it lay half buried in the surrounding débris.

There could be no question but that these bowlders had in some way been carried far from their original position. The valley is cut, through the greater part of its course, in sedimentary rock, but the waste that coiers its floor is mostly composed of lava fragments.

Yet it was evident that these rocks could not have been discharged from the crater of any of the volcanoes. Nixed with the piles of lava bowlders was much material of an entirely different nature. Considerable masses of old soil, great chunks of peat, remnants of vegetation, fragments of sandstone, and bits of tuff from an ancient eruption were all jumbled together in great confusion.

In addition to the heterogeneous character of the materials, their position and attitude furnished positive proof that they had not been thrown out from one of the volcanoes. If the bowlders had been hurled through the air, the marks of their impact upon the ground as they struck would have been conspicuous, but none were to be found. If they had been thrown out of one of the craters, they would have been strewn indiscriminately on all sides of the vent, but they are confined to a single sharply limited sector.

The terrane is restricted to the bottom of the valley. Beginning high up at the head of the stream, the débris is spread for several miles down the floor of the broad U-shaped valley, occupying the same position as a glacier. From a distance, indeed, it looks like a glacier completely covered with rock fragments.

On nearer approach, however, it is seen to contain no ice. Yet it resembles glacier work in so many ways that we supposed at first it must be some unusual form of glacial deposit.

In places its surface is pitted with characteristic circular puddles, exact miniatures of the "kettle-hole ponds" so familiar to students of glacial geology (see page I +3 ). Since these are most readily accounted for by the melting away of an embedded block of ice or snow after the mass reached its present position, their occurrence gave color for a time to the glacial theory.

But the terrane has several important features which show at once that it was not the work of any glacier. It has no moraines, no ridges of any kind at its end or edges, nor is there any sign of the push and shove always characteristic of ice work. 


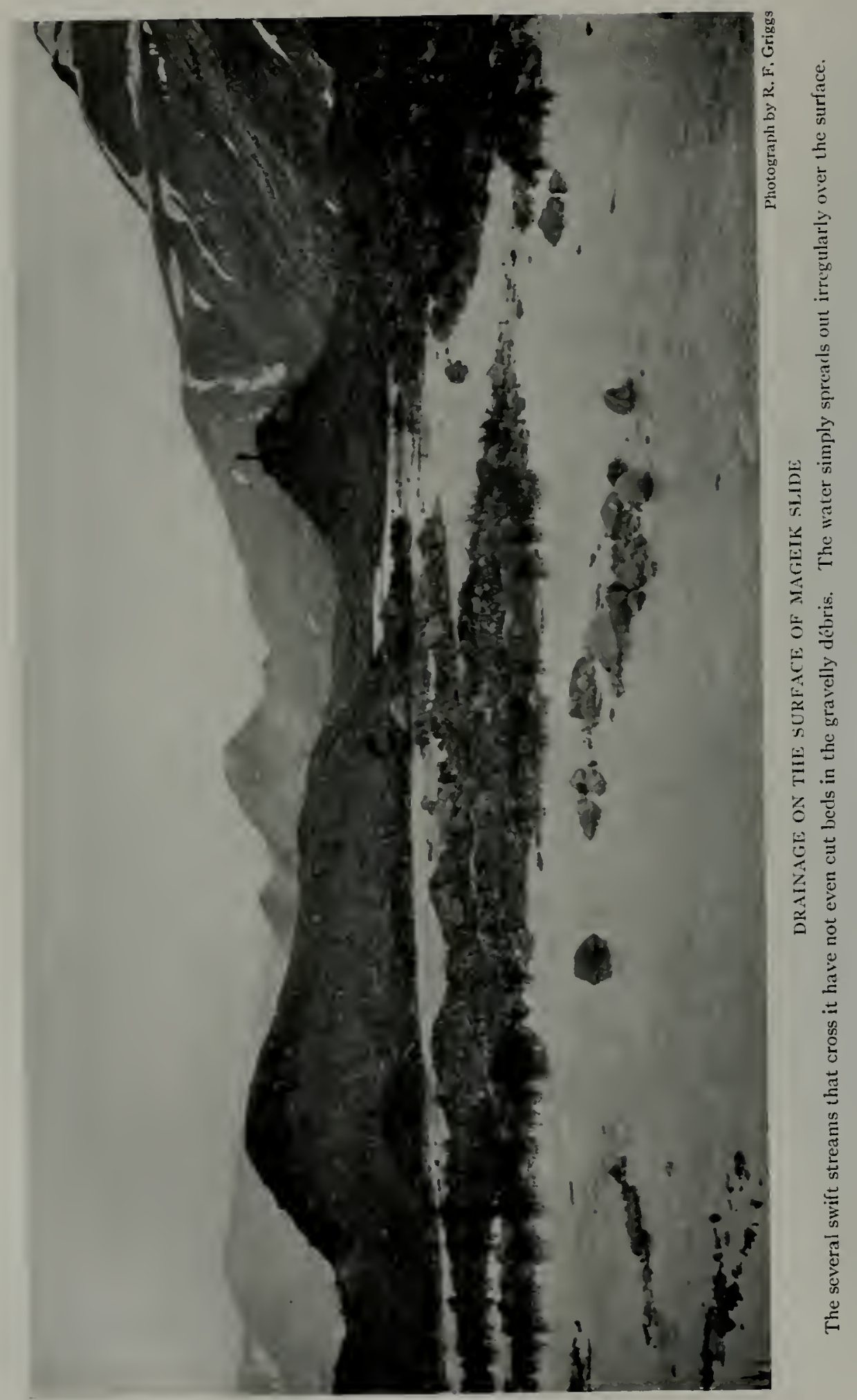


Yet the terminal edge is perfectly clear-cut and distinct; its barrenness contrasts sharply with the green grass beyond. In some places the margin is a steep convex bank, several feet high (see page I4I). In others, the débris is spread only a few inches deep over the ground (see page I4t).

\section{BROKEN BUSHES INTERMINGLED WITH THE DÉBRIS}

The effect on the bushes that lay in its path likewise affords clear and positive evidence that this is no glacial terrane.

An advancing glacier slowly overwhelms the trees that stand in its way, gradually pushing them over by piling débris against their trunks. But here the willows and alders were snapped off clean, as though struck by flying rocks (see page I $\mathbf{I}$ ). The bushes were never bent over before the advancing mass nor were they uprooted by its force; the line of destruction is as sharp as the edge of the débris itself.

There were many places where one could observe the clean-broken stumps protruding through their covering, within a few feet of similar bushes standing untouched beyond the margin of the drift.

The terminal portion of the mass is composed more largely of fine materials with fewer rocks. Here also are great chunks of black peat soil, sometimes scattered irregularly through it, sometimes thrown into rude windrows.

At the lateral edges, several miles back from the terminus, the débris instead of piling up sank away from the highest level reached, leaving a hollow rather than a ridge.

This is particularly well shown along a spur of one of the neighboring mountains, so located as to have stuck out squarely into the path of the flow. Here the rocks had evidently ground up against the obstruction, clearing the vegetation and soil from the hillside to a height of nearly ioo feet above the present level of the detritus.

But instead of lodging against the barrier, as glacial bowlders would have done, they slumped away again, leaving the hillside almost bare, and forming a deep hollow around its base in which has gathered a considerable body of clear green water in a horseshoe pond (see page I42).

Another very curious feature of this bowlder train is the fact that half-way down it forked, sending separate tongues down different portions of the flat valley. Its margin likewise showed a decided tendency to splay out into minor branches.

A forking glacier is, to be sure, no impossibility, but a mass of ice can be divided only when it meets an insuperable obstacle, capable of withstanding the enormous power of its advance. The divide on which this terrane split is merely the inconsequential rise between the two streams which come together farther down the valley.

It is evident, therefore, that whatever the explanation of this mass of débris may be, its movement was delicately adjusted to slight variations in the gradient of its bed. Notwithstanding its high percentage of rocks it gives every indication of having sought its level almost like water. This amazing evidence of fluidity is strengthened rather than weakened by detailed study.

ORIGINAL PLANTS STILL GROWING ON THE BOWLDERS

This bowlder flow, if we may call it such, shows unmistakable evidence of having moved much more rapidly than a glacier. It bears numerous fragments of the original vegetation which were not destroyed by the catastrophe. Some of these, indeed, still remain alive and have begun to grow again, as though never disturbed.

No such thing would have been possible in a glacier. It would require many years for a glacier to carry a bowlder like that shown on page $\mathbf{3} 8$, from the mountain top down into the valley, and all vegetation would almost inevitably disappear in the process. These 


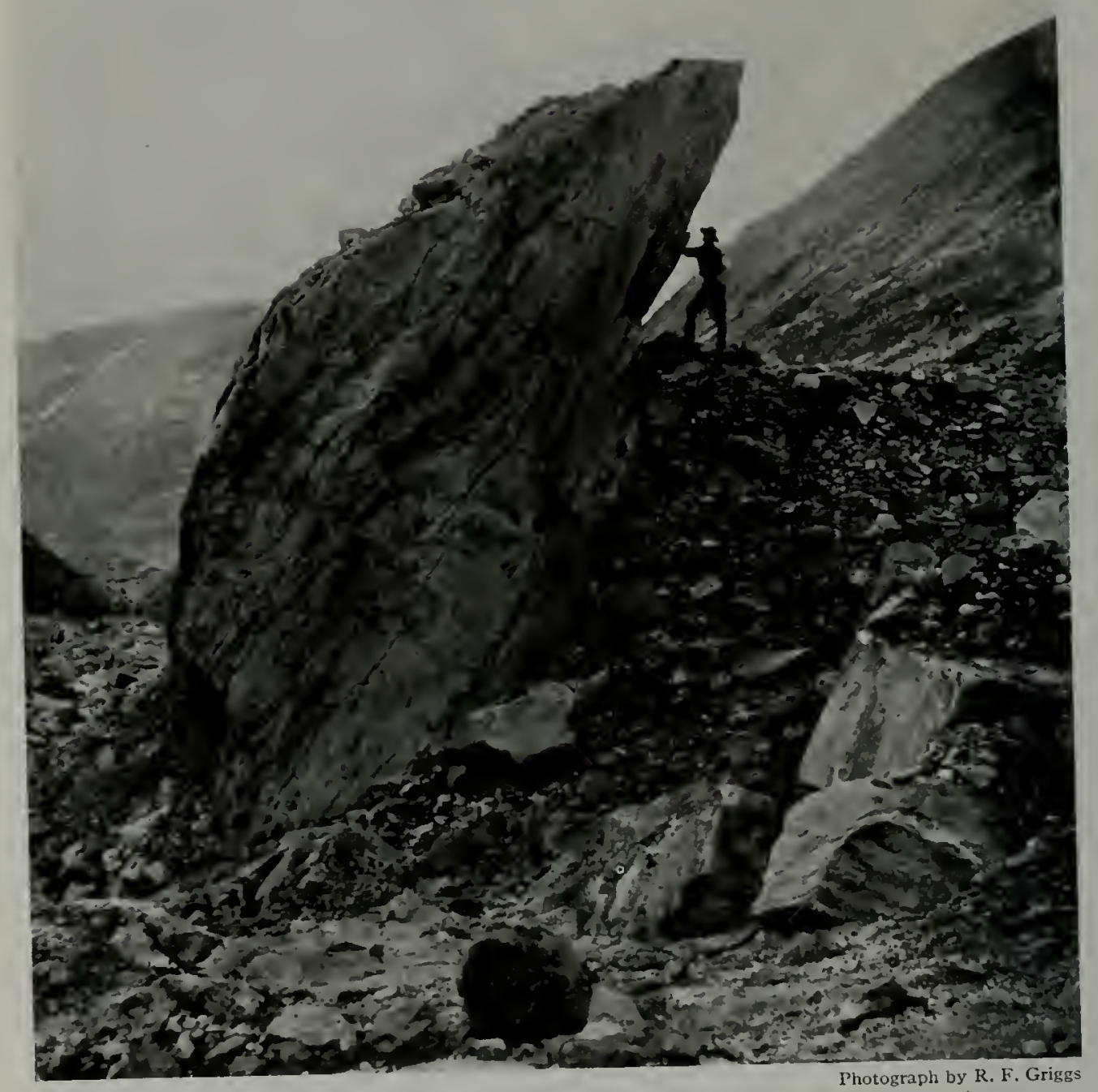

ONE OF THE LARGER ROCKS OF THE SLIDE, HALF BURIED IX SMALLER DÉBRIS

The largest bowlder observed, which was 75 by 35 by 20 fect, was not favorably situated for a photograph.

plants were, however, evidently carried "right sicle up with care" all the way down from the mountain top to their present resting place.

INDICATIONS AS TO DATE OF OCCURREXCE

Along with the indications of suddenness of formation is other evidence that fixes rather closely the date at which this curious mass of débris reached its present position. By all the criteria of physiography it is very young-indeed, infantile. The two streams which traverse its surface have scarcely begun to erode their beds. They spread out in most irregular fashion over the uneven surface of the débris, without having so much as scooped out a channel for themselves (see page 136).

The bowlders in their beds are still 
angular, like the rest of the material, in sharp contrast to the rounded cobbles of typical streams. The surface is so fresh that, despite the large content of soil in places, new vegetation had just begun to take hold in 1919 .

Many pieces of wood, fragments of the overwhelmed bushes, lie embedded in the débris in such a way as to leave no doubt that they were contemporaneous with it. They will, of course, rot away in a few years, but as yet they show little sign of decay. These circumstances combine to make it certain that the bowlders were thrown into position very recently.

On the other hand, it is certain that the bowlder flow goes back to the time of the eruption, for its surface is covered in many places with the layers of ash from Katmai. Because of local irregularities in deposition, I have not been able to satisfy myself whether all layers of ash are present, or only the upper strata. But in other spots near by the ash is either absent or thoroughly mixed with the detritus. This is taken to indicate that while the mass must, in the main, have reached its position before the end of the eruption, there were minor movements after the ashfall. All the evidence taken together seems to show definitely that the bowlder flow originated at the time of the eruption.

EVIDENCE THAT IT WAS SOME SORT OF LANDSLIDE

The manifest suddenness of its formation, its occurrence at the time of the eruption, and other features suggest that this bowlder flow was some sort of landslide. This idea is strengthened by the presence of tufts of antecedent vegetation here and there.

Fragments of the original ground were similarly transported in the great landslide at Frank, Alberta, as described by McConnell and Brock, ${ }^{1}$ who report, "One large bowlder retains on its upper surface a coating of moss and a fragment of rotten log lying quite undisturbed."

Vet it is altogether different from the familiar type of landslide. The ordinary landslip carries the evidence of its mode of origin so plainly marked in its every feature that no one could mistake it. While still fresh the tree trunks, pointing every which way out of the broken ground, advertise what has happened as plainly as though it were posted on a billboard. Even after the vegetation has adjusted itself to the new conditions and the broken ground has settled together, the hummocky, billowed surface and the crescentic ridges identify it indubitably to the student.

None of the recognized features of landslides occur here. In place of the irregular broken hummocks and billows, this terrane has a peculiar topography quite different from anything I have ever seen or read of in regions of ordinary physiography.

SURFACE STUDDED WITH REMARKABLE CONES

Like the Noisy Mountain Slide described on page 127 , the Mageik Slide is covered with remarkable conical piles of detritus which present many unusual features that make detailed discussion advisable (see pages 128 and I 34 ).

The general textbooks on physiography make no mention of the occurrence of such cones in landslide débris. Nevertheless they are mentioned incidentally and even figured in the accounts of a number of notable landslides in other parts of the world. Observation of the slides of the Katmai district leads me to believe that these cones are characteristic features occurring regularly in landslides of the most violent type.

VThile there is nothing to indicate their mode of origin, I am inclined to suspect that each represents a separate mass of material which held together and traveled intact throughout the movement of the slide, and settled down in a single spot when motion ceased.

While most of them are made up of lava fragments, occasionally one is found

I McConneli, R. G. and Brock, R. IV. Report on the Great Landslide at Frank, Alberta, Igo3. Ann. Rept. Dept. Interior, Canada, I903, p. 10 


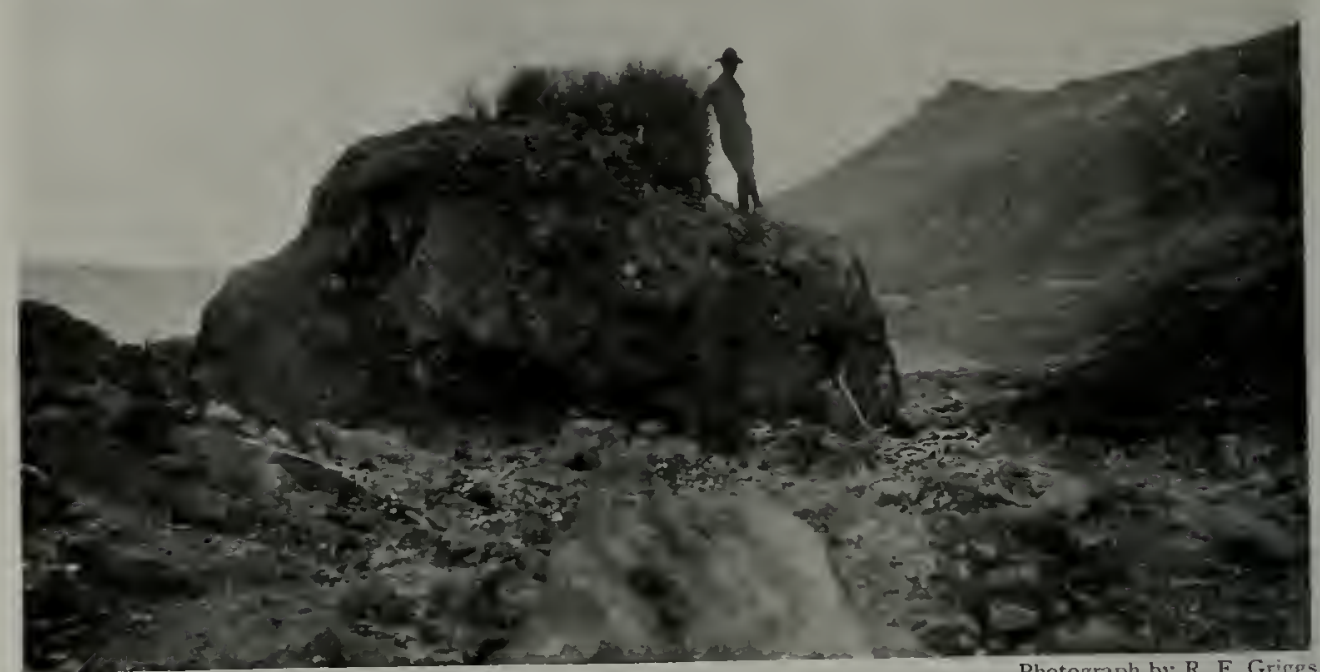

Photozraph by R. F. Griggs

ORIGINAL VEGETATION PERSISTING ON A ROCK IN MAGEIK SLIDE

By some freak this grass with the soil in which it grew was transported, "right side up with care," for two miles down the valley from its original position at the top of the cliff.

composed entirely of sandstone and shale, as though derived from a single block of sedimentary rock. V'ery likely these piles were at first irregular in shape, and asstmmed their conical form because the original block was too thoroughly shattered to hold together, its fragments rattling down symmetrically on all sides.

GEOLOGICAL STRLCTURE FAYORABLE FOR

\section{LAYDSLIDES}

An examination of the geological structure of the area where the slide occurred reveals conditions favorable for the development of landslides. Mlassive lava flows several hundred feet thick have been pottred out on a platform of sandstone dipping away from the vents. The strata are bent up against the volcanoes, as though blistered up by an injection beneath.

The lava flowing down the inclined surface of the strata often congealed before reaching the bottom of the slope. As it hardened, joint planes perpendicular to the sloping surface developed, more or less changing the solid flow into a series of slanting columns standing in unstable equilibrium like a "row of soldiers" ready to be knocked over.

Closely adjacent to the part of the cliff that fell away, colossal columns several hundred feet high are still hanging, apparently so ready to topple over that one wonders how they survived the shock that set off their neighbors (see page 134).

Through the joint cracks, water doubtless reached the original surface and, working along, may have facilitated movement by lubricating a bed for the unstable mass above.

Of the immediate cause which set off the fall we have no knowledge. Undoubtedly there were earthqtakes in connection with the eruption, but they seem not to have been particularly violent. It is not impossible that there may have been a further uptilting of the strata by the injection of new magma below. There is little if any independent evidence of recent uplift. Y'et an uplift of this sort would be the simplest explanation of the continual avalanches of Falling and Noisy Mountains (see page 24I). 


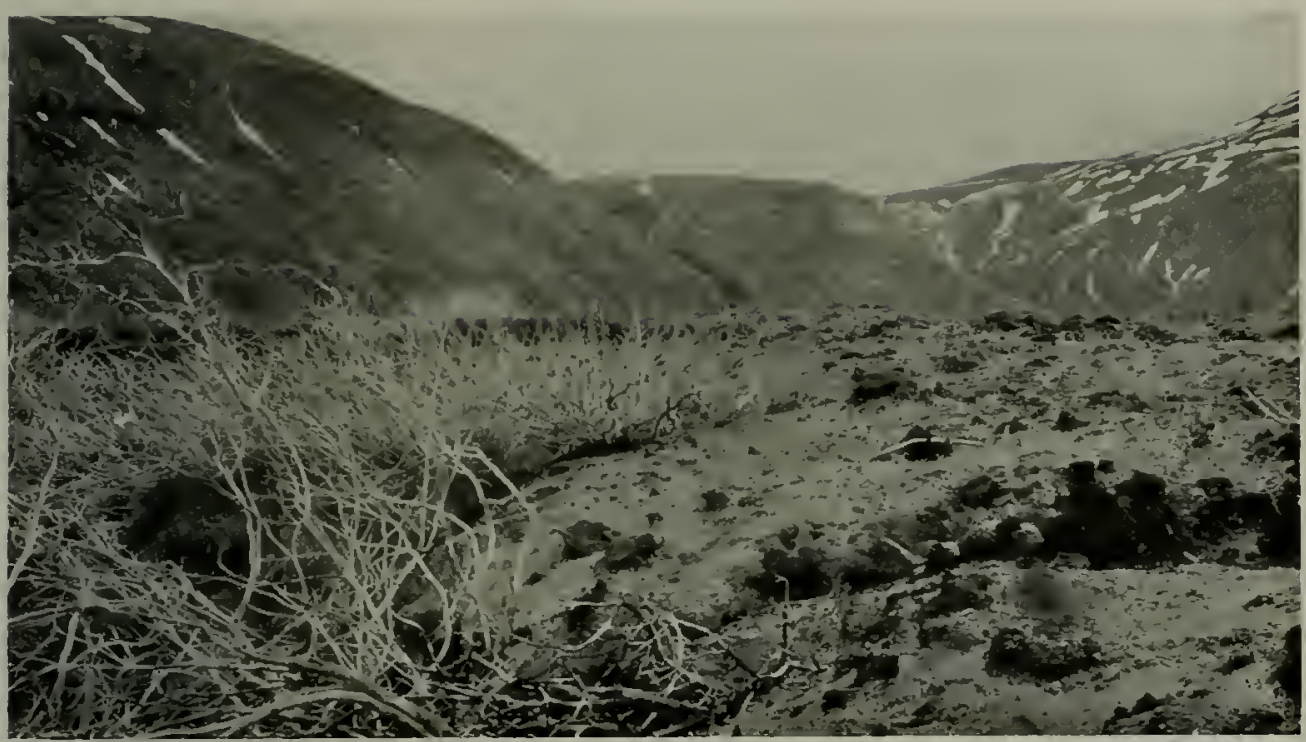

Photograph by R. F. Griggs

TERMINAL EDGE OF MAGEIK SLIDE

Although obliterating the alder thickets wherever it touched them, it showed no tendency to form ridges resembling moraines. At this edge the slide covered the ground only four or five feet deep. The black chunks are masses of peat.

It is interesting further to note that while the cliff at the head of the Mageik Slide was quiet during our observations in 1917 , it was subject to frequent heavy rock falls in August, 1919.

\section{DIMIENSIONS OF THE SLIDE}

The top of the cliff from which the rock started stands at an elevation of about 3,000 feet. The area from which the fall occurred is about 2,000 feet wide and $75^{\circ}$ feet high. It is a great gougedout cirque, whose bright unweathered rock contrasts strongly with the duller surface of the old cliffs. WTe have no means of estimating how far in front of the present cliff the original face may have stood.

The head of the slide is situated on a branch to one side of the main valley. From this point the rocks swept down half a mile of steep slope, falling about I,ooo feet; then across the flat valley floor for nearly two miles to the opposite mountain side, 400 to 500 feet lower. Then, deflected partly by the obstructing spur and partly by the mountain wall beyond, they turned $60^{\circ}$ from their course and continued down the milewide valley three miles farther, descending 600 feet more (see map, back cover).

The area covered by the débris may be estimated as two and one-quarter square miles. Of the quantity of material that fell away we are not in a position to make even a very intelligent guess, since we have no knowledge either of the original contours of the cliff or of the depth of the débris covering the ground.

From the reports on other slides of the same class it appears conservative, however, to estimate the average thickness of the débris at ten yards. On this assumption the cubage of the whole mass would be in the neighborhood of $70,000,000$ cubic yards.

The upper portion of the slide, just below the cliff, has somewhat the character of an ordinary talus slope; but its bowlders are of very great size, many of them 30 and to feet in diameter, and its general contours are concave, not convex as in an ordinary talus fan. Along with the large size of its bowlders goes a cer- 


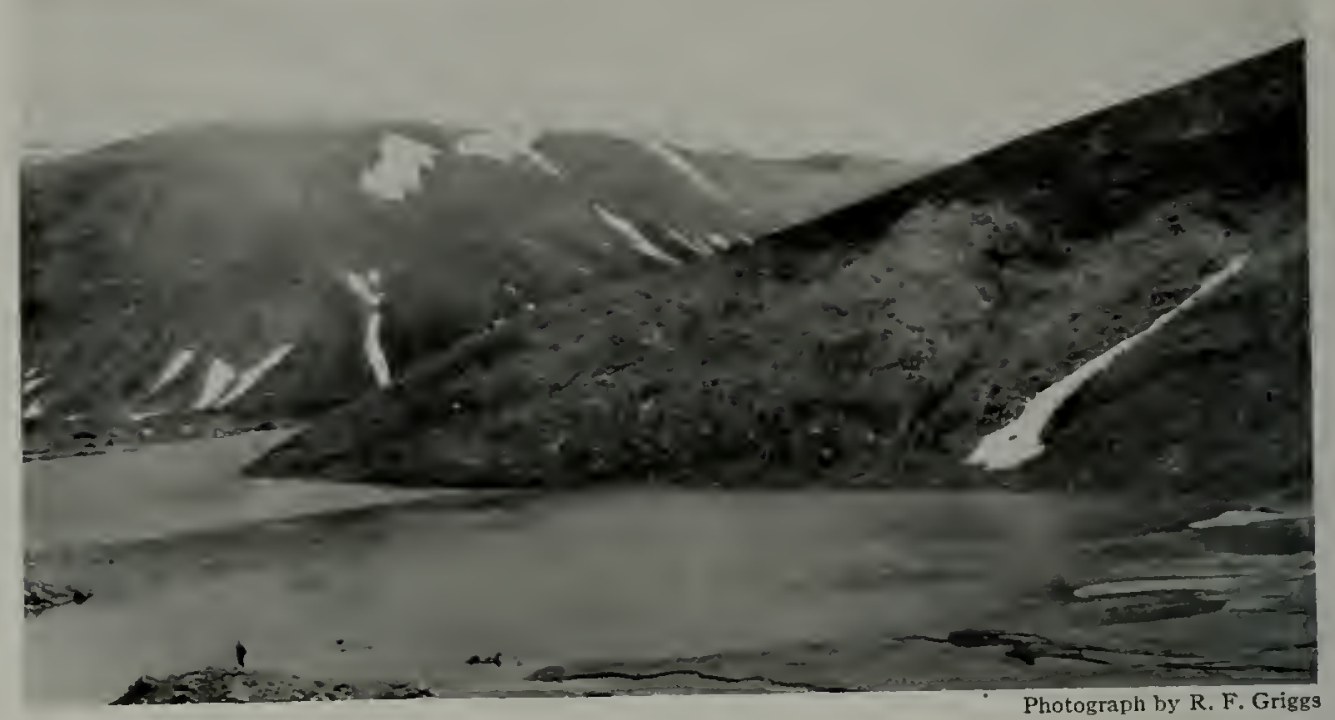

A HILL SCOURED OFF BY THE BOWLDER FLOW

The flying rocks scoured off the soil nearly a hundred feet up this hillside, yet before morement ceased the mass slumped away again, leaving a deep depression now filled with water, forming the Horseshoe Pond.

tain roughness and irregularity of surface not found in the typical talus.

The largest and most perfectly dereloped cones occur in the second portion, which occupies the flat valley above the bend. Here, also, the percentage of large rocks is much higher than in the lower portion. Cones and large bowlders gradually become smaller and less numerous toward the tip, although some cones and a few large bowlders occur near the end.

\section{SURPRISING LIQLIDITY MANIFESTED BY THE SLIDE}

Of all the curious features of this remarkable bowlder train none is more surprising to the observer than the clear evidence it presents of having behared like a liquid cluring the period of its motion.

In default of a better term, I have called it a landslide, but it cannot be considered as having slid down the valley in any accepted meaning of that term. It must have resembled rather the bowlder flows observed on Noisy Mountain (see page 129). It acted more like a flow of thin mud than a mass of dry bowlders.

The grade over which the débris moved in the lower part of its course slopes less than 200 feet to the mile ( $t$ per cent). Even if a bowlder were highly polished and its bed smooth, it would not slide on a grade of 1 to 25 . The attitude of many of the rocks shows plainly that they did not slide into their present place but were rather floated into position, buoyed up by the mass of finer débris around them.

It is incomprehensible that a mass of rough angular rocks could by any means be made to flow like a liquid. Nevertheless, the evidence convinces everyone who studies the terrane that this is exactly what happened.

\section{DESCRIPTION OF A SIMILAR SLIDE IN MOTION}

When opportunity came to look up the accounts of violent landslides elsewhere, my conclusions as to the remarkable fluidity of the mass were confirmed and strengthened. A similar "slide" 


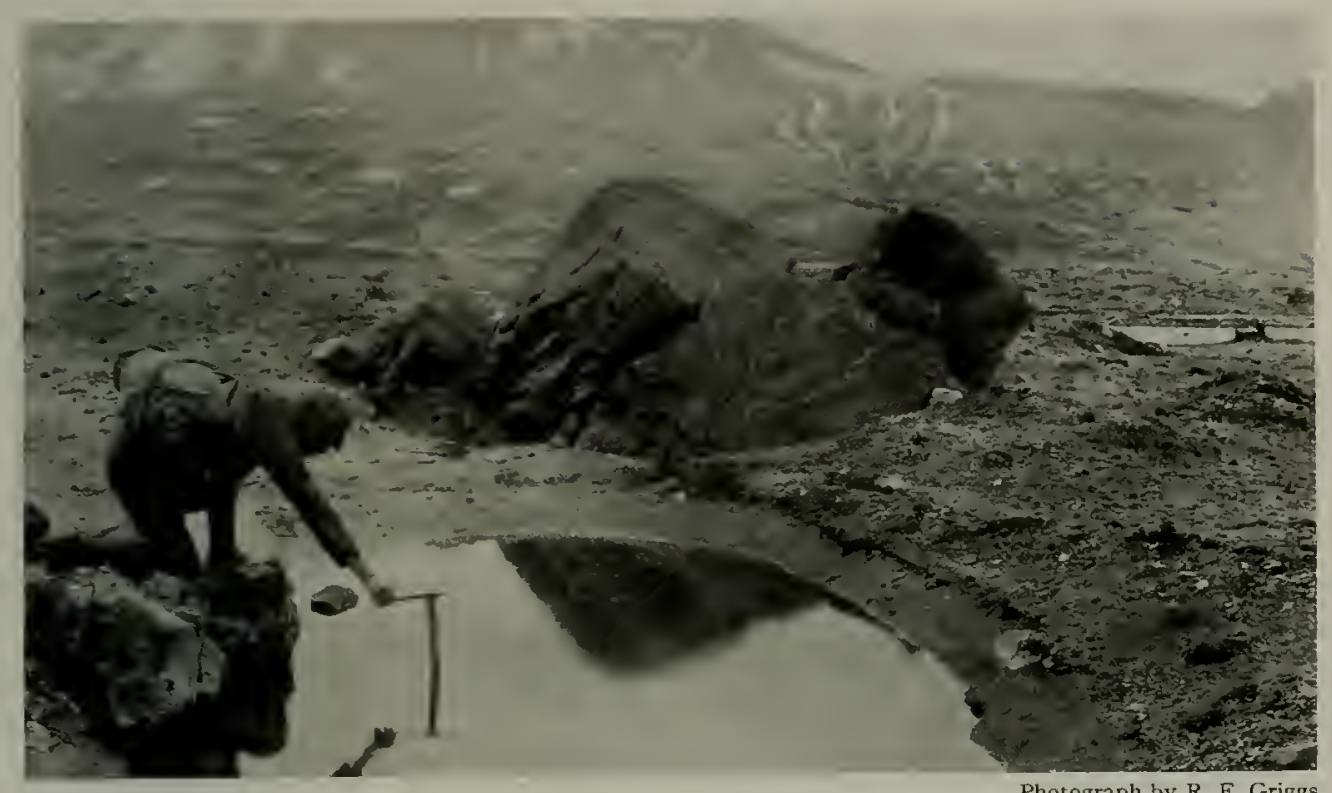

Photograph by R. F. Griggs

A DIMINUTIVE "KETTLE HOLE" POND NEAR THE TIP OF THE BOWLDER FLOW"

This may have been caused by the melting away of a chunk of ice or snow.

at Elm, Switzerland, was witnessed by a number of persons. From their stories Sir William Conway ${ }^{2}$ has written a description of the event which closely parallels what must have occurred in the Mageik slide.

"The last phase of the catastrophe is the hardest to imagine and was the most difficult to foresee. The actual facts are these. Ten million cubic meters of rock fell down a depth (on an average) of about $45^{\circ}$ meters, shot across the valley and up the opposite (Düniberg) slope to a height of Ioo meters, where they were bent $25^{\circ}$ out of their first direction and poured, almost like a liquid, over a horizontal plain, covering it uniformly throughout a distance of $\mathbf{I}, 500$ meters and over an area of about 900,000 square meters to a depth of from Io to 20 meters. The internal friction of the mass and the friction between it and the ground were insignificant forces compared with the tremendous momentum that was generated by the fall. The stuff flowed like a liquid."

${ }^{2}$ Conway, Sir William Martin, The Alps from End to End, pp. I76-184, I 900 .
Conway's narrative goes on to describe the death and destruction wrought by the catastrophe in the village of Elm. Fortunately, we have no need to follow him here. IVe may rather be thankful again for the good luck that the Mageik Slide occurred in an uninhabited valley, where no harm was done.

\section{MAGEIK SLIDE COMPARED WITH OTHERS}

The Elm Slide, although one of the best known examples of its class, is so far inferior in size as to make it interesting to inquire how the Mageik Slide should be ranked among similar phenomena.

The largest American slide of which I find record occurred some years ago in the Canadian Rockies, when a portion of Turtle Mountain slid down on the town of Frank, entailing great destruction. This was about three times as great as the Elm Slide, involving an amount of material estimated at $36,000,000$ cubic yards, spread out over I .03 square miles to an estimated average depth of 15 yards. ${ }^{3}$

${ }^{3}$ McConnell, R. G. and Brock, R. W. Report on the Great Landslide at Frank, Alberta, 1903. Annual Report, Dept. Interior, Canada. 


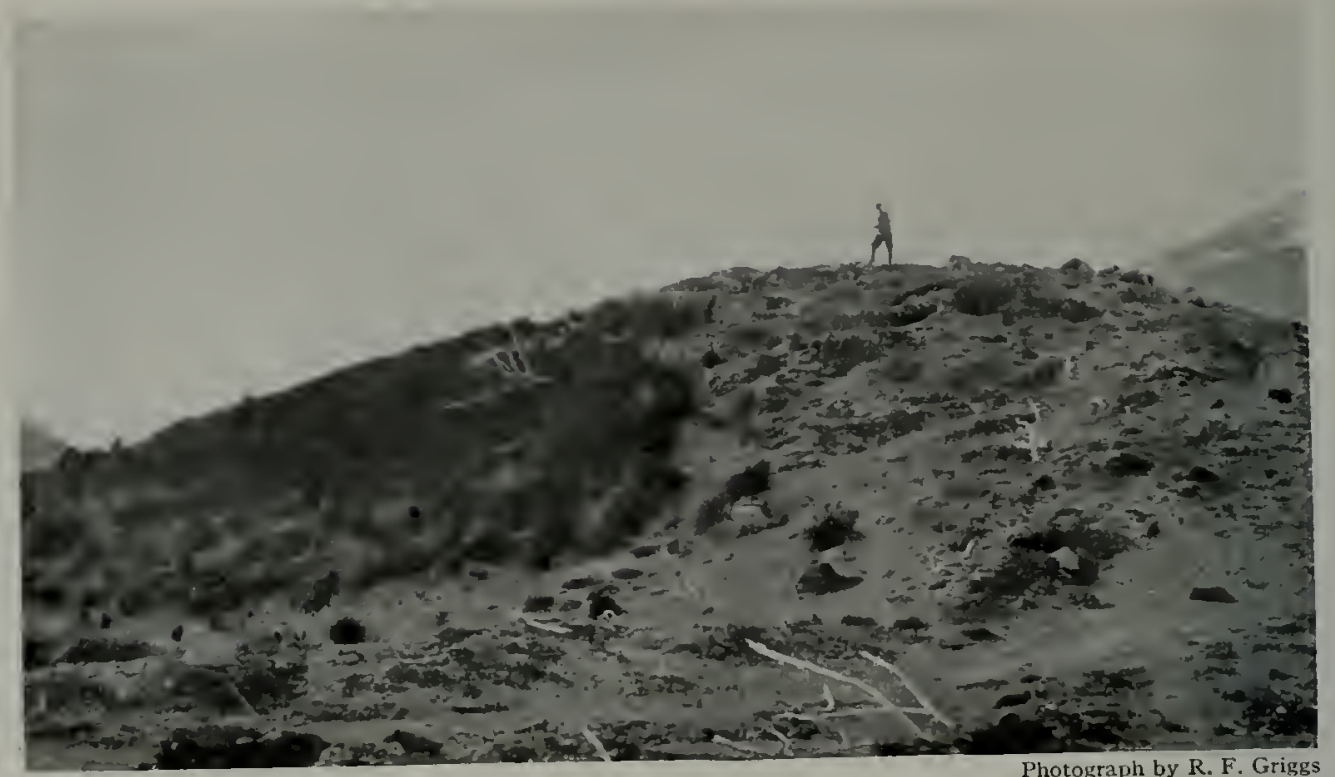

A THIN EDGE OF THE SLIDE WHERE IT RAN UP THE SIDE OF A HILLOCK The grass land at the left was not touched. The veneer of débris is so thin that it scarcely alters the
contour of the hill.

A slide at Rossberg, in the Alps, was still larger. This was 4,300 yards long, 349 yards wide, and totalled $51,000,000$ cubic yards. ${ }^{4}$

Of the landslides in the Katmai district three require mention here. The slide which dammed Katmai Canyon, causing the Great Flood when it broke, has been estimated by Maynard from his survey to contain $88,000,000$ cubic yards. The Noisy Mountain Slide appears far greater than the one in Katmai Canyon; but the survey has not yet been carried into that area, so that it is impossible to give any estimate of its dimensions. Y'et both of these seem to an average observer on the ground far inferior to the Mageik Slide, for which perhaps we have assumed too small an average thickness.

The slide from Falling Mountain, which was the opening event in the eruption (see Chapter xxI), may have exceeded all others in the Katmai district. Certainly the cirque on the broken face of the mountain looks as though fully as much rock had been gouged out as in any of the others. But there is no way of estimating the amount of the fall because all the débris is covered up by the deposits of the cruption.

As the slides described in the papers cited above were considered very remarkable events, it is evident that those of the Katmai district are to be ranked among the most notable examples on record. They are, however, by no means the greatest landslides known.

Aside from records of slow-moving landslips of the ordinary type, with which we have no concern, there are accounts of other catastrophes belonging to the same violent type, which so far exceed those we have described as to dwarf them by comparison.

\section{THE GREATEST RECORDED SLIDES}

The Gohna slide in the Himalayas in 1893 was much greater. An enormous mass of rock fell 4,000 feet from Mount Maithana into the Bhira Gunga at its 4 Zay, Karl, Goldau and Seine Gegend, page 318, Zurich, I807. 
foot. The violence of the fall was attested by the formation of great clouds of dust which darkened the neighborhood for miles around, and on settling covered the ground like snow.

The falls lasted for three days and continued in rainy weather for many months. The detritus formed a great dam, stretching along the river for two miles, filling the channcl to a depth of 900 feet; the length across the gorge was 600 feet in the bottom and 3.000 feet at the top; the thickness of the dam up and down stream I I,ooo feet at the bottom and 2,000 feet at the top.

Above the dam a great lake with a maximum depth of 777 feet accumulated, and was later released in one of the greatest floods of record (see Chapter IX). Although the surface covered by the débris was only 423 acres, it is evident that the quantity of material involved far exceeds those mentioned above, being estimated at $800,000,000$ tons, perhaps $5,000,000,000$ cubic yards. ${ }^{5}$

Greater still was a slide at Bandai San, ${ }^{6}$ Japan, in connection with the

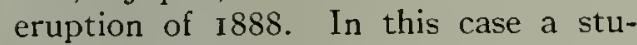
pendous mass of rock, set in motion by a volcanic disturbance, came flowing down from the mountain into the lowland, wreaking tremendous havoc on the inhabitants.

This event has gone into the annals of geology as an eruption, but it was clearly recognized that "the main feature of this eruption was the deluge of rock and earth." Consequently it has quite as much interest to students of landslides as to volcanologists. Its similarity to the Mageik Slide will be apparent from the following description:

${ }^{5}$ National Geographic Magazine, vol. 31, p. 277, April, 1910.

'Sekiya, S. and Kikuchi, Y., The Eruption of Bandai San, Journal, College of Science, Imperial Iniversity, Tokyo, vol. 3: pp. 9I-1 $7^{2}, 1889$.
"Among the various phenomena that constantly bewilder the eyes of visitors to the scene of the eruption, not the least striking are the numerous big bowlders, some of them measuring from 5 to Io meters each way, that are to be seen resting on the surface of the débris far away from the crater. These have evidently been carried along as part of the mud current, and not hurled through the air. Not less curious are the quantities of small cones, varying from a few meters up to I5 meters in height, which are scattered here and there over the surface, standing out of the débris like so many miniature Fujiyamas." 7

The material thus precipitated down the mountain side covered no less than 27 square miles (70 sq. $\mathrm{km}$.). Its bulk was estimated by the Japanese writers as $\mathbf{I}, 587,000,000$ cubic yards, more than twenty times as great as the Mageik Slide, putting it in a class altogether by itself.

The relocity of the Bandai San Slide was tremendous. Our authors estimate it as 48 miles, or 77 kilometers per hour. It was accompanied by terrific wind blasts (minimum velocity 90 miles an hour), which overthrew houses and tore up trees by the roots.

With the perspective furnished by these comparisons, we are enabled to rank the Mageik Slide among similar phenomena that have occurred elsewhere. Although a pigmy in comparison with Bandai San, it is so much larger than most of the better known slides and shows so many features of exceptional interest, that it must be considered one of the most remarkable in history.

7 This account is accompanied by drawings showing the innumerable cones studding the surface of the flow, in perhaps even more striking fashion than the photographs of the Mageik Slide reproduced herewith. 


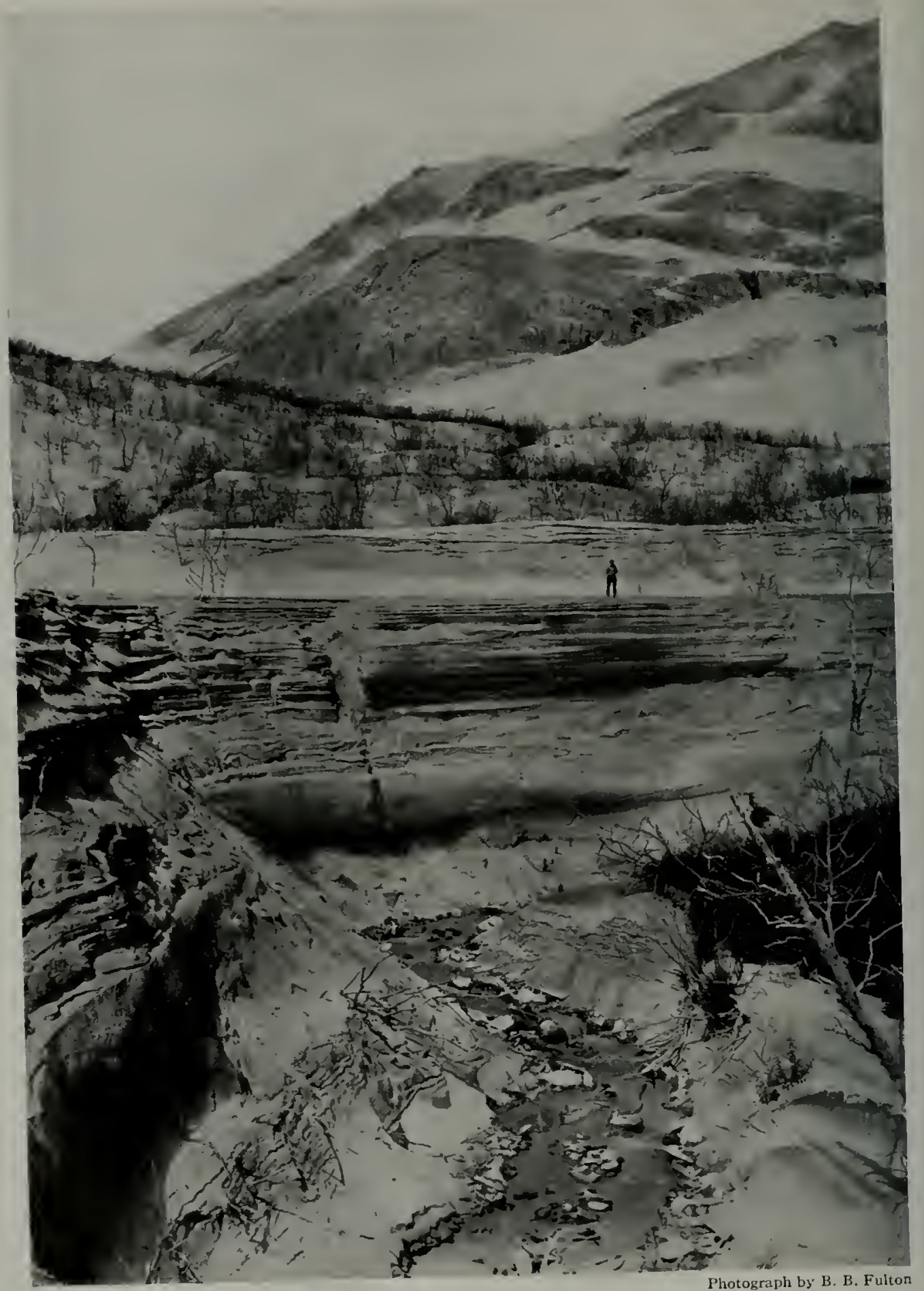

AN ASH ACCUMULATION ON A TRIBUTARY OF SOLUKA CREEK

The streams covered their beds with many feet of ash after the eruption. Later they began to remove the ash, sometimes cutting decp canyons. All of the material from the water up to the highest bank in front of the bushes is ash. The barometer indicated a thickness of 70 feet. 


\section{KATMAI VALLEY IN LATER YEARS-PHYSIOGRAPHIC INSTABILITY -ASHFALL-RETURN OF PLANTS AND ANIMALS}

When we landed on Katmai Beach again in 1916 we found the general appearance of the country much the same as the year before, though the mountains were a little greener and even on the flat a few seedlings were beginning to start; but when we began to examine the old landmarks we observed great changes in detail.

The site of our base camp of the previous year, for example, was found buried under twenty inches of fresh pumice washed off the mountain side, and a brook had cut its bed across the place where our tent had stood. The year before this stream had been 50 yards away. Indeed, it was by reason of just such changes that the country retained thesame general appearance from year to year.

If it once settled down so that the ground "stayed put," vegetation would begin to creep in and the whole face of the country would soon change. ${ }^{1}$

INSTABILITY THE KEY TO THE ABNORMAL PHYSIOGRAPHY

Instability is, in fact, the key to the abnormal physiography of the ashcovered region. Whether one observes the mountain tops, the hillsides, or the valleys of the streams, the one most striking feature of the landscape is its continually shifting surface.

On returning in 1918 to the camp-site at the base of Observation Mountain used in 1917, Sayre and Hagelbarger found that the ground on which the tents had stood was covered by about two feet of fresh pumice washed in during the interval. By 1919 the process had been reversed. The stream had not only removed the new accumulation but had cut away all the ash, clear down to the

1 More detailed discussions of the problems of the revegetation of the country can be found in original soil. On page 161 is shown the stump of a tree that was cut at a convenient height in 1917. In 1919 the cut end stood nine feet above the ground.

Some of the treadmill ash slides alluded to in Chapter vin were in continual motion. Near the base camp of 1915I 6 was a cliff from which there was an almost constant stream of fine ash sliding down a little channel and dropping off the edge, like the sand in an hourglass. But the "hour" of this glass never ended, for week after week the same trickle kept steadily sliding down, varying only with the wind, increasing as it rose and decreasing as it fell.

FREQUENT AVALANCHES FROM THE OVERLOADED MOUNTAINS

The general unsettlement of the mountains produced by the great loads of ash dumped upon them was not altogether relieved when the surface ash had slid off. Once started, the mountain sides continued to send down avalanches for a long time.

Some of the ash-cones were thus deeply covered with earth and rock, which fell after the slides of ash had ceased. On page 154 is shown a section of a slide produced under such conditions.

In 1915 rockfalls on a small scale were of constant occurrence; never an hour passed, night or day, without at least one being heard. Often we were awakened out of a sound sleep by their noise. While most of the rocks that fell were of comparatively small size, some were large bowlders capable of doing much damage (see page I48).

Entirely unused to such happenings, we could not at first believe that these

the Scientific Results of the Katmai Expeditions of the National Geographic Society, Ohio Journal of Science, vol. I9, pp. 318 et seq. 


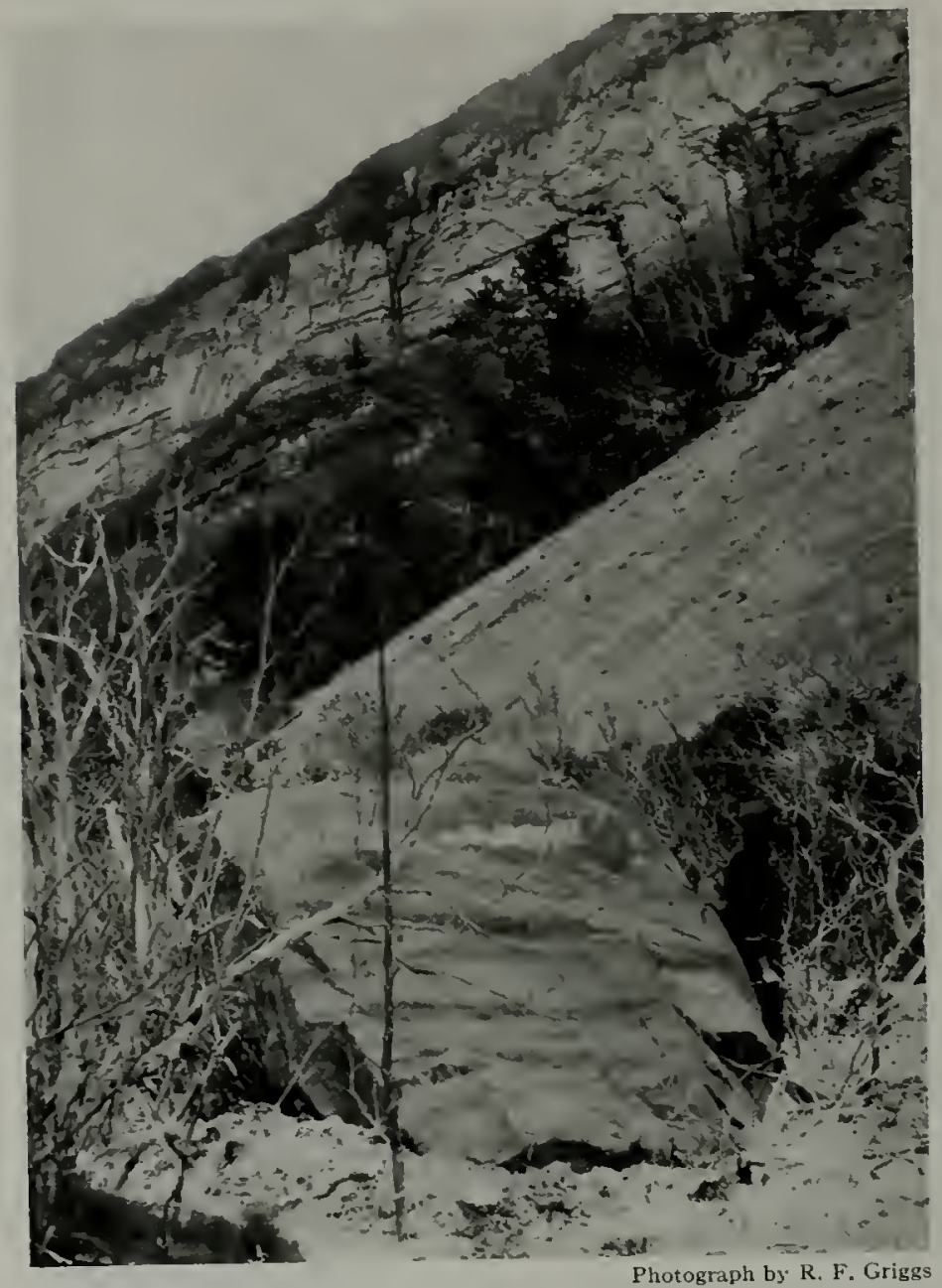

A ROCK THAT ROLLED OFF THE MOUNTTAIN SIDE NEAR OUR BASE CAMP, I916

frequent falls were due to natural causes, and for a long time supposed they must have been started by bears digging roots on the mountain side. But, after repeated failures to find Bruin with our glasses, it gradually dawned on us that they were merely part of the readjustment of the physiography after the eruption. They were, however, a passing phase, much less frequent in 1916 than the year before.

BURIED SNOWDRIFTS PERSIST FOR IEARS

Everywhere throughout the region one is made to feel the importance of wind action on the landscape. Almost every part of the surface of the country shows the effect of wind, being either eroded away by the powerful blasts or built up by deposits of wind-borne sand.

There are, to be sure, few such dunes of ash as have been formed near Kodiak, for the ash on the mainland is so much coarser and heavier that it seldom shows the characteristics of drifting snow. The deposits here are smoother, forming more regular veneers over the hills, and so fitting their contours as to be much less noticeable than the smaller deposits among the plants at Kodiak.

Allusion has already been made to the carerns formed by the melting of ash-covered drifts. We were astonished to find that in some cases an accumulation of ash two feet deep had been piled on the drifts since the last snowfall.

Ash is so full of air spaces that a layer of it acts like the sawdust of an ice house, protecting the snow from the sun's rays and greatly retarding melting.

At higher altitudes, where the ash covers the snow only in spots, its insulating property is very strikingly brought out by the differences in melting between the bare spots and those covered with ash. Even where the covering is very thin, melting is retarded and the protected spots soon stand up above the general surface. In this way the snow- 


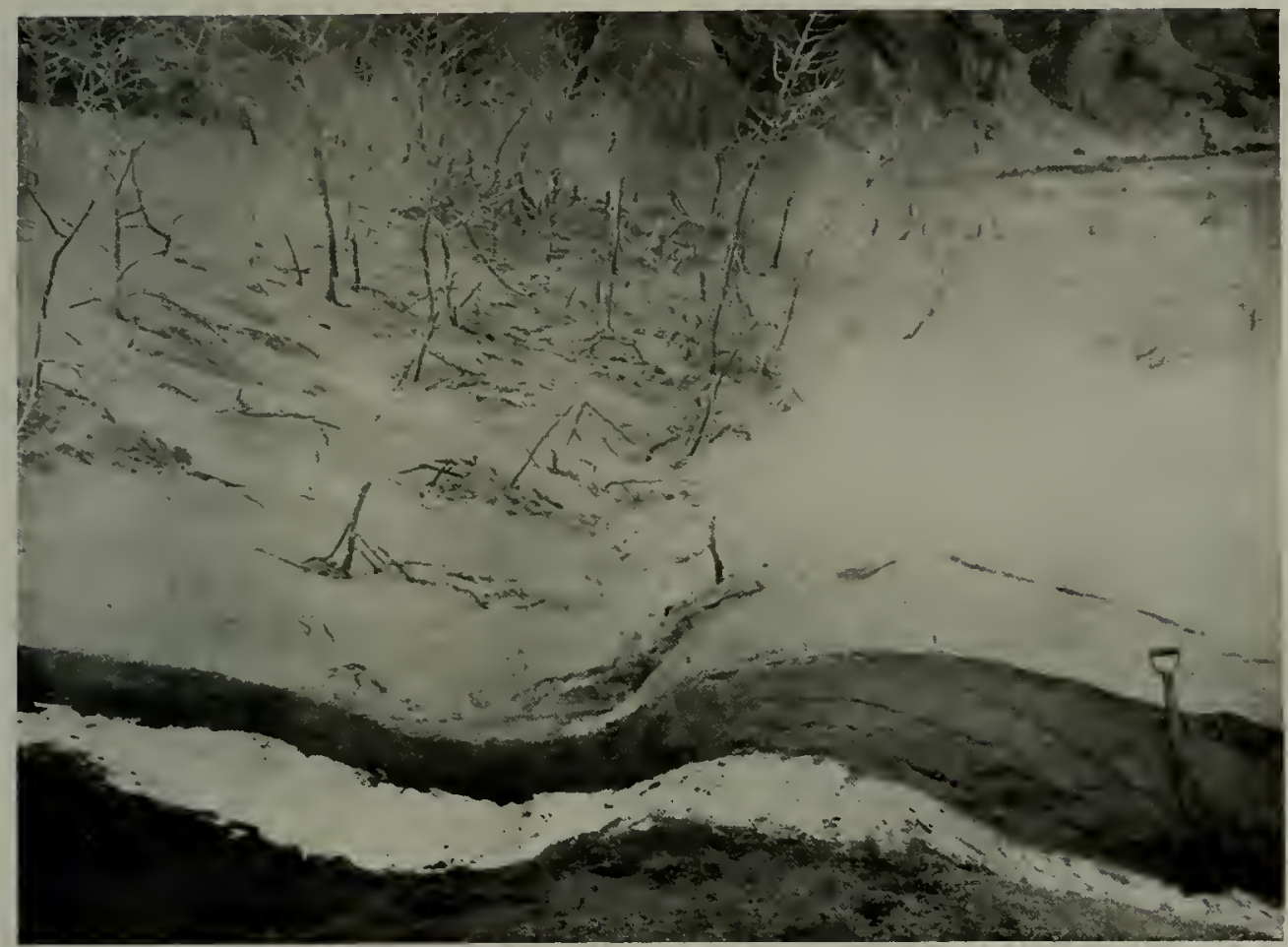

Photograph by D. B. Church

A SNOWDRIFT COVERED BY TWO FEET OF WIND-BLOWN ASH, NEAR KATMAI VILLAGE, AT SEA-LEVEL, JULY I5

Thus protected from the sun, melting of the snow is so retarded that in many places formerly uncovered early in the season the snow now fails to melt away and is accumulating year by year.

drifts come to be covered with the most curious, regular, ash-covered cones of ice (see page 156 ).

Where the ash-cover is deeper the melting of the snow is almost prevented, making permanent many drifts which formerly vanished early in the season. Thus, a secondary effect of the eruption may be a lowering of the snow line and an increase in the glaciers of the mountains.

In this connection it is interesting to observe that snowdrifts covered by the original falls of ash at the time of the eruption have melted away very slowiy.

Five years afterward we found caveins, where such drifts were just beginning to melt from under the regular strata of ash which covered them. As previously stated, the ash was not hot enough as it fell to melt the snow appreciably.

\section{WIND EROSION OF ASH SLOPES}

In more exposed places the wind has greatly eroded the deposits, smoothing the rough places and rounding off the whole surface. In planing down irregularities the wind has often cut through the various layers of ash, leaving the hillsides marked with bands and circles where deposits of different colors are alternately laid bare (see page I30).

Where wind-swept situations were occupied by birches, their dead trunks bear evidence of the power of the gales. On the northwest side the bark has all been cut away and in many cases the wood as well has been deeply abraded by pieces of ash and pumice flying before the wind (see page 9I). 


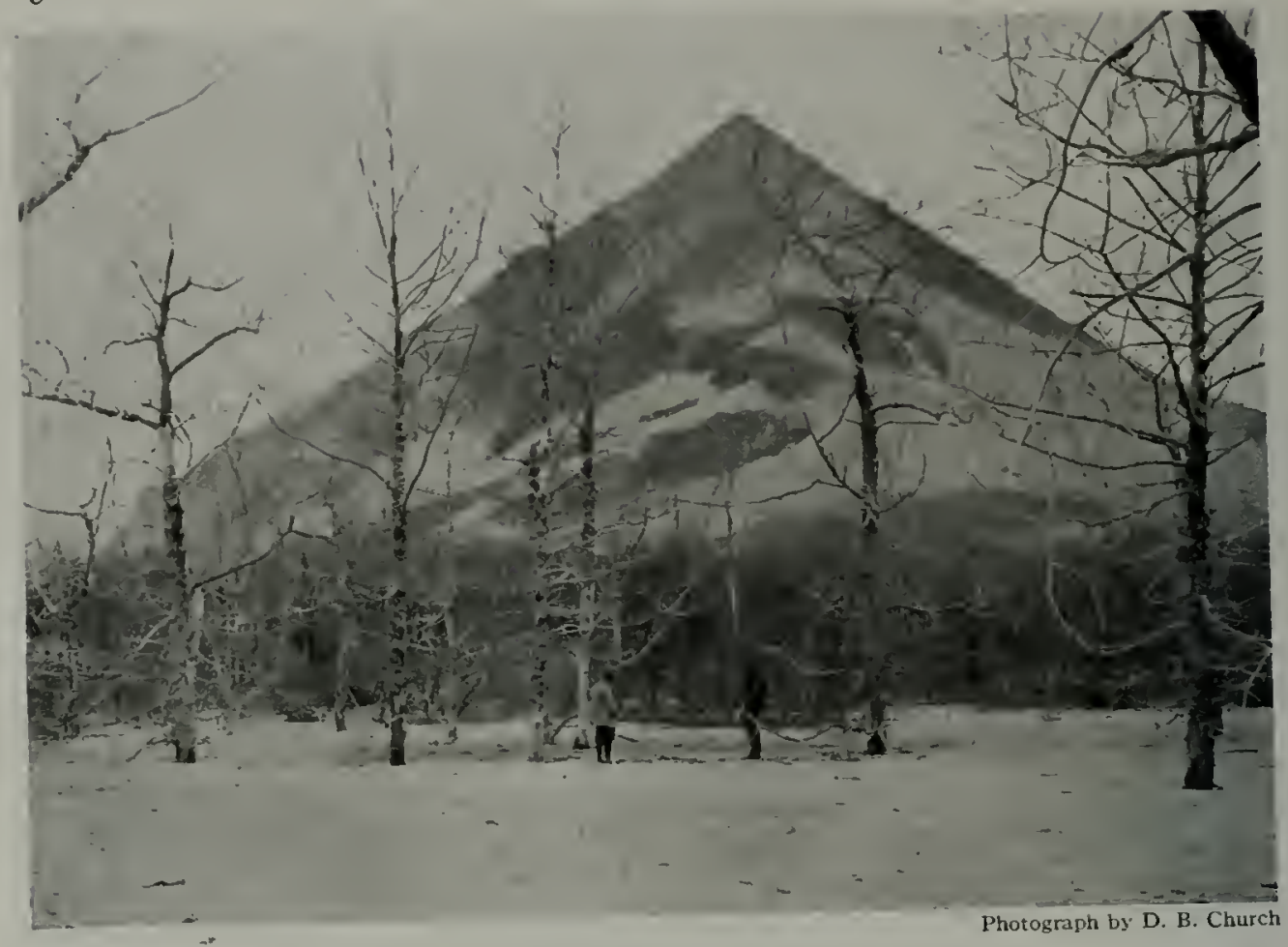

A CAMP SITE OF I9I5

On the first expedition our camp stood on the bank of Fickle Creek, whose channel, six feet deep, occupied the foreground of the present picture. During the year the channel was filled up and obliterated, while a new channel was dug a thousand feet away. Compare the picture on the opposite page.

One of the most astonishing instances of the instability of the country was noted near the mouth of Soluka Creek in 1916 . Here, as elsewhere, everything looked perfectly familiar, but when we tried to find our last year's camp our memories seemed to have failed. No one could locate it. How we could have missed it was a mystery, for it was conveniently placed on the bank of a tumultuous torrent which supplied us with water.

FICKLE CREEK SHIFTS ITS COURSE I,OOO FEET IX A YEAR

Curious to check up such an unusual lapse of memory, we hunted and hunted through the dead forest in searcli of the old camp. Finally we found the tent pins and the coals of the fire, just as we had left them, but the creek was nowhere in the vicinity. It had moved a thousand feet away.
Not only was the stream gone; its very bed was missing as well. The year before it had flowed in a steep-sided trench, six feet below the general level, but now the ground was smoothed off so perfectly that we could not, after the most careful search, detect the position of the former banks.

We were not so much astonished that the stream had filled up its bed and moved away, for that meant simply a fresh supply of pumice from a slide somewhere upstream; but that it could have done it so perfectly as to leave no trace was incredible.

When we studied such streams at work, however, we were enabled to understand the process. We observed that as they filled their channels the most tumultuous torrents gradually became subdued, more and more of their volume disappearing in the interstices of their 


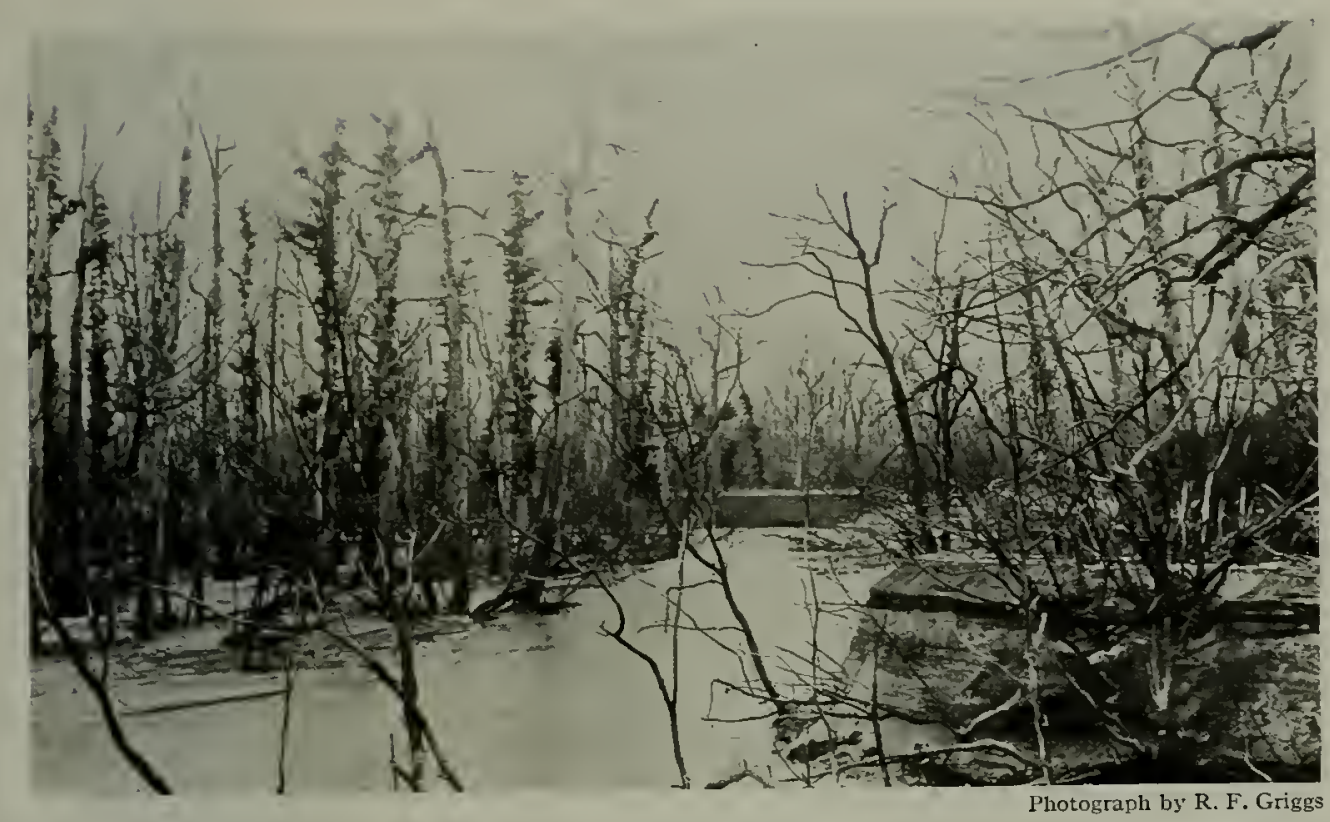

THE BED OF FICKLE CREEK IX I9I6

It had shifted a thousand feet in the year. We would not have believed that such a channel could be filled up so smoothly, without touching the coals of our old camp fire.

loose porous beds. Thus, their power was gradually dissipated, until at the end they became mere idle trickles spread out over broad flat plains of smooth-laid pumice.

In the case of Fickle Creek, a break in the banks upstream had stopped this slow process of aggrading just after the channel had filled up, turning the water in a new direction and giving it a steep gradient which enabled it to cut out another steep-sided trench.

\section{AXTICS OF PUMICE-CHOKED STREAMS}

Such streams, choked with ash and pumice, were extremely interesting things to watch. They spread out over the whole width of their flood plains, which had been filled with pumice several feet above the original level, wandering this way and that through the dead forest in a most fantastic way, changing their courses very rapidly, never the same for half an hour at a time.

As the supply of ash and pumice was practically unlimited, the water was always choked with more than it could carry. The pumice was so full of cavities that much of it floated, and the rest was but slightly heavier than the water.

The stream thus carried a much greater load of this sort of material than it could of ordinary sand or gravel, and this gave it a most peculiar appearance. The whole bottom was rapidly traveling downstream, its continuous steady motion reminding one of those moving platforms on endless belts sometimes used to transport passengers.

A brook near one of our camps had cut entirely through the accumulated mass of ash just below a fall, forming a bluff about 70 feet high (see page $1+6$ ).

A hundred yards downstream, however, the slope flattened out somewhat and the brook had been completely orercome by the enormous quantity of pumice in its way. It was ludicrous to watch the struggles of this stream as it wrestled with the pumice in its bed.

Dammed up in the failure of a previous attempt, it would gradually accumulate energy enough for a new effort. Then, suddenly breaking its bonds, it would 


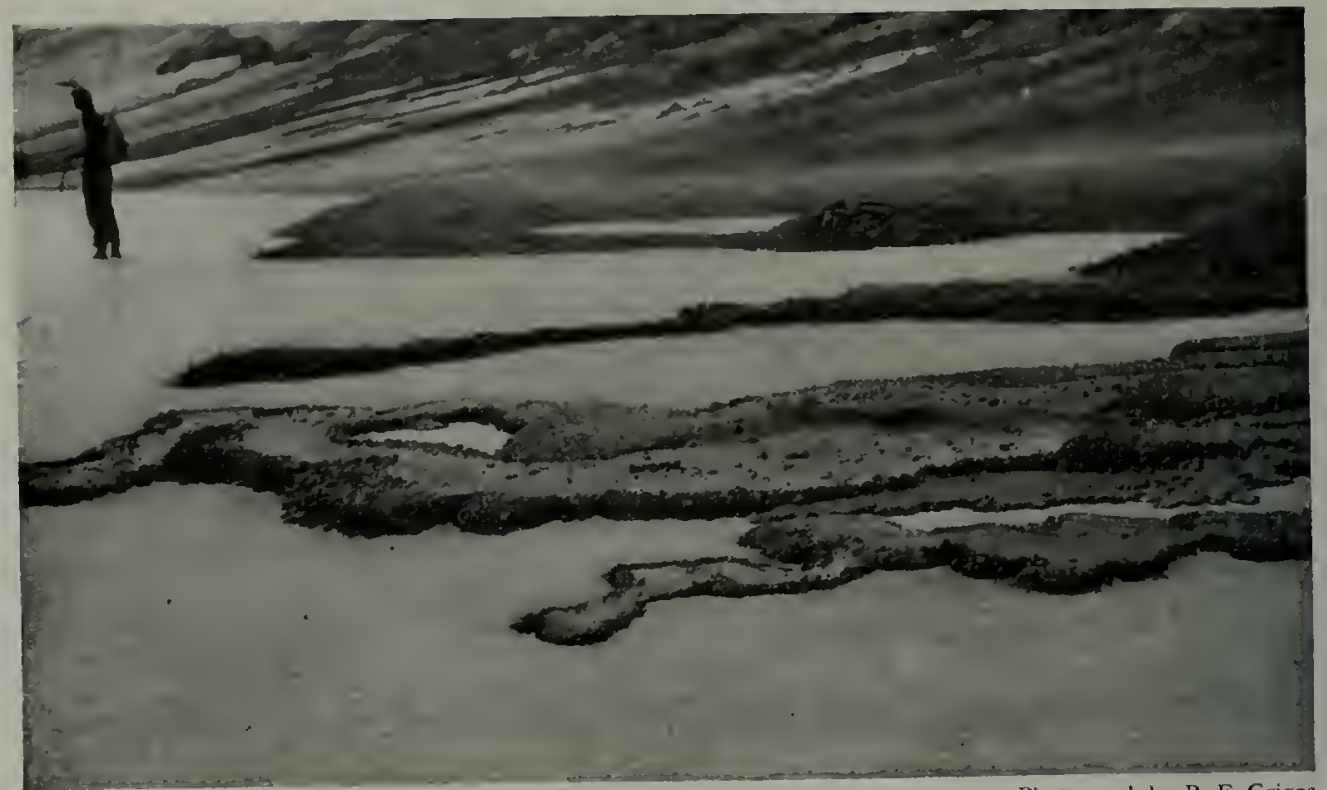

Photograph by R. F. Griggs

\section{RAISED CHANNELS BUILT UP BY OVERLOADED STREAMS}

By watching such streams one can see how the mighty Mississippi builds dikes in its channel, raising it above the level of the surrounding bottom lands.

rush forward down the slope, pushing a pile of grating pumice before it as though to engulf the onlooker, writhing this way and that like a live thing, picking up pieces of pumice and floating them along as it came.

Before it had gone far, however, its new load would literally choke it, and it would give up the struggle in a hiss of rattling pumice stones, only. to repeat. the process at another point in a few minutes.

CARICATURES OF AGGRADING RIVERS BUILDING FANS, DIKES, AND DELTAS

Watching these overloaded streams was instructive as well as amusing, for in their activities they furnished perfect miniatures - caricatures made diagrammatically simple - of the processes by which mighty rivers build their beds.

Here one could see in the course of a few minutes changes in channel which rivers require centuries to accomplish.

The lower Mississippi, for example, has built its banks high above the adjacent bottom lands, so high that when a break occurs the water spreads out far and wide, inundating everything except the immediate bank. The fact is evident, but I had never quite understood how a river could build such dikes for itself. It seemed too much like "lifting oneself by one's own boot straps." These streams furnish the demonstration.

Every one of their channels is built up high above the general surface, hemmed in by steep-sided dikes as regular as man himself could build. In an ordinary photograph it is possible to show only the finished channel standing as the stream left it, but in our motion pictures the whole process from beginning to end is beautifully portrayed.

Here one may see why it is that the deltas at mouths of rivers always assume a finger-form shape. For the process of building up the enclosing dikes soon reaches a limit. The stream bed is built so high above the general level that the banks can no longer restrain the waters, and they break out at the wcakest place.

The ensuing flood bursts over the lower ground, at first spreading over the 


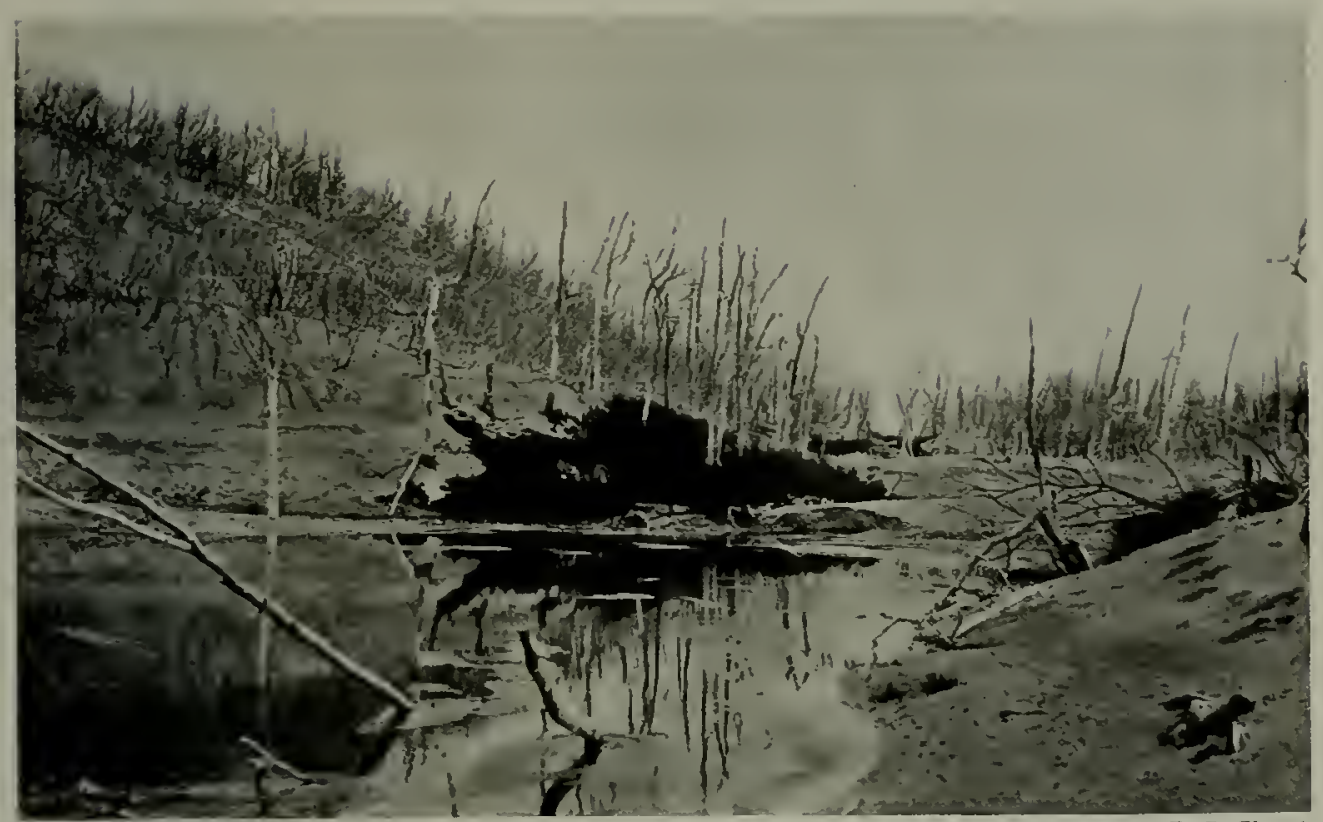

Photograph by D. B. Church

PATCHES OF RESURRECTED HERBAGE IN CLEARED AREAS

- Contrast the bare ash-covered ground round about. The roots from which these plants grew were buried for three years, but when uncovered by the great flood of July, 1915, quickly put up new growth.

whole surface, but soon cutting a new trench where the current is swiftest. The stream is thus entrenched in a new channel, which in turn is diked in and built up like an aqueduct.

Whether the slackening of current that causes the stream to drop its load is due to entering a larger body of water or to a change in grade, the land form produced is much the same. The repetition of the process of grading up, over and over again at different points, results in the formation of a smooth fan, spread out radially from the point where the current is slackened.

All the while the little brook, like the great river, is moving its load of pumice downstream. Before long there comes a time when it approaches the completion of its task. The supply of pumice at the headwaters begins to fail. As soon as this happens the energy of the water is released in part, and with renewed power the stream begins to cut away the earlier accumulation.
In this process, as in building up, the channels shift rapidly from side to side, cutting first here, then there, along their banks. This results in the formation of terraces, like those of ten found in large river valleys.

Sometimes one may count as many as a dozen of them, differing by no more than a foot in level, beautifully carved out by the shifting channels of one of these diminutive rivulets (see page 248).

\section{OBSERVATIONS ON THE DEPTH AND CHARACTER OF THE ASH DEPOSITS}

As we pushed our exploration into different parts of the ash-covered country, we kept records of the amount and character of the ashfall at various localities. The results of our study, combined with the earlier observations of Martin, are shown graphically by the map facing page one.

The most striking feature of the maps is the great irregularity in the courses of 


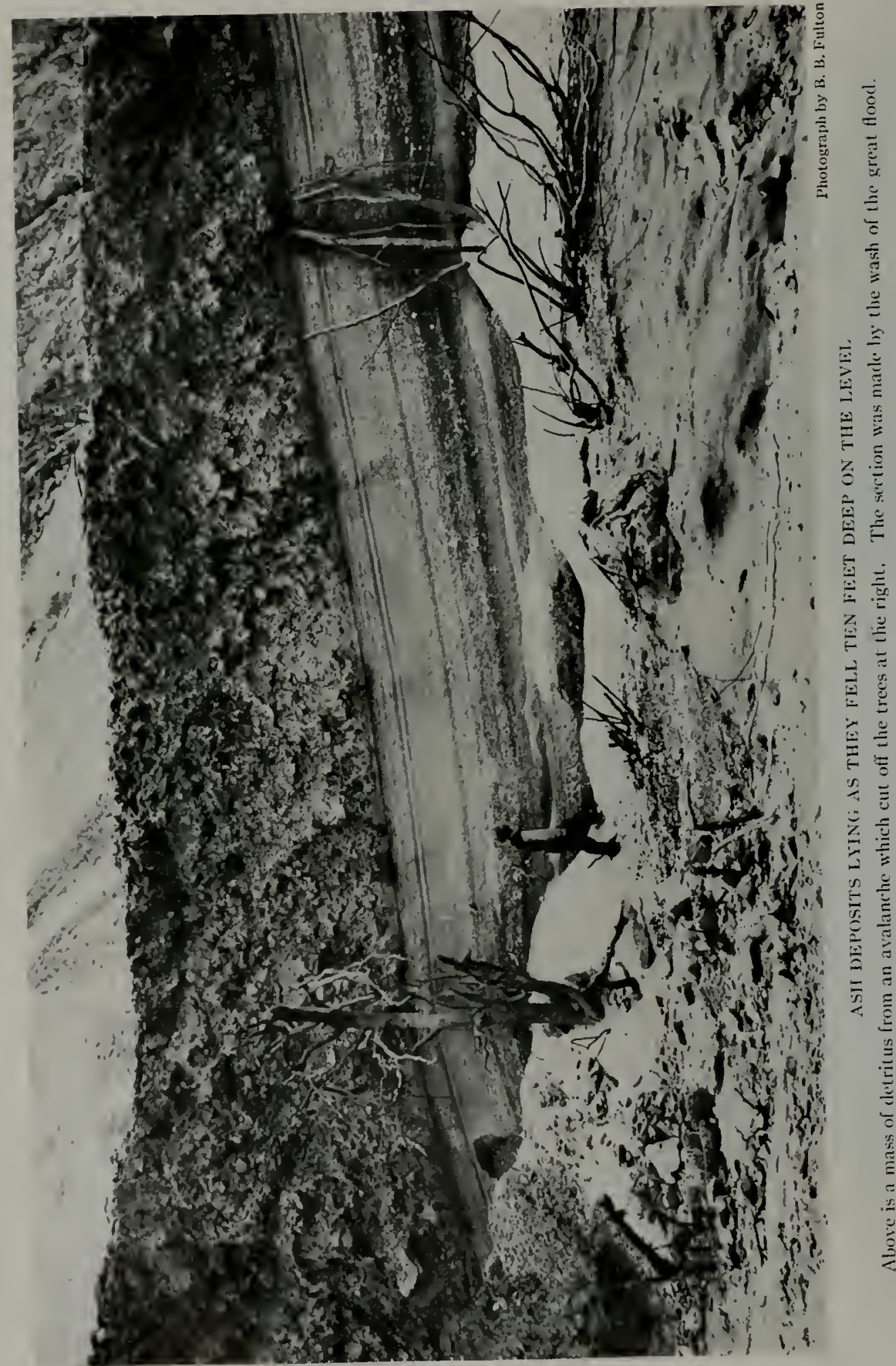


the contours. It is probable, moreover, that if we were in possession of full data from the unexplored areas north and east of the volcano, the lines would follow even more sinuous courses than those shown.

The occurrence of such irregularities, some of them so glaring as to appear almost like errors in the record, at first seems surprising.

It must be remembered, however, that the distribution of ashfall is largely controlled by the caprice of the variable winds. When one recalls the well-known irregularity of air currents around high mountains, the sinuous contours of the ashfall find, perhaps, a sufficient explanation.

In the deeper deposits of the mainland there are naturally many more strata than in the thinner falls at greater distance. Nevertheless, the major strata, a middle brown layer between two of a gray color, observable at Kodiak, are dominant everywhere in the sector southeast of the crater.

Down Naknek Lake and on the Bering Sea side of the range generally the stratification seems not to be correlated readily with that of the Pacific slope.

When we came up Katmai Valley under the volcano, we found a fourth layer of yellowish ash on top of the three primary strata. Close to the volcano this had a thickness comparable with the others, but it thinned out rapidly and disappeared within a few miles.

This layer we took to be due to a subsequent explosion of lesser violence, which had not thrown its ejecta high enough in the air to effect a wide distribution.

The very top of the deposits on the mainland is formed by a curious layer of dark, very fine, brown material so retentive of moisture that, under the climatic conditions obtaining, it always appears as mud rather than dust. On the slopes of the volcano this top mud layer is several inches in thickness. At greater distances it becomes extremely thin, but it is definitely recognizable as far away as
Katmai Village, where it gives a slight brown tinge to the top of the deposit. This layer differs from all the others in that it shows no tendency to drift about before the winds. Its presence and its thickness are so uniform as to suggest that, even as it fell, it was not subject to wind dispersal, i.e. that it may have been precipitated with the rainfall rather than by settling out of the air as dry dust.

\section{PLANTS LIE DORMANT, UNTIL UNCOVERED} BY FLOOD WASH

The most surprising change in conditions in 1916 was a resurrection of plants in places washed bare of ash by the great flood. The evidence that plants could survive burial for three years was here much more positive than that which we found later at Kodiak (see page I53).

At the "Flood Fall" and in numerous other places that had been deeply covered with ash until cleared by the flood waters, numerous plants had appeared. Most of them were survivals, coming up from old roots, which had remained deeply buried ever since the eruption.

Examination of the roots showed that there had been no attempt at growth during the three years intervening between the eruption and the flood, for the fresh shoots of the season were evidently the first to start since the old stems had been crushed down beneath the ash.

Resurrection was not restricted to any particular species, but appeared to include practically all kinds of plants that had originally occupied the ground laid bare.

Among them were several of the most characteristic species of the region, e.g., blue-top grass (Calamagrostis scabra), horsetail (Equisetum arvense), a sedge (Carex sp.), salmon-berry (Rubus spectabilis), a willow (Salix arctica), stonecrop (Rhodiola rosea), burnet (Sanguisorba sitchensis), wormwood (Arlemisia tilesii), twisted-stalk (Streptopus a mplexifolius), bitter cress (Cardamine umbellata), 


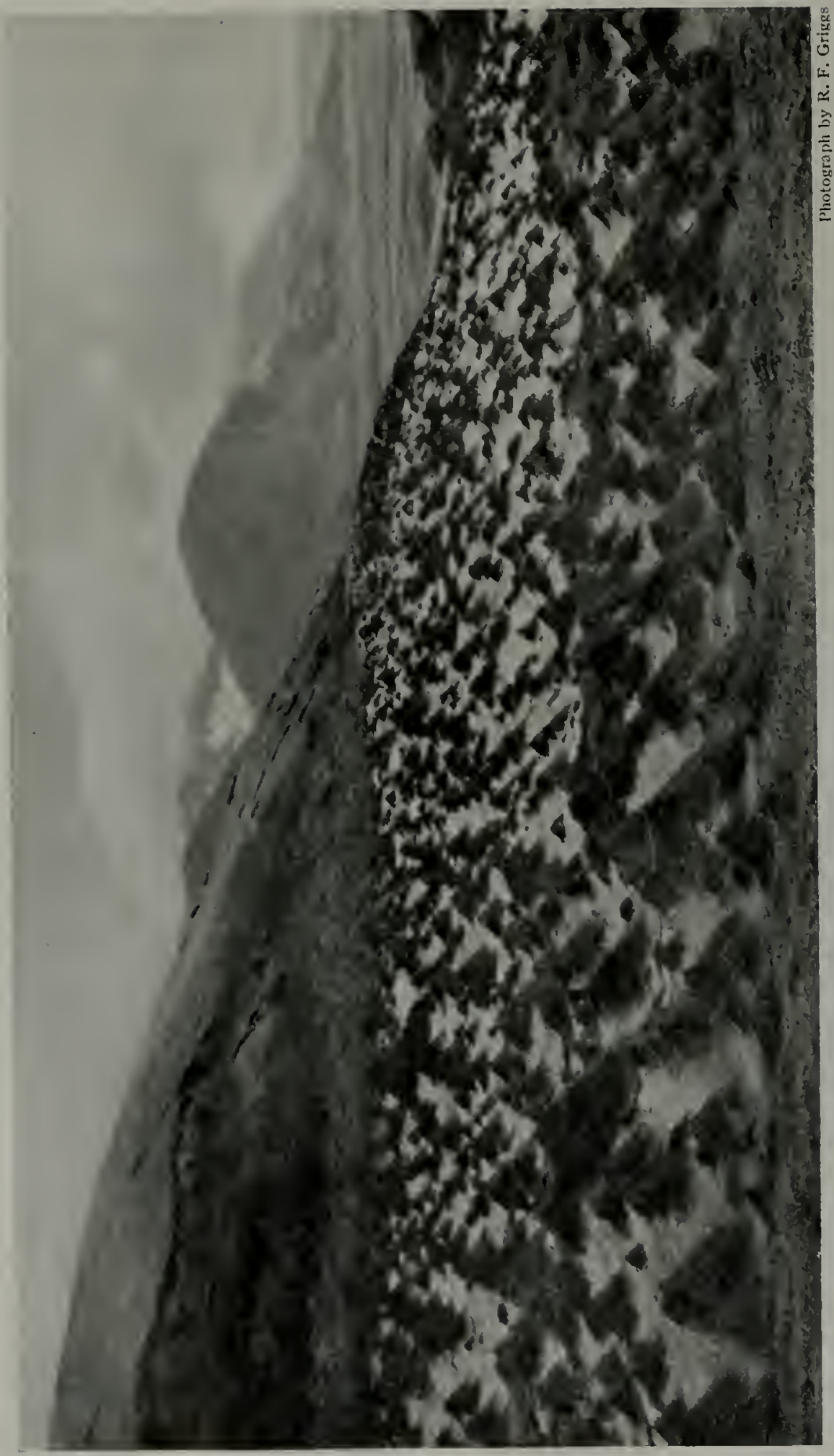

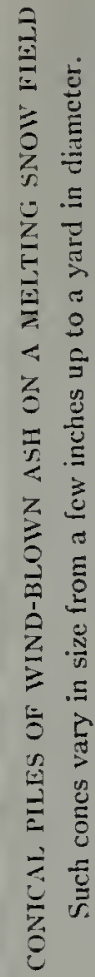




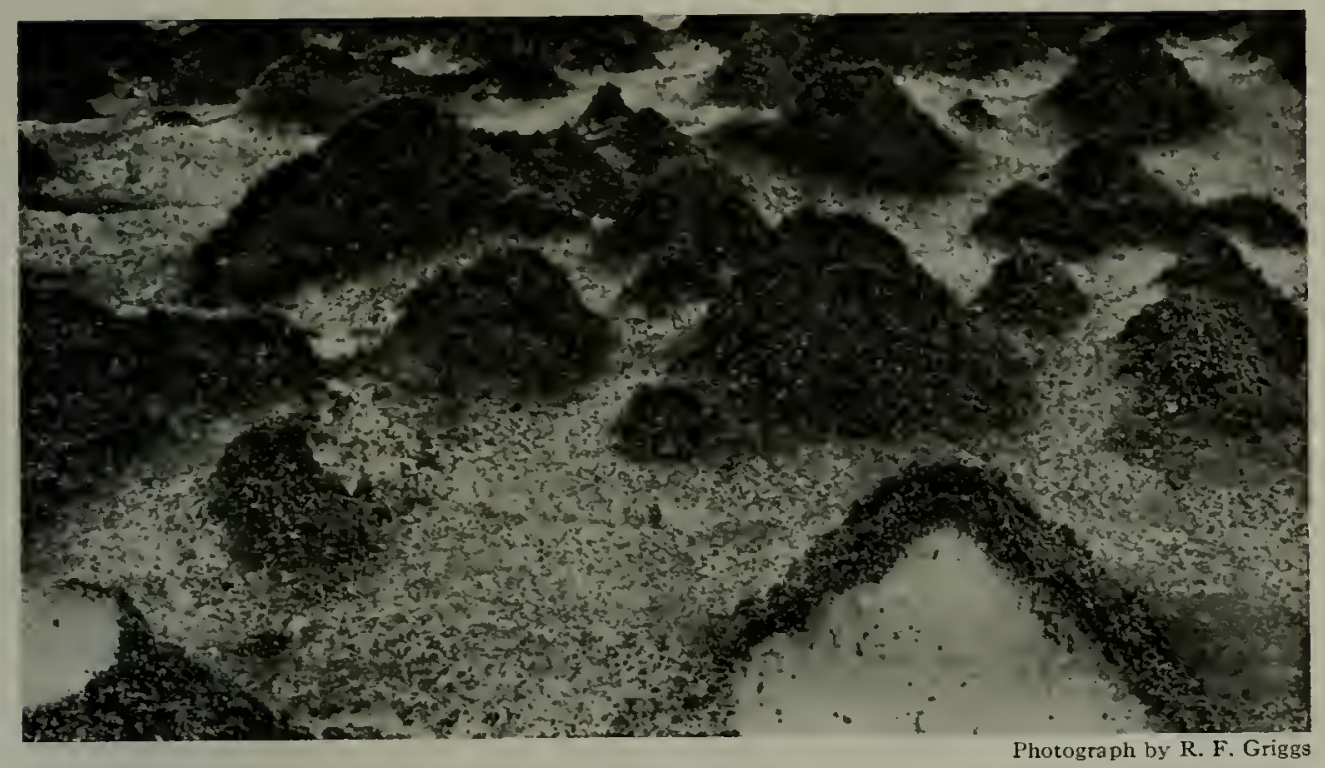

DETAIL FROM ASH-COVERED SNOW FIELD

When sectioned the cones are found to consist of ice which, blanketed by the ash, has melted more slowly than the bare snow round about.

chickweed (Cerastium sp.), a grass (Poa sp.), and a rush (Juncus sp.).

Together with these root-survivals were numerous seedlings, sprung from seeds that had lain dormant beneath the ash. Sedges (Carex spp.) and elderberry (Sambucus pubens) were abundant in all such stations; Geranium ( $G$. erianthum), and alum root (Heuchera glabra) were found less commonly, as was Polemonium ( $P$. coeruleum), which may, however, have been a root survival rather than a seedling.

If these plants had not been found in connection with the high-water marks of the great flood, the date of which was known, we should not have believed that they could endure such a long period of enforced dormancy.

But these survivals, together with what we found around Kodiak, led us to suspect that the resurrection of old plants usually plays an important rôle in recovery of vegetation after an eruption.

\section{THE BEGINNING OF REVEGETATION}

The reëstablishment of a plant cover over an area deeply covered by ash is, however, quite distinct from the recovery of scattered survivors, for the isolated spots where the ash is removed comprise only an insignificant fraction of the whole surface.

Real revegetation, the colonization of deep deposits by new plants, is obviously much slower and much more difficult than the rejuvenation of old roots.

New plants not only must start from tiny seeds, as contrasted with the extensive rootstocks of survivors, but they must draw their nutrition from the sterile ash rather than from the fertile soil beneath.

At the time of our first visit it could not be said that revegetation proper had begun, but in 1916 and in subsequent years definite though very slight beginnings in the formation of a new plant cover had started.

The handicaps that must be overcome by new plants in getting a foothold on the shifting ash are very great. When one considers the physiographic instability of the country, he marvels that seeds can find any situations stable enough to permit their starting. 


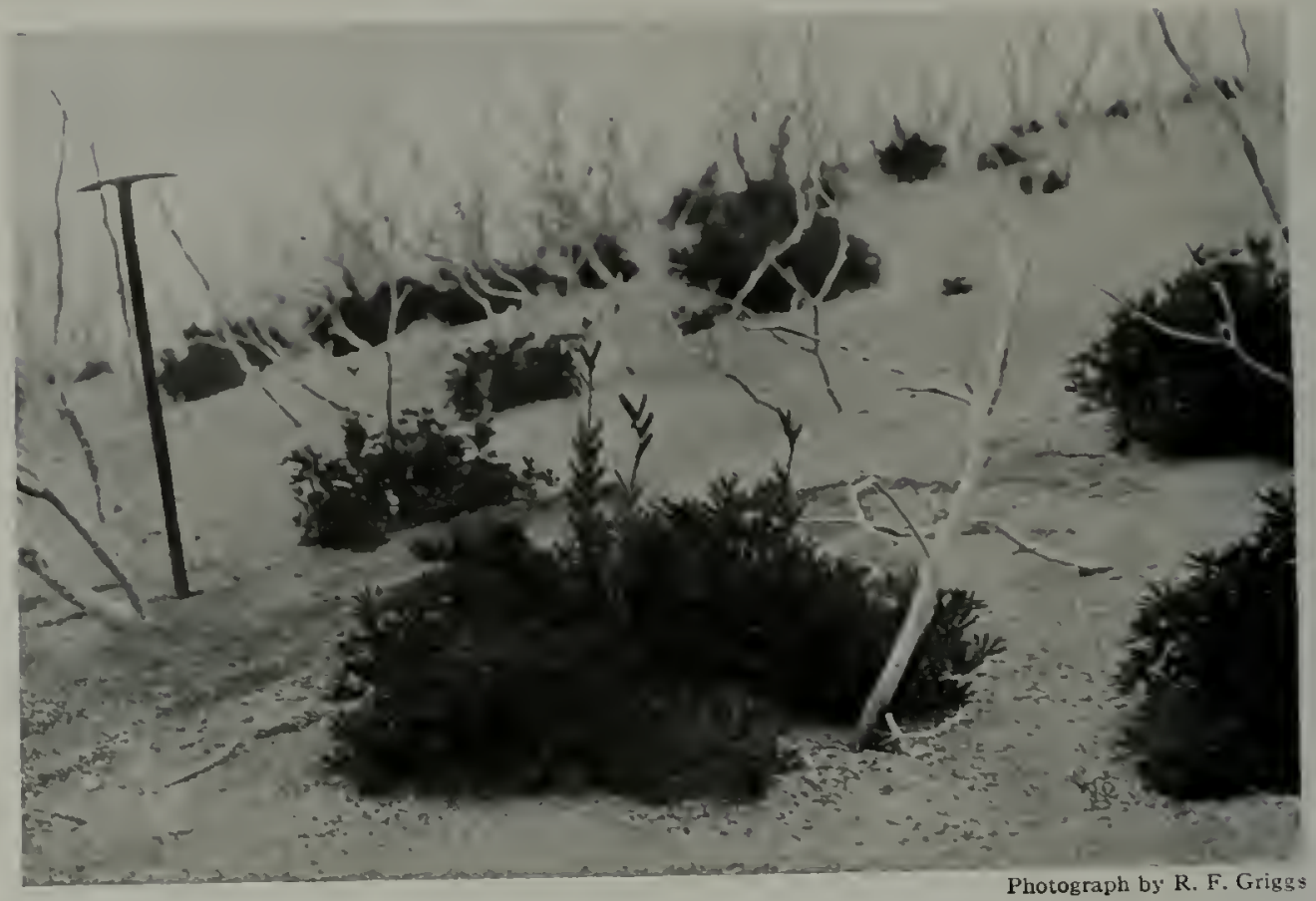

FRUITING LUPIXES GROWING IN DEEP ASH DEPOSITS

These plants are the most successful pioneers in the process of revegetation, because, on account of their root tubercles, they obtain nitrogen from the air, while most other plants are dependent on organic compounds. The vigor of the plants and the abundance of the fruit in the Katmai region organic compounds. sand blast.

One would suppose that the extreme poverty of the ash in all those salts necessary for plant nutrition, especially in nitrogenous compounds (as shown by analysis, page 46), would be the critical factor in retarding revegetation. Observation, however, shows that in reality it is the mechanical rather than the chemical factors which limit the process.

The instability of the soil discussed above in its physiographic bearings is, in fact, one of the greatest obstacles to reregetation.

The effect of sand blast on the colonization of the soil is not easily observed directly, because at best the seedlings are few and far between. It was clear, however, that revegetation was restricted to areas relatively free from both sand blast and accumulating drifts.

Seedlings nevertheless of ten revealed an astonishing degree of tolerance to drifting ash. Lupines, for example, had become thoroughly established in an area where the sand blast was severe enough to decorticate woody stems.

SEEDS, CARRIED BEFORE THE WIND, FAIL TO LODGE IN PUMCE FIATS

In addition to affecting revegetation by keeping the surface soil always drifting about, the wind controls to a large extent seed dispersal.

Regardless of the various adaptations of the different species for dissemination, the distribution of seed in this district is effected largely by the high winds which prevail. They are so powerful that they can carry even heary seed for long distances, thus assuring that adequate supply of seed throughout the devastated area without which revegetation would be impossible. 


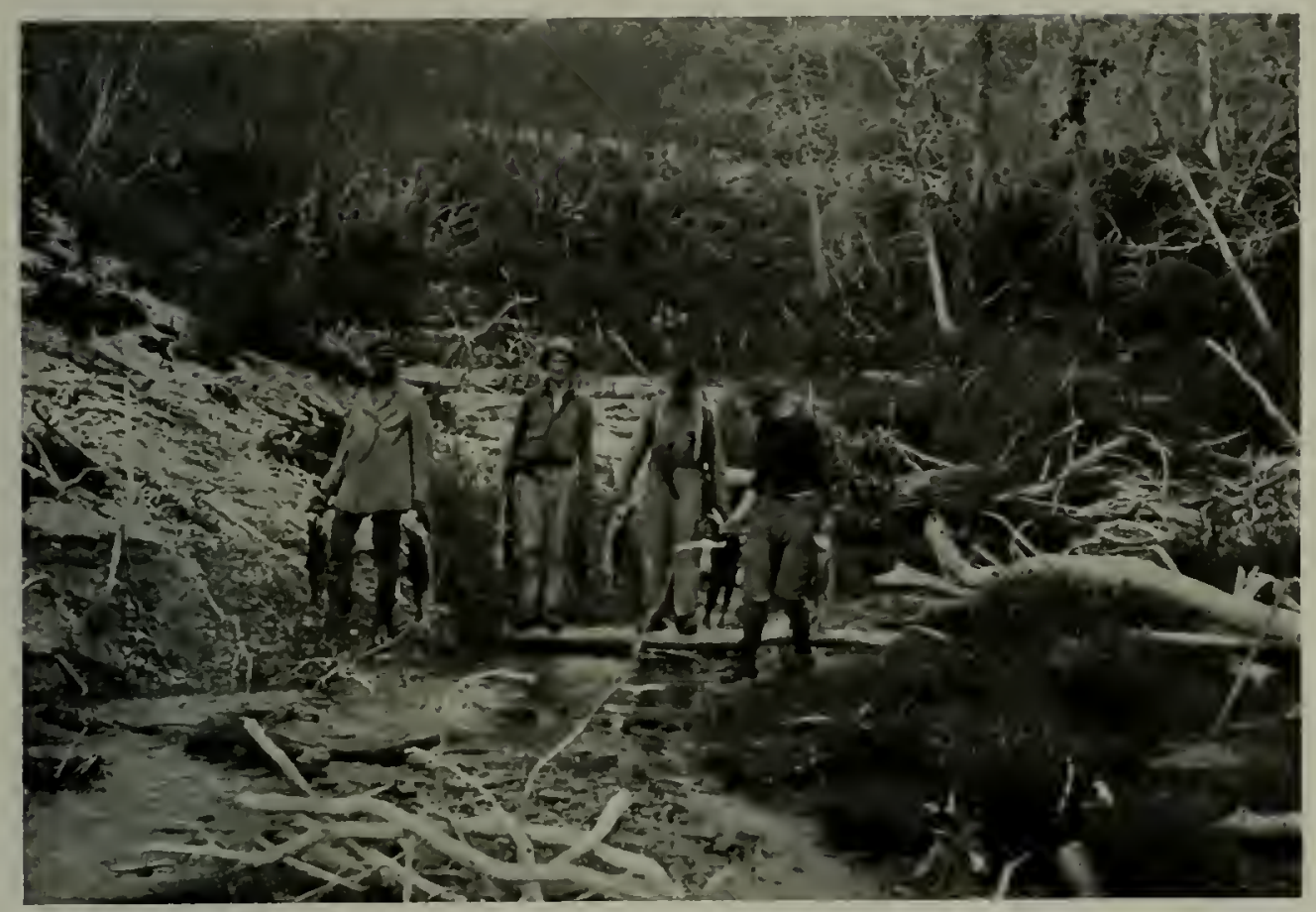

SOCKEYE SALMON SPAWNIING IN A SMALL BROOK

This was the only stream in the Valley in which they were to be found (see text page 16I).

I found by experiment that a breeze of only 15 miles an hour was able to pick up and carry off lupine beans, one of the heariest of native seeds. It is evident that the frequent gales must carry seeds beyond into every corner of the ashcovered district.

Under the circumstances the relative distances of different areas from sources of seed supply are of little consequence.

Yet the wind interferes greatly with the seeding down of any particular situation. The picture of the bear trail, reproduced on page 162 , gives the clearest testimony as to the conditions. The seeds, carried before the wind, found no lodgment on the smooth flat, but were caught in the depressions, perpetuating the transitory footprints.

Likewise, we found the old dry heaps of pumice deposited by the shifting streams the abode of numerous seedlings, in contrast to the bare ash round about. Evidently the seeds had been carried down by the water and planted in the pumice out of reach of the wind.

\section{LUPIXES THE MOST IMPORTANT PIONEER PLANTS}

In wet places on the flats, seedlings of many sorts were springing up sparingly, but in well-drained situations the lupine was much the most effective pioneer. It was not until 19I9, however, that new plants were found coming up in deep deposits on the hillsides, and then they had gained a foothold only on slopes sheltered from the most violent winds.

Yet in some localities they were so abundant and so thrifty as to seem to give a clear indication of the course that revegetation was to take.

There is every reason to believe that with the years ther will gradually spread into more and more exposed places, for it 


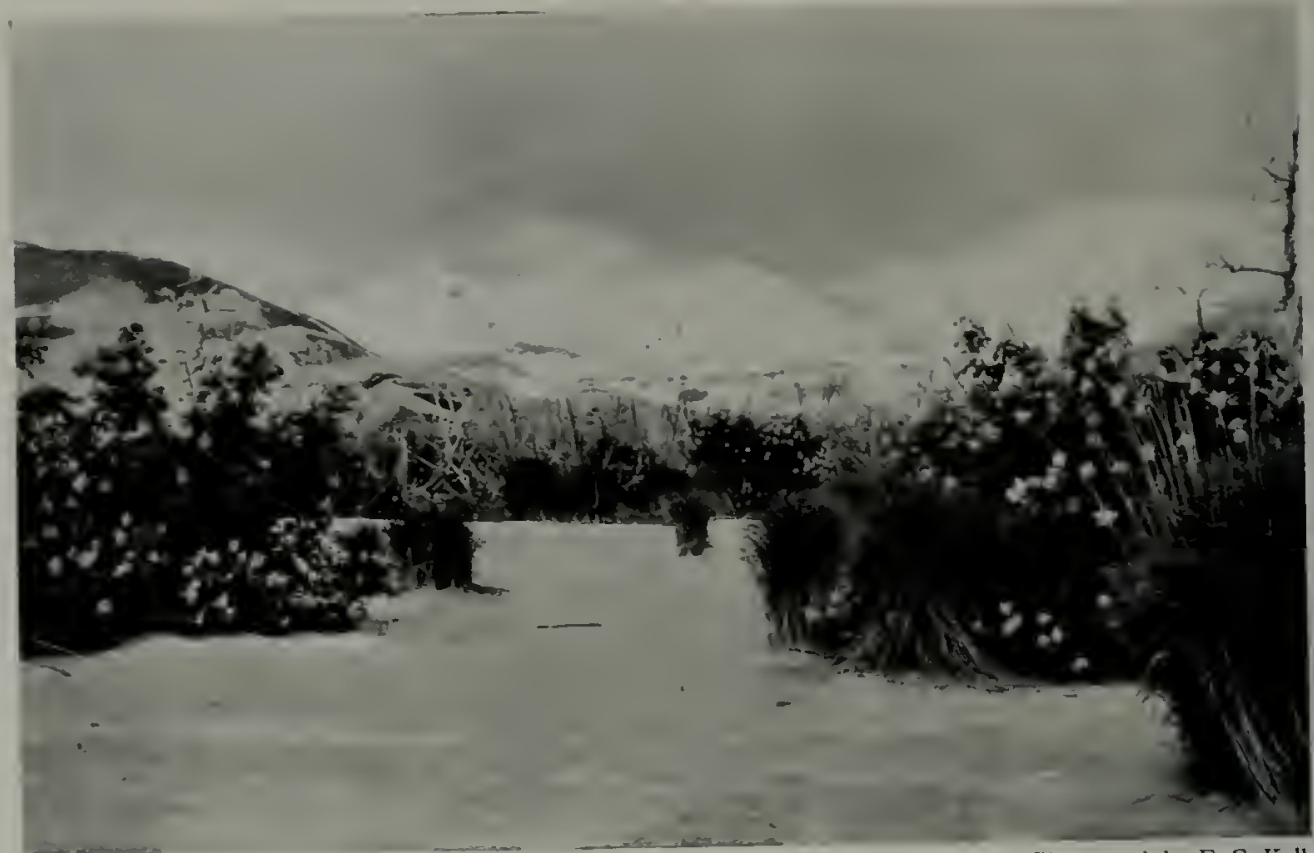

MOUNT MAGEIK FROM THE ASH FLATS

The elderberries and bunches of grass have come up through a heary blanket of ash and pumice.

is evident that the extreme instability of the country is gradually subsiding and that every new plant serves as a soil binder, helping to prevent further shifting in the soil which it occupies (see pages 46 and 47 ).

The lupine is in several ways peculiarly well adapted as a pioneer. Its heavy seeds can lodge where the lighter seeds of grass would be blown away. The large quantity of food stored in the seed enables the young plant to grow with great rapidity and establish itself in a much shorter time than species with smaller seeds.

It is, moreover, a leguminous plant, and like all the members of the bean family is provided with bacterial root tubercles, which enable it to utilize the free nitrogen of the air.

The lupines growing in the ash deposits all had very abundant and thrifty tubercles. Their ability to obtain the nitrogen necessary for their sustenance from the air must be an advantage of prime importance in a soil from which organic nitrogen compounds are practically absent.

Nature has here carried out on an extensive scale a field repetition of Helriegel's famous pot experiments by which he proved that legumes could live on nitrogen drawn from the air in soils where other plants perished for lack of that ability (see page 158 ).

Since nitrogenous compounds are essential to plant life, the conditions here would seem to prohibit the growth of any plants except those provided with some means of rendering the nitrogen of the air arailable.

With great interest, therefore, we observed that a few individuals of other plants had obtained a foothold in the same deep ash. They had somehow managed to obtain enough nitrogen to reach maturity and produce seed. These included blue-top grass (Calamagrostis scabra), a sedge (Carex sp.), and a rush (Juncoides sp.). Just how these plants managed to subsist in a soil so nearly devoid of all nitrogenous compounds is 


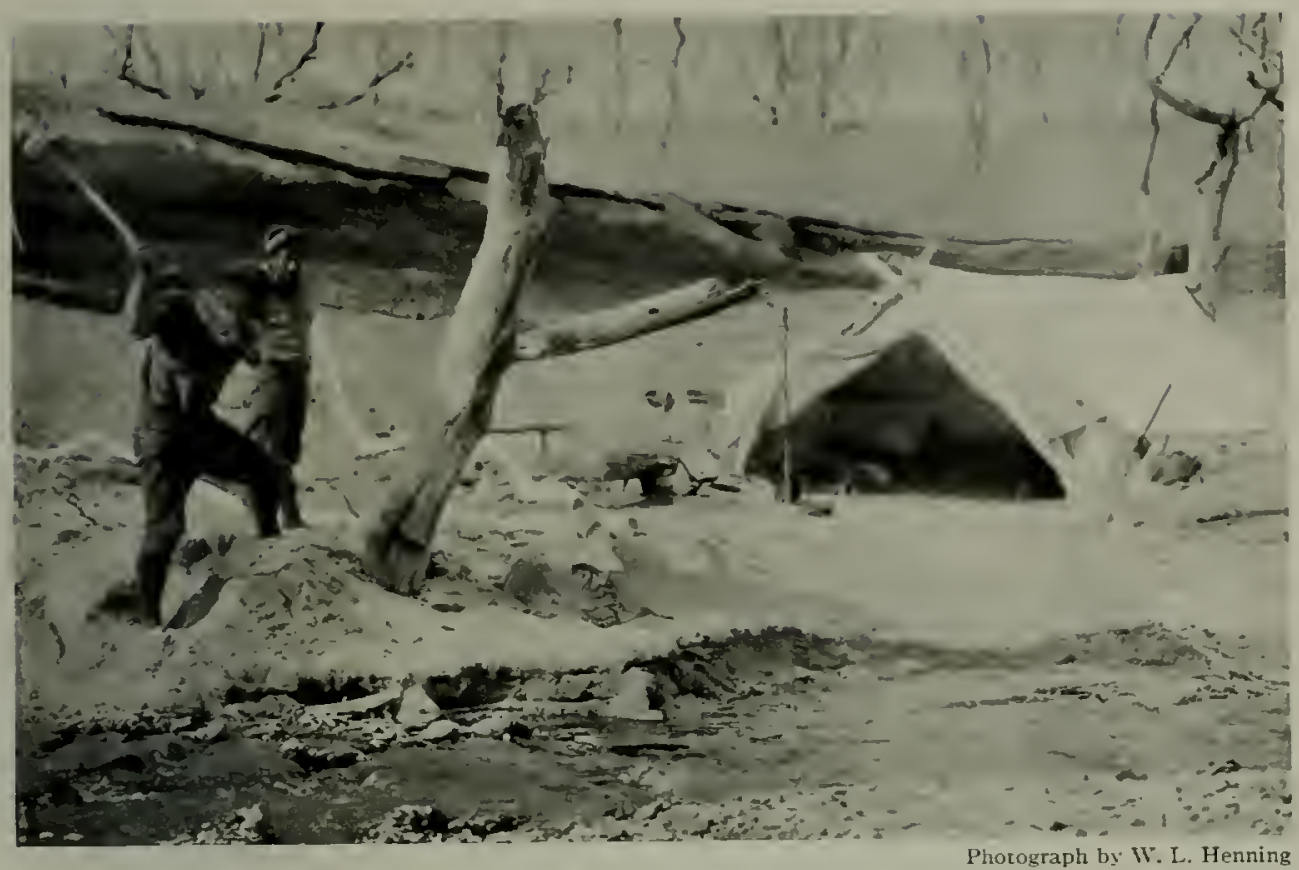

EROSION IN YOLCANIC ASH

We cut off the top of this tree in 1917 at a then convenient height. So much ash washed out in the ensuing years that in 1919 the cut end stood nine feet abore the ground.

a mystery, but that a few individuals did so is beyond question.

\section{A FEW FISH}

One might suppose that no fish of any kind could have survived in the pumicechoked streams.

We were thus surprised on our first trip up the river to find a few small fish, like minnows, playing over the quicksands. These were, however, unusual. We saw no more fish of any sort until 1917, when we discovered some Dolly Varden trout in a brook on the south side of the Valley, where the ashfall had been about 18 inches on the level.

As such a quantity of ash seemed sufficient to choke the stream, we supposed at first these must be migrants from outside the devastated area. But an examination of the scales of one of them, by Professor Charles H. Gilbert of Stanford University, indicated that it had been spawned in 1915 , probably in the stream where found, so it seems more likely that its ancestors had survived in a particularly deep pool which happened to occur in the course of the stream. No trout were found in neighboring brooks.

\section{A PERTERTED RUN OF SALMON}

Everywhere we kept a sharp lookout for salmon, but found none until 1917 , when we discovered one little brook in which red salmon were running in considerable numbers. This stream did not appear different in any way from a score of others which coursed down the mountain side to join Katmai River. But although we could find no fish in any of the other streams, we caught them here almost every time we came by, taking altogether about $5^{\circ}$ in the course of a month (see page 159).

Readers unfamiliar with the spawning habits of the salmon may be surprised to learn that fish two feet long could be found in a stream only a few inches deep; but the initiated will recognize that there is nothing unusual in such an 

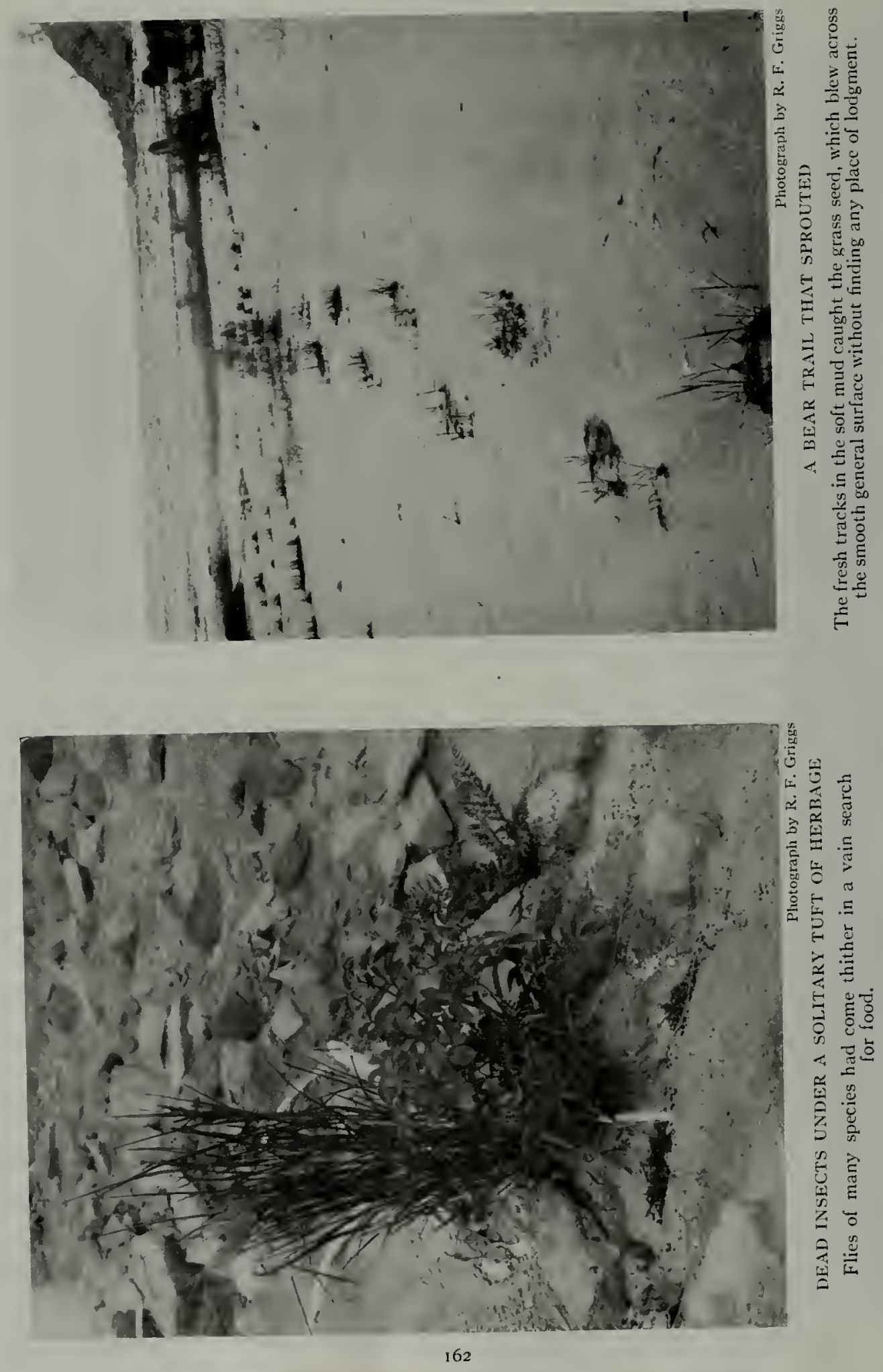
occurrence. It is well known that some species of salmon work their way up into brooks so shallow that their backs stick out before they deposit their eggs.

The remarkable thing about this run was that all of the fish taken were red (sockeye) salmon, a species which spawns in lakes and normally seeks only streams which have accessible lakes in their courses.

When we observed that our fish were sockeyes, one of the party examined the whole length of the stream to see whether there could be a lake on its course, but he reported that there was no possibility of there ever having been a pond in the stream.

\section{SALMON PROBABLY HATCHED WHERE FOUND}

Thinking, therefore, that the fish might be strays, diverted to this stream by the abnormal character of the country, we sent some of their scales to Professor Gilbert, who, after examining them, reported:

"It seems impossible to accept a suggestion that these fish were strays from some other region. . . . Each of the salmon from which you collected material had had an identical history. Each was five years old (that is, was in its fifth year when captured, having been spawned the year of the eruption) and each had lived two years in fresh water before going to sea. . . . I think it decidedly probable that they were hatched in the very tributary of the Katmai River in which alone they were to be found."

IVe were anxious to see whether similar runs would continue in subsequent years. The stream was visited again in 1918 , but it was on the $4^{\text {th }}$ of July, which is rather too early for the fish. In I9I9 we searched diligently for them a number of times during the spawning season, but none were found, either in this stream or any of the others.

We have little basis for theorizing on the significance of this anomalous run, but it is clear that here is a biological problem of great interest and importance.
If we understood fully why these fish ran into that particular stream at that particular time, we might gain an insight into the causes which lead to the wellknown peculiarities of their runs: the great variation in their numbers from year to year, their great abundance in some streams and theirscarcity in others.

Beginning at Soluka Creek, a marked change in the animal life of the upper valley was evident when we returned in 1916. The year before we had seen in this area only a solitary duck and a few small birds, all evidently waifs, though insects had been fairly numerous - including mosquitoes, black flies, and abundant dipterous larvae under the bark of the decaying trees.

In 1916 there were numerous flocks of chickadees and sparrows, and the insect life showed a marked increase, both in abundance and variety.

In upper Katmai Valley the change was much greater, for where there had been practically no life the year before, insects of many specieswere fairly swarming. They were everywhere, not only in the valley but high up on the mountains as well.

\section{FLIES DYING OF STARVATION}

The insects were all ravenously hungry. When we ate our noonday lunches they swarmed over our food until they became a nuisance.

They were, moreover, tame - so tame that we had no difficulty in catching specimens of all of them with our hands. This may have been merely the result of hunger, with its consequent weakness. However the larvae of these insects might have subsisted, there could be no doubt that the adults which we encountered all faced the same end - starvation.

At one place in the valley we found a little bunch of grass standing by itself, far away from any other herbage. IVe were astonished to observe, on examining it, that the ground beneath was covered with dead flies - half a teacupful, of all species. 
The blades had been gnawed and chewed by the scores of living insects which were clinging to them in the vain hope of sustenance from the lone bit of green (see page 162). That the grass was not the proper food for them was evident from the heaps of dead on the ground. But it was not until the speeimens could be determined at home that we fully realized the unusual character of this assenblage of insects.

\section{INSECTS MOSTLY PREDACEOUS OR PARASITIC}

When the collection was examined by Professor Hine it was found that less than 30 per cent were vegetable feeders, the remaining 70 per cent being composed of parasitic predaceous, blood-sucking, and dung-feeding forms. ${ }^{2}$

Ve were very much puzzled to account for these insects in a region from which they had been absent the year before. It was hardly supposable that they had bred in the vicinity. But if they had been blown in by the wind, why had they been absent the year before, when the gales had been more numerous? And if they had come in this way, why should there be such a curious assemblage of parasitic and predaceous forms, rather than a representative collection of the whole insect fauna?

Such study as we could give the subject did not enable us to solve these problems. After a severe gale which might have been expected to bring in a new supply, if indeed they were wind borne, we could detect no change in the inseet population around us. Moreover, when we returned to the Valley in 1917. we found it inhabited by the same species of insects that we had observed the year before.

Although we were unable to account satisfactorily for the peculiar assemblage

2 There were 35 species altogether, distributed as follows: 10 parasitic Hymenoptera (parasitic on other insects), 2 moths (larvae plant feeders), 2 mosłuitocs, I lepid fly (blood-sucking), Io syrphid flies (larvae mostly predaceous on plant lice), 6 anthomyid flies (mostly plant feeders), I scatophagid fly (dung feeder), I bibonid fly of insects which oceupied the devastated country, we could draw a certain parallel to it in the eharacter of the mammals encountered. These were all beasts of prey. Signs of bears, foxes, wolverines, and wolves were common. To these we added subsequently a weasel; but in the whole course of the work not a single herbivorous animal, nor the track of one, was observed until 1919 .

Not a sign of caribou, which formerly were abundant, nor of moose, was to be seen. Neither did we find any of the rodents which had swarmed over the country, including marmots, ground squirrels, rabbits, porcupines, and numerous mice. The only exception was one small "mouse" seen by one of the men, but this was quite as likely a shrew as a rodent.

\section{NOTABLE INCREASE OF HERBIVOROUS ANIMALS IN IOI9}

The progress in the return of animal life between 1917 and 1919 was striking. There was not only a notable increase in the number of animals, but herbivorous species began to come in.

The upper valley of Martin Creek, for example, where we spent a number of days in 1917, was then almost without larger animals. I particularly remember being startled, while wandering alone one day, upon finding a solitary loon floating about in Horseshoe Pond. My mind, which had been absorbed in studying the geological problems round about, was suddenly brought back to the utter desolation and solitude of the country by the sight of this lonesome bird, paddling about close by with no fear of the intruder.

But when we went up this same valley two years later, animals of many sorts

(usually a fecder on vegetable matter), I lacewing (larva predaceous).

We were interested to observe that the scatophagid $\mathrm{Ay}$, which is a common dung fecder all through Alaska, altered its habits under the stimulus of hunger to such an extent as to become predaceous, catching and devouring mosquitoes in the tent, giving a further indication of the straits to which these creatures were reduced by the lack of food. 
were abundant. Our footsteps were dogged all the way by the monotonous note of the golden crowned sparrow, "Oh dear me! Oh, dear me!", in endless repetition.

On one of the little ponds we found not only several loons, but two or three pairs of golden-eye ducks, geese, and even a swan, these contributing an element to our larder that had been sadly lacking in former years. On the hillside round about ptarmigan were nearly always to be found, and there were a number of colonies of ground squirrels, each with several hundred individuals, like a "town" of prairie dogs. To complete the fauna there were many short-tailed mice, busy about their affairs, as they worked along the ground with little heed to approaching footsteps.

Strangely enough, the return of all these animals did not appear to be correlated with a corresponding increase in their food supply, for the vegetation in this particular area had been abundant from the first and had not increased appreciably in the interval.

Similar conditions were observed among the birds about Kodiak, where with little doubt the food supply was sufficient after the first year. The well known varied thrush, or "Oregon robin," is a good example, since it is a noisy bird whose presence can hardly be overlooked. The year after the eruption I saw not one in my rambles through the woods. Two years later one or two were found and hailed as great rarities.
They became gradually more common in 1916 and 1917 , and in 1919, after seven years, were everywhere in grcat abundance.

The explanation lies, I suspect, in the homing habits of animals, which seek to breed in the very spots where they themselves were reared. If the birds that came to the forest at Kodiak every summer were merely chance visitors, likcly to settle in any favorable situation at the end of their migration, they should have reappeared in full force the year after the eruption.

But, if the bird life of any locality consists mainly of individuals that were hatched in the vicinity, the long period of scarcity followed by a sudden increase in numbers is just what would be expected. The varied thrush was so nearly exterminated at Kodiak by the eruption that if repopulation were restricted to the progeny of survivors a number of years must elapse before it would reappear in force. Once fairly started, however, the repopulation would tend to proceed in a geometrical ratio at a rapidly increasing rate.

The delay in the reappearance of ground squirrels on the mainland is readily explained in the same way. These animals were almost exterminated by the eruption. Although abundant only a few miles away, none seem to have migrated into the devastated district for some time. After the first pairs were established, however, large colonies quickly sprang up. 


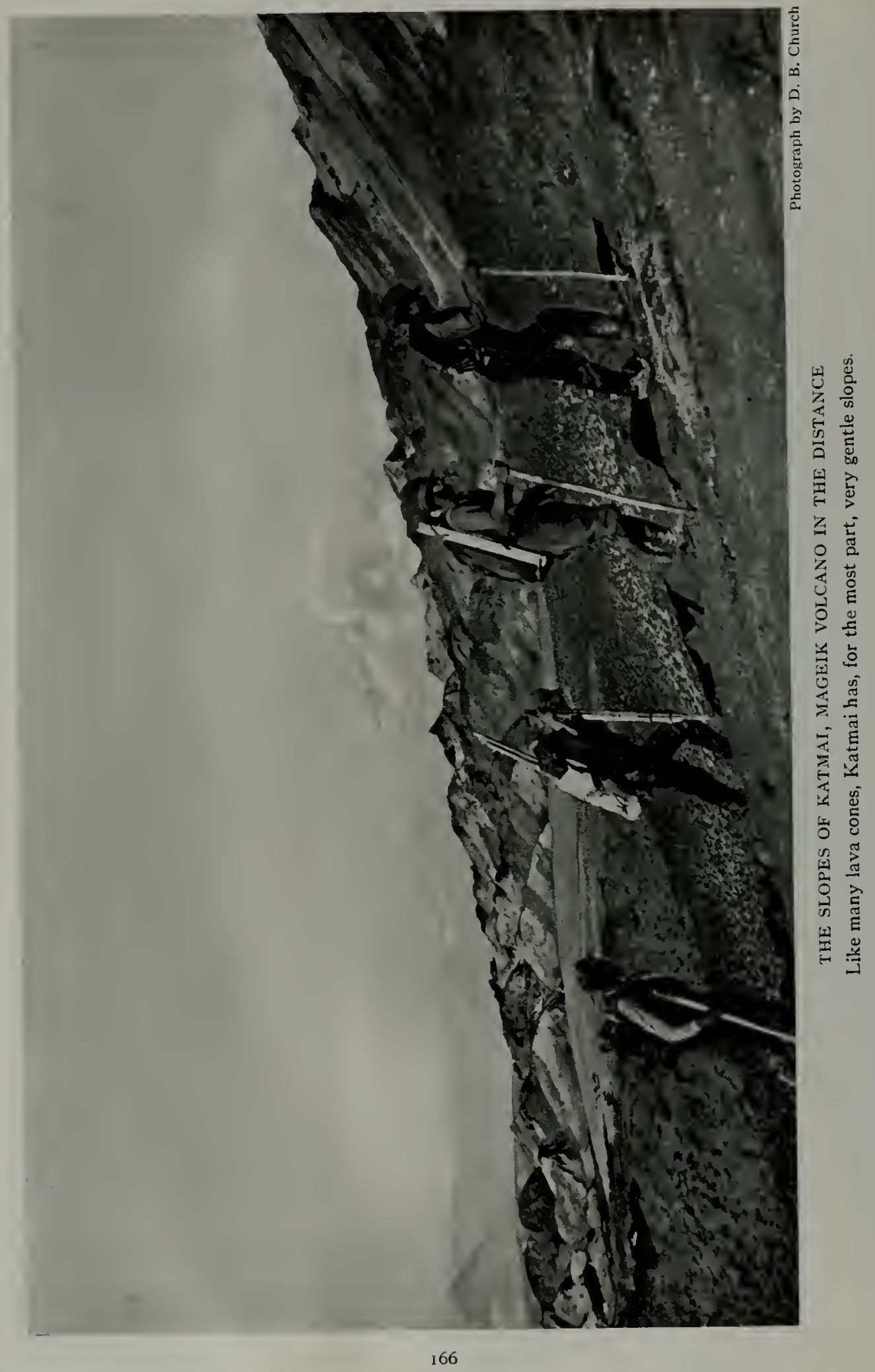




\section{KATMAI CRATER}

As we plodded up Katmai Valley the second year (1916), our objective was the volcano. The day after our arrival, July 19, dawned clear and fair, so we were up and away toward the mountain at an early hour.

When we started we had little idea of making the ascent, expecting to content ourselves with reconnoitering the lower slopes. Leaving the mudflow at about 800 feet, we proceeded by an easy grade over good hard ground up the long ridge that runs out parallel with the river, at the end of which we came into a magnificent riew of the canyon and the lakes of the upper valley - the first sight we had had of either. Here the real climb begins.

Should we turn back or should we go on? The weather was perfect, or so it seemed. The climb thus far had been so easy that as we proceeded we had become more and more anxious to try for the rim.

\section{CLIMBIXG THE IUD-PLASTERED SLOPES}

The slopes were all plastered with mud of raried colors - gray, yellow, chocolate, red, black, and blue - thrown out by the last spasms of the eruption.

At the lower levels the mud was dry and hard, making easy going; but it soon became slippery as we ascended and, a little higher, soft and sticky. Mlost of the way it was about ankle deep, but in spots it let us down nearly to our knees. At times it required all our strength to pull ourselves out (see page 169).

For many hundred feet we went up on the crest of the lateral moraine of a tumbling glacier which stretches from the lowest notch in the crater rim, near the sharp rock shown in the pictures, down to about 2,000 feet. The eroded badlands were grotesque enough, but the picture of confusion presented by the parti-colored, ash-clothed seracs of this glacier was bizarre beyond description.

At about 3,500 feet patches of snow began to alternate with mud and these, when covered with wind-blown mud and pumice, made much better traveling. But abore t,ooo feet the way was mostly through fresh soft snow, with only occasional mud patches, and the slopes became steeper as we adranced (see page 170 ).

From the higher levels the scenery was superb. Orer the tops of the nearer mountains, which presented a magnificent mass of sharp peaks with intervening snowfields and glaciers, we could see the blue waters of Shelikof Strait and the distant snowcaps of Kodiak Island, 50 miles away.

Notwithstanding the exceeding sharpness of the individual peaks the general concordance of their elevations suggested that they might be the remnants of an ancient land surface - a peneplain - as believed by Atwood. ${ }^{1}$

When we approached the top it began to cloud up, and we were afraid we should not be able to see anything if we did reach the rim. All the other summits for miles around remained clear, but Katmai became densely covered with black, heary clouds which permitted only occasional glimpses of the crest.

Furthermore, we were on the lee side of the crater instead of to windward, as we should have been. We knew the clouds must be due, in part at least, to the activity of the crater, because of the strong sulphurous odor which filled the air, but we could not tell how much was to be attributed to this cause and how much simply to the greater altitude of the rolcano.

The clouds were in rapid motion, 1 United States Geological Survey, Bullet in $4^{6} 7$, page $8_{3}$, paragraph 2 . 


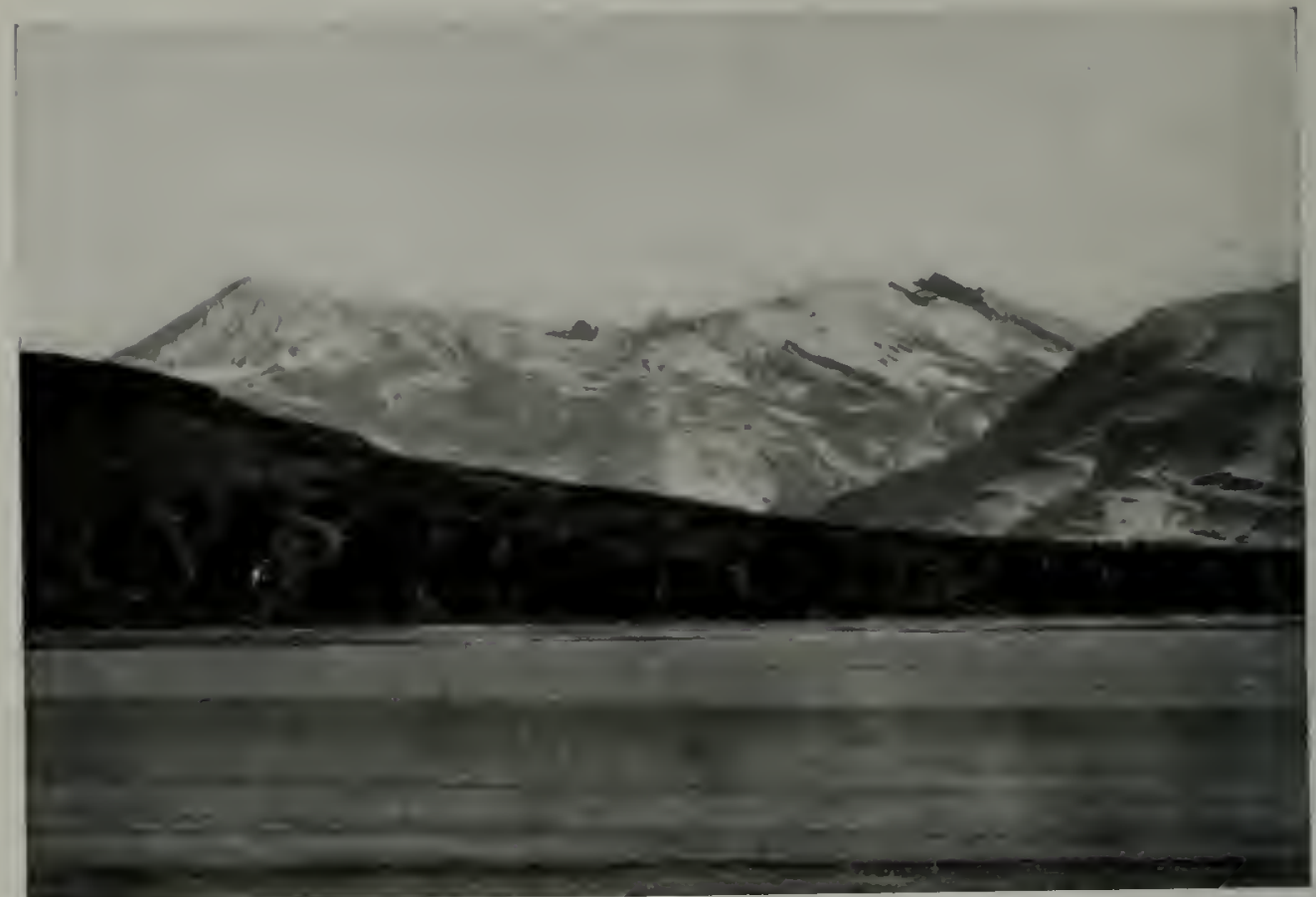

Photograph by R. F. Griggs

MOUNT KATMAI FROM NEAR THE BASE CAMP, 1917

From a distance of over 20 miles the volcano loomed up much bigger than the nearer mountains. The great jagged edges gave us all a new conception of the immensity of the crater within.

coming straight up out of the crater. What if we should reach the rim only to poke our noses into a steam jet, through which we could see nothing!

Yet we were unwilling to give up now, without at least a try, and so we pressed on. The slope increased in pitch toward the top, making the climb progressively more wearisome. Church expressed the feelings of all when he complained that the rim was farther away than when we started. No matter how far we went he insisted, "It's still a thousand feet to the top." And so it appeared up to the very crest. Finally at 5,500 feet we reached the rim.

\section{THE KNIFE-EDGE CRATER RIM}

We came to the rim so suddenly that we might almost have walked right over and tumbled down the precipice inside. The edge was unbelievably sharp - so sharp that a single step lifted the interior into full view. We stopped in our tracks, sank to our knces, then stretched out at full length, and, propped up on our elbows, peered over.

On this knife edge we lay, trying to fathom the cloud of steam that rose in our faces. For our fears had been realized: before we gained the rim the clouds had shut down, enveloping us in mist. Then there came a little rift, and for a second we could make out dimly something blue, far, far below. Then the steam cut us off again, and again we waited.

We could see only a few feet in any direction. To left and right a little of the precipitous wall could be made out, standing almost vertical. Yet the crest was made of loose fragmental stuff-ash from the eruption. I Its knife-edge sharpness was maintained by frequent slumping away into the depths.

Back from the crest was a series of 


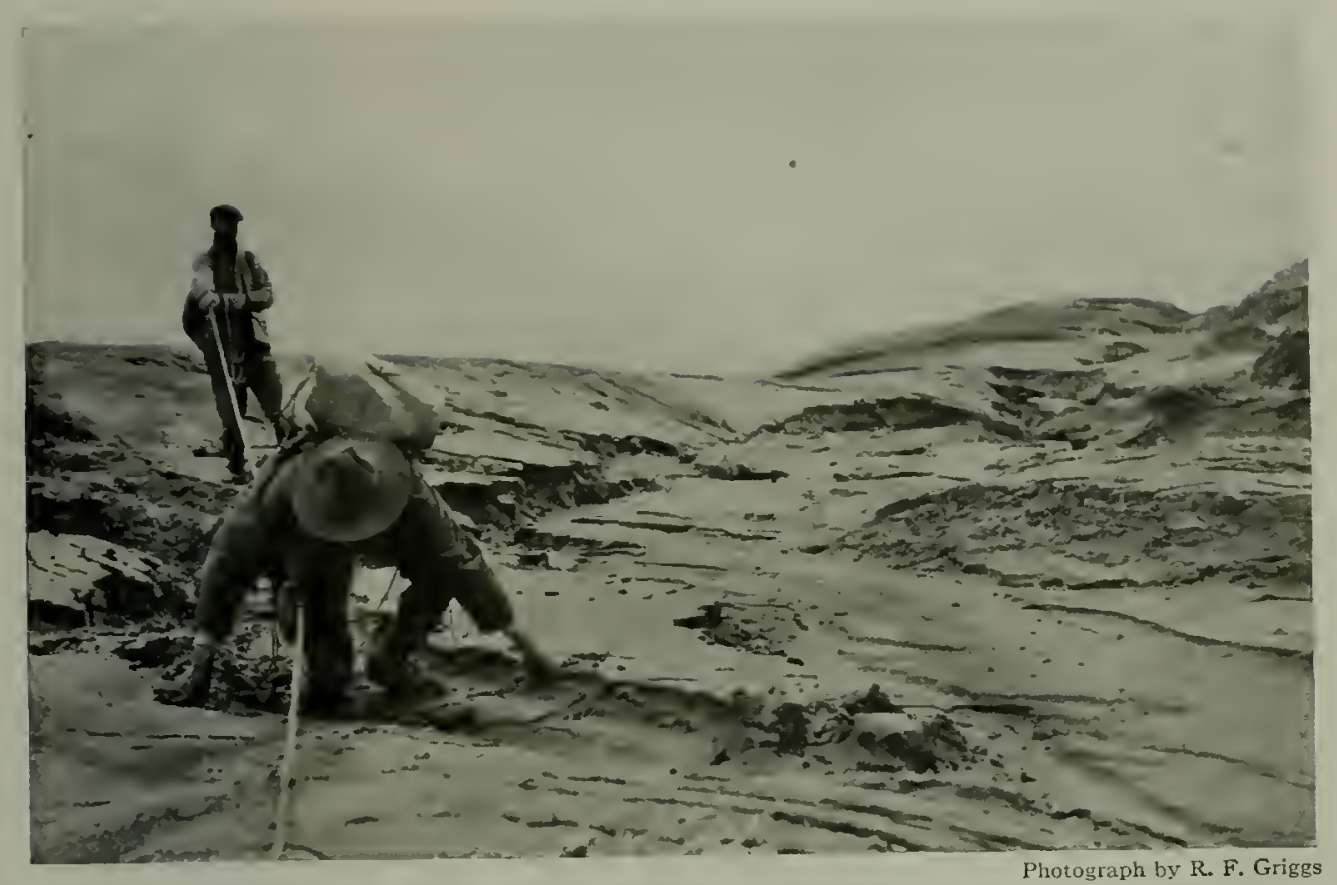

STUCK IN THE MUD ON THE WAY UP TO THE CRATER-FIRST ASCENT

The slopes of the volcano were covered with soft, sticky mud and slush (see text, page $16 \%$ ).

fissures running parallel with the edge, where the rim was cracked off, ready to drop over the cliff. These had compelled us to detour till we could find a place at least without visible signs of slumping off.

The ash lay in the same eren bedded layers as below. Although it was here 40 or 50 feet deep, three times as much as at the foot of the mountain, the fragments of which it was composed were little coarser than there (see page I7I).

Our suspense as we waited, perched on that eery crumbling edge, cut off by the encircling mist from everything else in the universe, would be hard to describe. Were we to be cheated, after all our effort?

Finally, the steam blew away, and we were struck speechless by the sight below.

\section{FIRST VIEIV OF THE CRATER}

We found ourselves hanging over the brink of an abyss of such immensity that, as the event proved, we were powerless even to guess its size. Down, down, down, we looked until the cliff shelved off and we could follow it no further.

In the bottom lay a wonderful lake, of a weird vitriolic robin's-egg blue, milky, like one of the glacial lakes of Switzerland. The middle of this was set with a horseshoe island, the remnant of a cinder cone evidently thrown up in the last spasms of the eruption. Around the margin hissed columns of steam, issuing from every crevice. On the opposite side of the crater were spots of yellow sulphur, and in two corners where the slopes were less precipitous were extensive snowfields (see pages 172 and 178 ).

All this we took in almost at a glance, for we were given no time to study details. Before we could get our tripod set up the cloud closed in again, and we waited amid a roar of escaping steam. What if we should fail to get the coveted pictures for lack of a clear moment! Finally there came a little rift and frantically we made our exposures.

I had planned to take bearings and measurements which would afford some 


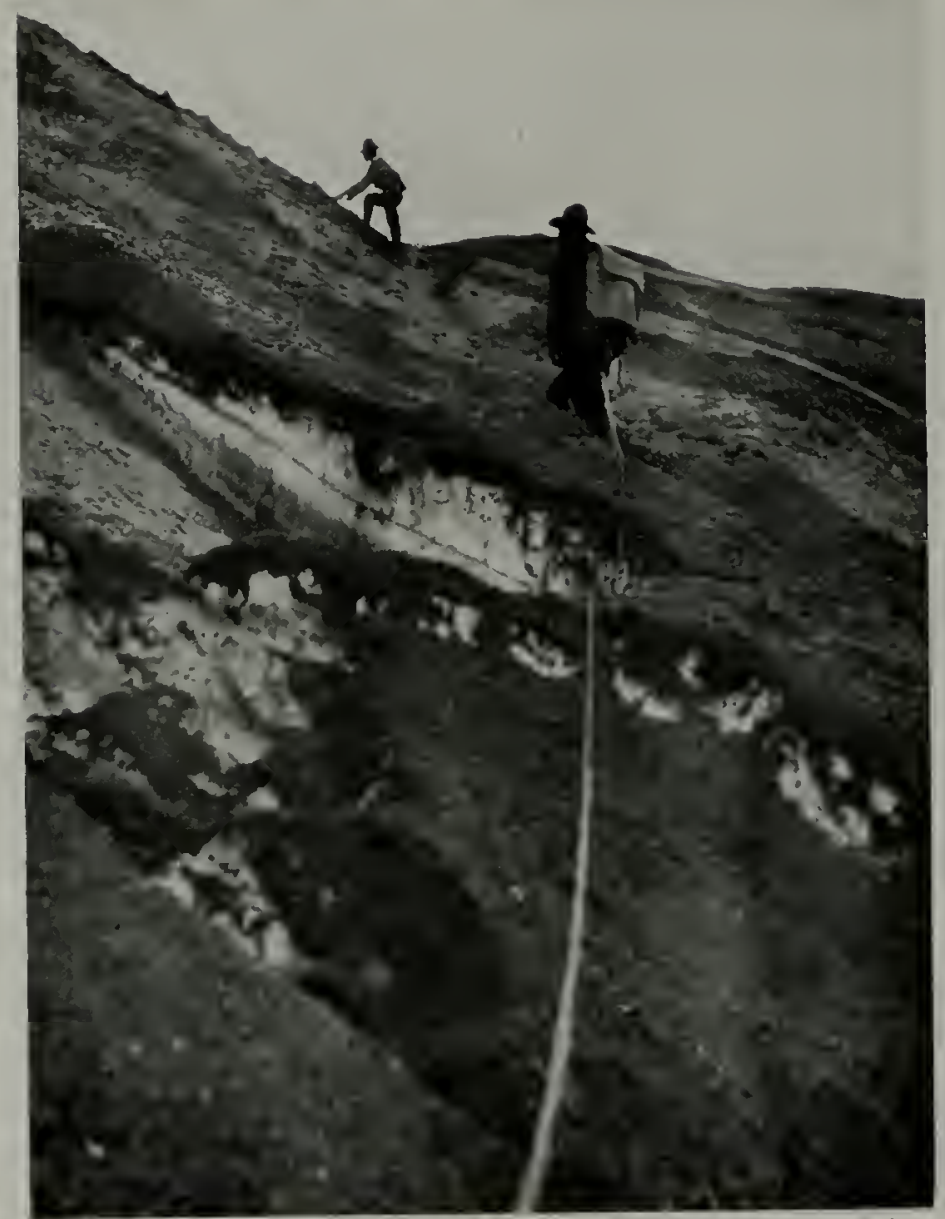

Photograph by L. G. Folsom

ON THE FIRST ASCENT WE ROPED UP FOR FEAR OF CAVE-INS IN THE MUD-COVERED SNOW

The climbers are within a few hundred feet of the crater rim. finish with that interminable succession of gullies and mud holes. It was a weary crowd that finally dragged into camp, but the awe inspired by the sight we had beheld counterbalanced the exhaustion of our bodies and kept our minds busy with speculations on the significance of what we had seen.

Next day, on writing up our observations, Folsom and I fell into argument as to the size of the crater. He maintained that it was about 500 feet deep, while I insisted that it must be more nearly 1,500 fect.

Later we were to find how ridiculously small both estimates were, for the abyss is so big that it is literally beyond the power of the imagination to grasp its dimensions, even when standing on the rim itself. The uncertainty of this and other details, which we had not been able to observe satisfactorily in our few brief glimpses of the abyss, proved to us that we must make another ascent to clear up the discrepancies in our observations.

\section{THE SECOND ASCENT}

But the opportunity for a second ascent did not come until July 30 , when for the first time since our arrival in the Valley, the steam from Mageik rose straight up into a cloudless sky. This time we chose a route up on to the lava plateau from near the mouth of Mageik Creek. 
The ground did not seem especially favorable from below and we were by no means sure of reaching the rim when we started; but we were anxious to examine Trident at closer range, and especially to sec what might lie behind the isthmus connecting this volcano with Katmai, because of our suspicions of activity in that direction.

\section{THE CRATER OF TRIDENT}

This course gave a fine riew of Trident, whose crater proved to be a simple fissure, out of which steam was continually issuing in comparatively small volume.

But we were disappointed in our hopes of seeing anything over the divide between Trident and Katmai. Although we traversed the whole length of the nearly level névé at an altitude of about 4,200 feet, we could see no indications of volcanic activity beyond. There were several jagged minor summits, but as we saw no large mountain and no clouds we quite dismissed the idea of a volcano in that quarter. How greatly in error we were in this conclusion we were to find out only the next day.

On our first ascent we had followed straight up a single ridge, and so avoided the necessity of crossing the gullies. But this time, for a good share of the way beyond 2,000 feet, our path lay across the lines of drainage, which had gashed the level surface of the ash with innumerable seams anywhere from two to ten feet deep. We soon found that continued jumping and scrambling across these gullies was very fatiguing, and we were thoroughly tired of the job long before we got through them.

\section{AN ASH-COVERED GLACIER}

For the last I,50o feet our way led across crevassed snowfields and ashcovered glaciers. The appearance of these ice fields was curious in the extreme.

Where a glacier was moving rapidly, the variously colored layers of ash were dumped about promiscuously among the glacial seracs, making a bizarre and

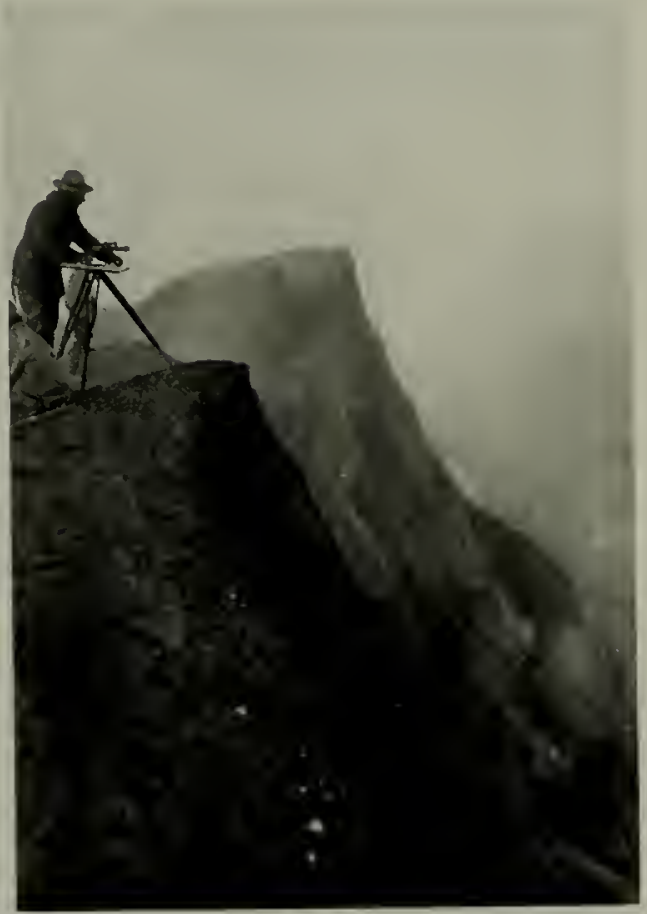

Photograph by R. F. Griggs

THE CRATER RIAI

The extreme sharpness of the edge is evident.

highly colored picture, the reds, browns, blacks, and yellows in vivid contrast to the pure blue ice.

Where the glacial motion was slower and steadier the ash deposit still lay as it fell. In such places drainage systems had developed which followed the slope exactly as on ordinary hillsides, regardless of the transverse crevasses beneath.

These lines of drainage were sometimes able to maintain their courses in competition with the crevasses, giving rise to a curious double system of topography. The square, straight-sided blocks of ash looked like so many huge slices of layer cake laid side by side.

Glaciers of this peculiar type extended clear up to the very rim of the crater, above whose depths the loose blocks of ice hung with such a precarious hold that we dared not approach.

Turning back, we made our way around the ice, descending somewhat until we finally reached the rim in the lowest 


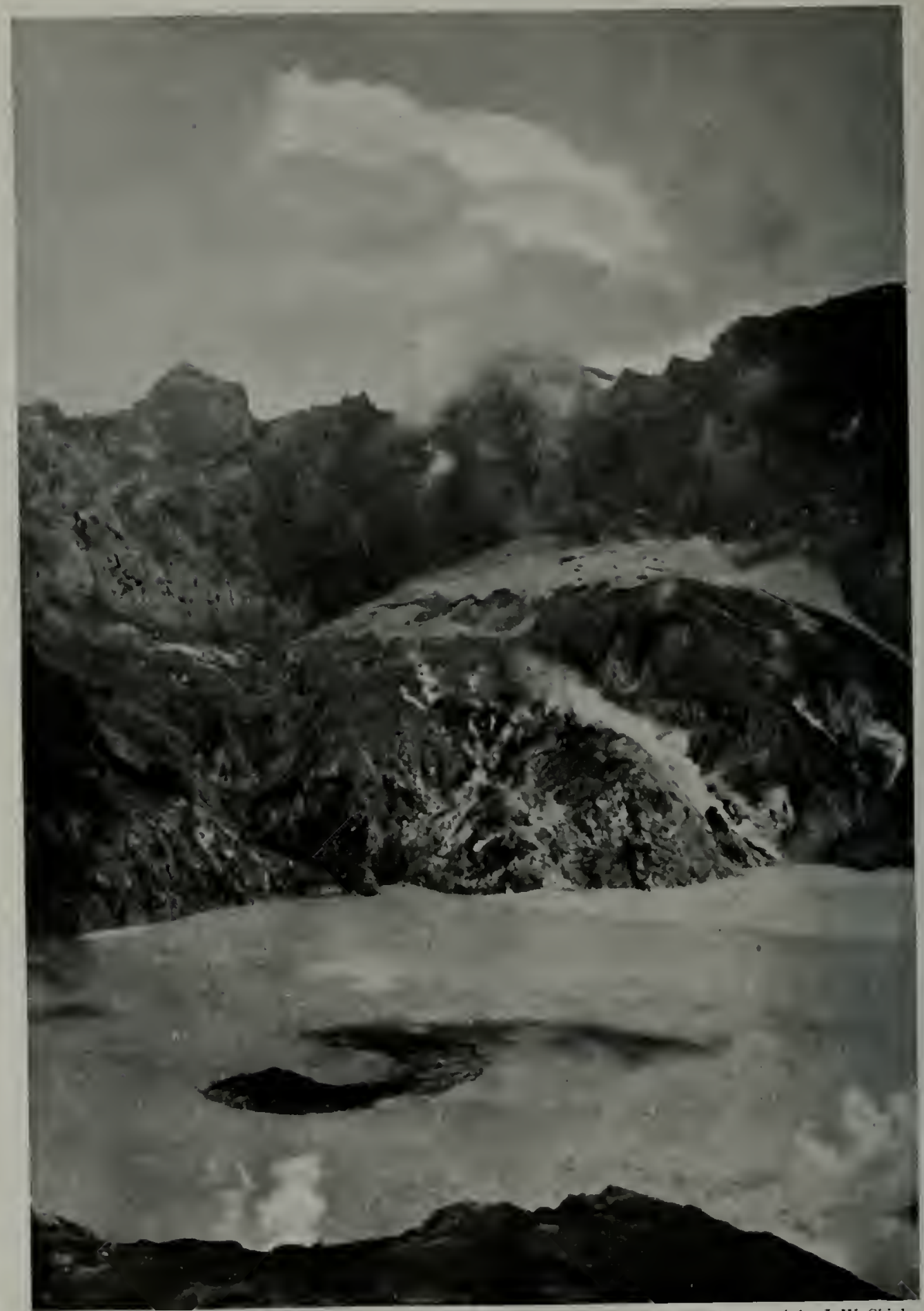

THE NORTHERN WALL OF THE CRATER

Photograph by J. W. Shipley

The steam from the numerous fissures evaporates about $\mathrm{I}, 500$ feet above the lake, but condenses again into a great cumulus cloud on meeting the outside atmosphere. 
notch (altitude 5,200 feet), beside the sharp tooth of rock which projects at that point (see page 10o).

From the foot of the mountain this tooth appeared as a small rock. Near at hand it proved to be a great column of jointed lava, two or three hundred feet high. Its position and structure suggested that it may be the solidified core of an old rent (see page 175).

From our position directly under the column, its perpendicular cliffs, though insignificant from the Valley, appeared immeasurably high! Frequently, in this land of stupendous proportions, we had occasion to realize how little conception we could really form of the true dimensions of the scenery around us.

INABILITY TO JUDGE HEIGHT OR DISTANCE

When one stands directly beneath a cliff, or looks down from the brink, 200 feet appears an immeasurably great height. Ten times as much appears little greater, unless there are trees, houses, or some such familiar objects by which the distance may be judged independently.

In a desert country without any such criteria we were frequently unable to form any estimate at all of the various features that met our view. We had an amusing instance of this when, sending a man up on a great ash slide to serve as a scale for a picture I found to my amazement he was hardly visible to the naked eye, and utterly lost on the ground glass.

IVe nearly always found our estimates too small rather than too large, and generally had to revise our statements upwards when accurate data were supplied by the survey.

Standing on the edge of the crater, we recognized our total inability to form any judgment of its depth. I'sing every standard of comparison possible, we concluded our former guesses were too small and that it must be at least 2,00o feet deep. Thus by slow degrees did we approach the real figure. But even yet our conjecture was barely more than half big enough.
Estimation of the width of the crater was somewhat easier because we could see the rim from below. We knew that its great jagged arc looked far bigger twenty miles away than from the foot of the mountain, and by laying it off on the chart reckoned that it must be about three miles in diameter. Nevertheless, as we stood there on the crest it was impossible to believe that the distance across to the high point opposite was the equivalent of forty city blocks.

\section{THE SECOND VIEW OF THE CRATER}

Both the weather conditions and our position were more favorable for observation of the crater than on our first ascent. The sun shone brightly, and it became evident why steam had given us so much trouble the first time. We found that the point which we had reached before stood directly above a prominent fissure stretching out from the edge of the lake.

The hot lake was now covered with wisps of steam, curling up everywhere from its surface. The vapor thus given off condensed into a hazy cloud, which hung in the mouth of the crater, concealing the rim opposite.

At the northeast angle we could see another low notch in the rim at about the same altitude as the one where we stood. But this one was occupied by a wall of ice which rose vertically, flush with the crater walls, as though sheared off by the explosion.

It was surprising at first sight to find that a glacier could have persisted on the crater rim, unmelted by the heat of the eruption. It might be supposed that, as the eruption approached, the temperature of the mountain would be raised enough to melt away its glaciers, or, at any rate, that the heat of the molten magma laid bare by the explosions would promptly liquefy all the ice near by.

It is clear, however, that no such thing happened. lce cliffs, the exposed ends of beheaded glaciers, stretch for several miles along the crater rim. The glaciers bear little if any indication of having 


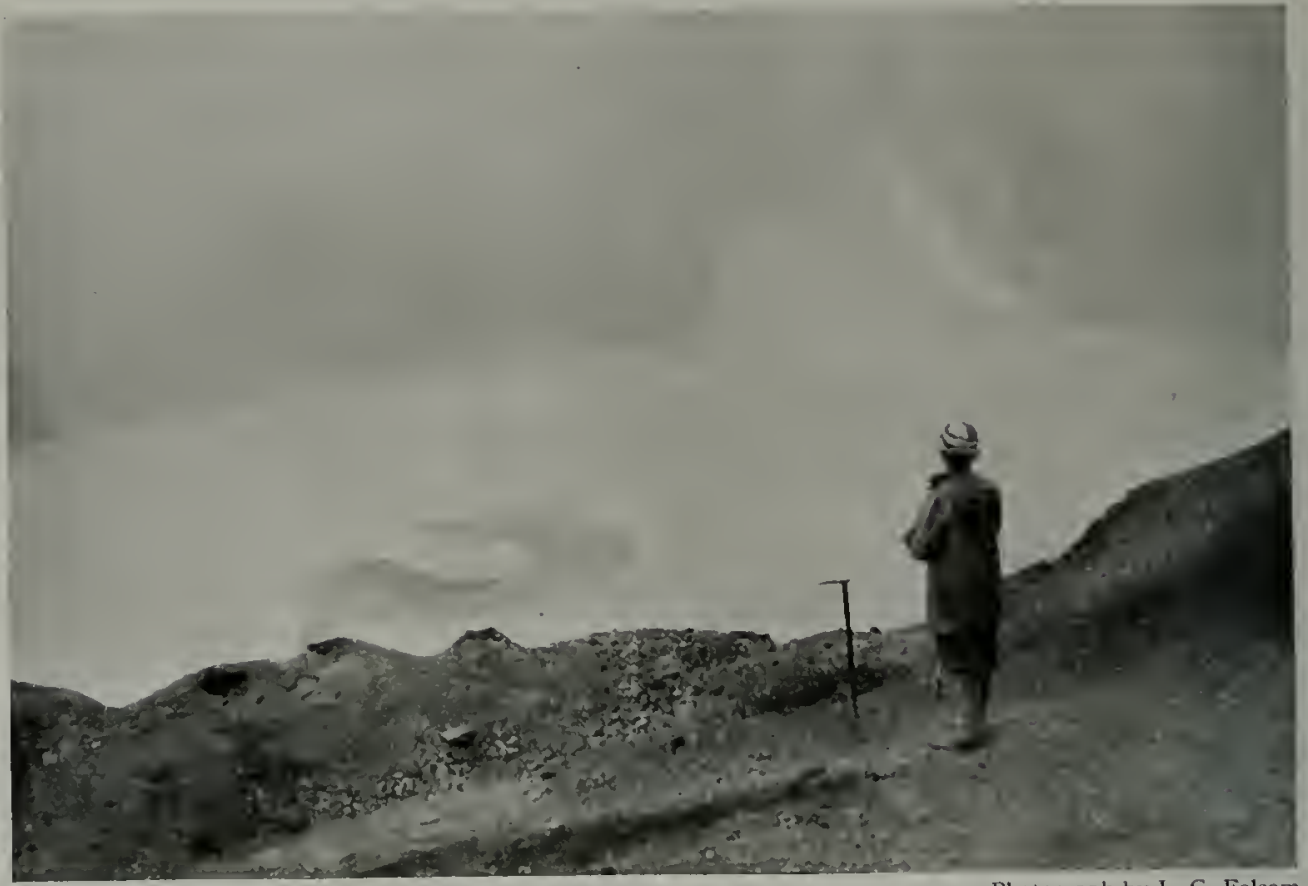

A LONE WOMAN VISITOR AT THE CRATER'S EDGE

Mrs. Griggs, spurred by an unconquerable optimism, climbed through the fog all the way, while a party of the men lingered behind, waiting in vain for a break in the clouds. She was rewarded by coming into clear air just before reaching the rim, but some of the men went home without having ever beheld this wonder of wonders.

dwindled during the eruption. The parts preserved on the outer slopes were outside the blast of the explosions, which must have been directed skyward.

The ice cliff, however, probably did not stand so close to the brink during the eruption. The crater wall has caved in considerably since the eruption and is still slumping away at short intervals. It is in such an unstable condition that it is no infrequent expcrience, while standing on the crater rim, to be startled by a roar as something lets go, and on searching for the cause to find a mass of ice and rock bouncing down the half-mile precipices into the abyss.

On our first ascent we had not fully appreciated the coloring of the walls, which are made up of variously tinted lavas and tuffs. The prevailing tones are soft warm browns, harmoniously framing the turquoise lake. But in many places these give place to brilliant reds and yellows, in strong rich contrast to lake and sky.

\section{ASCENTS IN 1917}

It was with very different feelings that we undertook the climb when we returned to the scene in 1917 , for then Iratmai was a secondary matter in comparison with the Valley of Ten Thousand Smokes. Our purpose was to survey the crater to ascertain its dimensions.

But for me personally there was an added incentive: I wanted to see how the new members of the expedition would act when they first popped their heads over the rim. I was not disappointed, for sated with wonders though they were, after a month's sojourn in the Valley of Ten Thousand Smokes, they were, if possible, more impressed with the crater than with the Valley.

They accused me of not having given them any true description of it. Yet I 


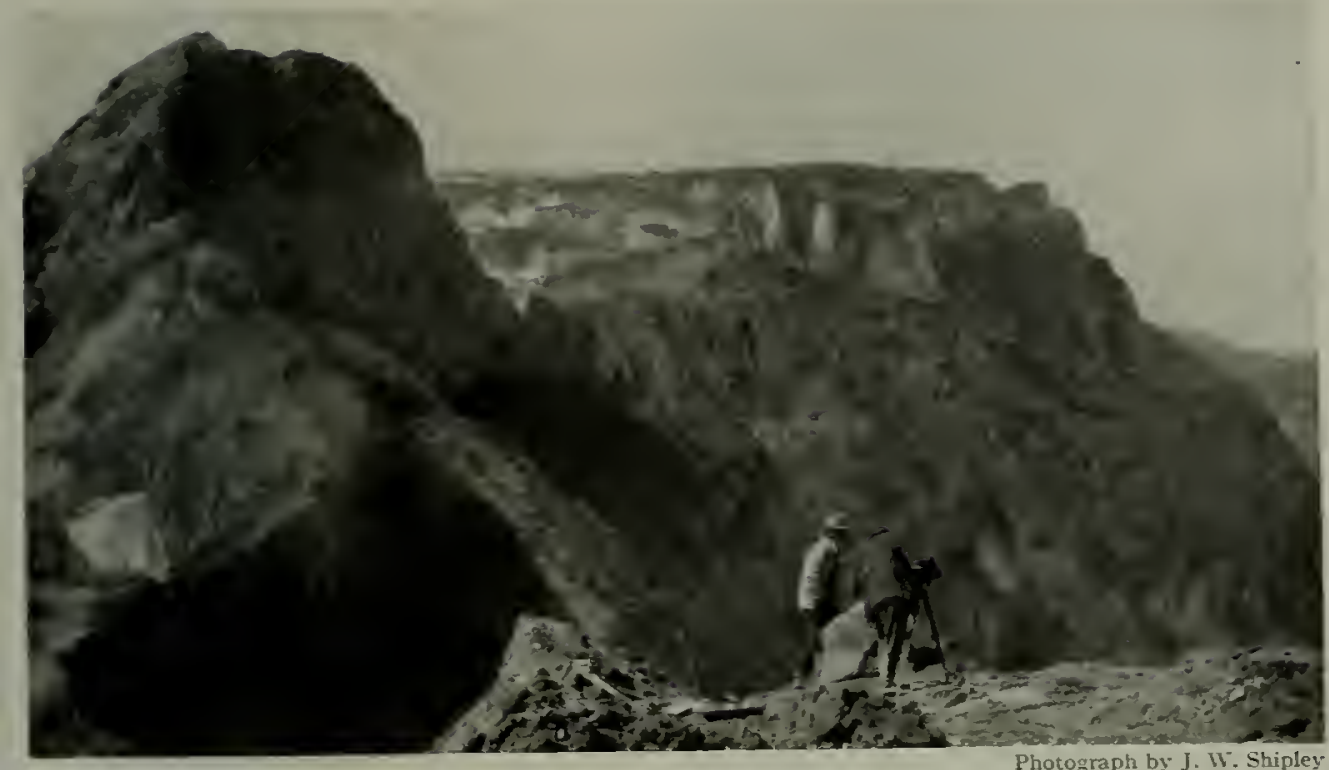

TOPOGRAFHERS WORKING ON THE CRATER RIM

The peak at the left is the inconspicuous tooth seen in the notch of the crater rim from below (see page I00\%. A portion of the beheaded glacier lining the rim is shown beyond.

had done my best and they had studied our photographs just before starting. Sayre epitomized the situation. $\mathrm{He}$ told the photographers: "Go ahead and take your d-- pictures. But you might as well tear them up now. They'll nerer help antbody to imagine what this place is like."

Recalling our previous difficulties with mud, we had decided to leave the ascent until late in the season, when the winter's snow was gone and the mud had had time to dry up somewhat.

Days for climbing the high mountains were very few in $19 \mathrm{I} \overline{7}$, and we had finallyto wait a full week before there came a chance to try. Even then we were cheated. Is we ascended, the clouds began to gather; and just as we reached the crest, they completely shut down. We had one fleeting glimpse of the crater, but before we could so much as set up a camera it was gone. We had to wait three day-s longer for another chance.

Our decision to defer the ascent till late in the season was well justified. In places where in 1916 we had floundered up the slopes in slippery mud, ankle deep, we found the ground hard and firm. so that the climb, which before had taxed our strength and endurance, was now made easily in four hours, even under 3o-pound packs.

Those who had not gone through the previous experience had difficulty in believing the first climb could have been so much harder, until we came upon our old trail. It was broken so deeply into the mud that it had persisted in spite of freezing and thawing through the winter, and was still deep and clear a good share of the way!

In spite of my experience of the previous year I found myself overawed by the grandeur of the abyss. Its immensity little comported with my recollection, huge as I had conceived it to be.

The proportions are so perfect that no one dimension appears exaggerated at the expense of the rest. If the crater were not so deep, its area would be more evident; if its walls were not so precipitous, one could better measure with his eye the distance to the bottom. 


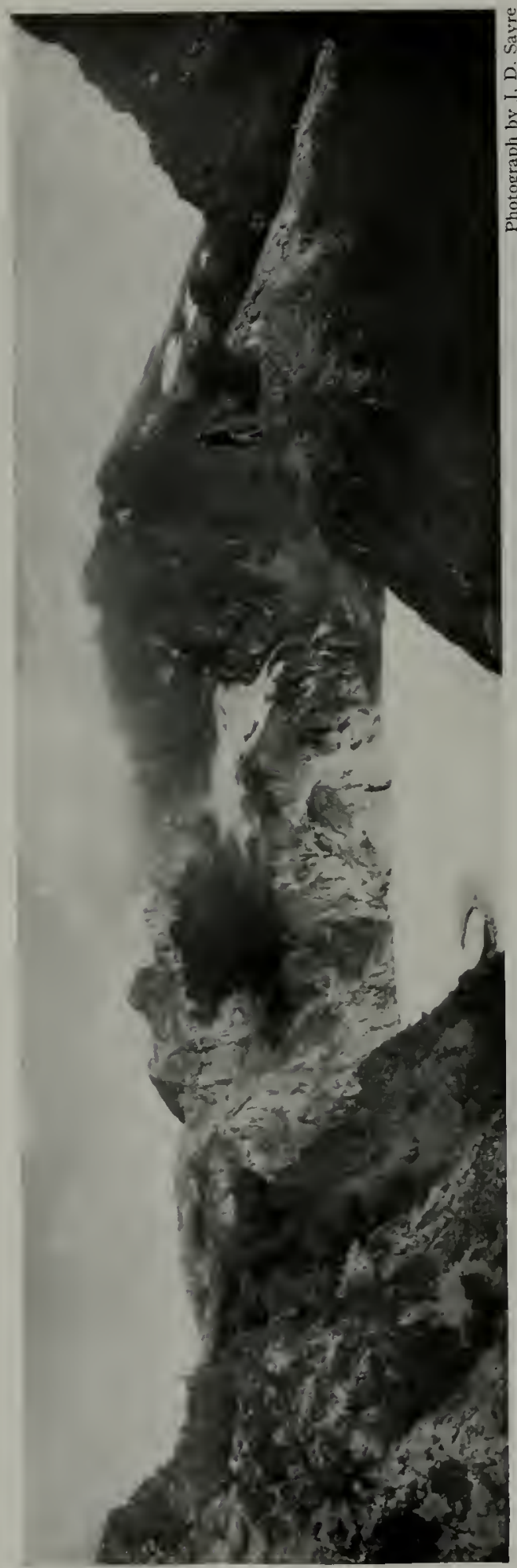

As one looks into the abyss, the dominant impression is one of enormous depth, but this is hard to render in the photographs, most of which give rather the impression of great width. The magnitude of the crater is literally inconceivable.

Yet as one stands on the rim and projects in his mind's eye the outer slopes up to the original summit, which stood 4,200 feet above the lake within, he does gain a conception, perhaps not to be duplicated elsewhere, of the tremendous forces that destroyed the majestic mountain that only a little while ago was Katmai.

There have been no evident changes in the crater during the four years covered by our observations. Some of the talus slopes have extended a little farther into the water, but there is no demonstrable change in the height of the lake.

Unless there is a subterranean outlet, which is very unlikely, its level must be controlled by the temperature of the crater floor. If the quantity of heat given off should increase, the water would be vaporized more rapidly, lowering the lake. If the rock should cool off, water from the abundant precipitation would accumulate and the level of the lake rise. The height of the lake is thus a good indicator of the quantity of heat supplied from the conduit below.

Ve wanted to estimate the depth of the lake, but could find no means of doing so and had to be content with such surmises as we could make from the character of the banks, which vary considerably.

Beneath the northeast cliff a conspicuous talus slope nearly I,ooo feet high has accumulated. But on the north and northwest 
the cliffs dip off into deep water, with no sign of talus.

When the extremely unstable character of the cliffs and the frequency of avalanches are recalled, it will be seen that the amount of detritus dumped into the lake in the years since the eruption must have been prodigious. That this rock waste could have entirely disappeared beneath the waters suggests that the lake is at least several hundred feet deep close up to the shore.

\section{A WEIRD CLOUD-ENCIRCLED CRATER}

The clouds hung off long enough for the topographers to make the observations necessary to triangulate the crater, but even after waiting so many days we were permitted only a brief view. Before long the clouds began to gather again. The struggle between the increasing mists and the heat rising from the abyss created one of the weirdest spectacles imaginable.

Long after the gathering clouds had blotted out all else, the crater cup remained perfectly clear. Above the cliffs on all sides stood impenetrable walls of mist, 2,000 feet high. The sun shone down on the lake out of a blue sky, just as it had before. The mist which kept filtering into the crater through the low notches in the rim was quickly dissipated by the heat rising from below.

For half an hour the elements maintained their balance in this uncanny fashion, but finally the increasing cloudiness gained the upper hand, and the lake slowly faded from view.

\section{DIMIENSIONS OF CRATER}

From his survey Maynard has computed the dimensions of the crater as follows: The width of the crater rim, as seen from below, which includes all of the concavity on top of the mountain, is 3 miles $(4.8 \mathrm{~km}$.). The circumference, measured along the highest point of the rim, is 8.4 miles ( $13.5 \mathrm{~km}$.). The area is 4.6 square miles ( $12 \mathrm{sq} . \mathrm{km}$.).

2 The capacity of the crater is 4,500 million cubic yards $(3,400$ million cubic meters). It
The precipitous abyss, which does not extend to the rim on the southwest side, is sonewhat shorter, measuring 2.6 miles ( $4.1 \mathrm{~km}$.) in length, 7.6 miles $(12.5 \mathrm{~km}$.) in circumference, and 4.2 square miles ( $10.8 \mathrm{sq} . \mathrm{km}$.) in area. The milky blue lake in the bottom is 1.4 miles $(2.2 \mathrm{~km}$. long and 0.9 mile ( $1 .+\mathrm{km}$.) wide, with an area of I.I square miles (2.8 sq. $\mathrm{km}$.). The little crescent-shaped island in the lake measures 400 feet (I20 meters) from point to point. The precipice from the lake to the highest point of the rim is 3,700 feet ( $I, 130$ meters) high.

THE CRATER WOULD HOLD WATER ENOUGH TO SUPPLY NEW YORK OTER FOUR YEARS

Statistics of dimensions of such magnitude, however, convey little meaning. Suppose we wished to fill the lake to the crater rim and had available the pumping stations which are employed to keep New York City supplied with water. If we should turn all the streams that supply the six million people of that great city into Katmai crater the pumps would have to continue working steadily for I,635 days - four and one half years before the water would reach the lowest notch in the crater rim. ${ }^{2}$

This does not begin to tell the story, however. If the hole were filled with water the cliffs still standing up around the lake would form a spectacle almost as impressive as the abyss we see today. The great cliff on the eastern side would stand I,700 feet above the water's edge and nowhere, except at the low notch forming the outlet, could we approach within hundreds of feet of the water level.

Because of the great irregularity of the crater rim, computation of the quantity of water necessary to fill it does not give an idea of its true size. The real magnitude of the hole is indicated by the quantity of material blown off the mountain during the eruption.

A comparison of the present stub with the original mountain shows a difference of more than I , ooo million cubic yards, would hold 900,000 million gallons of water. New York City uses $55^{\circ}$ million gallons daily. 


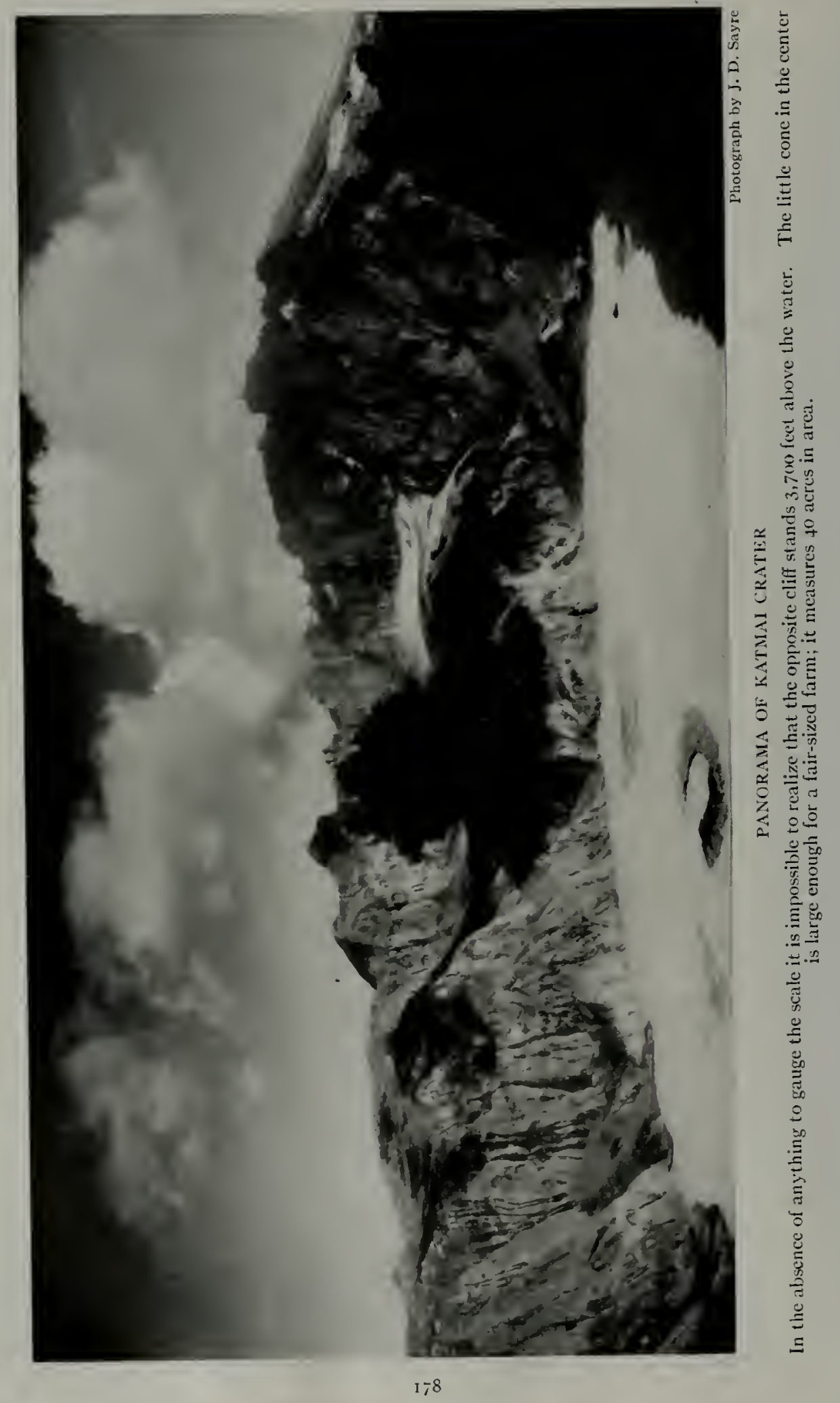


approximately 2 cubic miles $(8.5$ cubic kilometers). This is more than to times the amount of material dug in the greatest excavation cver attempted by man-the Panama Canal.

\section{THE SKYSCRAPERS OF NEW YORK WOULD} NOT FILL THE CRATER

In seeking more familiar comparisons to make vivid the proportions of the crater, I recalled my bewilderment when I first tried to see New York City. The endless rows of closely built blocks, series on series, supply an apparently inexhaustible number of objects large enough for units to measure cubic capacity of almost any dimensions.

If one could drop the blocks of New York into the crater of Katmai how many would it take to fill it? The truth is that if an average six-story tenement house were set against the crater wall, it would be hard to find in the picture.

But the skyscrapers impress the visitor to New York more than the tenement houses. How would they appear in the crater? The probability is that all of the skyscrapers of Lower Manhattan could be submerged in the lake and never a tower project. Before the bottom of the crater were well covered, all the buildings from the Battery far up town would have to be set in. The more put in, the more impressive the hole would become. And if every structure on Manhattan Island were thrown into the crater hardly a good beginning would have been made. As a matter of fact, all the buildings of all the boroughs of Greater New York-Brooklyn, Queens, the Bronx, and Richmond, as well as Manhattan would not fill the crater.

Indeed, according to the best estimate I can secure ${ }^{3}$ the buildings of fifteen cities like Greater New York would be less bulky than the material blown off the mountain!

\section{KATMAI LARGER THAN KILAUEA}

Kilauea, in the Hawaiian Islands, has always been accounted the largest active crater in the world, but it is clear that it must now yield the palm to Katmai. Kilauea's greatest diameter is 2.93 miles, its circumference 7.85 miles, and its arca 4.I4 square miles. Each of these dimensions is somewhat less than the corresponding figure for Katmai.

But the most significant difference is in the depth, which is less than one-serenth as great as that of Katmai. The highest point in the walls of Kilauea is only 500 feet above the floor of the crater, as compared with 3,700 feet in Katmai.

There is a good automobile road leading through a low notch in the rim into the caldera of Kilauea. But no one who has ever looked into the abyss of Katmai has been tempted to try the descent. For, interesting as a close-up examination of the bottom of the crater would certainly prove, no one has been able to suggest a means by which those sheer precipices might be ascended again, if by good luck one managed to reach the bottom with no broken bones.

As a matter of fact, there is little justification for comparing Katmai with Kilauea. Each is unique and unrivalled in its own way. Visitors to Kilauea are not so much impressed by the magnitude of the crater as by its incomparable fiery lake of molten lava, which, however, is a scant thousand feet in diameter. On the other hand, there is nothing at Kilauea similar in the least to the stupendous abyss of Katmai, its turquoise lake set round about by multi-colored cliffs.

Katmai and Kilauea stand, in fact, at opposite extremes in the series of the world's rolcanoes. While Katmai, during the brief period of explosive activity, furnished one of the most terrible examples of the titanic forces of volcanism, Kilauea has been called "the world's safest volcano." Its continual quiet welling-up of highly liquid lava is the antithesis of the explosive expansion of Katmai, wherein all the magma was blown to fragments.

${ }^{3}$ From data furnished by Herbert S. Swan, Secretary of the Zoning Committee, New York City. 


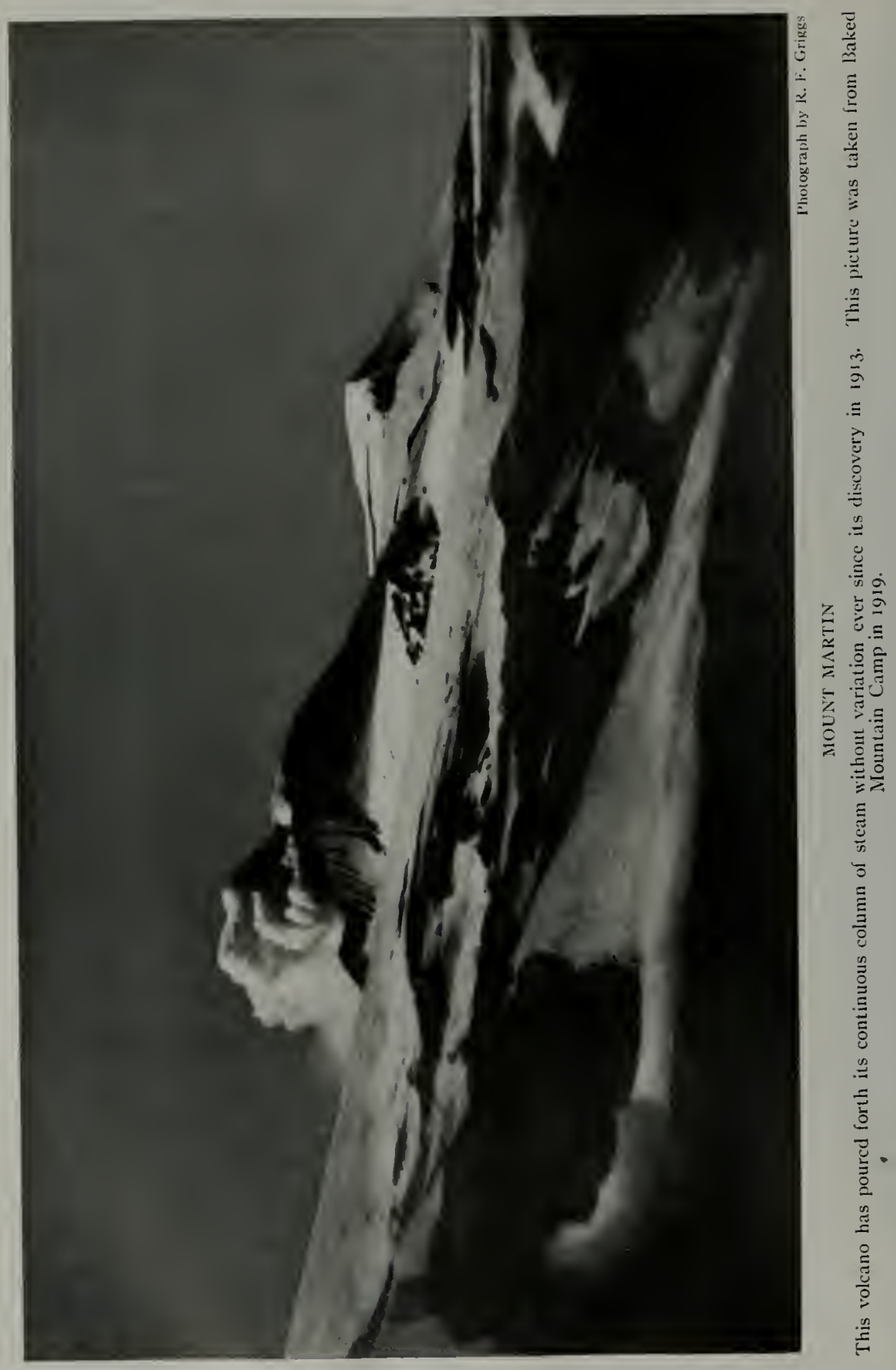




\section{MOLNT MARTIN}

After the attainment of Katmai Crater, Mount Martin, which was far more active than Katmai itself, became our prime objective. But for several reasons it is the most difficult of the volcanoes to study.

To get within striking distance is of itself somewhat of a problem, since it is located in the most inaccessible part of the range. Despite the definiteness of our plans for its ascent, pressure of other work prevented us from establishing a camp at its foot in 1917 until late in the season. During the week we watched, the mountain was continuously shrouded in a cloud, and we had to give up the attempt.

Lnfortunately, Mount Martin is so placed that it is the first peak to cloud up with an approaching storm, and the last to clear again. Worse yet, the strong updraft created by its column of steam sucks up from the lowlands a body of warm air, whose moisture promptly condenses into heary clouds when it reaches the upper levels.

While frequently clear for a time at morning and evening, it is of ten swathed in clouds during the middle of the day. It is, therefore, hard to choose a day suitable for the climb, for it is almost impossible to tell in the morning whether it will remain clear or cloud up before noon.

Knowing something of these difficulties in advance, we planned in 1919 to make the ascent early in June, when the weather is most favorable. But here again we were foiled. for we found that snow persists longer at the head of Martin Creek than anywhere else in the district, concealing the features we most wished to study.

Accordingly, it was not until August that we found ourselves encamped in the valley at its foot, waiting our chance.
The crater was clear on the morning of the first day after our arrival. So up I started without waiting for Hagelbarger and Henning, who were to meet me.

But before I had gone far a hard rain commenced, and although I could still see the rolcano it was of no use to try for pictures. Nevertheless, the day was not wasted, for I was enabled to pick out the best route to the summit and to study the glaciers and lava flows round about.

\section{MOLNT MARTIX A SUBORDINATE CONE ON} THE FLANKS OF MAGEIK

From the level of the lava platform on which the cone stands, it is evident that Mount Martin, although located directly on a projection of the KatmaiMageik axis, and the most active rent in the whole region, has somewhat the character of a parasitic cone on the flank of Mageik.

From the Valley some of the lava flows comprising the plateau look as though they might have cone from Martin, but from the higher levels it is evident that all the more extensive bodies of lava were poured out by Mageik.

Martin stands superposed on the sloping surface of these lavas. Its cone is composed of short, massive flows of the same basic andesite that characterize the whole region. But apparenty the lava was so viscous when extruded that it solidified close around the orifice. Is a consequence, a steep-sided pile was built up, which from the valley looks like a cinder cone, rather than a mass of solid lava.

The crater, which is about $\mathrm{I}, 000$ feet in diameter, appears from below as a funnel blown out of the top of the mountain. The lowest point in the rim, which lies on the east side, is several hundred feet lower than the high point opposite. 


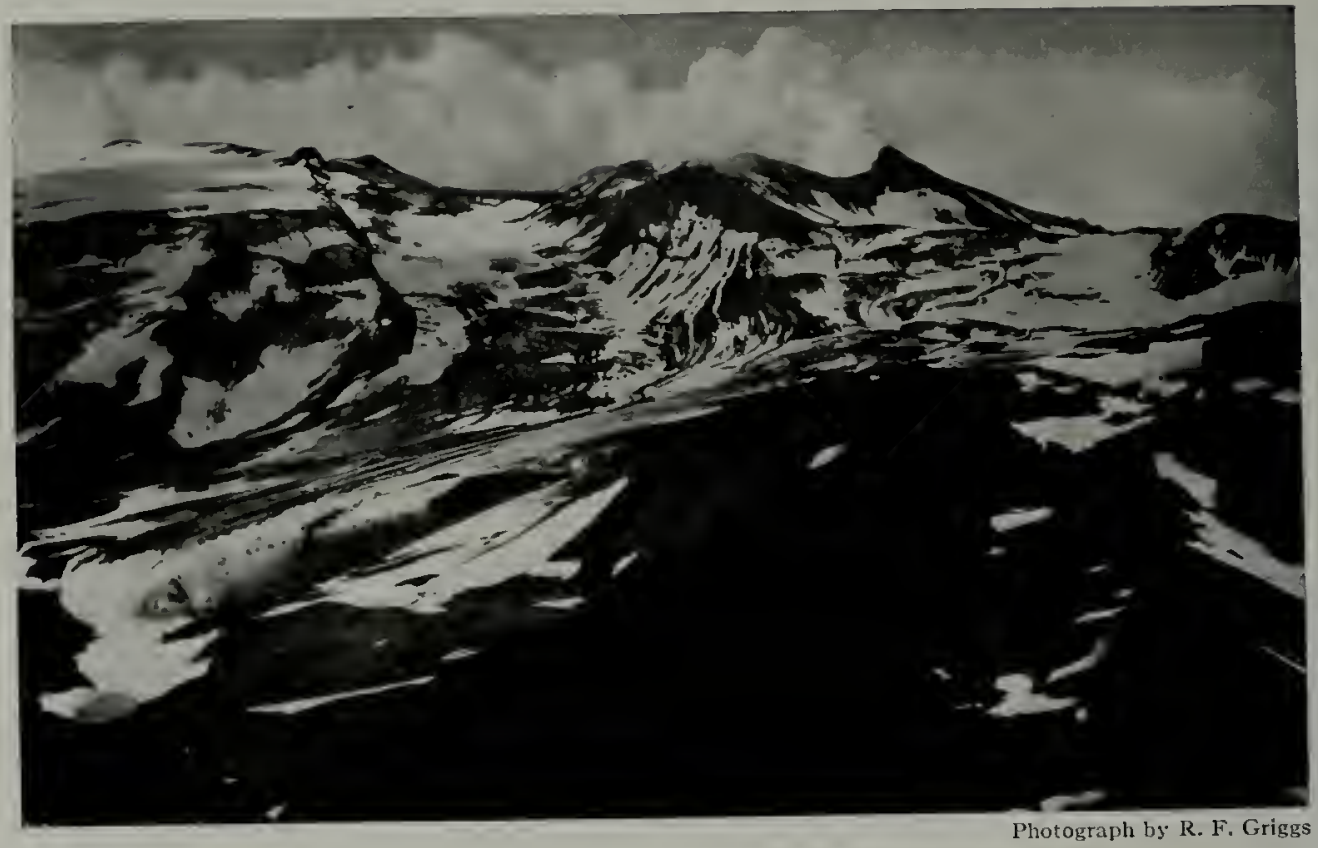

MOUNT MARTIN FROM THE PACIFIC SIDE

Three times we climbed this volcano and once descended inside, but we were baffled in our attempt to study its crater by the clouds which shut down before we could reach the rim.

Often the whole cavity is filled with a dense cloud of steam, which may rise high in the air in a solid column. But on a very dry day it can be seen that most of the steam comes out in two vents at opposite sides of the crater.

MARTIN SEEMS NOT TO HAVE THROWN OUT ASH OR PUMICE IN THE ERUPTION

We had hoped to be able to determine the character of the convulsions by which Martin was opened up, and the rôle it played during the eruption. The fact that its later activity has been greater than that of any other vent in the district suggests that it may have contributed a considerable share to the general disturbance. But we saw no evidence on the flanks of the volcano that it had ejected any ash or pumice.

The only deposit of unusual character observed in the vicinity was a considerable amount of coarse sand and fine gravel, made up of fragments of old crystalline rocks, which lay among the crevices of the lava flows, as though showered onto them by an explosion from the top of the volcano.

The summit, before the cruption, doubtless bore a quantity of glacial till that may very well have bcen the source of such a deposit. If the crater of Martin was produced by explosion, and this sand is the only débris left behind, the outburst must indeed have been mild, compared with the terrible blasts which wrecked Katmai.

\section{ALL VEGETATION IN THE VICINITY KEPT DOWN BY ACID RAIN}

Upon cxamining the neighboring country, I was astonished to see that for a distance of five miles or more in every direction the naked brown ground, though fertile and free from heavy ash deposits, remained bare of vegetation. It was quite different in this respect from any other area in the district.

Even if all vegetation had been destroyed seven years before, it should 
have returned by this time; everywhere else plants were growing vigorously whereever their roots could reach the old soil.

I could not imagine what might be preventing revegetation until I chanced to experience a local rain, in which the drops had been so strongly acidulated by the fumes that they were painful to the eyes and other sensitive parts. Such acid rains probably destroy the plant life as fast as it comes back within their range.

This country, indeed, resembles strongly the smelter regions of the West, where vegetation has been destroyed by noxious fumes.

On the second attempt to climb, clouds settled down on us at the 3,500-foot level, but, thanks to bearings secured the first time, we were able to keep on through the obscurity for another hour in hope of a break that would permit us to scale the summit.

Finally, having reached the main divide of the range, we sat down and ate our lunch, hoping for a rift that would show us where we were, for we had gone as far as we dared without new observations. Later, we found that we were right under the last steep pitch of the cone and could have reached the rim in a few minutes more, could we have seen our way.

But it would have been a useless exploit to reach the top under such conditions, since we should have seen nothing when we got there. It was a mournful party that descended the mountain that evening, for the demands of other work were imperative, and camp had to be broken next day with the crater yet unseen after two weeks of waiting for a chance to climb.

\section{THE THIRD CLIMB}

Five days later, as I lay awake at Baked Mountain Camp, I crawled out into the night to look at the Ten Thousand Smokes and the volcanoes in the spectral light of a wonderful full moon. There was Martin puffing away, beautifully clear, its unconquered steam column rising majestically over all. IVhy not do it tomorrow?
We were now on the wrong side of the range, and far from a favorable starting point; but it was the only chance, for there were unmistakable signs that the good weather that had favored us for two days was about to change. It meant covering a mile in altitude and $3^{\circ}$ miles in distance, but I was not to be turned back if there was any possible way of getting there, and I knew Charlie Yori was as anxious as 1 to try it.

Indeed, I should never have dared attempt to cross the glaciers that guard Mount Martin on the Valley side without the benefit of his experience in ice work. So I waited until a seasonable time to rouse the camp, and finding that we could leave without interfering with the chemists' work, Fenner, Yori, and I got ready in a hurry and started off double quick, in our eagerness to get to the top before anything should happen.

The whole of our course, after we had climbed out of the Valley, lay across glaciers and snowfields. When we surmounted the first slope, we found to our sorrow that between us and our goal lay a considerable hollow, into which it was necessary to descend several hundred feet before starting up the slopes that led to the cone.

The glacier that occupied this hollow was more extensive than any of the others which have developed on the flanks of Mageik. From its crest our view stretched out for many miles across the interior basin back of the low coast range.

A few miles beyond us the central range, which bears the volcanoes, gave way to a broad open lowland, occupied by a luxuriant growth of tall grass. Beyond this lay Becharof Lake, from whose shores these fine lands are readily accessible in every direction. Farther still, from the opposite shore, the symmetrical white cone of Peulik, the next volcano of the series, rose a mile high directly out of the lowland.

For the most part going was not difficult, except that we had to waste much time winding in and out around 


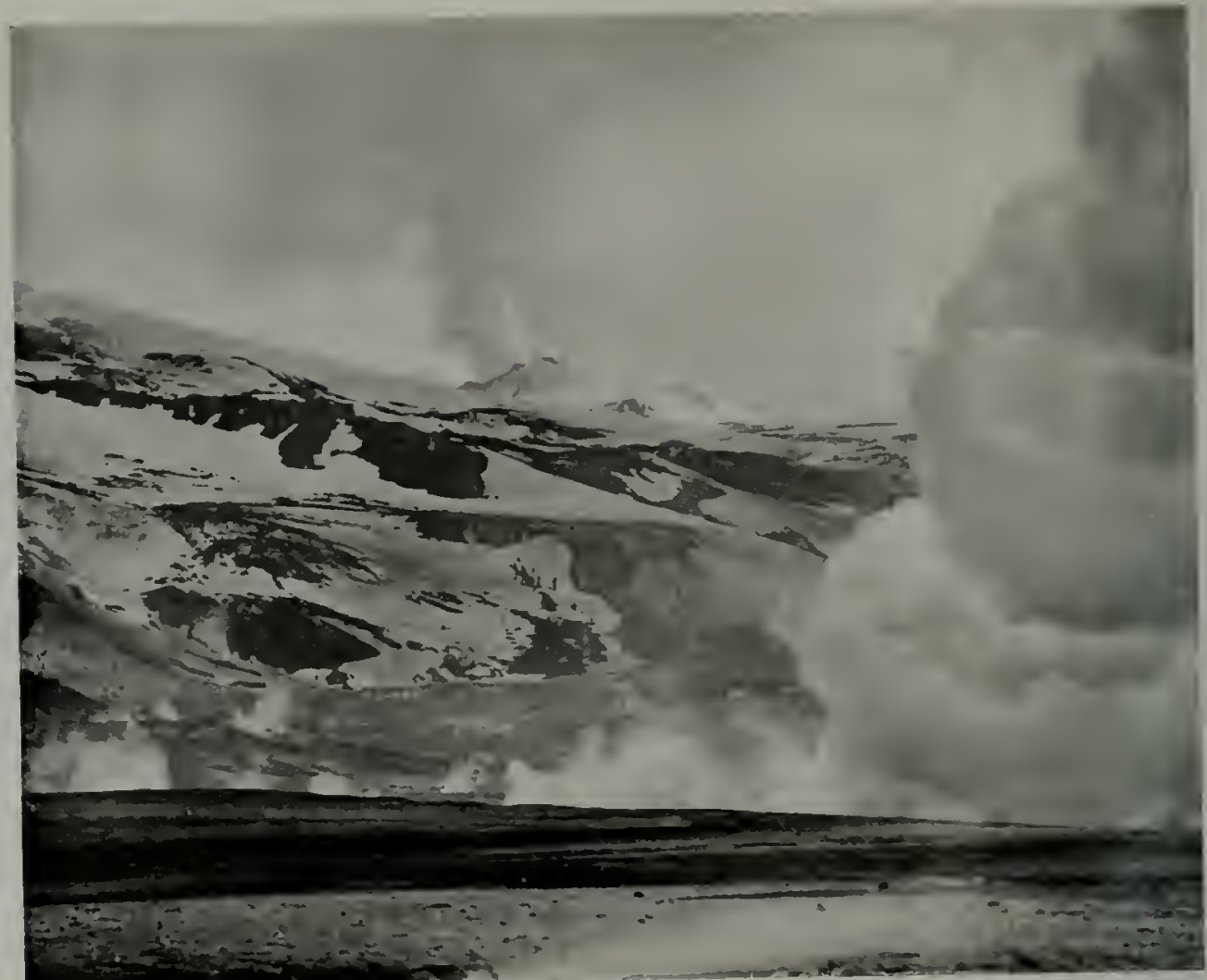

Photograph by Frank 1. Jones

\section{MOUNT MARTIN FROM BAKED MOUNTAIN CAMP}

The crater is thirteen miles distant in a straight line. After leaving the first slopes, five miles away, our path led entirely over ice and snow. Some of the glacier-work was extremely hazardous.

the irregularities of the ash-covered glacier, here following a drainage gully, there cutting across the ridges.

\section{A "REAL GLACIER"}

But between the hollow into which we had dipped and the high snowfields surrounding the cone lay an area badly cut up by close-set crevasses. As we entered this, Yori remarked. "This is a real glacier, all right enough."

With his customary hardihood, he professed to scorn a rope, and took a sort of frendish glee in trying me out in the most "ticklish" places he could find. I will not deny that I was somewhat tinid, for my hobnailed boots were worn out and I had been compelled to come in rubber-soled shoe-packs, which could get no grip on the slippery surface. This bothered me greatly, though the ice-axe which I carried probably counter-balanced the disadvantage.

Our way lay, as Fenner expressed it, "along the ridge pole," following narrow crests of glaring blue ice, themselves sloping both ways, between bottomless crevasses on each side. A slip would have meant certain death. But we crept along, using all the care we could, and finally reached the névé above without mishap.

Without stopping for the much-desired pictures we pressed forward feverishly, in the hope of reaching the summit while it was yet clear. A breeze had sprung up out of the northeast and we knew it was a question of only a few 
hours before our mountain would be hidden in clouds. Indeed, they had already begun to gather.

We made rapid progress now, traversing the smooth snowfields in a wide semicircle around the base of the cone toward the low point in the crater rim opposite. We were in the clouds here, but had a glimpse out on the other side of the range to the Pacific.

When we came around under the low notch in the rim we sat down and waited for a break in the clouds, to get our bearings before taking the last steep slope, and ate lunch as we waited.

Hardly more than a hundred yards away was the hillock where we had stopped on our attempt from Martin Creek. This time, however, we never doubted but that we should soon have our chance, for the clouds were only beginning to gather. Indeed, just as we started to eat they blew off a little.

There was the crater rim, seemingly only a few steps directly above us. Great masses of steam came rolling up close against it, but as we were on the windward side they were quickly carried off in the opposite direction. From a distance the smoke of Martin always appears snow white, but from our position it took on a weird lemon-yellow color, which Fenner suggested was probably due to reflection from a large body of sulphur within the crater.

\section{CLIMBING A 6O-DEGREE DIRT SLOPE}

The rim seemed so close that, dropping my cracker, I started for it. Before I could go a dozen steps the clouds closed in again, continuing until we had finished our lunch. But we had our bearings now, and started up, so as to be on the rim when the next break came.

That last pitch, 250 feet it proved when we measured it, was the steepest slope I have ever seen. If it had been rock it would have been easy climbing; but it was bowlder-clay, left there by a glacier that had capped the mountain during its dormant period.

The slope was 60 degrees by the cli- nometer (as compared with about 30 degrees in a steep railroad embankment). The round bowlders on which we depended for foot- and hand-holds were so loosely held in the uncemented clay that it was extremely difficult to hang on.

Finally we reached the top, at 5,300 feet, but were unable to see anything in the cloud and steam that surrounded us. Inside the first sharp edge we found a slight depression, and then a second similar sharp inner rim. The original rim had evidently broken loose and slumped down into the hole a little.

In the depression between the two rims was a little pool, over which we bent to secure a drink, for we had had only snow with our lunch, but, ugh! it was strong acid.

The fumes at the rim were very disagrceably acid, and I was glad to retreat into a little hollow where I could take notes in comparative comfort.

\section{DESCENDING INTO THE CRATER IN THICK STEAM}

After a little, Fenner came out of the cloud and reported that it was possible to go down inside the crater, using handkerchiefs as respirators. So we all put our handkerchiefs to our noses and plunged over the edge.

On the rim we could distinguish the outlines of objects 50 feet away; but once inside the steam thickened rapidly. A few feet down we could hardly see each other, though standing only four or five feet apart. Whenever a gust of wind swept the smoke back a few feet, we leaped on farther down, until the obscurity closed over us again and we were compelled to halt for fear of stepping off the edge of the precipice into the roaring vent beneath.

There we stood huddled together, like ninnies, panting through our handkerchiefs and pulling down our hats in futile efforts to protect our smarting eyes. If we loosened the handkerchiefs a little to get a freer breath, we met a suffocating draft that at once compelled us to clamp the protection back again. 


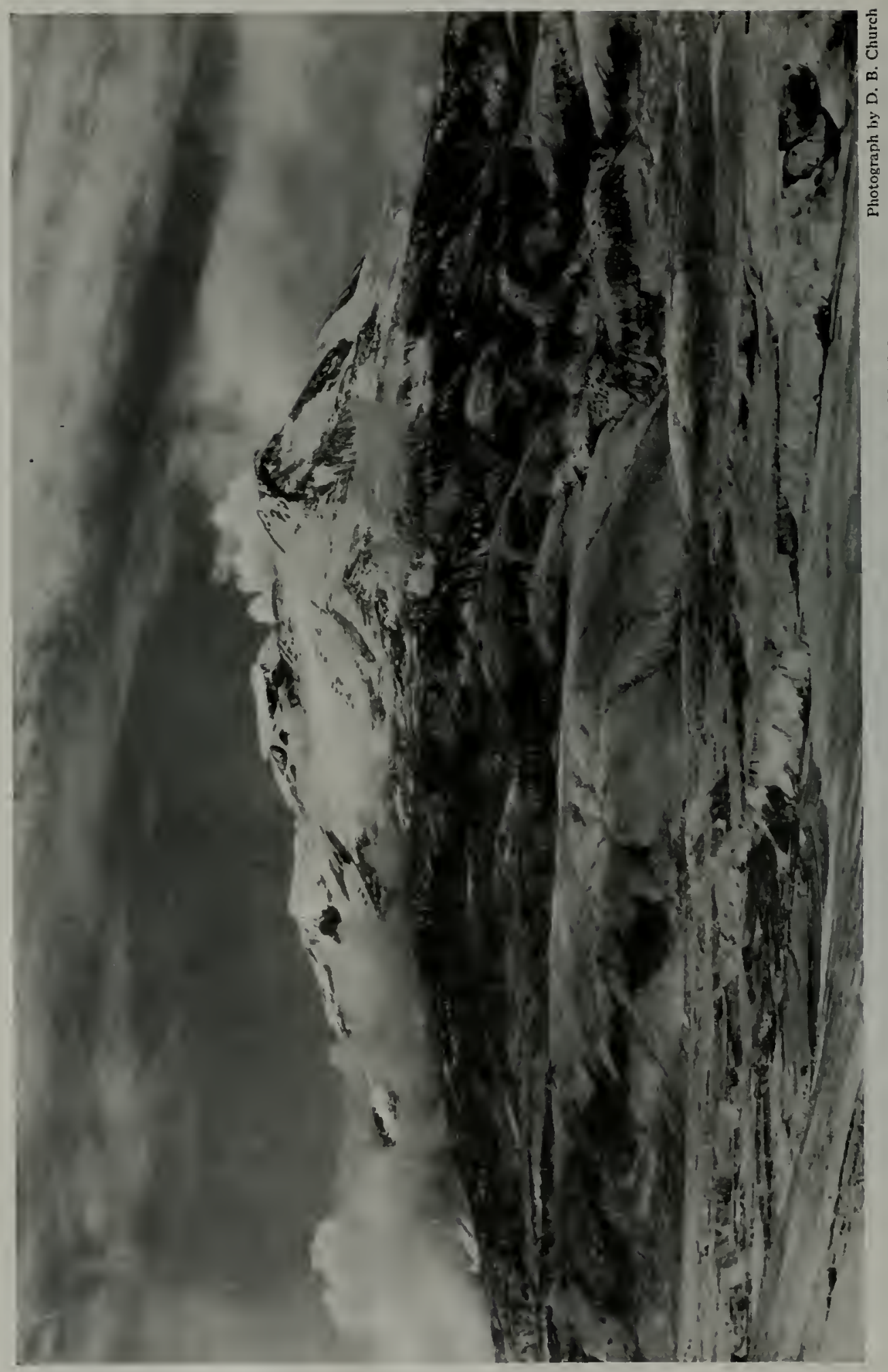

z 
Silent as ghosts we stood, until one of us, caught by the ridiculous attitudes of his companions, burst out laughing, setting us all a-snickering behind our handkerchiefs like school boys who fear the teacher's wrath, for we durst not lift our mufflers.

Thus we waited for nearly half an hour, but there came no further opportunity to proceed. We could see nothing around us. So we decided to give it up, and after picking up a few specimens of the rocks immediately around us (ordinary andesites) we scrambled back to the rim.

\section{RETURNING THROUGH THE LOWERING CLOUD}

Here again we sat down and waited for an hour. But there was not the slightest sign of a let-up; so, reluctantly, we started for camp. The momentary break that had come while we were eating was the only near-by glimpse of the crater we were to have.

Climbing up a dirt slope at an angle of 60 degrees is as nothing compared to wriggling down again. There was imminent danger of dislodging a loose bowlder to fall on one's companions below, and there were places where we simply had to "let go" and fall off, trusting to luck not to hit anything hard before stopping.

Regaining the snowfields, we found that the cloud cap had settled much farther down the slopes, and we had to descend several hundred feet before we came out into clear day again.

We had not turned back a minute too soon. Of that we needed no second hint. We all knew that to be caught in a fog on that crevassed glacier, where we could neither follow the route by which we had come nor choose a new path, might mean disaster.

As we worked our way back and forth among the crevasses, we got into an area of snow bridges which made even Charlie, with his long experience on glaciers, hesitate. He kept protesting that "he didn't like that ice," and we went forward with great caution.

But no better way was to be found, and the certain menace of the thickening clouds compelled us to take the uncertain risks of rotten snow bridges and go ahead regardless of danger. "All's well that ends well," however, and finally we crossed the last crevasse, reaching the solid floor of the Valley again without accident.

There was still a long four-mile drag across to camp, but we made it before half past eight, tired and disappointed, but yet with the knowledge that we had succeeded in a difficult feat, even though we had been denied the fruits of our labors.

And this, the sixteenth of August, had been the best opportunity to climb Mount Martin since the twenty-fifth of July! 


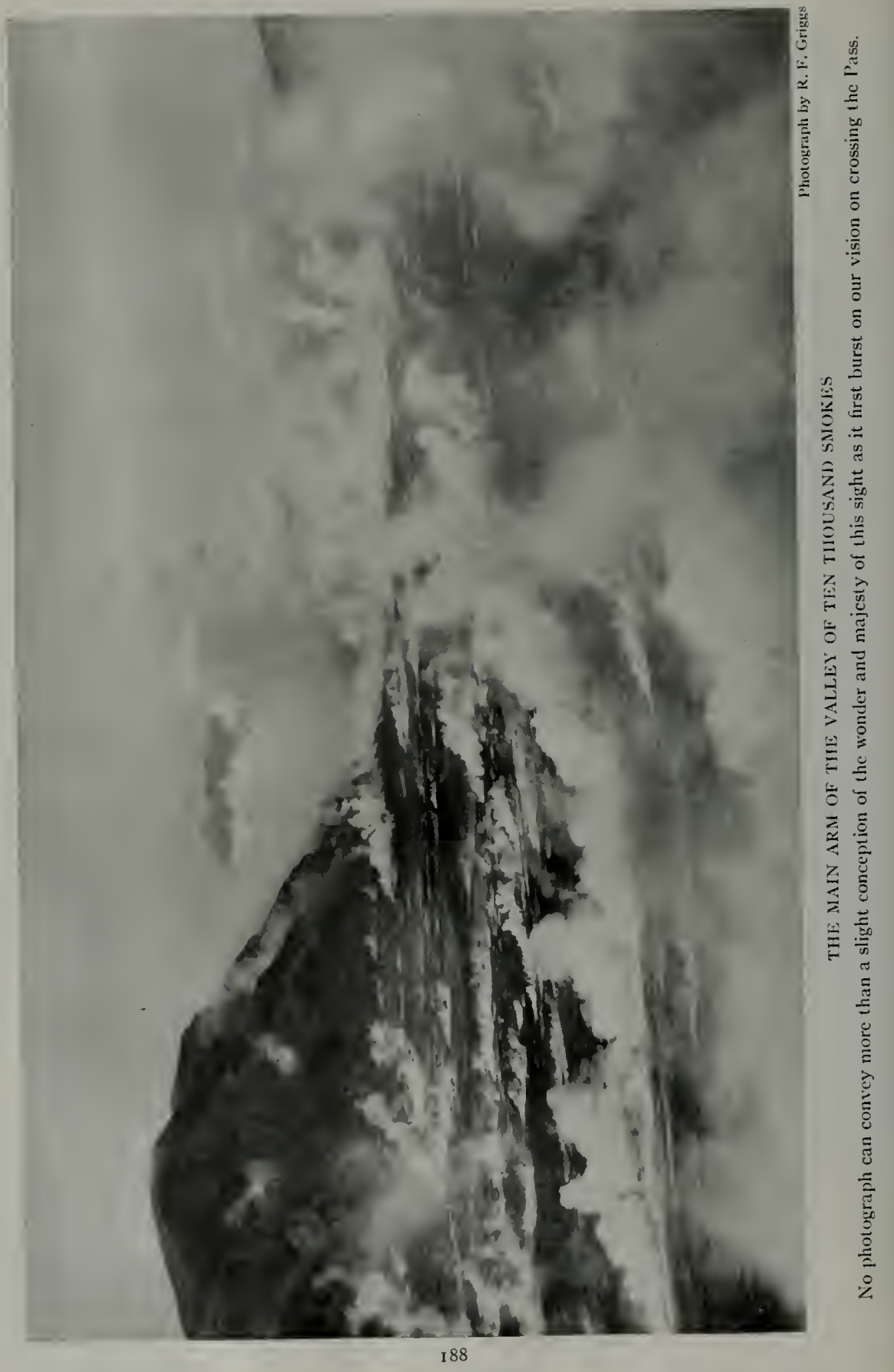




\section{DISCOVERY OF THE TEN THOUSAND SMOKES}

July 31, 1916, dawned clear and bright as had the day before, when we had made the sccond ascent of the volcano. But this time the steam from Mageik drifted off to the northwest, and small clouds were beginning to gather on the west side of the valley, so we knew it was to be the last day of good weather.

We had originally planned a twodays' trip across the Pass, to see if we could find the source of the clouds that had aroused our suspicions. But, remembering the bad name given Katmai Pass by Spurr (see page $268^{\circ}$ ), who states that it was impossible to cross it except in good weather, and fearing to be caught short of provisions on the wrong side, we gave up the projected trip and decided merely to reconnoiter.

Planning to make an easy day of it for we were tired after our climb to the rim the day before-we climbed around the shoulder of Observation Mountain and descended into the upper valley of Mageik Creek.

Here we found the most striking accumulation of ejecta we had yet encountered - a quantity of fine material which resembled the Katmai Mud Flow in its massive non-stratified character, although it was much more extensive and thicker, having weathered out into bad lands with bluffs nearly 100 feet high.

\section{ASCENT TO FATMAI PASS}

After stopping a little while to study the flow and to eat our lunch, we made our way across the bad lands toward the Pass, following now the ridges of the flow, now the bottom of the canyon, which rose at a gentle grade.

As we ascended the valley past the highest peak of Trident we came within view of the hollow between it and the next peak, from which we had thought sereral times we saw clear indications of rising steam. The sun illumined it brightly, and there was not the smallest puff of stean anywhere.

We were now up 2,500 feet, only a little lower than the Pass, and could see a long way through it. No steam was visible therc, either (see map, page 68.)

So again we concluded, as we had the day before, that we had seen nothing more than the ordinary clouds which gather so easily around the summits of all high mountains.

Church, incapacitated by too many flapjacks at breakfast, gave out, so Folsom and I left him with the packs, much against his wishes, while we went forward a little farther to see what we could discover.

Traveling transversely across the gullied bad lands of the mudflow, a route made necessary by the condition of the canyon below, was very laborious, and before long I was ready to turn back, satisfied with having seen through the Pass and, as I believed, having laid another ghost.

\section{THE FIRST FUMAROLE}

But just as I was about to suggest returning, I caught sight of a tiny puff of vapor in the floor of the Pass. I rubbed my eyes and looked again. Yes, there it was, a miniature volcano sending up a little jet of steam right in the Pass.

The very smallness of this steam jet made it of as much interest as a large volcano (see page 192), for we had been continually surprised at the absence of manifestations of secondary activity parasitic cones, fumaroles, mud craters, hot springs, and the like - features almost invariably associated with so great an eruption. 


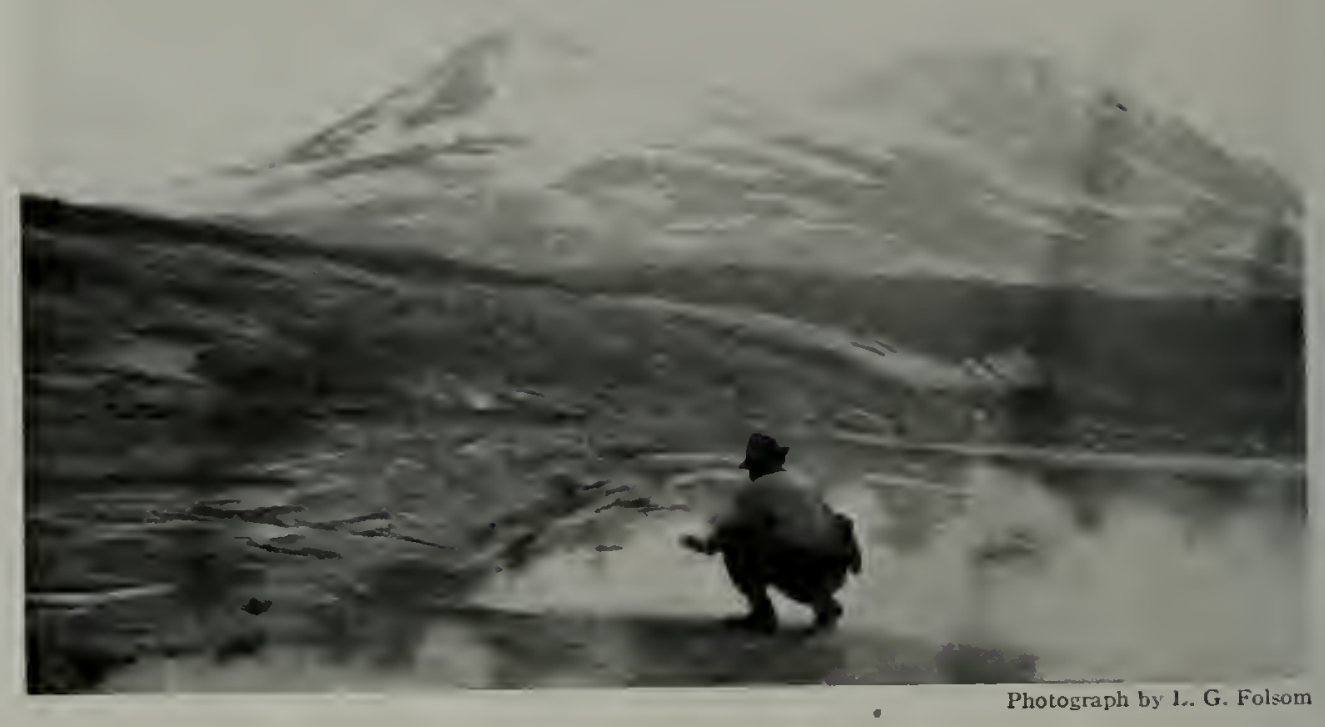

WARMING MS HANDS AT THE FIRST LITTLE FUMAROLE IN THE PASS

These little sentinels of the Pass continued unchanged through 1918, but had gone out in 1919. It was the sight of these which led to the discovery of the Valley.

Thus far we had seen absolutely no indication of signs of recent rolcanism outside Katmai Crater, except in the old volcanoes Mageik, Trident, and Martin. These, however, were singularly far removed from the main crater, and we had been at a loss to understand why activity should appear at such widely separated points, with no intermediate vents.

Earlier in the day we had found the streams from the hot springs near the Pass, which continued as described by Spurr before the eruption, except that the water now was not nearly so hot as stated in his account (see page 269). Aside from that, this fumarole was the first thing of its sort to be observed.

When we reached the Pass we found its floor all shot through with cracks and small fissures from which issued half a dozen good-sized jets of steam and perhaps a hundred small ones.

IVith some trepidation we approached over the fissured surface. Most of the steam escaped from small openings a few inches in diameter, whence it came with considerable velocity, giving forth a low, roaring sound. We could go quite close and warm our hands in the steam, which, though very hot as it emerged, soon cooled, like the moist vapor from a teakettle.

Coming off with the steam were various substances which gave rise to curious evil odors and precipitated a highly colored crust on the ground. Prominent among these was hydrogen sulphide, with its characteristic "rotten egg" smell, and sulphur, which gave a yellow tinge to the parti-colored sublimates of the crust.

I was anxious to return to Church, for we had already been gone much longer than we expected, and had reached a little eminence, when, turning round to urge Folsom to hasten back, I saw far down the valley, over the top of some rising ground beyond us, a puff of steam.

This had not been there when we came orer the Pass, and was cridently a good deal larger than the jets we had been examining. As the obstructing 


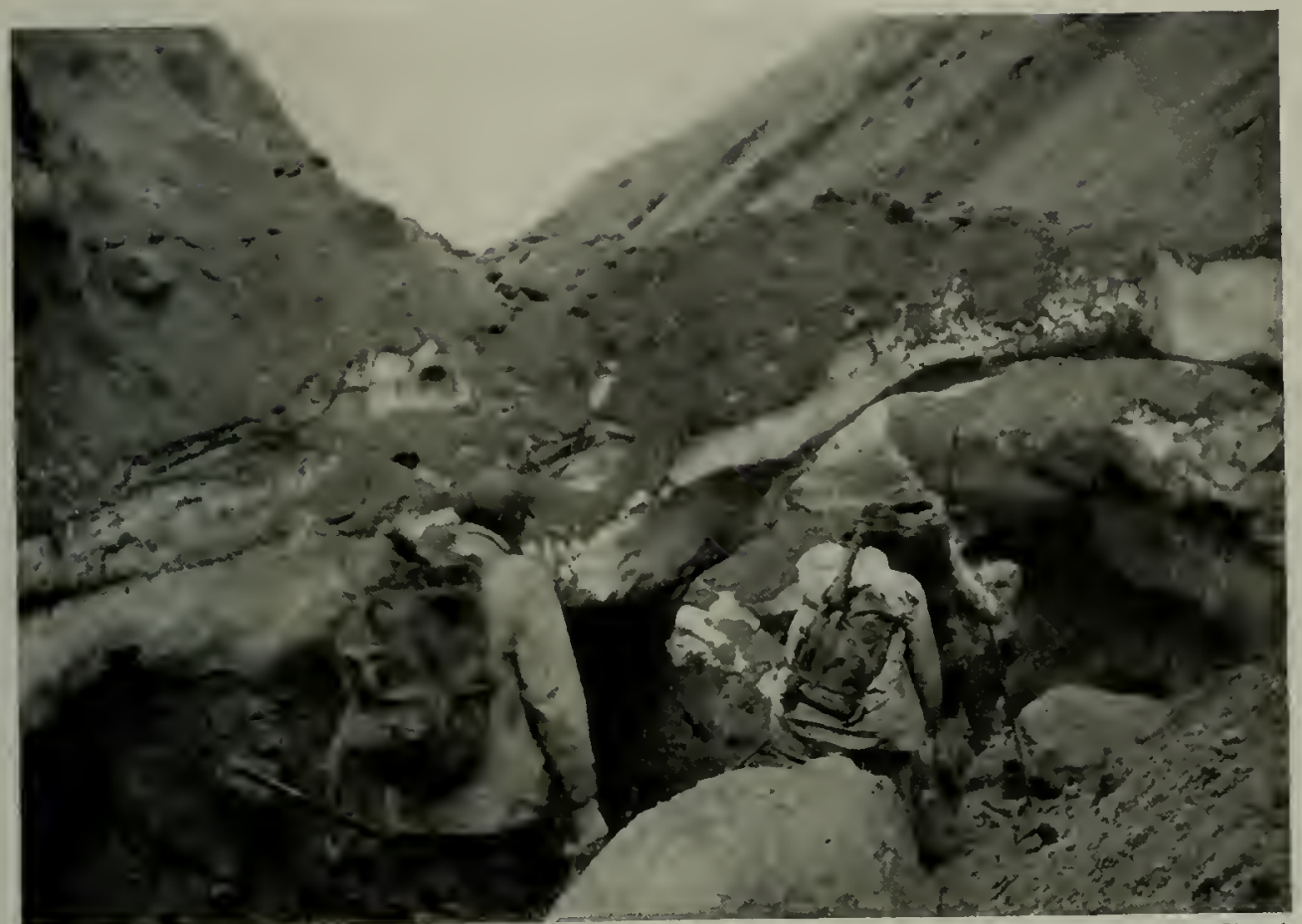

Photograph by D. B. Church

THE TRAIL UP TO KATMAI PASS

The way led over permanent snowdrifts, for the snow had been covered with ash during the eruption of Mt. Katmai, and this coating protects the drifts from the sun's rays. All the supplies for the camp had to be carried on the backs of the men through this pass into the valley.

hill was not far away I decided, late as it was, to go forward to "have a look."

\section{DISCOVERY OF THE STEAMING VALLEY}

The sight that flashed into view as we surmounted the hillock was one of the most amazing visions ever beheld by mortal eye. The whole valley as far as the eye could reach was full of hundreds, no thousands - literally, tens of thousands - of smokes curling up from its fissured floor.

From our position they looked as small as the little fumaroles near by, but realizing something of their distance we knew many of them must be gigantic. Some were sending up columns of steam which rose a thousand feet before dissolving.

After a careful estimate, we judged there must be a thousand whose columns exceeded 50o feet. A dozen miles away the valley turned behind a blue moun- tain in the distance. Plainly the smokes extended that far. How much farther we could not tell.

The first glance was enough to assure us that we had stumbled into another Yellowstone Park-unseen and unsuspected by white man and native alike until this hour.

I tried to "keep my head" and observe carefully, yet I exposed two films from my one precious roll in trying for pictures that $I$ should have known were impossible. For a few moments we stood gaping at the awe-inspiring vision before us, then plunged down to get a nearer view.

It was as though all the steam engines in the world, assembled together, had popped their safety valves at once and were letting off surplus steam in concert.

Some of the fumaroles were seen to be closely grouped in lines along common 
fissures; others stood apart. The biggest of all, the one whose steam had first caught my eye, stood well up on a hillside, in a nest of fissures, reminding me of the crevasses of a glacier, and was big enough to be plainly visible though thrce miles away.

Fortunately a strong wind was blowing through the Pass, carrying all the fumes down the Valley and away from us, or we might not have dared to go on. In addition to the active fissures there were thousands more, inactive at the time of our visit, which had encrusted the ground round about with colored deposits like the others.

Even from the hasty examination we were able to make on the day of discovery, we could see that the vents must be counted by the tens of thousands. And from this first impression came the name, The Valley of Ten Thousand Snokes.

\section{CHARACTER OF THE VENTS}

In some cases the steam issued from a large deep hole; in others there was no opening at all-the vapors simply escaped through the interstices of the soil particles.

There was no relation between the size of the vent and its output. Some of the largest jets had very narrow throats, while from some cavernous holes there issued only faint breaths of steam. In many cases steam pourcd from the sides of the drainage gullies, where it did not break through the more compact surface layer of sand.

The ground was hot in places where no visible exhalation was being given off, as we found to our dismay when we sat down to rest on a bank seemingly safe enough.

Fearing to ruin our shoe leather we dared not enter any areas except those which appeared moderately cool. But even with such precautions the heat in many places penetrated our thick soles.

I wish my vocabulary were adequate to describe the curious mixture of foul odors which the "Smokes" gave forth. Mixed with the omnipresent sulphurous gases were others which had a strangely organic smell, recalling at once burning wool, the musky smcll of a fox den, and the odors of decay.

IVe could not tell to what extent, if any, odorless asphyxiating gases, such as carbon monoxide, might be present in the complex. We did not experience any ill effects from the fumes, but we took good care to keep to windward most of the time.

\section{ENTRANCE TO THE MAIN VALLEY}

A mile and a half from the Pass we came out from between the two lava cones $^{1}$ that guard the main entrance, into full view of the Valley. It was clear that the fumaroles stretched along the range all the way from Katmai to Martin, linking into one huge area of continuous activity the widely separated volcanoes, which had hitherto appeared as isolated vents.

We did not take time to examine conditions to the west, for we beheld in the opposite direction a prodigious steam column from a volcano which we later named Novarupta.

As we drew nearer we saw that the main body of this steam was rising from a central mass of rock (stiffened lava), surrounded by a comparatively low crater ring, evidently composed of materials thrown out of the vent. The surface of the cooling lava plug was covered in most fantastic fashion with sharp angular fragments, which on closer inspection proved to be rocks several yards in diameter. These had been broken off by the too sudden cooling of the molten magma, just as a piece of hot glass is shattered if suddenly plunged into cold water (see page 276 ).

\section{AN INTERPRETATION OF THE FUMAROLES}

Even the hurried observations we were able to make were sufficient to bring out clearly, in its larger outlines, the significance of the Valley. With 


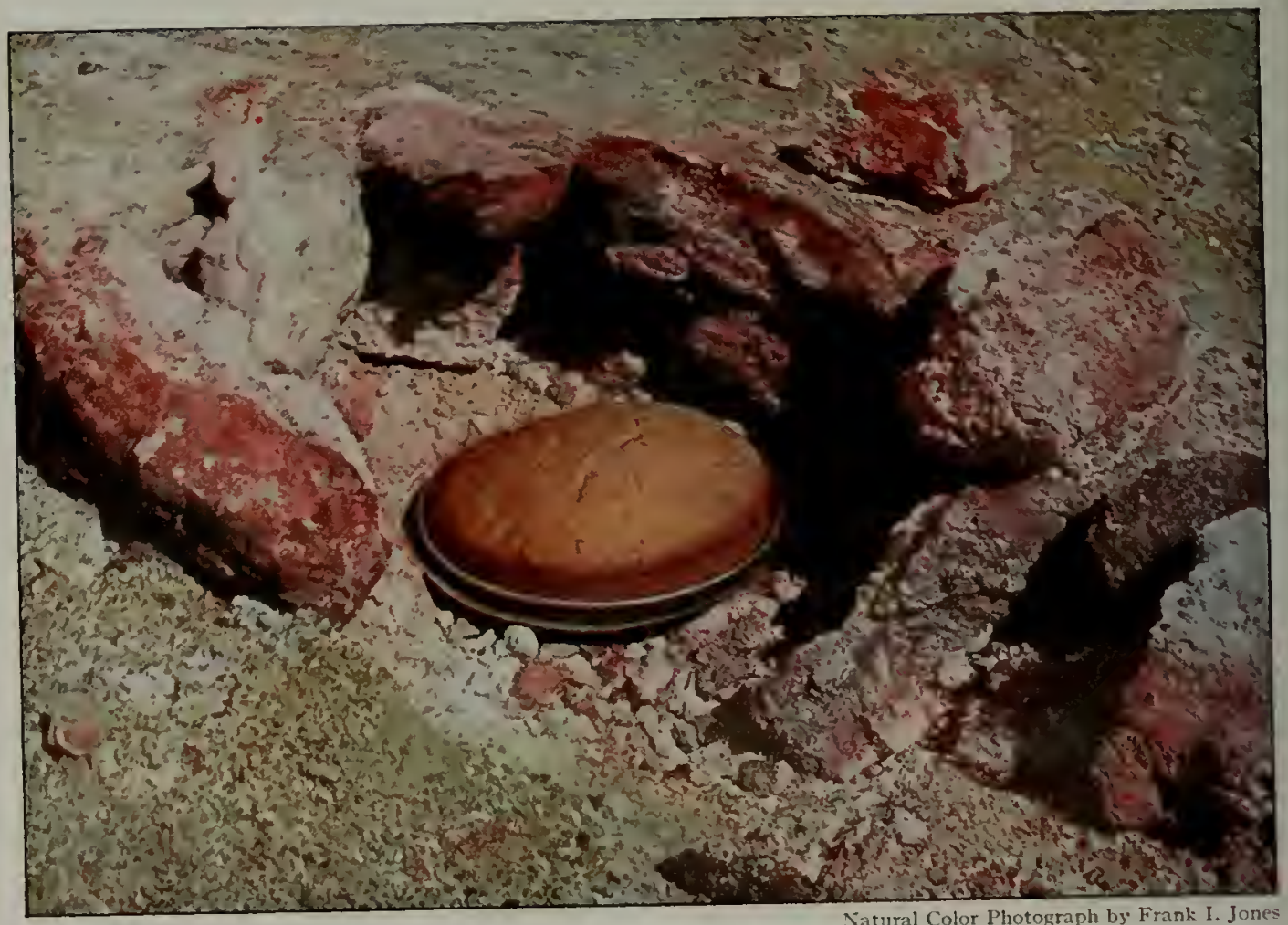

Natural Color Photograph by F
BI NATLRE'S FIRES THE OYEX WHERE COR.N BRE.AD M:AS BAKED BI NATLRE'S FIRES
If left too long it would quickly burn to a cinder over the grcatly superheated steam issuing here. 
the very first glance it was evident that although little fumaroles in the Pass might be secondary manifestations, the great steamers of the Valley must be true volcanic vents. They were altogether too big and too hot to be anything else.

The long fissures everywhere so much in evidence were apparently the outlets of fractures in the bedrock through which the emanations from a mass of intruded magma were escaping to the surface.

The gases rising through these fundamental fissures and seeping through the mass of accumulations from recent eruptions evidently found their vent in the myriad fumaroles, very much as many small leaks will break out on the surface of an old bicycle tire from a single puncture of the inner layer of rubber.

We were surprised to observe that the main trend of the activity was at right angles to the chain of volcanoes. We would have expected exactly the reverse, for in any general rise of the range, such as might have accompanied the eruption, the fracture lines would run parallel with the axis.

Another remarkable feature was the fact that so far as we could see the fumaroles were strictly confined to the low ground of the valleys and were not breaking out on the mountains as well. This indicated that whatever the nature of the intrusion below, it must have come so close to the surface that the position of the fractures was determined by relatively small differences in surface relief, i.e. in the thickness of the roof above the magma.

The great distance to which the fumaroles extended from the axis of the old volcanoes - I 5 miles, as we found by later surveys - further indicated that the subterranean magma must have a considerable extent.

It was late, and as we had now seen all that could be observed without extended exploration, we turned our steps homeward and hurried to rejoin Church, who had shivered in the cold wind for five hours, even with all our extra clothes. Once across the gullies, which were more than ever a terror to us now that we were nearly exhausted, we made good speed back to camp, which we reached a little after ten o'clock.

IVe had expected, of course, to outfit and return to our Valley of Ten Thousand Smokes for further exploration, and especially for pictures which would prove our story. For, on the day of discovery, so little did we anticipate what was before us that we had left the photographic outfit behind with Church, and had only a kodak with a single roll of film.

But the river had risen so fast under the influence of the warm weather that we dared not remain longer on the far side. IVe decided it was better to save what pictures we had than to try for more at the risk of not getting any of them out.

\section{REFLECTIONS ON THE NIGHT OF THE DISCOVERY}

Sleep that night was impossible. I had as yet only a very inadequate conception of the place we had discovered, but I had seen enough to know that we had accidentally discovered one of the great wonders of the world.

The responsibilities and the opportunities of our position came over me in a flood of problems that I could not drop. Here were we, alone of all the world, possessed of the knowledge of the existence of this marvelous place.

I kept wondering how the discoverer of the Yellowstone felt when he first beheld the spout of Old Faithful. I remembered Jim Bridger, and his stories - so incredible that no one would believe them, yet so phrased as to prove indubitably to posterity his familiarity with phenomena which by that time had become well known.

I remembered how the editor of a prominent Western paper had refused to publish any of "Jim Bridger's lies." It was sweet to recall that finally, years afterward though it was, that editor had 


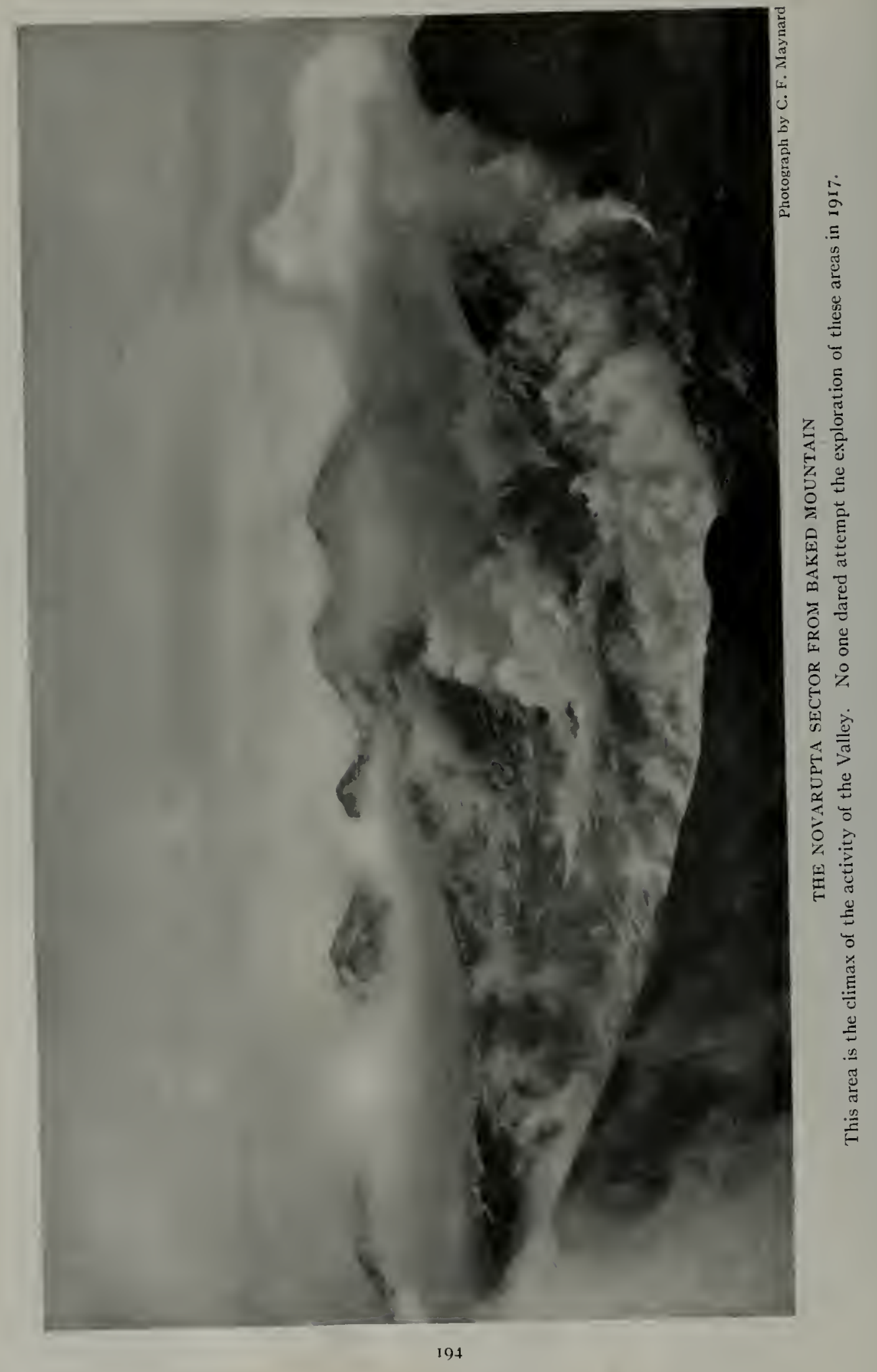


publicly apologized for the injustice he had done the great pioneer.

And when the reality of the marvels of the Yellowstone was definitely established everyone believed them hopelessly inaccessible. Yet what has happened? Anyone may visit the Yellowstone, surrounded by all the luxuries of modern civilization and within the lifetime of Jim Bridger too!

Could I hope for as much? Would our story be believed when we got back? Or would we be regarded as modern Munchausens? I did not underestimate the difficulty of the task that had been set me by that day's discovery.

I recognized at once that the Katmai district must be made a great national park accessible to all the people, like the Yellowstone. To make it known, to have it set aside as a National Park, and to secure the means necessary for its development would, I foresaw, require a tremendous amount of effort.

In the years that have followed I have had occasion many, many times to be thankful for the good fortune which had sent me out under the auspicies of the National Geographic Society. For in all the world there is no other organization so well fitted to bring such a discovery to the knowledge of the public.

The task of making the place known and of getting it set aside as a National Monument proved much easier than I dared hope, as I lay awake that night.

The President of the National Geo- graphic Society did not refuse credence to our account and deny us publicity. On the contrary he was quick to grasp the significance of our discovery, and did all in his power to assist further exploration and to stimulate interest in the reservation of the district as a part of our great National Park System.

Many times also have I been thankful for the tools which modern invention had placed in our hands. With kodaks and halftones and motion pictures to record our discoveries, our advantage over the old-time explorer, who could supplement his account with nothing better than sketches, was enormous.

Along with the difficulties, real and imaginary, that plagued me there was one practical problem which from that night assumed a large place in my mind.

How was the public ever to reach this region? Where was a landing-place to be found on that dangerous and inhospitable coast? For it went without saying that no great number of people could iand through the surf, as we had done; that before it could become the great National Park it was to be, a harbor must be found somewhere along that difficult shore.

A study of the chart next morning beld out little hope. But fortunately for our quest, the coast was very imperfectly charted and we discovered afterward a fine harbor within easy distance, lying in an area shown on the charts as dry land. 


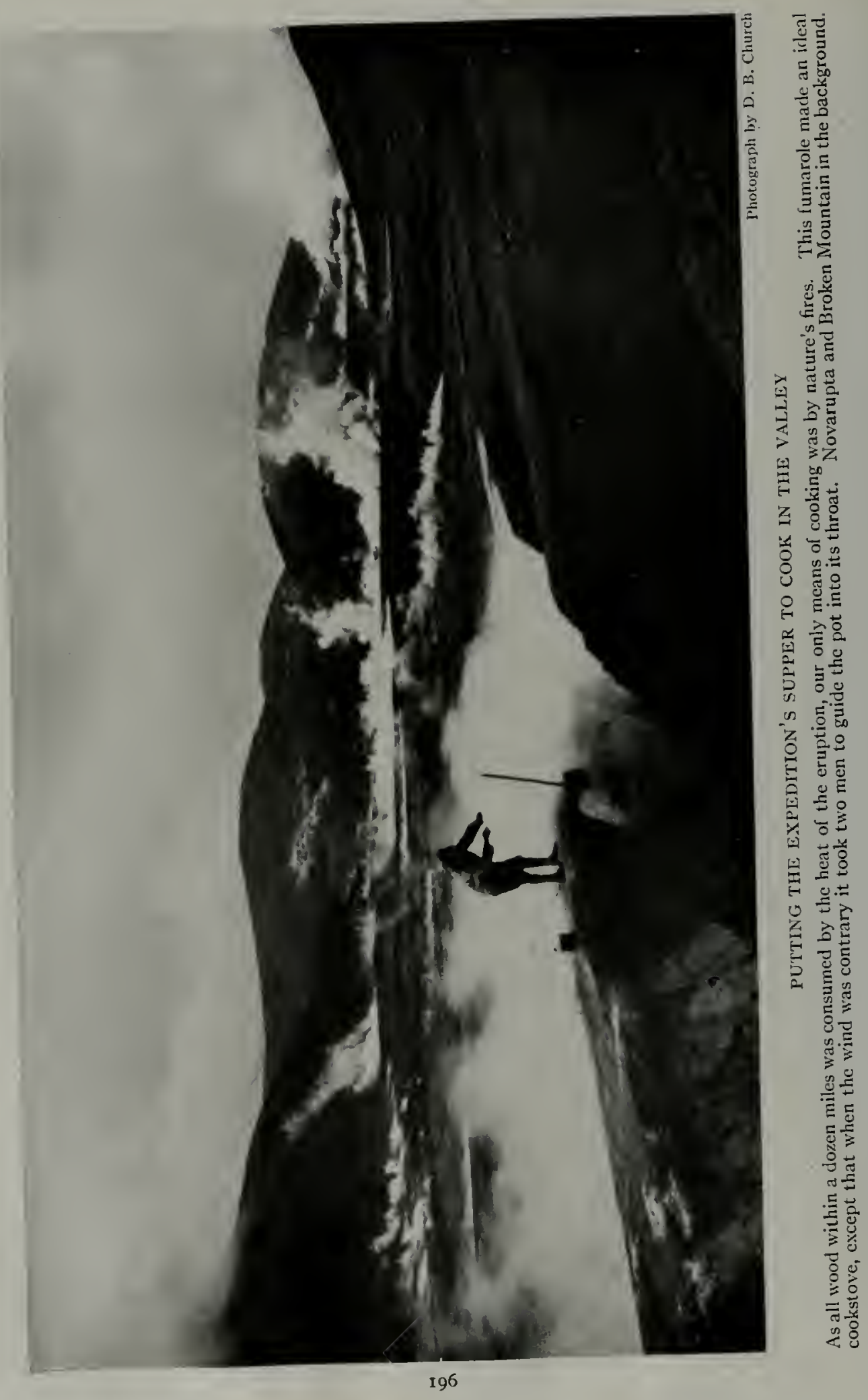




\section{EXPLORATIONS IN THE TEN}

Anxious as we were to see more of our wonderful Valley of Volcanoes, conditions compelled us to leave with only the scantiest evidence to substantiate the story of our discovery.

Fortunately the pictures secured from our one roll of film were enough to prove that our tales were not altogether mendacious, and the Board of Managers of The Society proposed to send us back in I917 equipped to explore the place in greater detail.

It was with great impatience that we awaited the slow course of the intervening months. After we had landed, the days required to pack our supplies up Katmai Valley to our camp at the foot of Observation Mountain (see map, page 68) seemed weeks of waiting. But we thought it necessary, before attempting to cross, to accumulate sufficient stores at the foot of the Pass to insure the maintenance of the party in the Valley.

Finally my impatience would brook no further delay, and I decided to celebrate the Fourth of July by a preliminary excursion across the Pass, to have one look at the place. So, luring Walter along with the prospect of a bath in the hot springs below Trident, I started out, without announcing my intentions.

\section{SMOKES UNDIMINISHED AFTER}

\section{A YEAR'S INTERVAL}

When we reached the Pass I saw at once that everything was just as it had been the previous year. There were the two little fumaroles which we had first discovered, steaming away exactly as they had the year before.

This was decidedly reassuring, for I had been tormented with the fear that we had seen only a passing stage in the declining activity, and that after all the time and effort spent in preparation for the expedition, we might find the Valley

\section{THOUSAND SMOKES IN 1917}

dead when we returned, and all its volcanoes things of the past.

When I got back to camp and reported the conditions, I found that some other members of the party had secretly been entertaining the opposite fear - that the whole Valley might blow up suddenly while we were in it!

On the contrary, all that we have seen indicates that the activity of this district, like that of the Yellowstone Park, has reached a stable stage which will continue without much change for a relatively long period.

Wherever we went, conditions were the same. All the vents, big and little, are remarkably constant in their activity. And now that the district has been made a National Monument, this constancy assumes a twofold interest and importance. In the first place, its wonderful sights are likely to continue for the admiration of tourists for years to come. Secondly, there is little likelihood of a sudden return to a condition of explosive activity.

\section{EFFECT OF THE VALLEY ON AN UNEDUCATED NATIVE}

Walter, who had been keeping camp on the day of the discovery the year before, had listened to our accounts of its wonders with polite incredulity. I was anxious to watch the effect of the Valley on an uneducated native, with no scientific interest to give significance to the sight.

When we had examined the little fumaroles in the Pass and had looked at the dozen or so of others round about, he turned to me with an air of, "Well, I thought so all the time," and asked, "And is this the Valley of Ten Thousand Smokes?"

"Oh! No!" I answered, "that is over the rise yonder." 


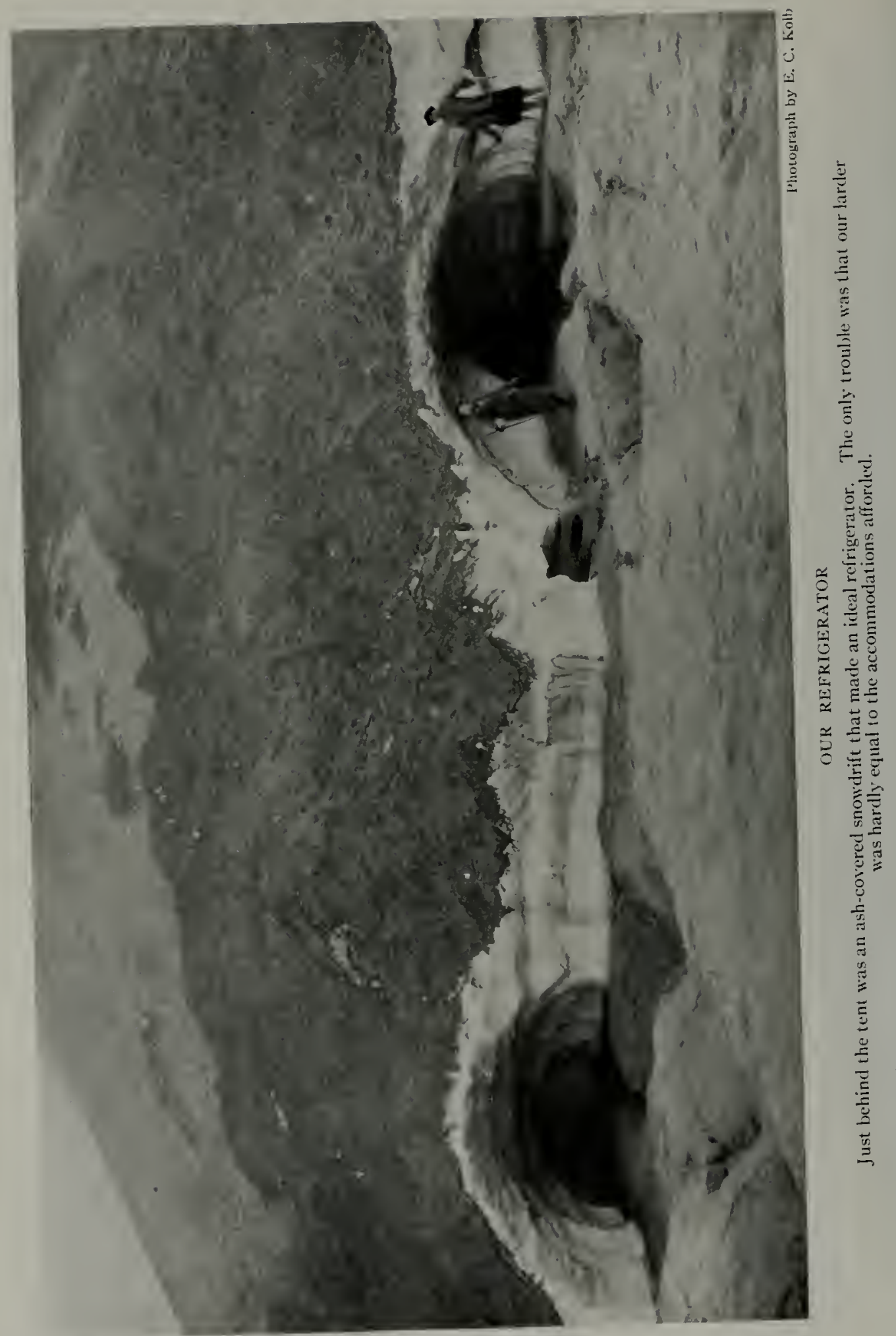


When we rcached a point from which we could sce on down the Valley, his amazement was unbounded. "Why," he exclaimed, "a whole big valley all full of smoke!"

I had planned merely to look in and turn back, for we had conie a long way so far that on the way up he had frequently remarked how far we had come and how fast I was walking, and had even asked to rest.

But once he caught sight of the Valley, he must go on. It was my turn to call a halt now, for I was thinking of the long way back to camp. But before 1 could stop him, he had gone a couple of miles beyond the Pass.

He came home with shining eyes, very much excited, and though very tired he kept talking to Andrean about the wonder he had scen until late into the night. How I wished I could understand his Russian!

\section{CROSSING THE MOUNTAINS AGAINST A HAIL OF PUMICE}

It was four days later before all was in readiness for the whole party to go over. The wind, which had been blowing uncomfortably hard for several days, freshened during the night until it began to carry away our dishes. The gauge in the sheltered nook we had selected for our camp showed a velocity of 25 miles an hour.

Out on the mountain it was blowing twice as hard, directly in our faces, lifting us off our feet at times. But worse than the wind itself was the hail of sharp pumice which it raised. This cut like a knife whenever it struck our flesh. The others protected their eyes with closefitting goggles; but I could not avail myself of that relief because of the necessity of finding the way.

Fortunately these conditions lasted only round the shoulder of Observation Mountain, and from there on the going was comparatively easy. This was by no means an extreme wind, however.

On a nother occasion the men bringing up the supplies were unable to make it and had to turn back. The wind gauge at the sheltered camp that day registered 60 miles an hour steadily, and much higher during the gusts.

MANY MORE THAN TEN THOUSAND VENTS

When the party reached the Valley, they were even more impressed with the sublimity of the spectacle than Walter had been. None had imagined anything so wonderful. All agrced that no description could convey any conception of its immensity and grandeur.

I found that my matter-of-fact chemist was counting the smokes, to see whether I had been justified in asserting that there were 10,000 of them! He soon announced that I was quite well within the truth.

There were certainly several times ten thousand to be seen, even on a clear day; and when the weather was moist myriads more appeared, for then the smoke from the millions of little holes, whose gases were ordinarily invisible, condensed until there were a thousand times ten thousand.

One member of the party, who had traveled considerably and found many of the sights of the world overdrawn, had been somewhat skeptical in advance about the Ten Thousand Smokes.

When once he felt its thrall, however, he repeated over and over again, "Why, you couldn't exaggerate it!" This statement is perfectly true. Although the statistics of length, area, and the like could be falsified, the enlarged figures would no more convey any idea of the stupendous number and size of the Smokes than do the real ones.

It can not be described. Only after one has spent many days exploring the Valley and realizes how many active areas still remain unseen, does one begin to get an idea of its magnitude.

No amount of experience seemed sufficient to enable us to grasp the proportions of the place, for as long as wc remained we habitually underestimated, in spite of ourselves, its distances and the size of its fumaroles. As we moved to 


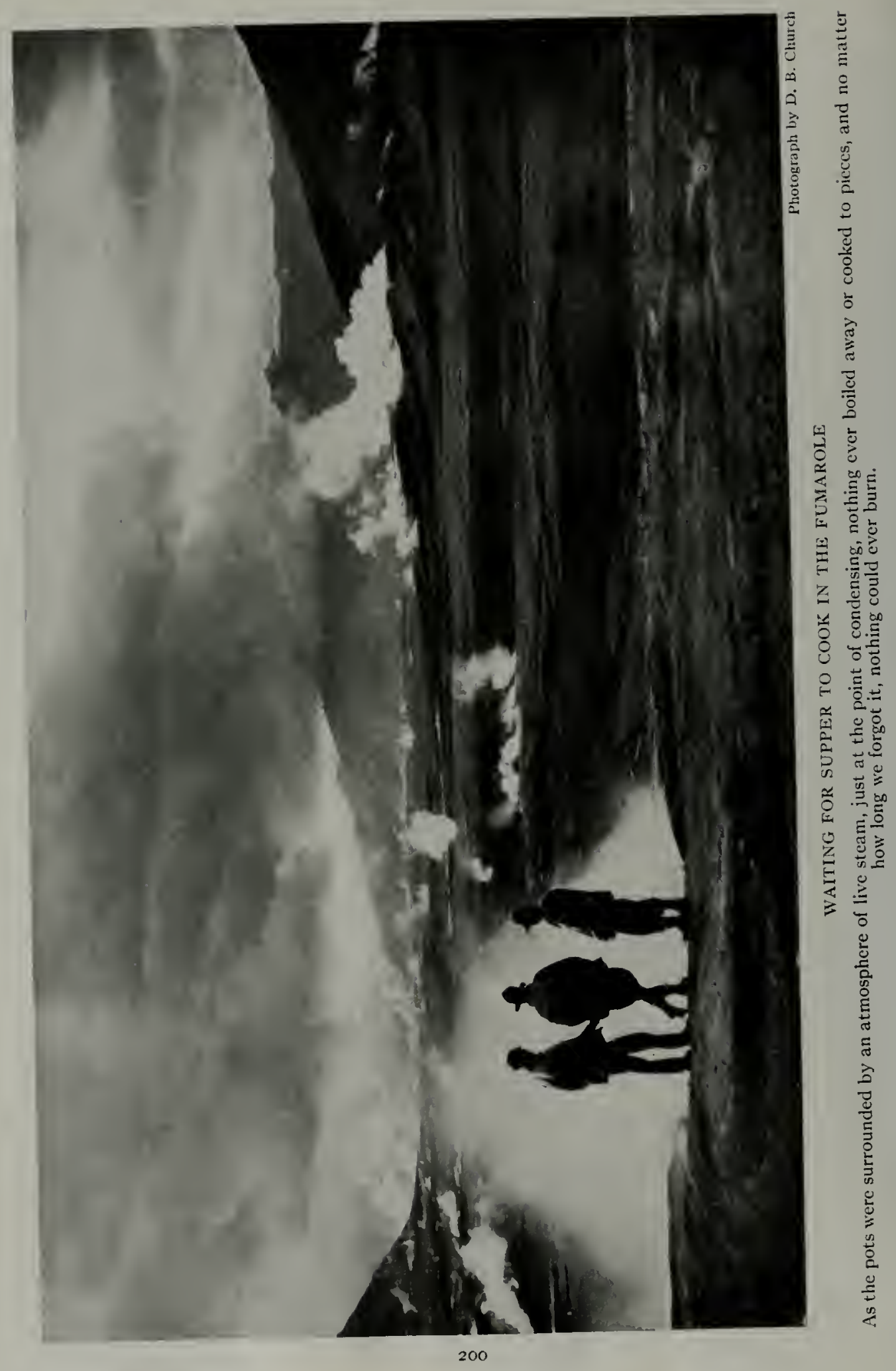


any corner of the Valley and came up to what we had supposed from a distance to be little fumaroles, we found instead monster vents, each group a more wonderful spectacle than the whole seen in panorama, so much larger was the area of activity than our powers of comprehension.

\section{OVERAWED BY THE WONDERFUL VALLEY}

No later visitors can ever experience the sensations that came over us as we prepared to camp for the first time within its confines. They will know in advance that it is safe, but we could not tell what dangers might lurk in its fumaroles.

Our feeling of admiration soon gave way to one of stupefaction. We were overawed. For a while we could neither think nor act in normal fashion.

It was a situation calculated to instill dread. Would we wake again, or would that insidious poison, carbon monoxide - colorless, tasteless, odorless - attack us and render us incapable of the exertion of climbing out, even if we did waken? We knew that it must be emanating from the fumaroles in considerable quantities and that it was deadly in concentrations as low as one-twentieth of one per cent. It was one thing to go into this "Death Valley" with all our faculties alert to ward off danger, but quite another to lie down and allow ourselves to lapse into unconscious helplessness in such a place.

I do not know whether the others were as worried as I. If so they, like myself, kept silent. But I must confess that when it came to lying down I chose for my bed the place next the window, where I would get the best air possible.

How I was paid for that selfishness! It was the windward side, and through all the fierce storms that followed I lay and took the brunt of it. The tent always leaked first on my side. My bed was always the first wet, my position the coldest and most uncomfortable.

No one slept much the first night; but as nothing happened to justify our fears, and dawn found us all hale and in good spirits, one great bugaboo had been laid. It was a long while, however, before we could regain anything like a normal mental attitude.

At night, as I lay in my blankets with the sight of the Valley cut off, I would upbraid myself for not having accomplished what I had planned, and make out a list of things I wanted to do the next day; but when the morning came I could not move myself to action. I could only look and gape.

Shipley, our chemist, was easily the most self-possessed member of the party. But for him we might have turned around and come home without the scientific material we had gone to collect.

After all, the whole Valley is very much of a gigantic chemical laboratory, and perhaps that acccounts for his greater command of himself. Yet, on the third day, even he remarked that he "did not feel like monkeying with his little bottles of chemicals."

One of the boys was frankly scared to death. He did what I told him, but when not at work sat in a dull-eyed stupor, like one at the funeral of his sweetheart, and from this state no efforts of ours could rouse him.

I can only guess the effort it must have cost him to go up to the fumaroles and get pictures of them. He said himself that he expected to go crazy before he got out again. When relieved of his duties and sent down to the lower camp he quickly regained his nerve, and in the end got as good control of himself as any of us.

I was utterly unprepared for the feelings which thus overcame us. At the time of the discovery I had not been able to stay long enough to get beyond the first sensations of wonder and admiration. I had by no means grasped the situation sufficiently to report it accurately.

This region should have been named "The Valley of a Million Smokes," for there are certainly not merely thousands, but millions of them all told. 


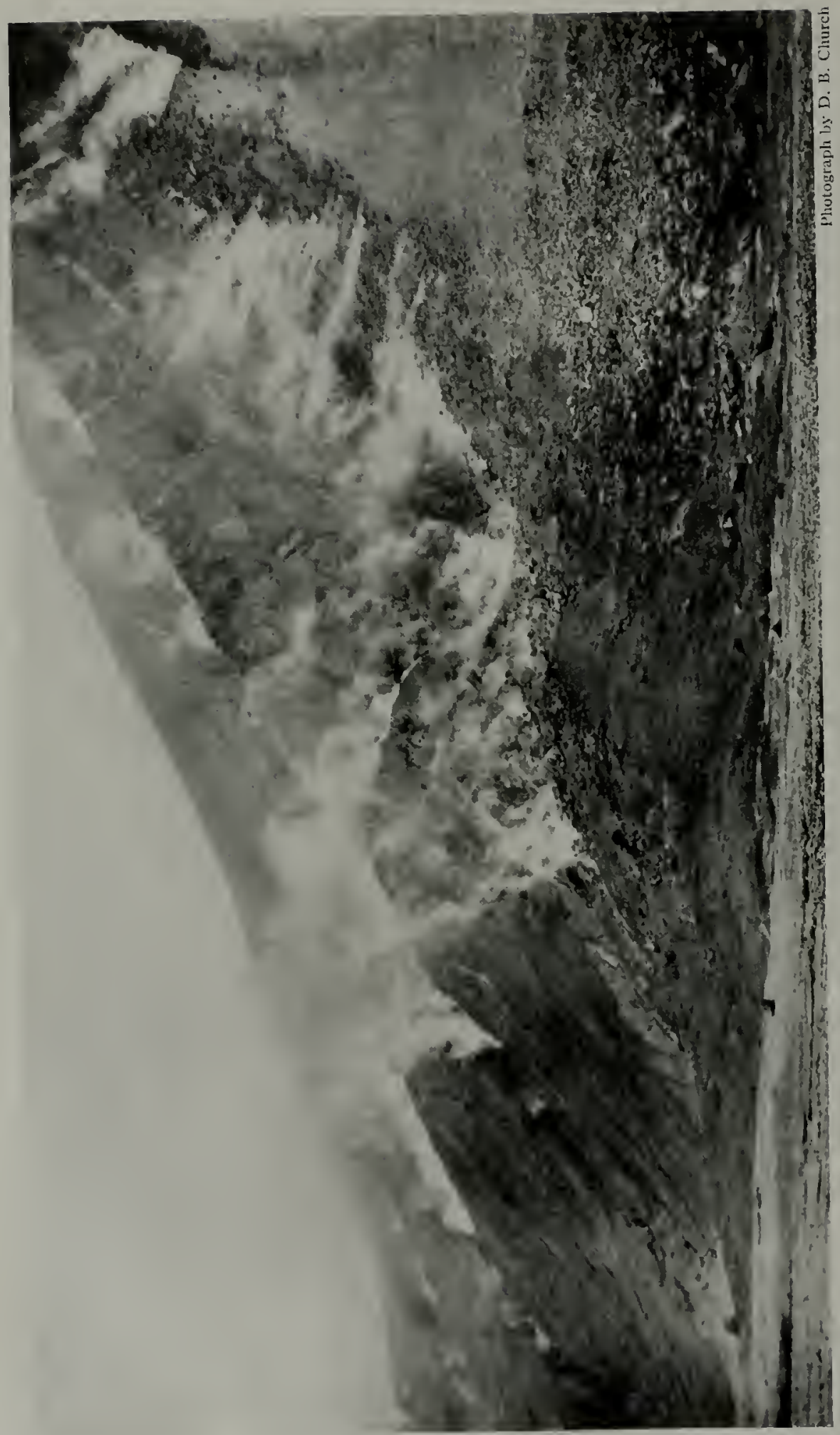

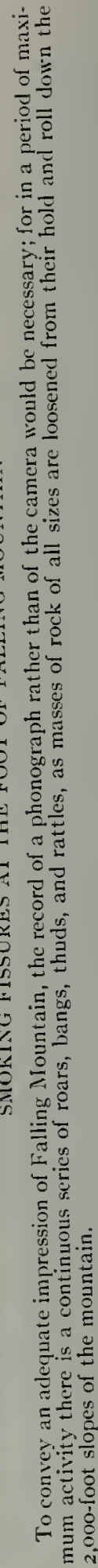


A large factor in my feclings was plain fear; pcrhaps I ought in honesty to say cowardice. The Smokes were so much bigger, so much hotter, so much more numerous than I remembered them that I was badly scared by the job I had undertaken.

\section{THE FEAR OF CAVE-INS AND FUMES}

As we explored the margin of the Valley (the worst place, as we afterward found), we could plainly hear the ground ring hollow beneath the "tunk" of our staffs, and more than once we felt it shake under our blows.

What if it should suddenly give way and precipitate us into a steaming caldron? Occasionally a breath of the steam blown around us by a chance breeze gave an uncomfortable burn. IVe knew that if once a man fell into such a place he would be instantly parboiled.

At first we roped up as for mountain climbing, and spread out, so that if one man went through the others could pull him out. When we came better to understand conditions, however, we discarded the ropes, having decided that if a man once broke through it would be more merciful to leave him than attempt to pull him out.

We had been assured by the best authority that there could be no danger from the fumes. Nevertheless, I brought along a chemist to keep us out of the dangerous places, for I knew this Valley to be unlike any other place in the world and reasoned that there could be no real basis for the assurances given.

Our apprehension was, to be sure, greatly relieved after passing the first night safely, and our fears diminished with each day. There was no telling, however, what we might encounter as we extended our observations into new areas.

Had we known, for example, that there was enough hydrofluoric acid in some of the fumes to etch the inside of the glass tubes in which they were collected, we should have been still more worried, for even a small dose of hydrofluoric acid is dangerous.
But, like most bugaboos, these dangers proved much less real than our imagination pictured. Experience showed that there was always plenty of air to breathe, and we found no insidious gases strong enough to strike us down without warning. Our noses always gave ample notice of dangerous places.

We suffered no injury beyond slight headaches and irritation of the mucous membranes caused by the corrosive gases.

\section{LEARNING TO TRAVEL SAFELY}

So also with care-ins. As we grew familiar with conditions we soon learned to pick our way about safely. The sublimations brought up by the fumaroles themselves so encrusted their throats and the ground round about that a thin roof over a cavern would support a man with safety.

The most dangerous places were those where fissures had been bridged over by ash and mud, so as to leave nothing to indicate their presence. After we had been in the Valley several days we had some experiences with such "crevasses" that probably would have turned us back, had they occurred when we first arrived.

Several times when we accidentally put a foot through a thin place in the crust, steam would come spouting out of the hole, forming a new fumarole. But it was always one foot only, and the owner did not take long to back out.

Once, while walking across a place that looked perfectly solid, I noticed a new hole midway between two old fissures and, on investigating, found that a steaming fissure two feet wide and ten feet deep was roofed over for 50 feet by a layer of mud so thin that I could perforate it anywhere by a slight thrust of my ice ax.

But such experiences rapidly led to a sort of technique like that of the mountain climber, by which we could judge the ground. It was, moreover, something like one's boyhood "banters" on 


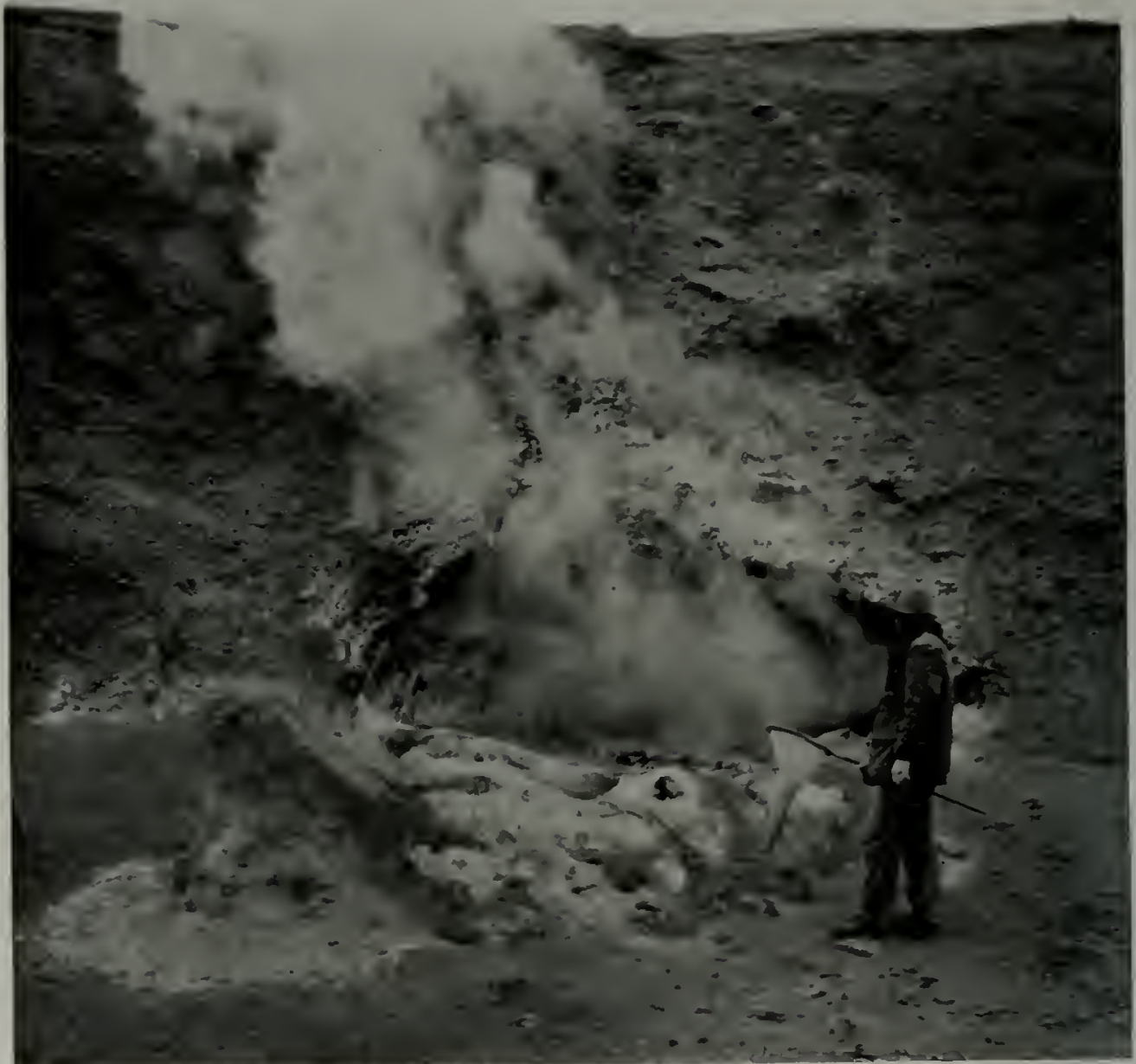

Photograph by L. G. Folsom

THE MOUTH OF A VENT IN THE SIDE OF A GULLY

The entomologist with his bug net seems incongruous in such a place, but around some of the vents are thousands of dead insects, killed by flying into the hot steam.

thin ice. After the first fellow had made it anybody was willing to follow.

If, like the actuary, we may judge the risk by the mortality, the Valley is far safer than Broalway, for never in the course of the four expeditions which entered it was there the slightest accident to mar our success.

To be sure, one could easily walk into a volcano if he were careless, but the very character of the Smokes engenders a respectful attitude on the part of the spectator, so that there is little if any real likelihood of accident.

There is no doubt that, with ordinary precautions, the Valley can be made as safe for tourist travel as the Yellowstone Park.

In many places the ground around the vents is covered with a peculiar blue mud, thinly coated with a chestnutbrown crust, which sometimes supports 
one and sometimes gives way suddenly, letting one down to his shoetops in the soft scalding mud beneath. At such times one is apt to feel that in all verity his "feet are taking hold on hell," particularly if the place happens to look "ticklish" otherwise.

EFFECT OF THE FUMAROLES ON SHOES

Sinking deep into scalding mud would appear to be very hard on shoe leather. Many have asked me what sort of foot gear we used. We wore our ordinary shoes. The ash is such a poor conductor of heat that even where it is hot enough to melt zinc a few inches underground the surface is little above the air temperature.

It is only when the surface is covered up, confining the heat, that the temperature rises. Consequently, one may walk - so long as he keeps moving - over ground hot enough to burn up his shoes in short order if he stood still, without any marked sensation even of unusual warmth.

Once, when we were careless enough to leave a packsack lying near a hot fumarole, we found its straps burned up in a few minutes. But our shoes had suffered no injury.

As for the patches of scalding mud, one naturally gets out of them with as little delay as possible. I fully expected, however, that the soil would be so impregnated with acids as to eat up our shoe leather with great rapidity, but fortunately there is here little or none of the free sulphuric acid prevalent in some volcanic districts.

Our shoes lasted far better in the Valley than on the pumice plains outside. Indeed, the pair in which I worked in I917, with a new pair of soles, went back into the Valley in 1919, and, again resoled, are still good for a trip or two more.

\section{COOKING AT A FUMAROLE}

We chose for our camp a site 250 feet above the Valley floor close beside a melting snowdrift. Here, although we were denied the pleasure of a camp fire
- for not a stick of wood remains anywhere in the upper Valley - we had "all the comforts of home." Fifty yards to the rear was our refrigerator, where we could keep everything freezing cold until needed (see page 198).

Just in front was our cookstove - a mild-mannered fumarole-into which we hung pots to cook our food. We were somewhat dubious beforehand as to the feasibility of this method of cooking, because of the noxious gases that came off along with the steam; but the results were more than satisfactory. We never detected the faintest taint in any of our food.

Everything was always done exactly right. Since the pots were surrounded by an atmosphere of live steam just at the point of condensing, nothing ever boiled away, cooked to pieces, or burned, no matter how long neglected or forgotten.

There was only one drawback; while we were in the Valley we had to do without our old stand-bys, bacon and flapjacks, for the "stove" we used that year would not fry. There were, however, many vents in the Valley quite hot enough to fry bacon, as we found to our satisfaction in I9I9 (see page 294). But in 1917 we were too much afraid of the big vents to try cooking in them.

IVe could not even measure their temperatures, for supposing in advance all the fumaroles to be merely "steamers" at the boiling point we had come entirely unprepared for high temperatures. Our thermometers did not read high enough, so we had to content ourselves with guesses until the following year, when Sayre and Hagelbarger, provided with pyrometers supplied by the Geophysical Laboratory of the Carnegie Institution, made a special study of temperatures. Thus equipped, they measured temperatures ranging all the way from boiling up to $432^{\circ} \mathrm{C}$. $\left(810^{\circ} \mathrm{F}\right.$.), hot enough to melt zinc ${ }^{1}$ (see page 22I).

\footnotetext{
1 For a detailed account of the temperature observations in I9I8, see Ohio Journal of Science, vol. I9, pp. $249^{-278}$.
} 


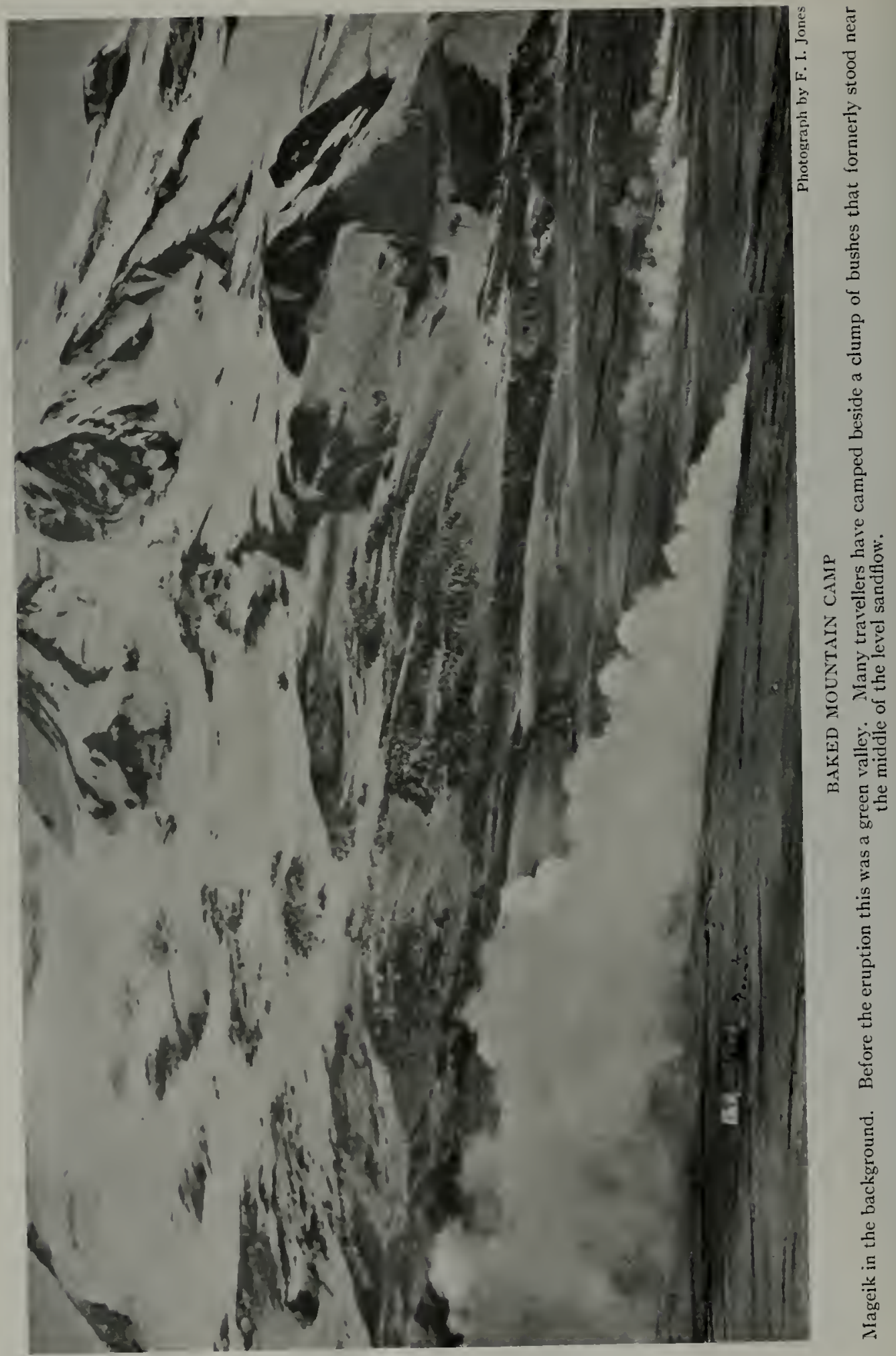


When we turned in the first night we were astonished to find that the ground under our tent was decidedly warm. On examination we found that a thermometer thrust six inches into the ground promptly rose to the boiling point. This was indeed a surprise, for the place had been vacated only recently by the retreating snowbank behind us.

\section{A STEAM-HEATED TENT}

IVe put most of our bedding under us to keep us cool!

Before long our blankets were as hot as the ground. Close to the snowdrift as we were, and at an altitude of about 2,300 feet, the air was at times decidedly. cold; so while we steamed on one side we froze on the other and had to keep turning over and over in an effort to strike a balance. Everybody expected to "catch his death of cold."

After a little we discovered that our beds were not only hot, but wet from invisible vapors which were everywhere seeping up through the soil. The condensation of the steam soon saturated our blankets, so that by morning we were in a most curious case. The sensations that greeted us on awakening in these warm, wet beds can in justice be compared only with certain distressing memories of one's childhood days.

This state of affairs worried us very much indeed, for such conditions were the worst possible for the films on which we were depending to rouch for our story:

By building a sort of crib with the walking sticks we had brought from the lower camp, we managed to keep them off the floor, and thus reasonably cool.

Our instruments also took up water and swelled, so that we feared we should lose everything. A tripod that had successfully stood the climate of a tropical rain forest jammed so hard that it could not be hammered loose. The cameras swelled until their focal points shifted.

A panoramic outfit upon which high hopes had been built refused to work and was altogether useless for the rest of the summer. It is because of this failure that the frontispiece of this book shows only the main arm of the Valley. After many trials and much jogging, we got it to rotate as far as Baked Mountain, but there it stopped dead.

As I saw ererything thus rapidly soaking up moisture, I was very much disturbed lest we should be caught in the rain; a fumarole night be an ideal cookstove but it was no good to dry clothes by. With the tent steamy also there would be absolutely no way of drying out when once we got thoroughly wet, as was sure to happen before many days. Transportation was so difficult that we had brought no change of clothing.

But in these fears I was most happily disappointed. We found that though everything in the tent was soon suffused with moisture, nevertheless anything brought in dripping wet from outside, being supersaturated, quickly became merely damp.

When we came in soaked through and chilled after a ducking, therefore, we merely crawled into our blankets. After a while both clothes and bedding would become as "dry" as when we started.

\section{THERAPEUTIC POSSIBILITIES} OF THE VALLEY

In spite of the exposure to which we were daily subjected, there was not a symptom of "colds" or other illness in the party.

On the contrary, the constant steaming seemed a good treatment for the rheumatic pains which usually derelop on such expeditions. During our stay in the Valley, and for some time thereafter, we were as free from such aches as if we had taken the "cure" at a hot spring.

W'e had no physician along, nor did we have time for any experimenting, but one does not have to be very well versed in medical lore to see the therapeutic possibilities of such a place. The healing powers of thermal waters are a matter of common knowledge; the thousands of patients who ansually journey to such places sufficiently attest their efficacy. 
The hot mud, which everywhere abounds, may possibly excel more than one hot spring in its healing properties. The virtues of a clay poultice are well known to us all, beginning with the mud plasters we used to employ when as boys we were stung in digging up a bumblebees' nest, and ending with the highsounding "antiphlogistene" poultice we now purchase at the drug stores to relieve bruises and inflammation.

One's imagination can readily picture the benefits that might accrue from the scientific employment of the hot muds of the Valley in the treatment of all disorders that yield to external applications.

\section{KATMAI PASS A NOTORIOUS WEATHER-BREEDER}

We came at length to appreciate greatly our steam-heated tent, for we found it always warm and comfortable, and there were times when the driving wind and rain outside were so bitter that we could scarcely have endured the place otherwise.

It would be a mistake, however, to suppose that with all our conveniences life in the Valley was wholly ideal. The Alaska Peninsula is notorious as a stormbreeder, and before the eruption Katmai Pass had a reputation for bad weather not to be matched elsewhere on the American Continent.

Now, with such enormous quantities of hot steam rushing into the air close beside the extensive glaciers and snow fields of the mountains, the weather is even worse than before. From the head of the Valley, where conditions made it necessary for us to camp, we could often look out of our door through a storm that threatened every moment to tear the tent from the ground, and see bright sunshine and good weather a short five miles down the Valley.

During the season of 1917 there was rain almost every day of our stay - not the gentle mist familiar to dwellers of southeastern Alaska, but real rain in big drops, driven before the gusty winds that penetrated everything, until our tent roof leaked like a basket.

How we wished to study the Valley from the shelter of a house with a real roof, where we could keep things dry and contemplate the wonders of nature with some degree of personal comfort!

But in the intervals between rains, the sunshine made up for all the hardships we endured. The weather here reminds one of the little girl with the curl. When it is bad it is undeniably horrid, but when it is good it is so very, rery good that one straightway forgives its evil moods. Whenever the skies cleared we instantly forgot the discomforts and one and all gave ourselves up to admiration of the surpassing beauty of our surroundings.

Having established ourselves in the Valley, we prepared to study the many scientific problems presented by this unique place.

\section{A FEW SIGNS OF ANIMAL LIFE}

One of our first observations was the number of dead insects around many of the vents, where they had been killed by flying into the live steam. Hine, therefore, came up for a few days to study the insects with the object of ascertaining how they got into the Valley and where they bred (see page 20.4).

The larger animals were practically absent, but we found occasional tracks of bears, wolves, and wolverines, which had crossed the Valley from one range to the other. Most of these were old, but one day I found the tracks of a bear that had crossed during the night.

I wished I might have watched him when his feet sank into the patches of soft scalding mud that lay in his way. He must have been treated to the surprise of his life! But however he felt, he kept right on, straight across the Valley, without making the slightest deriation to avoid the bad places, often sinking deep into the hot mud.

\section{SURVEYING THE VALLEY}

Maynard, with one of the others for assistant, toiled up to the summits day 


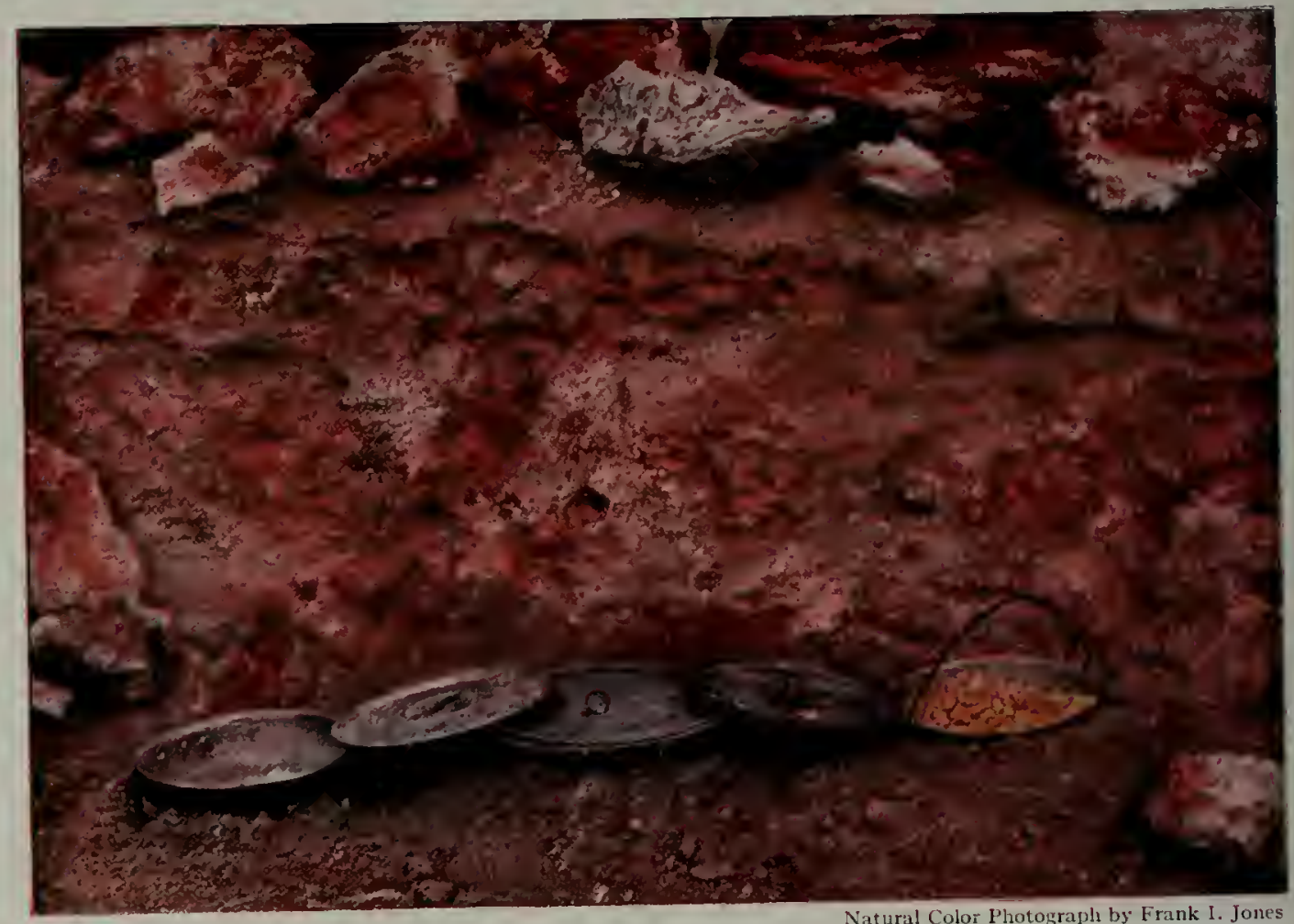

A ROW OF GORGEOUS "STOVE HOLES"

Here the rice and beans could be left to simmer indefinitely, held exactly at the boiling point. 
after day to secure the topographic map which is the necessary basis of all our statements of areas and sizes.

His was arduous work and the effort was often wasted, for perfectly clear days, which are necessary for this work, are rare around mountain passes anywhere, and here especially so.

Sometimes the weather seemed to take an almost fiendish delight in opposing his plans. Several times as we watched from the Valley we could see a thin cloud hanging all day to the very summit on which he stood shivering, while the mountains all around were clear.

The first time he tried to work Baked Mountain the wind happened to be just right to carry the steam from the biggest fumarole in the vicinity, No. 46 , square across the summit, preventing observations as effectually as though the whole region were enveloped in fog.

More than once it seemed as if there would not be enough clear days to complete the observations, but in the end he succeeded in getting the data for an excellent map.

\section{COLLECTING GASES FOR ANALYSIS}

The most disagreeable, as well as one of the most difficult tasks, fell to Shipley, who collected samples of gas from the vents for analysis (see page 246).

It looks easy, as the work is laid out in advance, to poke a glass tube into a vent and pump the gas into a container; but in the field all sorts of difficulties crop up, and to surmount these requires great patience and resourcefulness. Apparatus will not do what is expected of it; tubes clog prematurely or snap in the heat.

Moreover, a fumarole is not an easy thing to deal with at close range. When, after some trouble, one gets in a position where he can take his sample, and a sudden shift of wind brings a cloud of hot, acid vapor around him, he is placed in a difficult, not to say dangerous, situation.

More than once our gas collectors became lost in the blinding vapors and regained a place of safety only after some minutes of anxious groping through the steam. But fortunately the precious samples were all secured without mishap, and a considerable amount of other valuable chemical work done.

\section{PRACTICALLY AI.L PLANT LIFE DESTROYED}

Only the botanists were without employment, for in the formation of the Valley all life was annihilated. Plants were practically absent in 19I7. Not quite so, however, for around some of the mild rents moss and algae were beginning to start in places bathed by the warm breath of the fumarole.

From the vapors they derived, besides constant moisture, their supply of nitrogen in the form of ammonia, which is given off in considerable quantity by the vents. Beans dropped on the "kitchen floor" near our fumarole sprouted and grew rapidly on the warm ground, soon making a bright spot of green. But they were short-lived; the roots were killed wherever they touched the acid soil.

The absence of vegetation gave me opportunity to study the unique exhibition of geological forces here presented. Observation of the different types of fumaroles, of their relations to each other, to the old rocks and to the new deposits that filled the valley, endearors to correlate temperatures and incrustations, and similar problems of a merely descriptive character were more than enough to occupy my time.

But beyond these were the more important questions of the relations of the fumaroles to the old rolcanoes, to the subterranean magma whose rise brought on the cataclysm, and to the great forces of the inner earth responsible for the crumpling and fissuring of the outer shell, the building of mountain systems and the formation of volcanic chains processes in which the greatest of eruptions are but incidental details.

TESTIMIONY OF MY ASSOCIATES

Consideration of these questions will best be deferred, however, until the completion of the narrative of the expedi- 


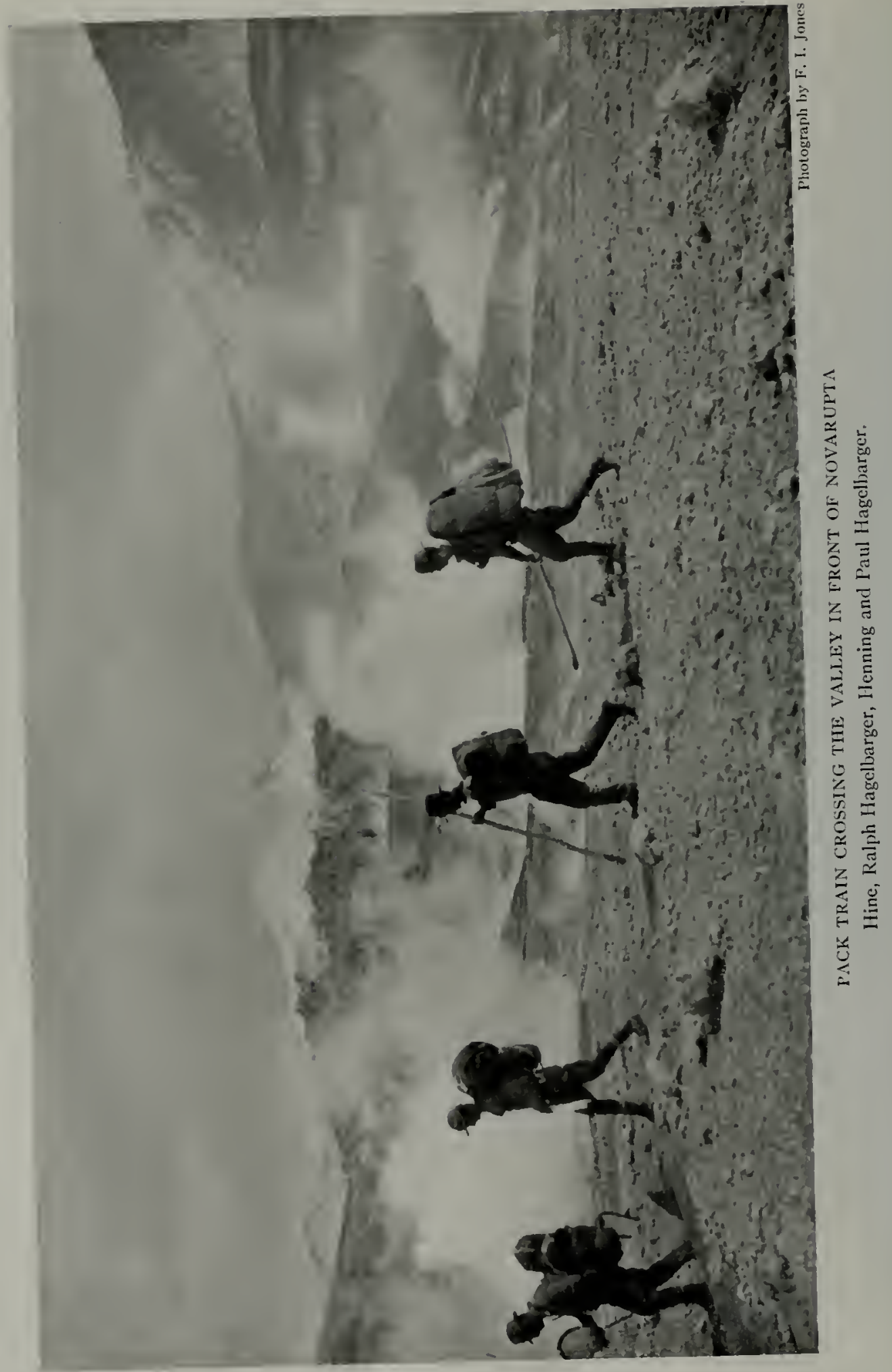


tions. My account of our experiences is necessarily influenced by the limitations of my own interests and point of view. The impressions which my associates have set down at my request, reflecting a wide diversity of temperament and experience, will give a broader view:

L. G. Folsom: "You ask me to write of my impressions upon seeing for the first time the "Valley of Ten Thousand Smokes.' I do not recall your ever having given me yours, and I suspect that you feel as helpless as I do in attempting to put impressions into words and for the same reason - that it would require a special vocabulary not found in any dictionary of present publication. It cannot be denied that such impressions are determined by point of view, and point of view by temperament, so I must be sincere or my statements are of no real value.

"You, and only you, whose companion I was in the discovery, can have an adequate conception of the emotions of one who knows he is the first of his fellows to look upon such a marvel of nature. In fact, the emotions of a discoverer must bear some similitude to the eniotions of a creator.

"To think again of what we had already seen, to feel again the explorer's urge, to suffer again the pains of pro: tracted exertion, to experience again the thrill and exaltation of achievement, produces a sort of exquisite languor, which, were it not that there is still so much to do, one might wish to be lasting.

"The thousands of little volcanoes were almost a more magnificent sight than the wonderful Katmai Crater we had visited the day before. We were in danger of being surfeited with "world wonders.'

"There comes in upon my consciousness yet, occasionally, a sort of startling memory of the experience. It almost hurts. Then I fall to dreaming of the causes and probable progress of such phenomena; of the unusual opportunities for study; the wonderful scenic display of natural forces.
"Upon first walking among the hissing fissures there was such a sensation as one might imagine if sitting upon the roof of a powder magazine - sputtering fuse - Kingdom-come. And yet, I cannot say I ever feared the Valley, but was awed by it. I could not decide whether it was Valhalla, 'IVorld of the Gods,' or a rendezvous of devils; an Elysium or a Tartarus.

"There was always a very conscious realization that the ground upon which we were walking was holey ground, also that it was not wholly ground, but in large part, cavity, filled with odorous and malodorous gases, chiefly the latter.

"In its bigness it is truly Alaskan; in its scenic effect it is marvelous; in its display of mighty force it is magnificent.

"You perhaps recall Walter Metrokin's story of his dogs, who had once caught a porcupine, with "needles all chuck full o' mouth.' While this first wonder of the world is not a thing to inspire humor, W'Valter's twisted vernacular would fittingly characterize it as 'smokes all chuck full o' valley.'"

\section{EACH INDIVIDUAL VENT MORE BEAUTIFUL THAN VALLEY AS A WHOLE}

Paul R. Hagelbarger, Assistant Botanist: "Bright sunshine bathed the Valley when I first saw it. Even though several miles away, I was awe-struck by the surprisingly large size and striking beauty of the spectacle. There were so many more steam jets than I had even hoped to see that I could only gaze in silent admiration.

"After living in the Valley and working among the fumaroles, my impressions began to change. My amazement at the great area was intensified by the knowledge gained on many trips across the Valley floor. The beauty of each individual vent was even more than that of the Valley as a whole.

"The thing that stupefied me, however, was the ever-present proof that some terrific energy or force had only recently exerted itself. Everything seemed on such a huge scale. Our tents looked 


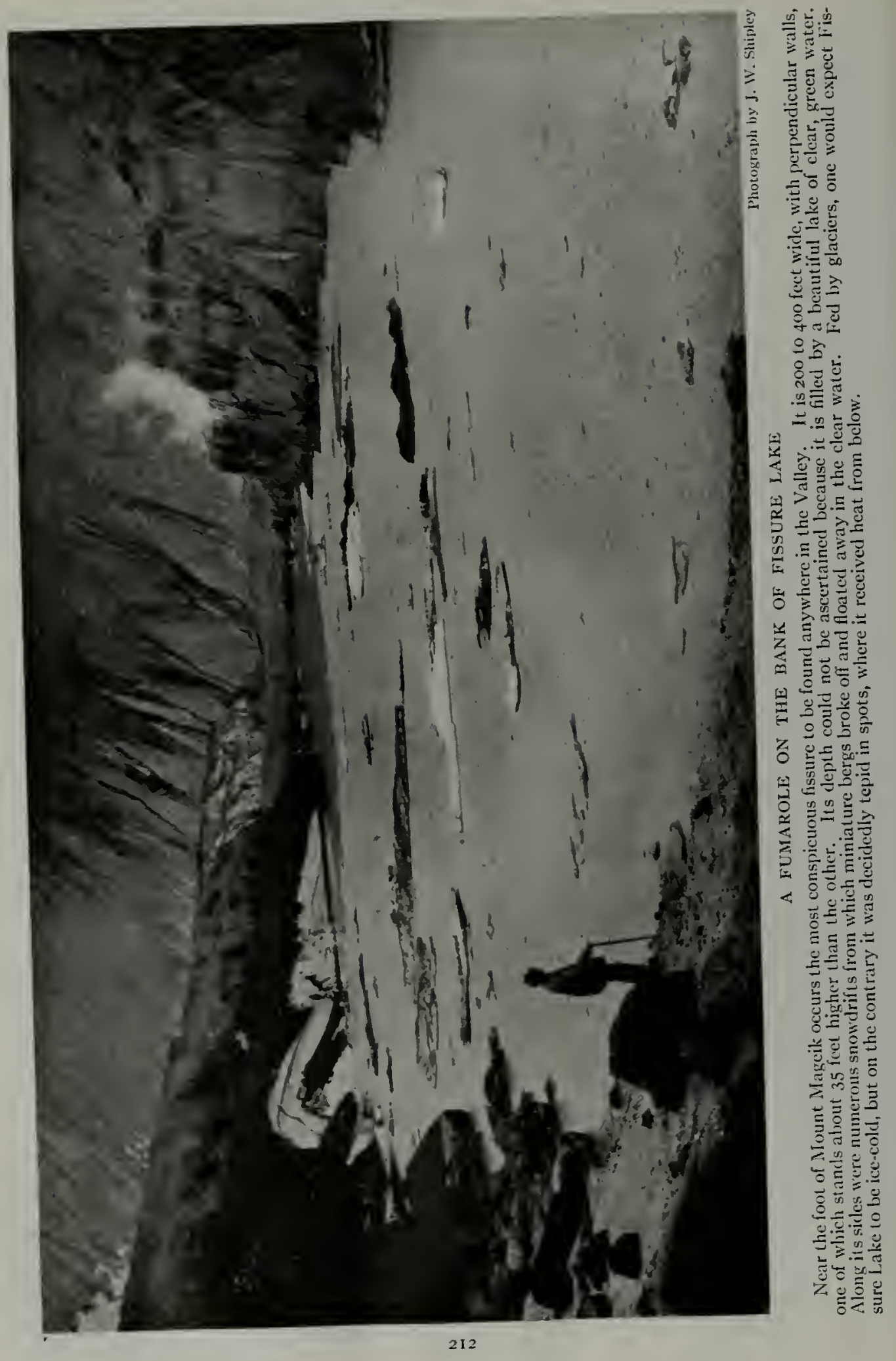


insignificant amid the roaring volcanic vents.

"As I came daily to know the area better, I was more and more impressed by the titanic forces that had been at work here. Human endeavor and achievement seemed dwarfed to insignificance by comparison. I felt out of place and like an intruder in this Land of the Gods. This Valley appeared to be on another planet that was in the process of formation.

"I spent 16 days in the Valley and was glad to leave, as will be seen in my diary for August 2: 'Came out of the steaming Valley for good. Lucky to get out. Glad to see trees and grass again. Feel like I am just awakening after a two weeks' nightmare. Valley is wonderful, but no place to camp. Walter says, "Lots of steam. Hell of a place." Heartily agree."”

\section{SURPASSED HIS WILDEST DREAMS}

J. D. Sayre, Assistant Botanist: "My sensation on first seeing the Valley of Ten Thousand Smokes was one of wonder and astonishment. I was astonished at the great dimensions of the Valley and at the countless numbers of fumaroles and fissures out of which the steam issued, to say nothing of the many other gorgeous and magnificent displays of nature. Never in my wildest dreams had I imagined anything to compare with these.

"Greatest of all was my surprise that so much energy could be released in such an easy and quiet manner without apparent injury or danger to any one or any thing. I experienced no sensation of fear while staying in the Valley, perhaps because my mind was so filled with astonishment and admiration at this great marvel of nature, or because I was foolhardy and did not realize the grave danger of falling into one of those hot places.

"I had no hatred of the place during my short stay there, although we were surrounded by many discomforts, and I said, soon after we left, that I would like to come back some time and see the place again. 1 am very proud to say that I was a member of the expedition which overcame the difficulties and hardships and first explored such a wonderful place."

\section{THE COMPLAINT OF A TOPOGRAPHER}

Clarence F. Maynard, Topographer: "To me the Valley of Ten Thousand Smokes is a stretch of country that offers all the usual difficulties of topographic surveying in Alaska, with a few rather unusual ones thrown in for good measure. It is hardly a country to make the heart of a topographer glad.

"The smokes did not impress me with their grandeur or with their wonder as a natural phenomenon. Their ability to make surveying next to impossible did, however, make a very decided impression on me. On the occasional clear days when the sun was shining down the Valley they seemed to be always at their best, as Griggs would put it, but to my mind at their worst.

"On these, the few rare days when it was not raining and the wind was not doing its best to move our camp (rather good judgment on the part of the wind, I should say), they would shoot forth jets of steam which soon took the form of clouds and obscured the country we were trying to work.

"I finally began to believe that the smokes were out to buck me, and became convinced of it when, on one of the rare fine days, I ascended to a peak which immediately became enveloped in fog. This was not unusual, but I was impressed on returning to camp to hear from the more fortunate members of the party that the whole Valley had been clear with the exception of the peak I occupied.

"I am not a vegetarian; furthermore, tea cooked in a steam pit is not tea. A tent that never sheds a drop of water is not a tent. A wool comfort placed on the ground which is $110^{\circ} \mathrm{F}$. in the above tent will steam beautifully. It is a natural phenomenon, but it is not a good bed. 


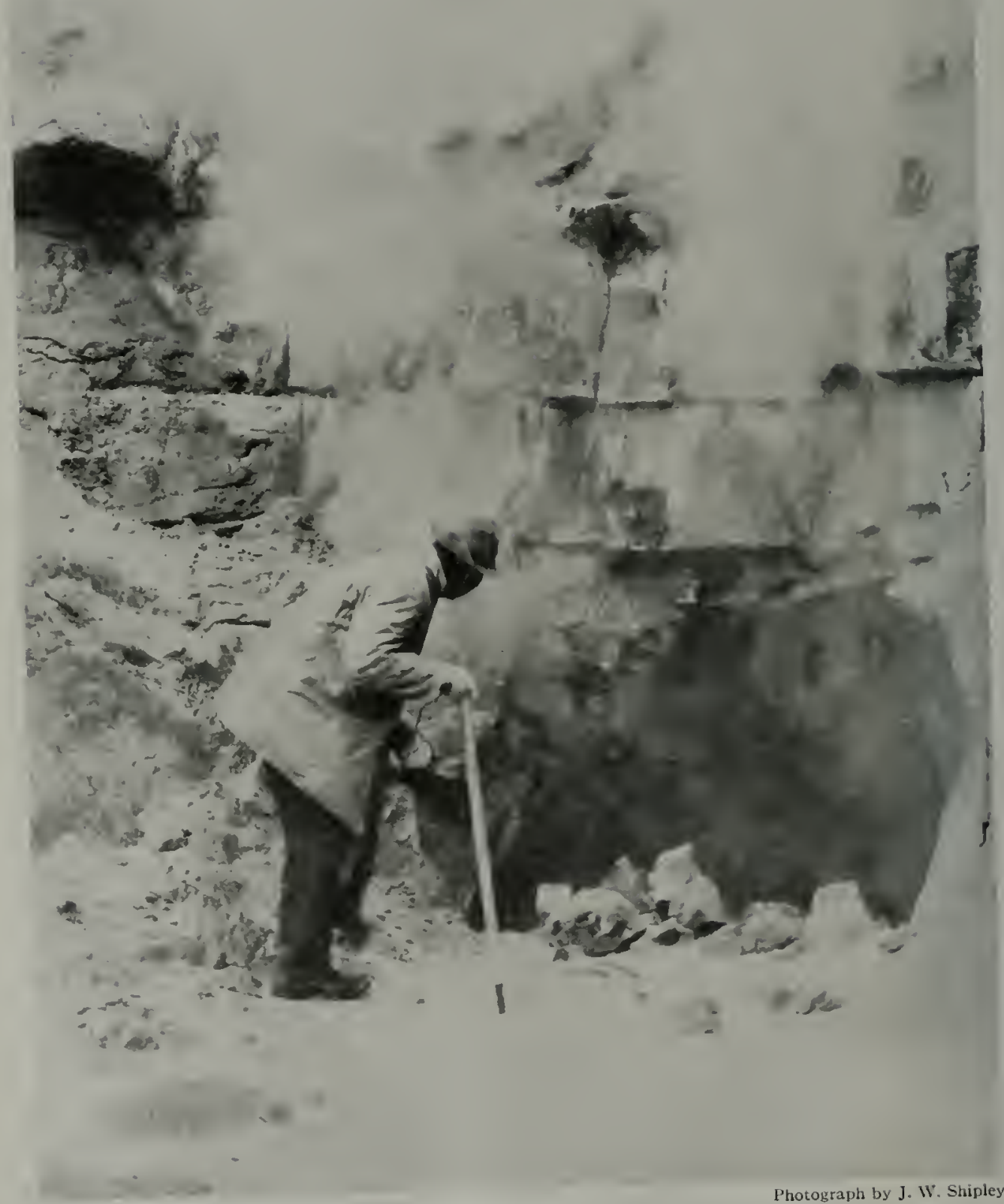

Photograph by J. W. Shipley HINE INSPECTIYG THE CAVERNOUS MAW OF A GAS-EMITTING VENT

rom these openings are transparent until they begin to condense in the atmosphere. The gases from these openings are transparentle to look far into the depths of the earth. 
"I believe I mentioned that I am not a regetarian. I like bacon in the morning; I like it fried. A steam jet, in spite of its being a glorious and natural phenomenon, will not do this. I am from New England and have decided ideas on baked beans. Again the steam jet fell down. It needs New England training. Baked beans are beyond the limit of its capabilities.

"I should say the coming of the smokes ruined what might otherwise have been a perfectly good country. My opinion, however, is probably valueless, as being out of tobacco always colors my views."

Fortunately Maynard was by no means the confirmed grouch that he makes himself out, but on the contrary was one of the best fellows in the crowd, his good-natured raillery contributing greatly to the pleasure of the summer's work.

\section{THE IIODERI IIFERIO}

James S. Hine, Zoölogist: "A hike of miles over devastation wrought by natural disturbances in the Katmai country naturally puts one into a peculiar state of mind. He is deeply impressed with the enormity of the whole aftair, and everything seems beyond comprehension. The unusual circumstance of summer with no plant life and no animal life surely is a strange realization.

"Having reached the summit of Katmai Pass, the Valley of Ten Thousand Smokes spreads out before one with no part of the view obstructed. My first thought was: IVe have reached the modern inferno. I was horrified, and yet, curiosity to see all at close range captivated me. Although sure that at almost every step I would sink beneath the earth's crust into a chasm intensely hot, I pushed on as soon as I found myself safely over a particularly dangerousappearing area. I didn't like it, and yet I did.

"I felt like a boy at a circus, for I couldn't take time to study the attraction before me because I suspected something more captivating farther on. Nor was I ever disappointed, for nothing was exactly like anything else.

"The broken hills, the falling mountains, the magnificent glaciers, the steaming fumaroles, and the rolling steams can all be described, but their wonderful profusion and the manner in which they encroached upon one another must remain largely in possession of him who is fortunate enough to make a visit to the locality where these things abound in extraordinary" splendor."

LIKE A HUGE CHEIICAL MANUFACTURIYG PLANT

J. II. Shipley, Chemist: "On first entering the Valley from between the two guardian volcanic cones, I experienced the same sensation as the man who on seeing a giraffe for the first time exclaimed, 'There ain't no such animal.' The quiet evolution of myriads of columns of vapor from the floor of a wide, desolate valley, the encompassing mountain ridges, the sequestered isolation, the avalanches of rocks, all vividly recalled Sindbad's adventures in the 'Arabian Nights.' It is so unreal!

"Hot streams issue from beneath banks of snow; extensive glaciers hobnob with steaming fumaroles; icebergs and hot water are found in the same little lake (see page 24). Enormous mud flows appear to have run uphill. A stick chars when thrust into a jet of steam. It is uncannily unreal.

"But the unreality suddenly vanishes when one's foot breaks through the crust and hot volcanic gases rush out. It is also sufficiently realistic to have avalanches of rocks galloping down the 2,000-foot face of Falling Mountain while we are collecting gases in the bottom of a 20 -foot hole at its base.

"The familiar fumes of hydrogen sulphide, sulphur dioxide, and hydrochloric acid transform the Valley into a huge chemical manufacturing plant, roofed over by a permanent cloud of vapors. And when one is cold and wet, it is rather comfortably lonesome to lean against the hot walls of a sheltered crev- 


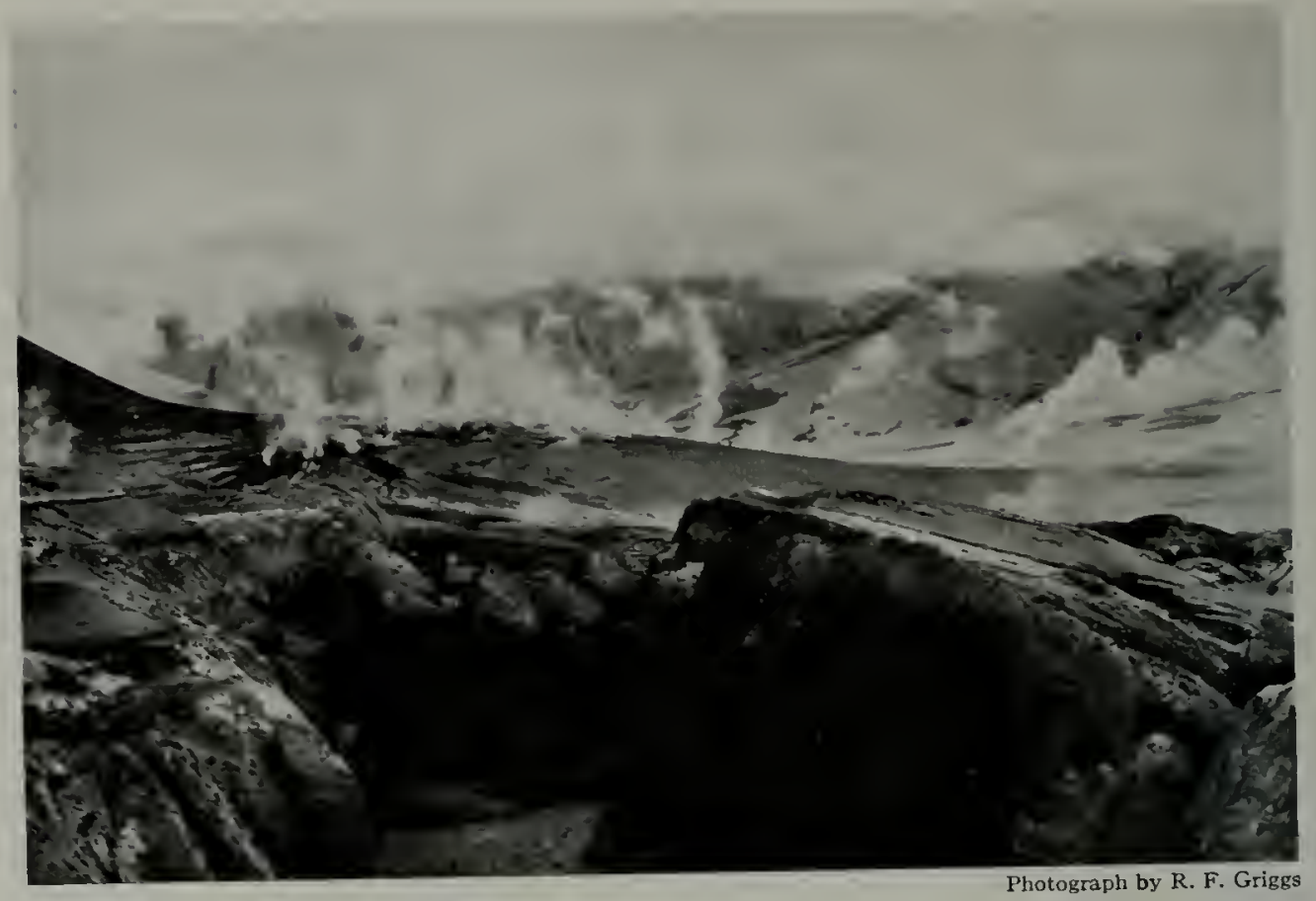

ONE OF THE GAPING FISSURES ALONG THE MARGIN OF THE VALLEY

The two sides were evidently pulled apart by contraction of the Valley foor; compare the diagrammatic section of the Valley given on page 263 .

ice and meditate on the dead bodies of hundreds of flies lying around the orifice of the subterranean chimneys."

\section{A SPECTACLE OF AWESOME MAGNitUDE}

D. B. Church, Photographer: "Regardless of our packs, we hurried through the Pass leaving behind the few faint, wispy steam jets that mounted from its floor just over the divide, craning to glimpse the first steam cloud to rise from the Valley beyond. There floated over the spur of the ridge to the north a billowy cloud that marked the largest steamer.

"Reaching the higher ground that had hidden my view, I gazed at the panorama before me. Flanked by Cerberus and Falling Mountain, spread the Valley - a maze of pearly columns that billowed skyward and bent before the strong westerly wind. Dows a narrow canyon we trudged and climbed out over its painted ash walls on to the Valley floor.
"The meager pictures of the previous year, and even the graphic descriptions of Griggs and Folson, had not prepared me to face such a spectacle of awesome magnitude. I had pictured the Valley as large; the actual view dwarfed my wildest imagery to insignificance.

"I started for the nearest fumarole; it seemed a few hundred yards distant. I found it half a mile away. It was a small fumarole and I crept cautiously up to its edge. From its red-painted throat, which vanished in deep blackness, the sulphur-reeking steam roared forth in a smothering blast.

"Passing back, I found a crack in the rocklike crust of the mud flow, through which sizzled the scorching steam and gas. A few prods with my staff opened a hole in to the underground conduit, from which the steam hissed forth. The fragility of the crust and knowledge of the result of a misstep startled me. My fears began to awaken - fears that for 
several days made me tiptoe over spots where the earth rang hollow beneath my feet. Familiarity gave me greater confidence, but I never ceased to tread carefully the color-daubed regions of subsurface activity.

\section{WORK DROVE AWAY FEAR}

"The next day I began my work in the Valley. This day activity and interest drove fear from me. The one conception that pervaded me was: How like this place to Dante's conception of the 'Inferno.' It seemed to me, as we stood on the edge of Novarupta, that this was the Devil's own private corner in hell itself.

"It seemed, as I gazed at the seething steam clouds that rushed from the cooling lava plug, and at the shattered, steam-smothered furnace that filled the rising vale beyond, that there was some vague fantastic form, a horrid dream, a hideous, potent 'thing;' which was not for human eyes to see nor human ears to hear.

"Then an endless night on the hot, moisture-teeming ground; an endless rolling from side to side to escape the torment of the penetrating heat that seeped up from the hot, sodden ground; and always, as I looked down the Valley through the open tent door, shone the marble-like stean columns, which, like tall, writhing specters, swayed in the dim twilight.
"There was always a certain awesomeness about the Valley which clung to me throughout my stay. I looked forward with relief to the time when I could put from my sight the curling steamy billows that rose from fumaroles and mounted ever skyward.

"Pictures cannot bring back the Valley of the Smokes. They have lost the awesomeness that lies in the setting. You may build in memory, but never reproduce the scenes which lie beyond the Katmai Pass. They seem too big to be a part of the rest of the world. They do not connect up with the little things which are built into our lives.

"Outstanding in my memory is the Valley as I left it. It was a brilliant day, with puffy silver clouds that floated on a sky of deepest blue, and sunlight that glinted on opalescent steam jets and sparkled on peaks fresh-capped with snow.

"As, homeward bound, we skirted Cerberus, the steamers turned in the dying sunlight to shimmering gold and the snowy crests of distant mountains glinted yellow. I forgot the heavy pack which bowed my shoulders as I glanced backward at the growing beauty which filled the Valley. Through its giant gateway the Valley of Ten Thousand Smokes sank from sight as we dropped over the Pass, and the sky above reddened to a crimson halo in the fading rays of the sinking sun." 


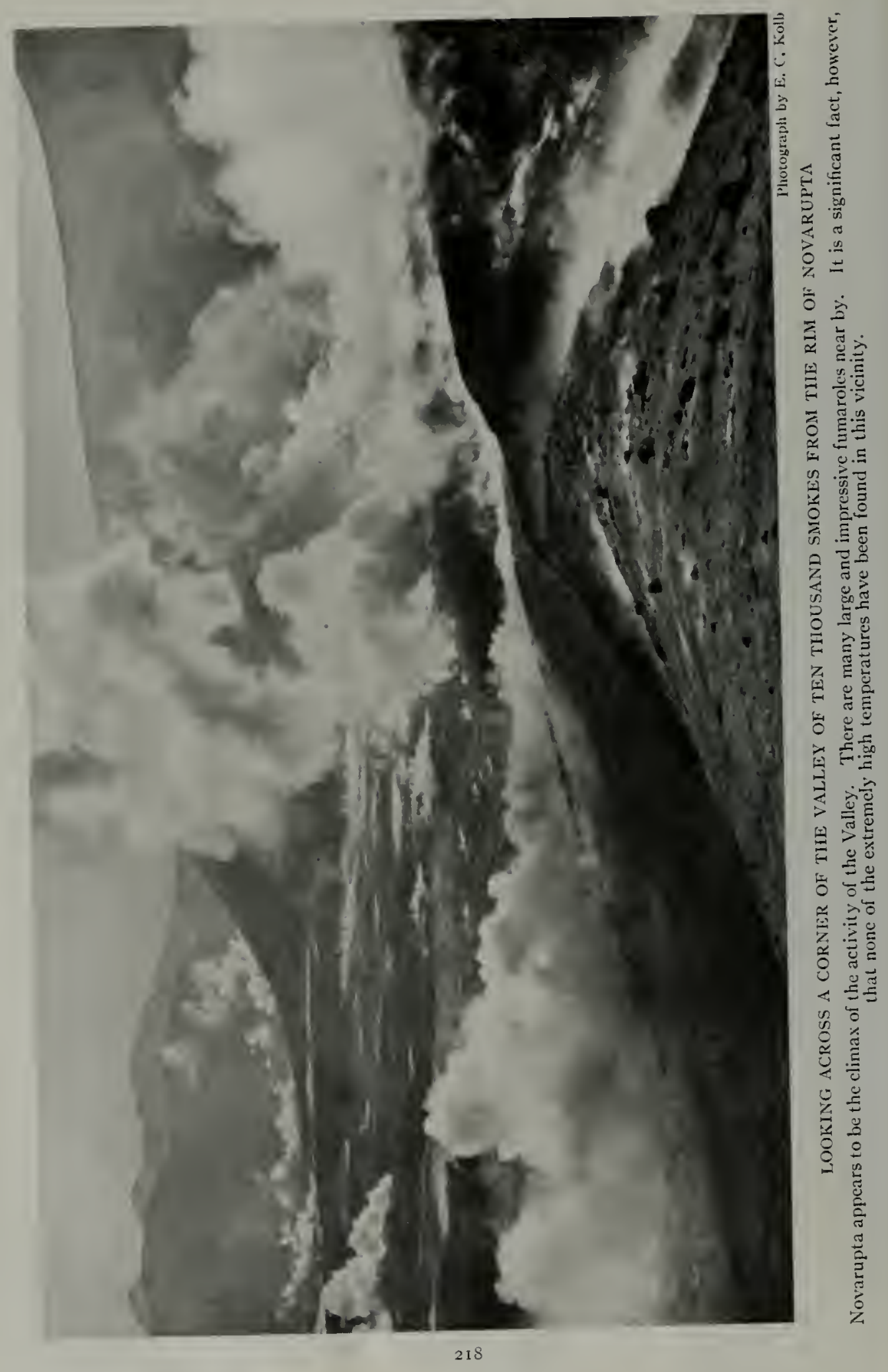




\section{THE TEN THOUSAND SMOKES IN 1919}

When, after months of preparation, we approached the Valley again on the first day of June, I9I9, we were intensely curious not only to see what changes time had wrought but also to observe the fumaroles at that early season.

It was thirty-four days earlier than anyone had entered the Valley beforeso early that the snow had only begun to disappear from the mountains and the great torrents that pour from the glaciers in July and August had not yet started. Many feet of snow still covered the south approach to the Pass, and the area of little fumaroles between Cerberus and Mageik was blanketed ten feet deep.

But the Valley itself looked just as in midsummer except for two or three diminutive white patches in quiet corners away from fumaroles. We had been curious to know how the fumaroles behave through the winter, and this view in early spring was next best to overwintering in the region.

FUMAROLES NOT VISIBLY AFFECTED BY SEASONAL VARIATIONS IN STREAMS

Aside from a somewhat idle curiosity to see the struggle between the elements when the winter's cold should intensify the temperature contrasts, there are scientific deductions of much importance to be made from a comparison of the winter activity of the Valley with its summer condition.

Practically all the drainage from the watershed tributary to the Valley is raporized by the heat and returned to the air, either through the fumaroles or as diffuse invisible vapor. The only way to estimate how large a proportion of the steam from the fumaroles is composed of surface water is to compare the condition of the Valley in winter, when practically no water runs into it, with that in summer, when the accumulated run-off of the whole year is largely concentrated in two months. If the fumaroles are due to surface waters they should dwindle in winter and grow with the increasing melt in summer. If on the other hand surface water plays but a small part, they should remain nearly constant at all seasons.

So far as our observations go, they point definitely to the latter supposition. The Valley looked exactly the same on June I, I9I9, as it had in $\mathrm{Au}$ gust, I9I7, and we could not detect any differences beyond the daily fluctuations due to changing weather conditions as the season progressed. Yet in early. June the slight streams from the glaciers quickly dried up, leaving dry beds through the main portion of the Valley, where in August ran foaming mountain torrents.

\section{SOIIE INDICATIONS OF SLACKENED ACTIVITY}

While it was evident at once that the general appearance of the Valley was the same as before, after we had had time to examine the ground in detail we could observe some slight indications of a slackening of activity around the edges.

The little fumaroles between Mount Cerberus and Mount Mageik at the head of the Valley, of which there were about a hundred in 1916,1917 , and 1918 , were reduced to two or three in I9I9. At the foot of the Valley a large number of springs of boiling water had started up in areas where there had been nothing but steam previously. The temperatures of some of the fumaroles in the same area were markedly lower than the year before.

Falling Mountain, likewise, though quite active enough to satisfy the newcomers, did not shoot forth its avalanches 


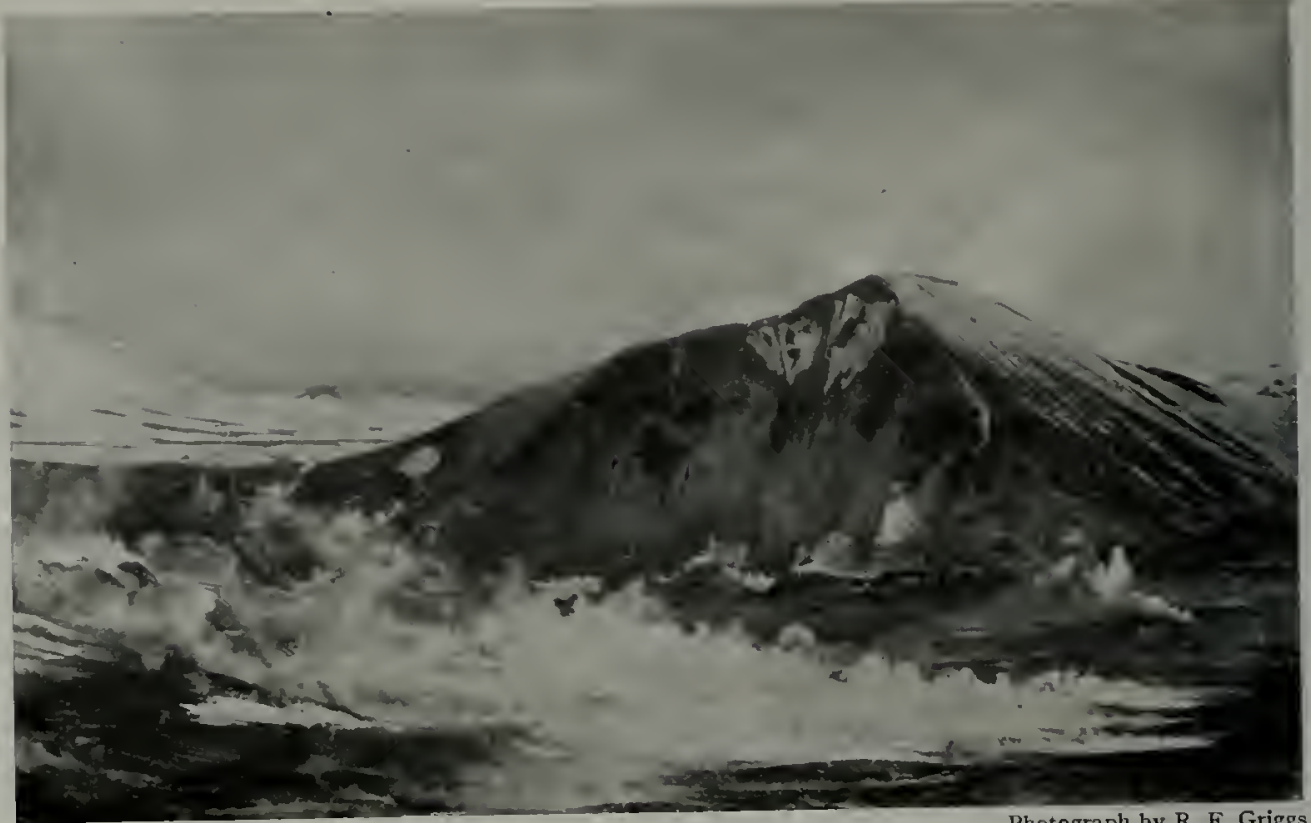

Photograph by R. F. Griggs

\section{FALLING MOUNTAIN FROM ACROSS THE VALLEY}

One of the most remarkable phenomena of the region is the constancy of the avalanches down the face of Falling Mountain.

with quite the same frequency as in former years. The old volcanoes, Katmai, Trident, Mageik, and Martin, also were less vigorous than in 1916 and 1917 .

This is, however, by no means a certain indication that the activity of the region is dying out. The big volcanoes, which alone were known at that time, had a similar period of slackening in 1915. We could not assure ourselves then that KKatmai was really active, and steam from Trident could be seen only at certain times.

But the two following years the output of both these vents increased measurably, so that no one could question the reality of the steam clouds issuing from them. Whether the slackening of the activity of the Valley vents observed in I9I9 was simply such a temporary fluctuation, or whether it represented a permanent quieting down can only be judged by the future.

In either case there is no reason to expect any sudden extinction of the Smokes, for the changes observed were so slight that we could not be certain that there was a real slowing-down until after many days of observation and comparison.

\section{MELTING LEAD AND ZINC IN THE FUMAROLES}

Despite the signs of decreasing activity that were detected around the edges of the Valley, the geophysicists found fumaroles very much hotter than any that had been measured before - hottcr, indeed, than any of us had supposed occurred in the Valley.

It was late in the season before any of these extremely high temperatures were discovered. We all felt that more and perhaps hotter places would have come to light if only there had been time to continue the work. But increasingly bad weather prevented further search.

There was great excitement one night when Dr. Allen, coming in late, announced, "Three times have we melted zinc this day." His party had found three widely separated fumaroles with 


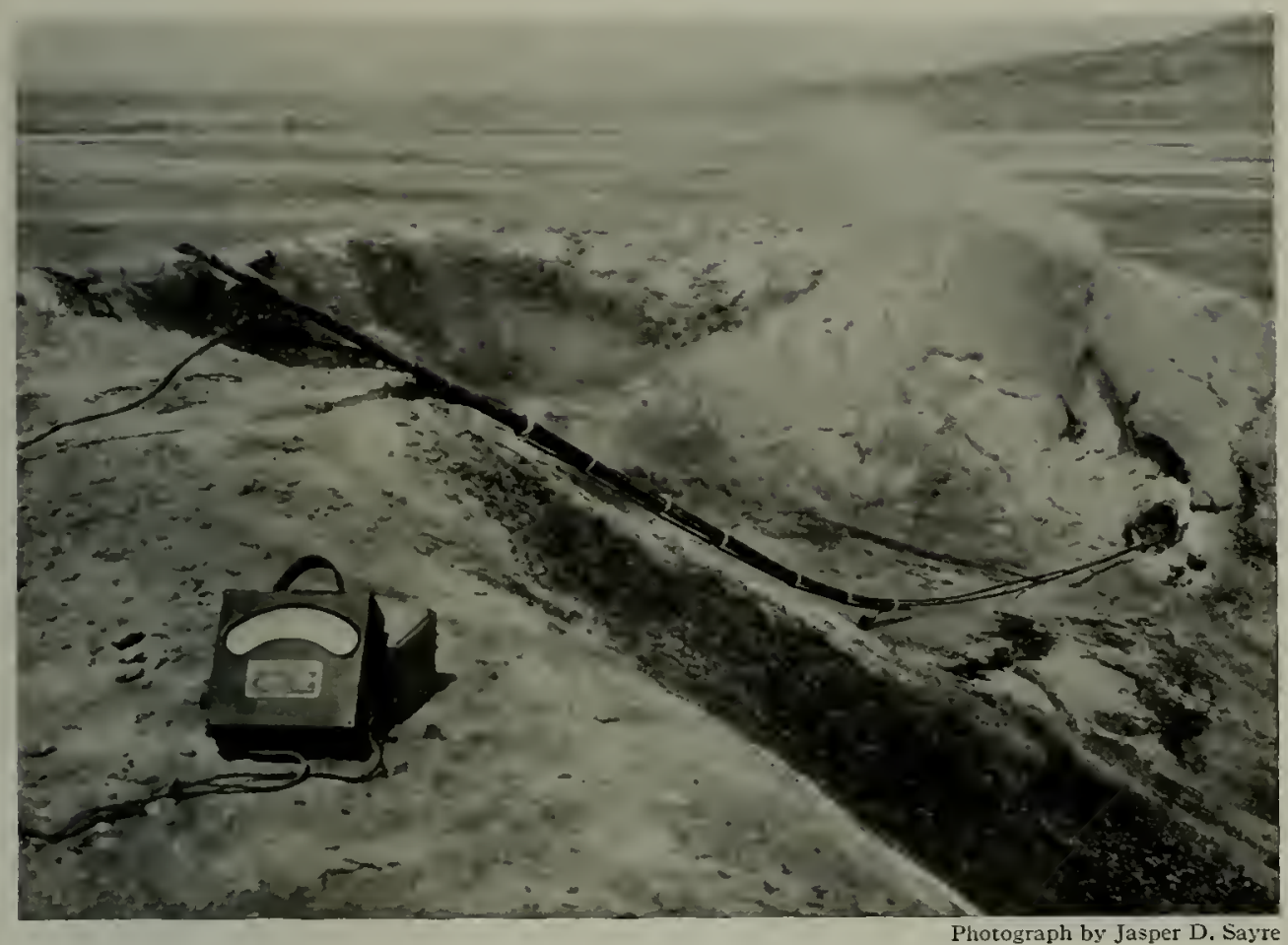

MEASURIYG THE TEMPERATURE OF A FUMAROLE

The temperature of this insignificant little hole was $300^{\circ} \mathrm{C} .\left(572^{\circ} \mathrm{F}\right.$.). Others in the same line near by ran above $400^{\circ} \mathrm{C} .\left(752^{\circ} \mathrm{F}\right.$.). The difference in temperature between the hot and cold junctions at opposite ends of the thermocouple sets up an electrical current whose intensity, recorded by the meter in the foreground, is a measure of the temperature (compare Plate $\mathrm{XV}$, facing page $3^{\circ}+4$ ).

temperatures above the melting point of zinc $\left(420^{\circ} \mathrm{C}\right.$. $)$.

The hottest of these was practically $500^{\circ}\left(496^{\circ} \mathrm{C} ., 868^{\circ} \mathrm{F}\right.$.). This was found in a fumarole where the steam broke through a myriad of small holes in the roof of a bridged-over fissure.

The rolume of gas coming from any one of these holes was so small that we could approach as closely as desired. IVe could easily reach into the hole with a foot rule. Within five seconds the end of a stick held in the steam began to smoke violently and when drawn out was a glowing coal. In less time than that a bar of lead slumped down and melted away.

KINDLING A FIRE BY PLUNGING A STICK INTO WATER

But even this performance was eclipsed next day, when the chemists came in reporting several temperatures above $500^{\circ}$. The highest, $6+5^{\circ} \mathrm{C}$. (nearly $\mathrm{I}, 200^{\circ} \mathrm{F}$.), was obtained in a small orifice not more than two inches in diameter, located at the bottom of a crater-like pit eight or ten feet across.

This was an inconspicuous little fumarole which had not excited our curiosity, although it was but little removed from the trail that we used constantly in traveling $u p$ and down the Valley. The gas rising in the ricinity was, however, so blue as to arouse Dr. Zies' suspicions, and lead him to examine the place in detail.

When we put an aluminum cup into the steam it was quickly softened, so that it could be cut with a knife like pewter. Yet it showed no signs of melting. The tinned handle of the cup was vigorously attacked by the gas, but the alu- 


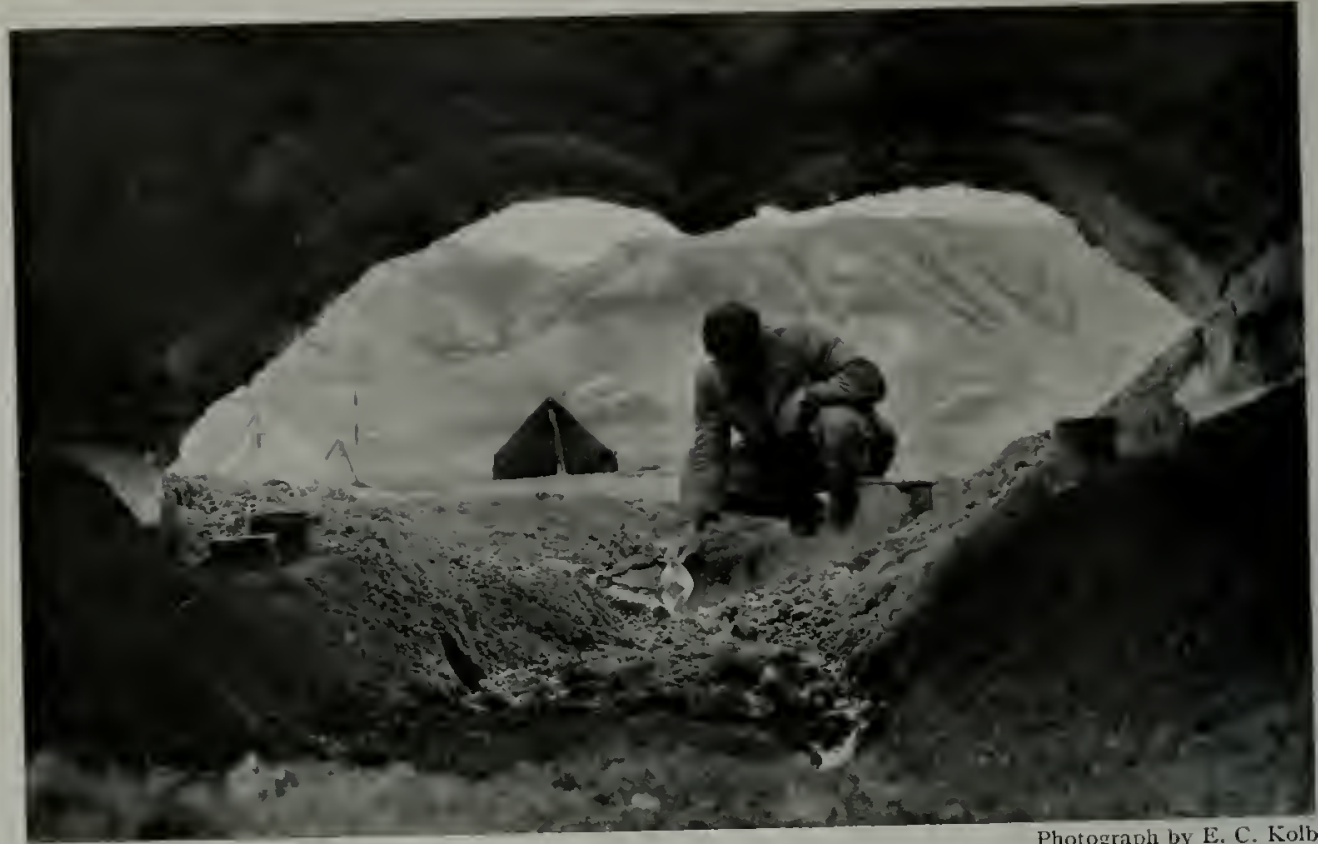

OUR DRINKING POOL AT THE MOUTH OF A SNOW CAVE

By moving the tents a few feet back or forward, we could obtain any desired floor temperature. Only a few rods beyond the tents was our cookstove.

minum body was neither corroded nor tarnished in the least degree.

Then we cut the end of a walking stick into a brush of shavings, such as one uses to light a fire, and thrust it into the fumarole. Instantly it began to smoke and char, and when jerked quickly into the air burst into flame, from which we kindled a bonfire by breaking up what was left of our canes. Since the vapor from this fumarole was almost pure stean - that is to say, water - what we really did was to kindle a fire by plunging a stick into water (see page 296).

\section{"A RED-HOT FUMAROLE"}

All of the very high temperatures measured were found in such relatively small and inconspicuous fumaroles as

1 A number of people whose knowledge of steam at higher temperatures was derived from experience with boilers have asked me why the Valley was not in great danger of blowing up from the tremendous pressures accompanying steam temperature of $I, 200^{\circ} \mathrm{F}$. It may be well to remark that while steam heated in a confined boiler to such a tempcrature would develop an enormous these, rather than in the big vents which one would suppose to be hottest.

The temperature of the gas as it first emerges is probably quite as high in the big vents as in the little oncs, but the wide-open throats, which the force of the escaping gases has blasted out, permit the emanations to cool down considerably before reaching the orifice. On this account the largest and most impressive vents, those which are actually delivering by far the greatest quantities of heat, are seldom more than two or three times as hot as ordinary steam, that is, $200^{\circ}$ to $300^{\circ} \mathrm{C}$. This temperature, although far beyond that ever found in a steam boiler, is yet much below the kindling point of wood. ${ }^{1}$

Even at $300^{\circ}$, however, the steam is perfectly dry as it emerges, and somepressure, in an open receptacle permitting free expansion, it could be raised to a high temperature, as readily as so much air, without developing increased pressure.

The gases from the fumaroles all come off at relatively low pressures, but little above the at mosphere. 
times does not condense until 20 feet from the vent. The dancing, swirling, feathery wisps which first appear in such a condensing column hold a peculiar fascination for the onlooker, as he watches them thicken and coalesce into a heavy cloud.

In the hottest rent the steam is not only so perfectly dry as to show no sign of condensing for a long distance, but so hot that in the dark the throat must glow with a faint redness. All of us would have liked to see a red-hot fumarole, and there was much talk of going down to the vent to observe it at night; but when it came to the test no one was quite ready to undertake the trip, for none cared to try picking his way around among the fumaroles in the darkness.

\section{VALLEY BECOMING GREEN IN SPOTS}

$$
\text { WITH YOSS AND ALGAE }
$$

The most conspicuous change in the appearance of the Valley was due to quite another cause - the beginning of an invasion of its hot soil by plant life. In the two years since I9I7 the few minute beginnings of regetation had increased until they formed in places conspicuous spots of bright green, visible sometimes for a mile.

The new growth was composed of "blue-green" algae and moss, which made a dense carpet around some of the fumaroles. The algae consisted of several genera that are common in hot springs; the moss was uniformly sterile.

These plants here show a very decided preference for hot ground. In fact, they are strictly confined to spots moistened by the steam. Sometimes a small fumarole will be surrounded by a mat of moss which approaches the orifice on all sides until its advance is stopped by the high temperature. Besides the living plants, one often finds brown seared remains of others that have been killed by the fumaroles, after having managed in some may to make a good growth inside the danger zone.

In addition to these visible plants,
Sayre found by incubating samples of the soil that the hot earth is inlabited by bacteria.

The scientific problem raised by the invasion of the Valley by these lowly plants is one of the greatest fascination. If one could work out the whole sequence of organisms from the lowest to the highest as vegetation is reëstablished he would perhaps be enabled to understand a great deal more than we now know concerning the peopling of this planet and its preparation for habitation by the higher animals and man.

\section{BEARS INVESTIGATE THE VALLEX}

In the seven years since the formation of the Smokes, the surrounding country had gradually been occupied by a new population of bears which, having probably grown up in the vicinity of the Valley, had come to regard it as one of the normal phenomena of their world.

When first discovered, the active area was as absolutely devoid of evidence of living creatures as can be imagined. The next year, as previously noted, a single bear ventured to cross the Valley during our stay.

But in I9I9 bears were frequent visitors, comprising indeed the only tourists that had yet visited its confines. Not merely here and there, but in many places, their tracks were to be found all through the Valley. These were not the work of any single bear, nor made at any one time, but were of many sizes, showing that most of the bears of the region probably enter the place from time to time.

They were not satisfied with merely crossing through the steaming areas, but were apparently attracted in some degree by the Smokes. Their tracks were often to be found close around the largest vents, even far up toward the head of the Valley, many miles from any possible source of food.

From their behavior, indeed, it seems not at all improbable that they may have enjoyed lying on the warm ground, seeking good places to bask in the heat, 
just as a dog picks for his bed the hottest place behind the kitchen stove. IVe could not assure ourselves in this matter, for we could never catch sight of them in the Valley, and the ground around the big fumaroles is baked so hard that only claw marks remained to show where they had walked. If they lay down their shaggy coats left no mark on the hard crust, so we were little the wiser concerning their real habits.

It was not unusual to find the tracks of a bear leading straight up to one of the large vents, where evidently he had stopped to peer into the mysterious hot hole. In one of the steaming areas Hagelbarger found a place where the hot ground had apparently excited the bear's curiosity, for he had dug into it until he started a small fumarole of his own. The appearance of a cloud of steam under his claws as he broke into the hot crust must have given him a great surprise. It did not scare him away, however, for not satisfied with a single experiment, he tried again in several places, each time digging down till he started the steam before turning away.

\section{BAKED MOUNTAIN CAMP}

When we first camped in the Valley in 1917 we were so afraid of its fumaroles that our guiding maxim was "safety first." But when we returned in 1919 we were willing to take a chance and try experiments we had not dared attempt before.

At the suggestion of the photographers, the camp was placed at a corner of Baked Mountain (see map, page 68), close beside some of the biggest vents in the Valley, a situation that commanded magnificent views of Mount Mageik and Mount Martin and was at the same time convenient of access from all directions.

Although this position proved untenable, as was afterwards demonstrated by a series of disastrous experiences, it permitted us to secure some photographs which could not otherwise have been obtained; for pictorial conditions in the
Valley are so dependent on fleeting light effects that one cannot hope to obtain the pictures he wants except by camping on the spot and rushing out with his camera when the light is right.

So far as conveniences for the camper were concerned, this location was all that could be desired. The big fumaroles in front furnished all degrees of heat for cooking, while the snowdrift directly behind the tents supplied an abundance of good water and served as refrigerator.

\section{ACID FROM THE COOKSTOVE EATS THE POTS}

The new location called for new methods of cooking. We soon found that it was impossible to hang a pot down into the fumarole, as we had done before. The steam from this group of vents was highly charged with acid (either hydrochloric or hydrofluoric), which in the course of a few moments attacked the rope to such an extent that it fell to pieces when we tried to pull out the pot. More embarrassing still was its effect on the pots themselves, for it was not long before they developed leaks where the fumes had eaten away the aluminum.

Instead of hanging the pots in a fumarole, therefore, we dug holes in the hot ground and banked up the steaming earth around them. The different holes stood at different temperatures, so that we were able to vary our procedure according to the results desired. If, on leaving in the morning, we wished to provide supper against our return, or if we wished simply to keep a pot warm, we would select a "slow" hole. But if we were in a hurry for something, we put it into a hot hole, where it would boil away vigorously.

The hottest places would burn up the food if we left it too long, just as a fire does. But a pot could be left indefinitely in the slow holes without coming to any harm. Once, when driven out by a storm, we found the oatmeal that had been put on for breakfast in prime con- 


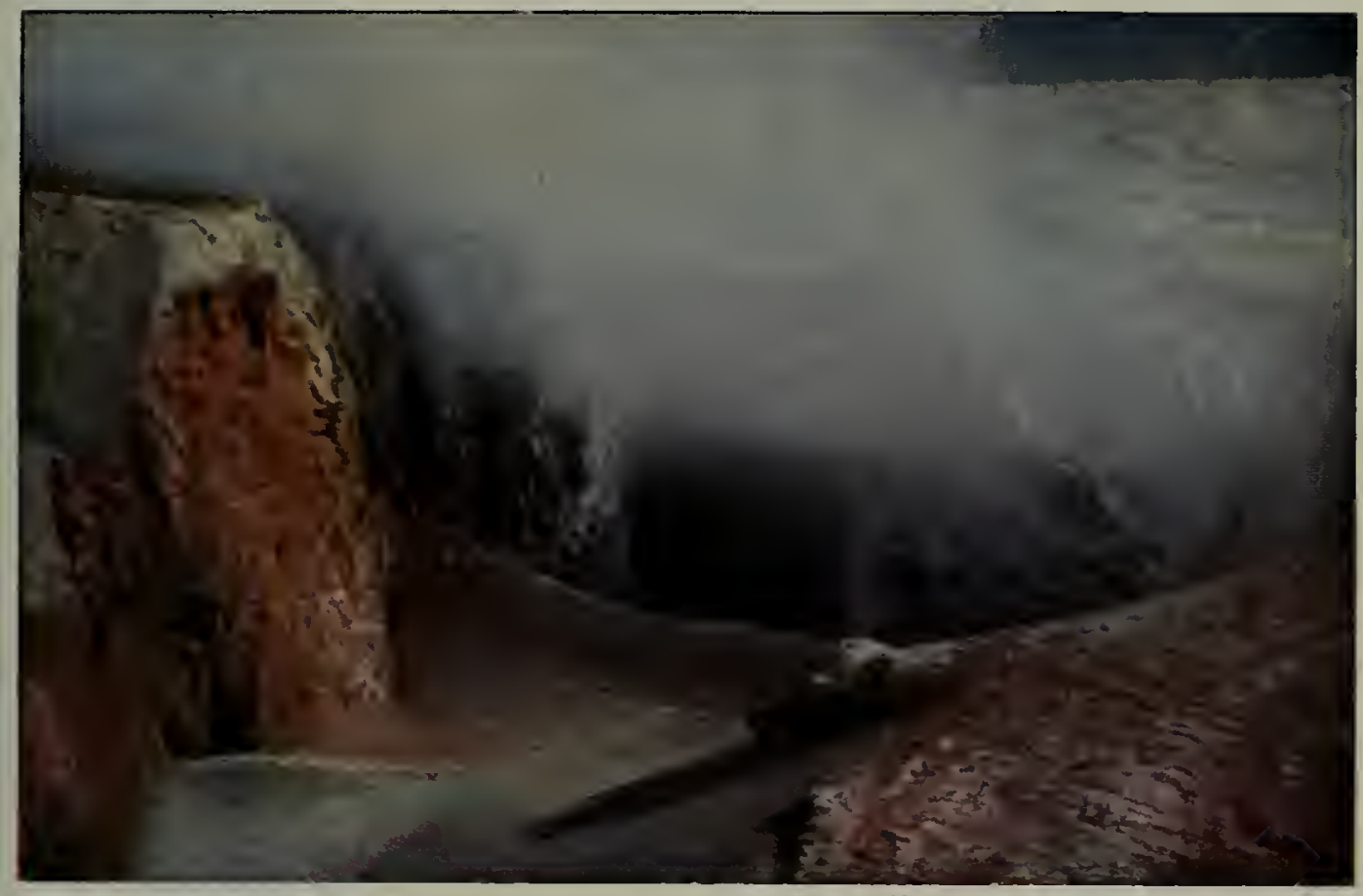

- Vatural Color Photograph bỹ Frank I. Jores

THE CAIERNOLS MOLTH OF ONE OF THE FLMAROLES

A long passage full of superheated steam could be followed with the eye for sixty or a hundred feet into the depths. 


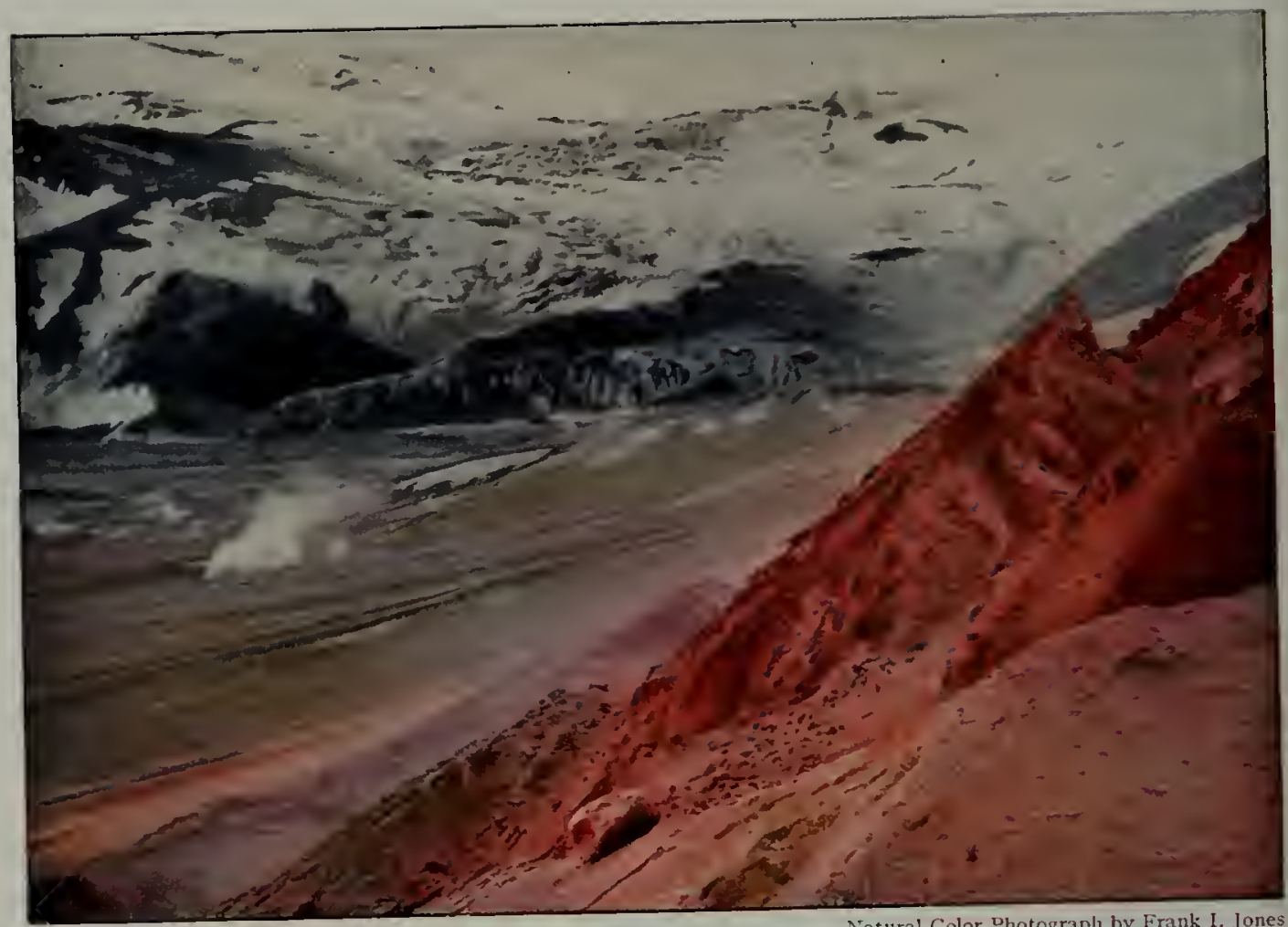

Natural Color Photograph by Frank I. Jones

A RED-BIR.NED FISSLRE ON THE WEST SIDE OF THE VALLEY, LOOKING TOWARD THE GLACIERS OF MAGEIK 
dition on our return two days later. The wind had entirely buried the pot in drifting pumice, so that it had to be dug out with a spade; but it was none the worse for having simmered away ten times as long as intended.

\section{CORN PONE À LA FUMAROLE}

With no fumaroles hotter than ordinary steam at hand we had been compelled in I9I 7 to limit our menu to boiled dishes. But the range of temperature at Baked Mountain was great enough to permit any sort of cookery we might desire.

The situation of the "cookstove" which made such varied temperatures readily available in a small compass was characteristic of many areas. It was located on the roof of one of the great bridged-over fissures that encircle the margin of the Valley. The cavern below was full of superheated steam under pressure (see plate IX, facing page 224).

Every little crevice in the arching bridge was the path for a small seepage of steam, the temperature of which, as it emerged, depended on the volume. The slow cookers were dug in places with little seepage; the hot spots had close connection with the steam below. We could not tell in advance, however, how effective any hole would prove as a cooker, for there was little visible emanation from any of those we used.

In the hottest of our "stove holes" the temperature was high enough to fry bacon or bake bread with ease. For some reason the tastes of the party centered on johnny cake rather than on white bread or biscuits, although the latter were occasionally made with equal success. The procedure was to put the pan of batter in a covered aluminum cooking pot which was then simply set on the ground in the proper place.

Baking over the fumarole required the same sort of watchful care that it does anywhere else. It would not do to go off and forget the bread, as we did the oatmeal, for if it was left longer than the allotted hour it was burned up, as it would have been in any other oven. When taken off at just the right time, however, it came out with beautiful crispy brown crust, as fine corn bread as was cver seen (see plate vi, facing page 193).

FRYING BACON IN SUPER-HEATED STEAM

For frying bacon we found it most convenient to repair to "Fumarole No. 5," at a little distance from the camp. Here a column of very hot steam emerged under pressure from a round hole about a foot and a half in diameter in such a way that it could be readily approached. The gas at this place was so hot and came out with such a rush that if we tried to pour a cup of water into the hole it never reached the ground, but was caught up by the outrushing steam and carried away before our eyes, vaporizing within a few inches. When we threw our hats into it, they would go sailing away 30 feet into the air before coming down.

The frying pan had to be held down against the steam, for even the weight of the pan and the five-foot stick we employed as a handle was not sufficient to balance the pressure of the fumarole. It would keep wobbling around, up and down, in and out of the rushing steam unless firmly held. Needless to say, the bacon began to sizzle promptly and was soon as well crisped as when cooked over the best of camp fires.

While experimenting to find the best place to hold the pan, we tried pushing it down into the cavern below the orifice, but immediately it was caught by the back draft and - piff! the bacon was whisked out of the pan, flying through the air in every direction, to be eagerly caught and devoured by the spectators, who howled with delight at this sudden turn of events. Discovered accidentally, this trick was repeated again and again till we tired of chasing the flying slices.

With such facilities at our command and a full stock of dehydrated fruits and vegetables, there was little in the way of "grub" that could not be concocted at 


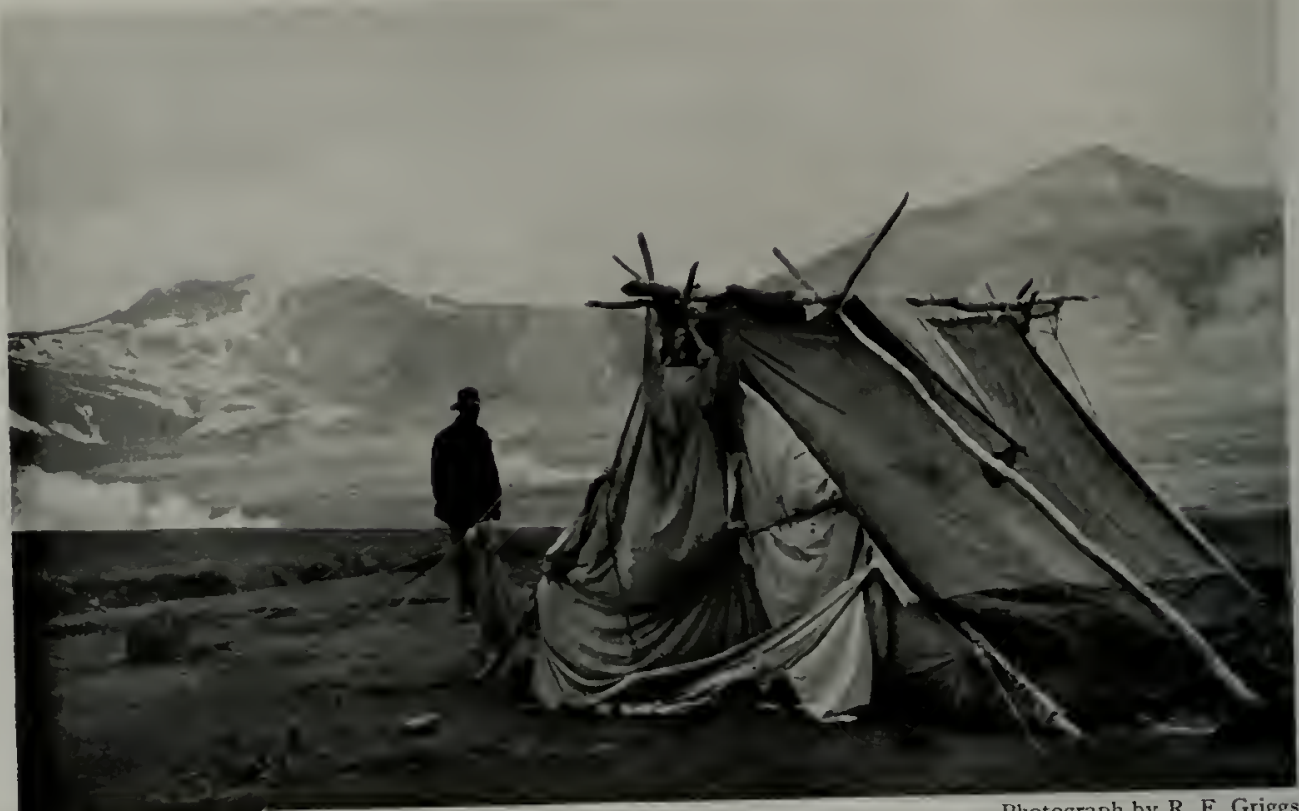

Photograph by R. F. Griggs

THE "DEFENSES" OF BAKED MOUNTAIN CAMP

Profiting by severai sorry experiences, Yori finally shored up the tents so thoroughly as to bid defiance to the winds, but it was no use. The condition of the camp when the next storm cleared away is shown on the opposite page.

Baked Mountain. The staples were oatmeal, rice, beans, cornbread, dehydrated potatoes with abundant butter, cheese, and pilot bread. These were varied with an occasional mess of cornbeef hash, or of trout when someone brought them up from the lake.

For green vegetables there were string beans, spinach, and "boiled dinner vegetables," the latter soon becoming a joke because of the superabundance of carrot, of which everyone quickly tired. Our fruits included apples, raisins, peaches, pears, apricots, loganberries, cranberries, and cherries, the last being such a universal favorite that they were soon used up. Soluble coffee was varied with cocoa and an occasional cup of tea. One hot day we even indulged in iced tea, but for the most part we preferred hot dishes.

$$
\text { THE "WILLIWAWS" }
$$

All went well at Baked Mountain Camp as long as the weather remained good, but when the storms struck we encountered a fury that no tent could withstand. The conformation of the mountains is such that Katmai Pass is a double-ended funnel, through which the wind sucks with terrific violence whichever way it blows (see map, page 68).

Curiously enough it is not on the windward, but on the lee side of the Pass where the heary "williwaws" or "woolies," as the boys called them, are experienced. The winds we had learned to dread on the Pacific slope were the westerly gales, but on the Valley side it is the northeasters that make the trouble.

We were blown out four times before we finally learned our lesson and moved to a safer, if less convenient, location. Fortunately; these storms came in a series of increasing violence, so that each time we were better prepared for trouble than before. Otherwise, they would have been even more disastrous than they were. 


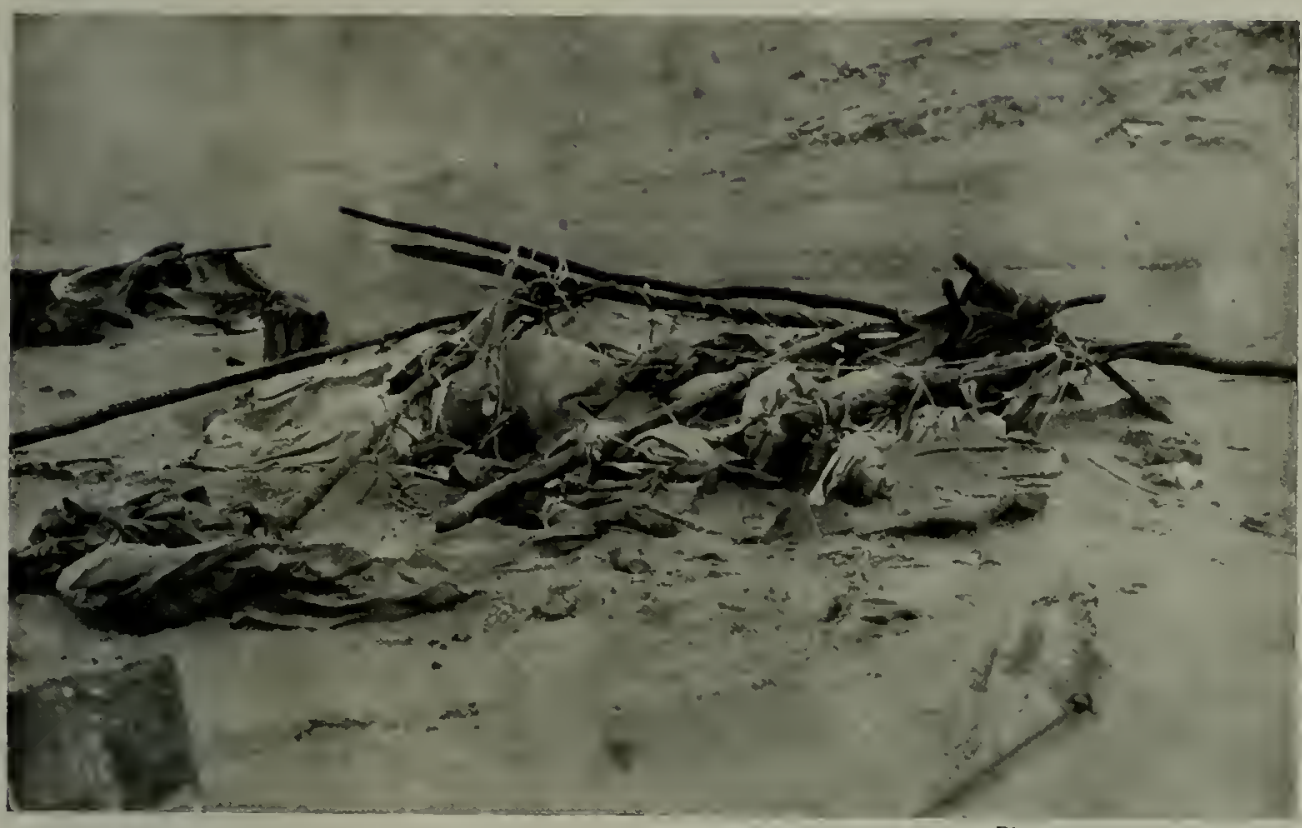

THE WRECK OF BAKED MOUNTAIN CAMP

Photograph by R. F. Griggs

We could never have believed that the boasted strength of our camp would be so completely demolished. Nearly a thousand feet of cordage had been used in lashing the poles together to resist the weather. The wreck was so heavily drifted over by flying pumice that it took the combined strength of two of us to peel back the fallen roof and get at the duffel on the floor.

As we came across the Valley on our way back from the ascent of Mount Martin (described in Chapter xIv), the northeast wind freshened in a way which I knew meant that the "woolies" were to visit us that night. We were too tired from the climb to care much, however, for we believed we could sleep through anything. And the tents had been so shored up as a result of previous experiences that, like the skipper of the Hesperus, we believed they "could weather the roughest gale that ever wind did blow."

The frame of the grub tent had been strengthened by a multiplicity of poles and braces sunk deep in the ground until it formed a veritable cage, inside of which we had patched together parts of four tents. Fully a thousand feet of cord had been used in lashing the structure together.

All the guys were anchored to bowlders as big as a man could roll, deeply buried in the ground. On every side except the front there were at least two thicknesses of cloth to protect us from flying pumice. A heavy duck tarpaulin had been thrown over the second tent and buried in the ground on the windward side, to reduce its resistance and prevent the wind from getting in under the eaves.

\section{THE FINAL WRECK OF BAKED MOUNTAIN CAMP}

After the first few warning blasts I called to Yori, questioning whether we had not best take additional measures to protect the camp, but he let out a whoop of defiance, "Oh, let it blow; we can stand it."

I was too tired to get up and go out looking for trouble, so I lay down again to get the rest I so much wanted. If I had gone out then I could have saved the: apparatus tent, which was afterwards sorely needed. But weariness is a great foe to will power, and I missed my chance. 


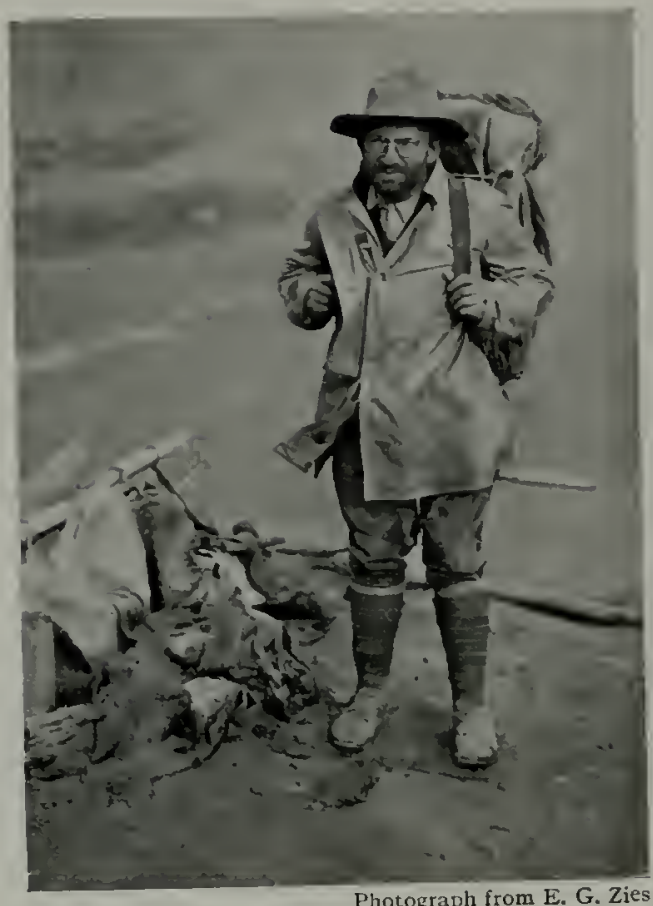

DR. ZIES LEAVING THE WRECK OF BAKED MOUNTAIN CAMP

The expression of grim determination caught by the camera was not accidental. It was due to the experiences recently passed through.

By the time it was fairly dark the storn had increased to considerable proportions. It came in great intermittent gusts, with intervals of quiet between. We could hear them coming over the mountains long before they reached us, their terrible roar as they tore their way down through the Pass for a while more frightful than the blow when it struck. Quaking with dread, we lay huddled together beneath the tent awaiting the crash.

\section{APPARATUS AND SLEEPING TENTS GO DOWN}

The apparatus tent went first, torn to shreds and exposing all the chemists' instruments, as well as cameras and other valuable equipment, to the soaking rain and driving pumice which Hew before the wind in sheets. By ten o'clock the poles of our tent snappcd, the broken ends tearing great rents in the fabric as they went down. Fortunately they went one at a time, giving us a clance to move our beds and duffel into the grub tent, which now alone remained standing.

After the last blanket was removed we managed to lay hold of the flapping wreck and weight it down with rocks, to prevent its being torn to pieces. It was all we could do to accomplish that, for by this time the fury of the wind was such that one could hardly manage even so small a thing as a prostrate tent, and the hail of flying pumice was impossible to face even with goggles for protection. IVe were well repaid for our efforts, however, for the saving of that torn tent was all that made a resumption of work possible after the storm.

\section{EXTRA TARP TEARS AWAY}

Crawling into the remaining tent, I stretched out in my sleeping bag to get a little rest, if I could. But it was not for long that such relaxation was permitted. It soon became a question whether even so strongly built a tent as ours could withstand the pressure.

Before long the spare tent, with which the lee side had been reinforced, gave way and, still holding to the frame by the corners, went flopping around in the wind to increase the general confusion. Two days later, when we returned, we found it, a new tent that had never been set up, torn clean in two!

No sort of rest was longer possible. So I got up, packed my bed with a little clothing inside my packsack to keep it dry, and put on all my extra sweaters and coats to keep wam, for the driving rain was intensely cold. Some of the others who continued to use their bedding as robes were less fortunatc, for it was extremely difficult to gather things together and to keep them dry in the final break-up.

About one o'clock the extra tarp lashed to the windward side tore away, lcaving only one thin sheet between us and the gale. It seemed impossible that any light cotton fabric could en- 
dure the strain. It soon broke all our boasted guying and then was held only by the frame.

The pumice came beating against it with the noise of a hailstorm on a tin roof; but these stones were sharp at every corner, not round and smooth like hail. The impact was so heavy that our flesh would not tolerate the pain if, trying to keep the tent in place, we pressed our bare hands or arms against the wall. Why the flying pumice did not instantly cut the tent to shreds was more than we could understand. But it held for half an hour or more, and then gave way all at once with the crack of a cannon, as a great rent opened from roof to floor.

\section{HUDDLED TOGETHER IN THE LAST CORNER OF THE TENT}

The hail of pumice that greeted us as we crawled out to see if anything could be done cannot be imagined. It could not be endured on face or hands for an instant. It hurt clear through our clothing. It drove in around our "dust proof " goggles, a constant menace to our eyes. Many of the pieces were as large as hickory nuts and all were armed with sharp corners that made them terrible missiles.

Once the tent ripped, the wet pumice began to collect all over us, down our necks, in our pockets, in our ears, in our noses, in our mouths - everything was permeated with it. Soon it was four inches deep on the floor, though more blew out through the other side of the tent than lodged within.

The five of us - Allen, Zies, Fenner, Yori, and 1 -huddled together against the windward corner that gave the last little shelter remaining. It was suggested that we crawl into a gully; but we remembered that such places were collecting grounds for the pumice which would hail down on us in greater quantities than ever. So we agreed to stick it out as long as possible, praying fervently for the dawn.

The nearest relief was at Ukak, ten

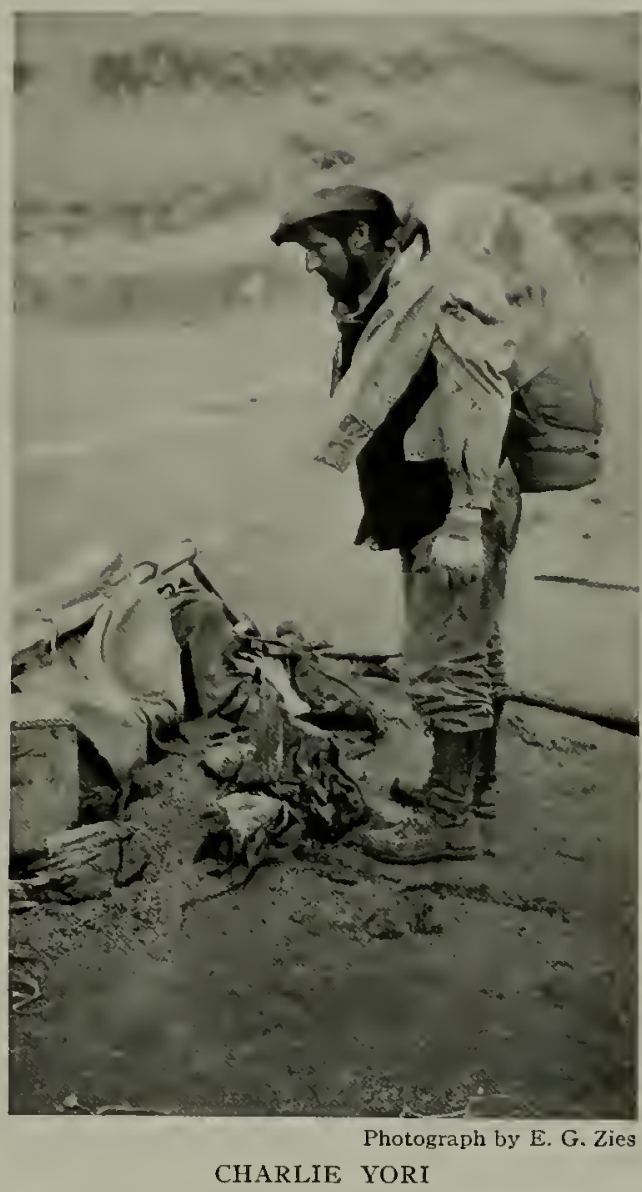

Leaving the wreck of Baked Mountain Camp.

miles down the Valley. The violence of the wind left us little control over our bodily movements, and we dared not attempt to flee down through that maze of fumaroles in the darkness of the night.

How we watched the diminishing shreds of our tent, and counted time against the wasting fabric! Could it shelter us until it was light enough to leave? Time and again the wind would pick us up as we braced our backs unitedly against the wall and roll us into a pile in the middle of the floor. I sat on a flat valise weighing 50 pounds, on which I had placed for protection a big rock weighing as much more, yet the wind repeatedly picked up the whole bundle - man, suitcase, rock, and all and rolled us into the middle of the tent. 


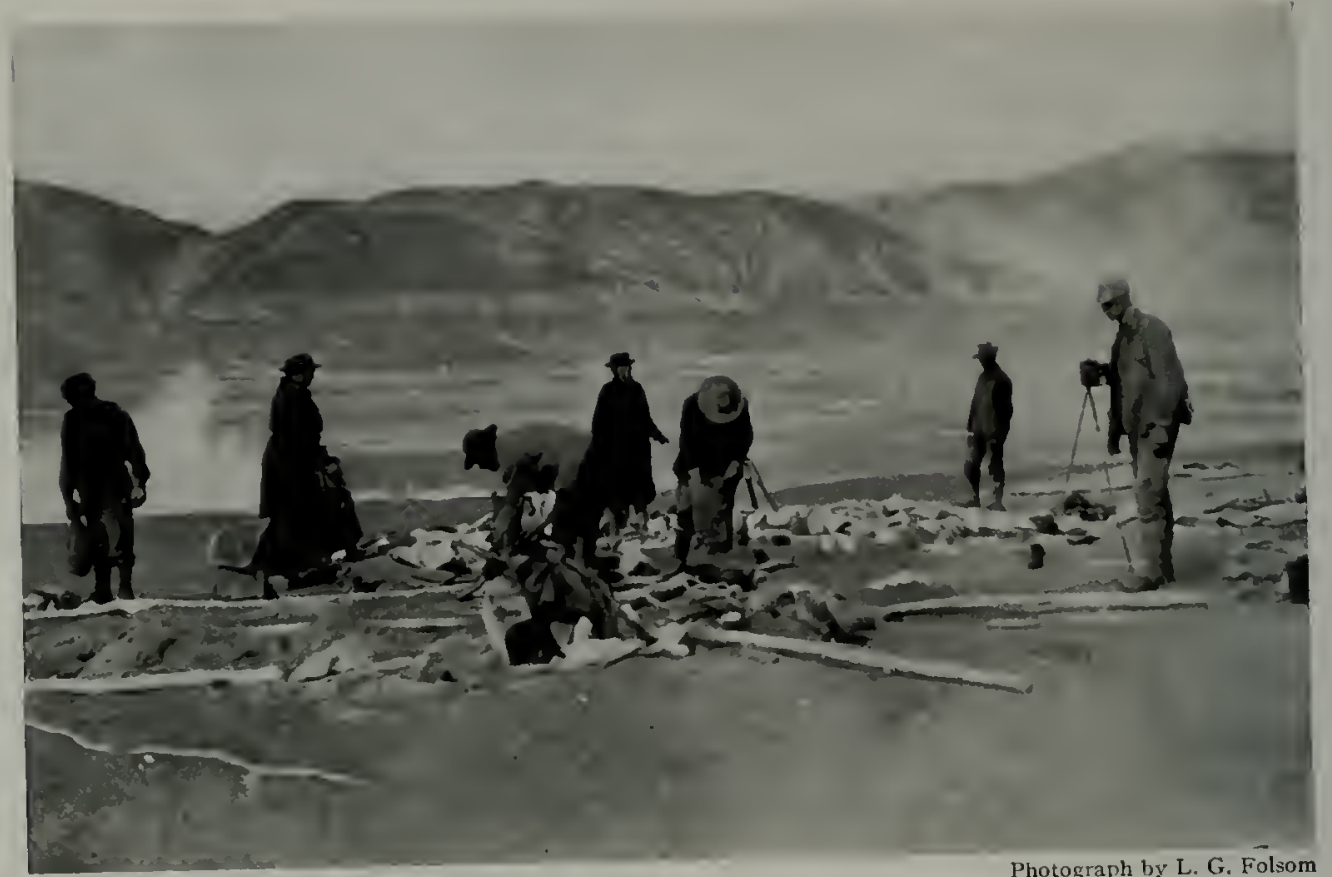

SORTING OUT THE WRECKAGE AFTER THE STORM AT BAKED MOUNTAIN

We looked and felt very much like rag-pickers on the dumps, but among the wreckage were many of our most cherished possessions.

Yori, with characteristic self-sacrifice, chose the most exposed end of the line. He drew a tarpaulin over his head and shoulders in a vain effort to mitigate the blast. Soon it was the only protection he had, and for some time he sat practically outside while the wet pumice was driven down his neck. He must have been bitterly cold, but never a complaint escaped him.

\section{THE WIND PICKS ME CLEAR OFF THE} GROUND

Finally, at four o'clock, the gray shapes of the fumaroles began to be distinguishable in the general blackness. I crawled outside and decided it was little worse than within, for there one could at least move around. So, though all were fearful of being driven bodily into a fumarole, it was agreed that the time had come when we must try it down the Valley.

Zies had a little flashlight which made it possible to gather up the things we most needed. But before they were collected Allen came out and was almost literally carried off before the wind.

Feeling that it was of the utmost importance for safety's sake that we keep together, I made frantic efforts to detain him, but he was gone like a ghost in the night, beyond recall, out of earshot almost at once. Then I tried to hurry the others. Zies and Fenner were ready and started ahead but Charlie was busy trying to save some extra conveniences for the geophysicists, and I turned back to urge him to come along.

To face the gale was impossible; so I started backing toward the tent, bracing with all my might against the wind. Suddenly I found myself flying through the air - I felt I was being carried off down the Valley, God knew where. My whole life flashed before me! The gratitude I experienced when my face landed in the mud only two gullies away was inexpressible. My feet kept on and nearly turned me another somer- 
sault, but I was safe on the ground again!

\section{FLIGHT TO UKAK}

After that I decided it was useless to try to go back, so I started on in an attempt to catch Allen and slow him down. Down the hill I sped, carried to windward with little chance of choosing ny course. In the distance I spied the gray smoke of one of the big fumaroles, dead ahead. I knew that I must avoid the yawning chasm by which it issued, if I were to live.

By desperate scratching I managed to deflect my course a little, but slid by so close that had there come just then another gust such as had picked me up 1 could not have avoided it. It was some time before I could find Fenner and Zies, who were waiting for Charlie and me in a deep gully. They had seen Allen go sailing by. We soon caught him and proceeded down the Valley in somewhat more orderly, if none the less precipitate, fashion.

The wind came obliquely over Baked Mountain, making it extremely difficult for us to avoid being carried out into the middle of the Valley, whereas our safety depended on keeping to the east side, in order to make the ford of Knife Creek above the point where it plunges into an impassable canyon. For if we missed the ford our flight would have ended in a cul-de-sac among the canyons, from which there would have been no escape.

Our legs fairly ran away with us. Despite the accumulated weariness of the day before and the strain of the night, we made the trip to Ukak in record time, covering the distance-nearly ten miles - in less than an hour and a half. Everyone jumped up to let us crawl into the warm sleeping bags, and we were soon sound asleep. The gale continued all that day, but in the night it calmed down enough to permit us to visit the ruins on the following day.

The site of our former happy camp presented a scene of complete desolation. Everything was covered with pumice blown into the fallen heaps of wreckage until no more could stick on. Where we had rolled a big stone over the sleeping tent to hold it down the pumice had drifted a foot deep. It lay so heavy on the tent that it took the united strength of Yori and myself to roll back the fallen roof, to expose the things that lay on the floor.

The friction-top tin cans in which we stored most of our supplies were scattered all over that section of the Valley. Fortunately for us the gullies had intercepted most of them and their lids had stuck tight. When we came to take account of stock, we found the real damage less than seemed possible. The single cot which had served primarily as a bench for keeping the photographic materials off the ground was removed from the fallen tent by ripping a hole through the wall, and the scattered effects gathered together and stowed on it in a secure cache.

Meanwhile we found that another party, camped at the old place under Cerberus, had experienced no difficulty with the gale. None of us who had been through that experience would have cared to try camping at Baked Mountain again. But here was another chance. Enough remained in the wreckage to permit a resumption of work on a restricted scale. No one was slow to grasp the opportunity, for the season was far advanced and we knew it was now or never. 


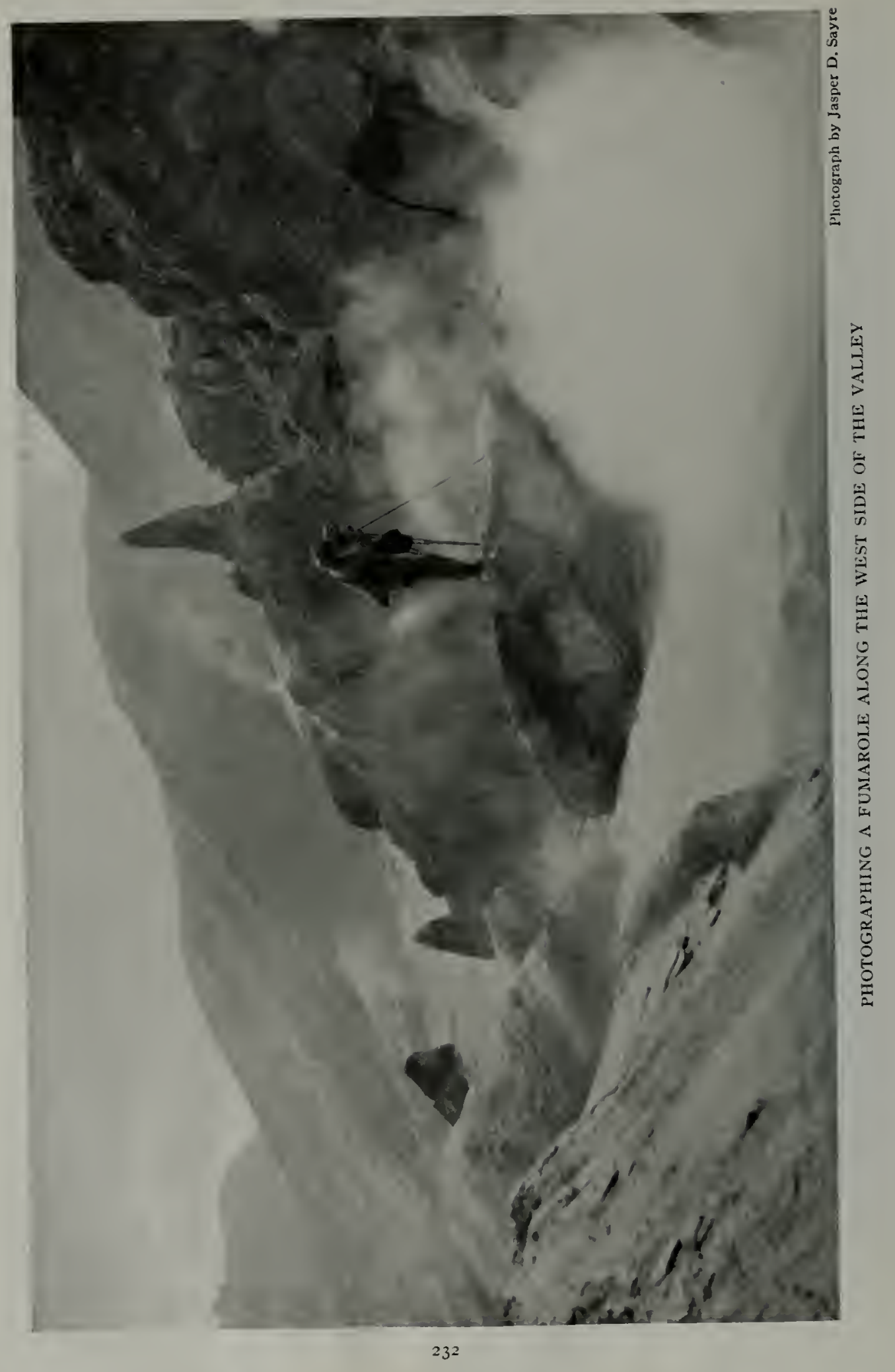




\section{XVIII}

\section{A DESCRIPTIVE ACCOUNT OF THE VALLEY OF TEN THOUSAND SMOKES}

If one will turn upside down the map reproduced on page 68 he will note that the Valley occupied by the Ten Thousand Smokes has the form of a gigantic heary-faced $Y$, stretching from the mountain axis of the Alaska Peninsula toward Naknek Lake. The height of the $\mathrm{Y}$, perpendicular to the trend of the main range of volcanoes, is 13 miles $(20.9 \mathrm{~km}$.). Its width across the top is 9 miles $(14.95 \mathrm{~km}$.). The width of the stem and of the right arm of the $\mathrm{Y}$ is about 2 miles; the left arm is approximately half as wide.

Each of the three extremities of the $\mathrm{Y}$ is expanded into a heav' ceriph, transforming the simple crotched $Y$, such as might be described in the basin of any forked stream, into a heavy Roman $\mathrm{Y}$ of very different form.

The expansion at the bottom of the $Y$ is due to the fact that the Valley divides at the base into two broad arms which reach Naknek Lake independently some ten miles apart. If, therefore, the rolcanic activity had continued beyond the present terminus, the Smokes would have assumed the form of an $\mathbf{X}$ still more gigantic.

So broad and open, indeed, is each of these lower valley's that travelers who formerly traversed the Valley in crossing Katmai Pass used to go sometimes by one, sometimes by the other arm, depending on weather conditions.

It is at the constricted area between the two upper ceriphs of the $\mathrm{Y}$ that the climax of activity occurs, for here are located Novarupta and Falling Mountain, as well as the most bewildering mazes of smokes to be found in the whole Valley.

The area enclosed between the two arms of the $\mathbf{Y}$ is occupied by a highland of which Baked Mountain and Broken
Mountain are the principal summits. This is bisected by a small valley, which extends up from the stem of the $Y$. Like the main Valley, this area is active. Its mouth is the seat of some of the most vigorous vents in the region, and smaller fumaroles occur farther up (see page 294).

The main entrance to the Valley is through a narrow branch which extends from Katmai Pass down between Cerberus and Falling Mountain. There is abundant evidence that this Valley also at one time gave vent to numerous fumaroles, though it is no longer active.

Near the summit of the Pass another branch runs out between Cerberus and Mageik, in which a considerable number of small fumaroles were still active in I9I 7 and I9I8. The nearest of these were the first little smokes that lured us on to the Pass on that memorable 3 Ist of July, when we discovered the Valley (see page I90).

\section{VALLEY UNDERLAIN BY SEDIMENTARY, NOT BY VOLCANIC ROCKS}

It is interesting and important to note that the rocks of the Valley are not volcanic, nor even igneous, but ordinary fossiliferous sandstones and shales. Where the lavas of the old volcanoes, Mageik, Trident, and Knife Peak have been poured out, the rock is, of course, igneous. But elsewhere the walls and floor of the Valley consist of sedimentary rocks lying in nearly horizontal, evenly bedded strata, almost as they were laid down on the bottom of the Jurassic sea which once occupied the region.

To attempt a catalogue of the vents or any description of the individual fumaroles would be futile. They vary all the way from microscopic jets of steam 


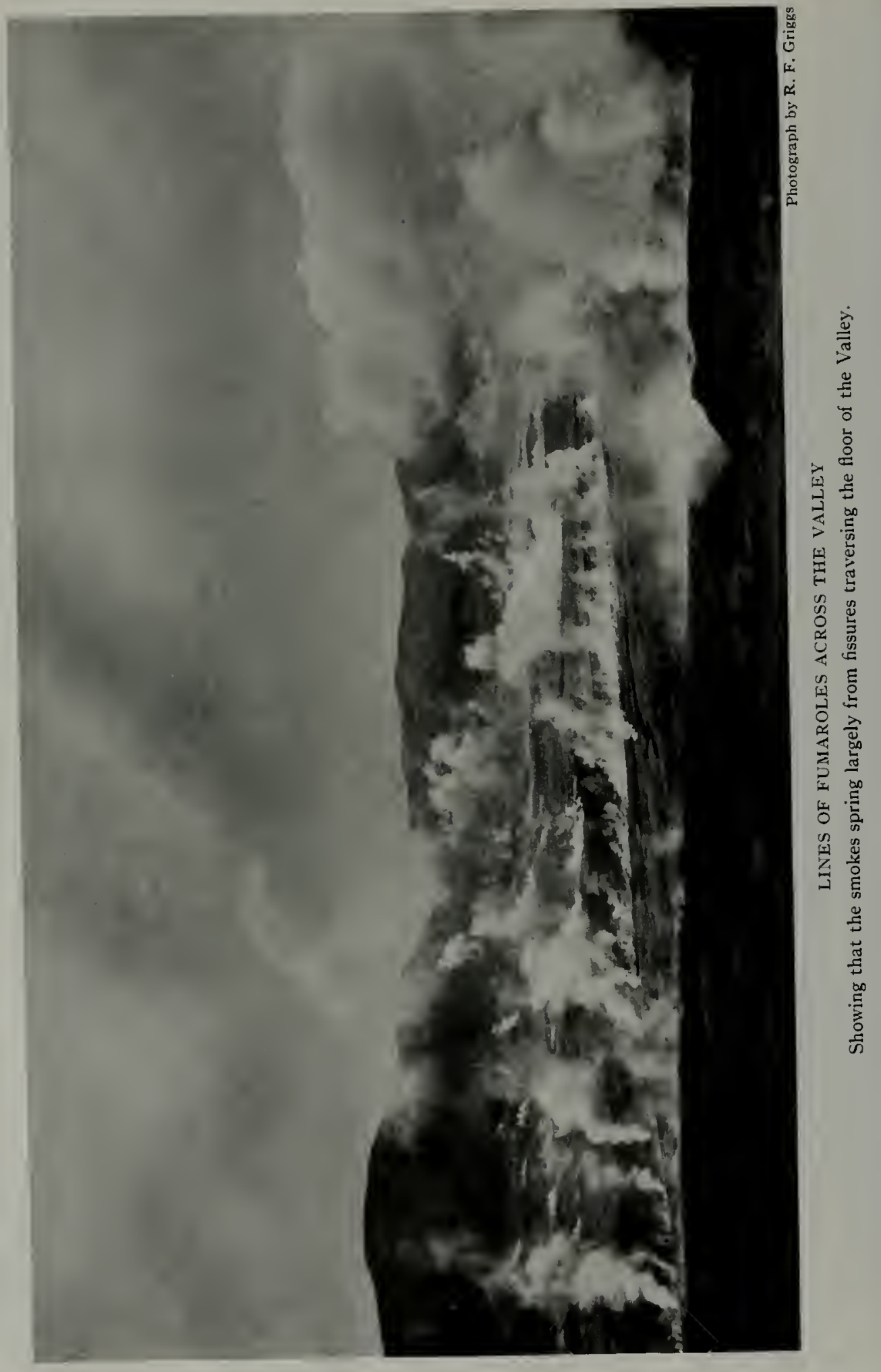


up to mighty columns that overtop the mountains. To explore the Valley thoroughly and become acquainted with the character of the various vents would require much more time than has ever been spent within its confines.

There are several square miles within the active area which no one as yet has so much as entered, much less examined carefully. The north arm of the Valley; under Knife Peak, which was supposed from the cursory inspection of I I I 7 to be of only subordinate interest, was found, for example, to be extremely active, containing the most remarkable craters of the whole Valles:

There can be little doubt, moreover. that a more thorough examination of areas whose general features have become faniliar will yield further results of importance. We were continually finding new and interesting fumaroles in places which we thought we had explored carefully. The extremely high temperature previously mentioned was discovered close to the trail, where we had all passed scores of times without noting anything unusual.

\section{THE FISSURE FUMAROLES}

By far the greater number of the fumaroles find vent through the fissures of the Valley. These readily fall into two classes: bands of marginal fissures, several together, running around the edge of the Valley in parallel lines; and single central fissures which criss-cross the floor in all directions.

While the marginal fissures are of ten evident for a distance of half a mile or more, the central fissures are usually marked only by the lines of incrustations or of small fumaroles stretched along their courses. The fissures in the center of the Valley are mostly closed, but one may frequently peer far down into those along the margin. They are great clefts in the tuff which forms the floor of the Valley. These narrow chasms are sometimes Io feet wide at the surface, and extend to bottomless depths, like the crevasses of a glacier.
For the most of their courses, however, the fissures do not gape open. but are closed over by curious bridges of stratified ash which have been stretched across in some manner. These arched spans usually sag a little, revealing both the width and direction of the tunnel beneath. But they are remarkably strong, considering how much they resemble the proverbial rope of sand, and even when only a few inches in thickness will support the weight of a large party.

IVe soon learned to cross and recross such places indifferently, notwithstanding the proximity of superheated steam in the cavern beneath. It was indeed the steam below that made the bridge safe, for its incrustations partially cemented the grains of ash together. After a soaking rain, however, they sometimes broke down.

One such care-in occurred on the bridge which we used continually in going down to our cookstove. When we came out the morning after a heary storm we found our path broken by a yawning chasm 20 feet long and half as wide, from which issued a new and impressive fumarole.

Most of the great fumaroles that fringe the edge of the Valley emerge from just such openings. Since the whole fissure for a long distance is full of steam under pressure, it is evident that any hole that is broken through will become the seat of a new fumarole. Variation in the number and appearance of these fumaroles does not imply, therefore, any change more fundamental than the mere opening of new orifices at the surface.

From some of the less active of these fissures the vapor lazily rises in diffuse clouds. From others it comes pouring forth in great rolling, expanding columns, reaching many hundred feet aloft or drifting off before the wind for a mile or more.

In other places, where a narrow crevice is the only opening from a large cavern, the steam may come out under pressure, emitting a low hissing or roaring sound. 


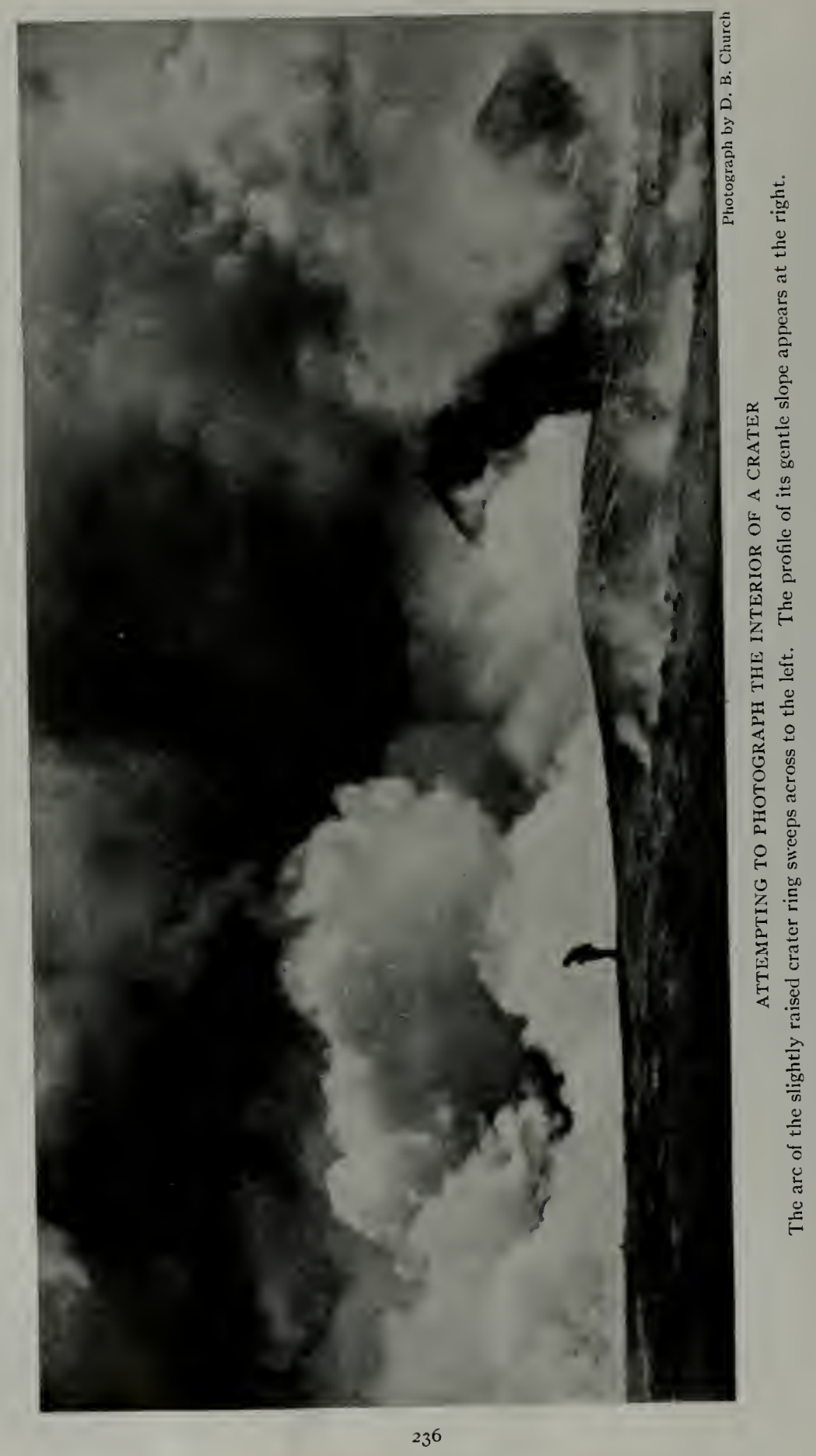


If one tosses pebbles into such rents, they are buoyed up by the rising steam and are either immediatcly spewed out, or sink slowly down, like feathers settling to earth. It was at such a rent that we fried our bacon, as described in Chapter xvII.

\section{DOMED FUMAROLES}

Some of the largest and most conspicuous of the fumaroles come, not from fissures, but from isolated elevations in the flat Valley, which may perhaps be best described as low domes. These appear to have been upheaved after the general level of the Valley floor had been fixed. They are confined to the lower half of the Valley, and are especially well developed at the junction of the two arms of the $\mathbf{Y}$.

The height of these domes is perhaps 5o feet and their diameter several hundred yards, but the slopes are so gentle that no definite boundary line can be drawn around them. The principal fumarole comes from a hole in the summit, whence cracks radiate in different directions. Surrounding the main vent are numerous satellites of lower temperature, which are interpreted as radial leaks from the central conduit.

The domes give off tremendous quantities of steam, making some of them the most conspicuous objects in the Valley. Sometimes the gigantic column of "No. 32," the biggest of all, rises vertically high in air, when all its lesser neighbors are held by the breeze close to earth.

\section{CRATERS}

The fissure fumaroles give no evidence of ever having been the seat of any sort of activity other than the present quiet evolution of vapor, but there is another class of craters which, though now steaming quietly or extinct, were evidently at one time explosive.

These vents have blown great funnelform pits in the floor of the Valley (see page 292). Around the edge the ground is commonly raised several feet above the general level by débris thrown out of the hole. The ejected material, for the most part, consists of small fragments, but occasionally includes lava blocks up to three feet in diameter.

Some of these cratcrs stand apart without evident relation to other vents, but by far the larger numbers occur in two regions: there are a score or more of them, mostly extinct, near the outside edge of the west arm of the $Y^{\top}$ under Buttress Mountain; in the north arm of the Valley, under Knife Peak, they are easily the dominant feature.

In these tracts they often stand close together with intersecting edges, forming compound craters. In a number of instances they are so numerous and thickset as to have coalesced into veritable nests of craters.

Two such nests in the north arm, now extinct and filled with smooth floors of inwashed pumice, are perhaps half a mile long and half as wide. Throughout each of these areas the floor of the Valley was blown out completely, giving somewhat the impression of a single, gigantic explosion crater. But the crenate margin, made up of the arcs of the individual craters, testifies to its composite character.

In other cases the craters stretch out in long lines, their position evidently determined by the presence of a deepseated fissure in the Valley floor. In a few instances where explosive action has built up mounds around points of special activity, the chain of miniature volcanoes stretching along the fissure furnishes a diagrammatic model of the conditions believed to underlie the great lines of volcanoes that girdle the earth (see page 292).

\section{STEAMING MUD AREAS}

In most of the fumaroles the vapors find exit through some evident break in the surface of the Valley floor; yet there is a large number where the escaping gases have no manifest outlet, but seep through the surface in innumerable minute hissing jets. The diffuse activ- 


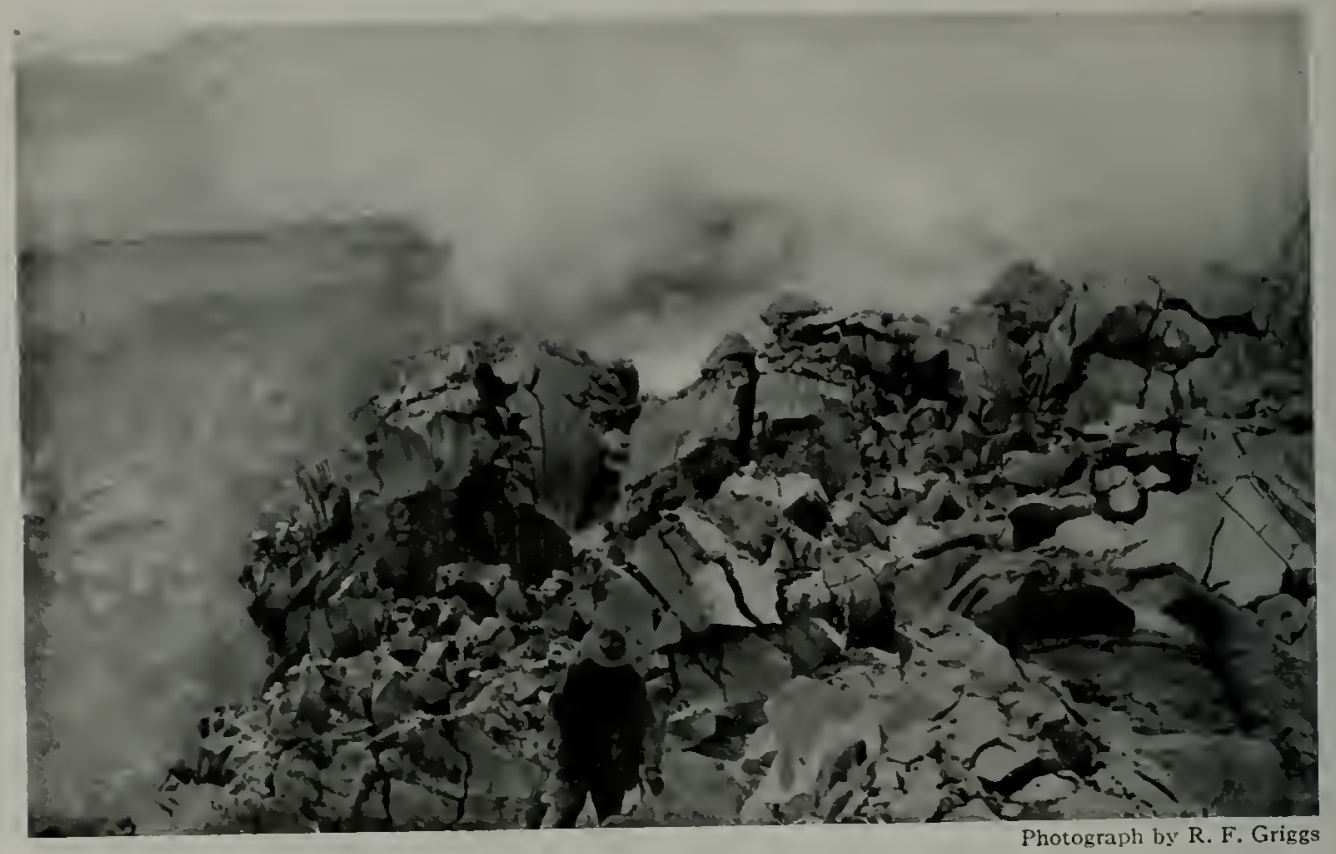

THE TOP OF THE LATA PLUG OF NOVARUPTA

Where the rock is in place in the center of the picture, the parallel concentric banded structure is evident.

ity of these steaming mud areas often covers an acre or more.

Throughout the area covered by the "mud hissers" the ground is every where full of steam, sometimes under pressure, ready to escape through any new orifice which may be broken through the surface. The surface itself is generally covered with a crust of some strength, stained a rusty brown by iron oxide.

But beneath, the vapors (which are never of a high temperature) commonly keep the ground in the condition of soft wet mud, having the appearance and consistency of steaming hot asphalt, as one sees it applied to a street in process of being paved. The illusion is heightened by the curious "organic" odors that are often liberated when the mud is stirred up, but the chemists tell us that the blackness is here due to iron sulphide.

\section{STEAM RISING THROUGH UNDISTURBED SANDSTONE STRATA}

One of the most conspicuous features of the Valley is the strictness with which the activity is confined to the Valley floor. All the big fumaroles come forth below the "ligh water mark" which is the boundary of the Valley, as described in the next chapter.

Careful examination showed, however, that there were some exceptions to this general rule of distribution. Steam was seen coming from a number of places on the slopes of the mountains which rise above the Valley basin.

Upon examination of a number of these high-level fumaroles, it was found that the steam rose directly through the sandstone strata of which the mountains are composed. In some cases the surface was covered with a mantle of fragments which obscured the relations somewhat, but in others it could be seen with the utmost clearness that the steam came dircctly out of crevices in the undisturbed sandstone strata.

By far the greatest number of the fumaroles coming from the sandstone occurred on Baked and Broken Mountains, though they were not confined to this 
locality, similar small steamers being found across the Valley at the base of Buttress Mountain. At the foot of the Valley, also, in the vicinity of "Three Forks" (the junction of Knife Creek, Lethe, and Windy Creek), we found places in the underlying sandstone which, though no longer active, had evidently once been the seat of fumaroles.

To a thoughtful observer these fumaroles, despite their diminutive size, are extremely interesting, for it is hardly necessary to state that they could not originate in the sandstone rocks from which they emerge. Neither could such activity be due to the gradual cooling down of a great mass of material thrown out by the recent eruption, as, conceivably, might some of the fumaroles of the Valley floor, which undeniably rise through a great mass of ejecta from the eruption. The only possible source of these fumaroles is a mass of magma intruded beneath the sandstone.

\section{HOT SPRINGS}

Hot springs, mud pots, geysers, and the like are such familiar phenomena in most regions where volcanic activities are spread out over wide areas that we naturally looked for them in the Valley of Ten Thousand Smokes.

As for hot springs, nothing of the sort was found in 1917 . The minimum temperature observed was the boiling point, so that all water appeared as vapor.

In 19I8 Sayre and Hagelbarger found a bathing pool at Three Forks, provided "with hot and cold water, as a white man's bathtubshould be." A considerable stream of water $\left(95^{\circ} \mathrm{C}\right.$.) poured in to the cold creek in such fashion that one could obtain any temperature desired simply by moving from one side of the pool to the other. The next year there were a number of such hot springs in the lower end of the Valley, in areas known to have had only fumaroles in 1917.

Among the most interesting of them were numerous hot spots which we discovered in 19 I9 in the bed of Ukak River, while fording at the foot of the Valley across ground formerly occupied by the sand flow which came down during the eruption (see Chapter XIX).

So much hot water was poured into the river at this point that, although it is a considerable stream of swift water, it was distinctly warm to the touch across a good share of the channel.

In this connection it is worth noting that, according to trappers, Iliuk arm of Naknek Lake did not freeze over until January 20 , in the winter of $1918-$ I9I9, a circumstance which suggests that the total amount of heat delivered by the inflowing streams may be very large.

The chemists brought back some samples of the water of these recently formed hot springs, but it has not yet been determined whether they represent merely the heating of surface waters by contact with the hot ground or are of deep-seated origin, like some long-established hot springs.

\section{MUD POTS}

True mud pots of long-continued activity, which are so characteristic of the Yellowstone and similar places, have not been found in the Valley. But occasionally a sort of ephemeral mud volcano develops, which for the time furnishes a counterpart.

After one of the heavy rains common in the summer months, streams of water run freely over the hot surface of the Valley. Naturally such water often finds its way into the basins of some of the little fumaroles, which, choked off from their usual method of escape, boil and bubble up through the water, quickly stirring up a thick soupy mud which sputters and splashes with miniature explosions until the rain water is boiled away, and the erstwhile mud pot becomes a steamer again.

Since it is the continuous disturbance of the sputtering mud that gives them their character, these mud pots make but poor "still" pictures (see page 284). In the motion pictures they are very interesting objects. 
One other type of vent requires mention. These, from their excrescent appearance, are what the boys have called "pimples" (see page 294). They are confined to the lower half of the Valley, where dust storms are frequent. Their formation appears to be due to the moisture which condenses around small vents so as to catch and hold the blowing sand, that is later cemented into place. The process is repeated again and again until a mound several feet in diameter is built up over the vent.

These little fumaroles are so smothered by their covering that they usually appear dead, but whenever we dug into them we found them hot, proving that the apparent lack of activity was due largely to the covering of sand which clogged the orifice and stopped visible exhalations.

\section{THE NEIV VOLCANO, NOVARUPTA}

There is only one place in the Valley where the underlying magma from which the Smokes take their origin has come through to the surface in such a way that its connection with the present activity can be.observed. This is in the throat of Novarupta, a new volcano of typical form and character which has arisen in the floor of the Valley between Broken Mountain and Trident.

Here, surrounded by a crater ring 0.8 mile $(1.25 \mathrm{~km}$.) in diameter, evidently formed by ejected materials, is a "dome" of lava 800 feet in diameter and 200 feet high that was pushed up through the throat of the volcano in a stiff, viscous condition (see pages 280 and 300 ).

The lava of the plug is a rhyolite whose predominant color is a light gray. Superficially it appears to be solid nuassive rock, but on close examination it is seen to be all blown full of minute bubbles which, under a lens, give it a very loose spongy texture.

In the process of cooling, this viscous lava naturally developed strains which shattered the upper portion into a confusion of broken blocks, heaped topsyturvy over the surface, concealing for the most part the bedrock and giving the lava plug the appearance of a huge stone pile (see page 238 ).

These great bowlders, standing in the most precarious attitudes of unstable equilibrium, would make the top of the lava plug one of the most dangerous places in the whole region, even if there were no stifling vapors to interfere with one's movements.

Many times, as Fenner and I walked over it on the day we examined it together, we found great blocks, weighing tons, balanced so nicely that they rocked back and forth under our feet. There was imminent danger of tumbling them down on ourselves.

Once, a pile of rocks on which I was standing suddenly crumbled, and when it came to rest again $I$ found myself dropped down several feet. But as I was on top of the moving bowlders, I was in small danger of being caught beneath them.

In spite of the unstable rocks we managed to examine nearly the whole of the plug, and that without very great difficulty; but an hour later, as we looked down on it from above (see page 280 ), it seemed altogether beyond the bounds of possibility for anyone to pick his way through the thick clouds that rose everywhere from among the loose rocks.

As we looked, we wondered whether we had been specially favored by atmospheric conditions at the time of our ascent, or whether the plug was really easier than it looked from a distance.

Like most of the ejecta of the recent eruption, the lava of the dome is not pure rhyolite, but contains a considerable admixture of basic andesite, like that composing the old volcanoes, as well as a small quantity of fragnients of the surrounding sedimentary rocks.

These foreign inclusions, which show clear evidence of having been partially digested by the new nagma, are arranged in striking dark bands, alternating with the lighter rlyyolite. Where the rock of the dome can be secn in place, it becomes evident that the bands are con- 


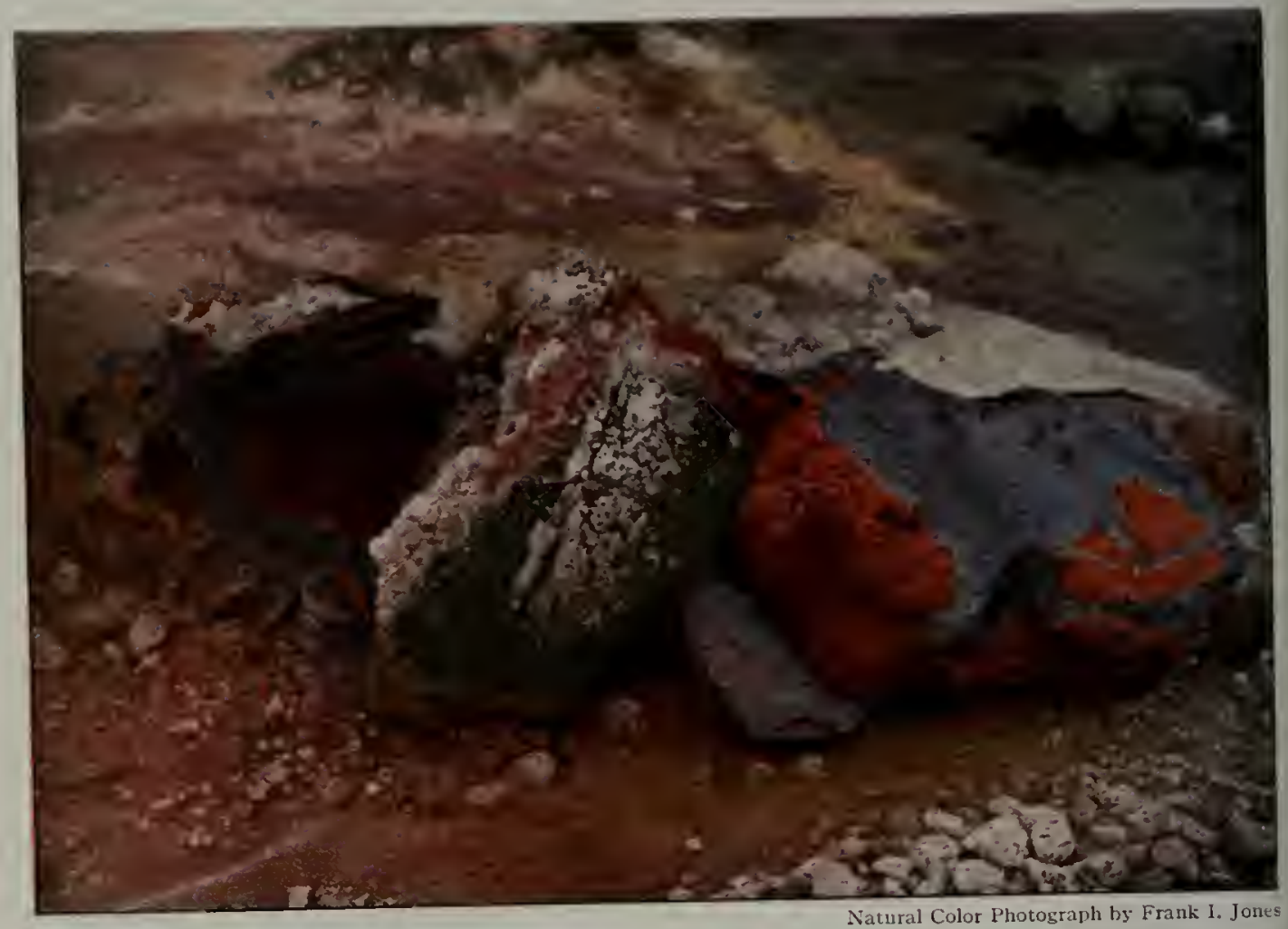

THE GAUDY MUDS OF THE VALLEY MAKE GOOD PIGMENTS FOR A PAINTER With no other materials, very creditable pictures have been painted. 
centric, running tangentially, parallel with the circumference of the lava plug, thus affording some indication of the manner of action of the forces of extrusion (see page 238).

The blocks of lava were evidently broken apart before they had entirely solidified; their surfaces frequently show evidence of flowage after breaking up. This is especially striking where the banded structure is well marked, for there it is erident that the rhyolite was more fluid than the andesite.

In many places the bands of rhyolite stand out beyond the alternating inclusions, giving the blocks a fluted appearance. When this is developed at the corner of a block, a striking cornice structure results (see page 296).

The greater fluidity of the rhyolite is both surprising and significant, since its melting point is undoubtedly higher than that of the andesitic inclusions. The explanation of the anomaly lies, I believe, in the fact that the andesite in the dark bands was "dead" lava in process of digestion by the new "live" magma - a matter whose interpretation is discussed in some detail in Chapter xxII.

\section{FALLING MOUNTAIN}

While the attention of the visitor who comes into that vicinity for the first time is certain to be absorbed by the sight of Novarupta, he could not gaze long upon its steaming lava plug without interruption.

Within a few minutes he would be startled by a crash behind him and, turning, would see an avalanche of falling stones, which had started high up on the face of the mountain side, galloping down the precipitous slope toward him.

Whenever it has been under observation, ever since its discovery in 1916 , this rock face, which we named Falling Mountain, has been subject to frequent avalanches. The constancy of their occurrence is one of the most impressive features of the Valley.

The falls of rock vary in size all the way from single bowlders up to large masses weighing many tons, which let go with a crash distinctly audible for miles around. During the first two seasons, a five-minute period never passed without a fall of some sort, but in 1919 the mountain was often quiet for half an hour at a time.

\section{FALLING MOUNTAIN AS A FOG SIGNAL}

The first time we heard it in 1919 was memorable. "Bill" Henning and I had started for Katmai Pass in a fog, from a camp pitcherl in the valley between Baked and Broken mountains. Neither had ever been over the ground before, and the fog was so thick that we could not see 20 yards.

We took a compass-bearing from the camp and started out over "Greased Hill," which connects Baked and Broken mountains. As usually happens in a fog, the land took on an unexpected aspect before we reached the divide, and we soon became uncertain of our direction and suspicious of our compass.

When we started down the far slope, we ran into a series of hot steaming fissures directly athwart our course. In reality, they were not very deep but in the dense fog we could not see the bottom. The slippery, variegated muds reeking with steam made progress both difficult and uncertain. It seemed that we were in danger of sliding straight in to "the bottomless pit."

IVe had traveled thus, working our way among the fissures for what seemed a long time, when suddenly, out of the distance, a great booming rock fall let go on the slopes of Falling Mountain, confirming us in our course and setting us at ease once more.

\section{CATACLYSM BEGAN WITH A GREAT SLIDE FRON FALLING MOUNTAIN}

Examination shows that Falling Mountain is a counterpart of Noisy Mountain, discovered later (see page I27), and of the cliff from which the Mageik Landslide originated (see Chapter xI). It is obvious from a glance at the great gouged-out face of the mountain that an 


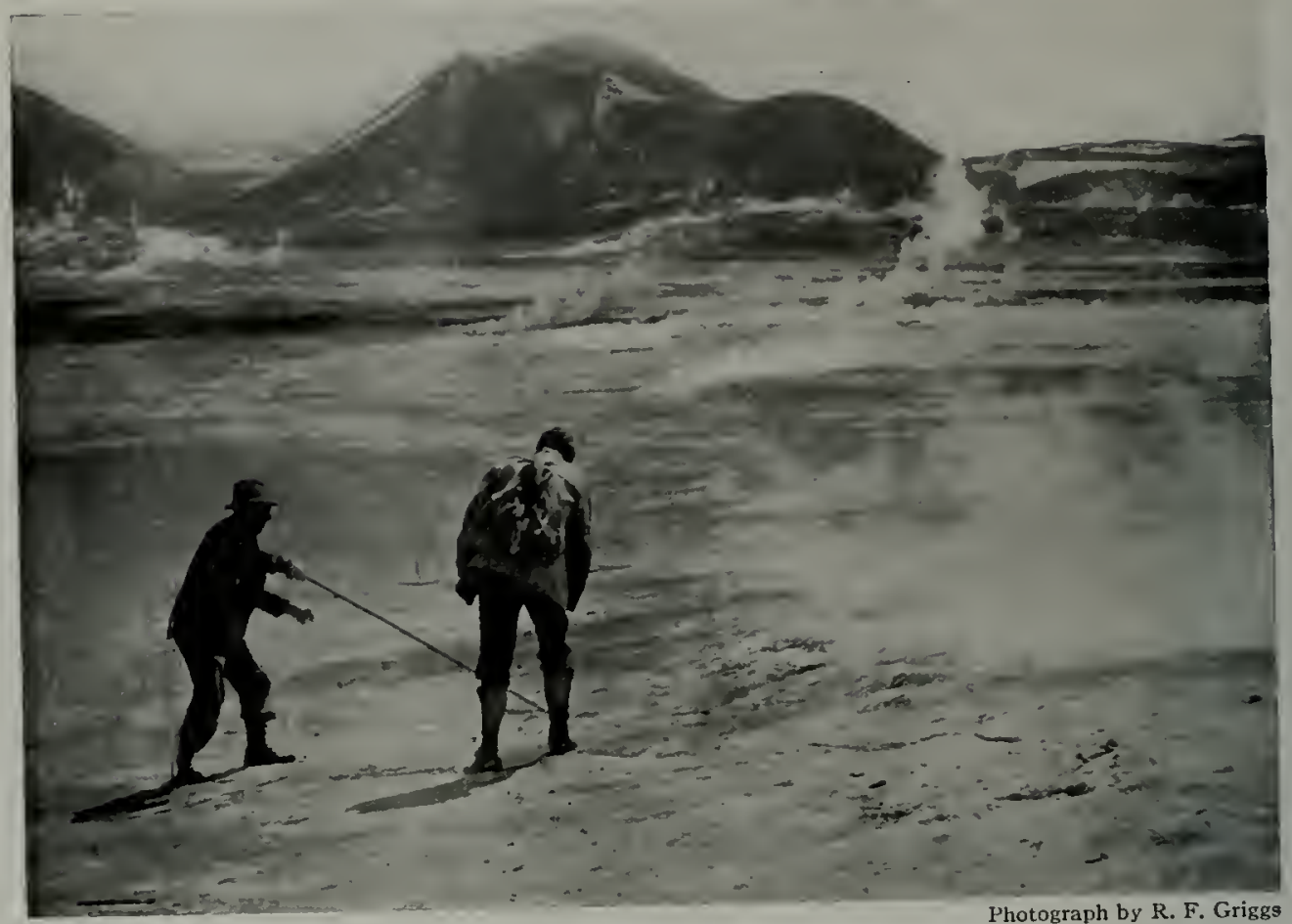

TAKING THE TEMPERATURE OF A HOT ONE

Many of the vents were far beyond the range of the thermometers we carried the first year. Compare the picture on the opposite page.

enormous mass of rock has fallen away recently - a mass quite comparable with the Mageik Slide or with the Noisy Mountain Slide.

But, although the broken cliffs give the clearest evidence that such a slide occurred, one looks about in vain for the débris. Nothing but a few rock concs are to be seen on the smooth-floored Valley. It is as though the whole side of the mountain had not only fallen from its place, but had been swallowed up into the bowcls of the earth.

In a sense that is exactly what has happened, for we can only conclude that the slide débris is so deeply buried under the ejecta of the eruption that the former irregularities of its surface have been entirely concealed. In other words, this slide must have occurred before the outpouring of the ejecta. It is thus the first event in the recent volcanic disturbance of which we have record.
As one watches the frequent rockfalls which come bounding down the face of the mountain, he gains, as perhaps is possible in no other way, some realization of the magnitude of the great mass of material that fell in the early slides. For while the present avalanches often involve the fall of an impressive mass of rock, the accumulated pile of fragments at the foot of the mountain has not grown appreciably in the four years since its discovery. It is now, as then, utterly insignificant in comparison with the total volume of the material that must have fallen away.

\section{FUMAROLE ACTION ON FALLING MIOUNTAIN}

In addition to its frequent avalanches, Falling Mountain possesses another feature of considerable interest. Far up on its bare rock surfaces are a number of small fumaroles, the highest vents in the region (except the craters of the old vol- 


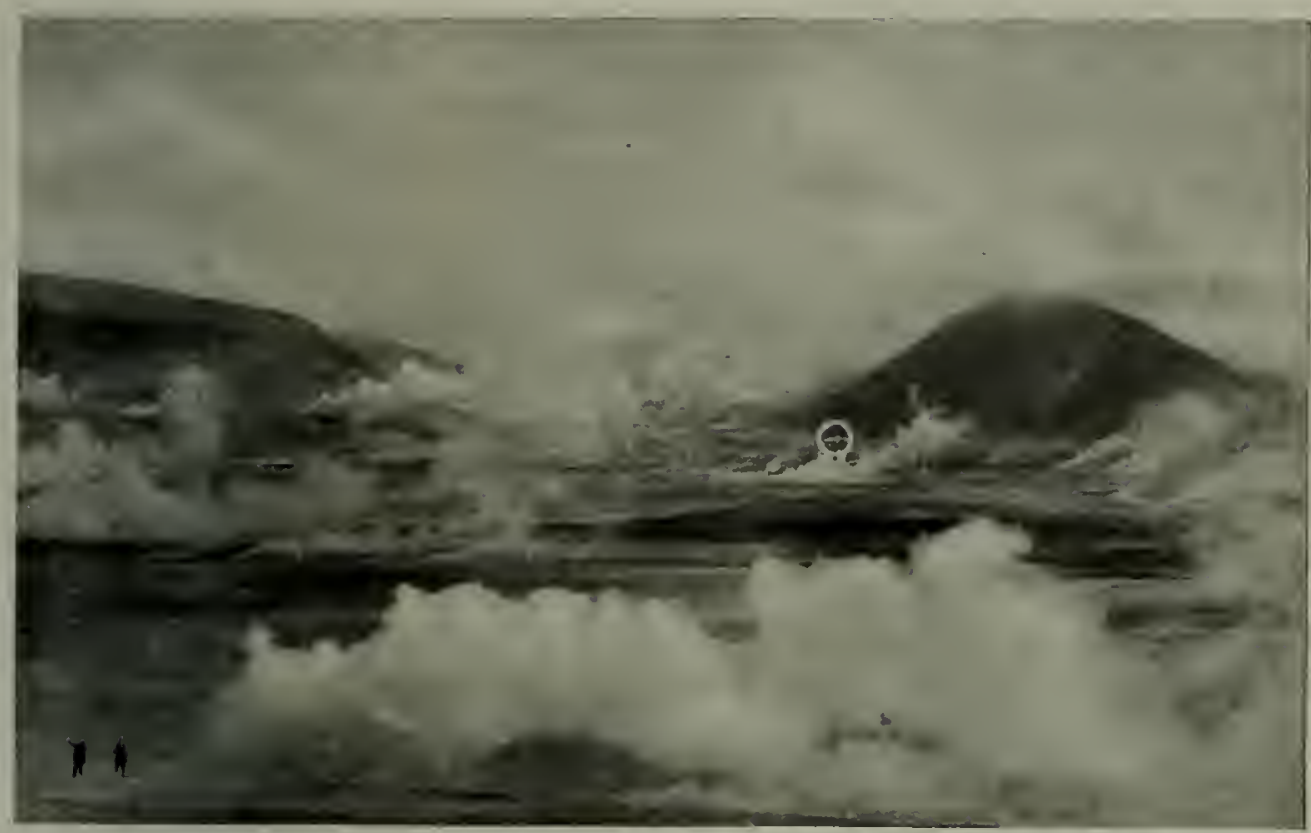

THE SAME VENT FROM A LITTLE DISTANCE

Photograph by R. F. Griggs

The steam is so hot that it does not condense until ten feet from the vent. The scale may be judged from the little steamer enclosed by the circle which was our cookstove (see page 196).

canoes) through which the subterranean gases reach the surface.

The petrological studies made by Fenner show that the gases from these, comparatively small though they are, have wrought notable changes in the andesitic rock through which they have come, apparently reacting with the constituent minerals in such a way as to form volatile compounds, "so that quantities of material have actually been removed by gaseous transfer." 1

Many of the pyroxene crystals have been replaced by aggregates of hematite scales, while tridymite was abundantly formed. As a result of this action, the rock has lost much of its cohesive strength, which fact may have some bearing on the continuance of rock falls.

\section{BAKED AND BROKEN IIOUNTAINS}

One of the most significant indications of the character of the subterranean disturbances at the time of the eruption is the present condition of Baked and
Broken mountains, which occupy the central space between the arms of the $Y$-shaped Valley, entirely surrounded by active vents. These mountains, which rise I,500 to 2,000 feet above the Valley floor, are, like the Valley itself, not volcanic, but carved out of horizontal sandstone strata.

Their mass is now criss-crossed by wide gaping fissures, accompanied by faults whose individual displacement is as great as 50 feet. These fault scarps show the deepest deposits of ash and pumice found anywhere in the district. In the sections here exposed, 50 feet of stratified ash may be seen.

The scarps do not, however, cut through to the original surface, so there is no means of telling how much greater the total thickness of the ashfall may have been (see page 244).

Where the slopes of these mountains are so steep that the ash has slid off and exposed the rocks beneath, they show a curious change wrought by the erup-

${ }^{2}$ C. N. Fenner, Journal of Geology, vol. 27, p. 586, 1920. 


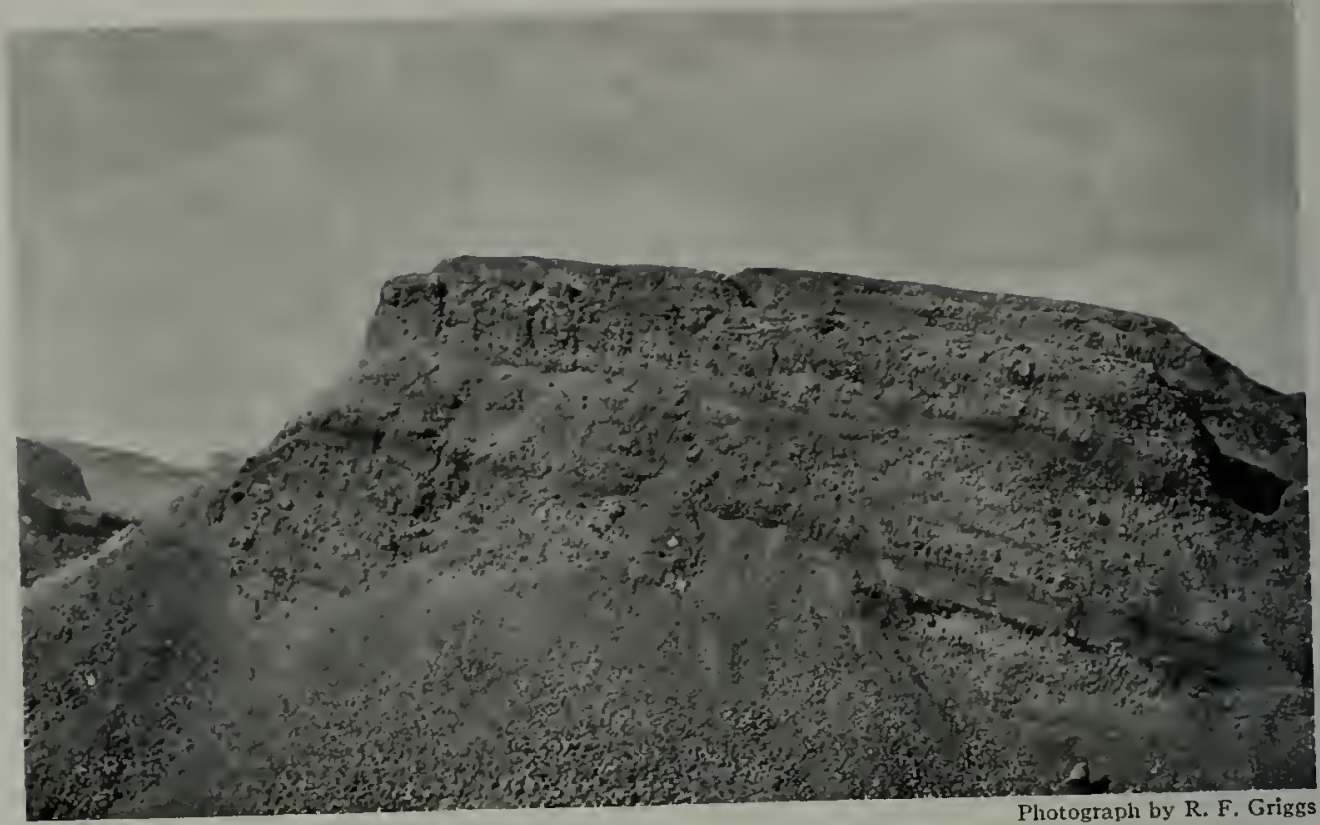

A FAULT SCARP ON BROKEN MOUNTAIN

The face of the scarp is composed of stratified ash mostly from Novarupta. The sequence of the ash strata show's that Novarupta burst forth before the explosion of Katmai, but this faulting occurred after the eruption.

tion, their gray-green sandstone having been turned a dull brick-red. The chemical change that took place is exactly the same as that which occurs when clay blocks are burned to red brick. But it is not certain that heat was the only agency at work in the coloration of Baked Mountain. Some of these cliffs are so extensive and conspicuous that their character may be seen from more than a mile away.

\section{FISSURE LAKE}

Near the foot of the glaciers that wind down from Mageik occurs the largest fissure to be found anywhere in the Valley. It is 200 to 400 feet wide, with perpendicular walls, one of which stands about 35 feet higher than the other. The depth could not be ascertained, because it was filled by a beautiful lake of clear, green water.

Standing just at the foot of the glaciers, Fissure Lake when first seen was one of the most picturesque spots in the whole
Valley. Along the sides were numerous snowdrifts, from which miniature bergs broke off and floated away (see page 212).

Unfortunately, the proximity to the glacier which gave the place its greatest beauty will result in its early extinction. The lake of necessity receives a large amount of glacial débris, and will be filled up in the course of a few years. A large delta had, indeed, been built out into it in 1919, considerably impairing its charm.

\section{WARM WATER FROM SNOWDRIFTS}

Fed by the glaciers and melting snows, Fissure Lake would be expected to be icy cold, but on the contrary it was decidedly tepid in spots, where heat was evidently received from below. One of the most amusing incidents of the whole work occurred when Shipley, the chemist, poking his thermometer into everything, discovered this fact.

I was coming along a little behind and 


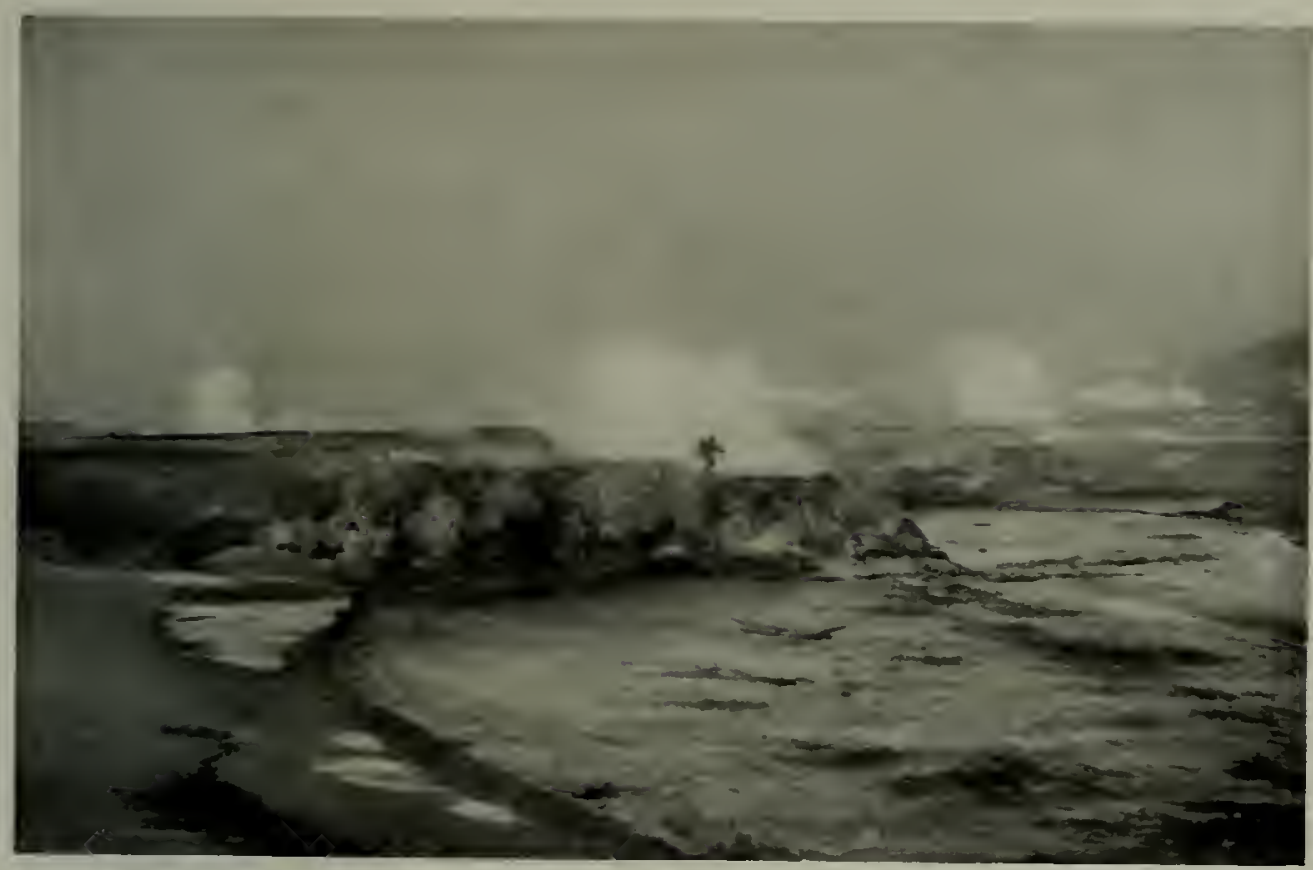

Photograph by R. F. Griggs

THE RIVER LETHE CROSSING A LINE OF FUMAROLES

The steam in places actually bubbles up through the cold water. The volcanoes and the surface drainage manifestly have no connection with each other.

he, pretending to need my assistance, asked me to tell him the temperature of the water coming out from under the edge of a snow field. Willing to answer even a foolish question, I had the words "ice cold" on the tip of my tongue when my fingers touched the water. The speaking expression froze on my face and I carefully dipped my hand in again. It was actually warm! How he did laugh at my discomfiture!

DRANIAGE WATER VEARLY ALL VAPORIZED IN THE HOT VALLEY

The snow fields which surround the Valley send trickling rills down its slopes, but these disappear long before the floor of its basin is reached.

Even the streams from the half dozen good-sized glaciers which discharge into the Valley were able to hold their courses clear across the hot area only during the warmest months, when the melt is greatest, and then in such reduced rol- umes that they were of ten scarcely more than muddy trickles at the lower end.

But in early June, when we first entered the Valley in 1919, the bed of the River Lethe, half way up the Valler; was one mass of hissing fumaroles, without a sign of the muddy torrent which coursed across the hot ground a month later.

It was rery striking, and at first sight surprising, to see how little the direction of the waters was affected by the fumaroles. As in ordinary streams, their courses were controlled by gravity, regardless of the position of the fumaroles which they often approached closely or even overran. IThen this happened the waters quickly washed in a thick deposit of ash, effectually blanketing the fumarole, whose vapors probably found a means of escape through some other outlet.

In some places, however, we found the steam still bubbling up through the cold water. But the waters of the river 
passed the hot spots quickly and were only slightly heated by their close contact with very large hot areas. We found that the River Lethe was still $48^{\circ} \mathrm{F}$, although the ash of its banks stood above the boiling point.

On the other hand there is no clear evidence that the steam of the fumaroles is sensibly increased by the addition of surface water, for, as observed on page 219, it does not appear to fluctuate with the seasonal variations in drainage.

\section{A BEWILDERING COMPLEX OF ODORS}

The mingling of the many substances rising through the vents results in an extremely curious combination of odors, which Dr. Shipley, with the trained nose of a chemist, thus describes:

"As we entered the Valley along a deep, dry watercourse, we observed from time to time a peculiar, indefinable and not unpleasant odor. Passing close to the active vents, the odors of hydrochloric acid and hydrogen sulphide could be detected easily. From certain of the active areas a disagreeable smell, unlike any odor that we had ever encountered, arose. It was somewhat suggestive of a pigsty, a horse stable, and sewer gas, yet we could not relate it definitely to any previously observed smell.

"Whatever the gases are, that rise from the vents in the floor of this wonderful Valley, collectively they offer a considerable task to the olfactory organs in differentiating the known from the

2 The statements herein are summarized from the following papers by the chemists:

Shipley, J. W. Some Chemical Observations on the Volcanic Emanations and Incrustations in the Valley of 10,000 Smokes, Katmai, Alaska. Am. Jour. Sci., vol. 50, pp. 141-153, 1920.

- The Nitrogen Content of Volcanic Ash in the Katmai Eruption of 1912. Ohio Journal of Science, vol. 19, pp. 213-223, 1919.

-The Water-Soluble Salt Content, the

Ferrous Iron Content and the Acidity of Katmai Volcanic Ash. Ibid., pp. 224-229.

Ammonia and Nitrous Nitrogen in

the Rainwater of Southwestern Alaska. Ibid., pp. $230-234$.

Allen, E. T. Chemical Aspects of Volcanism unknown. At a distance of 20 miles from the Valley, one was certain one moment that the gas was sulphur dioxide which the wind bore to him, the next moment it was hydrogen sulphide, and the next both or neither.

"This same elusive uncertainty clung throughout the whole period of our stay in the Valley. It was only in the vicinity of a vent that the individual gases could be identified with certainty by the sense of smell."

\section{THE CHEMISTRY OF THE FUMAROLES}

A thorough chemical study of the fumaroles would undoubtedly greatly assist in the interpretation of the dynamics of the volcanoes. The difficulties in the way of such a study are so great, however, that as yet only a good beginning has been made. ${ }^{2}$

Steam is the predominant constituent in all the gases examined, whatever the temperature. In the samples collected by Allen and Zies it varied from 98.4 to 99.99 per cent by volume. The most important remaining gases are hydrochloric acid, carbon dioxide, hydrogen sulphide, nitrogen, hydrofluoric acid, and sometimes marsh gas. Minor constituents are oxygen, carbon monoxide, argon, and ammonia.

Although part of the steam is undoubtedly derived from the vaporization of surface drainage, as stated above, much of it must be truly volcanic in origin $^{3}$ (see also Chapter Xvir).

The ammonia comes up largely in the

with a Collection of the Analyses of Volcanic Gases. Journal, Franklin Institute, vol. 193, pp. 29-80, 1922.

3 Allen and Zies have shown that the remaining volcanic gases by themselves could not possibly be hot enough to vaporize surface water in the quantities that issue from the fumaroles.

There is in this region no relation between the temperature of a vent and the composition of its gases. Deville's generalization that there is a progressive increase in the percentage of steam and of carbon dioxide with declining activity and falling temperature finds no support here. Nor is therc any simple system of temperature distribution, except, as would naturally be expected, that high temperature vents do not 
form of the chloride, sal ammoniac, which may sometimes be gathered in masses as pure and white as when purchased in a drug store. (One sample analyzed was 98 per cent pure.)

\section{AN UNPARALLELED PERCENTAGE OF FLUORINE}

The most surprising chemical discovery was the abundance of fluorine. The hydrofluoric acid in the fumes attacked the collecting apparatus, etching it until it looked as though made of ground glass. Even one of the vacuum tubes was attacked in the same fashion, the relatively minute quantity of gas it contained having enough hydrofluoric acid to destroy the polished inside surface.

The majority of the incrustations were found on analysis to contain fluorine. In one soft deliquescent orange deposit Shipley found 7 per cent of it. Such high percentages of fluorine have never been reported previously.

Sulphur is, of course, abundant. It occurs most frequently in small veinscracks in the mud which have been filled up. Rarely such veins reach a thickness of six inches. The throats of many fumaroles are lined with the most beautiful delicate needle-like outgrowths of sulphur crystals, appropriately named flowers of sulphur.

In 1917 we found one large deposit where sulphur crystals could have been gathered by the bushel, but by I9I9 it had disappeared. Sulphuric acid, which is troublesome in many volcanic areas, is uncommon in the Valley, but Shipley found one fumarole in which it reached a high concentration.

Arsenic was discovered associated with sulphur as an incrustation over several of the fumarole cracks. The mass consisted of yellow crystals of orpiment "King's Yellow" (arsenic trisulphide $\mathrm{As}_{2} \mathrm{~S}_{3}$ ) - with some red crystals which may have been the other sulphide of

occur around the edges. In other words the Valley does not conform with the central type of rolcano, where the climax of activity occurs in the main crater and its intensity decreases stead- arsenic, realgar $\left(\mathrm{As}_{2} \mathrm{~S}_{2}\right)$. These deposits analyzed I 9 per cent arsenic.

Corundum, aluminum oxide $\left(\mathrm{Al}_{2} \mathrm{O}_{3}\right)$, which in impure form is used as emery, was found as small crystals in several of the incrustations.

Potassium alum was perhaps the most conspicuous incrustation, forming striking lichen-like deposits in all the active areas. These lichenoid growths would become very conspicuous after a few hours of good weather, only to disappear when the rain began again (see color plate).

Iron is one of the most abundant elements in the Valley, and is largely responsible for its beautiful coloring. Welldeveloped crystals of pyrite $\left(\mathrm{FeS}_{2}\right)$ were found in several places. In other situations the mud had the lustre of fool's gold, presumably imparted by myriads of tiny crystals of pyrite.

Considerable deposits of "venetian red" $\left(\mathrm{Fe}_{2} \mathrm{O}_{3}\right)$ were forming in one gully examined by Shipley. In another fumarole discovered by Zies a quantity of good-sized black crystals of magnetic iron ore $\left(\mathrm{Fe}_{3} \mathrm{O}_{4}\right)$ had been deposited, sublimed by the hot vapors.

\section{PETROLEUM-LIKE EMANATIONS}

Another remarkable and puzzling association of products was found by both Shipley and the geophysicists in the vicinity of Novarupta. The gases here contain considerable amounts of marsh gas $\left(\mathrm{CH}_{4}\right)$, amounting in one case to 12 per cent of the total gases aside from steam.

The interest of this finding is that marsh gas, which is a principal constituent of natural gas, is generally assumed to be of organic origin. Its significance here is increased by the occurrence of other products, discussed by Shipley as follows:

"A most interesting organic deposit resembling coal tar in odor and appearance was observed saturating the ash around fumaroles on the western slope of

ily with the distance from that point. The wide distribution of activity here indicates rather the close approach of the magma to the surface over a large area. 


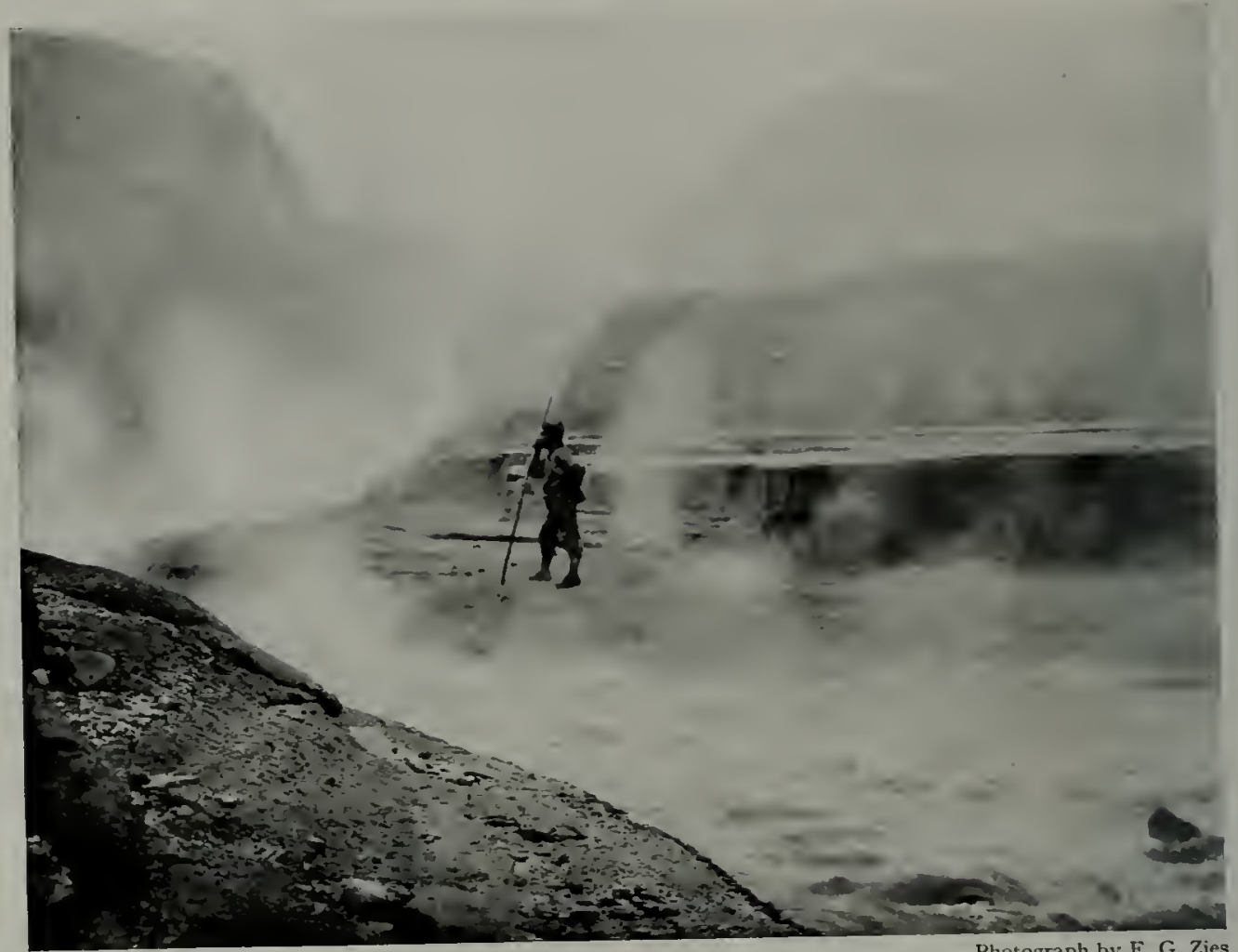

STEAM RISING FROM HOT SPRINGS IN THE LOWER EXD OF THE VALLEY

These streams were running cold in 1917 and 1918. At that time the hot springs of 1919 were fumaroles, whose steam escaped into the air without warming the surface waters. The terraces in the background are the exact counterpart of those often found in large river valley's (see text page 153).

Novarupta volcano and in the immediate neighborhood of the $\mathrm{NH}_{4} \mathrm{Cl}$ [Ammonium chloride] fumaroles.

"One fumarole in this same area was emitting nitrous acid. The gases from fumaroles in this area possessed a similar tarry odor and emitted much $\mathrm{H}_{2} \mathrm{~S}\left[\mathrm{H}_{\mathrm{y}}-\right.$ drogen sulphide]. On analysis of the impregnated ash the deposit proved to be of a very conplex character.

"A 20-gram sample was extracted with the following solvents successively until no further extract from each was obtained. The solvents in the order used were: ether, petroleum ether, carbon disulphide, benzene, carbon tetrachloride, ethyl alcohol and glacial acetic acid. Each of the solvents extracted organic matter varying in amount from half a gram to a centigram, $\mathrm{CS}_{2}$ [Carbon bi- sulphide] and $\left(\mathrm{C}_{2} \mathrm{H}_{5}\right)_{2} \mathrm{O}$ [Ether] being the most effective. Several of the solvents extracted considerable quantities of free sulphur.

"On evaporation, a brownish-black resinous mass was left by each solvent. None of the extracts belonged to the aliphatic series; none contained nitrogen and none were unsaturated.

"Steam distillation carried over the organic matter together with the free sulphur, and the first portion of the distillate gave an unmistakable odor of naphthalene.

"The occurrence of this deposit of aromatic hyddrocarbons may have some significance in the theory of rolcanic origin for such compounds. The deposit lies close to the most active area of the district and is associated with $\mathrm{NH}_{4} \mathrm{Cl}$ 
and sulphur, while $\mathrm{H}_{2} \mathrm{~S}$ is unusually concentrated in the cscaping gases.

"On the other hand they might equally well be attributed to steam distillation from the sedimentary rocks with subsequent condensation in the ash on the surface. The Jurassic sandstones meet the igneous intrusion in the immediate neighborhood." 4

The origin and relationships of these various products are most interesting and deserve much further study. It is not possible at the present time to suggest any satisfactory explanation of those of the "organic" series.

\section{THE COLORS OF THE DEPOSITS}

The members of the expedition of 1919 , while agreeing that the published accounts described the fumaroles accurately, were unanimous in the opinion that the printed accounts had given them no idea of the colors of the deposits. The previous articles had, to be sure, stated that the ground was painted "with all the colors of the rainbow" and that the "fissures were baked bright red for miles at a stretch," but somehow it was imagined that these must be wild exaggerations rather than careful scientific statements.

No one was more impressed than Kolb, who, having lived for years on the brink of the Grand Canyon, was not oversusceptible to striking colors. Along with most people, he lad supposed that the Canyon represented the climax of nature's coloring, and had never expected to see anything more brilliant.

The coloring is, however, so altogether different in character from that of the Canyon that the two cannot properly be compared. In the Canyon it is in the distance that the color is most remarkable. In the Valley it is in the foreground.

There are no bright and sharply contrasting masses of rock in the walls of the Valley. On the contrary, the Valley itself, seen under the heary clouds which usually cover it, is apt to convey an idea of sombreness. But, when one comes up to the fumaroles, he is almost overwhelmed by the indescribable riot of color. Not so in the Grand Canyon; its rocks are ordinary enough when closely approached. I have before me two vials - one given me by the keeper of the Bright Angel Trail, containing, according to his statement, sands of all the colors of the Canyon, the other filled with mud from the Valley. The one is so ordinary as never to attract a second glance; the brilliant hues of the other arouse universal interest.

The colors of the Canyon are due almost entirely to the wonderful atmosphere and the brilliant light which floods its recesses.

Another reason why the Valley as a whole fails to show much color is that when the hues of the spectrum lie close together, they blend into neutral grays or browns. But, while largely losing their effectiveness at a distance, the colors are, for this very reason, all the more striking when seen close up, for then each is heightened by contrast with the other.

The throats of the fumaroles and the ground around them are most often burned into some of the various shades of red which are familiar in the different tints of brick in common use. Sometimes it will be a light, pinkish tone; again a bright scarlet; or, in still hotter places, a dark, rich crimson, passing into purple and black in some of the very hottest vents. With such deep-burned purple patches there is frequently associated a deliquescent incrustation of brilliant orange. These two colors are most of ten found together in fumaroles bearing a high concentration of acid which has eaten away all soluble constituents, leaving the general ground snow-white.

In some places considerable areas are thus leached to a gleaming whiteness by the acid fumes. W'hen to this are added faint tinges of pink and yellow, there results a beautiful flesh color of the greatest delicacy. Again, the ground color of red, white, or gray may be overlaid with copious deposits of yellow sulphur. 


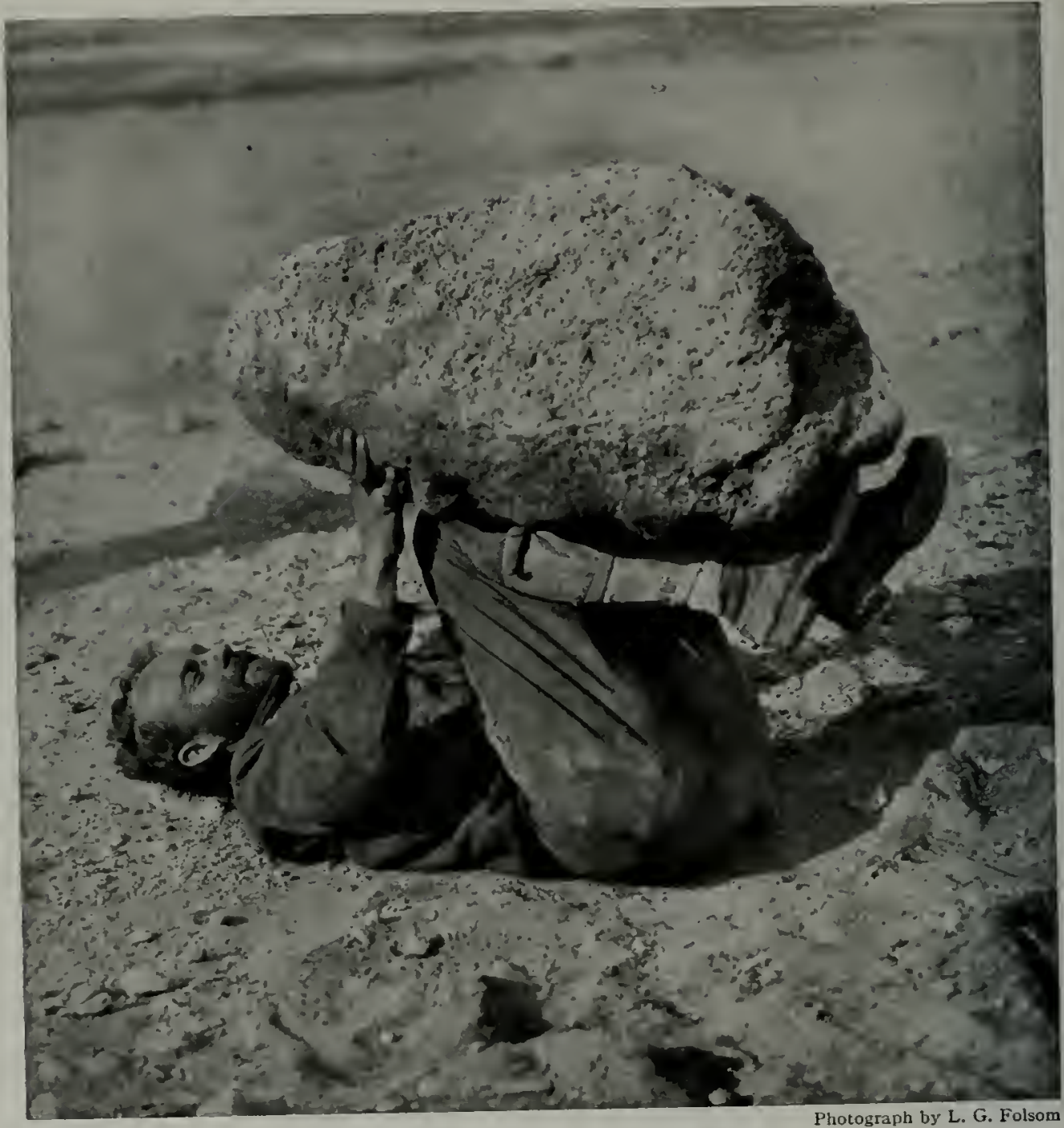

\section{KOLB IN THE KÔLE OF SAMSO:}

Photograph by L. G. Folsom

Balancing such a "rock" in the air is not so much of a feat as it appears, for the mass is a chunk of Balances by the gases of the eruption. It might even float on water. Such large pumice blown full of bubbles by the gamice are confined to the vicinity of Novarupta. All the ejecta of Katmai itself are very finely divided, because of the greater violence of its explosion.

THE TRATELER'S SHOES DAUBED WITH BRILLIANT PIGMENTS

Bright colors are by no means limited to the large and vigorous fumaroles. Over many hundreds of acres in the Valley, where steam is everywhere seeping up from beneath, the ground becomes a multicolored mud with the most brilliant colors imaginable.
Sometimes it is black, from iron sulphide, with the character and consistency of asphait. This grades through various shades of blue into delicate light pearl grays, or alternates (as the chemical conditions change from reducing to oxidizing) with the various shades of red, due to iron oxide. Round about are the more ordinary ochraceous yellows and browns. 
After a trip across such an area, one's shoes, covered with the particolored muds, take on a resemblance to an artist's palette, daubed with every possible color in a confused medley.

The fine-grained mud is indeed so sim. ilar to artist's pigments that it may readily be used as a substitute for them. With no other materials than mud from the Valley, and a piece of canvas from a ruined tent, Kolb painted several excellent pictures.

Where the ground is not too hot to prevent their growth, the patches of steaming mud are covered with a layer of bright green algae, adding the last color needed to complete the spectrum. One of the most striking color combinations in the whole Valley was produced by a green carpet of such algae in one of the great conical craters where the general rock color was a bright orangeochre.

In another place I came across a trail, made a few days previously, where the depressed tracks had served to collect a little water which had favored the growth of algae, making the tracks stand out green against the general brown surface. Occasionally a green, perhaps one of the salts of copper, is found among the mineral incrustations, but such deposits were never seen in quantity.

In other places one may find the most astonishing combinations of reds and blues and yellows by digging into the incrustations in the vicinity of a fumarole. The brilliance of the colors of such freshly exposed blocks is indeed quite beyond belief. One can simply stand and marvel at the never-ending variety of hues he uncovers, for each block is different from all the rest (see color plates).

\section{THE COLOR PHOTOGRAPHS}

To portray the gorgeous coloring by verbal description is impossible. Even pictures colored on the ground as carefully as might be would not serve. The most gaudy mixture of colors that could be daubed over the canvas would not surpass the shrieking effects presented by the impressionistic artists as their idea of the coloration of ordinary landscapes; wherefore many would doubt the accuracy of any painted pictures.

Ever since I first beheld the display of colors in the Valley I had been anxious to record them by color photographs, which should present what we had seen without the possibility of the personal equation entering in.

The problem was by no means easy of solution, for the obstacles to successful color photography, which at best are difficult to overcome, become greatly intensified in such a region as the Ten Thousand Smokes.

The plates are sensitive to adverse climatic influences and must be guarded from the hot damp ground with the most jealous care. The dust clouds frequently stirred up by the wind make it extremely difficult to keep things clean, and dust is much more serious in color photography than in ordinary black and white work. Films can be changed just before exposure, but the plates must be loaded beforehand. On a black and white picture it is easy to touch out a spot, but in the Paget process which we used any imperfections on taking-screen, plate, or viewing screen, must remain a permanent blotch on the picture.

Success in ordinary photography is dependent on one's ability to regulate two or three mechanical processes shutter-speed, diaphragm, and focus and at the same time to watch the subject and make the exposure when conditions are exactly right. But, in color work, the number of mechanical factors is increased and the demands of artistic conception on the part of the operator are far greater.

It is, therefore, a rare man who can do such work successfully in the rough-andready conditions under which we were forced to live. The results are so beautiful and preserve the natural colors with such fidelity as to reflect great credit on the artist. 


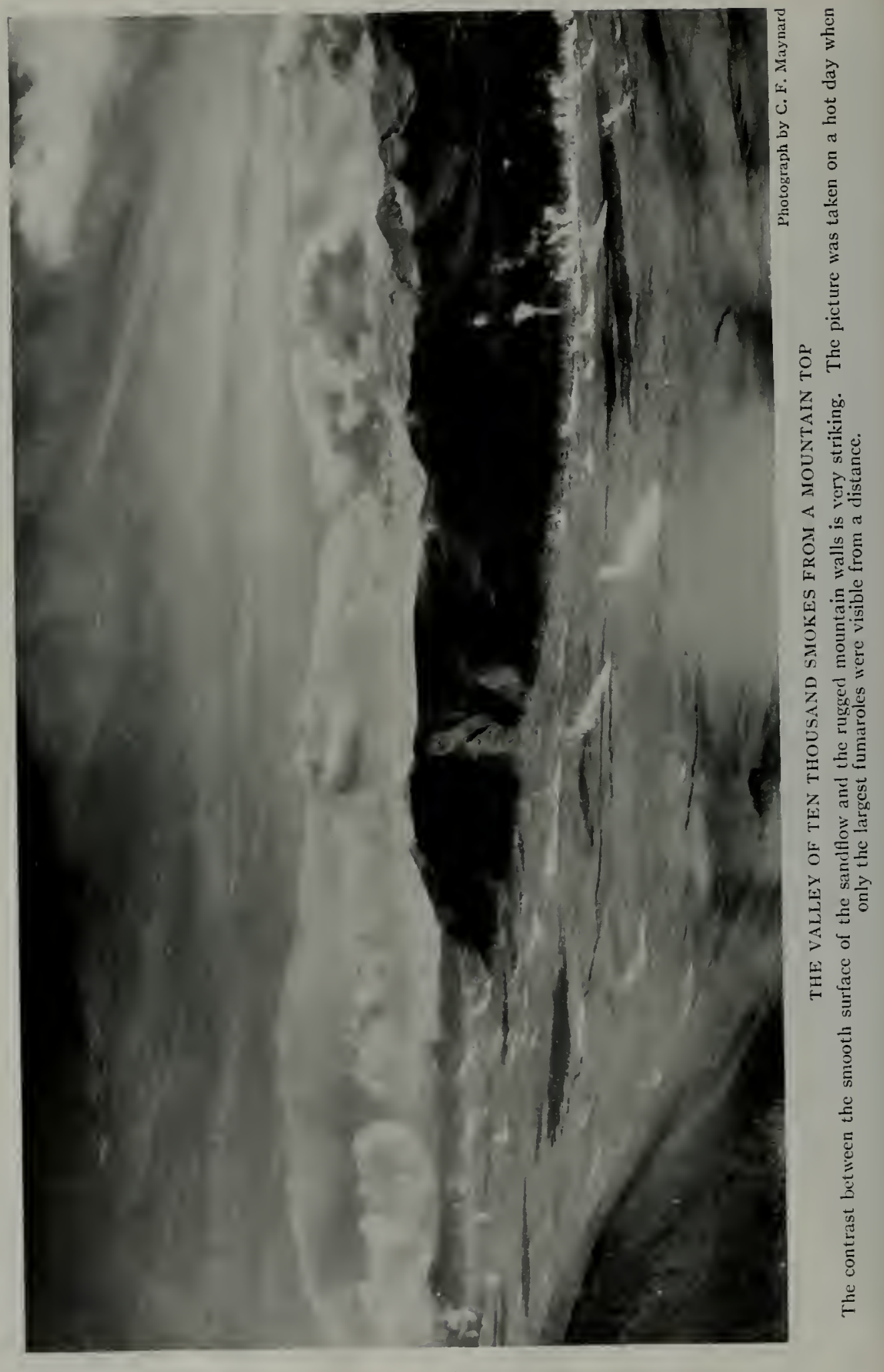




\section{$\mathrm{XIX}$}

\section{THE GREAT HOT SANDFLOW OF THE VALLEY}

The first thing that attracted our attention as we explored the fumarolic area - when we could look beyond the Smokes themselves - was a curious line that encircled the Valley almost like the high water mark of a flood. Above this line were the ordinary gray ash slopes; below it, covering the Valley floor, a great mass of compact, firm, terra-cotta tuff, which has no counterpart on the surrounding hills.

The interpretation of the character and origin of this tuff was, for a long while, our chief concern as we explored the Valley and its branches, for its evident peculiarity had at once excited our curiosity.

Surrounded as it is by high and rugged mountains, the most striking feature of the conformation of the Valley of Ten Thousand Smokes is the flatness of its floor. One could ride a bicycle for miles along its smooth surface, and there are many places between the lines of activity that would be ideal landing fields for airplanes.

IMIENSE DEPOSIT OF TUFF ON THE FLOOR OF THE VALLEY

The traveler peers into the canyons cut by streams in the hope of finding some clue to the thickness of the deposit, but in this he is disappointed. In such places one finds cuts 40,60 , or even Ioo feet deep, but none of them, except those near the foot of the Valley, reach its base and reveal the character of the ground beneath. Inasmuch as most of the trenches are located near the edges of the Valley, where the deposit is relatively. thin, it may be inferred that the total thickness is very great. An attempt to reconstruct in the mind's eye the original contours of the Valley before the tuff was poured out leaves the impression that its maximum thickness can hardly be less than 500 feet (see page 264).

This is very puzzling and very impressive, for when it is observed that the tuff maintains a great thickness over wide areas it becomes evident that the volume of the formation is enormous. The great quantity of this material was further emphasized as we extended our exploration through the Valley and found it spread over the whole of the active area.

First we discovered that the branch valley between Baked and Broken mountains was covered with tuff. Then we saw the great valley between Broken Mountain and Knife Peak filled in the same way, clear back to Novarupta Volcano, connecting with the main valley and forming a complete circuit (see map page 68).

Later we came to recognize that the massive "mud flow" we had found as we climbed up to Katmai Pass was part of the same formation.

From the point where we first encountered it, back of Observation Mountain, to its extremity down Ukak Valley is a distance of 20 miles $(32 \mathrm{~km}$.). From the divide back of Novarupta to the tip at the foot of the Valley is 15 miles $(24 \mathrm{~km}$.). The greatest width is about 9 miles ( $14 \mathrm{~km}$.).

Altogether it occupies an area of 53 square miles ( $137 \mathrm{sq} . \mathrm{km}$.). At its highest points, near Novarupta and in Katmai Pass, it reaches an altitude of nearly 3,000 feet, while at the tip it extends down to within about 200 feet of sea level. If its average thickness over this area is only too feet, its volume is a full cubic mile.

The bulk of the deposit is composed of fine fragments, many of them dust-like, 


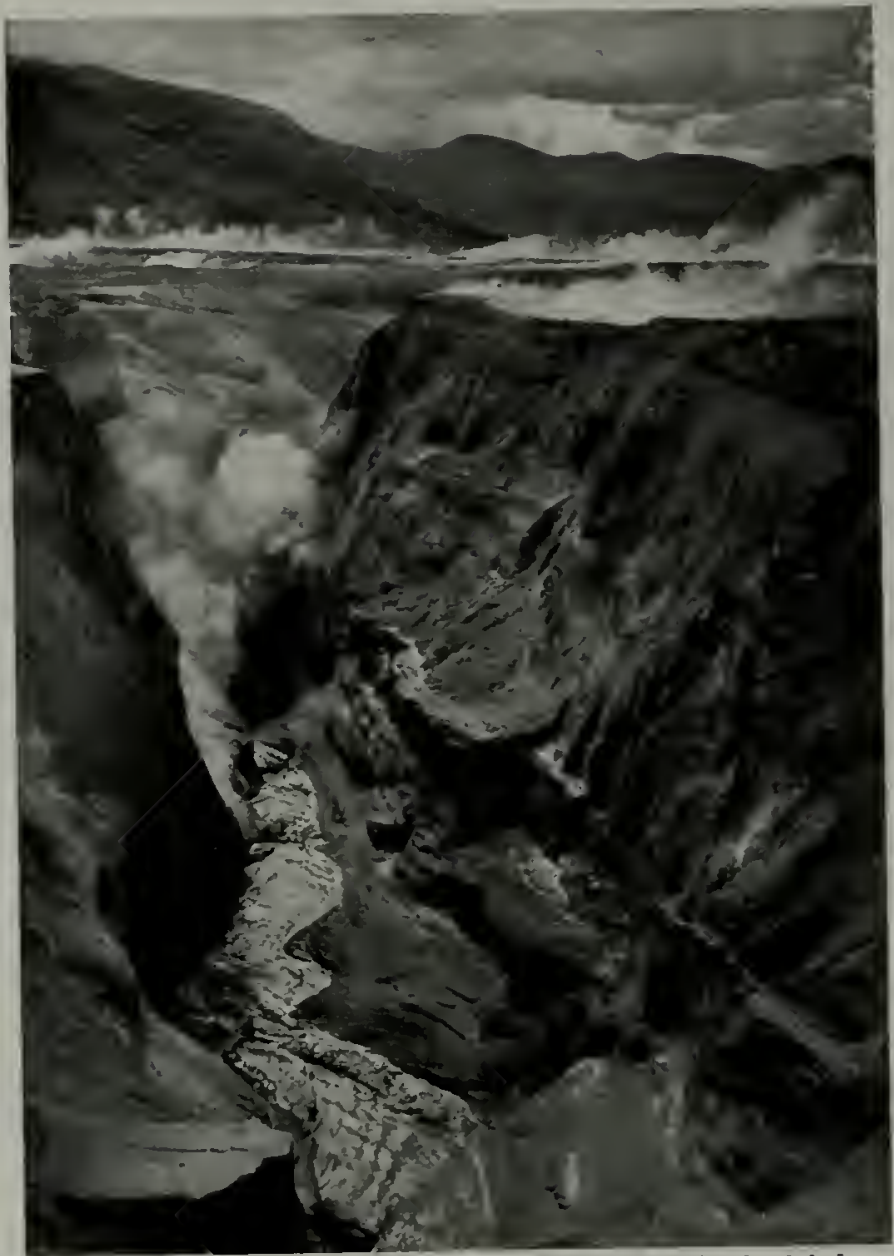

Photograph by Frank 1. Jones

KNIFE CREEK CANYON

The streams have cut most curious sinuous canyons into the stifiened mass of the sandflow. Although in places these canyons are a hundred feet decp, they do not cut through the flow to the soil beneath, except in the lower part of the valley.

but there are included numerous lumps of pumice which in places make up a considerable fraction of the whole. There is no trace of stratification of the materials, except where they were obviously subject to secondary readjustments af ter deposition. Where cut into by erosion or sheared by faulting the tuff breaks with irregular fractures, running in any direction according to the stress. From the character of its cleavage, it is of ten broken or weathered into fantastic blocks like the hoodoos of the bad lands (sce page 259). $\checkmark A L L E Y$ SURROUNDED BY A coNspICUOUS "HIGH WATER MARK"

The "high water mark" above alluded to, which separates the chocolate tuff-covered basin of the Valley from the gray ash slopes of the mountains, impresses one more and more as he studies its relations. It follows, in a general way, a contour line 200 to 300 feet above the floor of the Valley.

Although it thus reminds one of the shore line of a pond, it is obviously not quite level, like the shore of a body of water, but slopes gradually toward the foot of the valley, as though due to the movement of a heavy liquid like molasses, which had succeeded only imperfectly in finding its level.

The most conspicuous example of this occurs in the southwest corner of the Valley, under the glaciers of Mlageik, where the "high water mark" is more than a hundred feet lower than farther east along the foot of Mount Cerberus (see page 262).

All around the margin of the Valley, just below the "high water mark," runs the series of gaping marginal fissures described in the last chapter, as though the surface had been stretched by subsidence after its formation.

The situation reminds one of a temporary puddle which, after having frozen over heavily during a rise in a river, is drained again so as to let the ice down on to the bottom. with consequent stretching and cracking all along the shore. 
The analogy is carried further by the crisscross fissures which run in all directions across the middle, like the contraction cracks of a frozen pond. Where the ridges from the shoulders of the mountains project, the marginal fissures coalesce and run far out into the Valley, in just such a $\mathrm{Y}$ form as do the ice cracks at the point of a peninsula in our drained pond.

In another place, where apparently a considerable detached hill stood in the floor of the original valley, there remains a high area whose crest is occupied by a notable fissure, like that formed when the ice is let down over a hump in the bottom of the pond (see page 263).

About ten miles down the Valley there is a distinct horizontal line of the same red tuff plastered high up on the slopes of Buttress Mountain, a hundred feet above the present "high water mark," as though the liquid that filled the Valley had stood for a short time at this higher level and "frozen" a little along the bank before subsiding.

\section{PROOF THAT THE ACTIVITY OF THE VALLEY BEGAN BEFORE THE EXPLOSION OF KATMAI}

Detailed examination of the surrounding mountains confirmed the suggestion of the "high water mark," that the tuff was confined to the floor of the Valley,

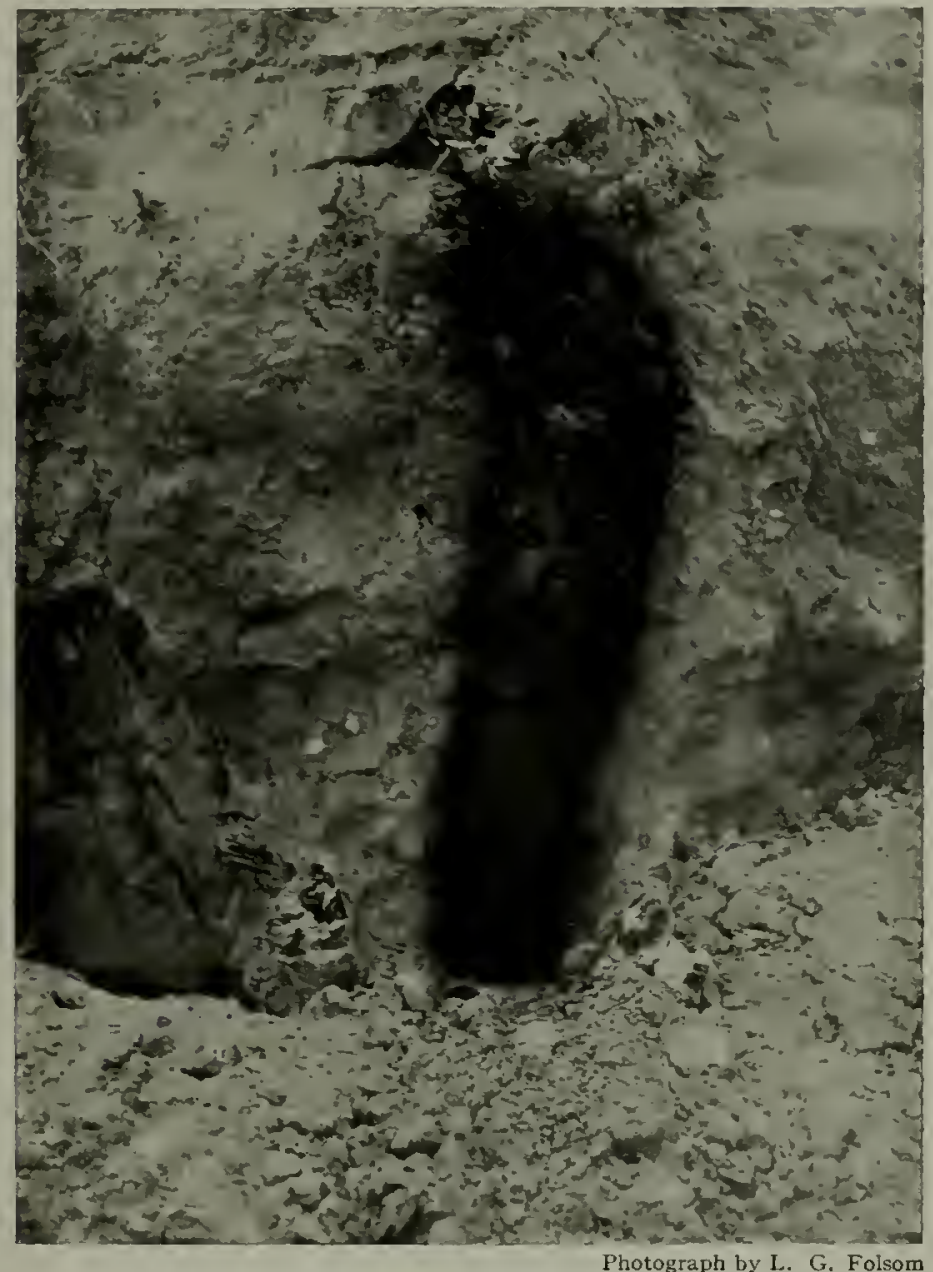

\section{PROOF THAT THE VALLEY OF TEN THOUSAND SMOKES OPENED BEFORE KATMAI BLEIV UP}

Beneath the three layers of ash from Katmai is seen the massive sandHow, which must already have run its course before the ash began to fall. This picture was taken close to the terminus of the sandflow. The charcoal $\log$, a foot in diameter, is striking eridence of the heat still retained by the sand 16 miles from the head of the flow at Norarupta.

for it has absolutely no counterpart on the slopes above. Like all the rest of the country the slopes are covered only by the layers of stratified ash from Katmai.

More significant yet was the observation that these same layers of stratified ash also extend out over the tuff itself, which they everywhere cover (see also page 258 ). This is indubitable proof that the tuff had reached its present position before the ashfall. Since, as will 


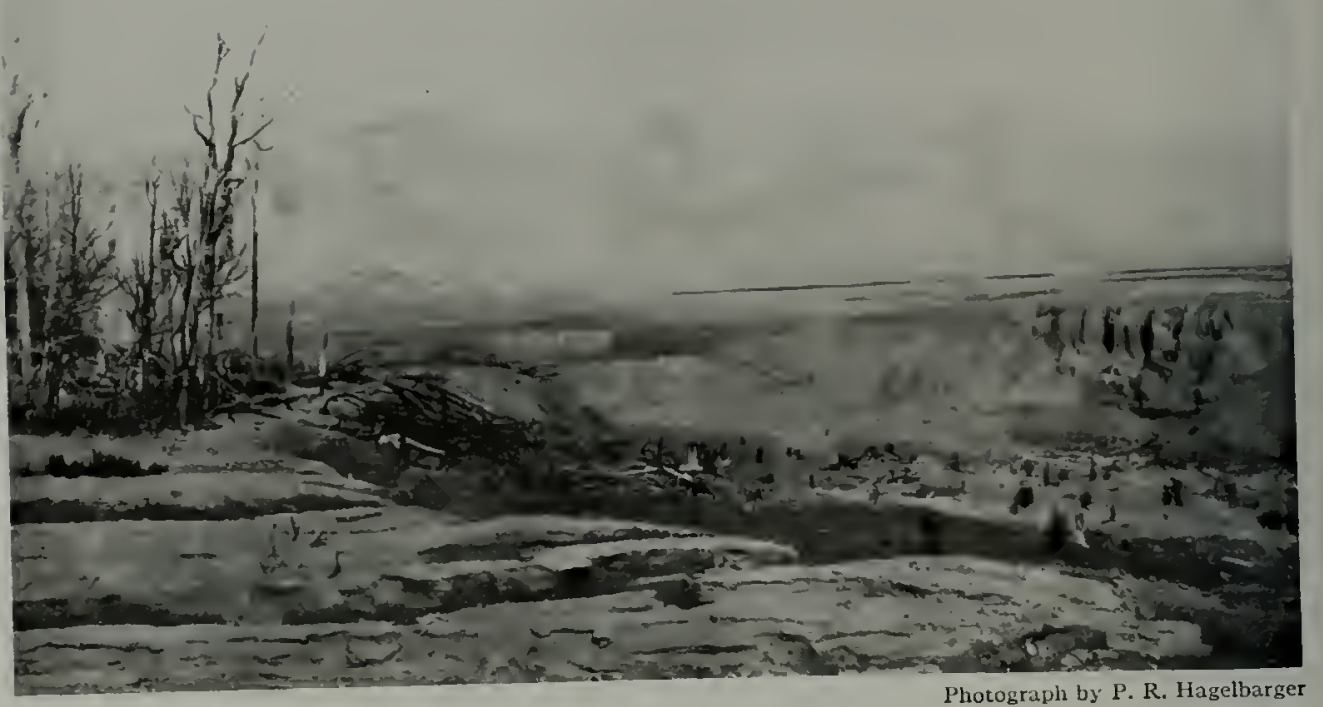

THE EDGE OF THE HOT SANDFLOW

The lower ground, exposed in the drainage gully, was originally covered with forest like the bank on the left. Here and there a burned stump remains to show what happened when it was overflowed by the hot sand. The destruction shown in the right half of the picture is complete and total.

be seen, the tuff is intimately related to the fumaroles, this can only mean that the Valley of Ten Thousand Smokes had already come into existence before Katmai blew up.

RELATIONS TO FOREST SHOW THAT THE TUFF WAS ONCE FLUID

When our work carried us down to the foot of the Valley, we found clear-cut and positive evidence of the manner of deposition of the tuff, making it certain that the sand of which it was composed must once have flowed down the Valley like a viscous liquid.

In the lower Valley, where the remains of the former forest still persist to tell the tale, the "high water mark" becomes yet more conspicuous and significant than it is in the upper Valley.

The remains of the forest embedded in the tuff show plainly that it flowed down the valley as a thick liquid would have done. Right down to the edge of the flow the trees stand undisturberl, but below that level they are overridden, twisted, and bent as before a moving mass. The remarkable sharpness of the line separating the uninjured forest from that covered by the tuff is plainly shown on the photograph reproduced on page 260 .

At the bend in the Valley, where the forest begins, the flow encountered a belt of morainic hills among which it pursued a most irregular course, overtopping some, leaving others standing free above the surface, slopping over in to the ravines, and in every way showing that it ran rather freely. In this vicinity a creek was dammed by the flow, forming a fairly large pond.

Beyond the bend in the Valley it continued for more than a mile, gradually thinning out until for some distance back from the tip it was only ten feet thick, in striking contrast to its massive character farther up the Valley. Everywhere it showed a surprising capacity to adjust itself to variations in the level of the ground over which it flowed.

At one place, near the middle of the 


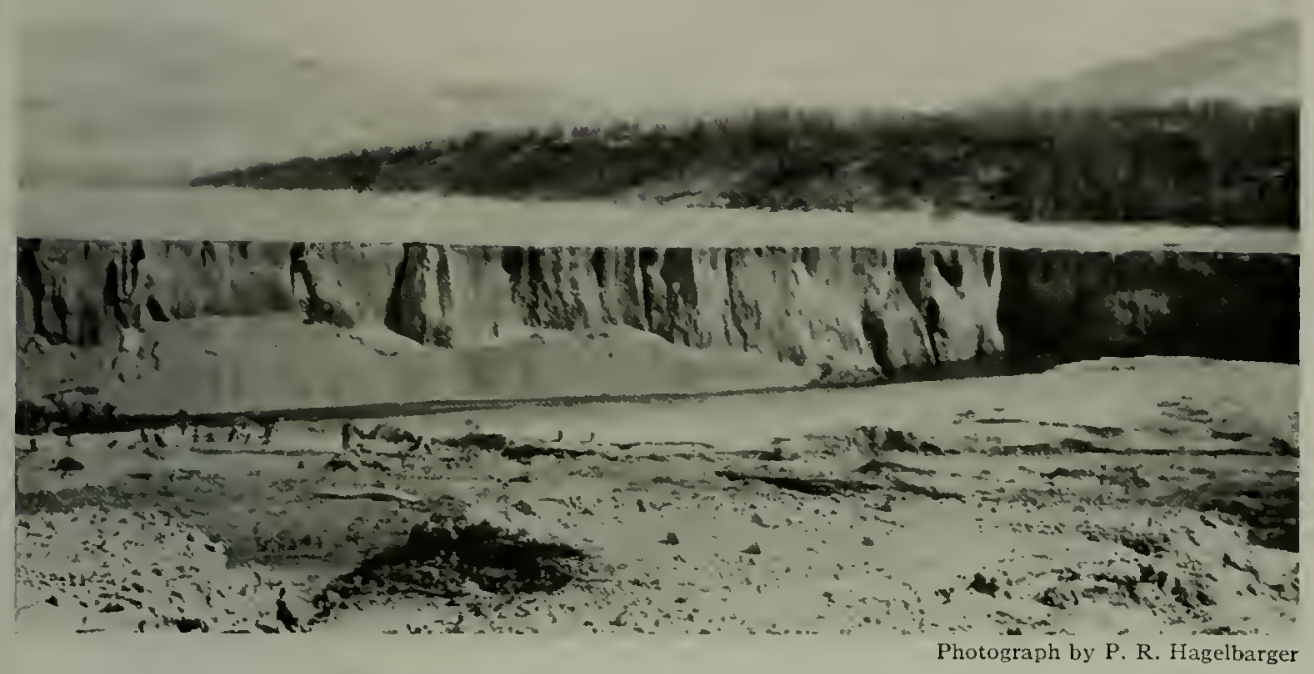

LOOKING ACROSS THE SANDFLOW NEAR ITS TERMINUS

This illustration is panoramic with the picture on the opposite page. The massive character of the flow and its relations to the undisturbed forest covering the hills beyond its reach are evident. The fiery torrent consumed everything it touched.

level flow, I noticed two or three trees projecting from it. Investigation showed that they had grown on the summit of a morainic hill which, after having been deeply buried, had been all but laid bare again by readjustment of the mass after the first wave had passed.

But there was none of that evidence of riolent damage which would have accompanied the rush of a flood of water down the Valley at high speed. Although the bushes were bent and twisted beneath the weight of the sand, they were not broken or uprooted as might have been expected. This seems to prove that the mass moved rather slowly.

\section{EVERY STICK BURIED BY THE SANDFLOW REDUCED TO CHARCOAL}

Near the edge of the flow a few trees remained sticking up out of the sand. When we took hold of them we found to our astonishment that they broke off a foot beneath the surface. The rest of the buried portion had turned to charcoal. Later, in gullies cut into the flow by erosion, we discovered that every particle of wood buried by the sand had been completely turned to charcoal.

In some places the mat of old tundra vegetation had been transformed into a thin sheet of charcoal lying between the flow and the old surface of the ground. Some of the trees engulfed had been a foot in diameter, but they were as completely charred as the fine twigs (see pages 255 and 260 ).

On returning up the Valley we observed that the degree of destruction steadily increases toward the supposed source of the sand. Around the foot of the Valley the trees had evidently charred rather slowly and there was no visible effect above the high sand mark. A little farther up, evidence of occasional grass fires appeared. Half way up, on the flank of Buttress Mountain, the bushes on the mountain side had been burned to the ground; but the roots remained, though charred at the surface.

Finally, around the head of the Valley, where no trace of vegetation remains, 


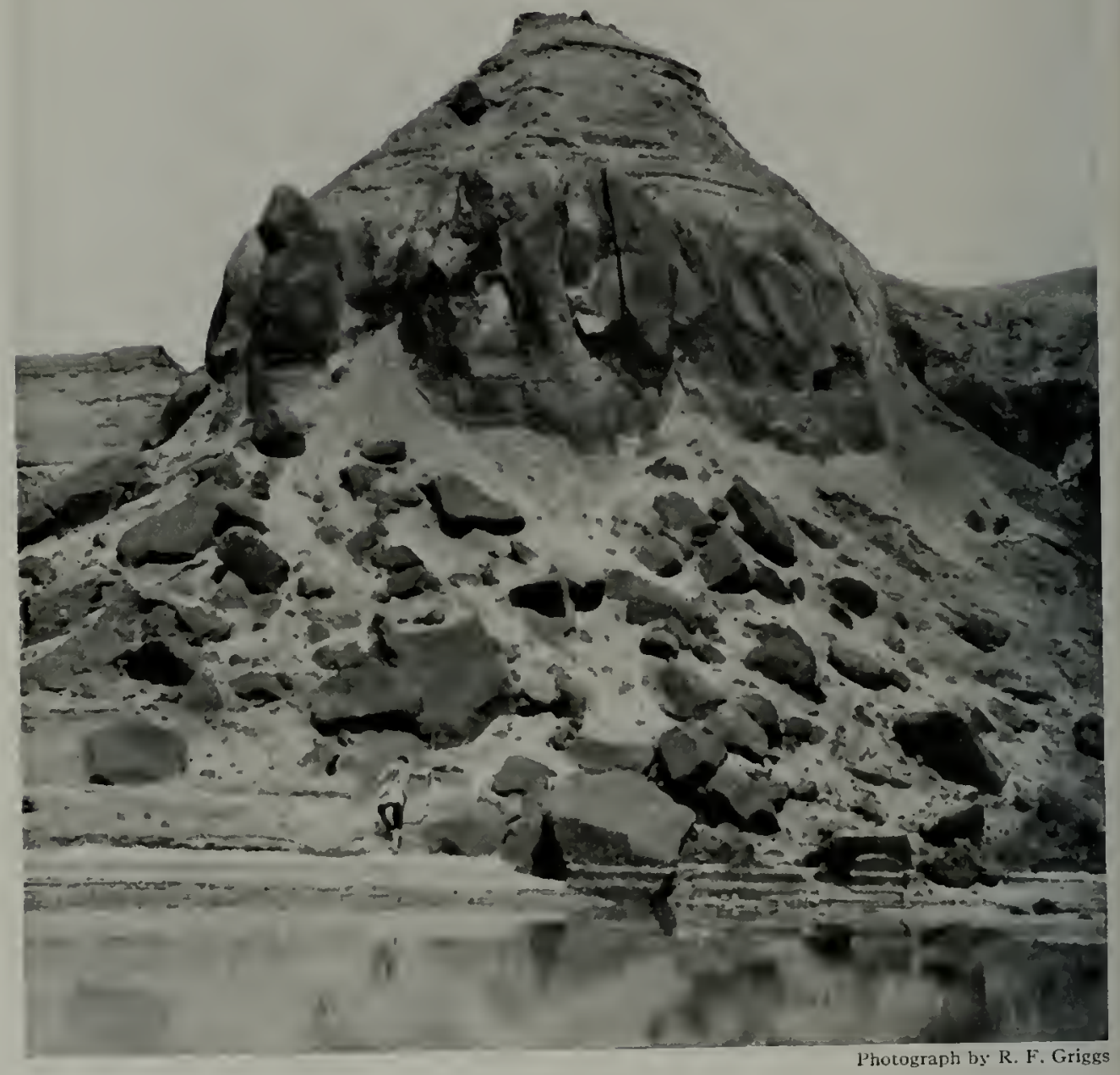

A "BUTtE" ERODED OUT OF THE SANDFLOW ON THE MARGIN OF FISSURE LAKE

The angular blocks that have broken off show the irregular cleavage. The horizontal strata at the top are the layers of Katmai ash which manifestly must have fallen after the occurrence of the hot sandflow.

the heat of the flow must have been so intense as to have completely consumed all plants, leaving no remains to prove their former abundance.

When proof of the extreme heat of the sandflow was added to evidence of its remarkable fluidity and tremendous proportions, it became apparent that the eruption had involved a cataclysm far more extensive than at first supposed.
It was clear that the explosion of Katmai, which alone was known to the outside world, was only one event in a disturbance involving much more than a single localized crater.

\section{SEARCH FOR THE ORIGIN OF THE SAND- FLOW}

Even before it had become certain that the sandflow had been intensely 
hot, we began searching the Valley for evidence as to its origin.

Katmai Crater was naturally the first place to be considered. But an examination made it certain that the Valley flow could not have come from Katmai. The slopes of the volcano over which the sand must have flowed, if it reached the Valley from that source, are covered with great glaciers, and it is hardly to be imagined that a mass of material hot enough to consume every vestige of vegetation could have rolled down over a glacier without melting it.

The high mark left by the sand, moreover, sweeps across the foot of this glacier in a steady grade, which shows very plainly that the sand flowed past the foot of the mountain, not down from it.

Similar evidence

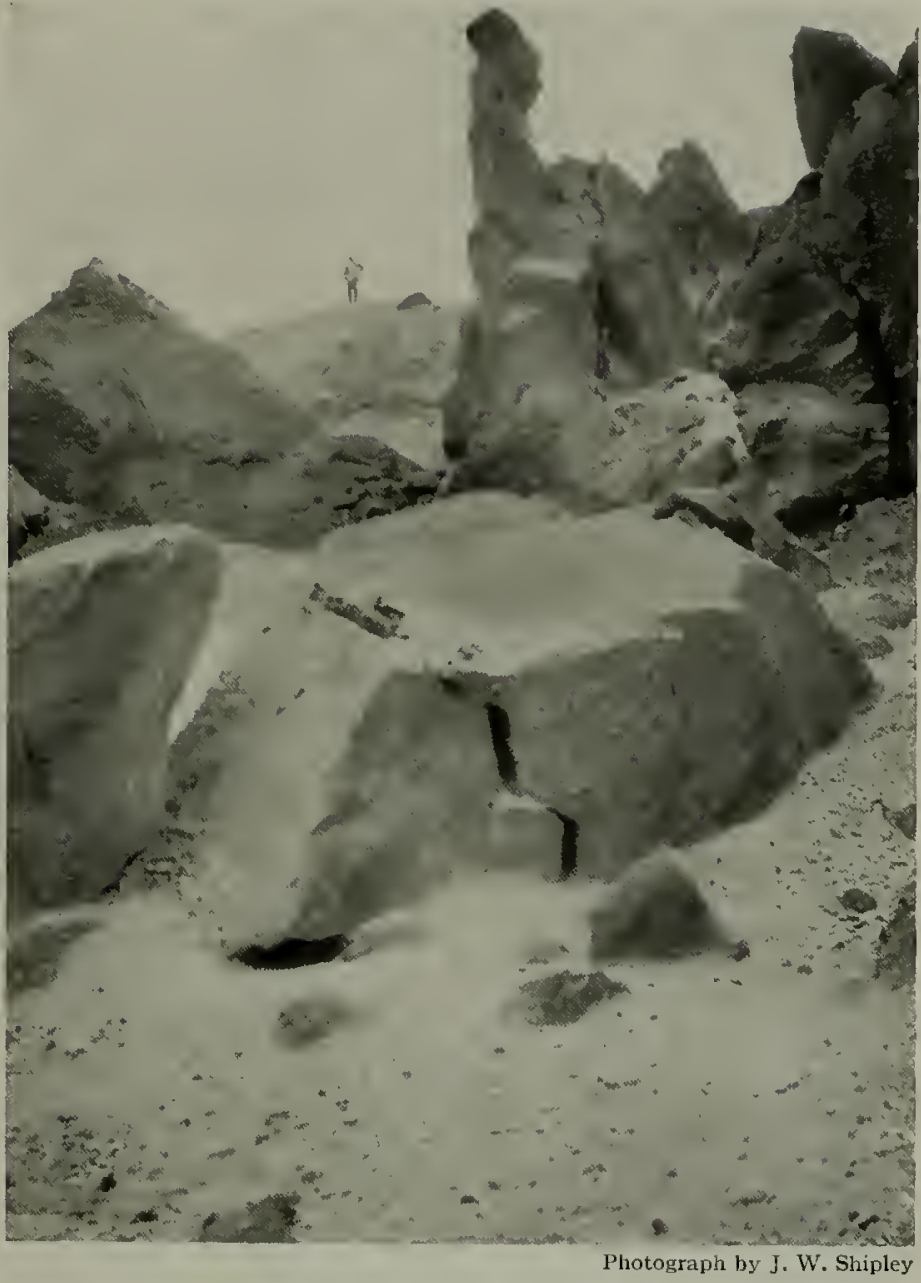

A HOODOO IN THE SOLIDIFIED SANDFLOW

These formations show the irregular fracture and the massive unstratified character of the deposit. They were broken out by faulting. proves that the sand did not come from Mageik; the sloping "high water mark" separating the rugged glacier-covered slopes from the sand-filled Valley could not have been sharper (see pages 262 and 264).

\section{THE HOT SAND MUST HAVE BROKEN THROUGH THE FLOOR OF THE VALLEY ITSELF}

The fact that the high sand mark is practically continuous all around the Valley excludes, in fact, all outside sources. If the hot sand had flowed into the Valley from any of the surrounding mountains, the mark would be broken at the point of influx.

The absence of such a break can only mean that the material welled up from within the Valley itself, just as many a lake is fed by submerged springs. The sand covers up and conceals the orifices from which it came.

Under the circumstances, we should not expect to be able to locate any inlet. Yet irregularities in the slopes assumed by the sandflow make it certain that no one vent could have supplied all the material. It flowed both ways from the 


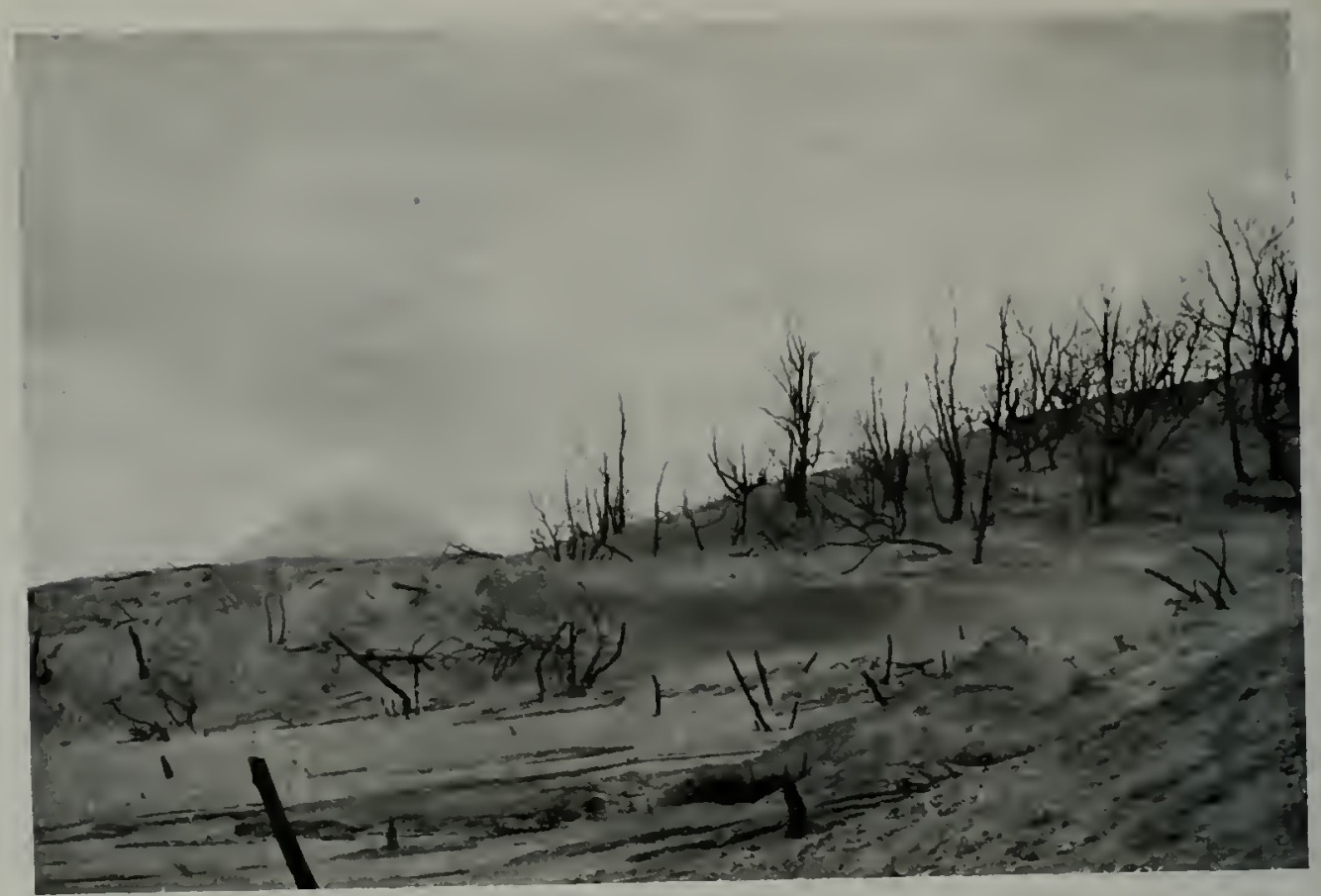

THE EDGE OF THE CHARCOAL FOREST ABUTTING UNINJURED TREES ABOVE THE EDGE OF THE ONCE FIERI TORRENT (SEE PAGE 256).

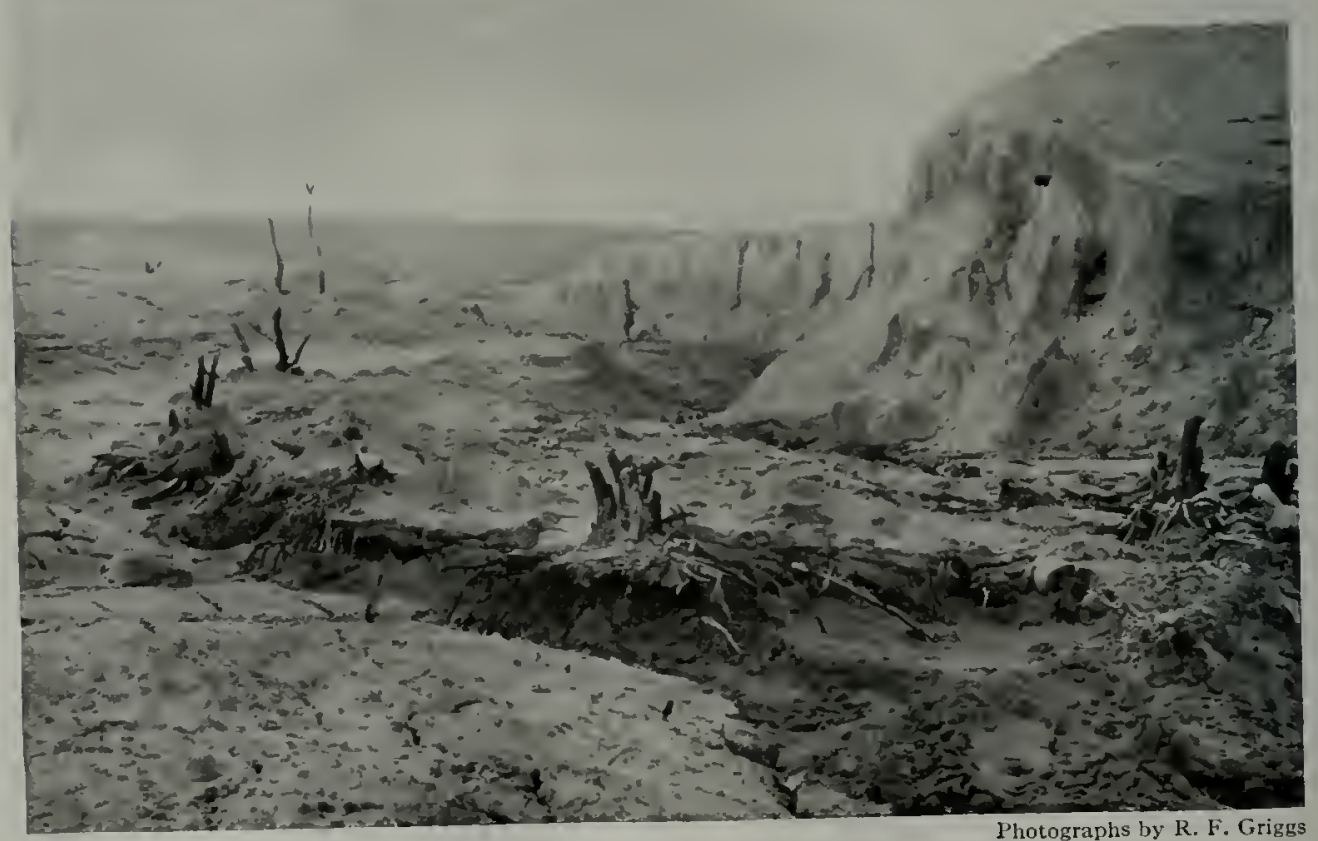

STUMPS OF TREES BURNED OFF BI THE HOT SANDFLOW; EXPOSED BY EROSION Near the terminus of the flow, where this picture was taken, the sand had so far cooled as not to burn the trees clear to the ground. 
stmmit of Katmai Pass and from the divide back of Novarupta, proving that at the very least there must have been vents near each of these saddles.

Novarupta bears every appearance of having contributed a large share of the material. But there is no considerable vent in the vicinity of the pass, nor any evidence that one existed at the time of the eruption. Appearances make it more probable that the tuff in the Pass and in Mageik Creek came from a number of small vents rather than a single large one.

So through the Valley as a whole. The remarkably uniform distribution of the tuff; the occurrence of high temperature vents at very distant points; the widely scattered craters, marking places that were once seats of such mildly explosive activity as we may imagine to be responsible for the outpour of sand; the striking coincidence between the boundaries of the active area and the edge of the flow - all these suggest strongly that the incandescent sand came from a large number of scattered vents. The most probable hypothesis is, therefore, that it was extruded from vents es: sentially similar to the present fumaroles.

\section{SANDFLOW AN ERUPTION OF A NEW TYPE}

Whether this theory is correct or not, it is clear that the present outburst differed radically from an eruption from a typical volcano of the central type.

In the past many eruptions are known, wherein great floods of magma poured out from fissures scattered over wide areas; but in all cases previously recorded, the ejecta consisted not of ash and pumice but of molten lava, which hardened in to solid rock, basalt in every case.

The incandescent sandflow of the Valley of Ten Thousand Smokes is, therefore, an eruption of a type hitherto unknown. Its nearest analogue is to be found in the incandescent avalanches from Mount Pelée, which overwhelmed St. Pierre. But our sandflow differs as much from the Pelean eruption as does the latter from the ordinary explosive type.
If a relatively quiet upwelling of magma such as filled the Valley had followed the explosion of Katmai, it would not have been so surprising. But for the quiet extrusion of a great quantity of magma to precede a violent paroxysm reverses the usual order of events and runs contrary to the accepted theories of volcanism.

The extrusion of the enormous amount of material entering into the sandflow would be expected to have relieved the pressure of the subterranean magma sufficiently to prevent the explosion of Katmai. But it did not even delay it. On the contrary, it might be argued that the Valley flow set off the great explosions.

On yet a third count, this remarkable Valley flow gives a new viewpoint of great importance to an understanding of volcanism.

Inasmuch as the sand of the Valley is as finely fragmented as the ash of Katmai, it seems fair to suppose that the amount of gas given off must have been comparable in the two cases. Yet the ash of Katmai was blown so high as to spread over the whole earth, while the sand of the Valley was never lifted beyond the "high water mark." The reason for this great difference in behavior of magma closely similar both in original composition and in end-products is not known.

The unique character of the incandescent sand thus raises a number of speculative questions of the greatest fascination to all interested in finding out the workings of this old world of ours. The aim of this chapter is, however, merely to present the facts as observed in the field and point out their possible significance, not to deduce conclusions of general application.

In Chapter xxII we shall attempt, on the basis of the observed evidence, to reconstruct the eruption sufficiently to give a picture of its events as they might have appeared to an eyewitness. Meanwhile we shall bring together the evidence of the condition of the Valley and of the volcanoes before the eruption. 


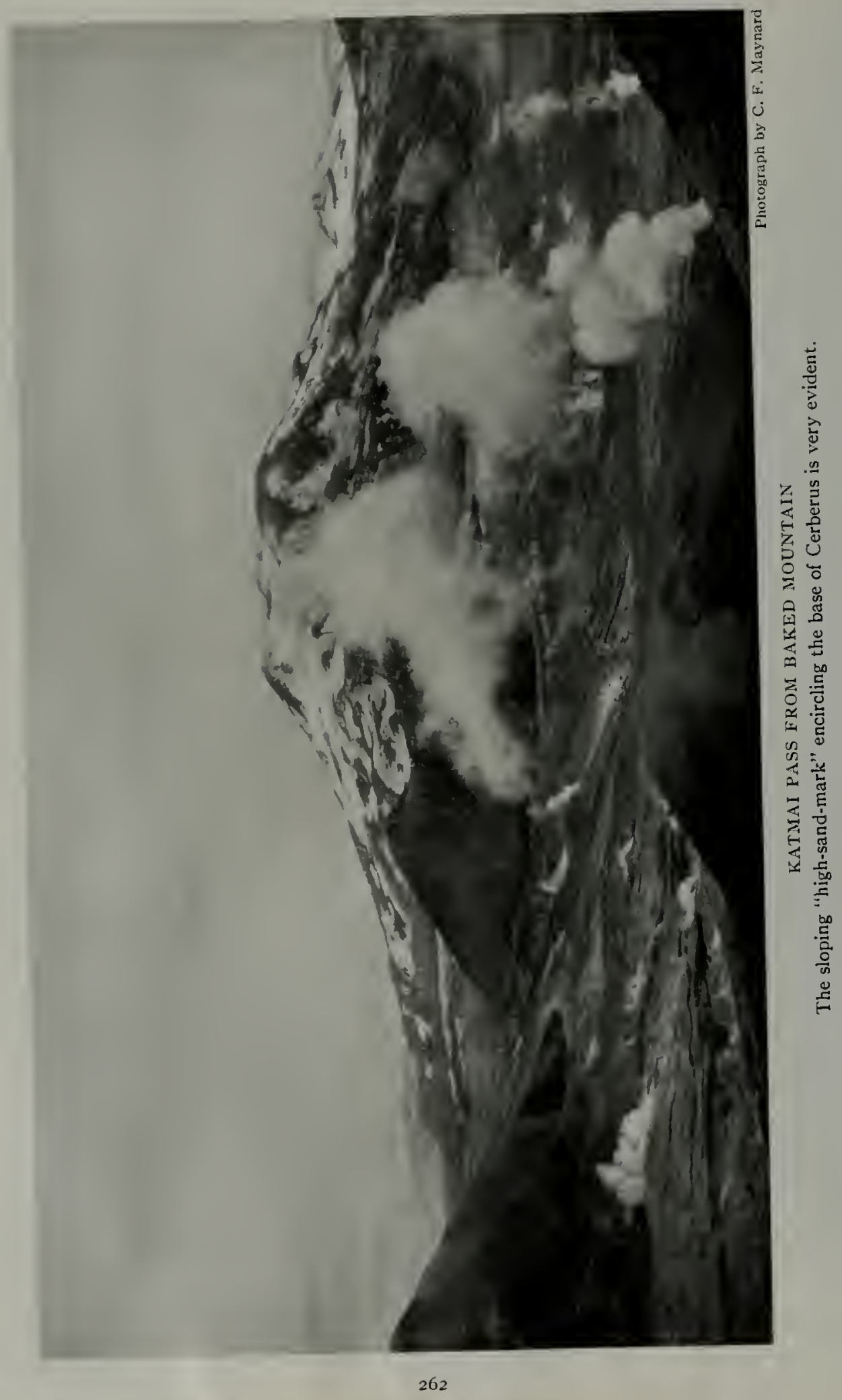




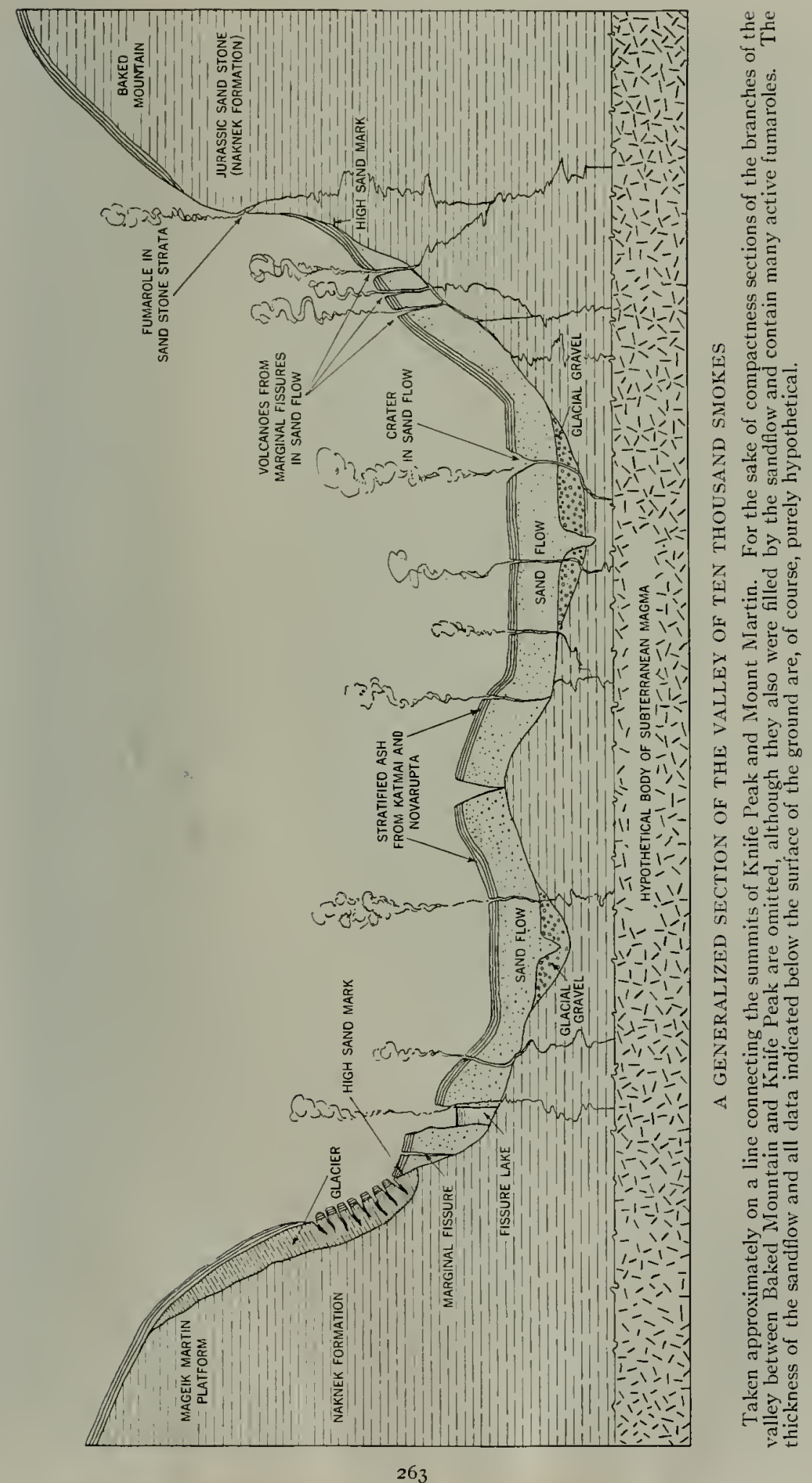




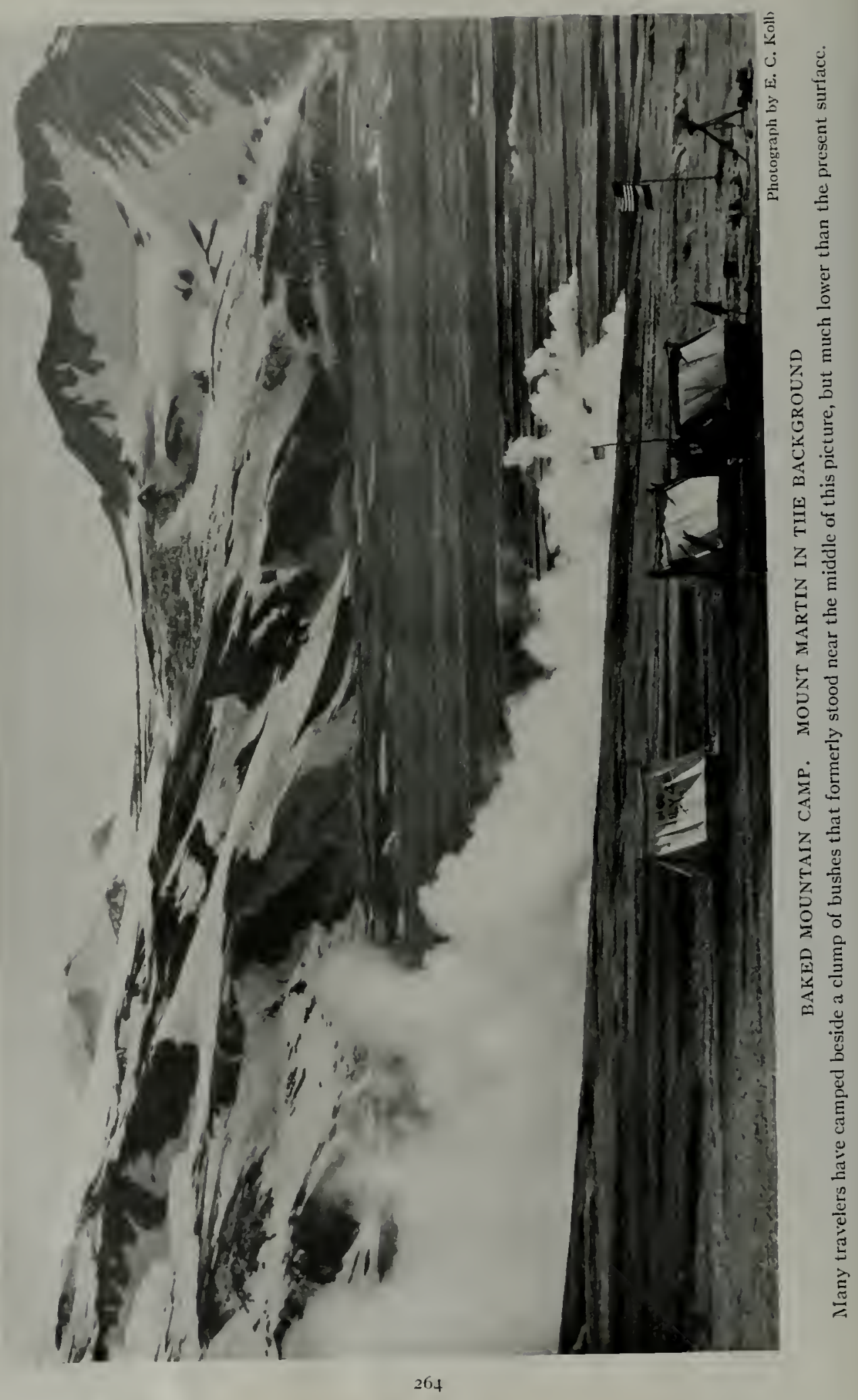


In his perusal of the preceding chapters the reader must have wondered many times what sort of country this may have been before the eruption. It has seemed best, however, to defer consideration of the previous condition of the region until the description of the devastation was complete. But we, like everyone else, had begun to inquire concerning the previous history of the volcano as soon as we heard of its recent eruption.

Had it ever been active before? What warning had been given? What changes in the face of the country were wrought by the disturbance?

And when we discovered the Valley of Ten Thousand Smokes and realized that the explosion of Katmai was only one of several manifestations of the disturbance, our interest in the previous condition of the country was redoubled.

But, unfortunately, knowledge of these antecedent conditions is very fragmentary. I have been at some pains to search out information concerning the former state of the country and especially to secure photographs of it, but the results are far from satisfactory.

\section{PETROF'S DESCRIPTION OF THE FATMAI DISTRICT}

From time immemorial Katmai Pass had been one of the most important routes of travel across the Alaska Peninsula. A very good general picture of the aboriginal conditions is given by Ivan Petrof ${ }^{1}$ in his report on Alaska for the Tenth Census, page $\mathbf{2 4}$, as follows:

"The country between Bering Sea and the Alpine chain of mountains extending along the eastern shore is a gradually ascending plain, dotted with lakes fed from the glaciers and eternal snows in the east, and having their outlets in the west.
"In the northern portion of the peninsula a belt of timber reaches down in the center to the vicinity of Lake Becharof, but beyond this the forest disappears, and only the deep ravines exhibit a stunted growth of creeping willow and alder brush.

"The reindeer browse in herds all over this region, retreating during the summer up to their inaccessible retreats among the snowy peaks of the mountain range, where they are often seen by the traveler below as a moving line of black dots winding around the summits. During the autumn and winter they seek the vicinity of the lakes and scatter over the tundra, where they are hunted with comparative ease.

"Foxes, land otters, martens, and minks are plentiful throughout this section, and the gigantic brown bear of continental Alaska rivals the native fisherman in the wholesale destruction of the finny inhabitants of lake and stream.

"The people of Port Moller and Oogashik are of the Aleutian tribe, which in former years made warlike expeditions along this coast, extending as far to the northward as the Naknek River and Lake Walker [Naknek Lake]. At the village situated on one of the feeders of the latter lake the present inhabitants still tell the story of the night attack made by the 'blood-thirsty' Aleuts long years ago, when every soul in the place was dispatched without mercy, with the exception of one man, who hid himself under a waterfall [Brooks' Falls, close by the village] and thus survived to tell the tale.

"The peculiar formation of this country led to the discovery at an early date of several portage routes across the

1 Petrof, Ivan, Report on the Population, Industries and Resources of Alaska in the Tenth Census, Vol. 2, $188+$. 


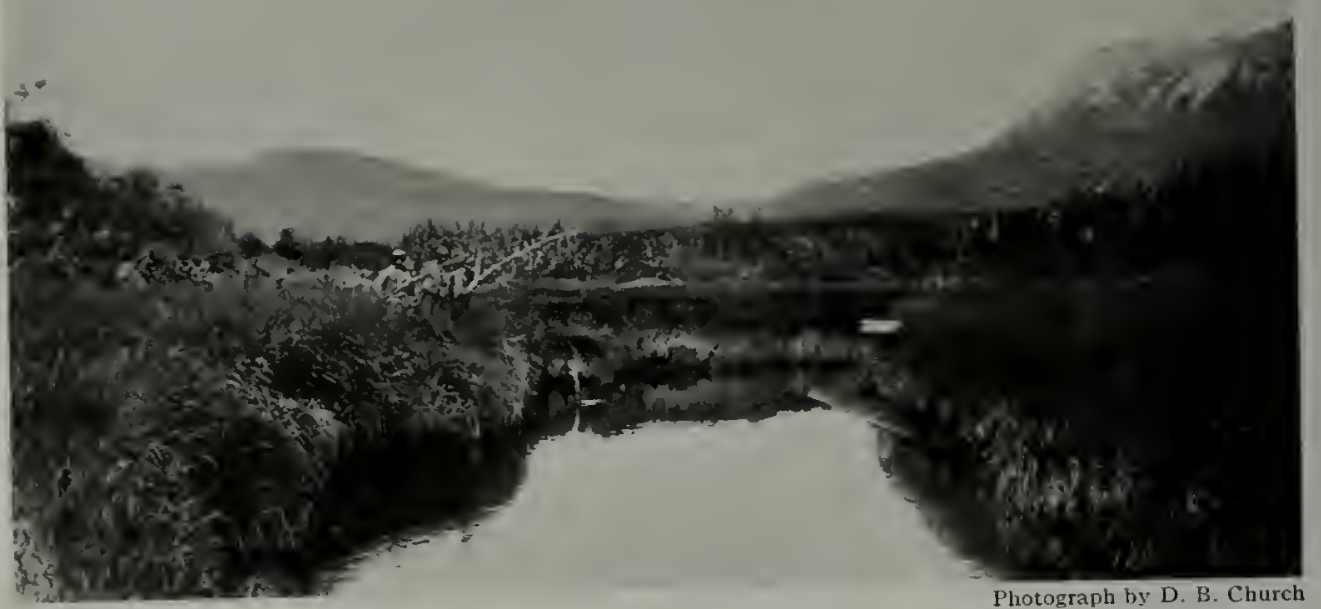

A POND IX THE SOUTHWEST CORNER OF THE KATMAI NATIONAL MONUMENT

This valley, adjacent to the devastated country, gives a good idea of the general character of the countr before the eruption, but in Katmai Valley the trees were much larger, forming a heary forest.

peninsula. The Russian promyshleniks first made their way to Bristol Bay and Nushagak across the peninsula from Kodiak, and found abundant evidence to show that this route of communication had been an inter-tribal highway for ages past.

"During the early years of the RussianAmerican Company's sway in these regions, a large proportion of their traffic was carried on in this way from Kodiak to Bristol Bay, and thence to the Kuskokwim and Yukon Rivers, and Saint Michael. This was a tedious and expensive mode of transporting merchandise, but it was long preferred to the risk and uncertainty of sending sailing craft around to Saint Michael through the shallow and stormy waters of Bering Sea.

"On the eastern side of the peninsula the mountains rise abruptly from the sea, a short day's climbing transplanting the traveler from tide-water into the midst of glaciers and eternal snows and scenes of alpine grandeur and solitude. ...

"The scttlement of Katmai, in this vicinity, was once the central point of transit for travel and traffic across the peninsula. Three different routes converged here and made the station a point of some importance; now Katmai's commercial glory has departed, and its population, consisting of less than two hundred Creoles and Innuits, depend upon the sea-otter alone for existence.

"The men could have reindeer in plenty by climbing the mountains that rear their snow-covered summits immediately behind them, but they prefer to brave the dangers of the deep and to put up with all the discomfort and inconvenience connected with sea-otter hunting, and in case of success purchase canned meats and fruit from the trading store, leaving the deer on the mountains undisturbed.

"The people of the two villages across the divide, in the vicinity of Lake Walker [Naknek Lake], come down to Katmai to do their shopping and to dispose of their furs, undertaking a very fatiguing tramp over mountains and glaciers and across deep and dangerous streams in 


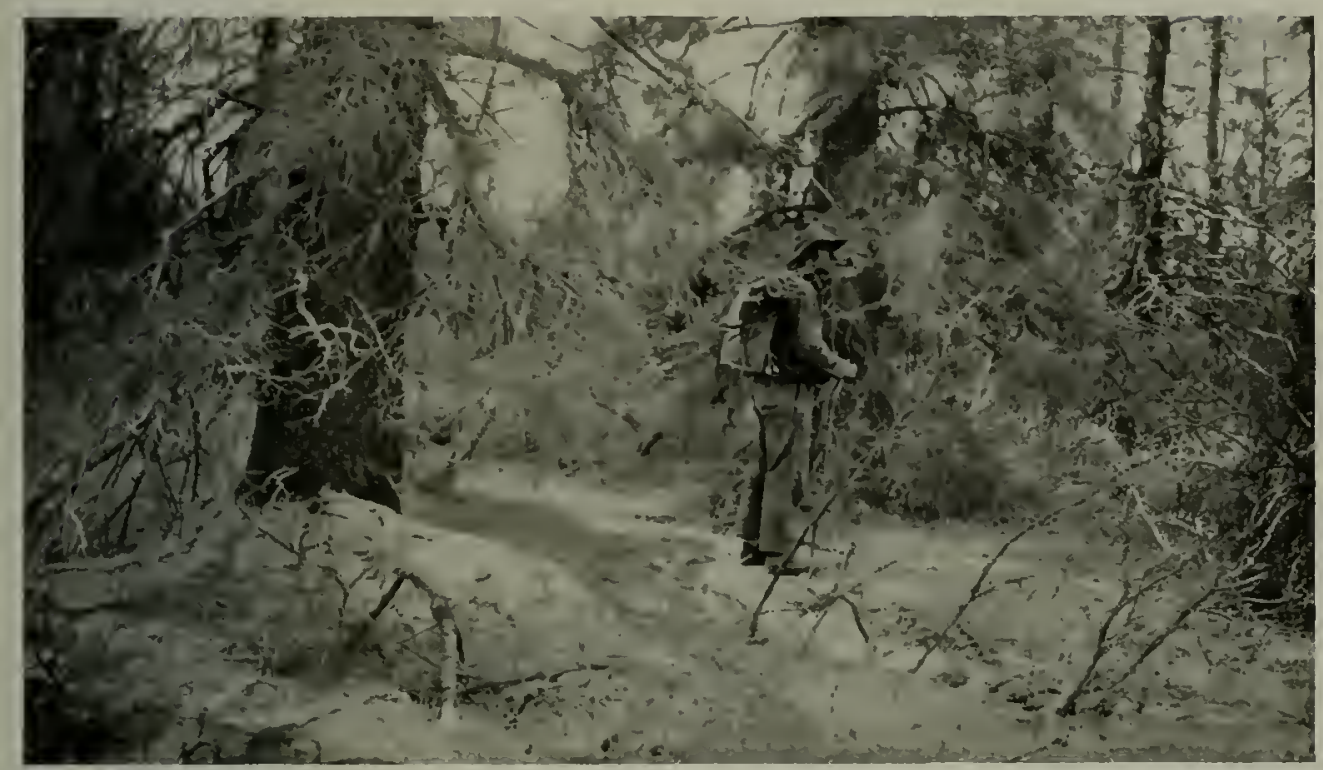

Photograph by P. R. Hagelbarger

SPRUCE FOREST NEAR THE SMOKES

Much of the area now covered by the sandflow was occupied by forest like this before the eruption. The spruce here occurs at altitudes above rooo feet.

preference to the canoe journey to the Bristol Bay stations.

"Only at long intervals a small party will proceed to Nushagak to visit the Russian missionary stationed there, to whose spiritual care they have been assigned without regard to locality or convenience."

\section{THE IMPORTANCE OF KATMAI REVIIED BY DISCOVERY OF NOME}

The importance of the Katmai route across the Peninsula was revived by the discosery of gold at Nome in I 898 . In the eager "stampede" to the gold fields, many availed themselves of the opportunity to shorten by several hundred miles the distance to the goal afforded by the route across Katmai Pass.

This sudden influx of travel must have utterly bewildered the poor natives, who were unable to provide accommodation for the travelers. As a solution of the difficulty, the village trader built a "Bunk House" at a little distance from the village, where a large number of transients could be accommodated.
Many of the men who thus crossed the Pass must be still living, and some doubtless retain vivid memories of the character of the country, but I have not yet found any photographs of the country covered by the eruption.

One of these pioneers was "Charlie" Carter, who carried the mail by dog sledge from Nome to Katmai one winter. He has told me that on the upper part of NaknekLake the ice was very treacherous, sometimes thawing out when the air temperature had not risen above $15^{\circ} \mathrm{F}$., which clearly indicated to him the presence of hot springs somewhere in the vicinity. As the country was altogether covered with a blanket of snow at the time of his trips, he learned little else of its character.

\section{SPURR'S ACCOUNT OF KATAIAI PASS}

The only scientific man who has left an account of the district is J. E. Spurr, who finished his expedition by crossing the Katmai Trail. His account is, therefore, almost the only published source of information concerning its condition before the eruption. 
Before quoting from Spurr's narrative it should be recalled that the reason for the location of the trail across Katmai Pass lay in the extraordinary fashion in which great valleys from both sides of the Peninsula penetrate the heart of the mountains at that point. Katmai Valley from the Pacific lines up almost precisely with the valley now occupied by the Ten Thousand Smokes on the Bering Sea side (see map). Spurr's account of his trip from the head of Naknek Lake is, therefore, a description of the former condition of the main Valley of Ten Thousand Smokes.

He left Savonoski on October I4, I 898 , and camped that night in the vicinity of the present terminus of the sandflow. The next night he camped in the middle of what is now the main arm of the Valley of Ten Thousand Smokes.

"On the I2th of October we started paddling across Naknek Lake, which is the largest body of fresh water that we encountered on our trip. The water was very calm and, on account of the danger of heary gales in these mountain lakes, the natives were willing to push ahead as fast as possible. At dark, after having made about 40 miles, a stop was made for supper, after which about 20 miles more was made at night till the head of the lake was reached.

"The next morning we reached the native village of Savonoski. At Savonoski our Nushagak natives went back, being in continual fear of being frozen in by the increasing cold weather. In order to make as quickly as possible the 60 miles or so of mountains which lay between us and the coast, ten natives from Savonoski were hired to help us carry over, in one trip, our outfit and necessary provisions, everything which was inessential being left behind.

"The trip from the lake to the seacoast occupied three and one-half days, an average of nearly 20 miles a day, all of which we made on foot, largely through swamps and deep moss. On the I6th of October we crossed the mountain pass and descended to the other side.
"This pass lies between two extinct volcanoes and is high, snowy, and rocky, and has no definite trail. The wind is often so cold and violent here, even in summer, that the natives do not dare to cross cxcept in calm weather, for the gusts are so powerful that stones of considerable size are carried along by them.

"On the sea side of the pass we came to a considerable stream of hot water which emerged from the side of one of the volcanoes and flowed down, steaming, to reach the cooler water of the other mountain drainage. [These hot springs still gush forth from the slopes of Trident, but now come out as many streams of warm, rather than hot, water.]

"On the 17 th of October we arrived at the Aleut village of Katmai, where we found a Russian trader. Having now reached the coast, we were disappointed to find that the difficulties in getting farther were even greater than they had been in coming so far, for there were no boats at Katmai except a couple of open dories, belonging to the trader, and one skin bidarka.

"We knew that in a few days the last steamer would leave St. Paul [Kodiak], on Kodiak Island, I20 miles away, for Seattle; but the Shelikof Strait which lay between was so rough and windy that the trader advised us very strongly not to attempt the trip in dories.

"Finally, the sole bidarka in the rillage was sent across to St. Paul with three expert native paddlers, with a letter to the Agent of the Alaska Commercial Company at that place, asking that a schooner or some other craft should be sent to us in order that we might make connection with the steamer. For several days the winds were so violent that the natives would not cross, and after they had crossed no news was heard of them for a long time, till considerably after we knew that the last steamer must have gone.

"On the 3Ist of October, however, we were awakened in our camp, on the beach, by the whistle of a steamer which 
we promptly boarded. The found it to be the Alaska Commercial Company's boat Dora, ${ }^{2}$ which had been delayed in Cook Inlet considerably past her usual time for returning home on her last trip, and so had got to St. Paul in time to receive our letter and to come to our assistance, a trip which involved a delay of two day's for the steamer and its passengers. In the Dora we reached Seattle on the I I th of Norember. ${ }^{3}$. .

"During the first part of the land journey the ascent is comparatively gradual, and the traveler passes over extensive swampy areas with drier knolls, where walking is made difficult by tufts of grass, called 'niggerheads' by the prospector or têtes de femme by the Canadian voyageur.

"The trail leads along the hillside above the bed of the small stream which runs into the lake at Saronoski, and frequently boiling brooks, tributaries to this stream, must be forded. The mountains on both sides of the small valley [i.e. Valley of Ten Thousand Smokes] grow higher, and, as one approaches the summit of the range, it is seen to be composed of a continuous chain of volcanoes, none of which, however, is at present active, although the natives informed us that one of them occasionally smokes.

"From the sides of some of these highest rolcanoes splendid glaciers wind down into the valley, and in other places great walls of moraine, damming mountain gorges, mark the former positions of glaciers which have now somewhat retreated. So far as observed, these glaciers seem to be more extensive on the northwestern than on the southeastern side of the range.

"The Katmai Pass, which leads down to the village of that name, lies between two rolcanoes and is extremely wild and rugged, being the most difficult mountain pass we crossed during the journey.

${ }^{2}$ It will be recalled that it was this same old Dora which was in Shelikof Strait at the time of the eruption and brought the first news to the outside world (see pages 10 and I5).

3. E. Spurr. A Reconnaissance in South-
For several miles on both sides of the sunmit there is no trace of regetation, the surface being composed of huge angular fragments of rock, piled together without even a covering of moss.

"Through this débris and the underlying lava the mountain streams have cut deep gorges. On all the upper part of the pass the snow lay thick at the time of our crossing, in the middle of October. Many natives have perished here by being caught in gales, for during storms, even in summer, the wind blows with intensity and piercing coldness. At such times stones of considerable size are picked up by the wind and carried through the narrow defiles where the traveler must walk, and we found many of these stones lying upon the snow. Owing to this danger the natives cannot be induced to cross except in perfectly calm and clear weather.

"Extensive hot springs emerge from the Katmai side of the mountains below the pass, and there are very frequent earthquakes and other evidences of rolcanic activity. Our party itself experienced a slight earthquake just after crossing.

"The descent from the summit in the direction of Katmai is much more abrupt than on the northwestern side, and in about io miles one passes from an altitude of nearly 3,000 feet to a broad, level flat which is at about the level of the sea.

"In this gravel flat, several miles wide, the Katmai River flows and on both sides of it are high and rugged mountains which run quite down to the coast, and, indeed, extend below the sea, as is shown by the fact that the water close to the shore is very deep, as it is nearly everywhere from here southward and eastward along the Alaskan coast. The

western Alaska in 1898 . U.S. Geological Survey Annual Report 20, pt. 7, page 59 .

Owing to the style of the Geological Survey Reports, Spurr's narrative is repeated three times with increasing amplification; hence the apparent repetition in the triplicate quotation here given. 

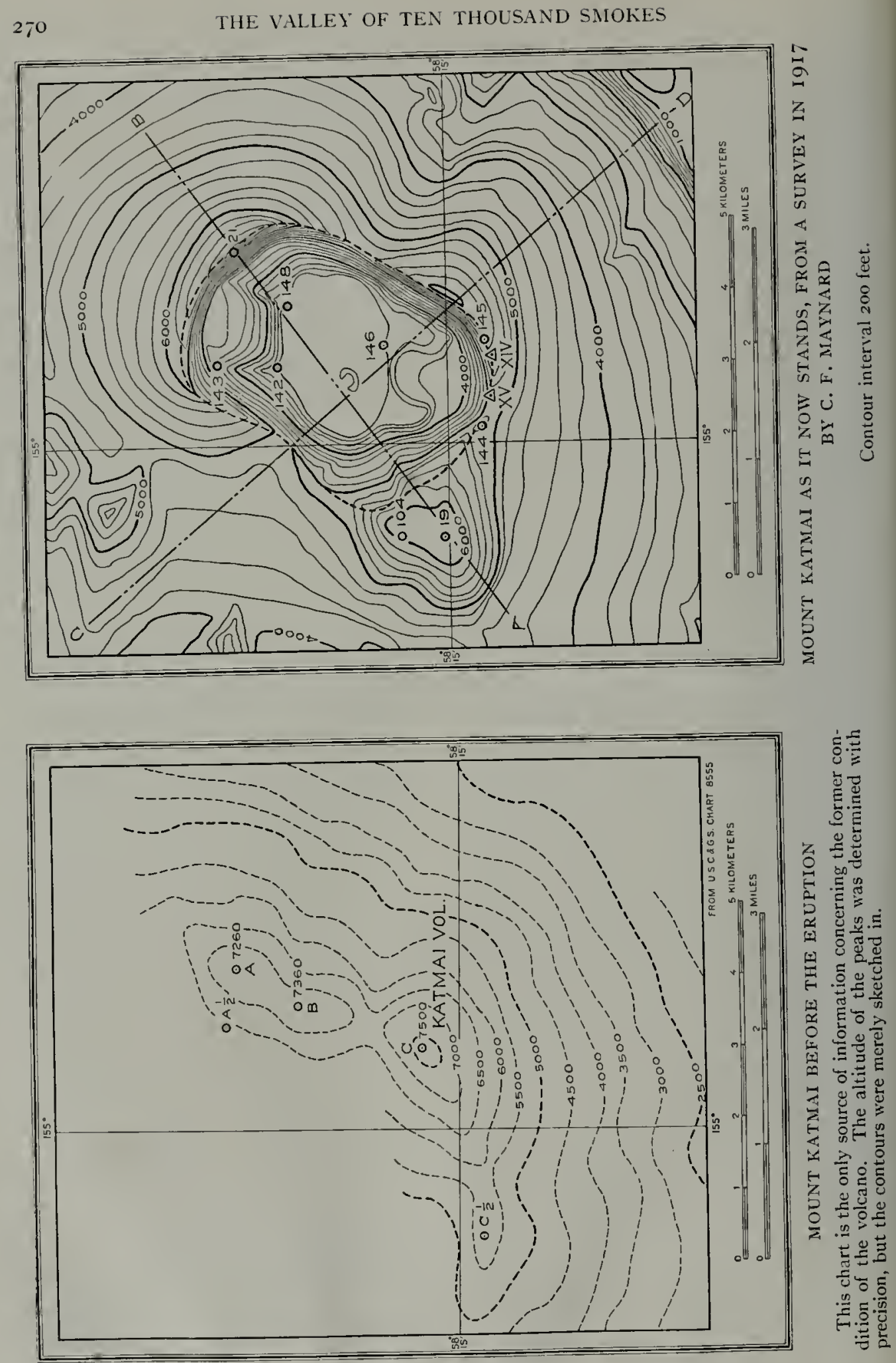
gravel flat of Katmai Valley forms on the seacoast a sand beach several miles long, which is effectually shut in on both sides by high mountainous promontories. 4

"The first 15 miles of the trail from Saronoski to Katmai lies through swampy flats in the broad valley which forms a continuation of the lake. Afterwards a series of rises over slight benches brings one to a larger plateau valley [Valley of Ten Thousand Smokes], which, however, is level and generally swampy.

"The trail lies along this until near the pass, where the plateau valley and the deeper valley of the stream come together. The mountains on both sides have well marked horizontal benches, up to $\mathrm{I}, \mathrm{ooo}$ fcet at least.

"At the first rock bluff above Saronoski, where the trail leaves the flats, is an outcrop of dark green granitic arkose, with nearly horizontal stratification. The rock of the sharply eroded mountains on both sides, nearly as far as the pass, is of the same horizontal bare green strata, which, by fragments included in the drift of the valley, are shown to be green arkoses and limestones. Jurassic fossils are found abundantly in these.

"Near the summit of the range is a continuous chain of volcanic peaks, some with the sides more or less furrowed by drainage, others smooth and perfect. Against one of these volcanoes the horizontal rocks are turned up, this being the only folding observed anywhere.

"Along the axis of the mountains are large and well-developed glaciers, especially on the sides of a tall volcano which stands directly at the head of the valley up which the trail runs [Mageik]. Here the glaciers are many and distinct, and have splendid moraines.

"The main valley is filled with horizontally stratified sand, in which are great angular bowlders, which are also beautifully arranged in layers. This deposit has a generally level top, but there are many sharp hillocks formed of bunches of huge bowlders. The streams have cut deep channels through this.

"On each side of the chain of volcanoes which form the axis of the range, the stratified rocks dip away very gently and are slightly undulating. On the Katmai side of the divide the green fossiliferous rock has perfect crystals of mica in it, giving it an igneous appearance. These have probably developed as a consequence of metamorphism.

"The pass lies between two volcanoes, the one on the right [Mageik] having a cone scarcely modified by erosion, while that on the left is somewhat furrowed, but carries no glaciers [Trident]. Below the pass, on the Katmai side, streams of very hot water burst out of the ground in many places and, joining together, form a considerable rapid stream. This water contains much sulphurated hydrogen and makes copious precipitates of iron and sulphur, so that the earth through which it oozes is colored a brilliant yellowish red [just as it is today].

"The valleys of the streams which drain both sides of the pass are deeply excavated, especially that on the northwestern side, which has cut down at least roo feet through lava bowlders. Owing to the excessive frost action the whole surface of the volcanoes is covered thickly with these large bowlders. On the northwestern side, near the summit, a lake half a mile long is dammed in by the débris from three volcanoes which rise above it. [Remains of lake still present.]

"On the sea side of the pass no glaciers or glacial phenomena on a large scale were observed. On this side are broad benches of great height, the material of which is rolled bowlders from the mountains above; on the surface the frost has cleaved these bowlders into jagged fragments.

"Fron the mountain sides below the pass one looks down upon a broad valley, a flat several miles wide, mostly covered with bare gravel, giving the appearance from a distance of an arm of the sea and 

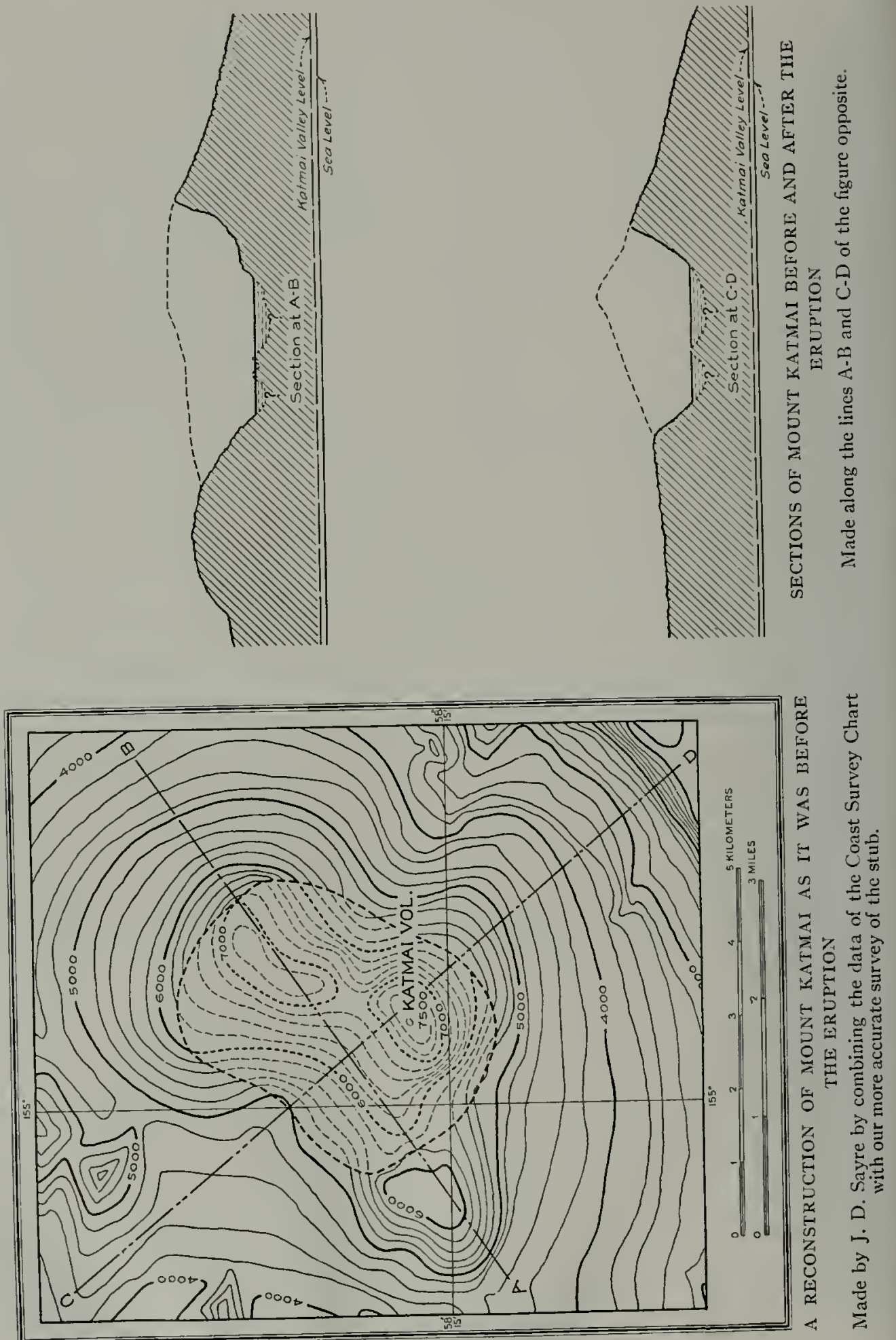
through this flat the Katmai River runs in many channels." 5

KATMAI PASS PROBABLY IN UNSTABLE CONDITION BEFORE THE ERUPTION

When I first informed the members of the National Geographic Expedition of 1917 that the wind in Katmai Pass was reported strong enough to pick up stones and throw them against travelers to their destruction, the boys very naturally hooted at the idea. But I reminded them that such a statement was written into an official publication of the United States Geological Survey, which is not given to wild exaggeration.

The heavy deposit of ejecta from the eruption has filled up the defiles mentioned by Spurr, and reduced the danger from rolling rocks. During 1917 we had little difficulty from this source, but the wind around the Pass is so fierce that before they had finished with their almost daily trips through it, all hands were quite ready to subscribe to any statement that might be made concerning Katmai Pass.

The assertion that the wind used to start rocks rolling down on travelers should not be dismissed as a fantastic invention of the natives. It may be recalled in this connection that I myself came near being killed in exactly that fashion in Katmai Canyon, where many tons of rocks were started down the banks by no more than a good breeze.

The importance of the statement lies in the fact that the wind could only start such stones as were already in an unstable condition, ready to topple down at the least impulse. These stories should be considered in connection with the frequent earthquake shocks of which Spurr makes mention.

It will be recalled also that the incandescent sand described in the last chapter was poured out in the Pass and in both approaches. This feature and the presence of extinct fumaroles on the Pacific slope as well as on the Valley side is clear evidence that Katmai Pass is traversed by a fissure such as opened in the Valley.

Slow movement along a fault line may have caused a continual unsettlement, keeping a considerable number of bowlders always in the unstable equilibrium indicated by the frequent rock falls.

To Spurr's account should be added the narrative given by Rex Beach in his "Silver Horde," pages 75-83. In a work of fiction of this sort the writer was of course at liberty to draw freely on his imagination for his descriptions. Nevertheless, his story of the crossing of Katmai Pass, drawn partly from Spurr's account and partly from his own experience in making the trip, is a very good description of conditions.

In crossing the Pass repeatedly I became well acquainted with its evil character and found Beach's account correct even in numerous minor details which no one would have expected him to grasp in a single trip. Our experience being confined to the summer season had, of course, no danger of the tragic ending that befell the party of the novel, but it required no effort of the imagination to believe that in winter temperatures the trip would be fully as dangerous as Beach pictures it.

\section{DIFFICULT TO JUDGE THE WEATHER ACROSS THE PASS}

It is very difficult from either side to judge the weather on the other side of the range. The experience of Beach's hero, who, after waiting for four days, started out in calm weather only to find a raging gale on the opposite side was duplicated by our parties several times. The curious thing is that the Pass itself is often quiet when the tumultuous blasts over the shoulder of Observation Mountain prohibit travel.

While we were camped in the Valley of Ten Thousand Smokes, we depended for our subsistence on supplies which had to be brought up almost daily from the sub-base camp in Katmai Valley. Several times the pack-train encoun- 


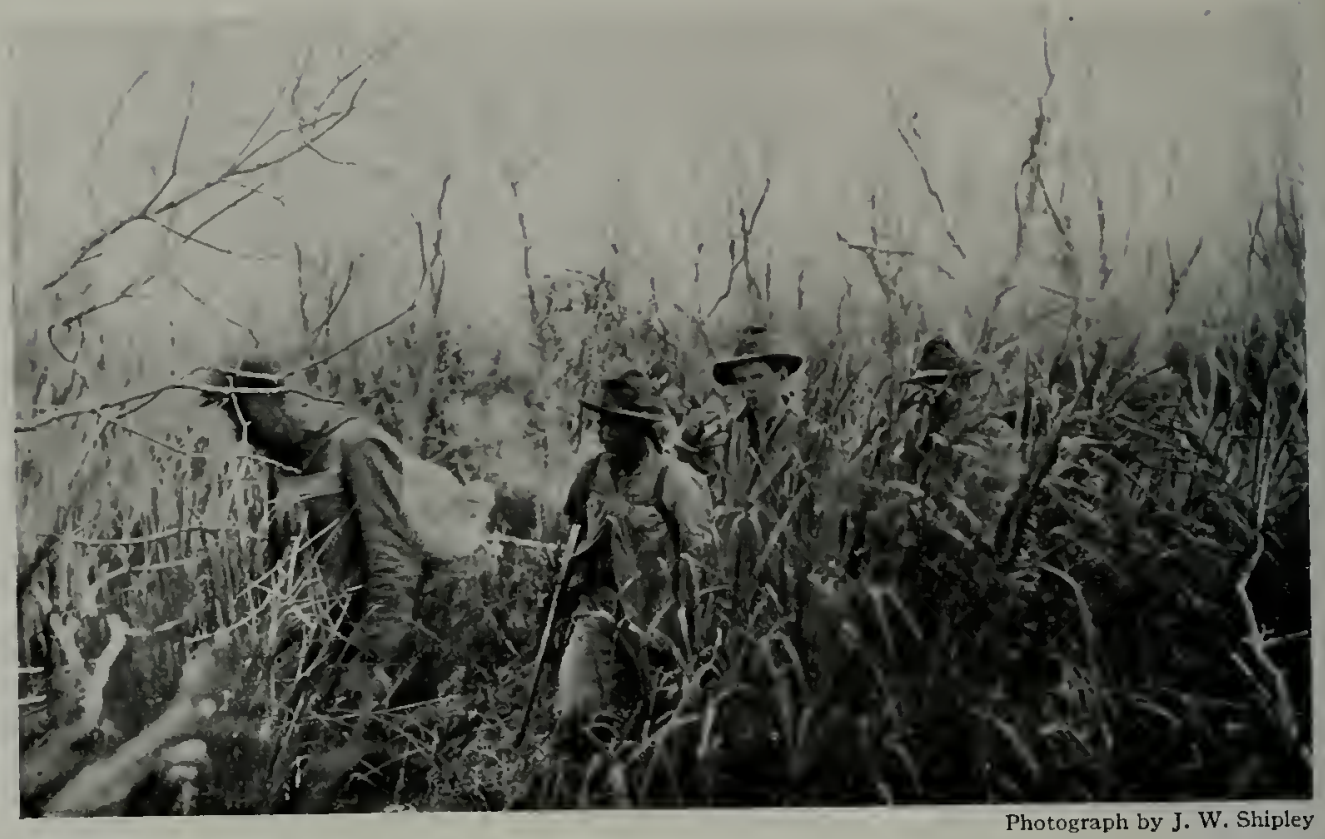

THE TRAIL THROUGH THE TALL GRASS ALONG THE WEST BANK OF FATMAI RIVER

Representative of conditions in the zone where the trees were killed but the ashfall was so light that the grass quickly recovered.

tered storms that would have turned back any but the hardiest of men. One day it was impossible to face the flying pumice. That day the wind gauge, at the sheltered camp, registered 60 miles per hour steadily, and much higher in the gusts.

The next day they came up prepared "to gather up the remains" of our camp among the Smokes, for they knew we could not weather such a gale as they had experienced, and reasoned that it must have been even worse with us at our higher altitude. But among the Smokes the weather had remained fine throughout and we had been quite unable to explain their non-appearance the day before.

The only other published account of crossing Katmai Pass which I have found is that given by the members of Frank Leslie's Expeditions, ${ }^{6}$ who also crossed

- Their accounts are scattered through the numbers of Frank Leslie's Illustrated Newspaper, volumes 70-73, 1890-189I. The material pertaining to Katmai Pass consists of an article by in the winter, when many of the features of the country were concealed by snow. They speak of a magnificent toboggan slide down the slopes of Observation Mountain, but give little geographic information. They state that the Pass is beside an active volcano whose summit was covered with cloud, "but from whose sides bubbled steaming sulphurous malodorous streams."

The most important item from our point of view is that, before going over, they camped " 3 ,000 feet high in the last thin little group of trees," which was probably located in the middle of the Valley of Ten Thousand Smokes under the protection of Mount Cerbcrus.

\section{OUR ONLY INFORMATION CONCERNING MOUNT KATMAI DERIVED FROM COAST SURVEY CHART}

Of the condition of Mount Katmai, the accounts of these travelers afford no

E. H. Wells, published Sept. 19, I89 I (p. I06), and one by A. B. Shantz, published Nov. 28, I 89 I (p. 268). 
information. Spurr gives no clue as to which one of the volcanocs was reported by the natives to smoke occasionally.

From the trail Mageik is much more conspicuous than Katmai, which is too far east to be seen to advantage from any point except the slopes of Observation Mountain. At that point, however, the anxious eyes of the pilgrims would naturally turn in the opposite direction toward their goal, the sea, which spread out in magnificent panorama before them.

Post's sketch map, which accompanies Spurr's report, although giving Mageik and Katmai Valley accurately and in some detail, is blank in the direction of Katmai. But on Coast Survey Chart Number 8555 , a section of which is reproduced on page 270 , Mount Katmai is shown as having three peaks, each higher than Mageik, i. e., 7,500, 7,360 and 7,260 feet. Around these peaks, whose position and altitude were determined by precise triangulation, are drawn dotted contours indicating the configuration of the mountain as it could have been seen from the triangulation station at Cape Kubugakli.

This chart supplies absolutely all the information we have concerning Mount Katmai before the eruption. But, curiously enough, search of the archives of the Coast Survey has failed to reveal the source of the information from which the contours of the chart were drawn.

There are no sketches in the field books of the Kubugakli party by whom the contours appear to have been drawn,

7 The estimate of the amount of material blown off the mountain in the eruption which was given in Chapter XIV was arrived at by comparing the reconstruction of Katmai with the stub that remains. The contours are 200 feet apart. By obtaining the areas enclosed by the different con- and the head of the party does not remember that any observations of Mount Katmai were made. But whoever drew them, they correspond well enough with the portions of the stub that remain to inspire some confidence in their accuracy.

\section{RECONSTRUCTION OF THE ORIGINAL}

\section{KATMAI}

By combining the outline suggested by the old chart with our more precise survey of the present volcano, it has been possible to reconstruct the original mountain with some degree of satisfaction. ${ }^{7}$

The hollows in the flanks of the volcano are occupied by the remains of glaciers which were beheaded when the top blew off. The original peak was certainly a majestic snow cap. In a general way, it must have resembled Mageik (see page 78 ), but it was higher and the summit was at the near end of the ridge, rather than in the middle.

We may be fairly sure that Katmai was the dominant peak of the district since it was customary to apply the name of any village to each of the most important geographic features of its vicinity.

That this peak, rather than Mageik, was honored with the name of the village is especially indicative of its former grandeur, because it was unfavorably located to receive such a distinction. Mageik is in full view from the village, making a wonderfully impressive spectacle. But Katmai lay behind the Barrier Range, which concealed all except perhaps the very summit.

tours around the old summit and within the crater, we can calculate the volume of the material that has disappeared. The average of four independent computations of this volume is I I, 000 millions of cubic yards. 


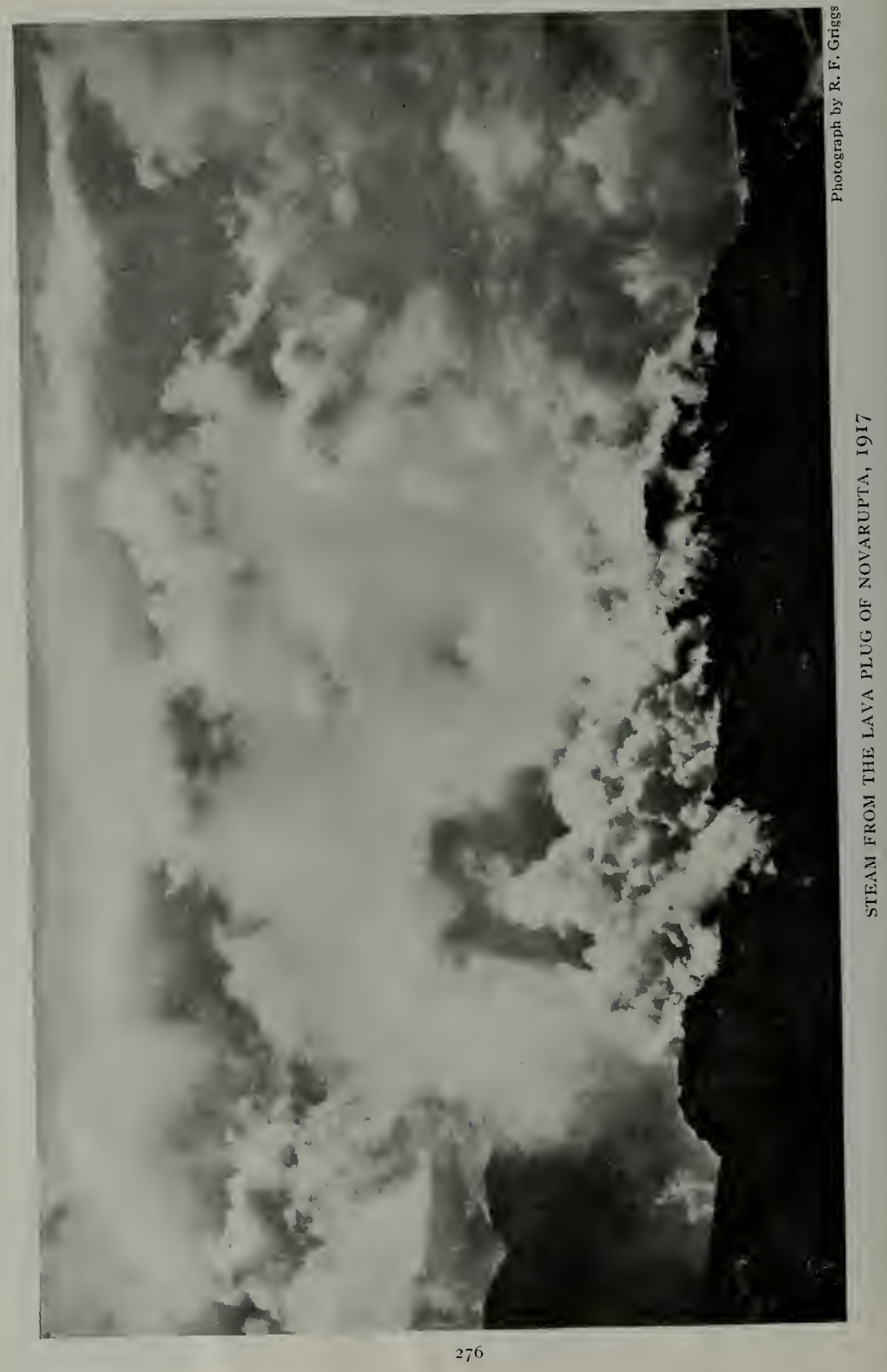




\section{A HYPOTHETICAL CHRONICLE OF THE ERUPTION}

The preceding chapters have given some description of the effects of the Katmai catacly'sm and of the rolcanoes it opened up, but little attempt has been made to relate the various phenomena in the order of their genesis or to discuss the actual erents of the eruption. It will be desirable now to attempt a description of the eruption as it would have appeared to an observer on the scene.

Since there were no witnesses competent to testify to the facts, we are limited to deductions from the study of effects on the surrounding country. It should be understood that our account must be made up of reasonable inferences and conclusions that follow from the evidence left behind. It must, therefore, be read as a mental reconstruction rather than as a chronicle of a series of observed events.

\section{IN THE BEGINAING A BEAUTIFUL GREEN VALLEY}

At the beginning, a beautiful broad valley, just turning green after the long winter, stretched down from Katmai Pass. Up to nearly I,500 feet it was covered with a dense forest of balsam poplar and paper birch, with occasional clumps of spruce, which became abundant at lower levels. There were numerous undrained hollows occupied by ponds or tundras, while the steeper slopes were covered with dense stands of tall grass.

Along the edge of the forest a herd of caribou may have been following up the melting snows toward their summer pastures among the alpine meadows; lower down in the woods occasional moose, stragglers here at the extreme edge of their range, might have been observed.

Within a few miles were undoubtedly several of the great brown bears of the region, busily engaged in digging out the roots of the spring plants to fill their empty maws after the long winter fast. A pack of hungry wolves, followed perhaps by a skulking wolverine, may have hunted a herd of caribou, or, failing such large game, contented themselves with snowshoe rabbits and ground squirrels.

\section{A GREAT LANDSLIDE FROM FALLING} MOUNTAIN BEGINS THE CATACLYSM

The first signs that anything unusual was in prospect were probably occasional earthquakes, which later must have increased ominously in frequency and violence, for, while details are lacking, it appears that earthquakes were the main cause of the alarm of the natives at Katmai Village and Savonoski. Presumably, also, the old volcanoes, one or more of them, soon began to manifest unusual signs of activity by way of increased smoking, accompanied perhaps by small explosions.

Although premonitory symptoms of this sort would have made themselves felt over a wide stretch of country, the opening scene in the catastrophe, so far as we know it, was more local in character. With a thunderous roar, the face of Falling Mountain let go, precipitating several million cubic yards of rock into the lowland in a terrific rock stream that must run for several miles down the Valley.

A wind started by the rush of falling débris roared down the Valley like a hurricane. Meanwhile, the sky was darkened by the great cloud of dust set up by the falling rocks, imparting a gloomy and portentous aspect to the scene and helping to make it an altogether appropriate prelude to the great tragedy.

Similar rock falls of almost equal magnitude may have occurred several times during the eruption, but the later 


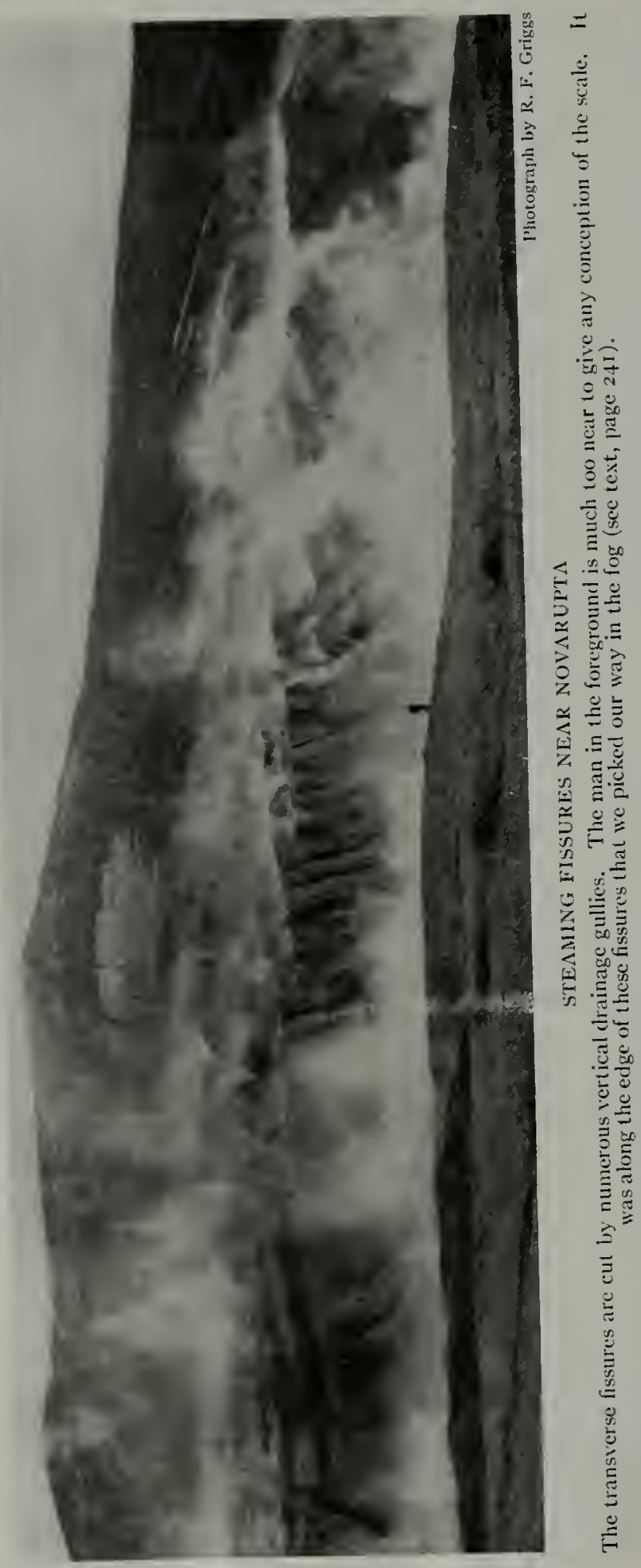

ones would have attracted little or no attention amidst the general cataclysm which by that time had broken loose. For it would have become evident that the whole region was rocking in the throes of tremendous subterranean forces which threatened every moment to rend the mountains asunder.

\section{VALLEY FLOOR CRACKS OPEN \\ AND SEETHING MAGMA RUSHES OUT}

Probably before the dust had settled, during an earthquake of more than usual violence, the Valley floor broke open. Immediately the seething white-hot magna appeared in the cracks, struggling for release from its prison in the rocks.

At first it probably appeared like a fire among the bushes. But it spread rapidly and soon its real nature became apparent. Floods of fire burst out now here, now there, until the whole Valley opened up and the molten viscera of the earth came pouring from every fissure. Tremendous columns of liquid fire shot out, driven skyward a hundred feet or more, gilding the mountains round about with their radiance.

The Ten Thousand Smokes, wonderful as they are at their best, can give no idea of what the Valley must have looked like at this initial stage. In addition to myriads of smokes, doubtless greater than any that now remain, other scores or hundreds of volcanoes must have been belching forth incandescent lava in veritable fountains of fire. 
A reconstruction of this scene is quite beyond the power of human imagination. The closest picture that we may venture to present is the description of analogous white-hot fountains which shot up during an eruption of Mauna Loa, as they appeared to an eye witness: ${ }^{1}$

"Each one shows a multiplied façade of spires composed of thousands of bunched jets of orange color, the spire to the extreme left the tallest and the others perhaps eight or ten - diminishing to the right. The component jets fall inward, when their upward impetus is lost, in graceful parabolas, excepting when, at every major ejection, there is a fierce explosive-like projection outwardly from the main spire.

"The whole effect is that of an illuminated Gothic cathedral's front. In ascent the velocity of the ejection is that of a rocket multiplied. Stupendous projective force is what impresses one, together with the extraordinary pyrotechnical beauty of the display.

"At the bases of the fountain there is an intermittent boiling and surging, and a sullen roar of awful majesty rises and falls. . . The jets are intermingled with a profusion of dark angular projectiles... which I am informed is pumice stone."

\section{IMPENETRABLE BLACK CLOUDS}

MUST HAVE VEILED THE SCENE

In the beginning, the many vents in different parts of the Valley probably remained distinct, each pouring forth its own contribution to the general chaos; but soon the outpoured lava must have begun to coalesce in a fiery flood.

It may have remained in pools of molten liquid for a little, but before long gases began to be evolved in enormous quantities, forming impenetrable clouds

${ }^{1}$ By Daniel Logan, as quoted from C. H. Hitchcock, "Hawaii and its Volcanoes," p. I29. The original speaks of the "façade of spines." This I take to be a misprint for spires and have so changed it.

${ }^{2}$ Dr. Zies has suggested that the properties be- somewhat like the horrible burning clouds from Mount Pelée, that brought destruction to St. Pierre.

Blending together, the clouds from the separate vents made a lurid canopy over all. Under different conditions they assumed various aspects: murky black, when overladen with included solid particles; blue, where clear steam was intensely hot; white where their high rolling peaks caught the sun, and purple or scarlet where illumined by the fiery abyss below. Clouds of smoke must have rolled over the whole country round about, carrying with them ashes, cinders, and charred leaves and twigs.

How all the manifestations of this sort which must have occurred could have passed unnoticed even in that remote country is a mystery. But there is no record of their having been seen, except perhaps from Cold Bay where the night before the great explosions observers noted a black and stormy sky in the direction of the Valley (see page 19).

\section{LATA FROTHS UP INTO A FIERY FOAM}

Other aspects of the eruption would have been more interesting to us, however, than these passing aërial disturbances, which left no trace behind. The lava gave off such great quantities of gas that it promptly lost its character of a molten liquid and frothed up into a fiery foam. Cooled by the expanding gases the non-volatile constituents quickly congealed into ash and pumice, the whole becoming a suspension of solids in the gases they themselves were evolving. ${ }^{2}$

The lower portions of the glaciers and the heavy snowdrifts that still lay deep in the Valley rapidly melted away before the incandescent lava. In the face of the great heat, the ice must have been converted into steam with almost explosive suddenness, adding great columns

lieved to have been exhibited by the ejecta at this stage may be imitated by igniting the powder of basic magnesium carbonate. The gas given off buoys up the solid particles so that it seethes and boils, flowing about in a manner extraordinarily like a liquid. 


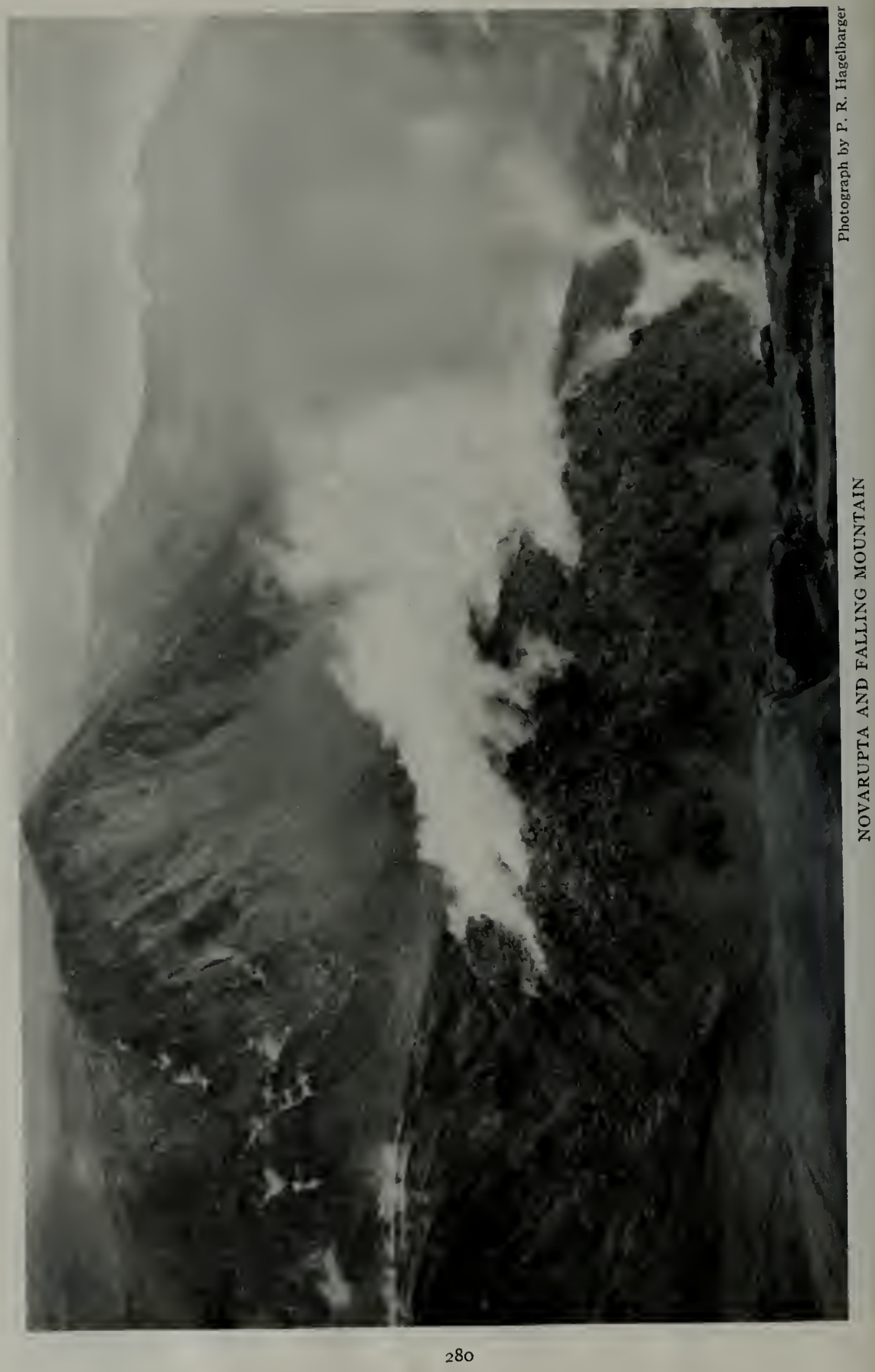


of its own to the clouds rising directly. from the lava.

\section{ROARING FIRES SIFEEP UP THE MOLNTAIN SIDE}

Almost before the snows had been dried up, the bushes began to crackle and soon roaring fires were sweeping up the mountain sides, consuming every living thing far beyond the reach of the incandescent flood.

With the smoke of the burning forest, the steam from the melting ice, and the clouds from the magma, the whole Valley must have been effectually masked. Yet the strong northwest wind which may have started even at that early stage perhaps carried off the smoke enough to reveal something of what was going on at the windward side of the burning pyre.

The misery of the wretched animals trapped in the Valley could not have lasted long. All were roasted alive, in short order. Soon their carcasses must have been cremated in the general conflagration. Under ordinary circumstances, the stench of this holocaust would have added another horror, but here it was lost in the fumes.

The odors of the fumaroles in the Valley as we found it five years later were repulsive enough. During the eruption the fumes were intolerable a hundred miles away. We may not attempt to suggest the sensations that would have smitten the olfactory nerves during the height of the cataclysm.

\section{THE YALLEY BECOMES A SEETHING FIERY TORRENT}

Long before the fires that consumed the surrounding regetation had run their course, the masses of incandescent fragments accumulating around the separate vents had probably run together until they covered the whole floor of the Valley; converting it into a single fiery torrent of seething, swirling, red-hot sand and rock, kept in continual turmoil by the constant escape of gas.

The gas presumably came off mostly in quiet ebullition, but at times it let go with violent explosions which tore wide holes in the mass of glowing fragments. These explosions must have been accompanied by the most spectacular upheavals of red-hot rocks hurled high aloft.

The fiery Valley at this stage doubtless presented a spectacle, if it could have been seen through the impenetrable black cloud, far surpassing the weirdest image of the place of everlasting torment ever conjured up by poet or preacher. Again, in default of language of my own, I resort to the description of an Hawaiian eruption: ${ }^{3}$

"At half-past three p.m. I reached the awful crater and stood alone in the light of its fires. It was a moment of unutterable interest. . . . I was I0,000 feet above the sea, in a rast solitude untrodden by the foot of man or beast; amidst a silence unbroken by any living voice, and surrounded by scenes of terrific desolation.

"Here I stood almost blinded by the insufferable brightness; almost deafened with the startling clangor; almost petrified with the awful scene. The heat was so intense that the crater could not be approached within forty or fifty yards on the windward side, and probably not within two miles on the leeward.

"The mountain seened to be siphunculated; the fountain of fusion being elevated some two or three thousand feet above the lateral crater, and being pressed down an inclined subterranean tube, escaped through this valve with a force which threw its burning masses to the height of four or five hundred feet.

"The eruption first issued from a depression in the mountain, but a rim of scoriae two hundred feet in elevation had already been formed around the orifice in the form of a hollow truncated cone. This cone was about half a mile in circumference at its base, and the orifice at the top may be three hundred feet in diameter.

\footnotetext{
${ }^{3}$ From description by Titus Coan, quoted from C. H. Hitchcock, "Hawaii and its Volcanoes," pp. $87-89$.
} 


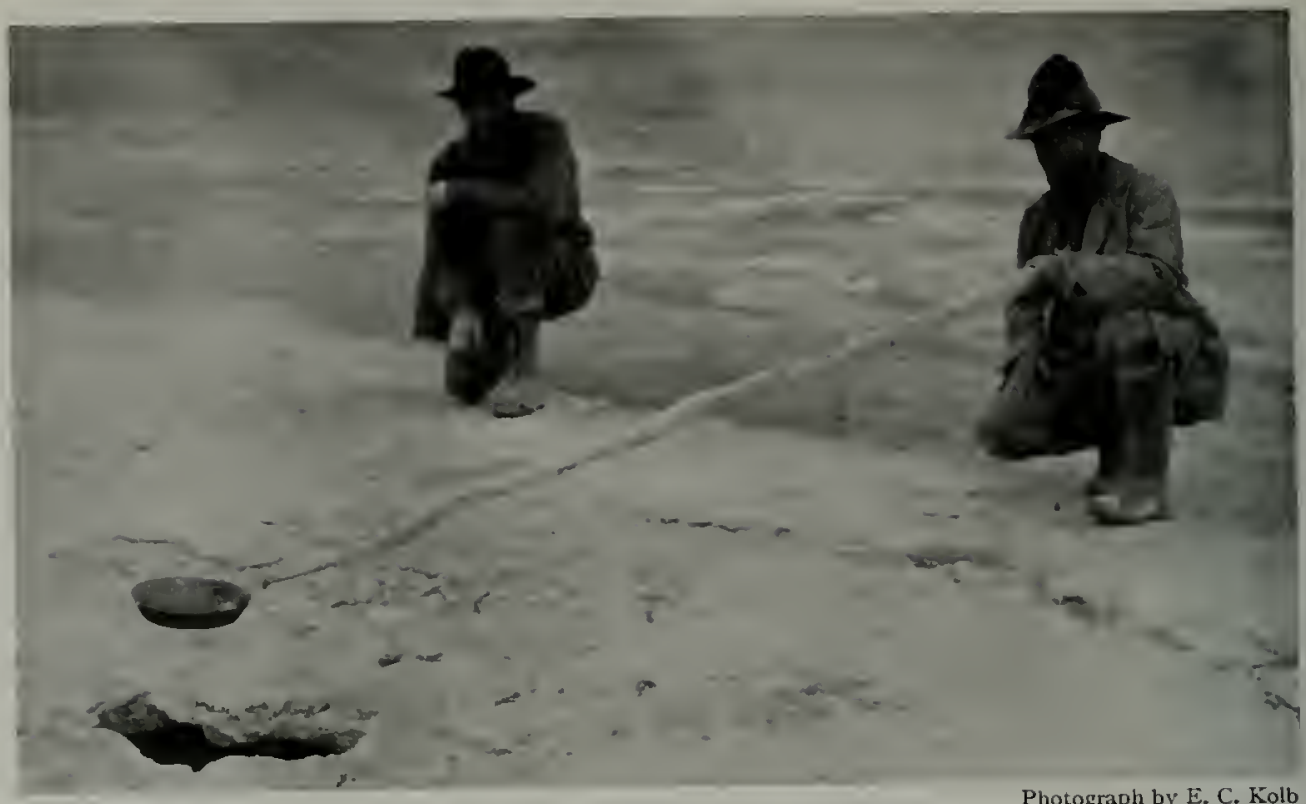

FRYING BACON OVER A FUMAROLE

It is hard to appreciate the situation from a still picture. The steam is so hot and dry as it rushes forth that it is perfectly clear. The pressure lifted the frying pan high in the air. It had to be held down against the outrushing steam (see page 225).

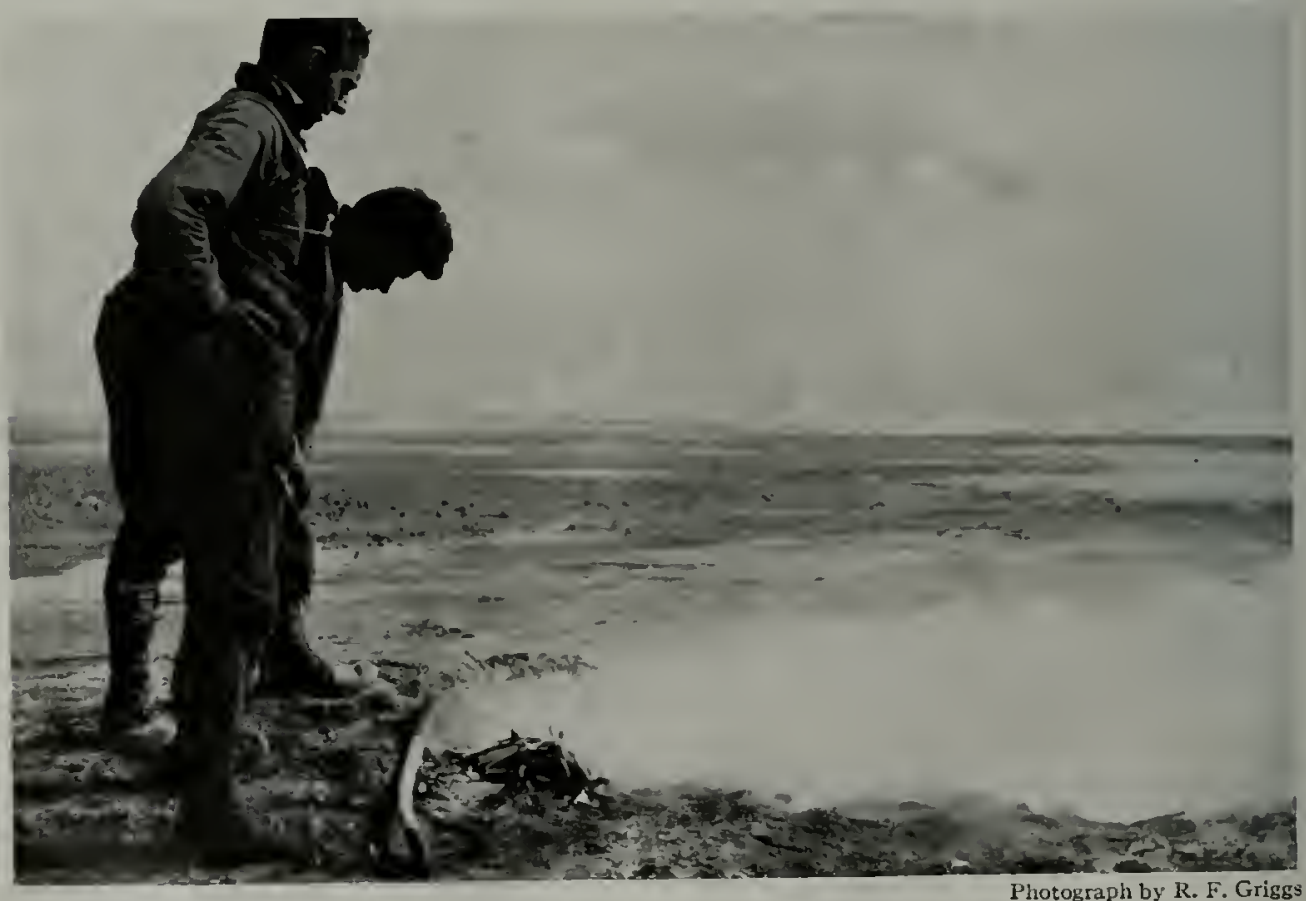

A BONFIRE KINDLED BY WATER (SEE PAGE 22I)

One of the fumaroles was so hot and dry that shavings burst into flame after being plunged for a moment into its hot vapor. Since this consisted of almost pure steam-that is to say, water-what we really did was to kindle a fire by poking a stick into water. Temperature measurements by the geophysicists showed that it was $645^{\circ} \mathrm{C}$. (nearly I $200^{\circ} \mathrm{F}$.). 
"I approached as near as I could bear the heat, and stood amidst the ashes, cinders, scoriae, slag and pumice, which were scattered wide and wildly around. From the horrid throat of this cone vast and continuous jets of red-hot and sometimes white-hot lava were being ejected with a noise that was almost deafening, and a force which threatened to rend the rocky ribs of the mountain and to shiver its adaniantine pillars.

"At times the sound seemed subterranean, deep and infernal. First, a rumbling, a muttering, a hissing or deep premonitory surging; then followed an awful explosion, like the roar of broadsides in a naval battle, or the quick discharge of pack after pack of artillery on the field of carnage.

"Sometimes the sound resembled that of I0,000 furnaces in full blast. Again it was like the rattling of a regiment of musketry; sometimes it was like the roar of the ocean along a rock-bound shore; and sometimes like the booming of distant thunder.

"The eruptions were not intermittent, but continuous. Volumes of the fusion were constantly ascending and descending like a jet d'eau. The force which expelled these igneous columns from the orifice shivered them into millions of fragments of unequal size, some of which would be rising, some falling, some shooting off laterally, others describing graceful curves; some moving in tangents, and some falling back in vertical lines into the mouth of the crater.

"Every particle shone with the brilliancy of Sirius, and all kinds of geometrical figures were being formed and broken up. No tongue, no pen, no pencil can portray the beauty, the grandeur, the terrible sublimity of the scene. To be appreciated it must be felt. . . .

"During the night the scene surpassed all power of description. Vast columns

4 It should be recognized that little, if any, of the material was transported the whole 15 miles. At frequent intervals along the way there were new vents which added their quota to the fiery flood. One of the most striking features of the of lava at a white heat shot up continuously in the ever varying forms of pillars, pyramids, cones, towers, turrets, spires, minarets, ctc., while the descending showers poured in one incessant cataract of fire upon the rim of the crater down its burning throat and over the surrounding area."

Had the quantity of gas evolved been less, the material might have remained liquid lava, as in the Hawaiian flows, and hardened into solid rock on cooling; but as it was, the rock-forming constituents of the magma were completely disrupted by the bubbles of escaping gas and blown into fine fragments which, on cooling, became ash and pumice similar to that of the typical explosive eruption.

\section{RED-HOT ASH ROLLS DOWN THE VALLEY} LIKE A LIQUID

Soon after reaching the surface, the tumbling rolling mass of glowing fragments must have begun to move downgrade toward the foot of the Valley. Aided by the quantity of gas that was still escaping from its substance, the fiery sand behaved like a liquid, adjusting itself closely to the gradient of its bed.

A dozen miles down the Valley the redhot flood encountered a belt of morainic hills that to a certain extent dammed its advance. But it quickly found a way around among these, seeking everywhere the lowest notch and flowing through it in response to gravity, almost as readily as a flood of water would have done.

In this way it continued down the Valley for 15 miles (counting its starting place as Novarupta and the Pass) before it finally came to a stop. ${ }^{4}$ After its forward motion had ceased, it continued to be agitated for a time by internal explosions, as evidenced by the craters which in places honeycomb its surface.

Valley is the close coincidence between the area of activity and the boundaries of the sandflow. It is not unlikely that the contribution of fresh magma from the lower vents supplied an important part of the material in the lower portion of the Valley. 


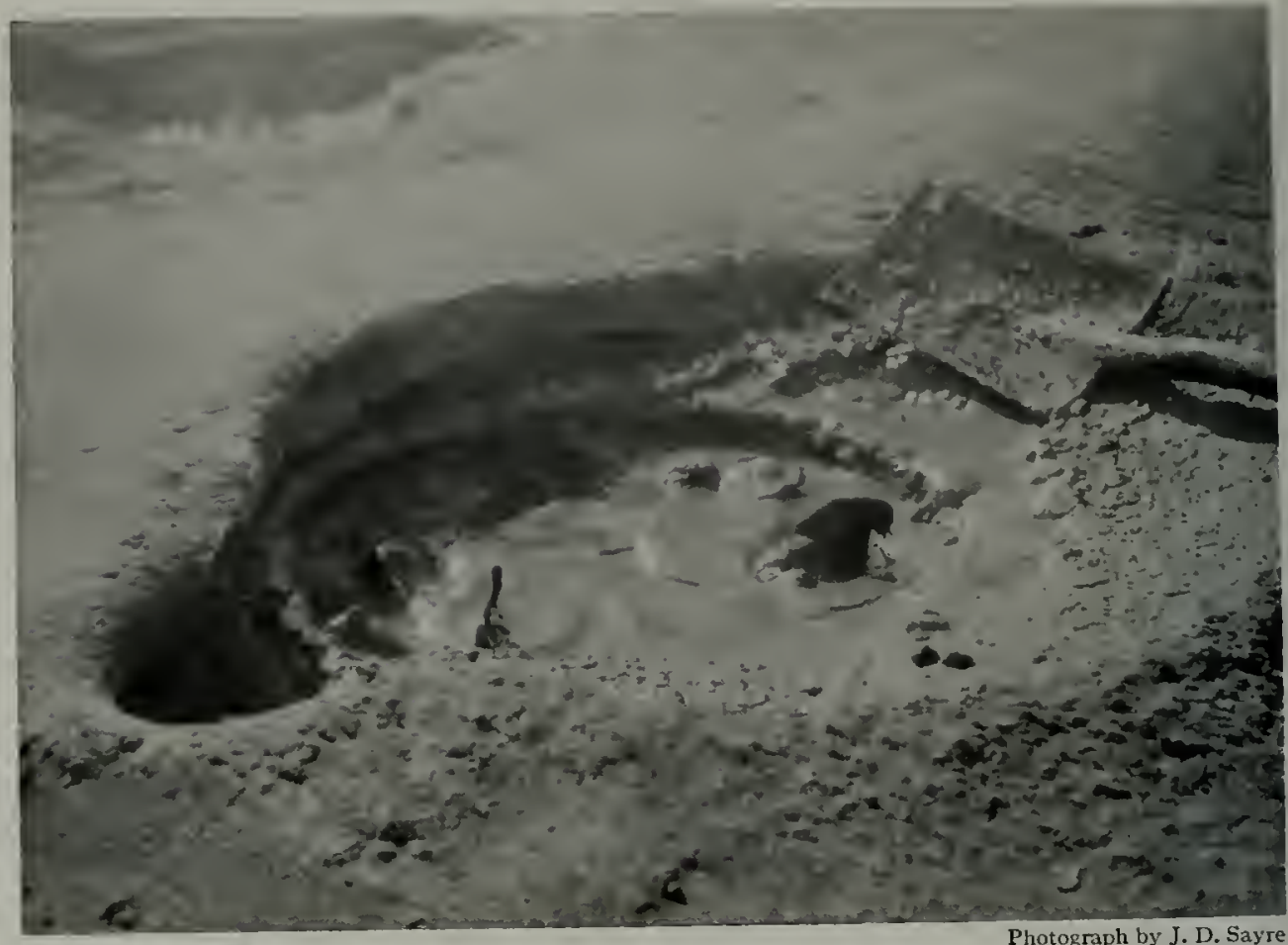

A LITTLE SPUTTERING MUD POT

Such phenomera are common in the Yellowstone Park, but by reason of the high temperatures in the Valley of Ten Thousand Smokes, they occur only where rain water that has run into small fumaroles is chumed into mud. After a few days they become fumaroles again (sec text, page 239).

\section{THE EXPLOSION OF NOVARUPTA}

The largest of the rents contributing to the Valley flood was probably Novarupta. Its action may perhaps have been more violently explosive than the others; at any rate, before the hot sand flow had fully settled down, Novarupta passed over into the paroxysmal activity of the typical explosive volcano.

Great blocks of red-hot lava ten feet long were hurled high in air, while glowing bombs nearly a yard in diameter were fired thousands of feet aloft clear over Falling Mountain to the far slopes of Mageik. Whether these large bombs could have been seen through the black cloud of rapor and fine ash given off with them is uncertain, but if they were visible their sky-rocket courses must have formed one of the most spectacular features of the whole eruption.

\section{OPENING OF KATMAI AND THE OTHER VOLCANOES}

What was going on at Katmai and at the other old rolcanoes during this early. part of the eruption, we have no means of knowing. It is not likely that they could have been altogether quict, but they were not active enough to leare behind discernible evidence of the fact among the mass of ejecta from Novarupta and the other Valley vents.

It is not improbable that the craters of Mageik and Martin had already opened, presumably with some explosive accompaniments which would have been recorded as considerable eruptions if not overshadowed by other activities of greater magnitude.

At all events Katmai must certainly have been preparing for its great explosions. Of the nature of these prepara- 
tions, we have some inkling from the character of the material thrown out, but many of the questions we most wish to answer are beyond our reach.

Among the most interesting and significant of these questions are the reasons, first, for the delay of the great explosions until after the Valley eruptions, and, second, for their beginning promptly after the extrusion of the incandescent sand.

We should have expected that Katmai would either have been set off by the shock of the bursting of the Valley or, having survived that cataclysm, would have waited until some new cause pulled the trigger to set off its magazine of accumulated destructiveness. But the mixture of the ejecta shows that before Norarupta closed its period of explosions, Katmai began its paroxysm with a riolence that far eclipsed anything that had preceded.

\section{SUMMARI OF THE EVENTS OF THE ERUPTION}

Ve do not understand the mechanism of such explosions well enough to add much to the account given in the early chapters. In closing, therefore, we shall merely summarize the events of the eruption in the order of their occurrence, for convenience of reference:

(r) A peaceful valley, covered with trees and grass, lying among dormant rolcanoes.

(2) Premonitory symptoms, especially earthquakes, sufficient to warn the natives.

(3) Rock fall from Falling Mountain, early June, I 912.
(4) Pouring out of the great hot sandflow from fissures in the Valley of Ten Thousand Smokes and its branches, covering 53 square miles to an estimated average depth of soo fect.

(5) The Smokes of the Valley begin their operation, perhaps coincident with the sandflow.

(6) Explosive activity begins at Novarupta; about one-half of a cubic mile of coarse pumice thrown out over an area Io to I 5 miles in diameter, overlapping with the explosion of Katmai.

( 7 ) Opening of craters of Martin and Mageik. (Sequence doubtful.)

(8) The Mageik and other landslides. (Sequence doubtful.)

(9) June 6th, I p.m. The first of the major explosions of Mount Katmai; responsible for first layer of gray ash.

(ro) June 6th, I I p.m. Second major explosion; second layer of ash (terracotta).

(I I) June 7 th, ro.40 p.m. Third major explosion; third layer of ash (gray).

(I2) Fourth major explosion. Fourth layer of ash (yellow).

(I3) Cap layers of fine red mud thrown out by Katmai.

(I4) Katmai Mud Flow. (Sequence doubtful.)

( 5 ) A condition of great but gradually subsiding activity, the interior of the crater retaining an incandescent heat, manifested by red reflections on the clouds as late as July 2 Ist.

(16) The end of the explosive stage, followed by a quiet evolution of vapor in great quantity from Katmai, Martin, Mageik, Trident, and the Valley until the present time. 


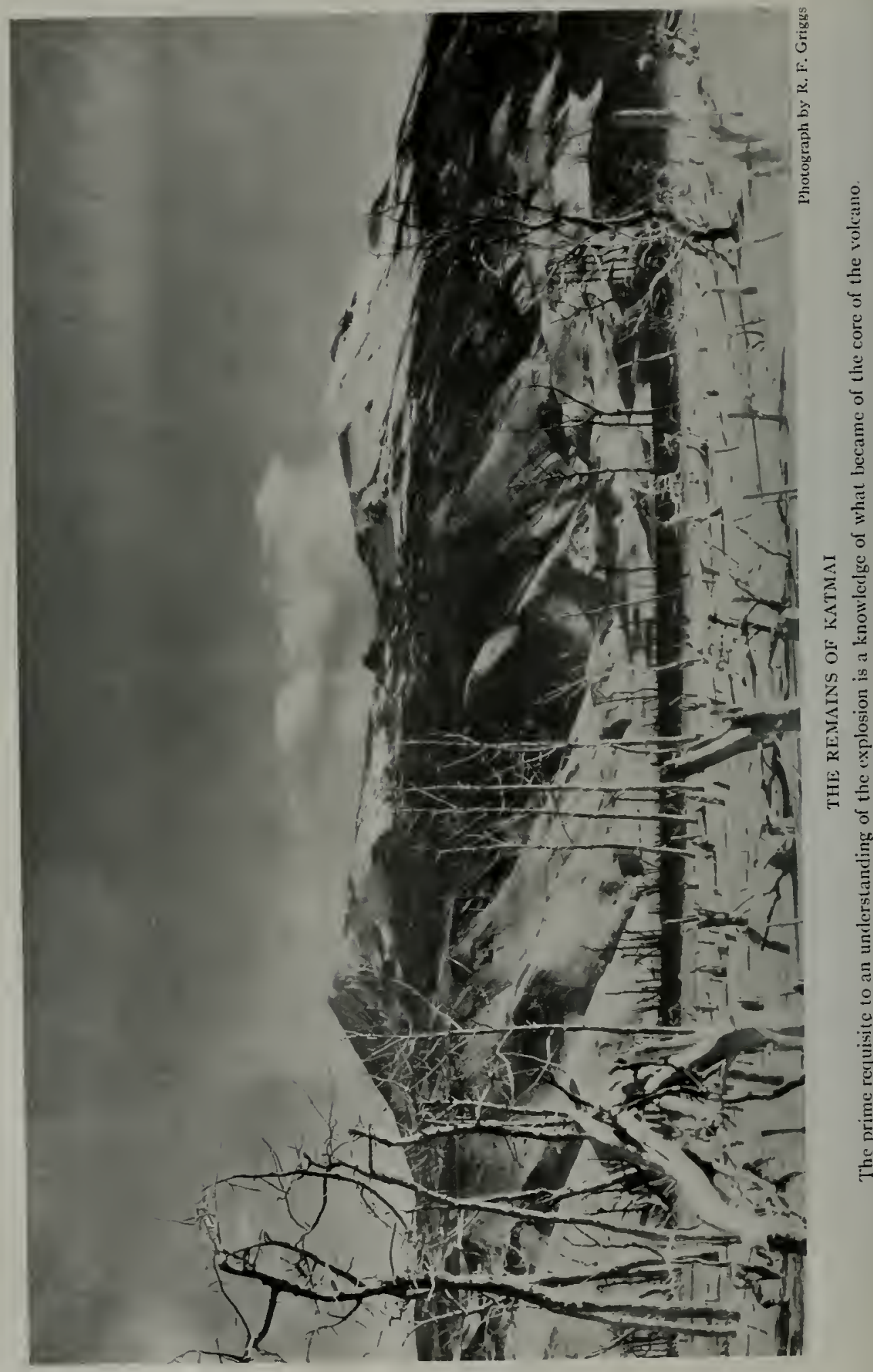


Beyond a reconstruction of the events of the eruption lies the problem of interpreting the subterranean disturbance responsible for the outbreaks observed at the surface. This is the real task of the volcanologist.

Until he has a clear idea of what goes on in the depths, it is impossible for him to understand, much less to predict, the outbursts at the surface. It is not the province of this book to develop an extensive theoretical discussion. Yet there are certain very significant facts that are apt to be overlooked unless they are considered in the light of the deductions to which they give rise.

Along with the impression of tremendous size which dominates everyone who looks into Katmai Crater, there comes to any thoughtful observer a question as to the fate of the enormous quantity of material that once occupied the stupendous hole in the top of the volcano. This may strike the reader as a superfluous query. Were not the great explosions powerful enough to blow the old mountain to atoms? Probably they were, but even a cursory examination shows that what happened was far more complex than the mere blasting away of the old rock.

ROCK OF THE ORIGINAL MOUNTAIN TOP DISAPPEARED UTTERLY

If the old mountain top had simply been blown off by explosions beneath, the slopes would be littered with the débris and one would find great chunks of it scattered about the crater. The two cubic miles of rock missing from the mountain, if spread evenly around the vent for Io miles in every direction, would make a layer 16 feet deep.

No such quantity of material could be concealed among the ash layers. As a matter of fact, the total thickness of the entire deposit of ejecta of all sorts at the base of the mountain is less than that amount.

We had expected, as a matter of course, that when we reached the volcano we should find great rocks, which had been heaved out by the explosions, and perhaps the most surprising thing observed on our first visit was the fine grain of the deposits, right up to the volcano. Everything was "blown to smithereens." In the ash and pumice, which compose the bulk of the deposit, the fragments seldom exceed six inches in diameter, the largest observed hardly reaching a foot in length.

Of the old mountain top no large pieces remain. Fragments of any size are comparatively scarce and seldom exceed a hen's egg in dimensions. All told, they would make only an insignificant fraction of the former summit.

\section{ROCK OF OLD MOUNTAIN VERY DIFFERENT FROM NEW LAVA}

It happens that the rock of the old mountain can be distinguished from the new lava at a glance. The mountain was built up entirely of flows of dark colored basic andesite, containing 60 per cent of silica. But the lava of this eruption was a white, acid rhyolite with 75 per cent silica (see page 290). This conspicuous difference makes it easy to follow in detail the action of the new magma on the old mountain.

There can be little doubt that the present hollow crater was originally occupied entirely by dark colored rock relatively poor in silica. The whole stub of the mountain as it stands to-day consists exclusively of the ends of ancient lava flows radiating from the former summit.

As the lava at the head of a flow must, almost necessarily, be the same as at 
its tip, the stub furnishes certain evidence of the character of the original summit. All the old lava is the same dark colored rock and there is no trace of the new white lava in the crater wall. The whole of the two cubic miles must, therefore, once have been filled by old dark lava.

This conclusion brings out the difficulty of the situation. If there were two cubic miles of dark rock in the beginning, and if only a fraction of it is to be found in the deposits, the rock of the old mountain was not merely renoved, it has to a large extent utterly disappeared. It could not have vanished into thin air.

Only two other methods of displacement seem possible: the whole summit may have caved in, slumping down into the void left by the extrusion of new magma; or, the new magma rising in the throat may have melted up the old rock.

COULD THE OLD MOUNTAIN TOP HAVE BEEN SWALLOWED UP IN THE BONELS OF THE EARTH?

For a whole mountain to slump away and be swallowed up into the bowels of the earth seems a catastrophe of incredible magnitude. Such an event would undermine our instinctive confidence in the solidity of the earth's crust on which we live. Yet just that process has been evoked in explanation of the famous Crater Lake of Oregon. And certainly it is quite conceivable that the emission of a vast quantity of ash might leave a cavity below big enough to receive the superincumbent mountain.

Subsidence of exactly this character occurred on a small scale in the case of Novarupta, after its paroxysm. As described in Chapter xix, the rock for half a mile round about is all broken to pieces by faults traversing it in many directions. In every one of these, the ground sank on the side toward the erater.

This means that Novarupta has settled below its former level, perhaps more than Ioo feet. Subsidence in this case was delayed, as would be expected, till after the close of the eruption. This is proved by the fact that all the ash layers, as well as the rock, are cut by the faults.

\section{NO EVIDENCE OF SUBSIDENCE}

But, according to eye witnesses, the top of Katmai had already disappeared in the early stages of its explosion. Of this we have independent testimony from two sources, in the stories of the natives of Katmai Village and of Savonoski, as detailed on page 17 .

The faults around Novarupta are straight lines, which crisscross over a considerable area. If subsidence of this type had occurred in Katmai, the result would have been a ragged irregular hole, not a clean-cut circular crater. Quite apart from subsidence, it would be expected that the terrific impact of the explosion would have cracked open the old mountain, opening fissures that would be seen radiating in every direction.

But not a break occurs in the crater walls and there is no sign of any fracture of the original contours of the mountain slopes. It seems improbable that subsidence of the proportions necessary to form an abyss like Katmai could have taken place without the formation of some faults that would radiate beyond the crater walls.

Another difficulty with the hypothesis of crater subsidence in the case of Katmai is that it involves definite and rather improbable assumptions regarding the shape of the magma chamber beneath the volcano. It would mean that the shape as well as the size of the cavity created by the eruption corresponded with the present crater; also that the reservoir lay close to the surface. Otherwise subsidence could not have produced a sharp, clean-cut hole like the present crater.

If the carity lay deep down below the mountain, the strong roof would sag gently rather than break sharply as a thin roof might. A magma chamber of the proportions necessary does not accord with the type generally supposed 


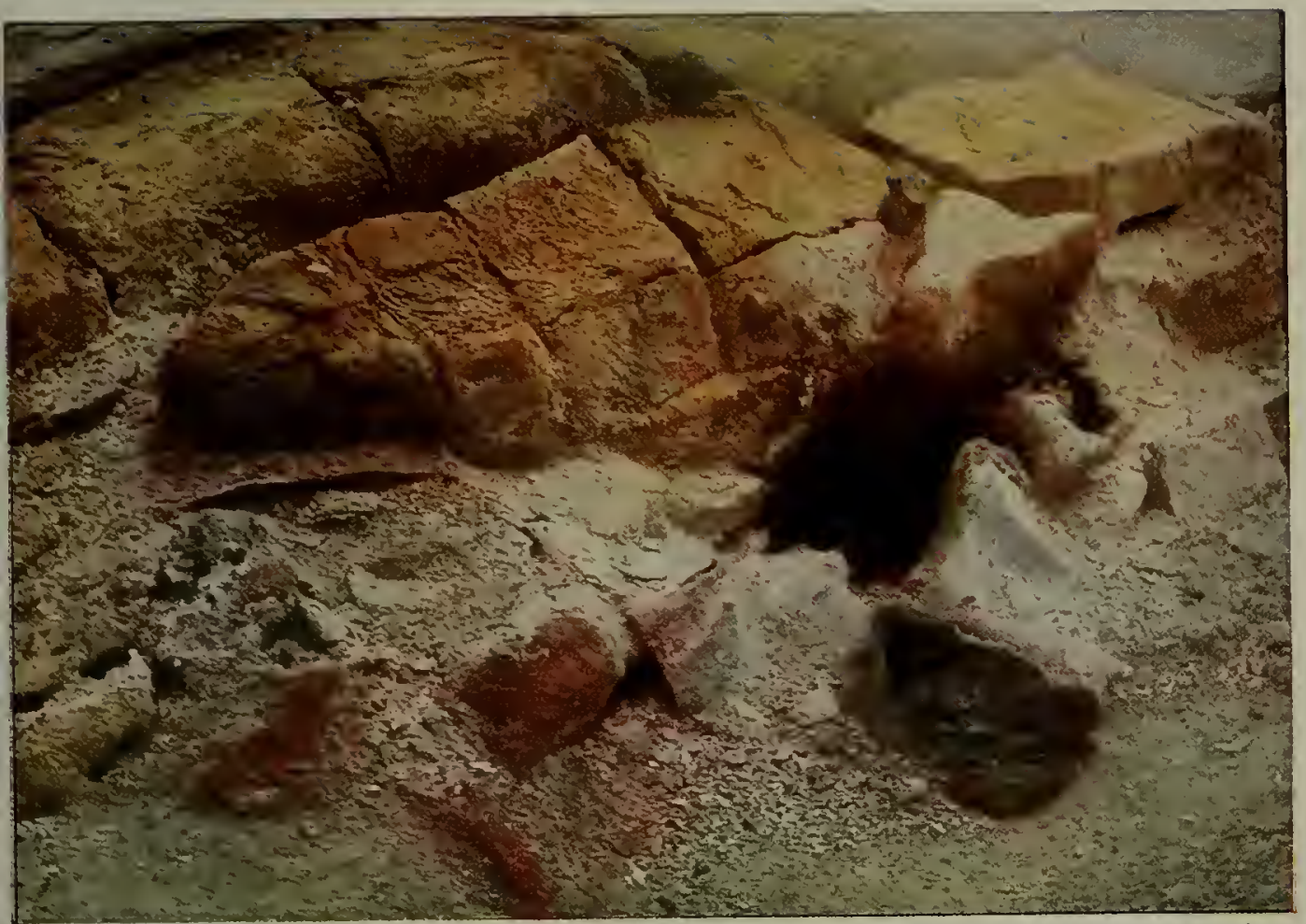

Natural Color Photograph by Frank I. Jones

HARD BAKED CRUST AROUND A SMALL FUMAROLE

The issuing steam, being perfectly clear, is invisible in the picture. 


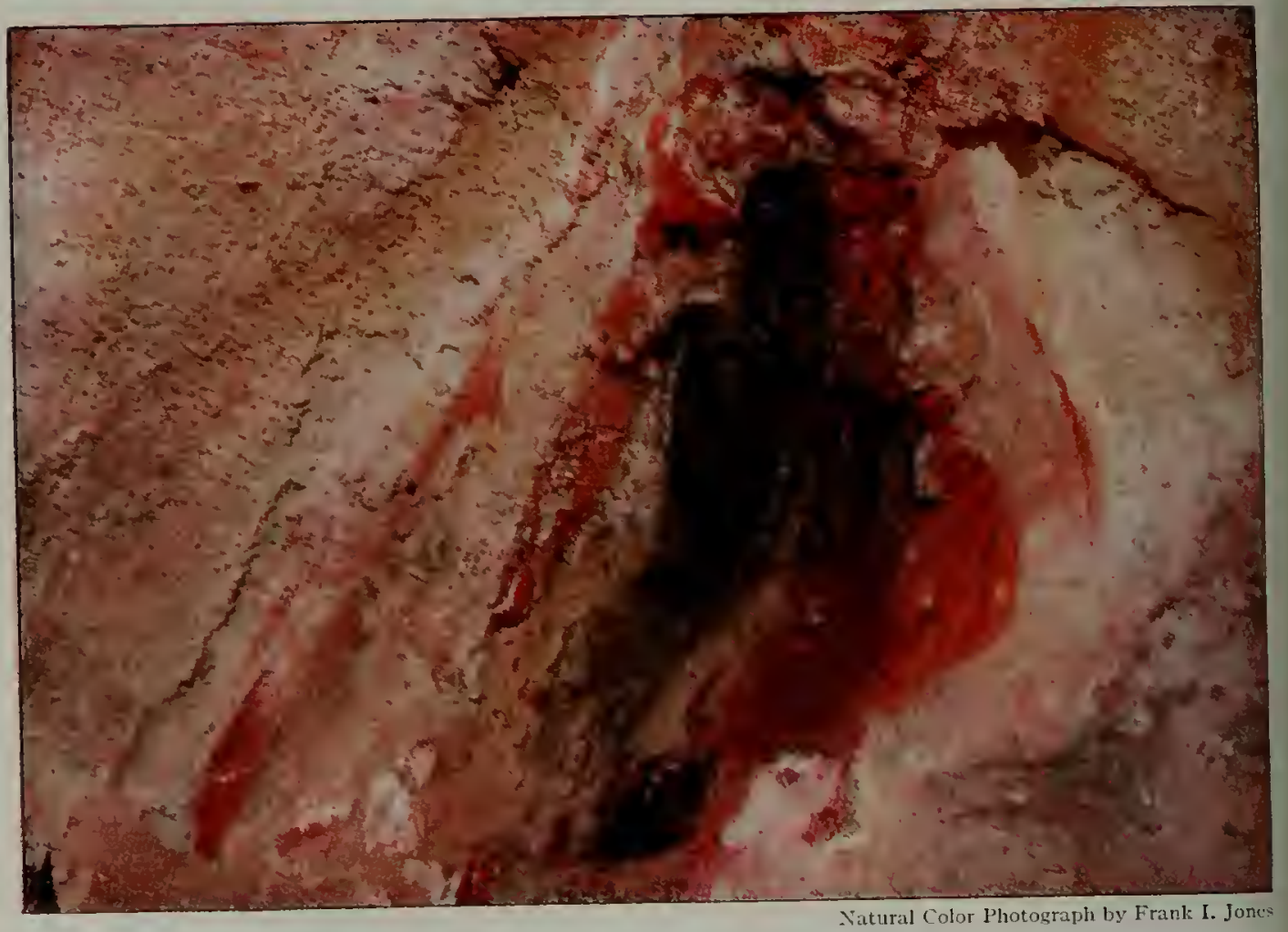

THE INTERIOR OF A FIMAROLE L.AII) BARE

A rent like that on the preceding page dissected by a stream. The darkening colors measure the increasing heat toward the throat. 
to underlie volcanoes. The reservoir commonly assumed is rather of the kind indicated by the subsidence around Novarupta.

We must, therefore, dismiss the theory of crater subsidence as highly improbable, for it seems hardly possible that such a process could have occurred without leaving more tangible evidence of the fact. ${ }^{1}$

\section{IUCH OF OLD IIOUNTAIS EATEN AWAY BY NEW MAGMA}

The third possible explanation may likewise appear improbable, yet it has the merit of being supported by a great deal of evidence of the most unequivocal sort. This is, that the old mountain was corrosively attacked from beneath by the new magma and in a large measure melted away or, better, dissolved by it.

All stages in the process of digestion are abundantly represented in the fragments blown out by the explosions. Almost every piece of pumice one picks up shows evidence of a remarkable, composite character. Everywhere, black fragments of the old mountain top are embedded in a matrix of the new white lava. Most commonly these remnants of the original rock appear as conspicuous black bands alternating with the lightcovered matrix (see page 29I).

The condition of these fragments shows that digestion of the old mountain was surprisingly thorough. Large pieces of unaltered rock are nowhere to be found; seldom do they exceed an inch in diameter, commonly they are much smaller.

\section{ALL STAGES IN THE SOLUTION OF OLD ROCK SHOTIY IX THE FRAGMENTS EJECTED}

When examined carefully either with the naked eye or, after sectioning, under

1 Slumping away of the unstable walls left by the explosion has undoubtedly played a large part in determining the present shape of the pit, and it is still occurring at frequent intervals. But this process is of insignificant proportions as compared with the disappearance of the whole mountain top in the depths of the earth, as contemplated by the hypothesis. the microscope, the included fragments show all possible stages in the penetration of the old rock by the new magma. In some blocks only the corners are rounded off where dissolved. Others are penetrated by narrow tongues of white magma. In still others the new magma and old rock are mixed together in the most intimate fashion, until the whole consists of the old minerals lying in a ground-mass which, while retaining the dark color of the original rock, nevertheless has an index of refraction characteristic of the new magma.

In other cases, all that remains are some of the old crystals. The faces of these are corroded in such a way as to show plainly that they were in process of solution when thrown out and cooled down. ${ }^{2}$

\section{ASH AT KODIAK CARRIES MANY CRISTALS FROM OLD MOUNTAIN}

The same duplex character is maintained with astonishing consistency throughout the ejecta wherever found. This remarkable feature was first recognized by Dr. WV. J. McCaughey, a petrologist particularly expert in the identification of dust particles, to whom I submitted samples of the various types of ejecta.

It developed that McCaughey was suspicious for a time that the samples of ash I had given him were "fixed." $\mathrm{He}$ found that the most abundant components were fragments of rhyolitic glass (from the new white lava) and crystals of labradorite. As these do not belong together, McCaughey felt very much as a naturalist would, if told that some newly discovered island was inhabited by giraffes and polar bears.

Except that all the samples from what-

${ }^{2}$ Even where none of the matrix of the rock remains with these crystals, there can be no question of their derivation from the old wall rock. They are for the most part plagioclase feldspar of the variety known as labradorite, exactly like those found in the andesite of the old mountain. The feldspar of the new magma, on the other hand, is of very different character, not to be confused with the labradorite of the old mountain. 

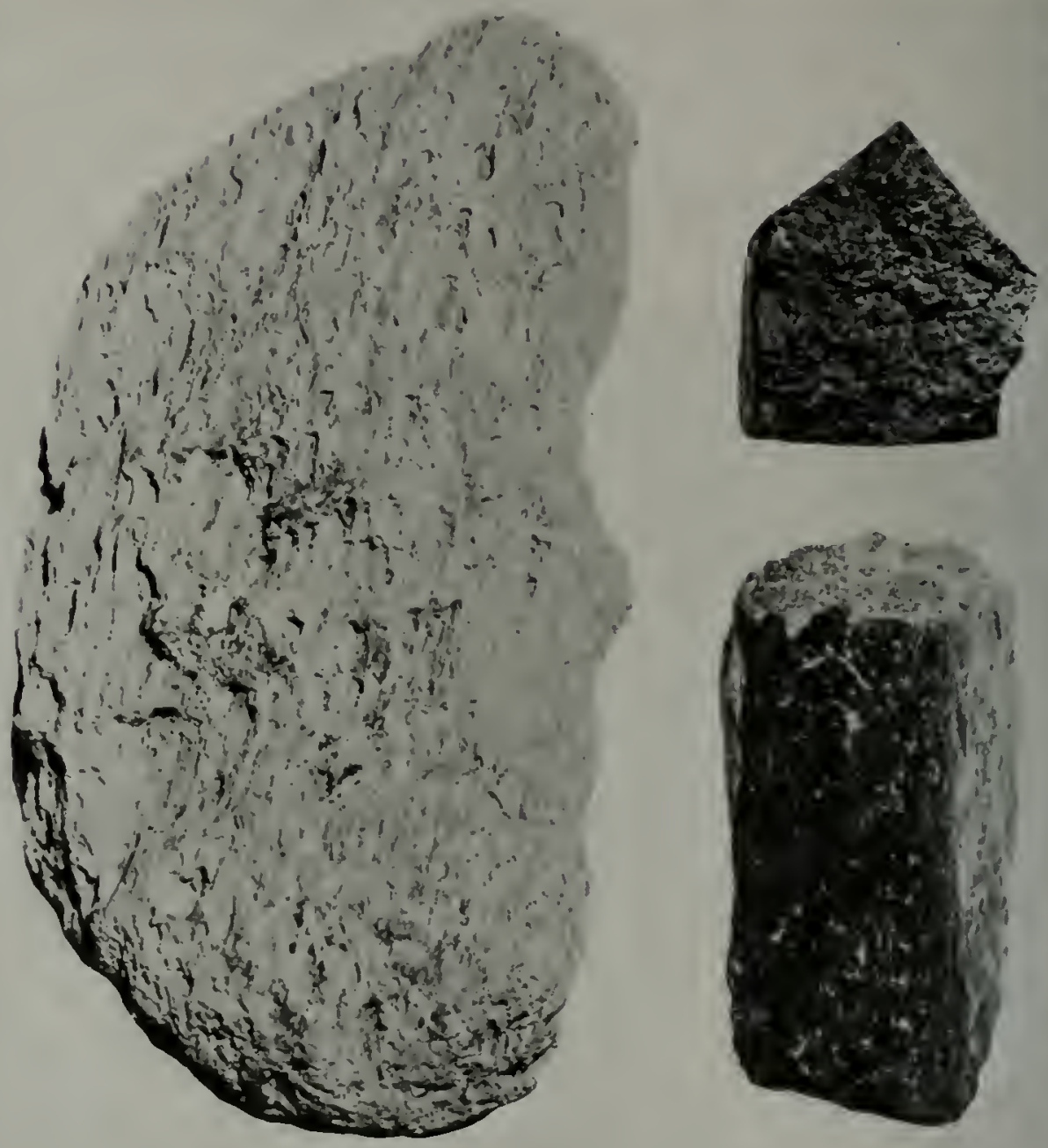

Photugraph by E. L. Wishard

NEW AND OLD LAYAS FROM KATMAI

Left: A very large piece of white pumice composed of new rhyolitic magma, silica content 75 per cent. Right: Two views of a column of old black anclesitic lava from a flow near the base of the volcano, silica content 60 per cent. Onc-half natural size.

ever source, whether Kodiak, Katmai Village, or the foot of the volcano, showed the same mixture, he would probably have rejected them unceremoniously as frauds. My reputation was not cleared until thin sections of the larger pumice stones, which meanwhile had been prepared, were examined with the microscope. Then the whole story of the dissolution of the old mountain top in the new magma was laid bare.

MUCH OF THE OLD ROCK PER.MEATED WITH G.ASES FROM TIIE NEW MAGMA

In the larger pieces of pumice there is a marked difference in the density of the white ground mass and of the intervening black bands. The new lava is 


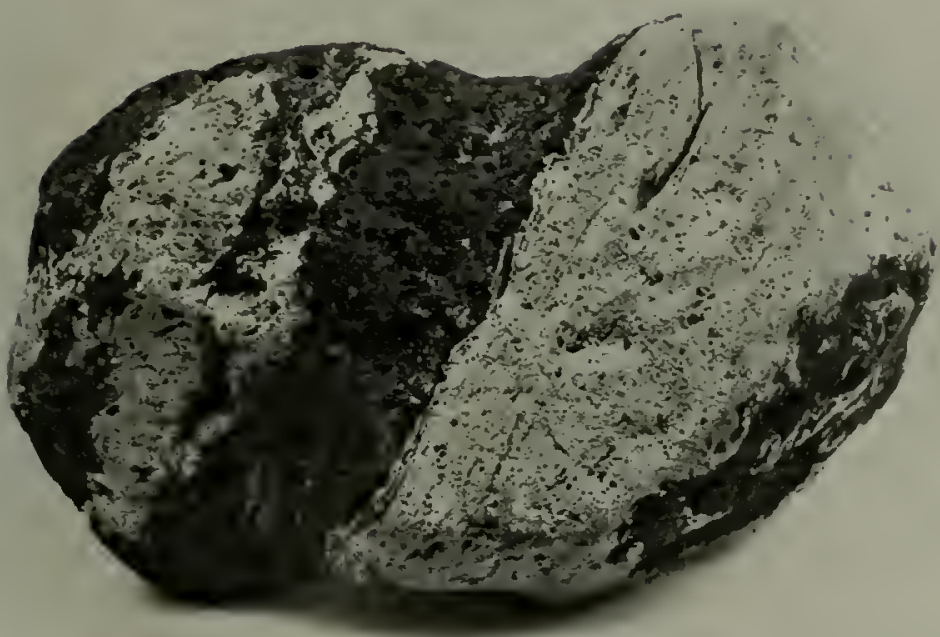

Photograph by E. L. Wishard

MIIED PUMICE FROM KATMAI

The white material is new lava, the black, old. Portions of the old lava in process of solution when solidification occurred are strenn through the white mass. Natural size.

generally much more porous, indicating that it had a much greater content of expansible gases. There is evidence also that the new component was more fluid. This is as would be expected. Compare the fluted cornice structure of lava in Novarupta (see page 296).

Yet even the black bands are very much more vesicular than the old lava from which they were derived. These dark masses as well as the light material often frothed up into a pumice. When this happened they also must have been heavily charged with gases that had diffused into them from the new magma.

The thoroughness with which the fragments are torn apart points in the same direction. If the mass had been less completely permeated, the heavier, inert, unaffected portions would have been thrown out in large unaltered blocks, such as we had expected to find on the mountain sides.

The fact that unaltered pieces of the old mountain are so small and so scarce is eloquent testimony of the completeness with which the exploding mass was penetrated by the gas from the new magma.

In the thoroughness with which its products were disrupted, Katmai stands at the very extreme of explosive volcanoes. Very rarely do all the products of an eruption show anything like such a fine degree of subdivision as the ash of Katmai.

\section{TEMIPERATURE OF THE NEW MAGMA} LOW - LESS THAN $I, 000^{\circ} \mathrm{C}$.

The thoroughness of permeation by the new magma raises the question of the means by which that penetration was accomplished. As will be seen, part of the old rock was dissolved in the pool of lava that occupied the top of the mountain during the eruption. This will be discussed in its turn. But before the magma reached the crater it had to eat 


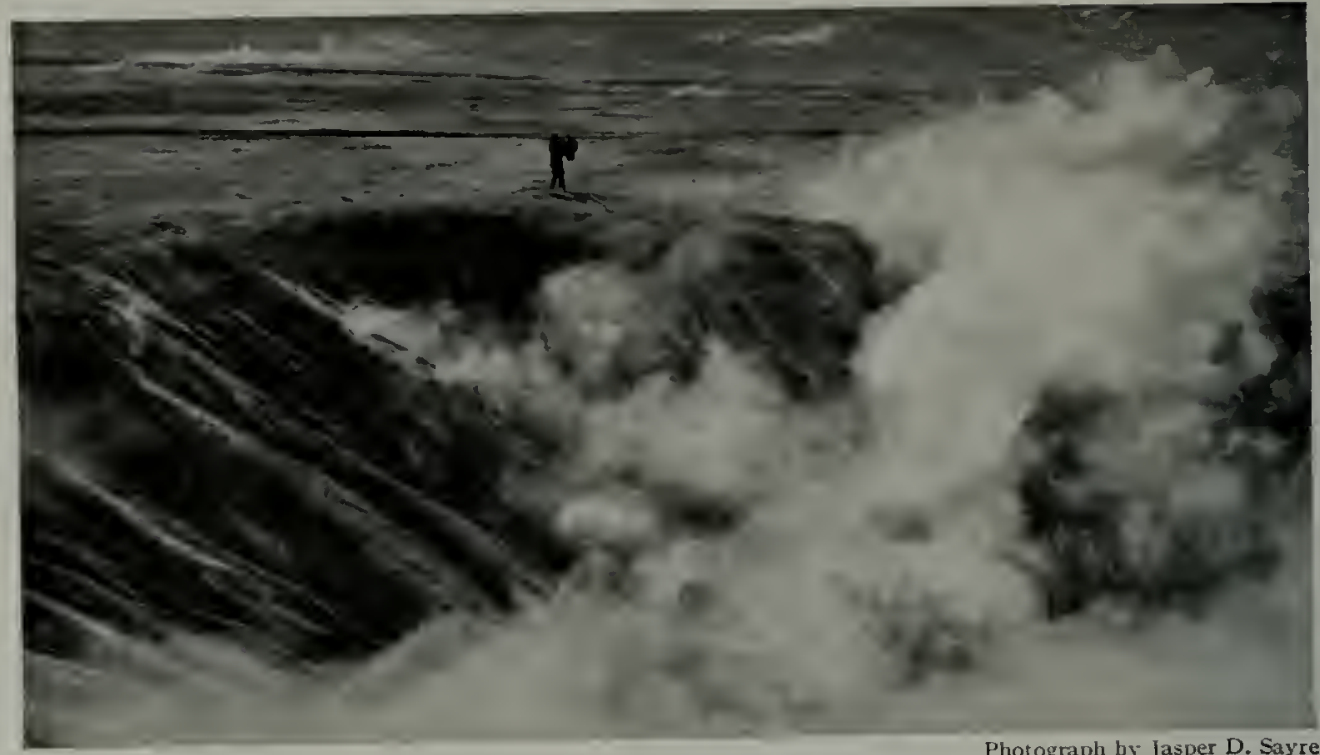

THE INTERIOR OF ONE OF THE CRATERS

The distorted perspective makes it impossible to get a satisfactory photograph of the interior of these yawning pits.

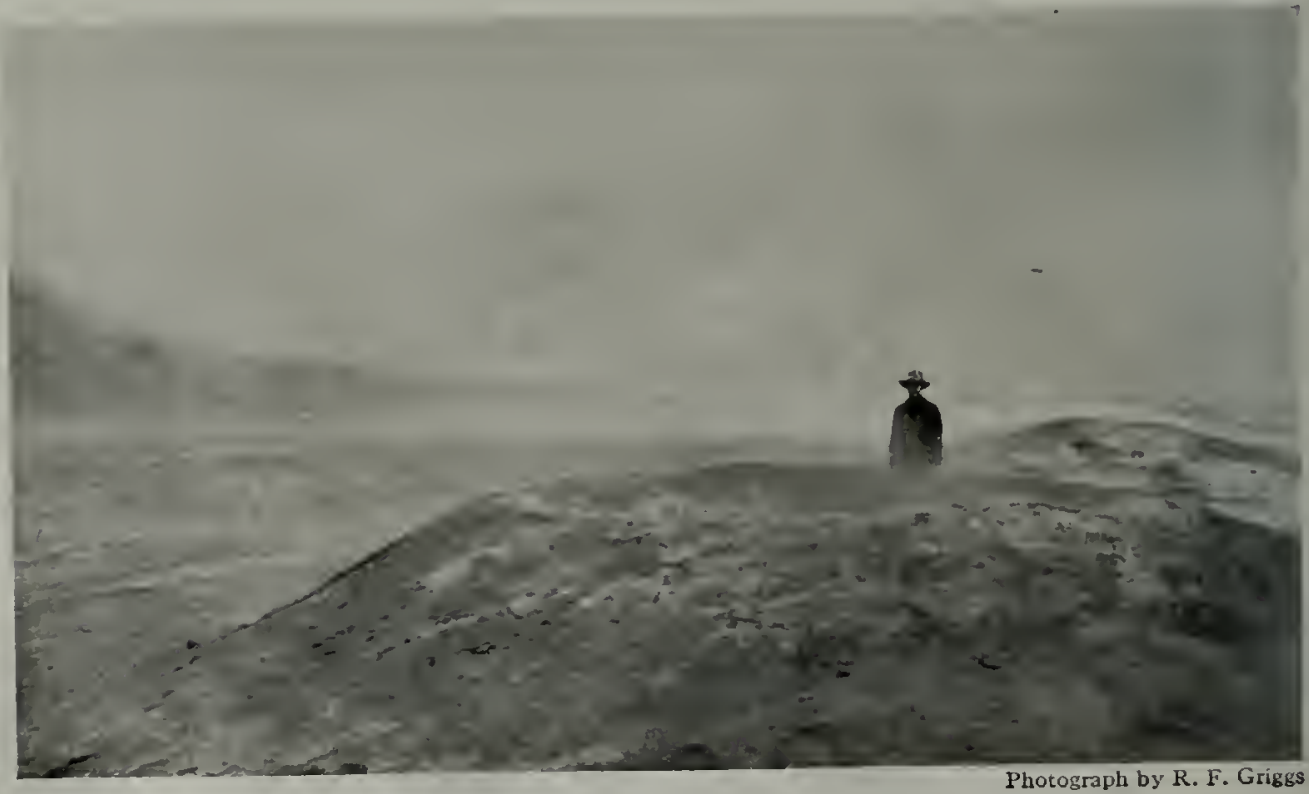

A LINE OF SMALL CRATERS ALONG A FISSURE

These miniature craters show the relations of the chains of volcanoes along great world fissures. The presence of numerous lines of craters strung along fissure lines strongly suggests that the fractures are fundamental, reaching down to the magma chamber below. 
its way through an unknown but certainly considerable thickness of old rock, forming the solid summit of the mountain.

Was the rising magma so hot that it could melt away the old rock without being chilled to the point of solidification? Assuredly not. There is good evidence that its temperature was low, probably lower than the melting point of the old rock.

It so happens that the new lava contains crystals of quartz, which is a firstclass "geological thermometer." In consequence of the properties of quartz, "we can be fairly sure that a temperature of less then $\mathrm{I}, 000^{\circ}$ prevailed " 3 in the magma.

As the melting point of the old rock can hardly have been much below $1,000^{\circ} \mathrm{C}$., and may have been considerably higher, it is clear that melting (in the strict sense) can not have occurred to any great extent. What happened was, rather, a process of solution. It was the enormous surcharge of gas carried by the magma that permitted it to attack the old rock, dissolving it somewhat as a lump of sugar dissolves in water or in an unsaturated sirup. 4

\section{ALL THE ASH COULD BE PACKED INTO THE CRATER}

A comparison of the material thrown out from Katmai with the size of the hole in the mountain gives further significant information concerning the nature of the eruption.

The volume of all the material ejected, as it lies on the ground, is estimated as 4.75 cubic miles (see page 29). Determinations of the specific gravity of a

${ }^{3}$ Fenner, Jour. Geology, vol. 28, p. 602, I 920. Under atmospheric conditions quartz cannot exist above $870^{\circ} \mathrm{C}$. At that temperature it changes to tridymite. The inversion point would probably be raised by the great pressure to which the magma was presumably subjected. "A thickness of 20,000 feet of rock strata might possibly. raise it $100^{\circ}$, but we can be fairly sure that a temperature of less than $\mathrm{I}, 000^{\circ}$ prevailed."

"Chemists draw a sharp distinction between melting and solution. A mineral melts over a fire only at a definite and constant temperature, but it may be dissolved in greater or less degree

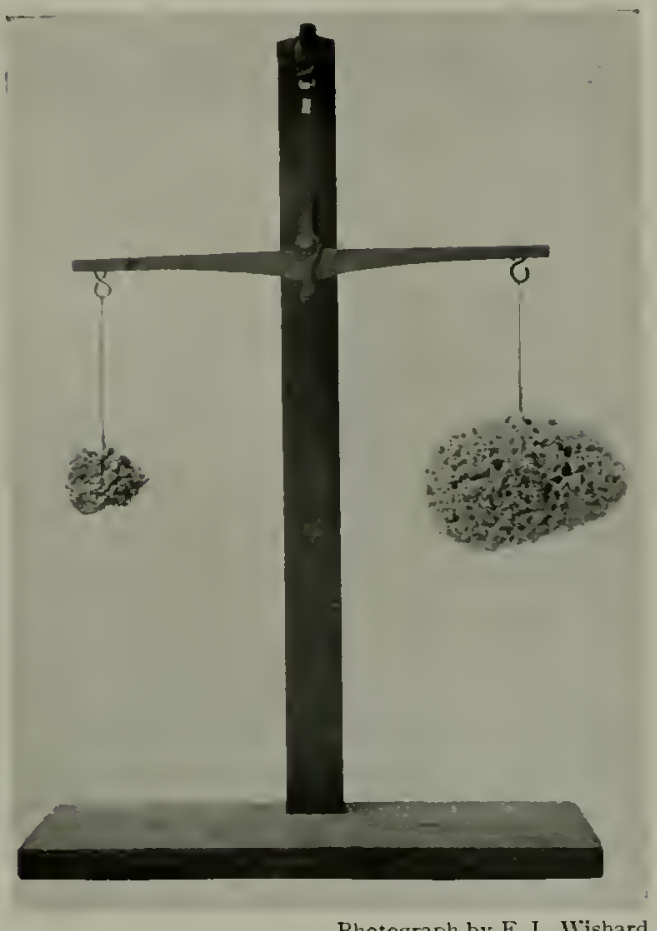

FROTH FROM THE LAVA LAKE AND AN EQUAL WEIGHT OF GRANITE

The two have the same chemical composition and were derived from similar magmas. If the pumice had solidified in the depths of the earth it would have become granite. Comparison of the densities of the two show that the pumice liberated twelve times its own volume of gas.

number of representative samples of different degrees of fineness average $\mathbf{I} .03$. That is to say, the ash is slightly heavier than water. Samples of the rock of the old mountain uniformly have a specific gravity of about 2.5. If we may assume that this represents the original density of the mountain top, we can compute the volume the ash would at any temperature, depending on the composition of the solvent. The new magma was in reality a mutual solution of many rock-forming constituents, together with quantities of volatile components, steam, acid gases, and other substances. Such a complex solution remains liquid at a temperature far below the melting point of the solid lava formed after it has been extruded and its vapors have been permitted to escape. Similarly, an excess of gases in a magma would give it a power of dissolving old rock far beyond what would be expected if its temperature alone were taken into account. 


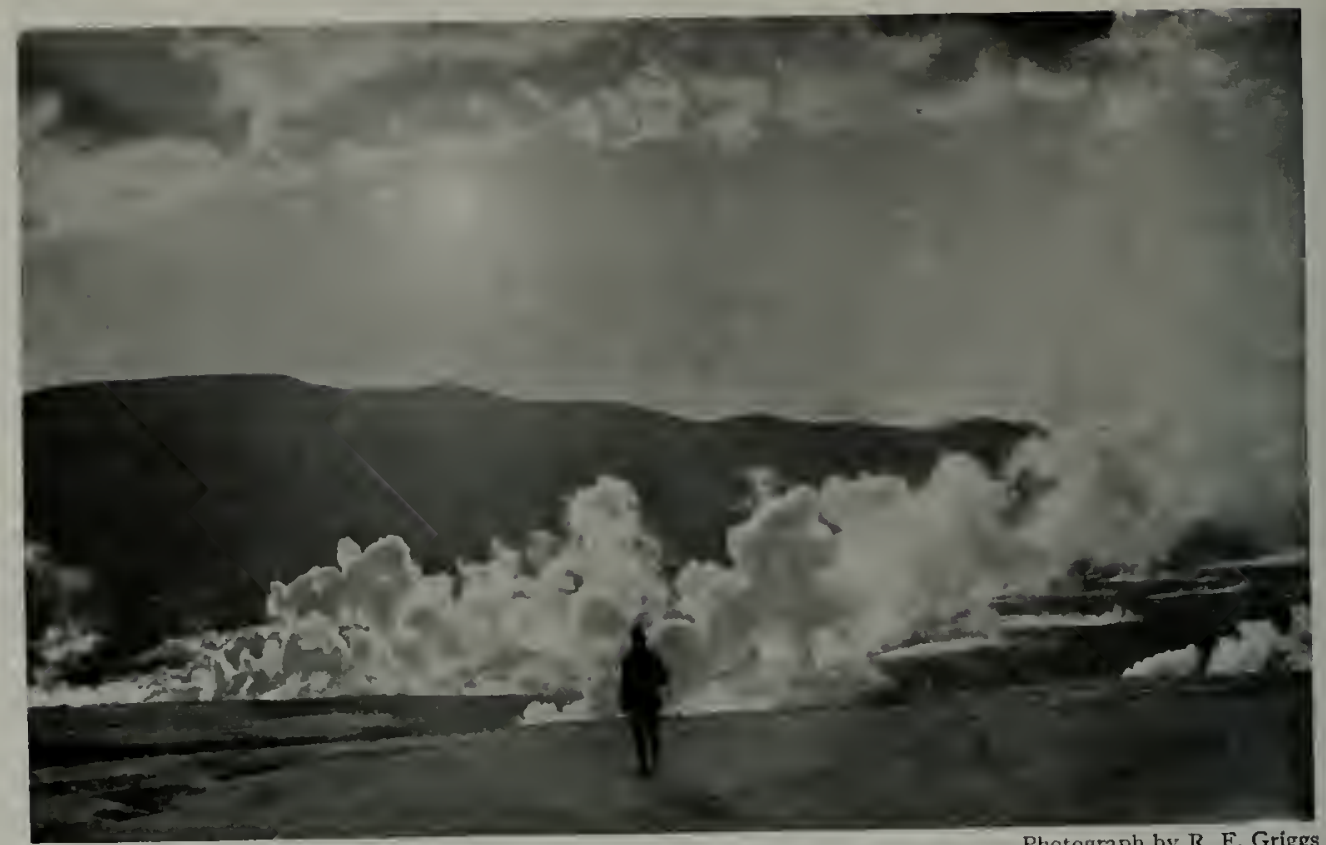

Photograph by R. F. Griggs

\section{FUMAROLES AT THE NORTHWEST CORNER OF BAKED MOUNTAIN}

One of the most active areas in the Valley. The temperature as measured was not especially high, but the quantity of heat delivered was enormous. The smoke of one of these fumaroles had a curious pink tinge, visible in every light.

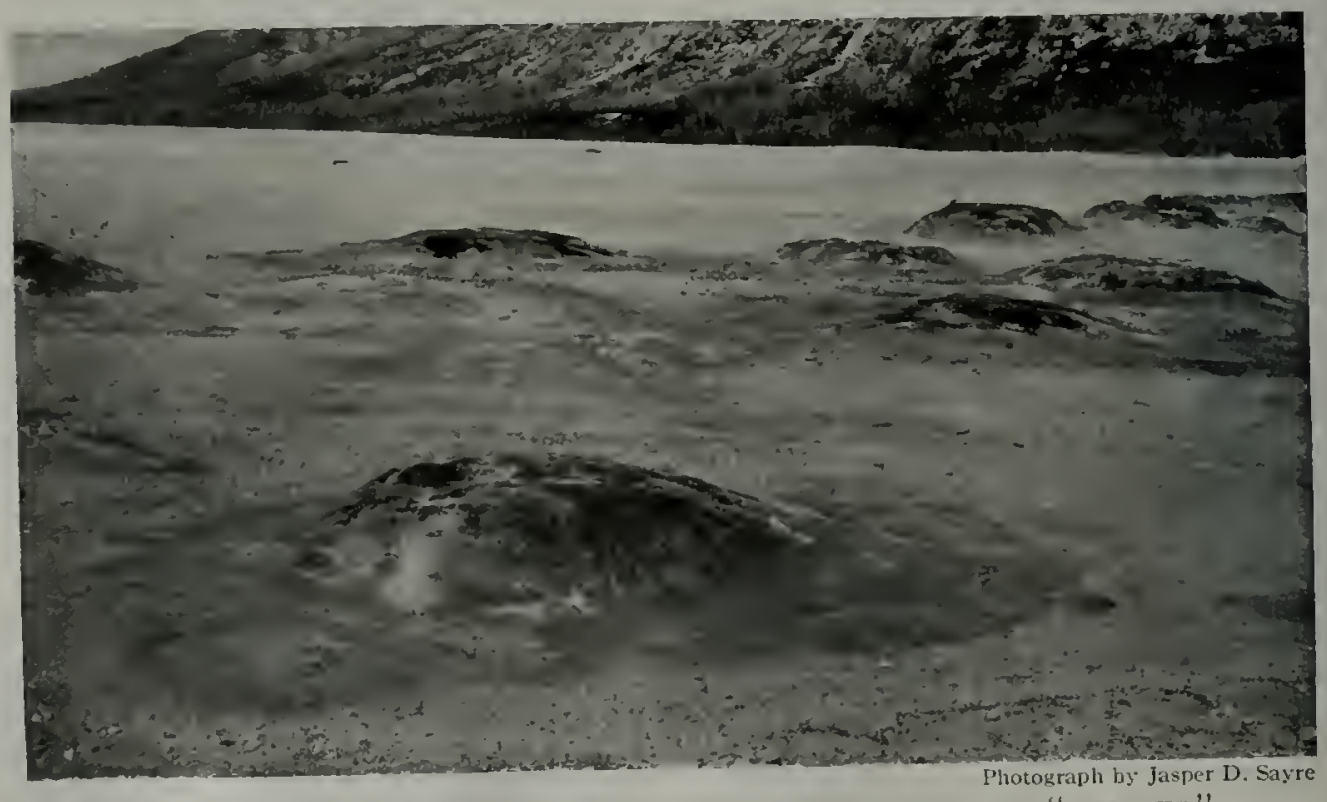

A GROLP OF THE SMALL FUMAROLES FNOWN TO THE BOYS AS "PIMPLES"

The moisture of the emanations catches blowing sand and builds up the pile. The forested slopes beyond the limits of the sandflow are the base of Katolinat. 
occupy if compressed to the density of the old rock, and compare directly the ash with the amount of rock missing from the mountain. The difference will thus give us a rough estimate of the quantity of new magma that rose from the depths during the eruption.

A sinple multiplication brings out the astonishing information that the mass of the material thrown out was substantially equivalent to that of the old rock missing from the mountain. ${ }^{5}$ In other words, the whole of the ash could be packed into the crater, if it were compressed to the density it occupied before exploding!

If this comparison is valid, it must mean that little additional magma came up from the depths during the explosion. The greater part of the huge amount of new material in the ejecta must already have been present in the mountain before the explosion began.

\section{A PORTION OF THE OLD MIOUNTAIN SEEMS TO HAVE SUNK INTO THE DEPTHS}

If the ash deposits as they stand are the substantial equivalent of the material that formed the old mountain top just before the explosion, the problem of the disappearance of the old mountain top takes on a new aspect.

It is clear that the greater part of the

5 The computation is as follows: Cubage, ash, 4.75 cubic miles $=25,800,000,000$ cubic yards of density 1.03. Rock blown off the old mountain: I 1,000,000,000 cubic yards of density 2.5 .

$$
\frac{11.0 \times 2.5}{25.8 \times 1.03}=\frac{27.5}{26.6}=103 \text { per cent. }
$$

That is to say, the hole actually appears 3 per cent bigger than the ash that came from it.

The fact that these figures so nearly correspond is, however, of no particular significance, because each term of the proportion is subject to large and uncontrollable errors. Nevertheless, the estimates are unbiased. They were made independently by different persons, with no thought of their ever being compared in this fashion. Each was, moreover, checked in every way possible.

The estimate of ashfall was made by summing the contours of ash of different depths. The data were not sufficient to permit more than a very rough estimate. ash is derived from new magma, decidedly less than half being directly traceable to the old dark rock. 'That is to say, a considerable portion of the old rock must have been replaced before the explosion. What became of it?

How did the new magma squeeze into a solid mountain? Dissolving up the old rock does not eliminate its materials. After solution was complete the complex must have occupied nearly as much space as the two components had before intermingling.

Even a half-and-half mixture would have required the addition of two cubic miles of new magma, enough to double the height of the mountain. That the outer configuration of the mountain was not materially altered before the beginning of the explosions, we may be sure.

There seems only one possibility: old rock to an amount equivalent to the rising magma must have been displaced downward. The new gas-charged liquid magma was undoubtedly less dense than the old solid rock. Consequently, any blocks of the latter which might become detached from the roof or wall of a chamber filled with the new liquid magma would certainly sink, if given time enough.

A mass of n11agma pressed upward with great force, and penetrating the joint planes of the adjacent rock, would almost

The cubage of the rock carried off the mountain top originally estimated by Maynard has been independently computed by Sayre, Hagelbarger, and myself from the reconstruction of the mountain. Maynard's figure was found to be close to the mean of the other estimates.

The specific gravity assumed for the old mountain top would probably hold, if the mountain at the time of the eruption had been composed entirely of old rock. Since, as will appear, it must have been to a large extent filled with new magma, the figure given is undoubtedly too high. Allowance for this error would make the quantity of ash somewhat larger than the holeperhaps as much as Io per cent. But it would not vitiate the general conclusion.

It cannot be held, therefore, that nothing at all was thrown out except the disrupted fragments of the mountain, yet it is safe to conclude that extrusion of additional matter played at most only a small part in the eruption. 


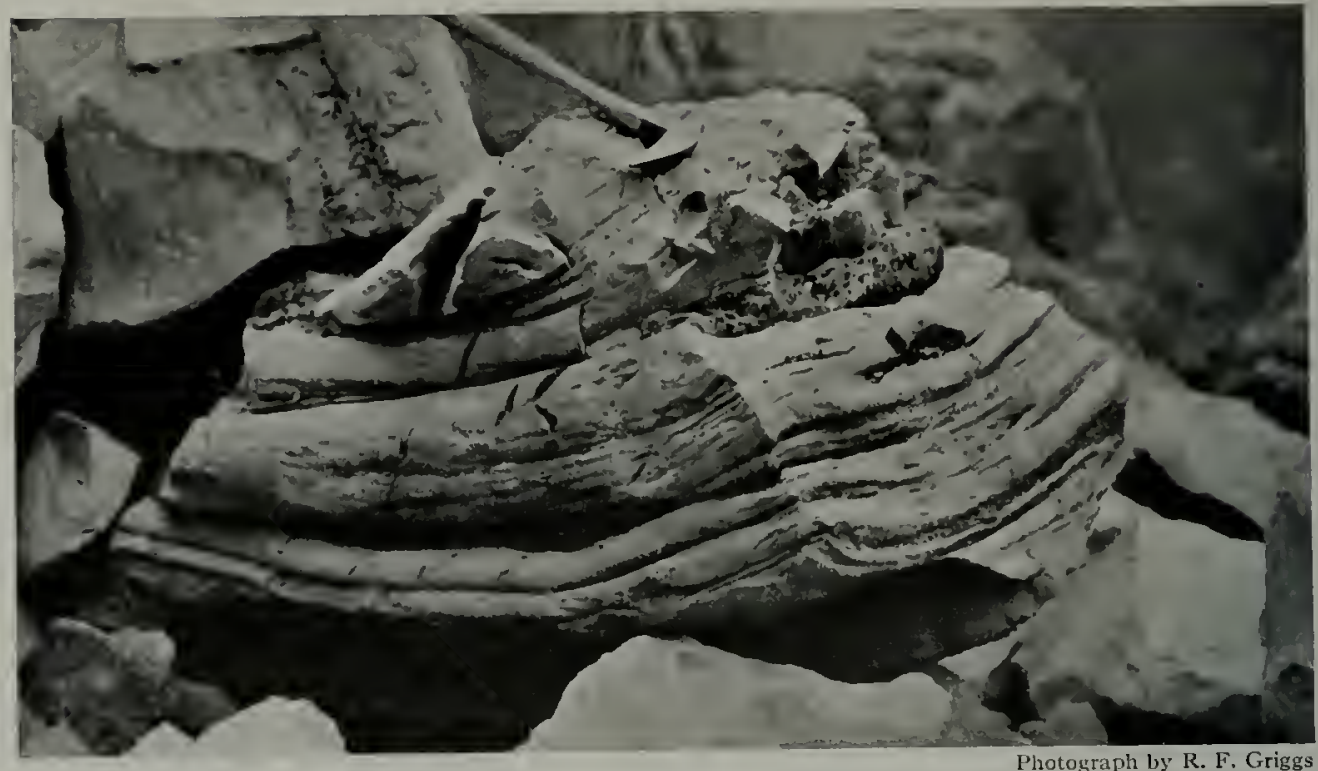

CORNICE STRUCTURE IN A BLOCK OF LAYA ON THE PLUG OF NOVARUPTA

It is evident that flowage took place after the block was broken loose. It is noticeable that the darker bands of old lava were less fluid than the alternating light bands of new lava, for they alone oozed out.

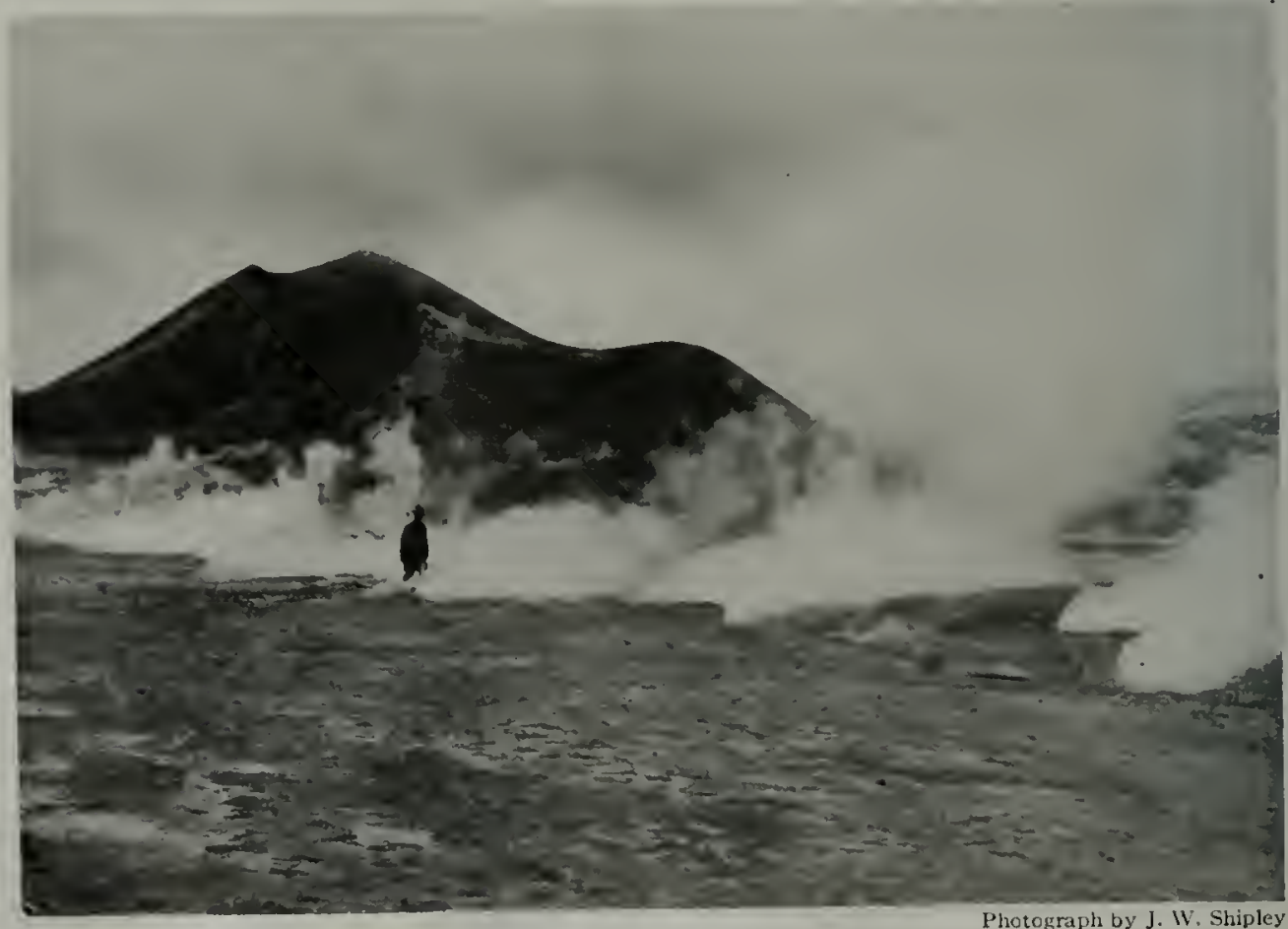

Photograph by J. IV. Shipley

MOUNT CERBERUS LYING ACROSS THE HEAD OF THE VALLEY LIKE A CROUCHING ANIMAL GUARDING THE ENTRANCE TO HADES

In the forcground a closer view of one of the lines of fumaroles shown on page 234 . 
inevitably break off loose blocks. In this way, the whole interior of the mountain could have been gradually replaced without any external disturbance. ${ }^{6}$

There is no means of estimating how large a part such "overhead stoping" may have taken in the removal of the old mountain. But it can hardly be doubted that a significant fraction of the missing dark rock is to be thus accounted for. Perhaps it was the major factor in its disappearance.

It is interesting to recall in this connection that the banded lava in the plug of Novarupta (see page 240) and the sand of the Valley show the same dual character as the ash from Katmai.

Novarupta and the other Valley vents were undoubtedly fed from the same magma chamber as Katmai. The synchrony of the eruptions leaves no doubt of that. What would be more probable than that the andesitic components in their lava were due to contamination by fragments of old rock from Katmai in process of sinking into the depths? ${ }^{7}$

EXPLOSIONS APPEAR TO HAVE STARTED AT THE SUMMIT OF THE MOUNTAIN - NOT IN THE DEPTHS

The remarkably fine fragmentation of the ash from Katmai leads to another deduction of much importance to an

6 This theory of "overhead stoping" has been elaborately worked out by R. A. Daly (see his "Igneous Rocks and their Origin"). As this is still a matter of controversy in some quarters, I have hesitated to follow it in a book of this sort, whose aim is to avoid taking sides on disputed questions. But the facts observed in the field almost compel a statement in terms of the theory of overhead stoping.

${ }^{7}$ Fenner thinks that the admixture of basic materials in the deposits of the Valley was probably due to the digestion of glacial bowlders which covered the Valley floor. But this explanation cannot be applied to the banded lava in the throat of Novarupta which, though never subjected to contamination from outside sources, shows fully as much admixture of andesitic components from old lava as any other.

Fenner's reason for supposing that the basic components were derived from glacial bowlders is that, "The limited degree of mixing of solutions shown by these specimens hardly permits us to understanding of the volcanic mechanism. My preconception of a volcanic explosion was that the magma, heavily charged with gases, bored its way upward until it reached a place where the weight of rock above was less than the expansive force of the gases confined below, when the lid was blown off and all the magma accessible to the newly opened orifice frothed up explosively.

The series of explosions which make up an eruption was supposed to be due to the rise of successive portions of the magma body through the conduit. This is the view generally held.

It is plain that no such theory fits the facts here. If the magma rising in the throat of the volcano had possessed anything like the explosive energy it later manifested, the inert crust over the top of the mountain would have been thrown off in short order. If this had occurred, remnants of the shell would certainly be found beneath the ash layers. But as a matter of fact, "the bottom of the deposit seems actually to contain less of the old rock than any succeeding stratum." 8

\section{A MOLTEN LAKE IN THE CRATER AT ONE STAGE}

Not only were the explosions delayed until after the crater was unroofed, but suppose that the solvent action was long continued." (Op. cit. p. 583.)

As a matter of fact, however, we have no real knowledge of the time element in the case. We only know that digestion was incomplete. Many able authorities deny that assimilation can occur at all, except perhaps on a very small scale.

It is only the absolutely inescapable character of the evidence that has induced both Fenner and myself to assign so much importance to it here. If, then, a magma is but rarely sufficiently charged with surplus energy to attack foreign rocks on a large scale, it might be argued $a$ fortiori that when assimilation does occur it proceeds slowly. Yet it is clear that if all the assimilation observed occurred during the brief period of the eruption, it must have been a rapid process.

But, below ground, no time limits are assignable, for no one can guess how long the present outbreak may have been brewing. The digestion of the old rock may have been going on below the region for centuries, for aught we know.

${ }^{8}$ Fenner, op. cit. p. 603. 


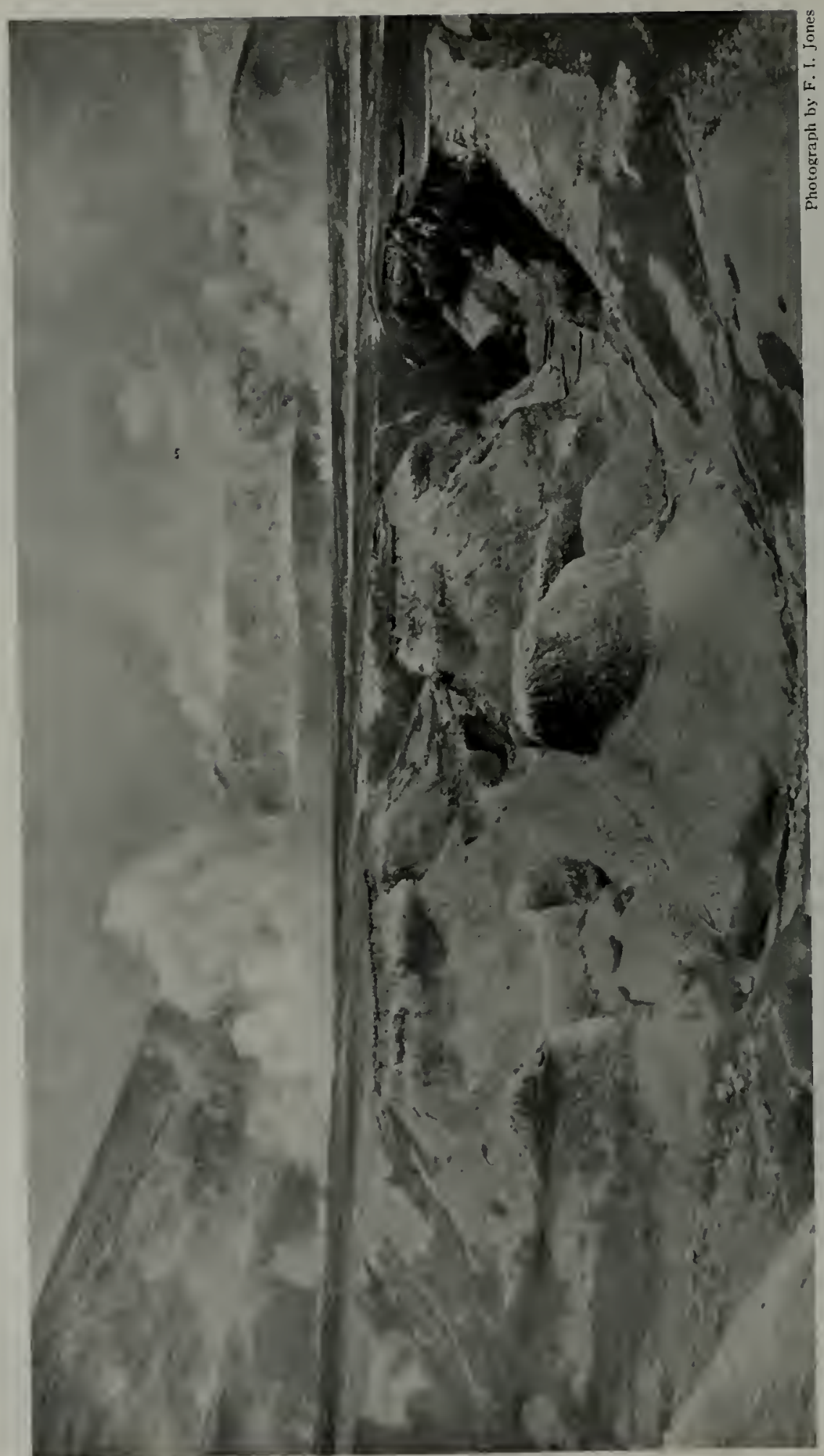

年 
there is evidence that eren then the magma lay for a time as a comparatively. quiet pool in the hollowed-out summit. This is shown by the condition of some of the fragments in the ash deposits, in which the bubbles are spherical and very large in comparison with the solid matter. Such pieces of pumice, though of course composed of the same constituents as the dense lava. are extremely light (see page 293).

Their spherical bubbles show that the escaping gases were free to expand equally in every direction. They must have formed on the surface of the molten magma, representing, in fact, frozen foam from the lava lake. Their extreme inflation makes them exceedingly brittleso brittle that they are difficult to preserve. These pieces are rather hard to find, but their scarcity is perhaps due merely to the ease with which they were destroyed in the hurtling hail of falling pumice. ${ }^{9}$

Besides froth, there are materials of a denser character, representing scum and chilled crusts on the surface of the lava lake. In these are frozen many inclusions - punice, separate crystals, old rock, other pieces of rolcanic glass, and even fragments of sandstone that must lrave come up from the depths. The condition of these materials shows that the lava was still actively assimilating foreign bodies at the time it was thrown out and chilled.

This permits another step in the interpretation of the eruption. The crater walls shaken by the initial explosions seem to have collapsed and tumbled into the lava lake, there to be broken to bits

\footnotetext{
${ }^{9}$ Highly inllated pumice of this sort furnishes an illuminating index to the quantity of gas that may be liberated from a surcharged magma. It will be remembered that this magma has the same composition as granite; if it had solidified deep down in the earth it would have become granite. A comparison of the volume of the piece pictured with that of the equal weight of granite shows that the magma liberated about a dozen times its own volume of gases! No wonder a violent explosion ensued when the gas let go.

${ }^{10}$ Fenner supposes that most of the assimilation of the old rock occurred in the open lake,
}

and stirred through the mass by the turbulence of the swirling lava. ${ }^{10}$

\section{MAGMA DID FOT EXPLODE IMMEDIATELY}

ON REACHING THE SURFACE

The even stratification of the ash layers shows that activity was intermittent, waxing and waning many times. This fact is likewise established by the testimony of those who heard the explosions, which kept up for about 60 hours. IThat now is the explanation of this succession of explosions? Why did not the whole lava lake go off at once in a single gigantic blast?

Evidently the magma did not froth up immediately with explosive violence, on its emergence from the depths. It paused long enough (before and after reaching the open air) to take up the great quantity of foreign rock which we find in the ash layers. Clearly the enormous pressure of the included gases developed at the time of the explosions was not present at first. ${ }^{11}$

This again runs contrary to our preconceptions of a rolcano - at least to my own. I had supposed that explosions were largely a simple physical process: that the magma, heavily charged with gases under enormous pressure, rising from the depths to a region of less pressure, suddenly released the gases with a violent explosion - exactly as a bottle of Vich pops when the cork is pulled.

Now evidence is supplied showing that this analogy breaks down. Instead of exploding immediately upon rising from the depths, the magma paused long enough to complete the process of assimi-

i.e. during the period of eruption. It seems to me, however, that the slow stoping away of the old rock before the crater was unroofed must have been at least as important an agency:

It is difficult to see how a very great quantity of foreign matter could be taken into the molten lake in the few hours of visible activity without chilling it to the point of solidification. The question, however, turns largely on the supply of energy necessary and this is a matter that is as yet obscure.

11 This idea was developed by Fenner, op. cit. pp. $602-604$. 


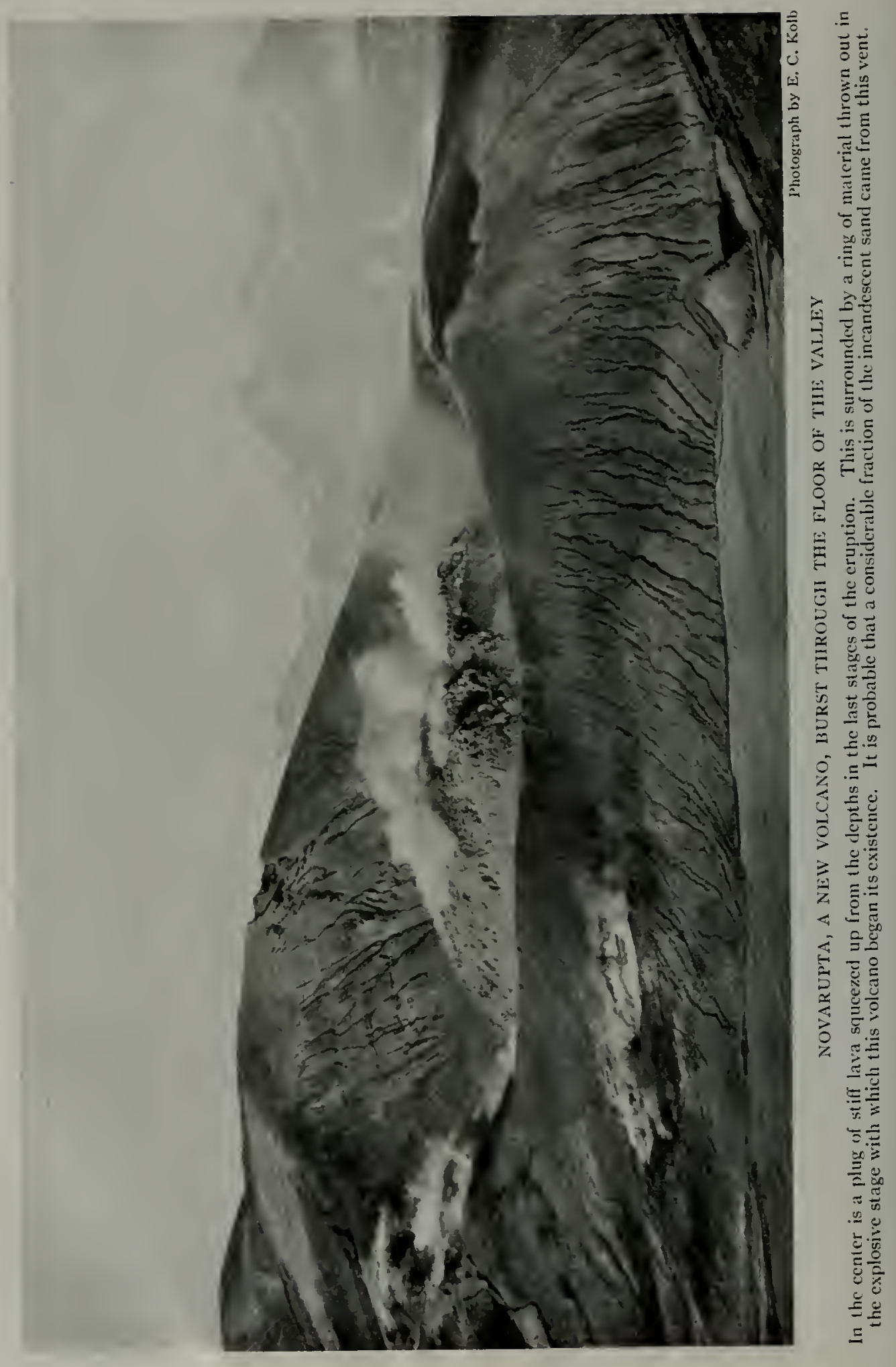


lation, before the gases began to come off explosively. The bottle did not pop until some time after the cork was pulled, proving that the liberation of gases must be due to factors other than those supposed.

Here we must stop. The discovery of the mechanism of gas liberation in the exploding magma is the next great problem awaiting solution by the volcanologist. At present, we can not discuss it intelligently. Nevertheless, recognition of the occurrence of a delay in reaching the explosive condition gives a new point of attack on the problem of the volcano. ${ }^{12}$

\section{WHAT IS THE CHARACTER OF THE MAGMA CHAMBER BENEATH THE REGION?}

One other question remains to be considered, and to the geologist this is the most important of all. What were the movements of the magma in the depths, that resulted in the observed eruptions at the surface? What is the nature of the magma chamber below the region? Our knowledge upon these points is so limited that we can do little more than state the problem.

Outbreaks so extensive imply that the magma approached the surface closely over a large area. The activity from Katmai to Martin, from the axis of the range to the foot of the Valley, covers a territory about I5 miles square. The magma itself certainly came within range of the surface over most of this area. What was the character of the intrusion?

\section{SILL OR BATHOLITH?}

So far as the Valley of Ten Thousand Smokes is concerned, there are two sharply contrasted possibilities: (I) The magma body may be a relatively thin sheet, an offshoot from the main body beneath the range of rolcanoes, squeezed in between the sedimentary rocks underlying the region - an intrusion of the sort known among geologists as a sill;

${ }^{12}$ See a suggestive paper entitled "The Development of Pressure in MIagmas as a Result of Crystallization," by George IV. Morey, Journal
(2) it may be a very large body eating its way up directly from the depths a batholith.

Both these types of intrusion are common and important the world over. Molten magma is often pushed in between strata of sedimentary rocks for long distances. The sills thus formed are sometimes of huge proportions, vertically as well as horizontally. Some are known which reach $\mathrm{I}, 000$ feet in thickness and extend many miles.

Solidified batholiths likewise play a very large part in the structure of the earth's crust. Most of the extensive granite regions of the world are batholiths pushed up from profound depths. Familiar instances are the great mountain mass of Southeastern Alaska and British Columbia, which is a single batholith, and the Sierra Nevada in California, which is another.

The country directly adjacent to the present region contains a smaller example of just such a batholith in a granitic area that extends northeastward for a number of miles from Iliuk Arm of Naknek Lake.

In favor of the sill hypothesis, which has been suggested by Fenner, it may be said that this minimizes the subterranean disturbance which must be assumed.

Most sills, to be sure, are different in composition from the lava here outpoured, being far less silicious - basaltic rather than granitic-but granite sills are not unknown.

It is manifest that only a sill of unusual thickness could have furnished the energy and materials for the eruption that occurred in the Valley. Not only was the magma that gave rise to the great sand flow poured out - of the order of a cubic mile, after inflation but enough remained to keep all the fumaroles of the Valley going ever since. Sills big enough to sustain such tremendous drains with scant diminution are rarely met with.

of the Washington Academy of Sciences, Vol. I2, No. 9, 1922, pp. 219-230. 


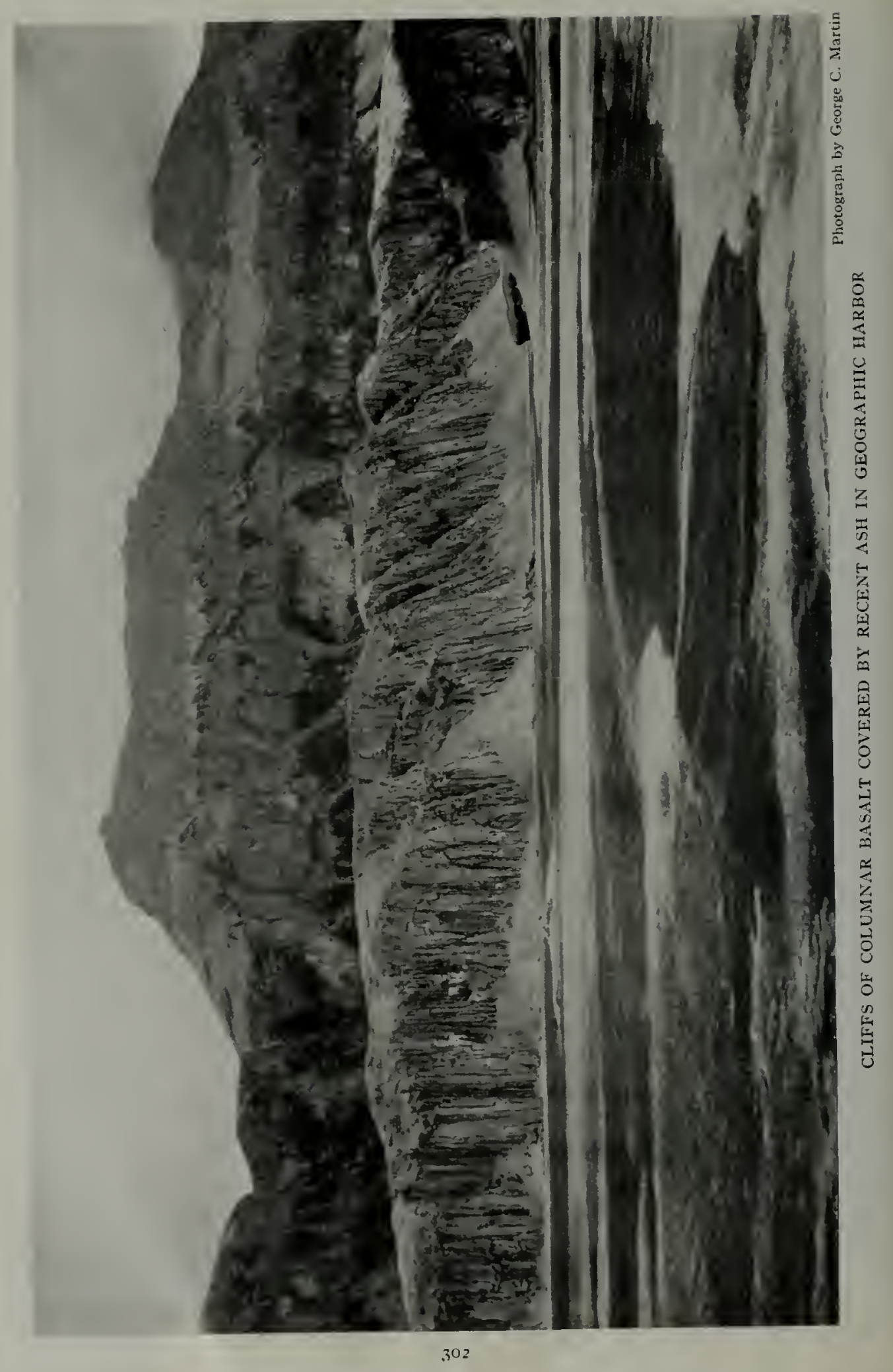


How a sill of sufficient thickness could make room for itself in the old rocks constitutes a puzzling problem. Such an intruderl body must, of course, displace older rocks by an amount equal to its own volume. When the sill is close to the surface, as this body certainly is, it would be expected that the surface would be upheaved, and probably much broken, when the sill was squeezed in.

But there is not the slightest indication of surface disturbance around the Valley. The only faults certainly demonstrable in the old rocks are those surrounding Novarupta, which occurred after the eruption, i.e., after the intrusion was complete. As has been seen, they are connected with subsidence, not with upheaval.

No appreciable changes of altitude occurred at the time of the eruption. The precise triangulation of the Coast and Geodetic Survey gives us information as to the elevation of the high peaks in 1908. These altitudes have been checked against many observations by our surveyors and found to be unchanged within the limits of a few feet.

A further question arises as to the nature of the parent body from which the supposed sill originated. The magma chamber giving rise to a sill must be of vastly greater proportions than its offshoot. Otherwise sufficient propulsive force to crowd the intrusion into the old solid crust could not be developed.

Finally, the most natural supposition concerning the dynamics of intrusion would be that the magma, rising in the fundamental fissure underlying the volcanic axis, came to a place where resistance to lateral intrusion was less than to further vertical rise, and that a part of its mass was accordingly pushed out to form the sill imagined. Such action might be aided by the weight of the magma column in the core of the volcano.

The difficulty here is, that if we liken the interior of Katmai to a standpipe wherein a liquid magma was held at a level higher than the surrounding valleys, a break at the base would inevitably. draw off the liquid and lower the level in the standpipe. The outflows in the Valley comprise about one quarter of the whole quantity of material thrown out.

It would seem that the withdrawal of so large a fraction would almost necessarily relieve the pressure and drain the higher levels in the reservoir if it were small, thereby forestalling an outbreak from the summit. The fact that the explosions were practically simultaneous would seem to forbid such an explanation of this case.

But if we hypothecate a batholith rather than a sill, all these difficulties vanish. If an extremely large body of magma, tens of thousands of feet deep and covering many square miles, were eating its way toward the surface, outbreaks even of the magnitude of the Valley eruptions would not consume an appreciable fraction of the total energy and might not draw off the magma accumulated under Katmai.

It would be much easier to think of the enormous amount of energy necessary for the observed assimilation of the old rock and for the explosions as concentrated from a large, rather than a small, magma body.

In the top of a batholithic mass of magma extending downward to immense depths, there would gradually accumulate a heavy charge of gas due to rising bubbles. An eruption in such a sy'stem, once begun, would continue until the whole of the accumulated gas had blown off.

If it be granted that a batholith could gradually work its way upward by overhead stoping, it would approach close to the surface before giving any indication of its presence and then it would break through in depressions without disturbing the mountains round about, exactly as happened in the formation of the Valley.

\section{DECISION ON THEORETICAL QUESTIONS BEST DEFERRED}

It is unnecessary, however, for us to decide betwcen these two hypotheses. 
Any opinion given now might look ridiculous in the light of subsequent developments. For the decision as to what may underlie the Katmai region will in reality be given by its behavior in the future.

If the Valley of Ten Thousand Smokes was produced merely by the injection of a sill, even of a very thick one, its fumaroles will be short-lived. If, on the other hand, a batholith is really rising beneath the region, the activity will continue indefinitely. We must, therefore, rest our case and leave the verdict to the future.

With respect to the explosion of Katmai we are not so fortunate. That is a closed chapter; we cannot expect future developments in this crater to throw light on the many important problems whose solution is necessary to an understanding of the mechanism of a volcanic explosion. Yet a more intensive study of the data available would certainly give us a much clearer picture of the inner workings even of Katmai than we now possess.

The prime purpose of the deductions suggested in the preceding paragraphs is not to set forth final conclusions concerning the points brought up, but rather to indicate the possible bearing of circumstances which might otherwise pass unnoticed.

The thesis of the chapter is, therefore, not to support any theory of the eruption, but to bring together a number of facts which must be taken intoaccount by any theory which is adopted, and to point out the unique opportunity presented by this eruption for gaining an understanding of the volcanic process in general. 


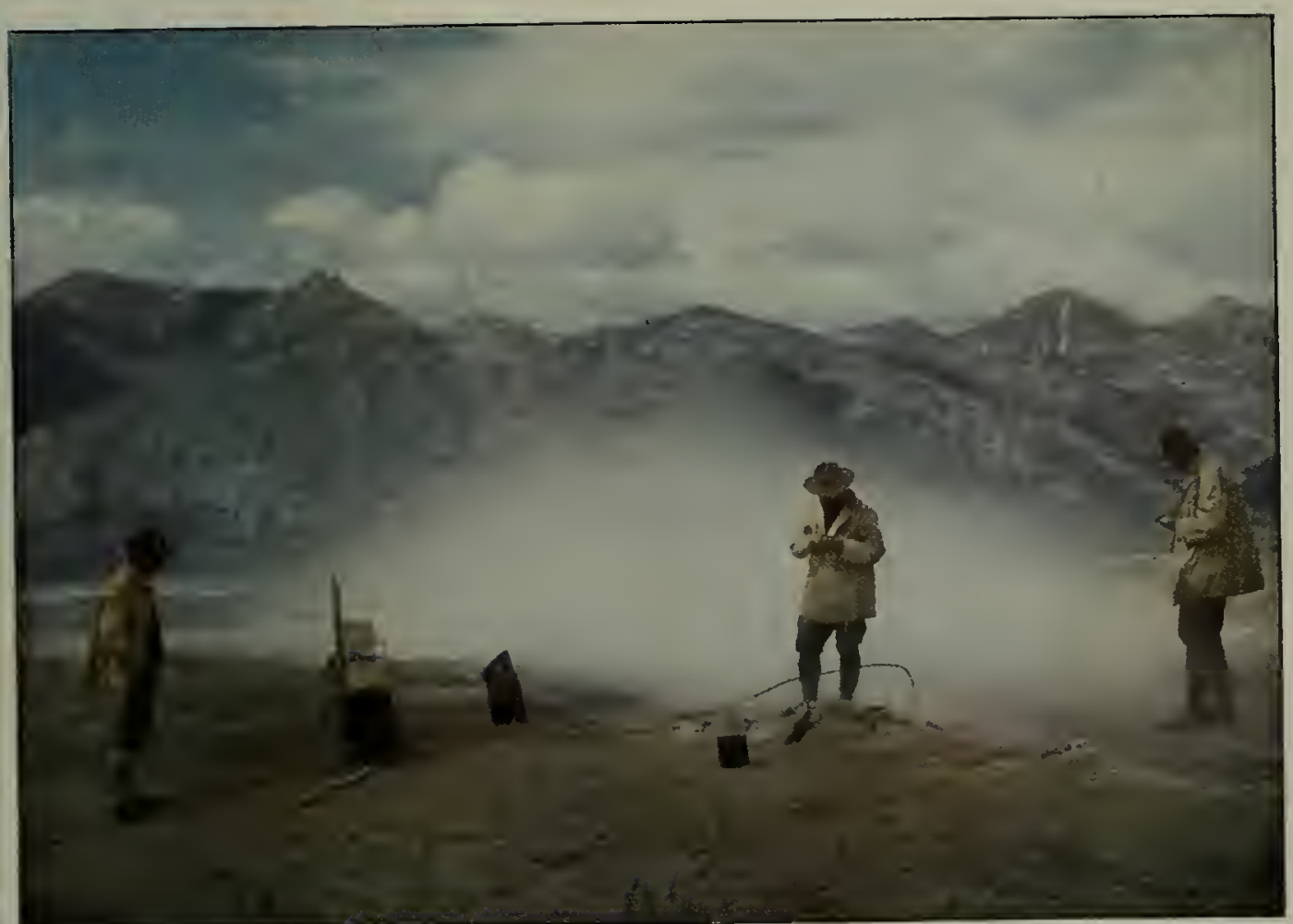

Natural Color Photograph by- Frank I. Jones

TAKNG THE TEMPERATLRE OF MOTHER EARTH

The geophrsicists with their thermo-couple working along a fissure.

\section{XV}




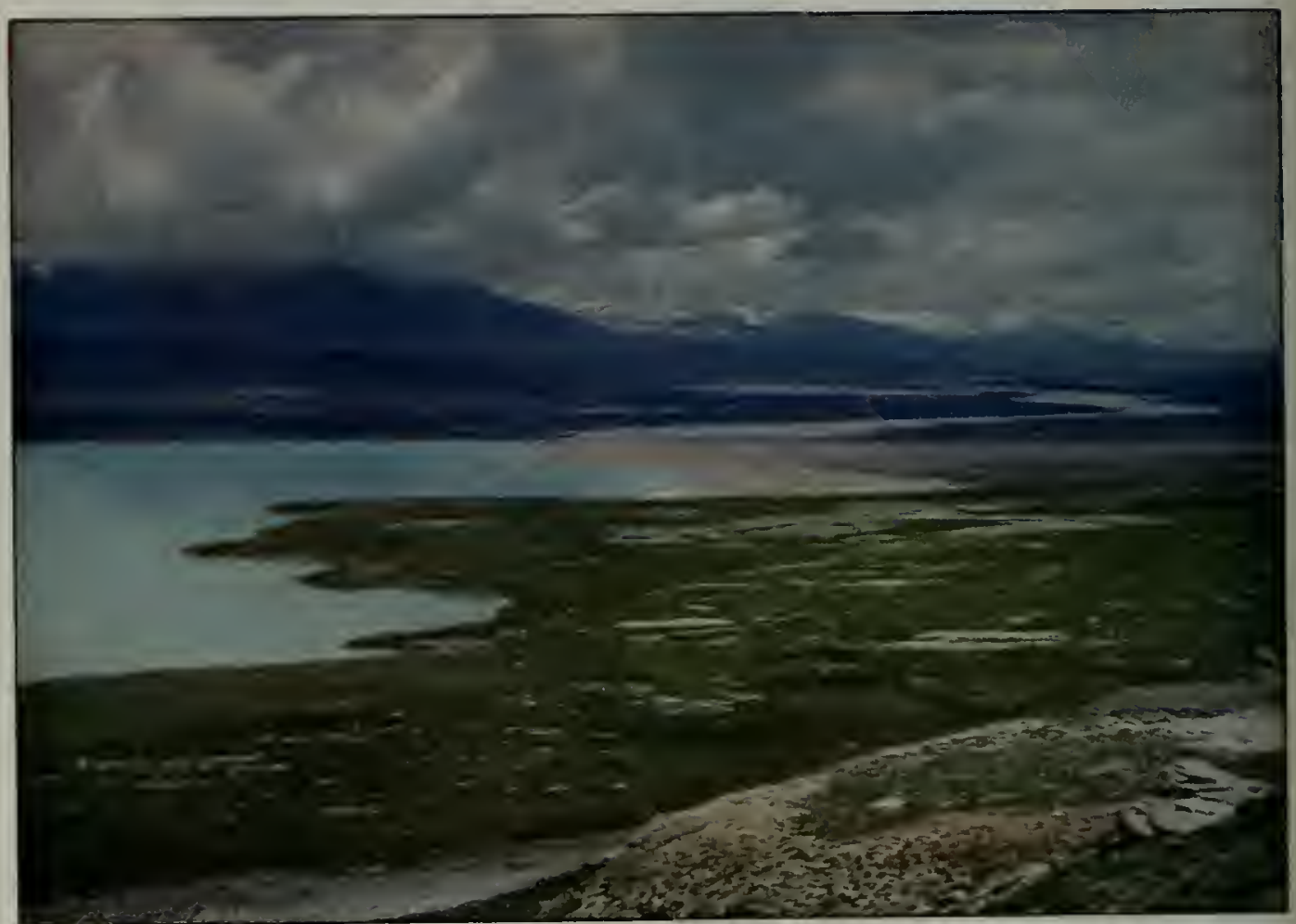

Natural Color Photograph by Frank 1. Jones

PEACFFUL FOREST AND PELLECID LAKE WITHIN A DOZEN MILES OF THE SMOKES The head of Naknek Lake from the shoulder of Katolinat. 


\section{XXIII}

\section{GEOGRAPHICAL AND BIOLOGICAL OBSERVATIONS IN THE SURROUNDING COUNTRY}

While the principal object of the expeditions was, of course, the study of the volcanic phenomena discussed in previous chapters, as time permitted exploration was extended in to the surrounding country. These side trips were very profitable, for the region is altogether unknown-a blank on the mapand we were enabled to discover a number of important geographic features, as well as to make observations on the biology and geology of the country.

It will be a matter of surprise to many readers to learn that there are fine forests within a few miles of the Ten Thousand Smokes. These escaped with little injury in the eruption, because the strong northwest wind which prevailed during the explosions carried the ash cloud off in the opposite direction toward Kodiak. Beyond the terminus of the sand flow the devastation rapidly decreases, and within five miles one enters a fine forest which is rapidly returning to normal conditions.

\section{THE CONIFEROUS FOREST-BORDER MIGRATING WESTWARD}

The Katmai district lies at the extreme western limit of the great Hudsonian coniferous forest, which stretches unbroken clear across the continent from Nova Scotia and Quebec.

The dominant and most characteristic tree is the white spruce (Picea Canadensis), but here, as in the Maritime Provinces, balsam poplar (Populus balsamifera) and paper birch (Betula Kenaika), the Alaskan representative of the eastern canoe birch, are almost as abundant as the spruce. Around the head of Naknek Lake the spruces reach a considerable size (see pages 267 and 310 ), but within 25 miles to the west they thin out and disappear.

The forest edge both here and at Kodiak challenged our interest, and led us to study the growth and reproduction of the trees, in an effort to determine the factors which fixed the linit of tree growth at this particular point.

In another paper I hope to present in detail the observations both on the mainland and around Koodiak. Here there is space only for the conclusions reached. There is no evidence that the forest margin in this region is fixed by the rigors of the climate.

The trees grow vigorously where established. They produce copious seed. Seedlings are abundant, and young trees, though greatly handicapped in starting by competition with other vegetation in possession of the soil, give clear evidence of being able to grow out beyond the forest border.

In short, the evidence indicates that the edge of the forest is not fixed but moving, that it has not reached its limit but is migrating out into the treeless country. The advance of the Hudsonian forest on the northern slope of the peninsula is slow, but the coast forest around Kodiak is traveling westward very rapidly, so rapidly that it has advanced conspicuously since the American occupation of the country.

\section{NAKNEK LAKE}

Naknek Lake is very irregular in shape, with steep shores and many picturesque rocky islands. It is between 40 and 50 miles long and twelve miles wide. United at the base into a broad expanse, it sends out from its head two long fingerlike extensions, separated by a high mountain.

One of these lobes, the Bay of Islands, is comparatively shallow and contains in its upper end scores of forest-clad granite islets. Another chain of islands is drawn across its mouth, effectually shutting out the seas which at times run up the lake. 


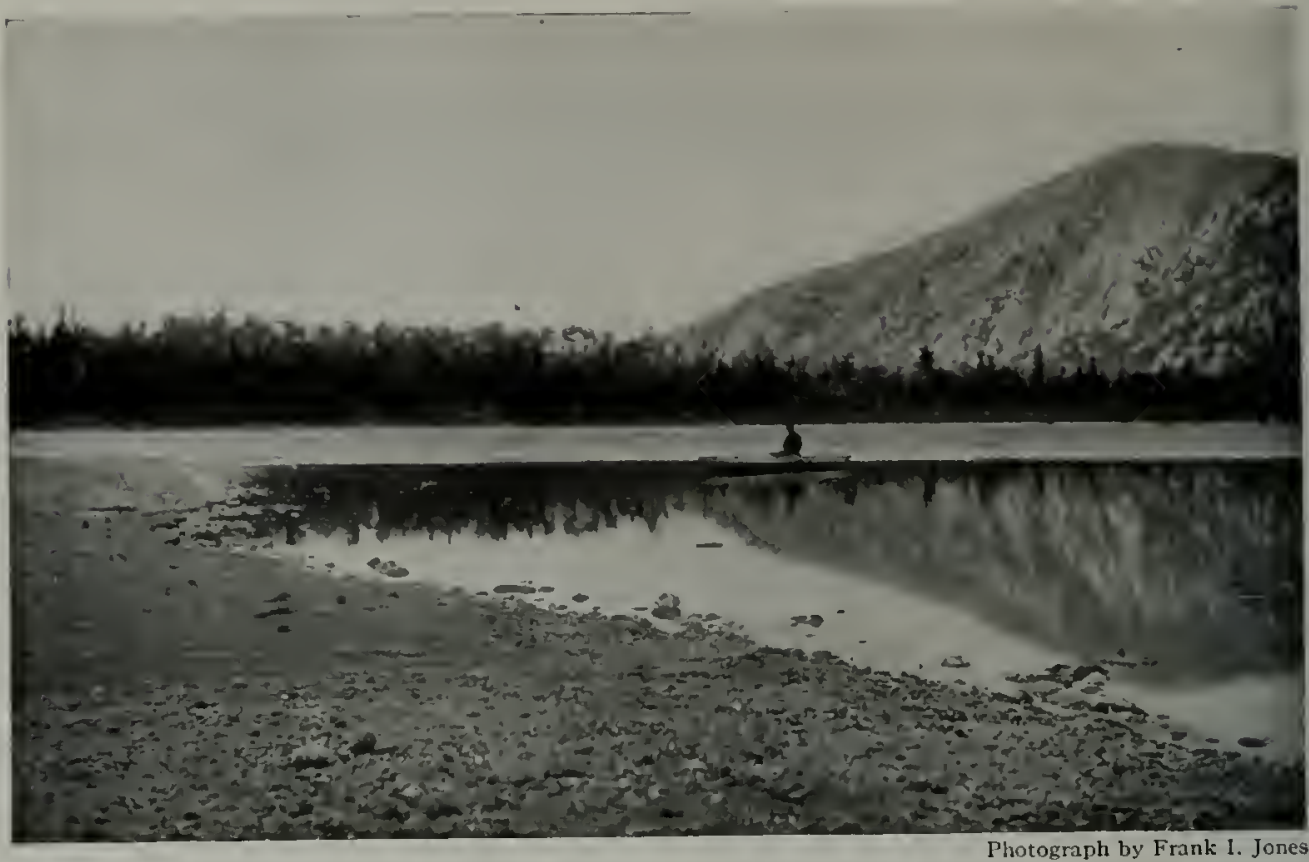

MOUNT LA GORCE FROM THE COVE AT SAVONOSKI BASE CAMP

lliuk Arm, the other lobe, is cut off by a pair of long spits built out from the opposite shores at a period when the water stood about 60 feet higher than at present. With the recession of the lake level, these barricrs, originally low sand bars, remain as high dikes, all but cutting it off as a separate body of water.

lliuk Arm is extremely deep. The boys were unable to find bottom with a 300-foot line anywhere except close to shore. Since its surface is only 35 or 40 feet above the sea, it is evident that the bottom of its bed lies far below sea level.

As a consequence of its great depth, lliuk Arm has clear-cut, rocky shores without the disfigurement of a wide fringe of marsh, which mars the beauty of many a fine lake. This portion of the lake, lying within the boundaries of the park, is set in between two beautiful mountains that rise directly out of the water. On the north tower the pink granite slopes of Mount La Gorce, 3,000 feet above the water.

\section{VIEW FROM MOUNT KATOLINAT}

On the south, Mount Katolinat sweeps upward for almost a mile $(4,700$ feet) in a graceful concave curve, ending in a series of remarkable castellated pinnacles. In contrast with its neighbor, Katolinat is carved out of sedimentary rocks. At the base are fine-grained sandstones and shales, but the pinnacles are cleaved out of a renarkable conglomerate made up of cobbles of all sorts of igneous rocks, many of them as large as one's head.

The origin of this great mass of conglomerate, which reaches the almost unprecedented thickness of 2,000 feet, forms a very interesting geological problem, whose solution would afford much information as to the past history of the country round about.

lvan Petrof, whose account of the country before the eruption is quoted above (page 265), was so impressed with the beauties of this combination of mountain and lake scenery that he inserted in his report a colored picture 


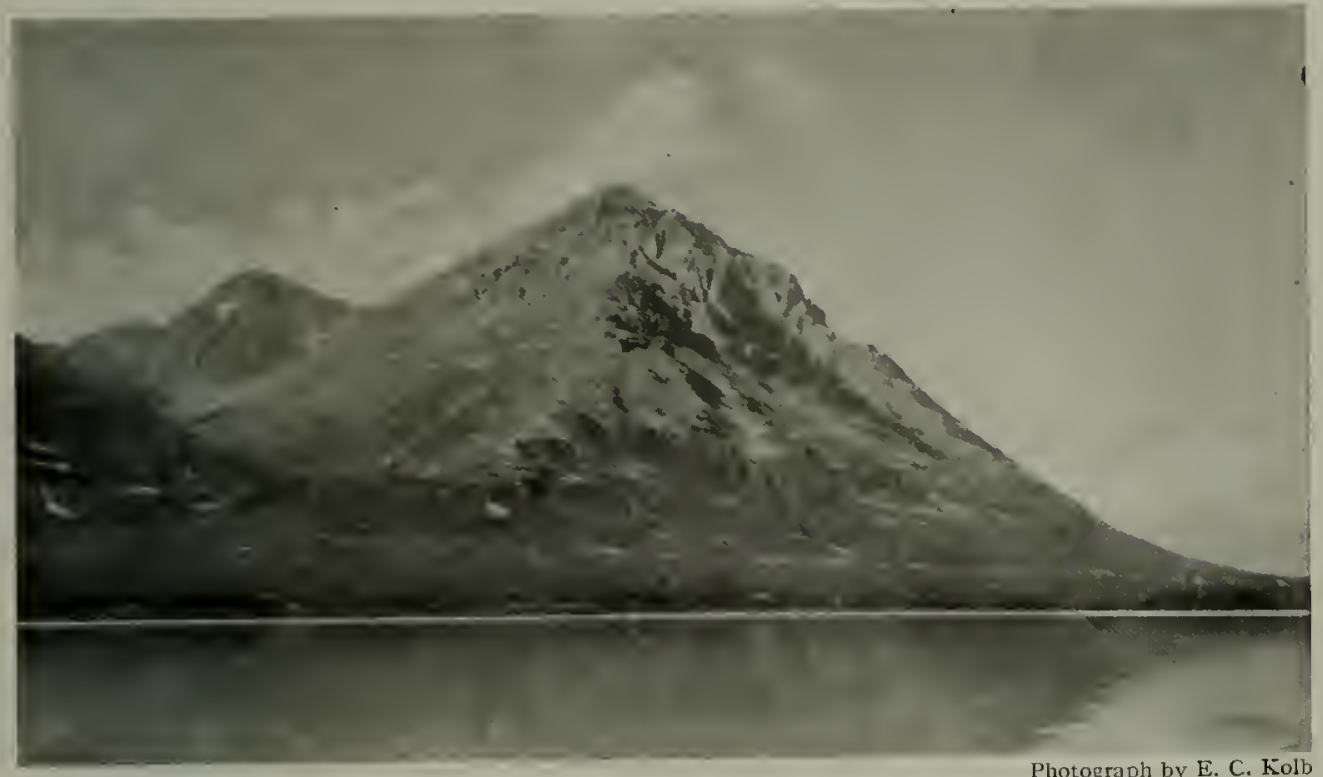

MOUNT KATOLINAT, STANDING 4700 FEET OUT OF THE BLUE WATERS OF NAKNEK LAKE

showing Iliuk Arm with Katolinat, the only plate devoted to scenery in an account of travels that reached almost every corner of Alaska.

On scaling the pinnacled ridge of Katolinat, a feat which appears well nigh impossible from below, but yet is easily accomplished, one obtains an unsurpassed view over wide stretches of country. Down the Lake one may look on a clear day out across the flat, tundracovered coastal plain to the waters of Bering Sea, nearly a hundred miles away.

Behind him, to the south stands forth the whole range of glacier-covered volcanoes, plainly visible for 120 miles from Douglas to Peulik. To the east lies the broad valley of Savonoski River, giving easy passage behind the range to the shores of Kamishak Bay on Cook Inlet. To the north is a great expanse of lake and mountain country heavily covered with forest (see Plate XVI, facing page 305).

\section{LAKES GROSVENOR, COVILLE, AND BROOKS}

Lying roughly parallel with Naknek Lake, one descries three other large lakes which were quite unknown to the outside world until news of them was brought back by the Geographic expeditions.

Two of them, which lie together, joined by a short but swift river, we named for the two men through whose vision and support the expeditions were made possible, the president and the chairman of the Research Committee of the National Geographic Society, Gilbert Grosvenor and Frederick V. Coville. The third we named after the dean of Alaskan explorers, Alfred H. Brooks, who likewise has had a large share in helping forward the work of the expeditions (see map, back cover).

Lake Grosvenor, which is 28 miles long, is perhaps even more beautiful than Naknek Lake. On all sides it is shut in by high, forest-clad mountains which give it a charm that will certainly make it a favorite place of retreat, when the Park becomes a popular resort (see page 308). It may be reached by an easy portage of a mile and a half from the Bay of Islands, or by ascending its outlet through Savonoski River. 


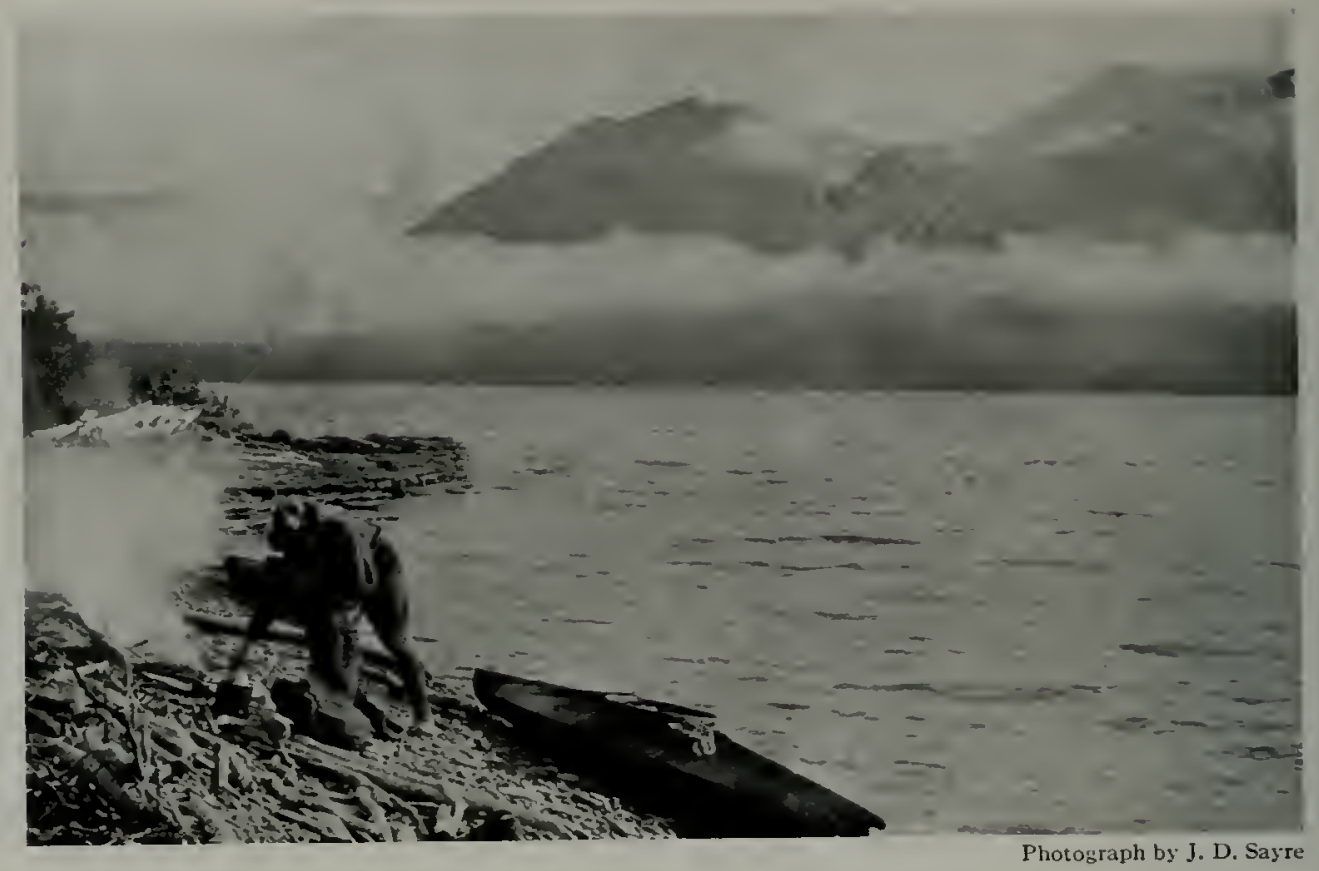

MORNING MIISTS ON LAKE GROSVENOR

For the exploration of the lakes the expedition made use of native skin kayaks, now almost a thing of the past. Our surveyors describe Lake Grosvenor as "the most beautiful place in Alaska," which is high praise from men familiar with the beauties of the celebrated "Inside Passage" of southeastern Alaska.

Lake Coville also is surrounded by high mountains which rise 3,000 feet, making it likewise an extremely wild and beautiful place. On the map it appears almost continuous with Lake Grosvenor, but it stands at a higher level. Although it lies between Lake Grosvenor and the coast its basin is shut off from the sea by mountains. It is therefore the head of the system and drains backward, so to speak, into Lake Grosvenor by a short but swift river.

Lake Brooks (see page 309) lies on the other side of Naknek Lake, to the south, separated from it by a high mountain. It also is very picturesque and quite large enough to be shown on the general maps of Alaska. Its drainage, as in the others, is reversed. The outlet is at the "upper" end, whence it connects by a short swift river with a bay of Naknek Lake. In its course it tumbles over an obstructing ledge about seven feet high, forming a fine waterfall. Here are re- vealed the enormous numbers of salmon which find in Lake Brooks congenial breeding grounds, as described below.

This group of lakes recalls the celebrated "Finger Lakes" of central New York. Besides the three that come within our immediate territory, there are five others farther to the northward, all longer than wide, and very deep. The northernmost, Lake Clark, was reported by its discoverer to be more than 600 feet deep.

Their basins were once occupied by extensive glaciers, which may have played a large part in their excavation. The shores of the southern members of the series which we examined show remarkably fine examples of glacial sculpturing. The valleys above the water level are full of conspicuous "roches moutonnées," rounded and smoothed by the ice. Conspicuous evidences of heary planing and deep grooving by overriding ice are likewise abundant (see page 3I2). 


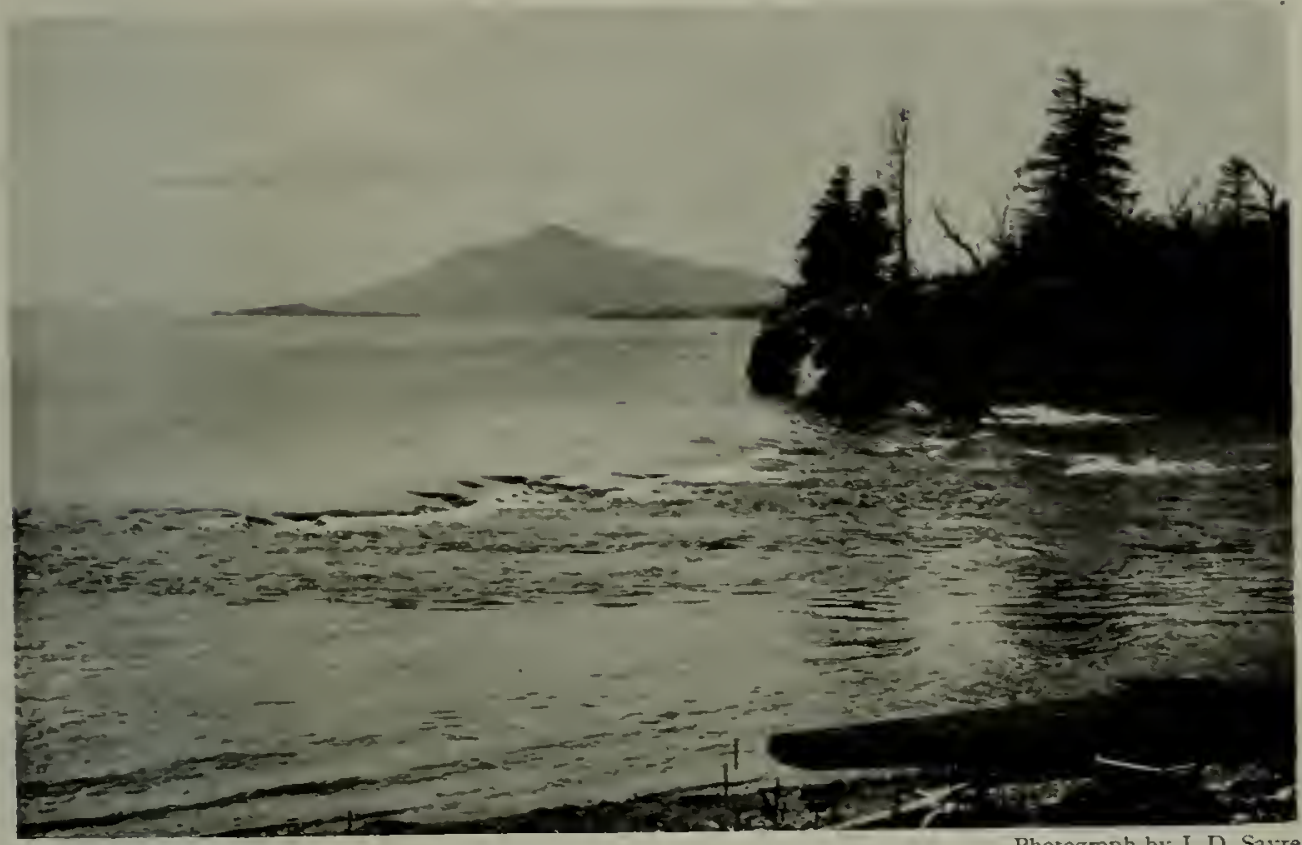

THE OUTLET OF LAKE BROOKS

Photograph by J. D. Sayte

This beautiful body of water, ffteen miles long, is one of the discoveries of the expeditions. The lake is named after Alfred H. Brooks, Alaskan explorer and for many years chief of the Alaskan Division of the U.S. Geological Survey. It was to this lake that the leaping salmon were running (see illustrations, pages $310,31 \mathrm{I}$, and 316 ).

\section{A. ANGLER'S PARADISE}

The fishing in these lakes and rivers makes the region an angler's paradise. Their waters are alive with giant rainbow trout. with such voracious appetites that the angler never need cast more than once or twice before he has a strike that keeps him busy:

There is no occasion for the varied artificial flies often necessary to lure the sophisticated fish of civilized streams. Our bait, a piece of bacon rind, was snapped up so quickly as to make it appear that anything white would have served equally well.

The only trouble our fishermen experienced came from the great size and weight of the fish; they were so big that they soon broke all our tackle. The average catch measured two feet, while the largest - caught by Wallace - was fully32 inches from head to tail. Probably expert anglers who read this will simply recognize in the damage to our tackle a confession of incompetence in the art. Of this we must needs stand convicted, but the success of such norices gires ample evidence as to the quality of the sport that awaits the skill of the expert.

Other fish undoubtedly occur in similar abundance. The natives secure large quantities of "white fish" in nets. But we were too much occupied with other duties to try catching anything except what could be had without special effort.

\section{ONE OF THE GREATEST OF SPAWXING}

GROUNDS FOR THE SOCKEIE SALION

The sockere salmon, however, occurs in such numbers that it can not be overlooked. The group to which Lake Naknek belongs is perhaps the greatest breeding ground in the world for the sockere (red) salmon, which is considered the choicest species by the connoisseur of tinned foods, though really inferior in flavor to some of the other species. 


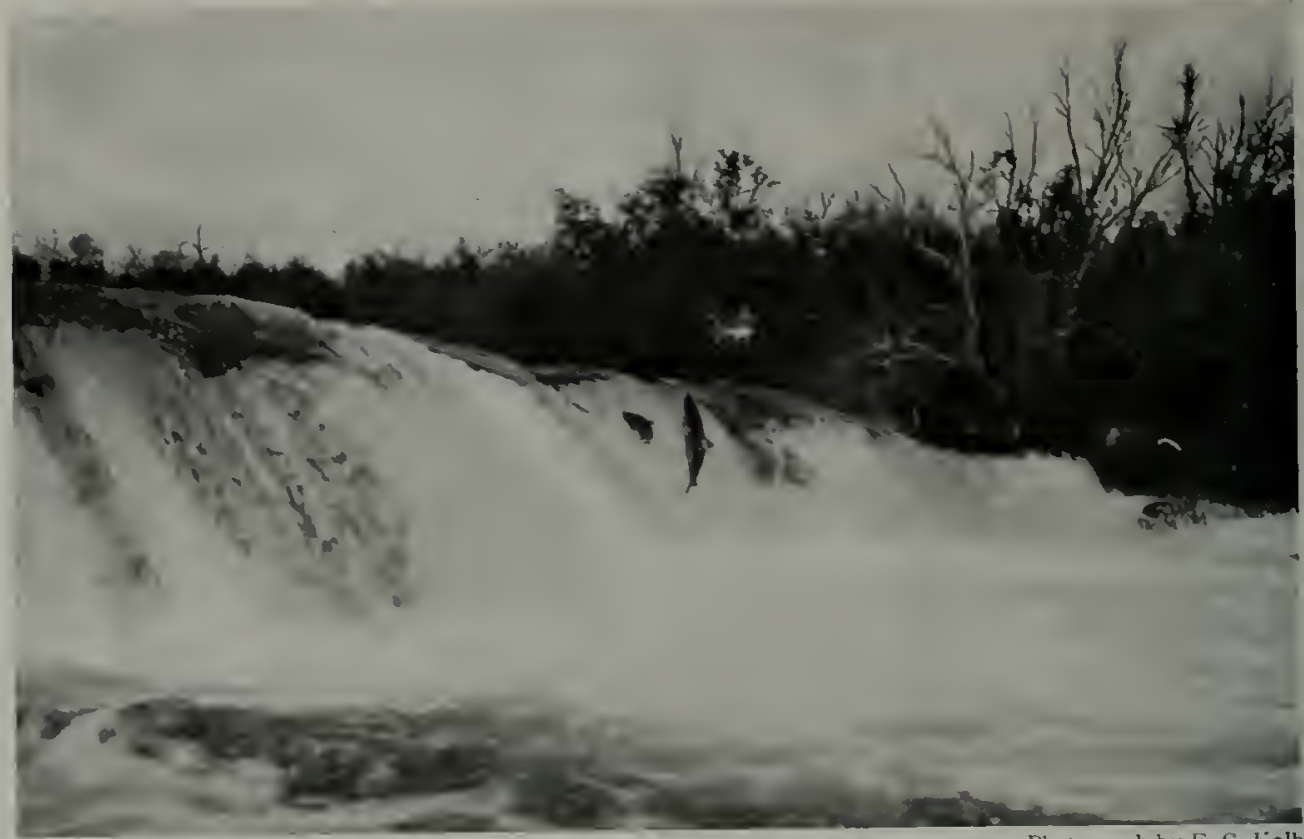

SALMON JUMPING THE FALLS AT THE OUTLET OF LAKE BROOKS

It was hard to catch them in still pictures. The motion picture films show that sometimes six were in the air at once.

An extensive canning industry has developed around the outlets of these lakes. The ralue of the "pack" every" year exceeds the purchase price of Alaska. In 1918 the salmon taken out of Bristol Bay was worth nearly $\$ 25,000,000$, more than three times the cost of "Seward's Folly."

Because of almost criminally shortsighted exploitation, overfishing has very greatly reduced the runs in recent years, but despite all the devices used to take them, the salmon still run into the lakes in incredibly large numbers.

\section{LEAPING SALAION WITHIN SIGHT OF THE VOLCANOES}

At Brooks Falls in the outlet from the lake of the same name, at the proper season one may watch the salmon as they jump clear of the water and ascend the falls. Here we stood for hours, held by the fascination of one of the most wonderful sights afforded by the animal kingdom, as the endless procession of fish kept leaping high in the air, up and over the falls.
Never did a second elapse between jumps. Sometimes as many as six fish were in the air at once. The jump appeared to require their full powers: none made the attempt except at the lowest notch in the falls, and none jumped clear over in a way to suggest that they could have gone much higher if necessary. Many of the leaps were so wide of the mark as to give the impression that they were not serious attempts, but rather in the nature of reconnaissances - efforts to learn the best place for the ascent. Often the fish struck themselves on the sharp rocks. Among those below the falls were many terribly lacerated by such accidents-so far gone that there was little probability of their ever succeeding in the leap.

At first we were inclined to think that very few were successful, but careful observation showed that great numbers were getting up. After a number of counts at different times, we estimated that they were ascending at the rate of about 20 a minute, or 1,200 an hour. 


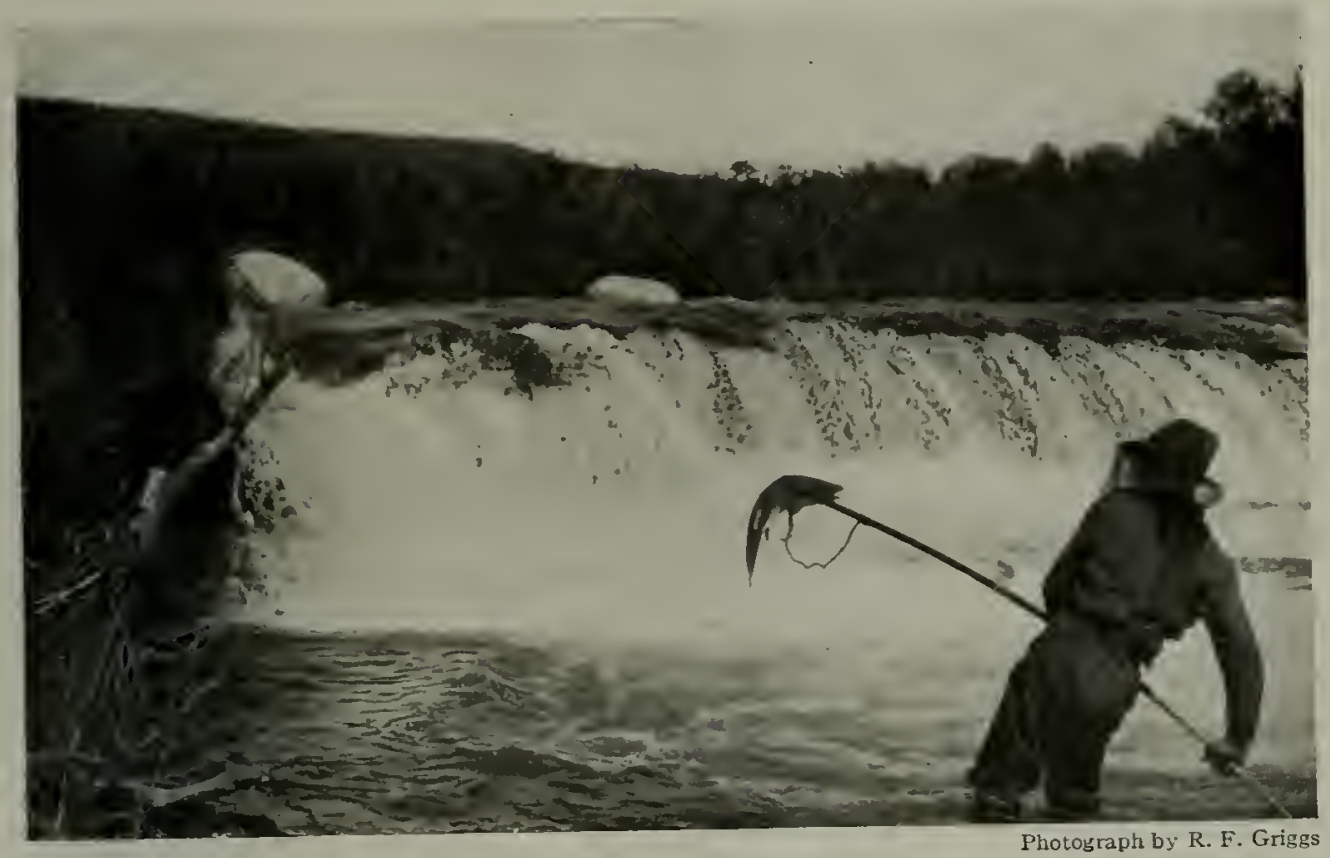

SPEARING OUR SUPPER AT THE FOOT OF THE SALMON FALLS

The salmon here were all the choicest reds, or "sockeyes," which command the highest price.

If the rate of ascent observed at the time of our random visit could be taken as a fair average of the forty-day run, we could conclude that a million fish were breeding in this single lake. But it is not safe to make numerical computations from the rate observed at any one time, for the runs are irregular and vary greatly from day to day.

The figures are given merely to emphasize the enormous numbers involved and the great importance of properly conserving this wonderful food resource, that our descendants may enjoy it as freely as do we. Nothing can be more certain than that if the present reckless exploitation continues, our incredibly rich salmon fisheries will be destroyed within a decade or two.

\section{THE REMARKABLE HONING INSTINCT OF THE SALMION}

Perhaps the most interesting feature of the whole performance is the instinct that urges the salmon over the falls. How can they tell that there is another lake above? Yet by some means they are unerringly guided to the outlets of lakes above, for they do not run to other streams. Why should they seek the upper lake, when the waters they have just passed through would serve as well, as is attested by the fact that they are perfectly satisfactory to other thousands of their brethren?

Professor C. H. Gilbert of Stanford University, who knows the habits of the salmon better than anyone else, tells me there is good evidence that the individual salmon returns to the particular water in which it was hatched. As indicated by the anomalous run observed in a tributary of Katmai River (see page I6I), they are apparently able to find, not merely the same general locality, but by some instinct are guided back to the particular spot where they began life. The mysterious sense by which they choose their way among waters apparently indistinguishable is quite incomprehensible to us.

If, like the bird migrations, it were a 


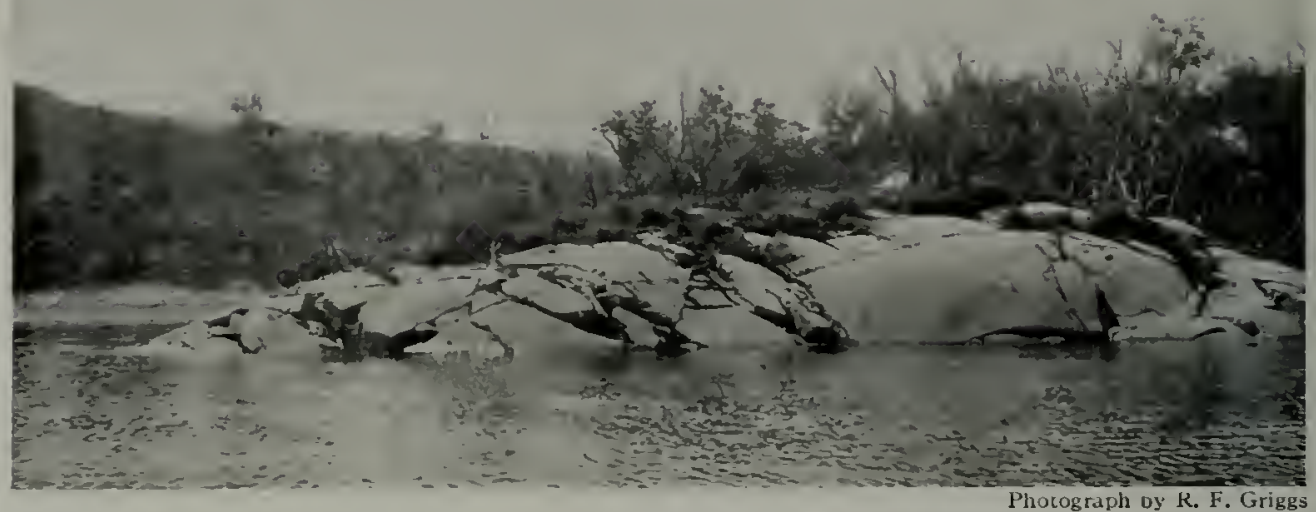

GLACIATED SHORES OF ISLANTD BAY

The smoothed surface of the granite bears the clear imprint of the glacier which scooped out the bed of the lakes.

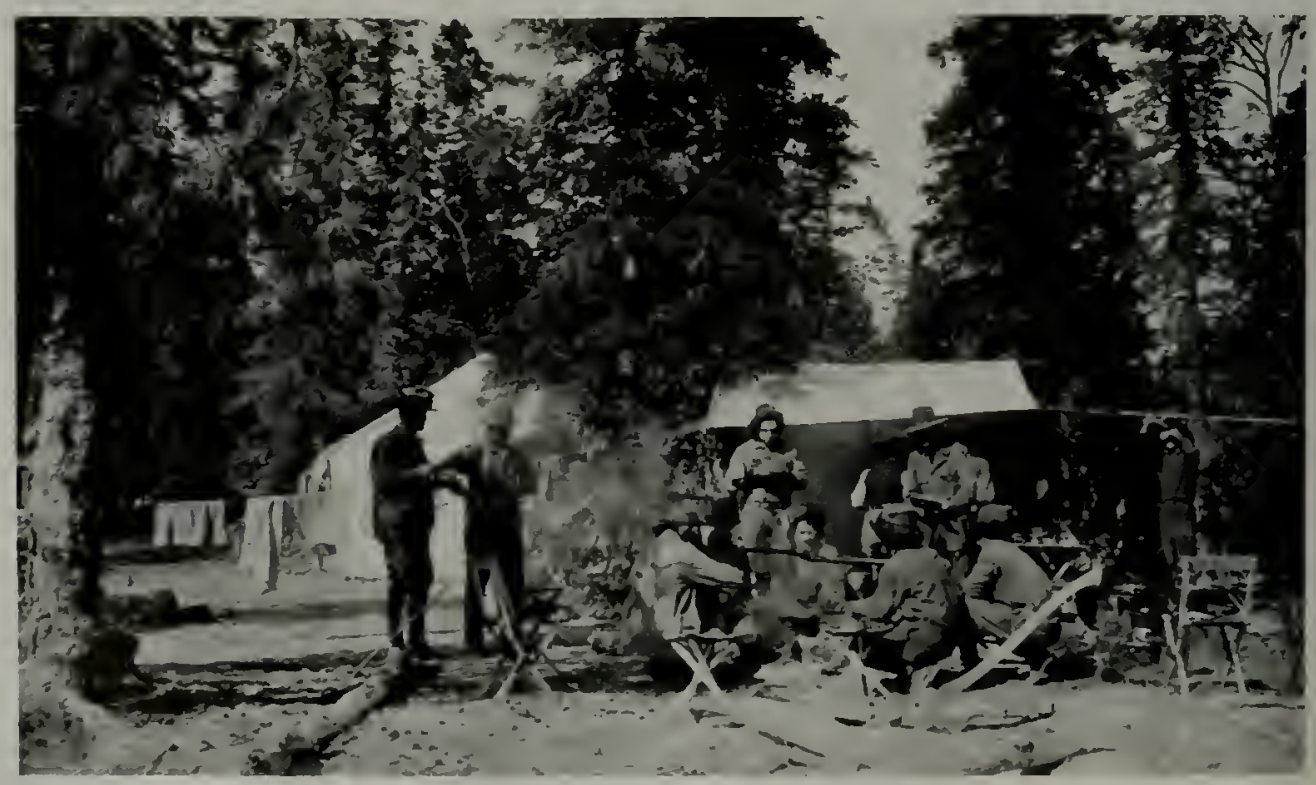

Photograph by R. F. Griggs

THE BASE CAMP IN THE FOREST AT THE HEAD OF N゙AKNEK LAKE

We were much surprised on finding such forest within a dozen miles of the Smokes. A fox used regularly to bring her little family to our garbage pile, and Wallace shot a bear on the beach in front of camp. The Katmai National Nonument is destined to become a great game preserve. 
journey undertaken every year during the life of the fish, it would not be so remarkable, for the old fish could teach the young the path. But the salmon make the trip only once, at the end of their allotted span. When they have spawned they turn over and die, leaving windrows of rotting carcasses on the shore.

Their only previous experience with the stream was when as small fry they passed down from the spawning ground and out to sea. Can it be that they retain something analogous to memory of the "landmarks" passed on their one previous journey? And, finally, why such frantic effort when all is to end so soon? These questions we may not answer. All we can say is, that these wonderful instincts, though leading to the death of the individual, are clearly to the advantage of the species, whose perpetuation is thereby assured.

\section{ABUNDANT BIRD LIFE AROUND THE LAKES}

The lakes and ponds round about are the abode of countless waterfowl. I had often read of the abundance of bird life in the north, but I was surprised at the great numbers of birds encountered. Many species of ducks, as well as geese and swans, were all about us. Right in front of camp one could of ten pick off half a dozen ducks in a few minutes.

Once we saw a single flock of swans, resting on a sand bar, which must have numbered 500 individuals. On another occasion the surveyors coming upon one molting, and unable to fly, ran it down with the power boat and picked it up out of the water. Flapping and squawking it made a handful, as may be judged by the expression of the captor's face.

For game birds ashore, there are grouse ("spruce hens") in the forest, and ptarmigan on the mountains and tundra, both of which were very scarce after the eruption, but are now returning in force.

Along with the game birds are numerous other species. Corresponding with

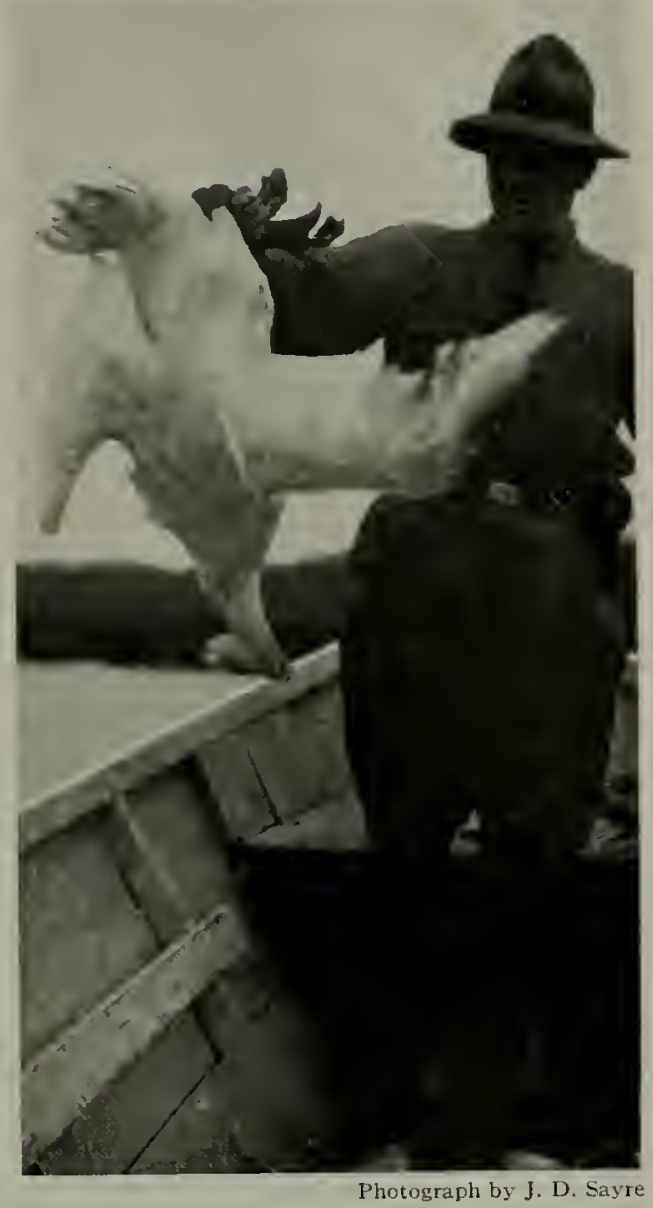

A WILD SWAN CAPTURED ALIVE BY MILLER

Being at the height of its molt, it was unable to $\mathrm{fly}$, and so was easily overtaken and captured by the power dory. It made such a disturbance with its great white wings that the captor was glad to let it go.

the difference in vegetation, there is a marked contrast between the birds of the lake country and those of the Pacific slope. Around the lakes were Steller's jays, shrikes, crossbills, three-toed woodpeckers, and robins like those of the east except in disposition, for instead of being sociable they were about the shyest creatures around the camp. These birds and others characteristic of the interior forest did not occur on the opposite slope. Professor Hine, our zoölogist, busied himself with studying them and brought back a representative collection. 


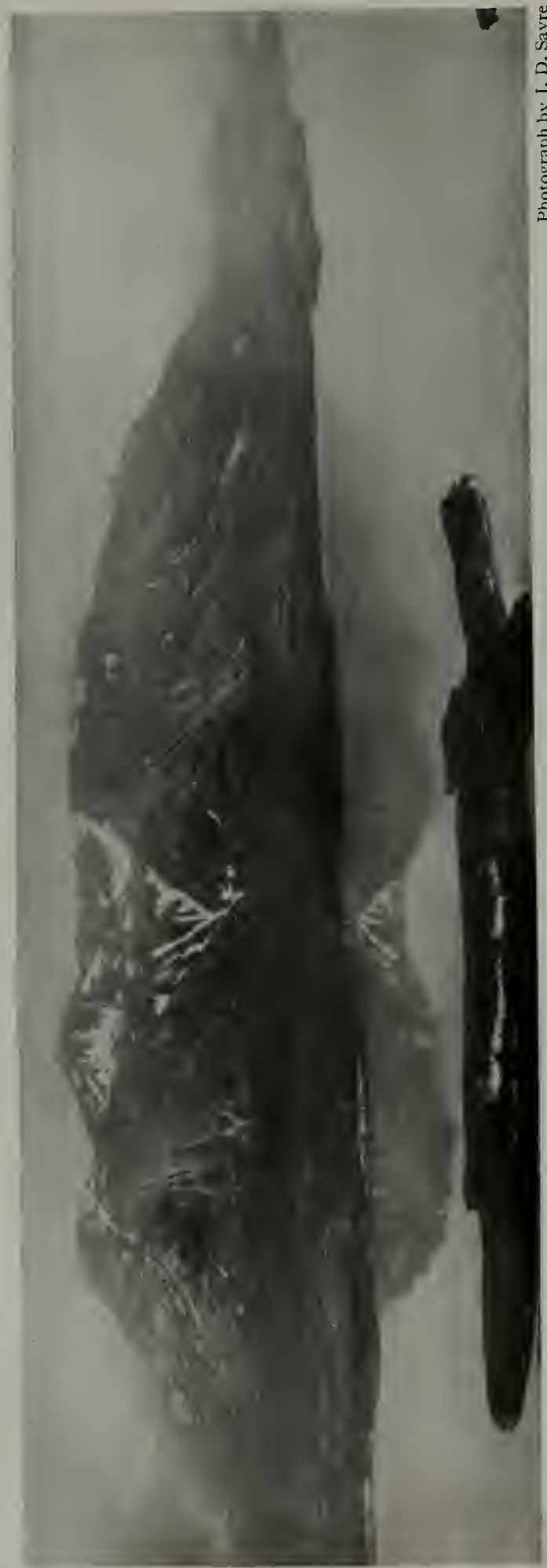

Of less interest to the general reader, but more important to the specialist, are the very large collections of insects which Professor Hine obtained. The insect life of Alaska is very little known, and he secured numcrous species new to science as well as many others not previously reported within a thousand miles. These will be dealt with in the technical papers to follow.

Each year Hine, because of his special interest in the outlying undevastated country, became the presiding genius of the base canp. In 1917 on the Pacific tundra, and in $191^{-}$on the Lake, the place was recognized as "Hine's Camp," because of his redoubtable powers as a woodchopper and his delightful spirit as a companion.

\section{LARGE MAMNALS RETURNING}

Many kinds of big gamc aninals were common in this country before the eruption. Caribou and moose were found in numbers, especially caribou, for the moose is here at the western edge of its range and not so abundant as in some other regions. After the eruption these herbivorous animals were very seriously affected by the coating of sharp abrasive dust on the vegetation, which quickly wore out their teeth. Large numbers of them are said to have perished through inability to feed properly.

But since the ash has settled down, and blows about less than in the earlier 
years, they are returning. Our parties saw signs of caribou and moose a number of times. For the latter, the forest country, interspersed with ponds full of lily pads, would seem to offer an ideal range.

The fur-bearers - marten, otter, mink, fox, and perhaps beaver - may likewise be expected to reappear in force, now that the native villages have been abandoned, leaving the country an uninhabited wilderness with no one to hunt them down. Foxes are common everywhere, though usually so shy as to be seen rarely. One of them, however, used to bring her litter regularly to our garbage pile at the lake camp.

Wolverines also were frequent travelers along the trails we used. Occasionally we would find the tracks of one on top of those of the bears that followed us. Evidently he was coming along to lick the bones the bear might leave. Once a wolverine passed very close to us, for as we climbed a mountain we found his fresh tracks on the pass at the top, and on returning followed his trail across our own.

Trappers have reported the capture of lynxes within the Katmai National Monument recently, but we had no experiences with them ourselves.

Wolf tracks also were occasionally encountered. In our first ascent of Katmai we found the trail of a stray wolf that had passed that way, 2,00o feet up the slope. It is reported that they used to run in dangerous packs during the winter. Walter Metrokin, our packer, told us a story of how a boy, by firing through the door, had once driven off a

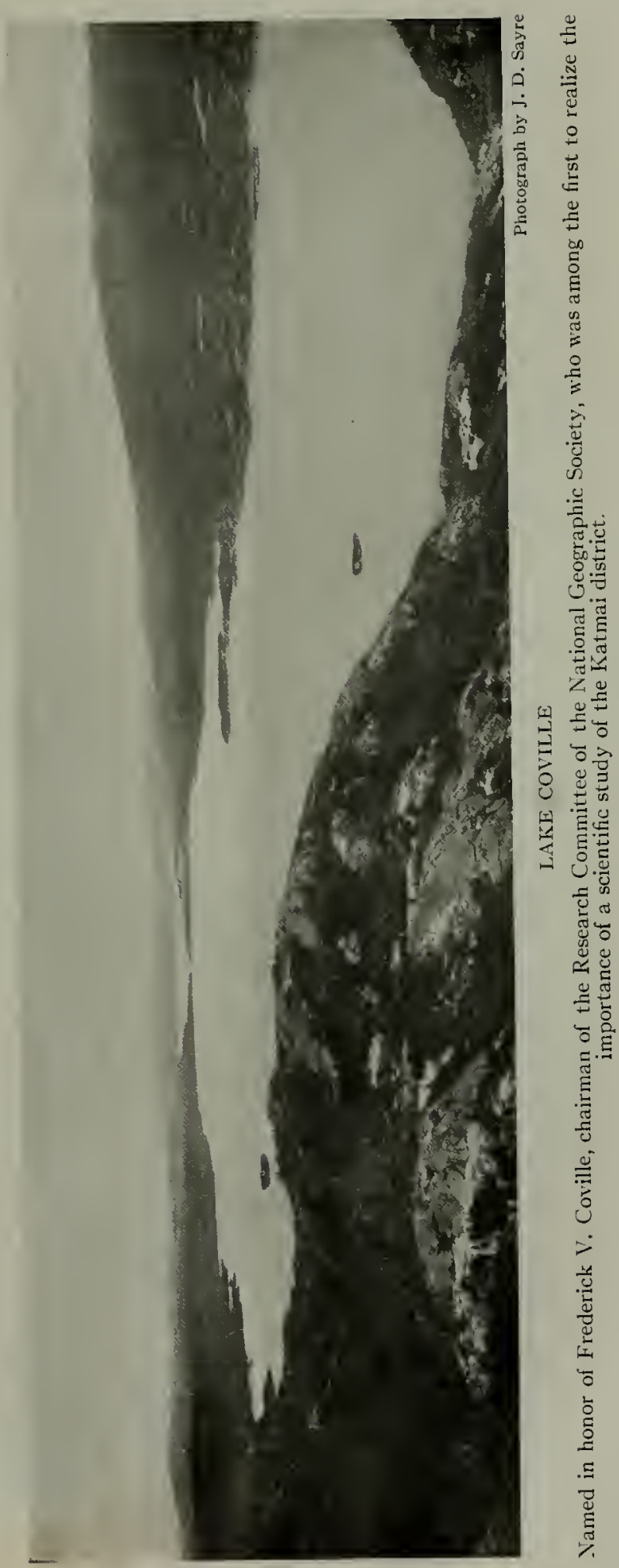




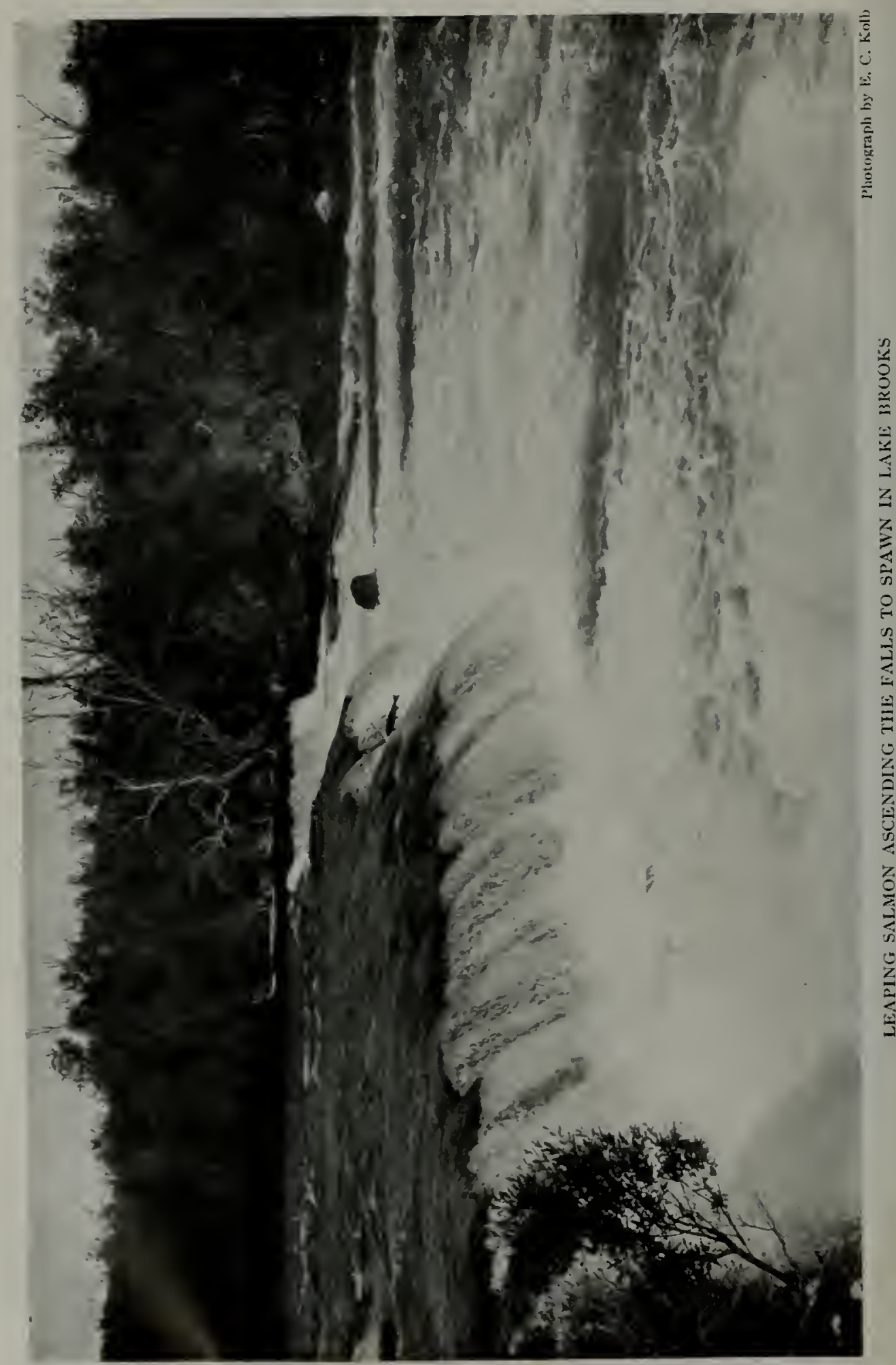


vicious pack, which had attacked a barabara in Katmai Village.

\section{BROWN BEARS ABUNDANT}

Of all the large animals, the great brown bears are the most abundant and most interesting. Although the Kodiak Island species has the reputation of being the largest bear in existence, few specimens taken on Kodiak are as large as some that inhabit the Katmai District. They are the largest carnivorous animals extant, far exceeding the lion or tiger in size. They stand as high as a cow, and their weight may sometimes exceed I,500 pounds.

The very fact that they are the largest of their kind has attracted hunters from all over the world until their numbers have been very greatly reduced. Walter, the most celebrated bear hunter of Kodiak, has told me that when he first went hunting in his boyhood, the bears on the hillsides were "just as thick as cows." Those were the days of muzzle loaders and single-shot rifles.

An old man still living in Kodiak at the time of our visit remembered bear hunts when the weapons were bows and arrows. These were supplanted by the muzzle loader of Walter's youth, and since then, as he says, there has been a constant improvement in guns. First came the breach loader, then the "Henry repeater," and then a long succession of better and better guns which enabled the hunter to pick off his quarry with greater and greater ease and safety, until now a pair of field glasses with which to find the game is as important an item in the hunter's equipment as his rifle.

\section{PROTECTION NECESSARY TO PREVENT EXTERAINATION}

Thus provided with a telescope and modern high-power rifle, the hunter may sight his game at a great distance and bring it down without giving it the least semblance of a chance to defend itself, thereby pretty nearly reducing the sport of the old time hunting to simple slaughter induced by the passion for killing.
No prophet was needed to foretell the result: the rapid decrease in the numbers of the bears, which will soon face complete extinction unless energetically protected. The problem of preserving such an animal is, however, not so simple. Congress years ago prohibited killing the bear on Kodiak Island, but scant attention was ever paid to the law.

The trouble was that it was made in the interest of the bear rather than of the settler. If it were enforced, the agricultural development of the rich cattle country would be impossible; bears and cattle do not mix well. Besides, no adequate means of enforcing the law was provided, even though there are stories of men having been arrested for defending themselves, asserting that when it came to a choice between being mauled by a bear or going to jail, the latter was undoubtedly the lesser evil.

It is not only impracticable but downright foolish to try to maintain such an animal in proximity with struggling pioneer settlements. But in the Katmai National Monument, which is bounded on the east, at any rate, by a large area of very rugged mountains never likely to be densely settled, the Alaskan brown bear should find a safe refuge in which it may be preserved for future generations without jeopardizing any interest of civilization.

\section{BEAR TRAILS EVERYWHERE}

Wherever we traveled through the devastated country, except under the very shadow of the volcano, we found the tracks of these great bears very numerous. Everywhere we went we apprehensively kept a sharp lookout, for the tracks were so thick that it seemed as though there must be a bear crouching behind every rock. At first we were much concerned lest we should come upon one suddenly, supposing that in such a barren country they must be ravenously hungry. When we first landed, one member of the party would not go for water fifty yards from the tent without carrying his rifle.

The reason for the abundance of bear 


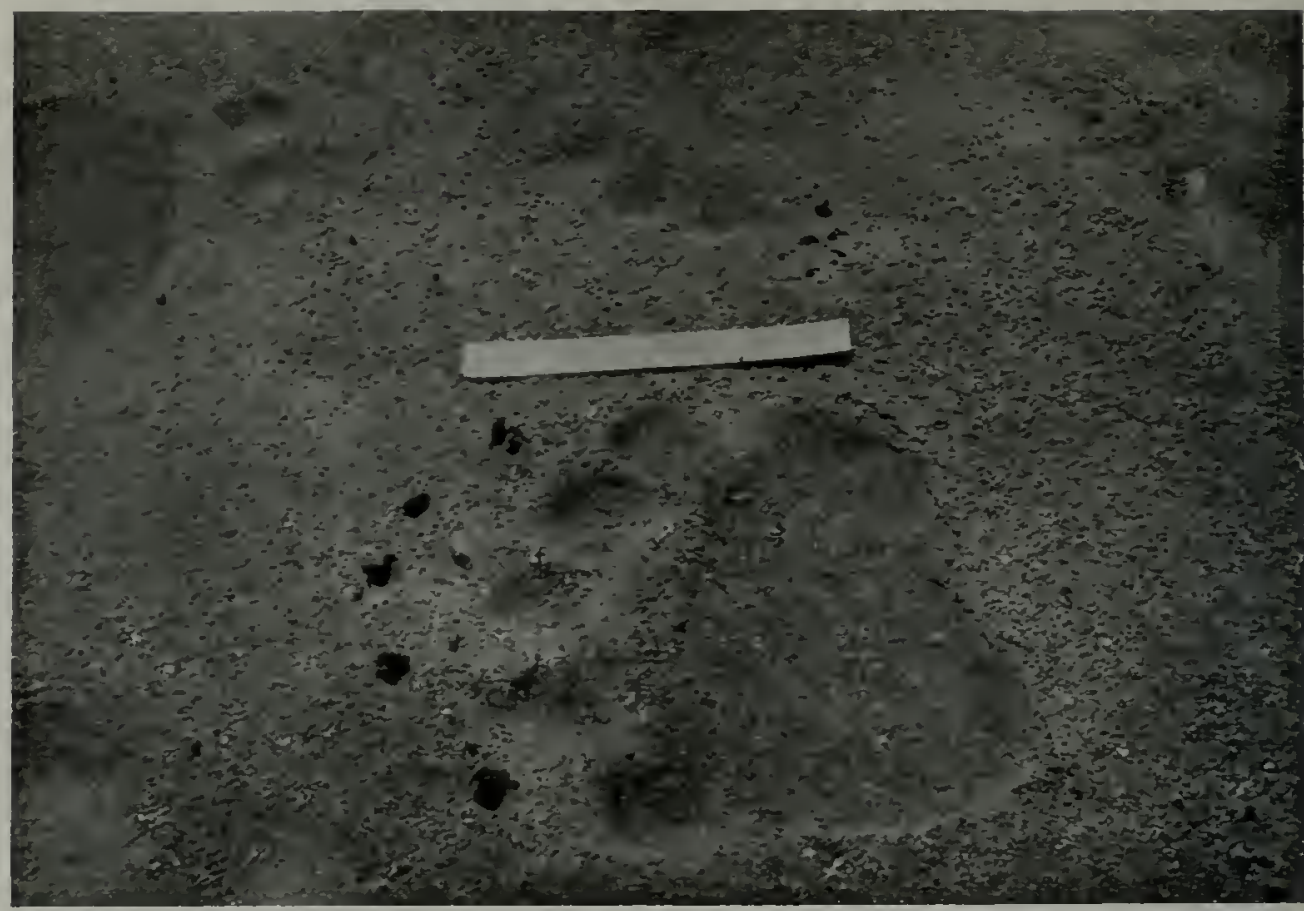

Photograph by R. F. Griggs

THE FRONT TRACK OF A BEAR, NINE INCHES ACROSS

The Katmai National Monument will probably become the only preserve for these, the largest of all carnivorous animals.

tracks is that the fine-grained surface of the ash is a remarkable medium for the preservation of any marks made in it. The tracks were often so clear that we could see the crisscross creases in their soles. The slightest details were so faithfully preserved that for a time wesupposed all the tracks had been freshly made.

As we became more familiar with conditions and had opportunity to examine the same tracks repeatedly, we found that they retained their appearance of freshness for a long time. In fact, it is a difficult matter to distinguish a track freshly macle in the ash from one several day's old.

\section{THE BEARS INSPECT OLR TRAILS}

Although much less abundant than the tracks led us at first to suppose, the bears no doubt watched us from the shelter of some safe cover many times; but they were very shy and kept out of our way, later coming down and sniffing along our trail out of curjosity to know what manner of beast the intruder might be. The country is entirely uninhabited and the younger of them at least may have been wholly without knowledge of man. IThen we thus saw beside our own puny footprints the trail of an enormous bear, we could not escape a somewhat creepy feeling.

Once, from the tracks we found, we concluded we must have surprised a mother and cubs that had been advancing toward us, for the trails suddenly reversed and turned back, indicating a hasty retreat. But the infrequency of cubs was surprising, in view of the abundance of bears and the fact that the young stay with the mother until two years old. Far down the Alaskan Peninsula, I once happened to have the opportunity of watching such a family. The mother had five cubs, two of them 


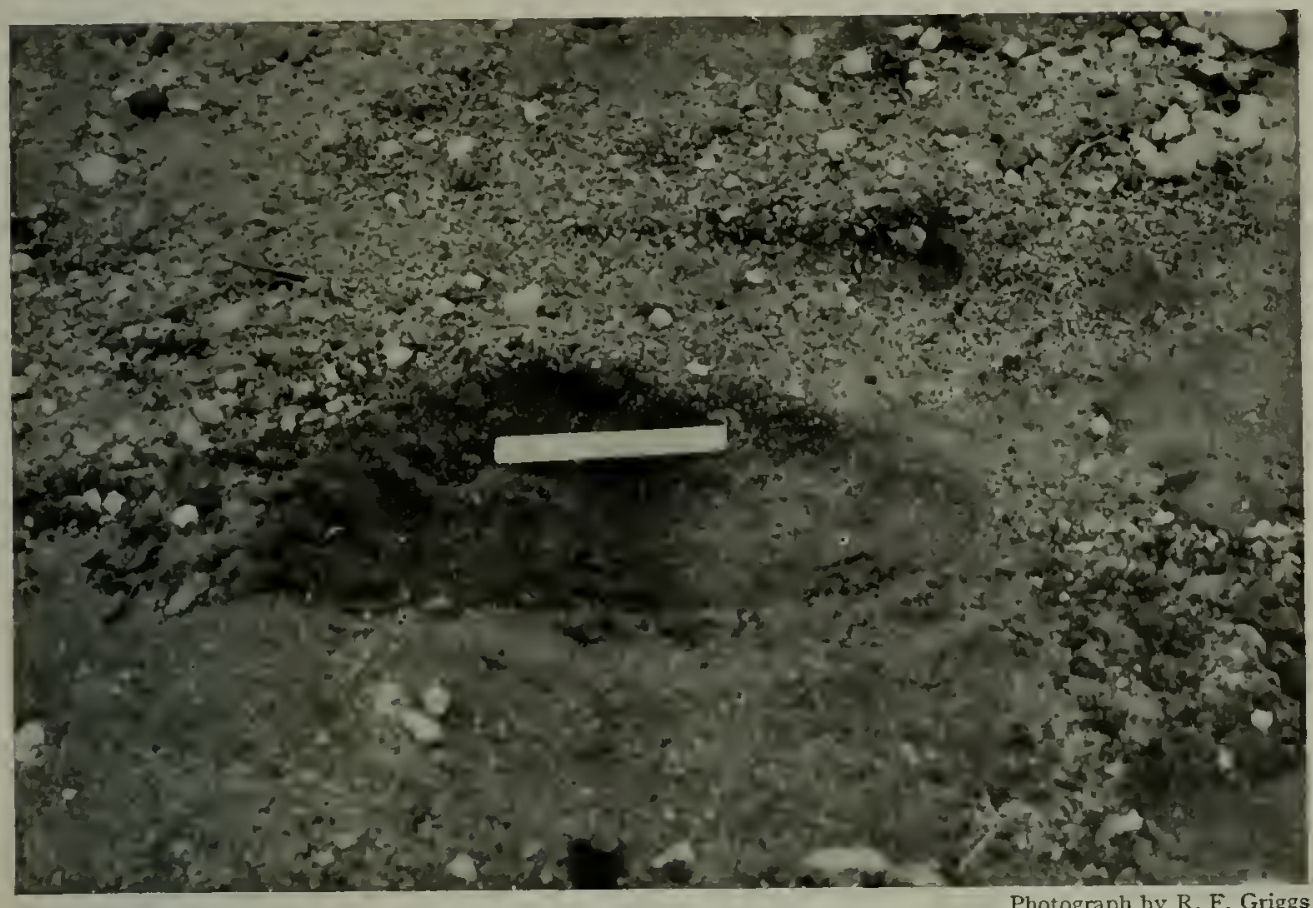

Photograph by R. F. Griggs

THE HIND TRACK MEASURING IO $\frac{1}{2}$ BY I6 INCHES

The white marker is a six-inch rule. A man inevitably feels pretty small when he finds that such an animal has been following his trail, especially if he is unarmed, as we were a good share of the time.

yearlings as big as heifers, the other three young ones no bigger than dogs. They were lying beside a stream, playing, after having filled up on salmon. Several sea gulls were hovering around, doubtless attracted by the refuse. Every little while one of the larger cubs would get too free with the mother and she would send it rolling with a cuff from her paw. Even from a mile away she seemed an enormous animal.

On one occasion, Folsom and Walter were quietly cleaning fish beside a small brook when they were surprised by a loud snort, like that of a horse, followed by much cracking of sticks as bruin made off through the bushes. Another time, at night, a bear came down on the camp without suspecting it until he got within twenty yards. Then, getting the scent, he galloped off with the noise of a frightened elephant.

Yet we never caught a glimpse of one the first year. As the days wore on without sight of the animals, we gradually became as indifferent to danger from an encounter with them as at first we had been apprehensive.

\section{GOING INTO THE INTERIOR UNARMED DESPITE THE BEARS}

When we came to start up into the interior for the first time, our packs were so heary we could not well add a rifle, and we finally went out into the wilderness armed only with a couple of pistols. Long before we were through with the country, the man who at first would not venture away from the camp-fire without a gun became so disgusted that he refused to lug his rifle even on long tramps through country in which bears were certainly plentiful.

Bears are much more in evidence during the early part of the season than later, for June is their mating time. 


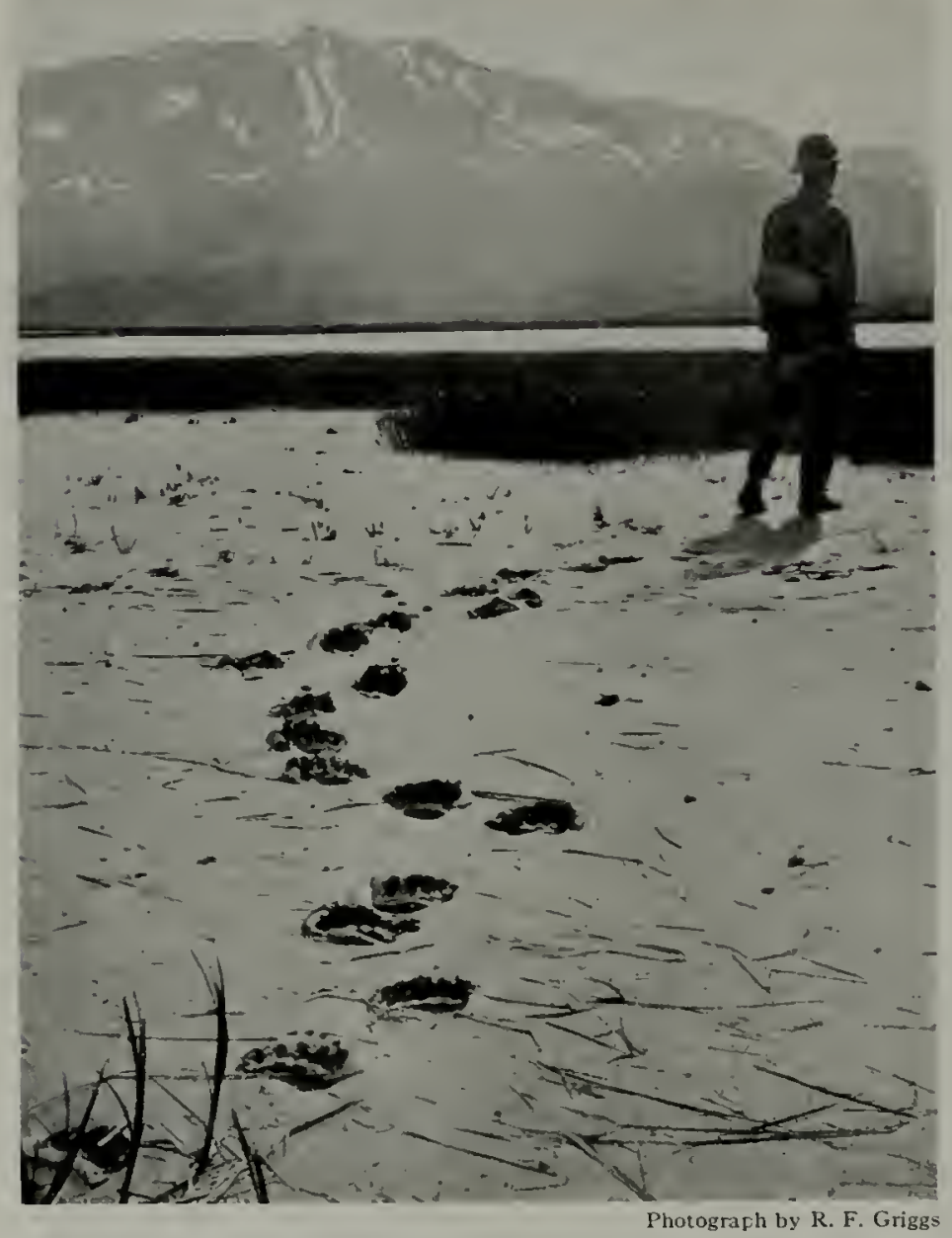

PAUL HAGELBARGER ON THE TRAIL OF A BROWN BEAR

The soft mud of the tide flats took deep imprints, but it was not possible to photograph the tracks of those which inspected the fumaroles. bears had inspected the trail left by the first party in the short interval since it had passed. Two of them were together, entering and leaving the trail at nearly the same point. One had a track 5 by 9 inches, and the other 6 by I I inches. They came up with the trail, followed it for a while, and then veered off up a valley. The tracks were so fresh we could probably have found their makers shortly, if we had had time to follow.

The other bear, which was considerably larger, with a track about 7 by 12 inches, had simply crossed the trail in his journey down the mountain side, following it a few rods, first one way, then the other, and after satisfying his curiosity had passed on. We had no desire to follow this one for During this period they wander uneasily over the country, and are especially curious about any strange animal moving about. If they hear any noise in the bush they will come up to find its cause, instead of taking to their heels as at other times.

Once, while we wcre "mushing" up the trail getting our outfit back into the interior, we happened to be divided into two parties, one of which traveled a few hours behind the other. On the way up the Valley the second party found that within three miles as many different the country was rough and covered with brush, which would have given the pursued all the advantage, permitting him to hide or to ambush the hunter at will.

Besides these, there were at that time at least two other bears in the ten-mile stretch of valley we were then working. The track of one of these on hard ground measured 9 by it inches. But when he stood up on his hind legs to inspect his surroundings, or traveled in soft ground so that the fur on his leg enlarged the impression made by his sole, his track reached the enormous dimensions of $\mathrm{IO}_{\frac{1}{2}}$ 
by 16 inches, more than big enough to cover two pages of this book (see page 319).

What a sight this bear must have been! Old "Ivan" in the New York Zoo is the center of an admiring throng from morning until night because of his great size, but the sole of his foot is only about six inches wide. I have a skin, the gift of Narshall Armstrong, of Kodiak, which seems about as big as any animal could grow. When stretched up to the ceiling of the room its claws drag on the floor, but it is by no means a large skin for a Kodiak bear - only nine feet six inches, with foot pads seven inches wide. Petrof in the census of $\mathrm{I} 880$ gives a record of one measured by him that was fourteen feet four inches long. This may perhaps be about the size of our big bear. We grew to be familiar with his tracks, but never caught sight of him.

\section{FEEDING HABITS OF THE BEARS}

From what I had read of the habits of the grizzly, I had supposed that bears must necessarily have large ranges which they patrolled in solitary state, driving away all intruders. This is not true. Whatever the habits of the grizzly may be, the bears of this region have no such habits. On the contrary, in the old days they were almost gregarious.

Despite their enormous power and the agility with which they can get around in rough country, these bears do not ordinarily hunt big game. Instead, they eat grass like cows. Around their resting places I have found the grass closecropped. Roots compose a large portion of their diet in the spring. We sometimes found places in the ash-covered country where they had dug down into the original soil for some root which their nose had detected, although there was nothing above ground to indicate its presence. They are said to dig out mice and ground squirrelswith great dexterity.

During the latter part of the season they frequent the salmon streams and the berry patches, and so are easily found by hunters who know their habits. The trader at Cold Bay told me that in I9I 8 he saw at one time seven bears fishing in "Moose" Creek in the southwest corner of the Katmai reservation.

\section{FIRST SIGHT OF A BEAR}

As intimated, we were forced during the first two years to make all our observations of the habits of the bears from their tracks. It was not until we began to work along the undevastated country on the west side of the river, in 1917. that we were fortunate enough to catch sight of one of the animals. Then one day soon after landing, as we rounded a rocky point, Folsom suddenly called, "Griggs, your glasses. There 's a bear!"

At first I could see nothing, but off in the distance there was a small graybrown spot which, when watched closely, could be seen to move. With the glasses it could be made out plainly as a bear. IVe could see him paddling around in the soft marsh, digging out the grass and eating heartily. I suppose he was getting his supply of salt by eating the saline plants of the marsh.

It was surprising how well we could see him with the glasses. He was a light, pale, washed-out brown, not nearly so rich and beautiful as some of the dark brown skins one sees. The mane on his shoulders was long and shaggy, giving him a curious sway-backed appearance. He looked indescribably ungainly and clumsy as he mushed around in the marsh, often sinking half way up his legs in the soft sticky mud. I could not but compare him with some of Knight's pictures of restorations of animals of bygone ages. ${ }^{1}$ He seemed no part of the present world, but rather a relic of the past somehow dropped down here for me to study:

Quite naturally, I was anxious to bring him down, but Andrean advised, "Wind no good." We could not hope to get close, as he was already somewhat

${ }^{1}$ Familiar to readers of H. F. Osborn's "Age of Mammals." 


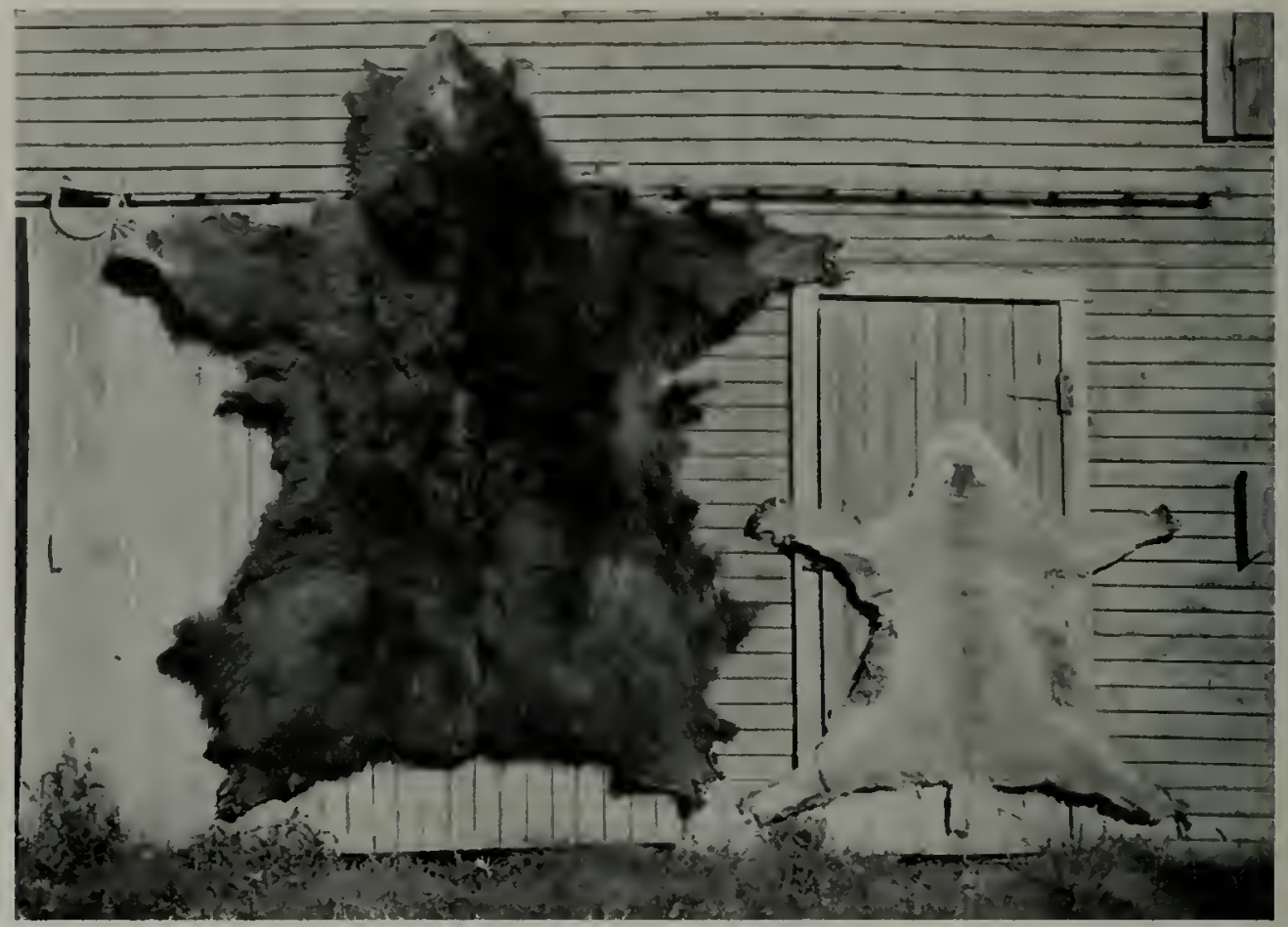

SKINS OF A KODIAK BEAR AND A PUMA

Photograph by R. F. Griggs

This is by no means a large skin for a Kodiak bear -9 by $9 \frac{1}{2}$ feet. The track was only about seven inches wide. Petrof records one, probably stretched, over 14 feet long (see note, page 265).

nervous, frequently raising his head to sniff uneasily, having evidently detected a taint in the air. Nevertheless, we decided to try it, so we turned back into cover and sneaked through the grass and alders along the hill in the hope of getting close. As our course took us more and more out of the wind, we hoped we might get to windward and approach closer. But it was of no use. He had had too strong a scent, and before we had covered more than half of the distance, he made off, now walking, now bounding in great awkward jumps.

After all I was not sorry, for he was only a little bear - that is, little in comparison with those tracks we had followed - with foot-prints only four or five inches wide. Still, he must have measured nearly seven feet long. I was just as well satisfied to wait another chance in the hope of getting a big one later, for our permit allowed us to take out only one.
The program of our work was so strenuous as never to allow us the luxury of taking a day off to organize a real hunt and stalk a bear. Our only chance was to stumble into an opportunity of getting one without wasting our time in preliminaries. Finally the opportunity came, but not when we were altogether prepared to accept it.

\section{AN ENCOUNTER WITH A SLEEPING BEAR}

Paul Hagelbarger and I were climbing an unnamed mountain back of our camp to get a view of the upper valley. The alpine flowers were wonderful, and we busied ourselves studying and photographing them as we went along.

We had rambled in this way up to about 1,500 feet when, rounding a shoulder of the mountain I saw a curious round gray-brown object that looked quite different from the rocks that littered the mountain side. They were 
sharp and angular, but this one was smooth like a water-worn boulder, such as one finds in a stream bed. "Quick, Hagelbarger, give me the glasses," I whispered.

They were buried deep in his packsack, and it took some time to find them. Meanwhile, the brown object was as still as the rocks, and 1 concluded I must be mistaken, for a bear would be moving about. So, when the glasses were finally fished out, I felt it almost foolish to use them.

But one glance through the binoculars was enough. There he was, sure enough - a big brown bear, curled up in the sunshine, fast asleep. His back was toward us and his head tucked in, as though to shield him from the blinding sun. Fortunately the wind was right. He was restless, turning every little while first one way and then the other. Part of the time he turned his head directly toward us and once he stood up, but did not see us - bears have very poor eyesight - and lay down quietly to sleep again.

What were we to do about it? This was no bear hunt, but a botanizing excursion. Our rifle was at camp I,500 feet below, and three miles away. IVe had only revolvers. Should we tackle him with these, or should we quietly back out over the mountain with the hope that no risions of men would disturb Bruin's slumbers? We counted our shells. Each had enough to reload. I was hesitant; but what were we carrying those revolvers for except for protection against bears? Here was an opportunity to see what they were good for and under much more favorable circumstances than we could ever expect if attacked. Besides, as compared with the bows and spears with which the natives had formerly hunted bears, pistols were, indeed, formidable weapons.

\section{GOING AFTER BRUIN WITH A PISTOL}

Accordingly we worked back out of sight and carefully picked our way around over the shoulder of the mountain till close upon him. The only cover as we came up over the ridge again was a thin square slab of stone that stuck up, exactly like a tombstone. I remember wondering, as I crawled up to it, if it might be my own tombstone before 1 was through. Even such bad augury, did not greatly disturb me, however, for as I got into position and aimed, my hand was as steady as though only shooting at a mark. I was so concerned for fear he would escape that 1 could not wait for Hagelbarger, but opened fire before he came up.

My position could not have been improved. The bear was still sleeping quietly only twenty yards away, his great shaggy head as big as a washtub and turned directly toward me. If I had remembered all I had been told about the thickness of a bear's skull, the result might have been different, but that head was too fair a mark to be resisted. I took careful aim and fired.

It hit hin square; the shock knocked him clear off the rock, and started him tumbling down the mountain side. I was on the point of going down to get him. The second and third shots glanced and went whistling off across the valley. Their noise evidently persuaded him that the trouble came from that quarter. Instead of rolling farther down hill, he suddenly gathered himself together and started back straight for us. Things began to look bad, so I hurriedly gave him another. This turned him off along the side of the mountain below us.

By this time I was wondering what on earth my gun was good for, anyhow, and was more anxious to reload than to pursue. I began to fear that the affair might change from an offensive to a defensive campaign. Judging from the effect of the first five shots, we should have been as helpless against him, if he had charged, as though armed with pocket knives.

I had heard many tales of the ability of the liodiak bears to walk off with lead, but I had been very cocky about my heary service Colt, confident that 


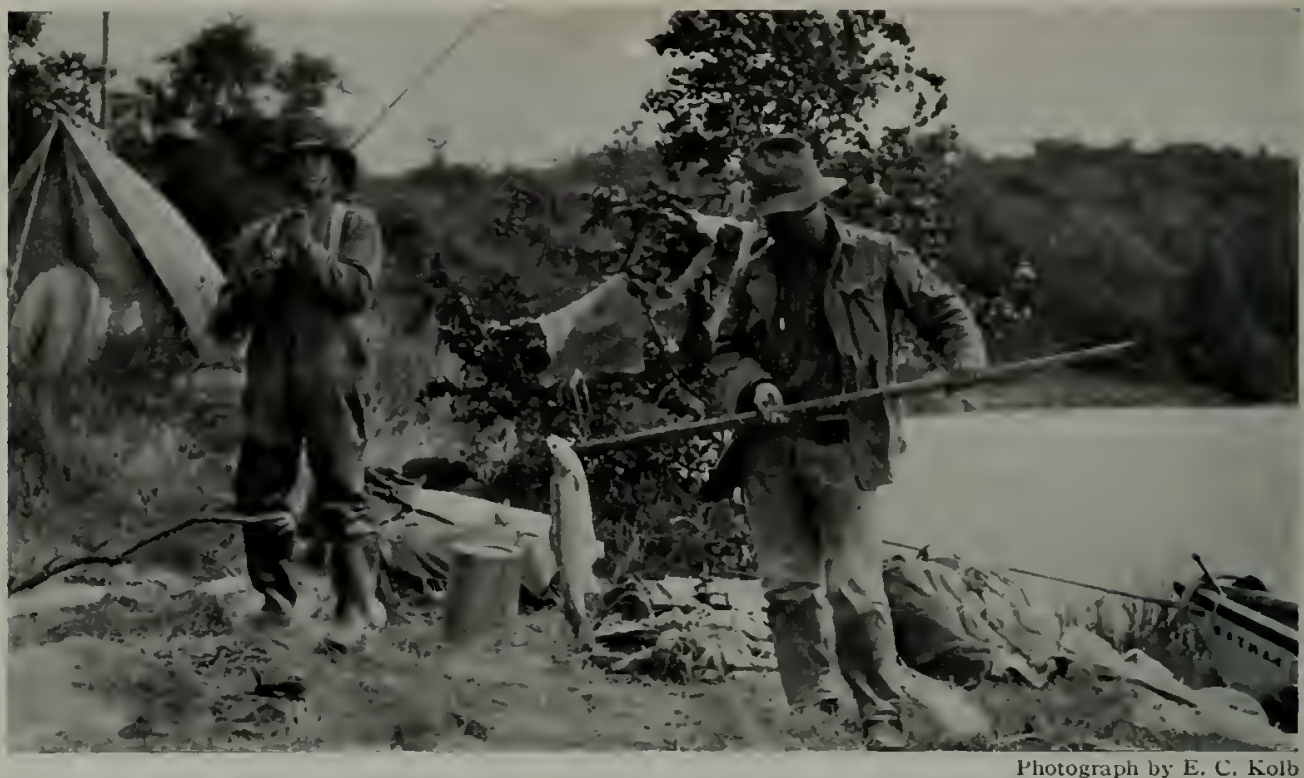

RAINBOW TROUT, NAKNEK RIVER

It is only the little ones that get photographed. They a veraged two feet. The largest was thirt $y^{\prime}-t$ wo inches. Seldom were more than one or two casts necessary to secure a strike that kept one busy.

a shot properly placed would kill anything. But now I was inclined to throw it into the river.

No bears were killed on any of the expeditions until 1919, when two were secured, both the results of accidental encounters. One morning Hine discovered one fishing on the beach directly in front of the base camp on Naknek Lake. He fell easy prey to Wallace's rifle. The other one was found by Captain Nyman of the Nimrod, swimming about among the islands of Geographic Harbor. It was a simple thing to overhaul him with the power boat and shoot him at close range. Either of these bears would have been a fine subject for motion pictures, but unfortunately both times the camera was a hundred miles away.

\section{THE PROBLEY OF FINDING A HARBOR}

Along with the biological and geological work projected in 1919 was a problem of another sort - search for a better means of access to the district than was open to us.

The spectacular character of the rol- canic activity naturally aroused widespread public interest in the region, coupled with a desire to visit it. But it was clear that no great number of people would ever brave a landing through the surf and go up into the country by the primitive means that had to be adopted by our expeditions. The first requisite to opening up the new park was the finding of a safe harbor, suitable for the use of large vessels.

It was doubtful at the outset whether a port such as was needed could be found. Between Cape Douglas and Cold Bay, harbors of any sort are singularly scarce, considering the irregularity of the shore line. Although the much indented coast somewhat resembles that of southeastern Alaska, where there is a superfluity of harbors, protected bays with sufficient depth are here few and far between.

There are a few bay's to the eastward which from the chart appear sheltered, but the mountains back of them are so very rugged as to give but poor prospect for a road. Westward, the mountains are separated by broad open valleys very favorable for road building, but the 


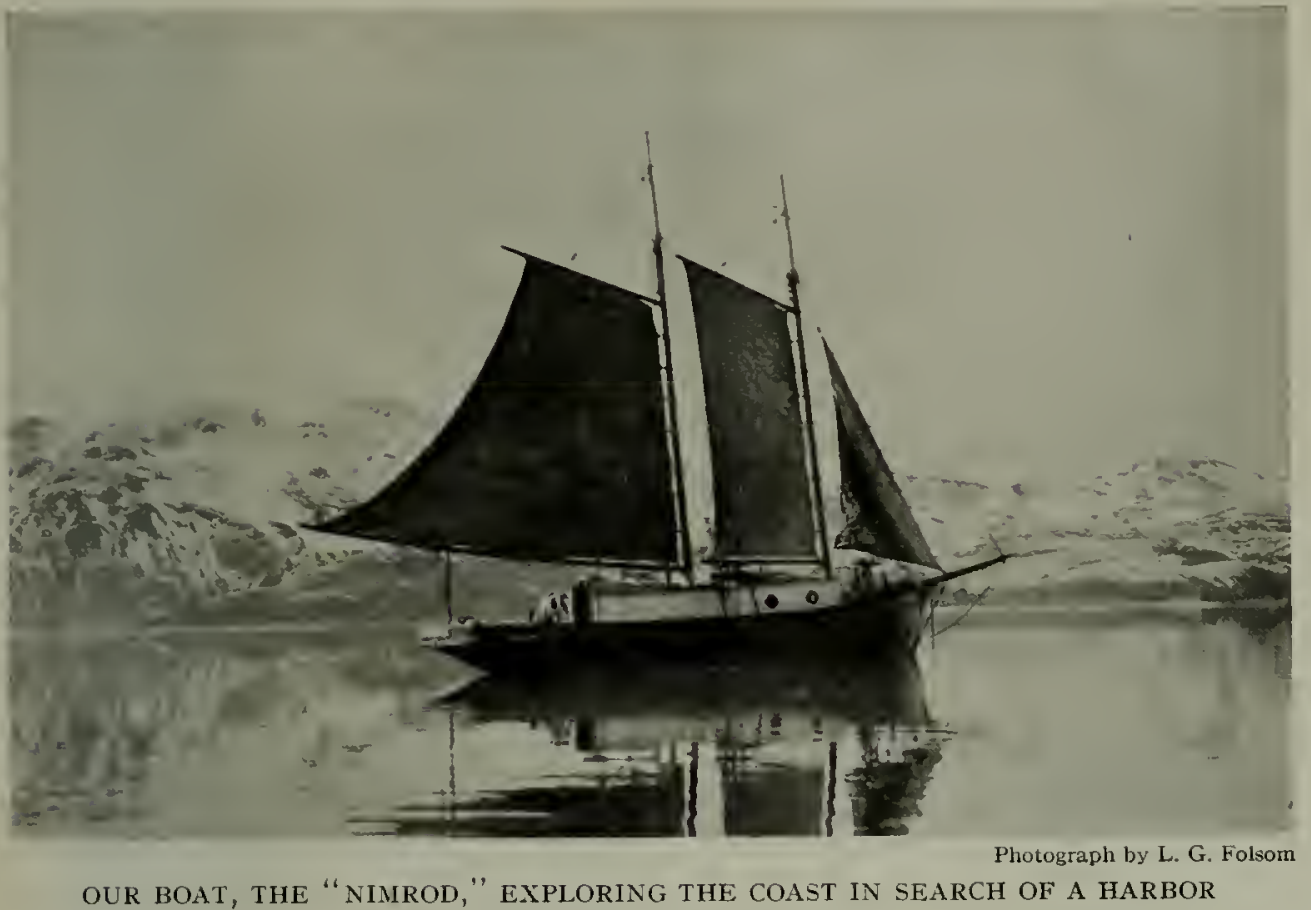

bays are both shallow and exposed. From the scenic point of view, it is important, moreover, that the projected road should run up Katmai Valley, since from any other direction Mount Katmai loses the impressiveness that makes the first sight of it from the lower Valley so memorable.

\section{THE POSSIBILITIES OF KUKAK AND KINAK BAYS}

The testimony of local pilots and a study of the chart seemed to indicate that our best prospect was Kukak Bay, which the Russian surveys showed to be deep as well as spacious. But it is too big to afford altogether satisfactory protection and is exposed to bad "williwaws" in easterly gales. From its head, however, a broad open valley leads straight through the mountains in the direction of Mount Katmai, running practically at sea-level across to the head of Kinak Bay. This easy passage at once ruled out all of the intervening bays between Kukak and Kinak.

But, when we examined Kinak Bay, we thought it a better entrance than Kukak. Its head bears little resemblance to the chart. It is constricted between two great cliffs into an exceedingly narrow passage which opens into an exceptionally beautiful basin, which we named Hidden Harbor. Its water is deep and clear of dangers close up to the mountainous shore. It is, moreover, nestled in among the mountains, secure from all manner of tempests, and there is no chance for the dreaded "williwaws" to reach it.

But this same mountain wall offers the greatest objection to its use as a port of entry, for it stands a thousand feet high all around, and would make road building very expensive. The same obstacle would have to be overcome by a road from Kukak Bay, for after traversing the level valley connecting the two it would take the sane route.

\section{DISCOVERY OF AN IDEAL HARBOR}

We did not suppose that the next bay west, Amalik, would prove as good an entrance as Kinak. According to the 


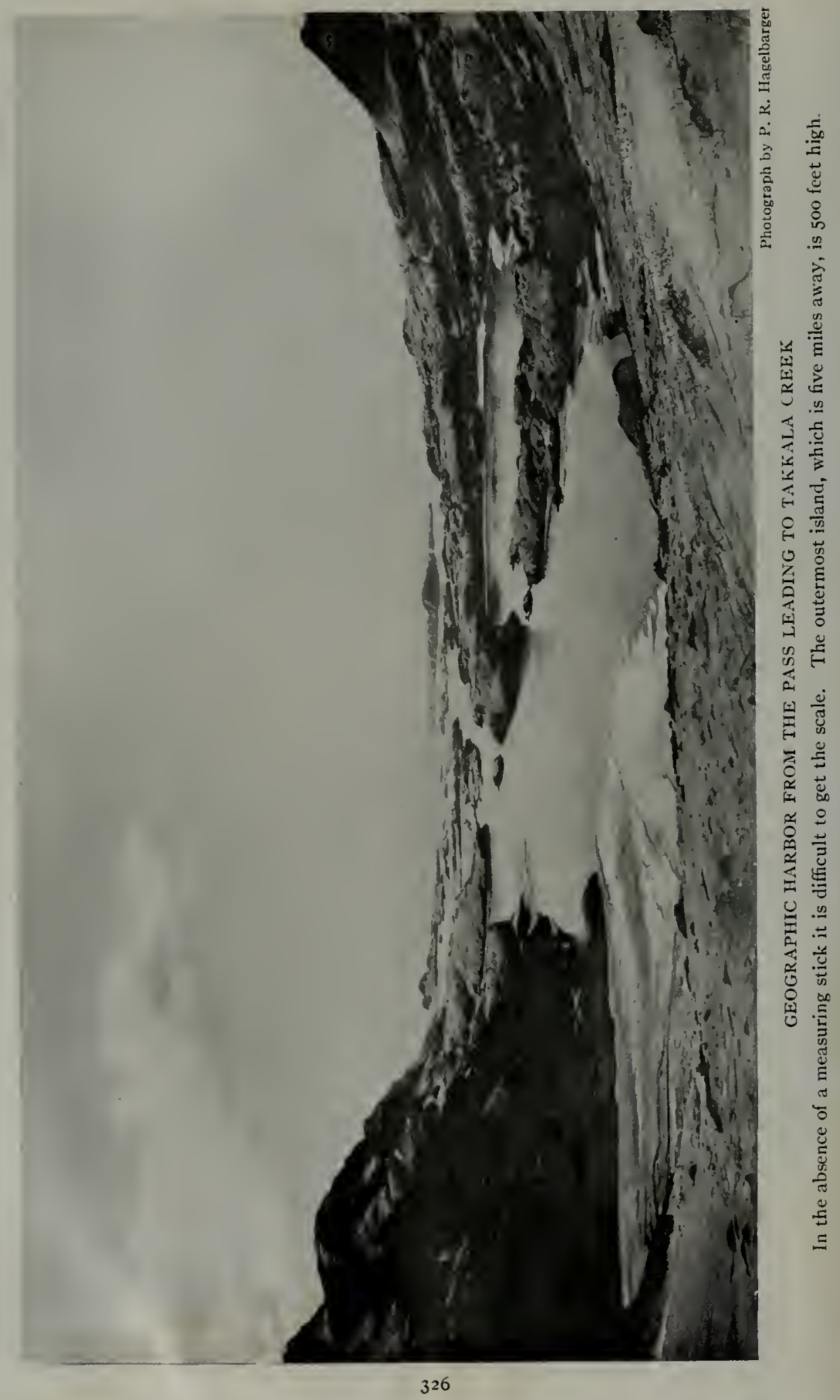


chart, it is not nearly so deep an indentation in the coast line. But upon examination we found, to our astonishment, opening back of the outer barrier (which is indicated as the head of the bay by the chart), a broad deep basin forming an ideal harbor.

When we entered the narrow opening, we found ourselves in a long straight canal leading back among picturesque islands far inland behind the "coast." Finally, the canal opened into a broad inner bay, itself bisected by a chain of islands. Passing through the opening between these, we found the upper portion of the bay a perfect harbor, with deep water throughout, except where a stream had washed a delta into its head.

So far as we could detect, with the means at our disposal, the waters are free from hidden dangers. Captain Nyman of the Nimrod sounded through the channel with nine fathoms ( $5+$ feet) of line, but found no bottom at any point. The new harbor is, therefore, suitable for ships of the largest size.

Its channel is straight clear sailing, and once inside there is abundant room for maneuvering. It is, moreover, easy to get into, for the mouth of the outer bay is a wide opening between conspicuous landmarks, readily entered in the roughest weather. A ship coming down the coast, picking up a light placed on the island off the Cape (Ilktugitak) and making a single turn would steer right in - reaching quiet water, protected from both wind and sea, a mile or two before entering the channel.

In honor of the Society responsible for the exploration of the Katmai district and for its being set aside as a national monument, we named the new harbor Geographic Harbor.

\section{GEOGRAPHIC HARBOR A FITTING EN- \\ TRANCE TO THE VALLEY OF TEN THOUSAND SMOKES}

Not only is Geographic Harbor a secure and commodious haven, it is a fitting entrance to the Katmai National Monument. It is doubtful whether any of the superlatively beautiful bays along the Alaskan coast surpasses this one in the grandeur of its setting. On both sides the mountain walls tower aloft 3,000 to 3,500 feet directly out of the water, the irregular weathering of their stratified cliffs producing a very striking effect. The many picturesque islands of the bay give its shores an appearance of alluring mystery. One has the feeling that he could spend many days in a canoe, poking into its recesses without seeing all that was worth while.

The islands are the protruding hummocks of a great lava flow that came down the bay from some Tertiary vent. Their out-shore faces are weathered into the most striking columnar structure, (see page 302). That the eruption responsible for these great lava masses far antedated the recent period is well shown by the inshore faces of the islands. They have been all planed off into smooth, round, gentle slopes by a glacier which came down the Valley after the lava had been poured out.

Back from the head of the bay, above a sightly waterfall, is a considerable lake whose water may be presumed to be full of fine trout.

\section{A FEASIBLE ROUTE FOR A ROAD INTO THE INTERIOR}

On the land side, conditions are as favorable for the use of Geographic Harbor as from the sea. There are two practicable routes by which a road could be carried over into the Valley of Soluka Creek, the principal eastern tributary of Katmai River. Only 50 or 60 miles of road would be required, not only to penetrate the Valley of Ten Thousand Smokes, but to connect with the head of Naknek Lake and Bering Sea as well.

Some novel engineering problems might, to be sure, arise from the desirability of keeping such a road as clear of drifting ash and snow as possible. But these could undoubtedly be overcome with a little study.

It may be stated in passing that in addition to the desirability of making the 


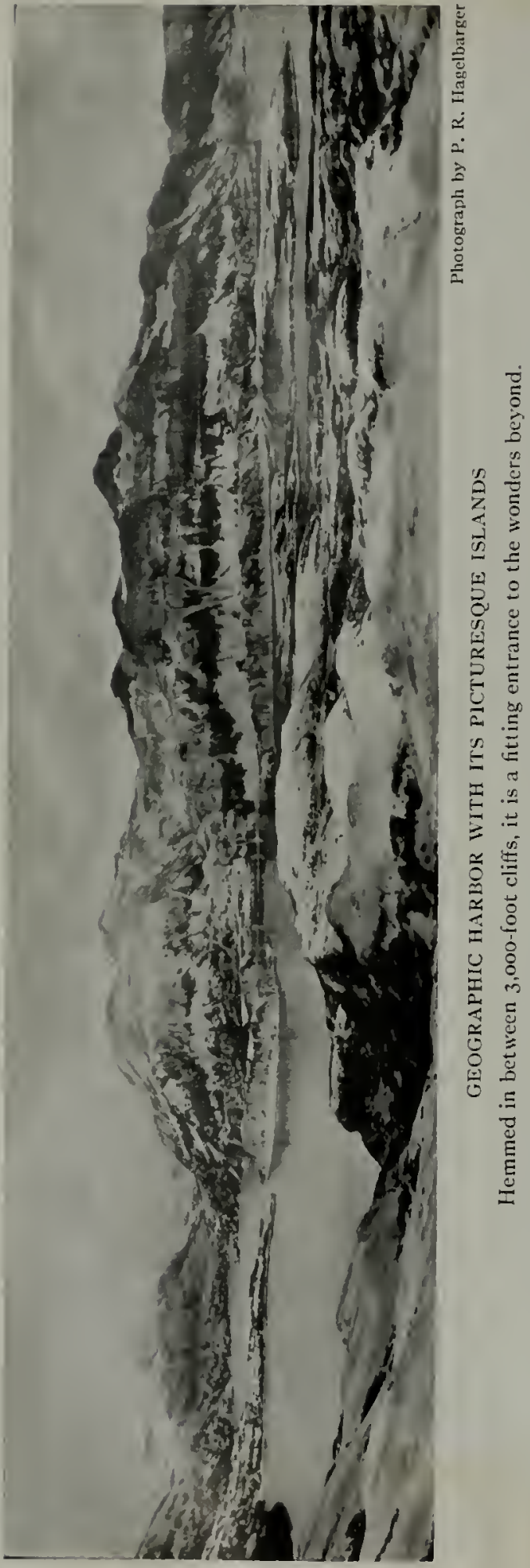

volcanic features accessible, there is another important reason for the construction of a road across the Peninsula. The canneries tributary to Bristol Bay give the district a summer population of 10,000 men. To reach these people, it is necessary at present to make a voyage of a thousand miles around the whole length of the Alaska Peninsula.

This trip is so time-consuming, expensive, and dangerous that the whole community is practically isolated, except for the radio. In the old days, when commercial operatious were conducted on a smaller scale than at present, it used to be considered better, as stated by Petrof in the quotation given on page 265 , to carry supplies across Katmai Pass on man-back than to attempt the royage.

When in 1918 and 1919 the Katmai Expeditions desired to enter the country from the Bering Sea side, we found that it was practically impossible to get in and out except by the kindness of the packers, who permitted us to travel to and fro on their sailing vessels. As this required an absence from April first to October first, in order to work through June and July, it will readily be seen how inadequate are the transportation facilities.

A road thrown across the base of the Alaska Peninsula, through the Valley of Ten Thousand Smokes, ${ }^{1}$ would afford the people of Bristol Bay district access to the frequent steamers that serve the Pacific slope of southwestern Alaska, providing adequate mail service and that ready communication with the outside world which is essential to the development of any country. It would save the packers several million dollars annually; by permitting them to take in their crews in June and get them out in August, instead of holding them for six months, largely in idleness.

\footnotetext{
${ }^{1}$ Other routes have been suggested, but no other starts from a good harbor on the Pacific.
} 
From a military standpoint, such a road would have great strategic importance. If it should ever be necessary: to dispatch a military force into Bering Sca, such a road would be indispensable, since without that route an enemy could land its forces at any point of Bering Sea as readily as we could ourselves.

SIXTY MILES OF AUTOMOBILE ROAD WOULD OPEN UP THE WHOLE DISTRICT

For the tourist, the construction of an automobile road, fifty or sixty miles long, would permit the whole district to be traversed in a single day.

Many were the times, as we plodded up the hills with loads which, though taxing our strength, yet contained only a pitifully small store of provisions, that our thoughts turned to the future and we could see in our mind's eye swift motor trucks rolling through the Valley, transporting in an hour more than we could carry in a month. How often, as we were held miserable in camp by a trifling storm, we thought of the day when closed cars should run over Katmai Pass without regard to weather, carrying their passengers in ease and comfort through weather conditions practically impossible for us.

To some these visions may seem chimerical. They are not. The Katmai district is nearer to civilization and more accessible in every way than was the Yellowstone at the time of its discovery. Let any who are skeptical of the future of the
Katmaidistrict consider the Yellowstone. Its vast area is tramped under foot by. innumerable campers, until there is conplaint that the natural wonders are in danger of being spoiled. Almost one in every hundred of the entire population of the country visits the place every year!

Yet, to reach the Yellowstone in those days, before the development of the automobile, the expense of building a railroad was necessary before it could become accessible. Even after the contpletion of the transcontinental line, the nearest boundary of the Park lay sixty. miles from the railroad. Contrast conditions here, where ocean steamers can land their passengers within fifteen miles of the crater of Katmai.

It was no longer ago than 1902 that Brooks undertook the first epoch-making journey from Cook Inlet through the interior to the Yukon. It was one of the most courageous attempts to cross the absolutely unknown that is recorded.

At the start the residents of the district agreed that it was a foolhardy project, impossible of success; and at the end the natives would not believe that the party had actually come overland from the Pacific, as they said. Yet within twenty years we see a railroad and a string of settlers' cabins spanning the trackless wilderness which Brooks penetrated for the first time. Who can doubt that before long the Katmai National Mlonument will be made readily accessible to all who desire to see it? 


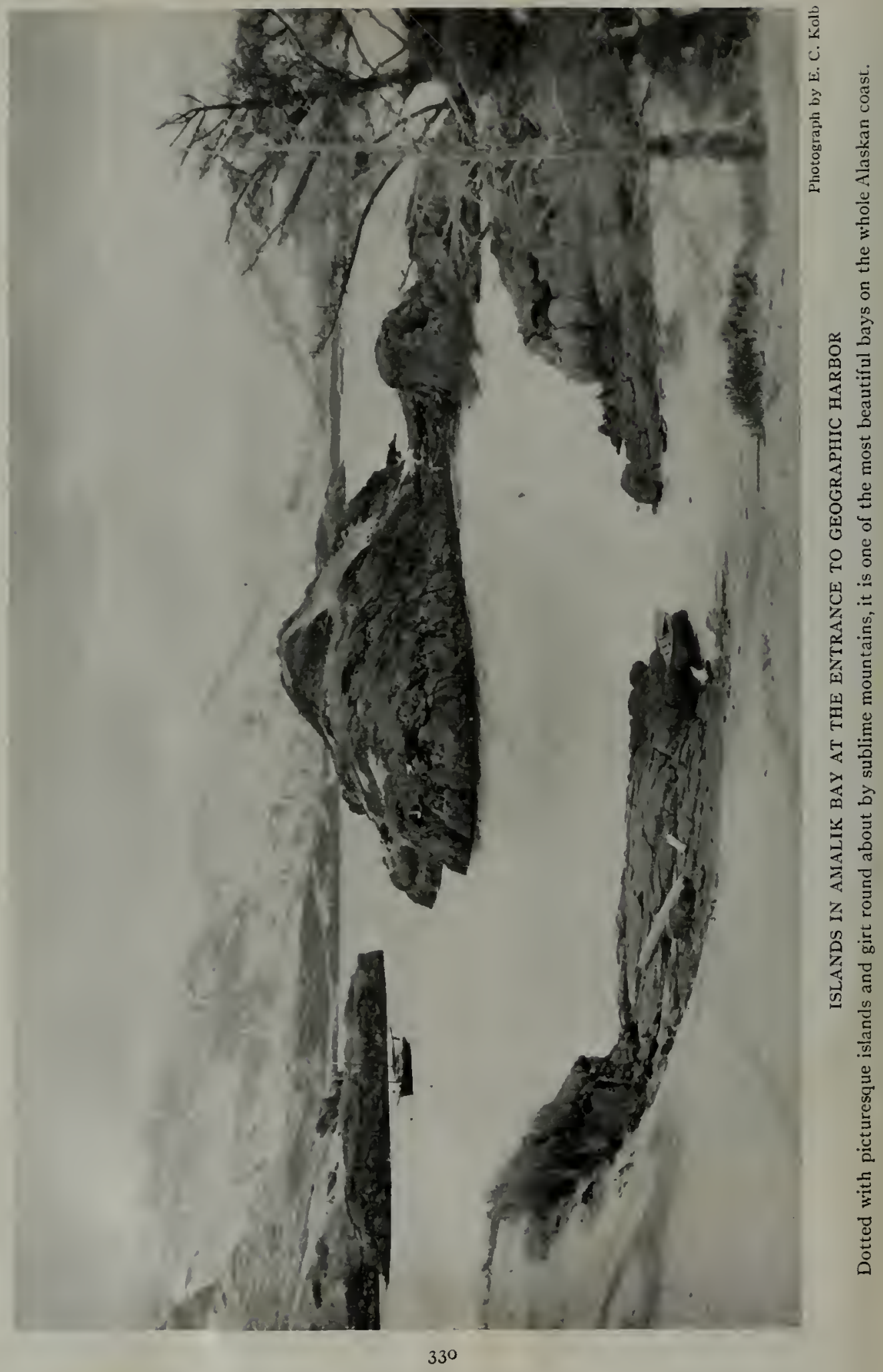




\section{PRESIDENTIAL PROCLAMATION ESTABLISHING THE KATMAI NATIONAL MONUMENT}

IVHEREAS, There exists upon the southern coast of Alaska a belt of unusual volcanic activity which has during the last several years exhibited at various points energy of violence which attracts the special attention of scientific watchers,

ANd Whereas, Mount Katmai, one of the volcanoes in this belt, has proved upon investigation to have unusual size and character, and to be of importance in the study of volcanism, inasmuch as its eruption of June, I912, was one of excessive violence, ranking in the first order of volcanic explosive eruptions and emitting several cubic miles of material during its first three days of activity,

AND Whereas, The results of this eruption are still fresh, offering excellent opportunities for studying the causes of the catastrophe and its results and affording a conspicuous object lesson in volcanism to visitors interested in the operation of the great forces which have made and still are making America,

AND Whereas, The volcanic neighborhood is shown by the explorations of the National Geographic Society to contain many other striking features of an active volcanic belt produced so recently that they are still in the formative stage; and in particular The Valley of the Ten Thousand Smokes, a valley of hot springs in a condition of development toward a possible future geyser field, in distinction from the present dying geyser field of the Yellowstone,

And Whereas, This wonderland may become of popular scenic, as well as scientific, interest for generations to come, in- asmuch as all its phenomena exist upon a scale of great magnitude, arousing emotions of wonder at the inspiring spectacles, thus affording inspiration to patriotism and to the study of nature,

Now, Therefore, I, WoODrow WILson, President of the United States of America, by virtue of the power and authority in me vested by section two of the Act of Congress entitled "An Act for the preservation of American Antiquities," approved June 8, I906 (34 Stat., 225), do proclaim that there are hereby reserved from all forms of appropriation under the public-land laws, and set apart as the Katmai National Monument, certain lands particularly described as follows, to wit, beginning at the United States Coast and Geodetic Survey triangulation station, latitude $57^{\circ} 52^{\prime}$ I $7.040^{\prime \prime}$, longitude $155^{\circ} 05^{\prime} 20.33^{\prime \prime}$, established in 1908 about one-half west of Katmai Bay on top of a hundred-foot bluff on the Alaska Peninsula, named Cape Kubuga$\mathrm{kli}$; thence north $40^{\circ} \mathrm{oO}^{\prime}$ west to the intersection with longitude I $55^{\circ} 40^{\prime}$; thence due north to the intersection with latitude $58^{\circ} 35^{\prime}$; thence due east to the intersection with a line bearing north $60^{\circ}$ $\mathrm{oo}^{\prime}$ west from Cape Gull; thence south following said line to the shore line at Cape Gull; thence west following the shore line of the coast to a point directly below the triangulation station, situated on the bluff at Cape Kubugakli; thence up the bluff to the said station, the point of beginning; embracing approximately I,700 square miles of land, as shown upon the diagram hereto attached and made a part of this proclamation. 
VTarning is hereby given to all unauthorized persons not to appropriate or injure any natural feature of this monument or to occupy, exploit, settle, or locate upon any of the lands reserved by this proclamation.

The Director of the National Park Service, under the direction of the Secretary of the Interior, shall have the supervision, management, and control of this monument, as provided in the Act of Congress entitled "An Act to establish a National Park Service, and for other purposes," approved August 25, I9I6 (39 Stat., 535).

IN IVITNESS IVHeREOF I have hereunto set my hand and caused the seal of the United States to be affixed.

DONE in the District of $\mathrm{Co}$ lumbia this twenty-fourth day of September in the year of our Lord one thousand nine hundred and

[SEAL.] eighteen, and of the Independence of the United States of America the one hundred and forty-third. WOODROW IVILSON.

By the President:

RoBERT LANSING, Secretary of State. [No. I487.] 


\section{ACKNOWLEDGMENT}

Ready as the National Geographic Society always is to reach out with new fields of interest to its members, it is not surprising that with the first news of the eruption a representative, George C. Martin, was dispatched to the devastated district. The report of this first Katmai Expedition has furnished the basis of the earlier chapters.

There the matter might have stopped had not Frederick V. Coville, Chairman of the Research Committee of The Society, recognized the importance of studying the revegetation of the ash deposits. Because of my familiarity with the region about Kodiak as a member of the United States Bureau of Soils Kelp Expedition of I9I3, I was selected to carry on the investigation. To Dr. Coville the writer owes a large debt, not only for the original stimulus to undertake the work, but for unceasing help and counsel throughout.

The work early enlisted the enthusiastic and constant support of Gilbert Grosvenor, President of The Society.

In the field the expeditions were generously assisted by friends of the Society. The people of Kodiak considered it a privilege to help. To M. D. Snodgrass, then in charge of the Experiment Station, and to W. J. Erskine we were especially indebted. On two occasions Mr. Erskine, placing at the disposal of the expeditions his large acquaintance with dealers in San Francisco, purchased the whole season's outfit for us. The expeditions of I9I 8 and I9I9 were similarly indebted to Frank B. Petersen, President of the Naknek Packing Company, and his associates, Superintendent P. Larsen, Captain George IVester, and Fred Sparks, whose generosity made it possible to send in parties and supplies through the Bering Sea.

In the preparation of the topographic map accompanying the book, The Society has had the cordial coöperation and assistance of the Alaska Division of the United States Geological Survey, under the direction of Colonel Alfred H. Brooks. The map has had many vicissitudes, owing to interruptions incident to war and to the oil boom which at various times drew away the men who were working on it.

Finally, the writer owes a great deal to the searching and sympathetic criticism of his friends, John Oliver La Gorce, W. J. Showalter, and other members of the Staff of the National Geographic Magazine, to C. S. Scofield and F. L. Ransome, of the Research Committee, and to William R. Maxon. 


\section{INDEX}

Page numbers in ordinary type (e.g. 24) refer to subjects metely mentioned or to brief comments. Figures in bold face type (e. g. 24) refer to important comments or discussions at length. References in italic figures (e. g. 24) denote illustrations. Page references followed by $n($ e. g. $2+n)$ indicate footnotes. References in parentheses after Roman numerals [c. g. PI. IX (22.4)] locate plates.

Abbot, C. G. $35 n, 37,39$

Abrasion of trees by wind-blown ash 149

Accessibility of Katmai 327

Acid in air II, 2 I $2,25,27,33$; in soil 200

Admiral Sampson (steamer) 25

Afognak. Alaska 7

Agriculture, bearing of volcanic ash on 3

Airplane, possibility of using in Katmai region 75

Air wave from volcanic eruptions $\mathbf{3 5}$

Alaska Peninsula $15,58,67,208$; base of, map, front cover: need for road across 328

Alaskan volcanoes 57-63

Alder (Alnus sinuato) exterminated near Katmai $\$ 3$

Aleutian, volcanic chain 57-6I ; length of 61 ; Islands 58,61 ; volcanoes 65 . volcanoes and hot springs, map facing 60

Aleuts 265

Algae around fumaroles $200,223,25$ t

Algeria, haze in from Katmai eruption 36

Alinchak Ray In

Allen, E. T. 77, 80, 220, 229, 230, 231 , 246

Alumina 46

Alum 247, Pl. XI (240)

Alum root 157

Amalik Bay 69, 325, 330; field of floating pumice in 30

"American Pete," story of 17

Ammonia $2+6,2+8$

Andaman Islands (Bay of Bengal) 35

Andesite roI, I8I, I87, 240,24I, 287; changes in by gases 243,289

Andrean [Yagashof] 74, 199, 32 I

Animals trapped in Valley $28 \mathrm{r}$; herbivorous, effect of ash on 314

Animal life, in Katmai region 81, 95; return of to Katmai Valley $16 \mathrm{x}-165$; in Yalley of Ten Thousand Smokes 208; before eruption $265,277,314$; increase in Katmai region 355

Arctowski, Henryk $35 n$

Argon 246

Arkose 271

Armstrong. (U. S. Deputy) Marshal I2, $32 \mathrm{I}$

Arsenic compounds, around fumaroles 247

Artemisia tilesii 155

Asama-yama (Japanese volcano) 33

Ash 3,7-14,21, 23, 34, 148 ; views of Kodiak immediately after fall of 4. $5,6,16,20$; during fall 9 ; depth of $8,12,19,26,55,169$; greatest 243 ; area covered by $25-27$; plants growing through and in $40,42,47,40,51$. $52,54,160$ : composition of 41,158 ; roots survive fall of $45,50,5 I, I 55$; on trees 45 ; contribution to soil 46 ; analysis 46 ; drifts and dunes of 46 . 50; effect of in stimulating plant growth 47-49; experiments showing growth of plants in, as compared with sand 50 ; wind-blown $\mathbf{5 2 - 5 5 , 5 9 ;}$ effect of on tree growth $53,83,133$; cracks in 22,53 ; moved by water 55,81 ; from Bogoslof 65 ; slides 87 , $147,82,86,126$; climbing slopes of 88 ; in streams $10,80,150,151,152$, 153: caverns in 89 ; bridges 89.91 ; cool when it fell 95 ; retarded melt ing of snow 148 ; colors of 171,285 thrown from Katmai 285 ; specific gravity of 293 ; on plants wore out teeth of herbivorous animals 314

Ash-covered, roofs 16,24 ; trees 20,28 , 38,48

Ash deposits, affected by earthworms 55: support moss $55:$ cross sections of $93,146,140,154,255$; erosion in I6I. 298; bad lands in 209

Ashfall I, I2, I3; map showing depth facing $I$; in Kat mai Valley $153-155$ affected by winds 155 ; volume of 29 from Tomboro 34; from Iliamna and Redoubt 61, 62; at Kodiak in 1867 . 62

Asia, rolcanic festoons of, map facing $56,57-61$

Asiatic volcanoes, Katmai's relations to 57

Astronomical observations affected by eruptions 37

Atwood, W. IV. I67

Augustine Volcano 60,62

Austin, O. P. 341

Automobile road feasible in Katmai region 329

Avalanche Mountain (Katmai region) 99

Avalanche of ash, remains of, Kodiak I 4

Avalanches $1.47,241,242 ;$ of ashes 9 ; wind caused small 125 ; from Falling Mountain 241, 277

Bad lands in ash deposits 254. 298

Baked Mountain 233, 235, 241, 243, 253; camp 183, 224, 226, 26. wreck of $227-23 \mathrm{I}, 227,230$

Bandai San (Volcano, Japan) I45; landslide $I+5$

Banks of overloaded streams I 31

Baptist, Nission. Wood Island I3; orphanage, Kodiak 45, ash-covered garden at 48,40

Barabaras (native houses) I7, pronunciation of $17 n, 24,103$; interior of 29

Bartier Range (Katmai region) 90, 275

Basalt 46, 261; cliffs 302

Basinger, A. J. 77.79, 80

Batholith, theory of to account for Valley activity 301,303

Beach, Rex 273

Beaches of old Katmai Lake 120,125

Bear trail that sprouted 162 ; starts a fumarole 224 ; tracks $318,310,320$ : hunt with a pistol 321 ; shin 322

Bears 84, 85, 95, 164, 208, 223, 265 . $277,315,317-324$; feeding habits of 321

Becharof Lake I5, I 83, 26 =

Bell, Alexander Graham 34

Bell, Charles J. $3+1$

Bering Sea $58,61,67,69,266,307$.
327,329 ; expedition of 1918 from $77,79,328$

Berries, salmon, vines appear through ash 51,155

Betula kenaika 83

Bhira Gunga (gorge, India) I4:

Bidarka (skin boat) 17,268

Birch (Betula kenaika) almost exterminated in Katmai region 83, 305

Birds, in Katmai region $93,95,163$ I 65,3 I 3 ; injured by falling ash if Bitter cress 15.

Blue-top grass 155,160

Boat, cauvas 97

Bogoslof (volcanic Island, Alaska) $6 \mathrm{I}$.

$63-65,64$

Bonfire kindled by water $2 \$ 2$

Borneo (Island, East Indies) 58

Bolinvell (U. S. Coast Guard Cutter) 65

Boudry, C. L. 17, 2 In

Bowlder trains (Hows) I 37, 142, effects of $1.42,143$

Bowlders, moved by streams 96,108 , $100,110,113$; as big as houses 135 ; in Bandai San landslide 145

Bridger Jim (comparison) 103

Bridges of ash 89,91 ; over steaming fissures 235

Bristol Bay 266, 310, 328

Brock, R. IV. 139n, I $43 n$

Broken Mountain 233, 238, 240, 24r, 243,253

Brooks, Alfred H. 307, 329

Brooks Falls 265, 310, 3I1, 3IO, $31 I$

Brooks, Lake 307, 308, 300

Brown (Capit.) 12

Buried, wood 127, I39; snowdrifts I 48-I 49

Burnet (plant) I55

Buttress MIountain 237, 239, 255

Calamagrostis scabra $155, \mathrm{I} 60$

California, haze in from Katmai erup. tion 36

Camps 74; system of relay 75,79 ; views of $206,226,227,230,264,312$; near Observation Mountait 197; near Baked MIountain I83,224, 226 , $227-23 \mathrm{I}, 227,230,26$

Cameras o6, 207

Camosun (steamer) 27

Canning industry near Katmai region 310,328

Canyon, of the Katmai River 69, 95 , 97, II 4, II $6, I I 8, I 21, I 22, I 24,127$, $I 30, I 32,273$; and second valley of the Katmai 123-133; of Mageik Creek 124

Carbon dioxide, 246; question of liberation bv, of volcanoes of extreme importance to $m$ inkind 43,44

Carbon monoxide 246

Cardamine umbellala i 55

Carex sp. 155, 157, I60

Caribou, absence of in devastated region before rgro, I64

Carnegie Institution, Geophysical Lahoratory of $78,79,80,205$

Carter, Charlie 267

Castle Rock (Bogoslof Island, Alaska) 63,65 
Cattle, herd of Galloway, Kodiak 44 Caverus in ash $89,91,93$; in Valley of Ten Thousand Smokes 203

Cerastium sp. I5?

Cerberus, Mount PI. V (192) ror, $192 n, 233,254,262,274,296$

Charcoal forest. 260

Charred log, in sandflow 255; trees 257

Chemical work 200

Chemistry of fumaroles 246-249

Chester, C. MI. $34 \mathrm{I}$

Chigmit Mountains (Alaska) 59

Chicken (town) 23, 26

Chickweed 157

China Sea 58

Church, D. B, 72, 73, 74, 76, 189, 190 193, 216,217

Church. Greek at Kodiak 9: Russian I03. 267 ; at Katmai village 10.7

Clark, Lake 21, 23, 61, 308

Clarke, F. IV. 4 I $n, 43$

Cliffs of columnar basalt $30 z$

Climate in Katmai region $90,158-159$, 208, 209; glacial, night be caused by volcanoes $39-4$ I

Climatic effects of the eruption 33-44

Climbing ash slides 87

Clothing 207

Clouds, volcanic $15,21,279$; edge of 8 ; about Mt. Katmai 167. 173, 177 steam I68; about Mt. Martin 18I

Coan, Titus $281 n$

Cold Bay (town) I7, 21, 279, 324

Color photography 251

Colors, of Katmai cliffs 123, 124; of mud 167; of ash I7 1, 285; of Katmai crater walls 174 ; about fumaroles I00, 192, 204, Pl. VI (103), VII (208), VIII (209), IX (224), X (225) XI (240), XII (24I), XIII (288) XIV (289); of cliffs on Baked Mountain 244; due to iron compounds 247 in the Valley $\mathbf{2 5 0 - 2 5}$

Commander Islauds 57

Condition of country before eruption 265-275

Conglomerate 306

Conical mounds, probably result of landslides $127-128,128,134,139$, 142 ; in Bandai San landslide 145 ; on melting snow field 156,157

Conway, Sir William M. $143^{n}$

Cook, Captain (early explorer) 62,63

Cook Inlet 21, 61, 62, 269, 307,329

Cooking 81 ; over fumaroles 106.200 Pl. VI (193), VIII (209), 205, 224226,282

Copper Center (town) 23

Cordova, Alaska 23, 25

Cornice structure in hlock of lava 206

Corundum in incrustations 247

Cotopaxi (volcano, Mlexico) 43

Country around Katmai, geograplic observations in 305-327

Coville, Frederick I? $307,315,34 \mathrm{I}$

Coville, Lake $307,308,315$

Crater, of Katmai $167-179,287,288$; nature of rim of $168, I 7 I, I 75$; view into $169,172,874,176,179$; lake in 169 ; size of $170,173,176-179$; compared to that of Kilauea I79; of Mt. Martin 181 ; descent into 185

Craters, in Valley floor $236,237,26 \mathrm{r}$, 202

Crater Lake (Oregon) 288

Crust (earth's) deformation of 59

Culebra Cut (comparison) 117

Daly, R. A. $297 n$

Dam formed by landslide in Katmai
Canyon, I15-117, 156, 125; in Mageik Valley i 17 ; in Himalayas 145

Dangers of the Valley 201, 203-204

David's Falls 123

Darwin, Charles 55

Dawson (city) 23, 26

Davidson, George $61 n_{1} 62$

Dead forest 87,95

Deformation of strata 61

Deltas, process of formation 152

Dennison, Vapier 23,27

Depth of waters near Aleutians $6 I$

Desert, as result of ermption 45

Desolation of Katmai region, 82, 94, 95. 127

Devil club growing through ash 40

Deville, C, $2.16 n$

Digestion of old rock in magma $24^{\circ}$ $21 t, 289,297 n, 299 n$

Dikes built by shifting streams 152

Disturbances, preliminary is

Dora (steamer) Io, $12,15,2 \mathrm{I}, 260$

Dormant, plants, under ash 51,52 ; seeds 157

Douglas, Cape 324

Douglas, Mount 307

Drainage in Valley 245

Drinking water 88,89 ; pool 222

"Dry fog" 33

Dunes, ash 59

Dust, rolcanic $11,27,33$; fell at great distances 27 ; cloud 33 ; from Tomboro 34 ; sun's heat absorbed by 37 ; in air 81 ; storm in Katmai region 84 ; clouds from landslides $I+5$

Eagle (village) 26

Earthquakes 12, 17, 19, $21,115,140$, $260,273,277,278,285$; distant records of 23

Earthworms, in ash deposits 55

East Indies 58

Eastern Sea (Tunghai), Asia 58

Edgecombe, Mount (volcano) Alaska $56,56,57 n$

Edson, Johr Joy $34 \mathrm{I}$

Effects of eruption, climatic 33-44; at Kodiak 45

Ejecta, quantity of 20-31, I 44,189 , $275 n, 285,295 n$; from Tomboro 34 ; character of from Katmai Ior, 28,5

Elderberry I57

Elm Landslide (Switzerland) 143

English Harbor (Port Graham) Alaska 62

Equiselum aravense i 55

Erosion, of ash 55, I7I; of volcanic cone 65 ; of mountains 129,131 ; beginning of on Mageik landstide 138 ; by wind 148, 149; in ash 161,298 ; in sardflow $254,258,260$

Eruption, and its significance $1-5$; as experienced at Kodiak 7-13; phenomena accompanying 7-13, 15-31, $33-39,65,115,139,144,242$; records of from other localities I5-31: sky phenomena following 37 ; condition of Valley hefore 19; effects of on air pressure 35 ; on forests 45.53 ; on climate $33-44$; on animal life I $6 I-165,314$; at Kodiak 45; sandfow a new type of 261 ; condition of country before 265-275; hypothetical chronicle of $277-285$; summary of events of 285

Eruptions, 3, 13, 25, 33, 34, 61-65, I 45 Expeditions to Katmai region 69 ; of $1912,15 n, 71$; of $1915,71,72,97$; of I9]6, 7I, 72, 97, I 47, I55, I57, I63, 167 ; of $1917,72,73,77,97,147,174$. 175, 181, 197-217, 273, view of members of $76 ;$ of $1918,17,77 ;$ of 1919. 77, 79, 147, 159. 181, view of members of 77 ; Frank Leslie's 274; effect of WVorld War on 70; preparations for 74 ; headquarters of Kodiak 6

Experiment Station, Kodiak, herd of cattle belonging to 44

Explosions (volcanic) $3,7,15,19,21$, $33,34,35,41,281$; heard at distant points 23; of Augustine 62 ; of Bogostof 65 ; of Novarupta 284 ; of Katmai delayed until crater was unroofed 297, 299

Explosive character of Katmai 291

Ewing. Dr, U. IV. 27

Eyewitnesses of eruption I5-2I

Fairbanks (city) 23, 26

Fairchild, David 34 I

Falling Mountain (in Valley of Ten Thousand Smokes) PI. IV (97); 128 , $192 n, 202,219,220,233,241-242$, 280 ; avalanche 277,285

Fault scarp. Broken Mountain 24

Faults in Katmai region $132,243,273$. 288,303

Fenner, C. N. $77,80,183,184,185$, $229,230,231,240,293 n, 297 n, 299 n$, 301

Ferric oxide $46 n$

Fertility of volcanic soils varies 46 ; of ash tested 47

Fertilizer, ash from Katmai did not act as 46 ; used in testing ash 47 ; nitrate 47 ; effect of on plants grown in ash and sand 50

Fickle Creek 150, I5 I, 151

"Finger Lakes," New York (comparison) 308

Fire, evidence of in Katmai region 95. 257 ; set by lava in Valley 281

Fireweeds in ash-covered region 45,46

Firewood 8

Fish in Katmai region $150,16 \mathrm{r}, 16_{3}$, $308,309,310,310,311,311,313,316$

Fishing in Katmai lakes 300

Fisher, Franklin J. 341

Fissure Lake $212,244,258$

Fissures 17, 202, $216,235,244,254$. 255 ; steaming 278; fundamental 303 Flies $163,164 n$

Flood, a freak of the Ioo, II3; the Katmai 103-I2I, I3I; destruction by $102,105,106,107,110$; the Gohna I19; the Mageik 13 ; ; the JohnsLown i 19

Flood fall of Katmai River $I I I, I I z$, II 155

Flowers in Katmaj region 82, 322

Fluorine, surprising abundance of in gases 247

Fogs near Alaska Peninsula 67

Folding (of strata) 27

Folsom, L. G. $71,72,73,74,76,77,80$, I I $3,127,170,180,190,2$ I I, 319, 32 [

Food of expeditions 75-77, 225-226

Fording, streams $87 ;$ Katmai River 96; Soluka Creek 89; with help of rope 97

Forests, effect of eruption on, 45, 53: near Katmai 82, 305; dead 87.95; effect of Katmai flood on 107, of hot sandflow 256,257 ; in Katmai region $267,312 \mathrm{Pl}$. XVI (305); in Valley before eruption 277; Hudsonian 305; border migmting west ward 305

Formosa (Island, Japan) 58

Foulk, C. IV. $46 n, 47 n$

Fowle, F. E. $35 n, 37$

Foxes 164,315 
Frank (Alberta), landslide 139,143 Franklin, Benjamin, on "dry fog" 33 Fujiyama (volcano) Japan 57.63, IoI Fulmer, Elton $46 n$

Fulton, B. B. $71,72,96$

Fumaroles 1, 3, 69, 71, 100, 106, 197 . $200,204,209,212,214,234,243$. 252,294 ; colors around 190,223 . PI VI (193), VII (208), VIJI (209), IX (224), X (225), XI (240), XII (241). XIfI (288), XIV (289), temperacures of $77,205,259,220-222$, highest $22 \pi$; mocion pictures of 79 ; the first seen I89-190; relation to old volcanoes 193 , 209; cooking over $\mathrm{Pl}$. VI (I93), VIfI (209), I $96,200,205$, $224-226,282$; steam from not dependent on surface water 219 ; slackening activity of 219 ; measuring temperatures of Pl. IX (224), XlV (2S9), XV (304), 22I, 242: started by a bear 224; photographing 232; types of 235-239; domed 237; in a river 245,245 ; chemistry of $246-$ 249: lighting fire from 282

Fumes $9,21 \%, 25,33,185,192,203,28 \mathrm{I}$

Game 165

Gaseous transfer of rock constituents 243

Gases I, 25, 22 I, 28 I, 283, 29I, 293: quantities of liberated from magma $4 \mathrm{I}, 299 n$; changes in rock wrought by hot 243 ; collection of samples of 209; odors of 246; composition of unrelated to tempature $246 n$; problem of fiberation of, from magma 301 ; beavy charges of, in magma 303

Gautier, A. 4 I

Geographic Harbor 5, 69, I33, 302 $324,326,327,328$; entrance to and islands in 330

Geographic importance of Katmai Pass 60, 72, 74, 79, 99, 265, 267, 328

Geography of Katmai regioe $67-71$, 305-327

Geological formations in Katmai region 59, 101, 124, 135, I 40, 233. 238 249. 271, 306; Jurassic measures of IOI, I 25, 233, 249, 27 I

"Geological thermometer" (quartz) 293

Geophysical Laboratory of Carnegie Institution $78,79,80,205$

Geraniun crianthum 157

Gilbert, C. II. 3 I I

Glaciated. surfaces $124,124,125,125$ 308, 327 ; shores of Island Bay 312

Glaciers, on Katmai V'olcano 99, I67, $171,173.275$; in Katmai region 124 , 269. 27 I ; largest 131-132; on Mount Martin $\mathrm{IS3}_{3}, \mathrm{IS}_{4}$

Glisan, Rodney L. 80

Gohoa (India) Flood I I 9 ; land siide I44

Gore, J. Howard 34I

Grand Canyon (of the Coloradol 122. I 23. 249

Granite gives off water when at high temperatures 41 ; relation of to ash, 4 r, $299 n_{\text {; }}$ soil formed by 47 ; weigbt of contrasted with that of pumice 203; in batholiths $30 \mathrm{r}$

Graph. showing relations of temperature,isun-spot numbersand radiation interisity (pyrheliometric values) as affected by volcanic eruptions 32 ; of monthly averages of solar radiation intensity $3 \%$ : showing effect of dust from Katmai on skylight polarization, insolation and temperature 36
Grass comes up through ash 42: growth following ashfall 45; tall growth of after eruption 27

Graves, Ralph A. 34

Greased Hill 24 I

Great Khingan Mountains (Asia) 58

Greek Church. Kodiak during eruption 9

Greeley, A. WV. 34 I

"Green Kodiak": appearance of village before eruption 2

Grewingk (Nolcano) 63,65

Grewingk. C. 63

Griggs, Robert F, 72, 82n, 74, 76,77 84.87. I32: MIs. Robert F. I 23.174 David I23; Julian 123: Rosamond I 23: Ruth I 23, I30

Grosvenor, Edwin P. 34

Grosvenor. Gilbert. I I 5, 307, 333.311: Foreword by $\mathrm{XV}^{7}$

Grosvenor, Lake 307, 308, 308, 314; dimensions of 3 r 4

Gull. Cape 331

Hagelbarger, P. R. $17,74,75,77,77$ 80, I 47, I8I, 205, 2 I0, $211,213,224$ 230, $295 n, 320,322$

Hagelbarger. Ralph 80, 210

Hagelbarger's Pass 133

Harbor 131, 195, 322-325; Geographic $5,69,133.302,324,327$, Hidden 325 Haze from eruptions 33-37

Helriegel, Hermann $x 60$

Helt, Richard E. 77, 79. 80

Hematite 243

Hesse, William A, 71, 86

Heuchera glahra 15

Henning, ITilliam L. $77,80,18 \mathrm{I}, 250$, 2.41

"High sand mark" Pl. V' (192), 262, 263

Hildebrand, J. R. 34 I

Hine, J.S. $74,76,77,80,208,210,214$. 215. $313,314,324$

Hissong. J. E. 29

Hitchcock. C. H. $279 n, 28 I n$

Hobbs, IV. H. $57 n, 58$

Horner. MI. A. 7 I, 86. I 35

Horsetail (plant), growth in ash 47 . 52. I55; as a soil binder 53

Horsehoe Pond (in Katmai region) r6

Hot and cold lake ( $F$ issure Lake) 244

Hot ground, camp on 207

Hot springs, map facing $60,132-133$, 197. $219,239,248.269$

Houses, effect of ashfall on $5,1+16,18$

Hudsonian forest 305

Humphrey's, WV. J. 29n. 33. 35n, 39.4I

Hutchinson, George WV. 341

Hydraulic effects of flood, peculiar I I O-II 3

Hydrocarbons, aromatic, in fumarole deposits 248

Hydrochloric acid 2.16

Hydrogen sulphide $190,246,248$

Hydrofluoric acid $203,246,247$

Hymenoptera I64n

Ice cliffs, in Katmai crater I73. I74; climbing 184

Ice ages, relation of volcanoes to $39-4$ I

Iceland, volcanoes in 33

Jgneous rocks, chemical make-up of 46

Jliamna, Volcano I5. 6I; Lake 23; Bay 23

Iliuk Arm (of Nakrek Lake) 69, 127. $230,301,306,307$

Jlktugitak, Cape 327

Innoko 20

Innuits 266

Insects in Katmai region 95, I63, 208,
3I4; dead in upper Katmai Valley $162,163-164$

Insolation graph showing effect of dust from Katmai on (chart) 36

Iron, in incrustations 247 ; in water 27

Isanotsky Peaks (Unimak Island) 62

Islands, adjoining Alaska Peninsula map, front cover; glaciated shores of 312; Bay of 305.307; in Amalik Bay. entrance to Geographic Harbor 330

Tacob. Harry E. 79, 80

Jaggar, F. A. $63 n$

Japan 57 ; volcanoes in $33,58,145$

Japan Sea 58

Johnstown Flood (comparison) 119

Jones, E. Lester 341

Jones, Frank I. 80, 251

Julian's Falls 123

Juncoides sp. 160

Juncus sp. I5

Juneau (city) I5, 23, 26

Jurassic strata in Katmai region 10 I I $25,233,249,27 \mathrm{I}$

Kaflia Bay, 17; experiences of people at 19

Kalsin Bay 52

Kamchatka 57,58

Kamishak Bay 307

Kanatak (village) Io

Kashvik Bay I7, 74

Katalla (village) $23,26,20$

Fatmai, pronunciation of 1 n

Katmai Bay Pl. Il (8I), 8I, I03, I33. 331

Katmai Canyon 69, 95, 97, I14, 116 $I I 8,121,122,124-127,130,132$ 273; and Second Valley 123-133

Katmai crater $167-179,287,288$; nаture of rim of $168,171,175$ : first. view into $169,172,174,176,178$ lake within 169; size of 170,173 $176-179$; compared to that of Kilauea 179

Katmai Flood, I03-I2I, I3I

Katmai Lakes 115, I 17,127

Katmai, Mount (volcano) 13, 15, 17. $57,7 \mathrm{I}, 100,126,158,286,331$; quantity of ejecta [rom 29-3I, I 4 . $189,275 n, 287$; comparison of with other volcanoes $34.39,62$; first ascent of 72,167 ; first journey 20 85-I0I ; first sight of 99 ; glaciers on slopes of 90 ; description of roo; previous activity of 124 ; deposits on slopes of 155 ; clouds about 167,173 . $I 75$; climbing $I 60, I 70$; second ascent of 171 ; ascent of, in $1917,174-$ I75; slackening activity of 220 ; relations of eruption of, to Valley activity 261,285 ; sections of before and after eruption $2 ; 2$; before eruption 270,275 ; beginning of eruption of 285 ; remains of 270,286 ; what became of top of? $287-303$; at extreme of explosive volcanoes 291 ; activity of, intermittent 299

Katmai National MIonument 5,74, So, I95. 197, 31 5. 31\%, 327; central portion, map 68: topographic map, back cover; proclamation creating 33I-332; accessibility of 329

Katmai Pass 19,69, 189, 208, 233, 253, $265,267-273,275,329$; geographic importance of $69,72,74,79,99,265$, 267,328 ; views in $100,191,262$

Latmai region, geology of $59,101,124$, I35, I40, 233. 238, 249, 27I, 304; geography of $67-71,305,329$; lakes of 69 , II5, 127, 305-3II; desolation 
in $82,95,127$; fowers in 82 ; Jurassic measures in $101, I 25,233,249,27 \mathrm{I}$; entrance to, discovered 132 : types of landslides in 144; conditions in, before eruption 265-275

Katmai River 67, 69, 71, 103-104, 260 vietws of $87,100,105,108$; fording 96 ; upper reaches of 127 ; source of 132

Katmai Valley $23,60,71,74.268,275$ views in Pl. If $(81), 73,86,04, I 11$. II2. II4: devastation of $81-101$; features of $95,103,104$; second II 5 . I $17,127,131$; in later years $147-153$ physiographic instability in $147-$ 153: ashfall in 153-185; return of plants and animals to $155-165$

Katmai V'illage 17, 19, 71, 103, 155 . $266,268,27 \%, 288$; desolation of, after eruption IS. 104

Katolinat, Mount Pl. XII (305), 294. $306,307.307$

Katz, F. J. $61 n$

Kauffmann, Rudolph 34

Kayaks (skin boats) 308

"Kettle hole" pond $I 43$

Kikuchi, Y. I.45n

Kimball, H. H. $26 n, 35 n, 36 n, 39$

Kisak Bay 131, 132, 325

K̈nife Creek 69, 239; valley of 69,127 . 23I; canyon of 254

Knife Peak ; 0, 233, 237, 253

Knight [Charles R.] $32 \mathrm{I}$

Kodiak (Island), Alaska I, 67; a ppeatance before eruption 2 ; scene on 2 $4,5,6,0,10,14,20,22,38,44,48$ 49. 51 : appearance after eruption 4. 5. 6 ; eruption as experienced at 7 13: during eruption 9 : cattle on 44 i recovery of vegetation at $45-55, \mathrm{Pl}$ I (80); waters around $6 \mathrm{I}$; communications with 67 ; birds on 165 ; bears on 3 I7

Kodiak Radio Station 8

Kolb, Emery C. 77, 80, 249, 250, 251

Korea 58

Krakatoa (volcano), Java $25,33 n, 34=$ 35,37

Kubugakli, Cape I7, 275, 331

Kukak Bay 325

Kupreanof Straits I5

Kuril Islands 57,58

Kuskokwim River 266

\section{Labradorite 289}

Lacewing (insect) I $64 n$

La Gorce, John Oliver 341

La Gorce, Mlount 306, 306

Lakes of Katmai region 60, I15, 120 $127,212,306,307-313,307,308$. $300,314.315$

Landing, first 8 I

Landslide 142 ; in Katmai Canyon 116 Mageik 69, 74, 135-145, 136, 138 , $I 40, I 4 I, I 44$. Noisy Mountain 128 129, I31, 142; Frank, Alberta 139. 143; Elm. Switzerland I43; Rossberg. Switzerland 144; Gohna, India I44; Bandai San, Japan 145

Landslides 285 ; and rivers, an intermediate between 131; typical features of 139; previous 139,143-145 conditions favorable for 140 ; types in Katmai region 1.44

Lansing, Robert 332

Latouche (town) 25

Lava 41,279 ; composition of in Katmai region 101; bowlder, moved by stream 108; from Novarupta 238. 240,241 ; lake of 299 ; new and old from Katmai 200 ; peculiar structure of 200
Lava fows i $n, 33,124,125,126,140$; greatest during historic times (Japan) 33 ; old, from Katmai 287

Learn. The Rev. George A. 48

Lee, Jack I 7

Lu-Chu Islands (Japan) 58

Leslie, Frank 274

Lethe (stream) $239,2.45,245$

Life dependent on volcanic action 43-44; no destruction of 3 , I9

Lightning $7,8,11.23 .65$

Lime $46 n$

Limestone 2 iI

Logao. Daniel $279 n$

Long Island, roof crushed by ashes 16

Loring (town) 27

Lupine in ash covered region 45,158 . I $58,159^{-160}$

AfClaughey. IV. J. 289

MIcConsell, R. G. I $39 n$, I $43 n$

IcCulloch, (U. S. Coast Guard Cutter) 65

McCulloch Peak (Bogoslof Island, Alaska) 63,65

McMullen, (Capt.) C. B. 15

MicPherson. J. L. I5

MacDonald. T. L. 34 I

Mageik, prosunciation of $60 n$

Mageik Creek 124. I89; food of II 7 . I3I

Mfageik Landslide 69, 74, I35-145 $136,138,140,141,144 ;$ dimensions of I4I; compared with other slides $143-145,241,285$

Mageik, Mount (volcano) 19, 69, 78 $85, \mathrm{Pl} . \mathrm{V}(192), 99,124,160,166$ 186. 190, 220, 233, 254, 271, 275. 284, 285: ejecta from searched for 86; relation of to Mount Martin I $8 \mathrm{I}$

Magma, definition of $I n, 41,209,247 n$, $26 \mathrm{I}, 288$; intrusion of 140, I93,239; reached surface in Valley 240,278 ; mixture of old and new $280-291$; ate way upward 201, 205.303; new. temperature of $291-293$; lake of io crater before explosion 299; approached surface over considerable area 301

Magraa chamber 288, 292, 301, 303

Magnesia $40 n$

Magnetic properties of ash $46 n$

Maithana, Mlount (Himalay'as) I/44

Afalbat Station (Vancouver Island) 27

Man-back transportation $\mathbf{7 5}$

Manganese oxide $46 n$

Manning (U. S. Revenue Cutter) 8 , $10,11, I 3$; refugees on board $I I$

$M$ larsh gas from fumaroles 247

Martin, George C. $15 n, 2$ In, $26 n, 29$. $34 n, 6 \mathrm{I} n, 71,86, \mathrm{I03}, \mathrm{I} 53$

Martin Creek 97,124 ; bridge orer 92 valley 69,74 . 335

Martin, Mount (volcano) PI. III $(06)$ $71,85,180,181-187,182,184,100$ $220,264,285$; ejecta from searched for 86 ; attempts to climb $18 \mathrm{I}, 183$; crater of $18 \mathrm{I}, 185$

Mather, Stephen T. 34

Mauna Loa (Hanaii) 279

Maynard, C. F. 74, 76, I1I, 208, 213 215. $295 n$

Merriam, C. Hart 34

Metcalf Peak (Bogoslof Island) 63.65

Metho Nelson (schooner) 8

Metrokin, Walter $72,73,74,76,197$ 315

Mlititary importance of road across Alaska Perinsula 329

Miller, August E. $77,80,313$

Minerals, formation of 3
Moose, absence of in devastated region 16.4

Ioose Creek 321

Morey. George W. $301 n$

MIosquitoes $17.95,163,164 n$

Moss, caught ash 38.53 ; network of on lorest floor 53, 55, 58; around fumaroles 209,223

Moths $164 n$

Motion pictures, of volcanic phenomena $71,79,195$; of pumice-choked streams I 52

Motorcy cle, attempt to use, in 75

Mounds, curious conical $127,128,128$. 134, 139, 142; in Bandai San landslide 145

Mud, from Katmai Volcano 23, 155, 285 ; in Katmai Valley 81,103 ; flow Pl. I1 (8I), 96, I 23, 253, 285; slides 129-131; on slopes of Katmai 167; stuck in the 160 ; steaming 238 ; pots and "pimples" 239 ; pot 284

Naknek, pronunciatlon of $69 n$

Naknek, Lake 17, 69, 77, 79, 155, 233. Pl. XVI (305), 265, 266, 267, 268, $305,307,307,308,309,324,327$

Naknek River 77, 79, 265

Naknek Village I7, 2 I

National Monument, Katmai 5, 74 80, 195, 197, 315, 317, 327; proclamation creating $331-332$; accessibility of 329

National Park Service. Director of, in charge of Katmai National Monu. ment 332

Native huts (barabaras) 17 and $n, 24$. I03; interior of 26

Névé $131,171,184$

Nimrod (boat) 324, 325, 327

Nitrogen compounds, absence of, in ash 160 ; in fumes $209,246,248$

Noisy Mountain (Katmai region) 74 II7. $24 I$; landslides of $I 28,128-129$, I3I, 142

Nome stampede, use of Katmal Pass during 99,267

Norman (motor boat) 13

North, S. N. D. 34

Novarupta (volcano) 29, 192, 194 233. $238,240-24 \mathrm{I}, 253,276,280$ $297 n, 300:$ part played by, in Valley sandflow 26I; explosion of 284 ; quantity of ejecta from 285 ; subsidence of 288,303

Nushagak (village) I 9, 266,267, 268

Nutting, P. G. 37

Nyman, [Gus] Captain 324. 327

Observation Mountain 124, 147, 189 , 253. $273,274,275$; camp $\mathrm{I} 97$

Oceans, relation to volcanoes 43

Odors 25, 167, 190, 192, 238, 246, 281

Okhotsk Sea (Asia) 58

Olga (town) 20

Oogashik (village) 265

Orloff, Ivan, letter of 19,2 I

Osborn, H. F. 32 In

Outfits for expeditions 74

"Overhead stoping" 297n, 303

Overloaded streams I 50-153; channels built up by 152

Oxygen 2.46

Pack train 210

Park, Katmai (properly Katmai $\mathrm{Na}$ tional Monument) $306,307,324,329$

Pass 131, 132: Katmai 19, 69, 72, 74 $79.99,189,100,191,208,233,253$. $262,265,267-273,274,329$; Hagelbarger's 133 
Pavlof Volcano 66

Peat 135,137

Pedmar. Mount 8

Pelée Volcano (West Indies) 10I, 26r. 279

Pembertoa, C. C. 27

Peneplain 167

Perry, (Capt.) K. IV. 8, 9, II, 15, 48

Personnel of expeditions, 1915. 71, 72 ;

$1916,72,73 ; 1917,74,76 ; 1918,77 ;$ I010, 77, $77,79,80$

Petrol, lvau 265.306.321, 328

Petroleum-like emanations in Valley 247-248

Petrological studies Ior, 243

Peulik (volcano) I 5, I 83,307

Phosphoric acid 46,$4 ; n$

Photography 207, 224, 25I

Physiographic instability in Katmai Valley $147-153$

Physiography, curious I2S, I3I

Phenomena accompanying eruption $7-13,15-31,33-39$, I I 5, I39. I it. 242 ; sky, following eruption 37

Picea canadensis 305

"Pimples", a ty pe of fumaroles 240, 204

Plagioclase feldspar $280 n$

Plants, effect of ash on $3,45-55$, of fumes 33. of reduction of average temperature 39; herbaceous in Katmai region 82 ; grown in ash experiments 47,50 : resurrected $I 53$ : prevent ash blowing 52 ; effect of ash on growth 53; retura of. to Katmai Valley 155-16r; practically absent Irom Valley in $191 \%, 209$; return of, to Valley 223

Plowing before ashfall, effect on revegetation 54

Plug of Novarupta 238,240

Pod sp. 157

Pogromai Volcano (Uaimak Island) $62,63,63$

Polarization of skylight, affected by eruptions 36 ; graph of 36

Polemonium cocruleum I5 7

Pompeii, contrast with Kodiak 13

Poad, io Katmai Natioaal Monument 266

Ponds, in upper Katmai Valley 127

Poplars, Balsam (Populus balsamifera). in Katmai region $82,83.305$

Port Graham (Eaglish Harbor) Alaska 62

Port Moller (town) 265

Port Townsend, Washington 27

Post. IV. S, 275

Potassium compounds $46,47 n, 247$

Powers, Sidaey $65 n$

Preliminary symptoms observed at outlying stations Io

Preparations for expeditions it

Pressure, air, reduced by volcanic eruptions 35

Priace Rupert (town) 27

Prince IIIlliam Sound 25

Printer (tug) 13

Property, destruction of 7

Proportions, laod of stupendous $I 73$

Pumice 1\%, 29, 41, 72, 75, 8I, 147 floating $30,81,89,103$, I51; sharpness of 88 ; straining, out of water 88; choked streams 150-153, I52; wind-blown, cuts faces 199,229 lightoess of illustrated 250,293 mixed, from Katmai zor; bighly inflated $299 n$

Putaam, George R, 34I

Pyrheliometric values, curve of (graph) 32

Pyroxene crystals 243
Quartz 46, 293 and $n$

Quicksands 75, 88, 89, :04; fording stream through 87 ; of Katraai River 108

Radiacion intensity, graph showing 32

Radio 9

Radio Station, Kodiak 8

Rains, frequent in Katmai region $\mathbf{5 2}$

Rampart (city) 26

Redoubt (volcano) I5, 6I

Refrigerator, a natural 108

Relugees, Kodial II, IT

Reindeer 265, 266

Remoteness of Latmaj 6

Return. of plants to Katmai Valley 155-I6I; of animals $16 x-165$

Revegetation 3, 45-55, $7 \mathrm{I}$; in Katmai Valley 155-16I; preveation of by acid rains 183

Rhodiola rosea 155

Rhyolite, acid 46, IOI, 240, 24I, 2ST

Rhyolitic glass 289

Richtoien. [Ferdiaaod Baron von] $57 n$

Rishiri (Island), Japan 57

Road across Alaska Peninsula, military importance of 329

"Roches moutonnees" 308

Rocks, "balanced " 23: hurled during eruptions 33 ; slides (falls) 2 In, 128 , $128-129,145-147,148,24 \pi$; changes in wrought by hot gases $2+3$; old and aew mixed 289,290

Rodents 165 ; absence of in devastated regions before 1010,164

Rodriguez (Island, Indian Ocean) 25.35

Roots, two sets of on plants 40 ; sur. vived ashfall $45,50,51$, I 55; conditions encountered by $46 n$; "twostoried", result from ashfall $5 \mathrm{I}, 83$; of willow at ash surface $133 i$ rejuvenation of 157

Rope, crossing river with 97

Rosamond's Falls 123

Rossberg Landslide 144

Rouge, C. D. 27

Rubus spectobilis I55

Ruby 26

Russian American Company 266

Russiao. Church at Katmai Village I03; missionary at Nushagak 267

Ruth's Falls 123, 130

St. Michael (city) 266

St. Paul (old oame for Kodiak) 268, 269

St. Pierre (Mlartinique) 26I, 379

Salihalio Island (Asia) 57

Salix arclica 155

Salmon in derastated district 150 161,163 ; in lake region 308,309 ; leaping vp lalls $310,3 \mathrm{ro}, 316$ : remarkable instiact of 3 I 1,313 ; spearing $3 I I$; fisheries $3 I I$

Salmoo-berries 51,155 ; since eruption $5 \mathrm{I}$

Sombucus pubens 157

Sandblast 52; effect of on trees $9 I_{i}$ effect of on plants 158

Saadflow I, 3. IJ. IT, 29, 253-26I, $254,255,256,257,258,260,263$ $284 ; 285,301$; dimeosions of 253 , 283 ; heat of 258 ; fracture in 259

Saudstone I24, I25. I $40,233,238$, $243,249,263,306$; fragments of in magma 299

Songuisorba silchensis I55

Sargent, R. H. 65

Saronoski, River 307 ; Village 17,268 , $269,271,277,288$
Sayte, Jasper D. 74, 76, 77, 77, 79, 80, 147. 175, 205, 213, 239, 295n

Scenery, beauties of 306-307, 325

Sedimentary rocks in Katmai region $101,135,140,233,240,306$

Seedlings 162 ; slow to start 52 ; timothy io ash $54:$ start in forest 55 istart in Katmai Valley 147,157 I58, 159; of trees abundant 305

Seeds (dormant) 15 ;

Sekisa, S. I $45 n$

Seldovia (town) 10, 2I, 23

Seward, Alaska I5. 25

Shale 140,233, 306

Shaotz. A. B. $274 n$

Shelikof Strait 1, I5, 67, 75, 167, 268

Shifting streams $150-153$

Shipley. J. 11. 74, 76, 201, 209. 215. $246,247,2498$

Ship Rock (Bogoslof Island. Alaska) 63

Shiras, George, 3d 34I

Shishaldin (volcano) 62, 63, Ior

Shoes, effect of hot ground a ad pumice on 205

Showalter, William J. 34 r

Sierra Fevada (Mountains) 301

Silica $46 \pi$, IOI, 287

Sill theory to account for Valley activity $301-303$

"Silver Horde" 273

Sitka (city), Alaska 56, 57n

Skaptar Jökull (volcano. Iceland) 33

Skin hoats (bidarkas) 17, 268 (kayaks) 308

Skylight polarization, graph showing effect of dust from Katmai on 36

Sky phenomena following eruptioas 37

Slide Mountain (Katmai region) 97

Slides, ash $82,86,87$; land II5-1I7,

128; rock 128,178 ; the Mageik 138. 140, 141,144 : drainage on 136

Smith, George Otis 34 I

Smith, W: R. 65

Smoke (volcanic) I5. I7, 2I $n, 279$ Irom fissures 202

"Sraokes" ia Valley", oumber of I99-20I

Soodgrass, M. D. 53

Soowdrifts, buried under ash 148-149, I 49

Snowy Mountain (in Katmai region) I3 I

Soda $46 n$

Soil, formation of 3 ; contribution of ash to 46 ; granite 47 ; tests of ash as 47

Solar radiation inteasity. graph showing monthly averages of 34

Soluka. Valley $69.83,33,327$; Creek $82,87,88-89,90,133$

Solution of old rock io new magma $280-293,290 n$

Spearing salmon $3 I \mathbf{I}$

Spencer. Cape 25

Spriags I27; hot 132-133, 197, 219, $239,243.269$

Spruce, white 305

Spurr. J. E. 189, 190, 267, 269n, 273. 275

Squentna Valley 6 I

Squires, Grant 34 I

Stanovoi Mouatains (Asia) 53

Steam (volcanic) 3. 5, I7 I, 208; origia of $4 \mathrm{r}, 246$; estimated volume of liberated $4 \mathrm{I}$; rising from Katmal I26: clouds of, continued Irom Katmai 168, 169; in Valley of Teo Thousand Smokes 190, 237; effect 
of, on weather 208; not visibly affected by surface water 219,246 ; predominant constituent in gases 246; from Novarupta 276

Steam-heated tent 207-208

Steaming, mud areas 237-238; fissures 278

Stone. Julius. Jr. 77,80

Stone-crop (plant) 155

Stoping, overhead $297 n, 303$.

Storm at Baked Mountain camp 226231

Streams, ash in 19, 89, 150, 151, 152 , I53; overloaded 152 ; views of $15 I$. 153, 245

Streptopus amplexifolius I 55

Subsidence, of Novarupta 288, 303; no evidence of, in Katmai Crater $288 \cdot 289$

Suess, Eduard 43,57

Sulphur 9. 33, 271; fumes 65, 167; in Katmai crater 169; in Martin crater 185, 190, 192; dioxide 246 . around furiaroles $\mathbf{2 4 7}$

Sulphuric acid $46 n$; rains at great distances 25 ; in air 27 ; little in Valley $205,2.47$

Sumatra, volcanic chains between Alaska and $5^{-}$

Sunsets affected by volcanic dust 34 . 37

Sunsbine, intensity of, reduced by eruption 33, 35

Sun-spot rumbers, graph of 32

Supplies 75 ; dependence on 85

Surveys of Katmai region 77

Swan. Herbert S. I79n

Swan, wild, captured alive 313

Taft, William Howard 341

Tahoma (U.S. Coast Guard Cutter) 65

Takkala Bay 133

Talus $128,141,176$

Tatoosh Island, Washington 29

Taylor, Boyd 34I

Temperature, at mospheric during ashfall 1I; departures, graph showing 32: world. reduced by eruption 33 . 34. 35.37 (table) 39 and $n$; graph showing effect of dust from Katmai on 36 ; increased in high altitudes by dust 39; of fumaroles 205,219 220-222; of new magma 291-293

Terraces, stream-carved 153

Terrane, remarkable in Martin Valley 135

Tertian lava 327

Therapeutic possibilities of the Valley $207-208$

Thermocouple $22 \mathrm{I}$, Plate $\mathrm{Xl}^{\prime}(304)$

Three Forks (in V'alley of Ten Thou. sand Smokes) 230

Thunder 7, I $1,23,65$

Thraites, J. E. 10

Till (glacial) 125

Timothy, seeded in ash 52,54

Titanium oxide $46 n$

Tittman. O. H. 341

Tomboro, East Indies (volcano) 34

Topographic map, back cover; work 209

Tourists to Valley 80 ; need road 329

Trail, views along the $73,74,191$; through tall grass $27 \%$

Transportation in Katmai region
74-75, 207; man-back 75; facilities inadequate 328 ; problems would be solved by automobile roads 329

Tree growth, limit of 305

Trees, ash in $20,28,38,53$; surviving in Katmai Valley $47-49,82,83$. effects of ash on $53,83,133 ;$ dead in volcanic region $90,91,98,102$ 107, 151: affected by sandflow 256-257

Trident (volcano) $98,99,171,190$. $220,233,240,271,285$

Tridymite $243 ; 293 n$

Trout, rainbow, in Naknek River 324

Tuff $235,253,254,256,26$ I

Tundra 74,314

Tunrels in ash 9

Turtle Mountain (Canadian Rockies) landslide at 1.43

Twilight lengthened by volcaric dust in air 37

Twisted-stalk (plant) 155

Ukak Valley $I 7,229,231,253$; Ukak River 239

Unalaska (Island) Alaska 63,65

Unfinished work in Katmai region 80

Unimak (Volcano and 1sland) 62 ; peaks on Island $\sigma_{2}$; Pass $\sigma_{3}$

Uplift 140

Uyak (Village) I5, 19

Valley. Katmai 23,69, 71, 95, 103 104,163 ; Second (Katmai) 74,115 $117,127,131$; Soluka $69,83,133$

Valley of Ten Thousand Smokes, be fore eruption 19 ; position of 69,233 discovery of $72,189-195$; exploration of 73,74 ; exploration of, in 1917 197-217; first adequate description of 74 impression on first seeing 21 1-217; in 1019, 219-231; descriptive account of 233-25I; dimensions and shape of 233 ; entrance to 233 unexplored parts of 235 ; activity in, began before Katmai eruption $\mathbf{2 5 5}$ 256; nature of activity in 278-283 views of $188,194,106,200,202,204$. $206,210,212,214,216,218,220$ $226,227,230,232,234,236,238$, $242,243,245,248,252,262,264$ $276,202,204,206,208,300$; a generalized section of $26_{3}$

Valleys prominent topographic feature near Katmai 67, 69, 268

Van Campen, F. R. 25

Vancouver, B. C. 2 7

Vegetation, effect on, of volcanic ac tivity $3,25,82$; recovery of at Kodiak 45-55: transported by slide 137. 140 ; recovery of in Katmai region 147; absence of in Valles 209; return of to Valley 223

Vents, volcanic 3 ; reawakening of 65 hot sand probably came from local 261

Victoria, B. C. 27

Virginia, haze from Katmai eruption in 35

Visitors, first to Valley of Ten Thou sand Smokes 80,320

Volcanic activity, subsidence of 21 220 ; area of 301 , carrying work into $67-79 ;$ axes and structure lines, map faciog 56; axis, relations of fuma roles to 193 ; festoons $57-61$

Volcanism, problems of $3,77,79$; Kat . mai presents unique opportunity to study 304,33

Volcano (Katmai) first journey to 81 I0I

Polcanoes I 7, 33, 34, 43, 57-65, 6o, 62 , $63,64,66,67,70,78,85,98,160$ 166, $168,171,172,174,175,176$ $178,180,182,184,186,190,220$ $233,240,271,285$; dormant 7 ; capable of causing ice ages 39-41; the Alaskan waterfow! $313,57-65$; series of, including Katmai $99 ; \mathrm{min}$ iature $\mathbf{2 3 7}$

Walker Lake (properly .Naknek Lake) 265

Vallace, H. AI. 77. So. 309, 324

Valter [Mletrokin] $73,74,76$

Viater, drinking $8,81,89$; liberated in eruptions, importance of in economy of nature $41-43$

Waterfalls $81,109,123,530,265,310$, $310,311,316,327$

Wateriowl 3 I 3

"Water slides" 129-13 I

Waves (in sea) caused by volcanic dist urbances 62

Weasels 164

Weather in Kat mai region $90,97,158$ 159, $189,208-209,220,226,269$, 273 ; effect of eruption on 33,268

Viells, E. H. $274 n$

White, Henry 34

"Williwaws" (violent winds) 226-23I, 325

Willow:s effect of eruption on $\mathbf{8}_{3}$

Wilson, (President) Whoodrow 5, 74; proclamation of creating Katmai National Monument 331-332

Wind, caused small avalanches 125 . 273; action on landscape 148-149; caused irregularity in ash deposits 155; chief factor in seed dispersal $158-159$; violent in Valley 199,226 231; violent through Katmai Pass 268,269 ; protected forest near Katmai 305

Wind-blown ash 52-55, 59

Windy Creek 239

Wisconsin, haze from Katmai eruption in 35

Wolves $164,208,315$

Wolverines $164,208,315$

Women's Peninsula, dunes on 50

Wood Island 8, I 3

World War, effect on expeditions 79

Vormwood I 55

Wrangell, Nount (volcano) $56,57 n$

Yagashoff. Andrean 76

Yellowstone Park (comparison) 191 195. 197, 204, 239, 320

Yori, Charles $77,80,183,184,227$ $229,220,230$

Yosemite Valley (comparison) $\mathbf{1 2 3}$

Yukon River 266,320

Zay, Karl I $44 n$

Zies, E. G. $77,80,221,229,229,230$, $231,246,247 n$

Zinc, melted in funeroles $\%, 220$ 


\section{NATIONAL GEOGRAPHIC SOCIETY}

GEOGRAPHIC ADMINISTRATION BUILDINGS

SIXTEENTH AND M STREETS NORTHWEST, WASHINGTON, D. C.

GILBERT GROSVENOR. President

JOHA IOY EDSON. Treasurer
BOYD TAILOR, Assistant Treasurer
HENRY WHTE, Vice-President O. AT STIN, Secretary

GEORGE W. HTTCHISOX, Associate Secretary

FREDERICK $V$. COVILLE. Chairman Commitzee on Research EDWIX P. GROSIENOR, General Counsel

\section{EXECUTIVE STAFF OF THE NATIONAL GEOGRAPHIC MAGAZINE GILBERT GROSVENOR, EDITOR}

WILLIAM J. SHOWALTER Assistant Editor
JOHN OLIVER LA GORCE, Associate Editor RALPH A GRAVES ARANKIIN L FISHER Assistant Editor Chiel of Illustrations Division

J. R. HILDEBRAND, Chief of School Service

\section{BOARD OF TRUSTEES}

CHARLES J. BELI

President American Security and Trust Company

JOHN JOY EDSON

Chairman of the Board. Washington Loan \& Trust company

DAIID FAIRCHILD

In Charge of Agricultural Explorations. U. S. Department of Agriculture

C. HART MERRIAMI

Member National Academy of Sciences

O. P. ACstiN

Statistician

GEORGE R. PUTNAM Commissioner U. S. Bureau of Lighthouses

GEORGE SHIRAS, 3D Formerly Mernber U. S. Congress, Faunal Naturalist, and iVild-game Photographer

E. LESTER JONES

Director UT. S. Coast and Geodetic Survey
WILLIAM HOWARD TAFT Chief Justice of the United States

GRANT SQUIRES

Iilitar Intelligence Division, General Staff, New York

C. M. CHESTER

Rear Admiral $U$. S. Navy. Formerly Supt. U. S. Naval Ob. servatory

FREDERICK V. COVILLE

Botanist, U. S. Department of Agriculture

RUDOLPH KAUFFMANN

Managing Editor The Evening Star

T. L. MACDONALD

I. D.. F. A. C. S.

S. D NORTH

Formerly Director U. S. Bureau of Census

JOHN OLIYER LA GORCE

Associate Editor National Geographic Magazine
ALEXANDER GRAHAM BELL

Inventor of the telephone

Died August 2, 1922

J. HOVIIARD GORE

Prof, Emeritus Mlathematics, The George Washington University

A. W: GREELY

Arctic Explorer, Major General U. S. Army

GILBERT GROSVENOR

Editor of National Geographic Magazine

GEORGE OTIS SMITH

Director, U. S. Geological Survey

O. H. TITTMANX

Formerly Superintendent U. S Coast and Geodetic Survey

\section{HENRY WHITE}

Member American Peace Com. mission. Formerly U. S. Ambassador to France, Italy, etc.

STEPHEX T. MATHER

Director Vational Park Service
ORG.ANIZED for "the increase and diffusion of geographic knowledge." the National Geographic Society" was founded thirty-five years ago.

IN addition to its work of exploration and research conducted in the Mount Katmai volcanic region, as set lorth in the preceding pages. The Saciety, at an expense of more than $\$ 50,000$, sent a notable series of expeditions into Peru to investigate the traces of the Inca race. The discoveries of these expeditions form a large share of our knowledge of a civilization which was waving when Pizarro first set foot in Peru.

THE Society also had the honor of subscribing a substantial sum to the historic expedition of Admiral Peary. who discorered the North Pole.

NOT Iong ago The Society granted $\$ 25.000$, and in addition $\$ 75.000$ was given by individual members through The Society to the Federal Government when the congres- sional appropriation for the purchase was insufficient and the finest of the giant sequoia trees of California were thereby saved for the American people and incorporated into a National Park.

THE Society is conducting extensive explorations and excavations in northwestern New Mexico, which was one of the most densely populated areas in North America before Columbus came, a region where prehistoric peoples lived in vast communal dwellings whose ruins are ranked second to none of ancient times in point of architecture. and whose customs, ceremonies and name have been engulfed in an ohlivion more complete than any other people who left traces comparable to theirs.

TO achieve the purposes for which it was founded, the National Geographic Society publishes the Natroxal GeograpHic MAgazINE, and all the receipts of The Society are invested in the Magazine itself, or expended directly to promote geographic knowledge. 







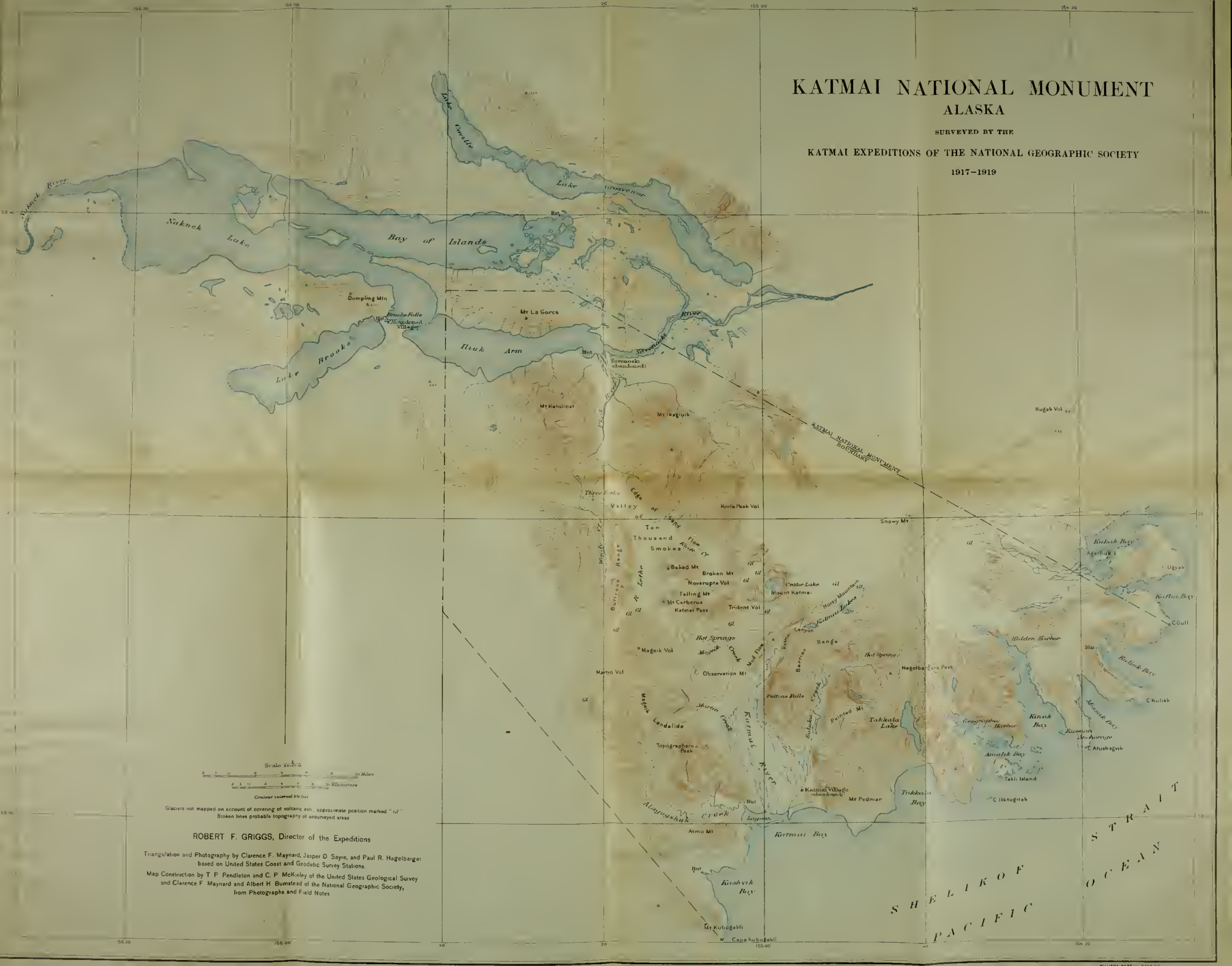




